Multi-authored monograph

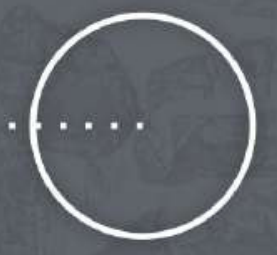

\title{
PROSPECTS FOR DEVELOPING RESOURCE-SAVING TECHNOLOGIES IN MINERAL MINING AND PROCESSING
}

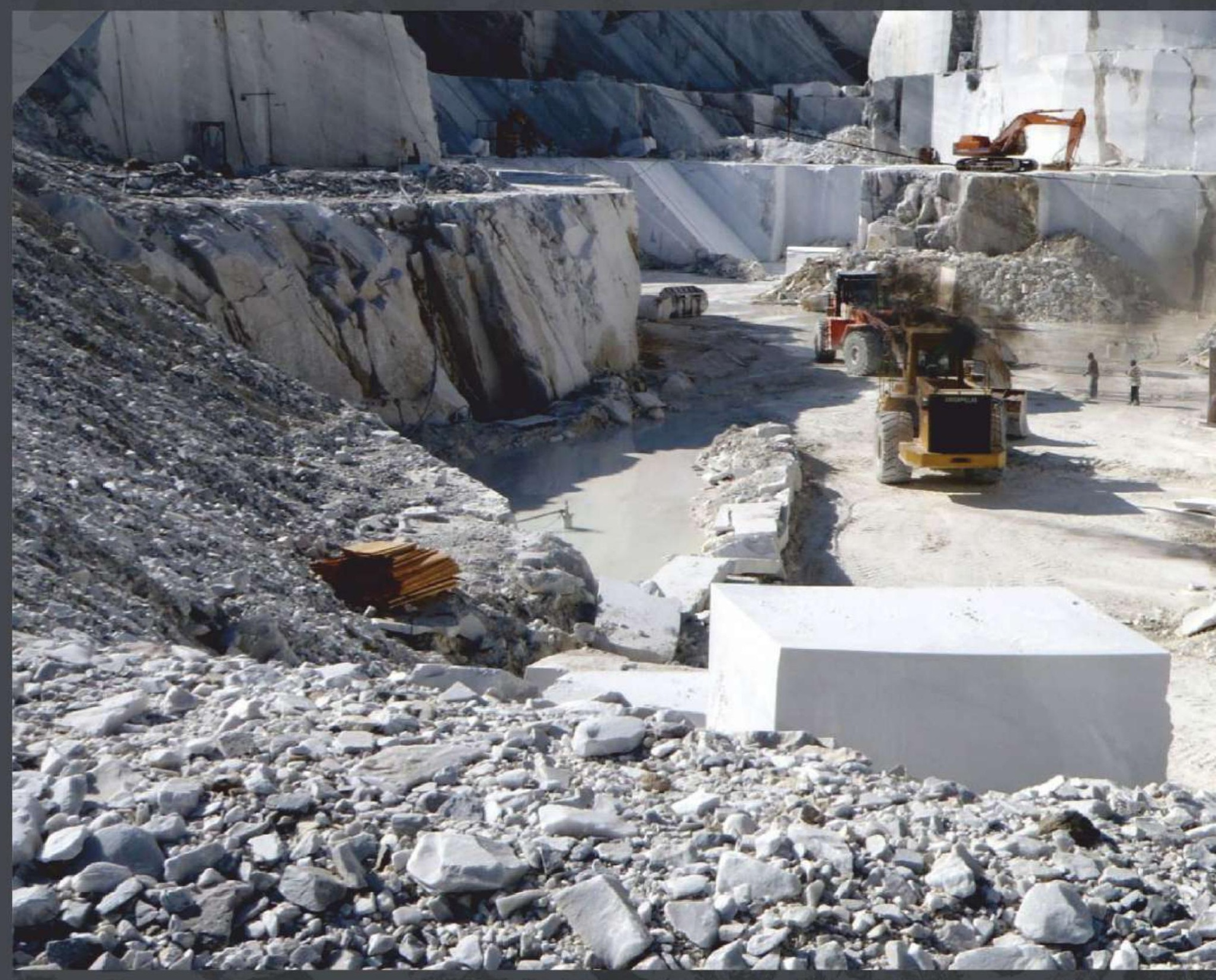




\section{PROSPECTS FOR DEVELOPING RESOURCE-SAVING TECHNOLOGIES IN MINERAL MINING AND PROCESSING}

Multi-authored monograph

UNIVERSITAS Publishing

Petroșani, 2022 
Recommended for publication by Board of Directors of the University of Petrosani, Minutes №792 as of February 03, 2022

Reviewers: Mihaela TODERAS, Professor, Ph.D.Habil.Eng., Vice-Dean Faculty of Mines University of Petroșani, Romania

Vladko PANAYOTOV, Professor, DSc. (Engineering), Correspondent Member of the Bulgarian Academy of Sciences, Bulgaria

Anzor ABSHILAVA, Professor, DSc. (Engineering), Dean of Mining and Geology Faculty, Georgian Technical University, Georgia

Prospects for developing resource-saving technologies in mineral mining and processing. Multi-authored monograph. - Petroșani, Romania:

UNIVERSITAS Publishing, 2022. - 682 p.

ISBN 978-973-741-820-3

The monograph considers potential technological development of ore mining and processing industries through updating mining machines and technologies

The book is intended for a broad mining audience of scholars, practitioners, postgraduates and students.

UDC 622.002

The materials of the multi-authored monograph are in the authors' edition. References are obligatory in case of full or partial reproduction of the monograph content. All rights are reserved by the monograph contributors including their scientific achievements and statements. 

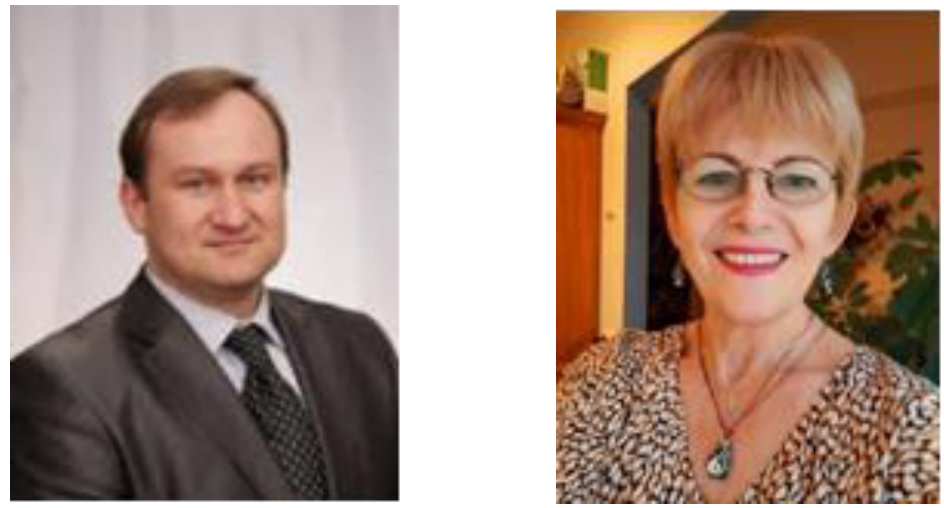

\section{PREFACE}

The multi-authored monograph Prospects for developing resourcesaving technologies in mineral mining and processing is brought to your attention.

Problems of environmental management have always been important for humanity. Yet, they have acquired the greatest relevance in recent years as human economic activity have greatly affected the natural environment.

There is a need to develop scientific principles of environmental management based on the principles of sustainable use of natural resources via resource-saving technologies and optimal placement of production facilities.

The monograph considers application of resource-saving technologies to mining mineral deposits.

The authors apply a comprehensive approach to solving this problem by analyzing the entire range of works related to mining and processing of minerals. The monograph examines resource-saving technologies in open pit and underground mining of ore and non-metallic minerals.

The monograph is intended for a wide audience of mining scientists, practitioners, postgraduates and students.

Co-editors,

Valerii KORNIYENKO, Professor, DSc. (Engineering), Head of Department of Development of Deposits and Mining, National University of Water and Environmental Engineering, Ukraine

Maria LAZAR - Professor, Ph.D., Research Vice-Rector University of Petroșani, Romania. 


\section{Table of contents}

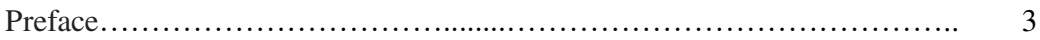

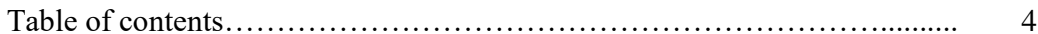

Zinovii Malanchuk Tuff extraction technology in rivne-volyn region .......... 6

Krukovskyi O.P., Krukovska V.V., Vynohradov Yu.O. Technology for application in gas- and water-bearing rocks development of roof bolting

Demin V. F., Kamarov R. K., Zhumabekova A. E. Development of geotechnological methods for strengthening the disturbed rock mass

Victor Mutambo, Draida Mikoloni Investing the causes and effects of mining induced subsidence due to sink holeson the south and eastern limb at lubambe mine, Zambia

Pogrebnyak V. G., Chudyk I. I., Perkun I. V. Solutions of polymers in the oil and gas technologies

Dreshpak O. S., Dreshpak N. S., Vypanasenko S. I. technology of raw material enrichment of inhomogeneous carbonate deposits and evaluation of its energy efficiency

Kolosov, D.L., Samusia, V.I. . Bilous, O.I., Tantsura, H.I., Onyshchenko, $S$. $V$. Design-induced operational changes of stress-strain state in flat rubbercable tractive element of hoisting and transporting machine

Krzysztof Tomiczek A case study of determining the intensity of vibration accelerations and the potential impact on structures

Slobodyanyuk V.K. Prospects for surface mining of iron ore deposits in Ukraine

S. Lutovac, B. Gluščević, M. Gligorić, J. Majstorović R. Tokalić, Simplified model for determining rock mass oscillation velocity at limestone deposit

Yelchenko-Lobovska A.S., Lavryk I.O., Liashenko A.V., Pedchenko L.O., Pedchenko M.M. Bitumen extraction technology from bituminous sand deposits

Yelzhanov Yerbol Abdrakhmanovich, Yussupova Saltanat Abenovna, Aben Yerbolat Khalidillaevich substantiation of rational parameters of the explosive breakout technology in a structural block array

Khilov V.S. Resource-saving control systems for electric drives of modernized drill rigs for open-mines of Ukraine

Pedchenko N.M. Improving the efficiency of the technological complex for the development of marine gas and gas hydrate deposits

Berezutskyi V.V., Berezutska N.L., Khalil V.V., Ilinska O.I. Electric treatment and regulation of biotoxic properties of drilling waters 
Belmas, I.V., Kolosov, D.L., Samusia, V.I., Kolosov, A.L., Onyshchenko, $S$. $V$. Stress-strain state of flexible composite tractive element with cable breakages at tubular-shaped and transitional areas

Toktosunova B.B., Abdibaitov Sh.A., Kushnazarova S.Z., Tutasheva A. Z., Kozhogulov M.B. Disintegration of ore-bearing rocks and its effect on the content of constituent components

Zhuravlev F.M., Chuprinov E.V., Tarakanov A.K., Kassim D.O., Lyakhova I.A. Possibilities of using alkaline earth bentonite clays of cherkasy deposit in pellet production processes

Avksentieva A.P, Kuris Yu.V. Analysis and research of resource-saving technologies for anaerobic digestion of biomass

Panteleienko V.I., Karpushyn S.O. Machines and equipment for the arrangement of recess for foundations of quickly installed technological mining facilities without digging

Vynnykov Yu.L., Petrash O.V., Vovk M.O., Volchenkova A.V., Novozhenina A.R. Classification the salt stock areas (sakhalin field) with the detection of hydrocarbon potential for optimization of exploration work and drilling for oil and gas

Koshliakov O. Ye., Dyniak O.V., Koshliakova I.Ye. Experience in implementing the method for determining the integrated risk assessment of engineering and geological processes for the territory of the Volyn-Podilsky plate

Frolov A. A., Zhukova N. I., Lytvynchuk I. D., Beltek M. I., Lukomskyi V. R. Establishment of regularities of fluvioglacial deposits and problems of their extraction in the development of rock deposits of building materials

Mykhailovska O.V. Method of calculating the stress-strain state of the depth well and area around the well

Vynnykov Yu.L., Kharchenko M.O., Lartseva I.I., Yaholnyk A.M. Experience of improving the operating reliability of drilling machines at the installation of extra deep wells in complex geological conditions 
https://doi.org/10.31713/m1102

\title{
TUFF EXTRACTION TECHNOLOGY IN RIVNE-VOLYN REGION
}

\author{
Malanchuk Z.R.
}

National University of Water and Environmental Engineering (NUWEE), Doctor of Technical Sciences, Professor, Department

of Development of Deposits and Mining, Ukraine

\begin{abstract}
Interest in volcanic tuffs has grown significantly in the world due to the discovery of zeolite tuff deposits with valuable sorption, cation exchange and other properties. The estimated resources of such zeolite-containing volcanic tuffs in the RivneVolyn region are hundreds of millions of tons, they are almost inexhaustible. The analysis of the tuff deposit and the results of geological research, according to Rivne and Kovel exploration expeditions, show that it is impossible to openly develop the deposit, as much of it is under productive privatized agricultural land and lands, and partly under forests belonging to protected area. The impossibility of open development is also due to excessive flooding of the territory and increasing the depth of tuff in the northern regions to 200 meters.

Due to the widespread use of zeolite-smectite tuffs, the issue of using well hydro technology for their production is included in the state program for the development of mineral resources of Rivne region and recorded in it a separate item with some funding.
\end{abstract}

\section{Physical and geographical haracteristics of the area}

Administratively, the territory of geological and ecological research is located within the Volyn and Rivne regions of Ukraine (Fig. 1). In terms of physical and geographical zoning, it occupies the north-eastern part of Volyn Polissya in the interfluves of the Stokhid - Styr and Styr - Goryn rivers.

The terrain is mostly slightly undulating, poorly drained, little runoff with some moraine hills and poorly defined valleys of small rivers. The research area is largely swampy (up to $30 \%$ ). The main massifs of swamps are in floodplains of the river, on the low-flowing plain, in smaller numbers on watersheds. The maximum absolute mark of the surface is south of the village Kostyukhnivka (tablet M35-16-G) - $h$. Polish, 206.2 m; minimal - in the floodplain of the Styr River on the northern border of the territory near the village of Cheeks $-154.8 \mathrm{~m}$. The ratio of the highest and lowest points is 51.4 
$\mathrm{m}$, the excess of watersheds over the valley of the river Styr, as a rule, are $17-25 \mathrm{~m}$, and reaching maximum values of 40-50 m only in areas of development on the interfluves of the Aeolian and moraine ridges. The relative height of individual hills reaches $23 \mathrm{~m}$; the steepness of the slopes is mostly $15-20^{\circ}$, rarely up to $30^{\circ}$. Styr Horyn is slightly dismembered, relative elevations are not more than 14-18 $\mathrm{m}$, the slopes are gentle.

Of the rivers it is necessary to note the river Styr - the largest water artery of the territory of works, its small tributaries Kormin and Stublu, and also small tributaries of the river Goryn - Virka and Chopelka. All these rivers belong to the basin of the Pripyat River. The largest waterway in the Styr district flows in the western part of the territory in the sub meridian direction. The width of the floodplain is mainly $1.5-2.5 \mathrm{~km}$, the riverbed $-20-50 \mathrm{~m}$, the depth of the river - $0.7-4.5 \mathrm{~m}$, the current speed up to $0.5 \mathrm{~m} / \mathrm{s}$. The river travels a lot, has many straits and old houses.

The left tributaries of the Styr River - Okonka, Pishchanka, and Gorbach stand out from the small rivers; right - Kormin, Stubla and left tributaries of the Goryn River - Chopelka, Virka, Berezhanka. All of them are canalized, in some areas serve as water intakes of reclamation systems. The hydrogeological regime of the Styr River is characterized by high spring floods and low summer lows, which are disturbed by torrential floods. The average annual amplitude of fluctuations is about $2.2 \mathrm{~m}$, the maximum reached $5.0 \mathrm{~m}$. The intensity of water rise is to some extent regulated by the Khrinniki Reservoir, located in the south of Volyn region and water-regulating facilities of reclamation systems on small rivers. River runoff during the year is uneven and, depending on the water content of the year, is distributed as follows: spring - 51-83 \%, summer - 3.8 \%, autumn - 5-12\%, winter - 8-29\%.

On the territory of the research there is one large lake - White, with an area of about seven square kilometers and a maximum depth of $48 \mathrm{~m}$.

The climate of the district is temperate-continental, humid, with mild winters, unstable frosts, frequent thaws, mild summers, and long rains in spring and autumn. One of the main factors in the formation of climate is solar radiation. The average annual intake of direct solar radiation is $92.7 \mathrm{kcal} / \mathrm{m}^{2}$. Annual albedo varies from 70 - 
$75 \%$ in winter to $9-10 \%$ in summer on the water surface. The annual radiation balance is positive and is $34-38 \mathrm{kcal} / \mathrm{cm}^{2}$. The vast majority of solar radiation (about $89 \%$ ) is spent on evaporation. The average annual air temperature is $+6.6{ }^{\circ} \mathrm{C}$, the average January temperature is $5.2{ }^{\circ} \mathrm{C}$, the average June temperature is $+17^{\circ} \mathrm{C}$. The annual rainfall reaches $700 \mathrm{~mm}$, which creates sufficient, and in some year's even excess moisture. Sometimes the amount of precipitation reaches $900 \mathrm{~mm}$, but it is never less than $400 \mathrm{~mm}$. The average humidity is $70 \%$. Here the winds of the western direction prevail: in the cold period - southern, south-western, and western; in the warm northwest. The average annual wind speed is $3.1 \mathrm{~m} / \mathrm{s}$, varying from $2.4 \mathrm{~m} / \mathrm{s}$ in August to $3.8 \mathrm{~m} / \mathrm{s}$ in March. Strong winds with a speed of more than $15 \mathrm{~m} / \mathrm{s}$ are infrequent, occurring mainly in the cold season.

Spring begins in the second half of March and lasts 70-80 days. This time is characterized by very intense floods, with heavy flooding of rivers. Summer is always warm, with sufficient humidity, begins in late May, when the average daily temperature exceeds +15 ${ }^{\circ} \mathrm{C}$. Autumn begins in late September. During this period, the amount of precipitation decreases. Winter comes in late November or early December. It is mild, with gloomy weather, frequent light precipitation in the form of snow and rain, with ice. The greatest snow cover is observed in February, on average $20 \mathrm{~cm}$, in some years it reaches 60-80 cm. In mid-December, swamps freeze, the greatest depth of freezing $-50 \mathrm{~cm}$. The depth of soil freezing averages about $60 \mathrm{~cm}$, but in some years reaches $100-110 \mathrm{~cm}$.

Ice cover on rivers is unstable, during thawing there is an increase in water level, and in some areas and river overflow.

A large area is covered with forests and wetlands. Of the woody vegetation, pine predominates, smaller areas are occupied by mixed deciduous-pine forests, in the south there are oak-hornbeam, and in the north - spruce forests.

The work area is densely populated (about 30 people per $\mathrm{km}^{2}$ ), but there are no large settlements. It is possible to note only the regional center of Vladimirets, Varash, villages Rafalivka, Stara Rafalivka, Stary Czartorysk, Tsminy, Romeyki. The main occupation of the population is agriculture and forestry. The largest industrial enterprise is the Rivne Nuclear Power Plant (Rivne NPP). In the city of Vladimirets there are objects of the food industry, in the village of 
Rafalivka concentrated woodworking enterprises and railway transport facilities. There are several quarries for basalts and sands.

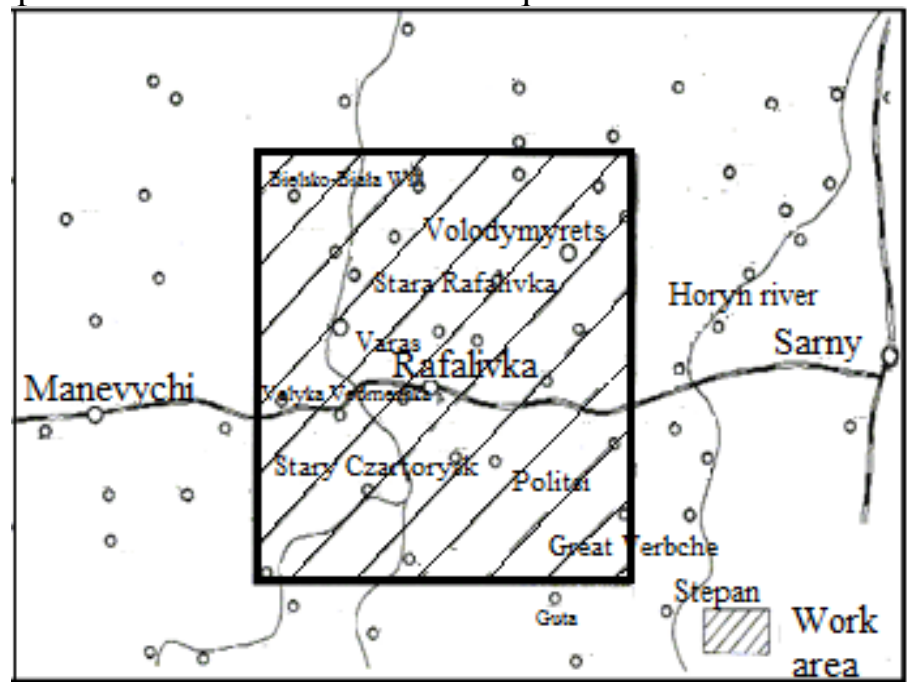

Fig. 1. Overview map of the area of geological and ecological research

Ways of communication are developed satisfactorily. The KovelSarny railway is available, the Volodymyrets-Varash-Rafalivka asphalt roads pass, it is a pass between Kyiv and the Western border. The villages are connected, both with each other and with the district center, and mostly with paved roads, less often with dirt roads.

\section{Characteristics of the relief}

The territory of geological and ecological research is located within Volyn Polissya, Polissya lowland of Ukraine [1] and is a denudation-accumulative plain, which belongs to the joint zone of the Pripyat embankment, Volyn-Podolsk plate and the north-western slope of the Ukrainian Shield. Volyn Polissya is located within the morphological structure of the same name, consists of the following morphogenetic sculptures.

I. Volyn water-glacial accumulative gently undulating and gently sloping plain with areas of stone hilly-ridge relief.

II. Sculpture Volyn gentle-hilly hill with smoothed forms of marginal moraines.

III. Turia-Kostopil gently undulating denudation plain. 
Volyn water-glacial accumulative flat-wavy and gently-hilly plain, with areas of the main moraine and stone hilly-ridge relief occupies the northern part of the sheets M-35-16-G and M-35-17-B, borders on the south with the Volyn Upland. Its formation is mainly due to the degradation of the Dnieper cover glaciation. The relief is flat and wavy with marks from $155-160 \mathrm{~m}$ in the north and up to $170-180 \mathrm{~m}$ in the south. The calm nature of the relief is disturbed by the gently undulating and hilly-ridged areas of the rocks formed in the inner zone of the regional glacial complex.

Exceeding the stone forms of the relief over the water-glacial plain from 2-3 to 10-20 m. Lake. It consists of ridge-hilly areas, not connected to each other, based on the raised surface of Paleogene and Cretaceous rocks, preserved from erosion in the form of plinths, covered by low-power marine moraines, dissected by weakly incised river valleys. Depth of vertical dismemberment from 5-10 to 20-30 $\mathrm{m}$. Karst relief forms are widely developed on the hill. Absolute surface marks range from 180-190 to $215 \mathrm{~m}$.

Turiysko-Kostopil gently undulating denudation plain occupies the southern part of the territory and borders on the north with the Volyn Upland. The described morphogenetic sculpture is formed by joint activity of denudation and erosion processes. There, glacial waters have shown accumulative activity, and the deposits formed by them cover more ancient sediments. When studying the geomorphological structure of the work area, an analytical method of mapping was used, a distinctive feature of which is the separate display of genesis and age with the inclusion of units of different taxonomic rank.

The geomorphological characteristics of the territory are based on the principle of selection of genetically homogeneous surfaces, including areas of the territory, both relatively simple genesis and more complex origin, due to the simultaneous action of a complex of different factors. The relief elements characteristic of this region are reflected in the following separate forms of relief.

\section{Denudation relief surfaces}

These surfaces are scattered on all morphogenetic sculptures of the work area. The relief of the hills and plains is complicated by karst and karst-suffusion funnels and depressions. Absolute marks of the plain are 160-170 m, height - 175-207 $\mathrm{m}$. 


\section{Accumulative relief surfaces}

Surfaces formed by swamp and lake-swamp accumulation of the Holocene age are very widespread and form wetlands of different configurations and areas within all morphogenetic sculptures.

The Volyn water-glacial plain is characterized by the largest wetlands, where the largest wetlands are developed, and biogenic accumulation predominates over terrigenous accumulation. The largest wetlands belong to the valleys of the rivers Styr and Stubla, hollows, lakes Bile and Stav.

Within the Turia-Kostolola denudation plain, wetlands are less developed, in the form of small isolated depressions, in interfluves, or in narrow, more deeply incised river valleys, where biogenic accumulation predominates over terrigenous. Within the Volyn Uplands, wetlands are poorly developed, mainly in isolated depressions and floodplains of small rivers. All wetlands of the study area are mostly lowland. The position of their surface below the surrounding area and the curved profile, cause the inflow to the swamp of groundwater, pressure and flood waters. By the nature of microlandscapes swamps are divided into grass, forest and moss. Plant formations are mainly pine-sedge, sedge, alder and reed. Transitional and upland bogs are limited, on the Volyn Upland and the TuriaKostopil Plain. Their surfaces are flat or weakly concave, fed by groundwater. Plant formations are mainly birch-alder-pinesphagnum. A large number of wetlands have been drained, which significantly changes the morphological accounting of the characterizing surface.

\section{Surfaces formed by alluvial accumulation}

Their formation is associated with the erosion and accumulation of rivers and streams of the Styr and Horyn river basins. The general plan of the hydro grid, due to the relief and geological structure of the territory, belongs to the branched-pinnate type, although the tributaries of the Goryn River often form a lattice-pinnate pattern. River valleys are asymmetric, trough-shaped, box-shaped, tray-shaped, with a flat bottom and gentle or gently concave slopes. Floodplain Holocene and the first floodplain Upper Pleistocene terraces were formed on the area of works by alluvial processes. Floodplain terraces are developed in the valleys of all watercourses that exist in the area of work, and the floodplain terrace was found only in the valley 
of the Styr River, which can be traced for $52.5 \mathrm{~km}$ and is the most pronounced element of the valley. The transverse profile of the floodplain of this river is trough-shaped. Its bottom is flat, or flatwavy, and the sides of various shapes, from sloping to steep 1-4 m high, and in areas of erosion of the valley and washing away bedrock - up to 6-7 m. In the lower reaches of the river floodplain sides are gentle height not more than $1 \mathrm{~m} \mathrm{[2-5].}$

Most of the floodplain terrace of the river is occupied by a flat, swampy, low floodplain, with a large number of old houses and exceeding the water cut from 0.5 to $3 \mathrm{~m}$. among low floodplains, erosive remains. The surface of the high floodplain is gently undulating, often complicated by eolian deposits. Its height above the low floodplain is $0.5-1.5 \mathrm{~m}$.

The width of the floodplain is 1-2 km with narrowing strips up to $0.5-0.7 \mathrm{~km}$ and widening up to $2.5 \mathrm{~km}$. Absolute marks of the surface of the floodplain of the Styr River vary from 166.5-170.0 $\mathrm{m}$ to 154.0 $\mathrm{m}$, decreasing downstream. The floodplain is embedded in the first floodplain terrace and adjoins the root slopes only at the intersection of the Volyn Upland. The bed of the Styr River is narrow, winding in relation to the floodplain, and it travels poorly in areas. Travels are diverse - segmental, sinusoidal, chest. In areas of modern elevations, the channel forms straightened areas, knee-shaped bends, the coefficient of mandrake is 1.03-1.08. Marks of water cut vary from 165.3 to $153.8 \mathrm{~m}$, the magnitude of the slope of the river Styr is 2.19. The floodplains of the Styr and Horyn tributaries are of the same type, narrow, from 5-10 to 500-700 m, winding, swampy, in the upper and middle parts of the flow they are weakly incised, almost not expressed in relief, covered with peat beyond the floodplains. Lower well expressed in relief, incised at 1-2 m, trough-shaped, with a flat bottom and gentle slopes. The tributaries of the Goryn River in the area of works (Verka, Smuha, Chopelka, Melnytsia) have 2-3 m inlets, chests, with a flat bottom and steep slopes. The valley of the Stubla River occupies an intermediate position between the Styr River and its tributaries. Its floodplain is wide (1-3 km), clearly defined in plan, trough-shaped, with a flat swampy bottom, low-alluvium (1.0-1.5 m). Terrace accumulative type, has a width on both banks from several meters to $3.5 \mathrm{~km}$. The surface is mostly flat, weakly dissected, and swampy, especially in the rear, often complicated by 
Aeolian landforms and eolian-deluvial deposits.

The height of the first floodplain terrace above the water level in the channel is 3-8 m, above the low floodplain 1-5 $\mathrm{m}$, and above the high floodplain 1-3 m Sopachi, as noted above, the rear seams of the floodplain are poorly traced. The rear seams of the floodplain terrace are practically not expressed in the relief. Absolute marks of the terrace surface vary from $154-155 \mathrm{~m}$ - in the north, to $165-170 \mathrm{~m}$ - in the south.

\section{Surfaces formed by lake-alluvial accumulation}

Near the settlements of Bielska Volia, Kolodia, Staryi Pidtsarevychi, Volodymyrets, Berestivka, and Politsi, small river valleys up to $0.5-0.8 \mathrm{~km}$ wide with a weak concave swampy bottom, gentle slopes and slow current are noted for lake-alluvial morphogenesis.

\section{Surfaces formed by glacial, water-glacial and lake-glacial ac- cumulation}

The formation of these surfaces took place during the activity of the Dnieper cover glaciation and its melt water.

In the proximal zone of the glacial complex, a sandy plain was formed, consisting of water-glacial flat and gently undulating surfaces, separated by depressions, depressions of melting glacial waters and complicated by hilly-ridge relief of rocks, eolian dunes and ridges, and sometimes.

In the periglacial zone a sandy flat-wavy plain was formed, complicated by areas of gently undulating lake-glacial surfaces, eolian forms of relief and karst-small-depressive relief. In the area of the village the smoothed small hills of marginal moraines are noted. The Volyn gentle-hilly hill separates the above-described zones. Its morphological structure was formed by marginal moraines lying on high plinths of Upper Cretaceous and Paleogene rocks, separated by depressions of melting glacial waters, which, inherited by modern drains and wetlands, are often complicated by Aeolian dunes and ridges and karsts. Depth of relief within the Volyn ridge $25-30 \mathrm{~m}$, on zander plains is $5-10 \mathrm{~m}$. Absolute marks of zander plains $157-160 \mathrm{~m}$ in the north and up to $165-175 \mathrm{~m}$ in the south, and moraine and stone hills from 175 to $206.2 \mathrm{~m}$.

\section{Eolian landforms}


Forms formed by wind accumulation are a regional feature of the Polissya relief. Developed in the study area is very wide, but uneven. The largest number of eolian forms is found along river valleys, on the slopes and at the foot of glacial and water-glacial hilly-ridge accumulations.

The described landforms of dunes, ridges, hills of parabolic type are presented. The dunes are oriented naturally and turned with the top of the parabola to the east, and the wings, which are located parallel - to the west. This orientation of the dunes indicates the predominance of westerly winds in their formation.

Dunes often merge to form parallel shaft-like shapes. The strands in the plan are rectilinear in shape, often oriented sublatitudinally, or from northwest to southeast. The slopes of the ridges, in contrast to the dunes, are gentler (steepness from 5 to $10-20^{\circ}$ ). The height of dunes and ridges is from 1-3 to 10-12 m, width up to $50-100 \mathrm{~m}$, rarely $200-500 \mathrm{~m}$.

\section{Eolian-deluvial landforms}

Scattered eolian, screened water-glacial, alluvial and moraine sands often form areas up to $1-2 \mathrm{~km}^{2}$, gently undulating and hilly plains, which rise above the adjacent surfaces by 0.5-2.0 $\mathrm{m}$.

They are located at the foot of Aeolian dunes and ridges, fluviocamps, moraine hills, along the brooches of summer terraces and other irregularities.

\section{Glacial landforms}

At the boundary of the glacial marginal zone and the per glacial zone is a strip of small smoothed remnants of marginal moraines, expressed in relief in the form of low, various configurations, domed hills with smoothed peaks and gentle slopes. Such forms of relief are often found on sheets M-35-17-B and M-35-29-A.

\section{Water-glacial landforms}

Kami formed in the proximal zone of the lattice glacial complex are one of the most characteristic features of glacial morphogenesis.

In modern relief, positive isometric or oval domed and conical slopes are represented. Often kami merge into a single whole, forming linearly elongated, gently hilly kami strands.

The sizes of stones change in wide limits, from $200-500 \mathrm{~m}$, to $1,5-2 \mathrm{~km}$ in cross section, and their height over adjoining surfaces makes from 1-2 $\mathrm{m}$ to $5-10 \mathrm{~m}$. 


\section{Fluvial forms of relief}

The relief forms formed by the activity of water flows are represented by erosional ledges, ravines, ravines, and valley-like depressions of the dead hydrogrid.

Erosion ledges are most pronounced in the valley of the Styr and Kormin rivers. Typical floodplain ledges are often slightly curved, 1$5 \mathrm{~m}$ high $6 \mathrm{~m}$.

Gorges and ravines in the study area are very rare: on the steep slopes of the Volyn Upland, adjacent to the valley of the Styr River, near the settlements of Babka, Stara Rafalivka, Tsmina, Kozlinichi, Stary Czartoryisk. V-shaped ravines, with steep walls up to 1-2 m deep, can be traced to a distance of not more than $50 \mathrm{~m}$. weakly concave, turfed, flat bottoms.

\section{Proluvial landforms}

Relief forms formed by temporary currents are found on the steep slopes of the Volyn Upland, near the settlements of Novaky, Rafalivka, Tsmina, Kozlynychi, and Staryi Czartoryisk. In the upper parts of the slopes, these are narrow, linearly elongated, sometimes branched runoff basins, along which small particles of rocks are transported by temporary currents, forming small removal cones and plumes at the foot.

\section{Karst landforms}

Karst in the study area is represented by both deep and surface forms, where marl-chalk rocks are karstic. Deep karst is developed throughout the territory in the form of cavities and cavities, which are filled with sand-clay-carbonate mass. The most complete underground karst has been studied at the karstological site near the Rivne NPP. Surface karst is developed in areas of high-basement Upper Cretaceous rocks, mainly in areas undergoing neotectonic uplift. Surface karst morphology is divided into 2 forms: funnel-shaped and saucer-shaped depressions, in the section of which certain patterns are observed in area.

Karst pits are widespread in the Volyn Upland, especially in the settlements of Novaky, Volodymyrets, Dovhovolya, Lyubakhy, Lozky, Varash, Zhovkin, Velyka Vedmezhka, Stary Czartoryisk, where there are accumulations of karst pits up to 20 or more pieces per $1 \mathrm{~km}^{2}$. They are much less common in the Turia-Kostopil plain (up to 10 units per $1 \mathrm{~km}^{2}$ ) and even less common (up to 5 units per 1 
$\left.\mathrm{km}^{2}\right)$ in the Volyn plain.

Karst pits, in plan, are isometric or oval, and their size varies widely - from a few meters to $110 \mathrm{~m}$ in cross section. The walls are steep (up to $40{ }^{\circ} \mathrm{C}$ ), often steep, turfed. The bottom is swampy or flooded with water. The depth of the visible pit is 1-3 m.

Karst and karst-suffusion saucer-shaped depressions are much larger (up to $300 \mathrm{~m}$ in cross section) and small (up to 0.5-1.0 m). The bottom is flat or slightly concave, sometimes swampy or flooded with water. Slopes are gentle (1-3), so their boundaries in relief are weak.

No new forms of karst on the territory of the works have been identified, but the violation of the hydrodynamic regime of groundwater by anthropogenic activity leads to the intensification of karst and suffusion processes. This is especially noticeable in drained areas, where karst-suffusion processes are intensifying. In the area of Rivne NPP after violation of the thermal regime of groundwater, there is an intensification of underground karst.

\section{Lakes}

Lakes are common only in the northern part of the territory and in the valleys of the rivers Styr and Stubla. Lakes outside the river valleys, near the settlements of Bilska Volya and Rudka, were formed as a result of glacier flooding of its melt water or filling of thermokarst depressions in the proximal zone of the glacial complex with water. The shape of these lakes is oval or round, the area from several tens of square meters to 80 thousand $\mathrm{m}^{2}$.

The largest lake Bile is of karst-glacial origin. Only its southeastern part is located on the territory of the works. It arose on the site of a large karst depression formed by the Dnipro Glacier, up to $43 \mathrm{~m}$ deep, with high northern and eastern and low wetlands - western and southern shores. Closed reservoirs of summer old women were also found on the first floodplain terrace of the Styr River. They are round in shape, sometimes elongated from $300-500 \mathrm{~m}$ to $1-2 \mathrm{~km}$, $50-150 \mathrm{~m}$ wide. The depth of the old houses is not great, from $1.0 \mathrm{~m}$ to 2-3 m, with low wetlands [6-9].

\section{Denudation ledges}

The ledges formed by the predominance of denudation processes over erosive ones were found on sheet M-35-28-B, north of Varash, 
north-western and south-eastern village of Velyka Vedmezhka, convex and steep $\left(10-40^{\circ}\right)$.

\section{Man-made landforms}

The forms of relief formed by human activity play a significant role on the territory of the works. They are divided into forms related to industrial-residential, agro-industrial, hydro-ameliorative, road construction, as well as mining.

During the industrial and residential construction there were various constructions, embankments and excavations not only within the settlements, but also outside them. Livestock farms, manure dumps, silo pits, etc. are connected with the agro-industrial complex. $\mathrm{Nu}-$ merous embankments and excavations are formed during the construction of highways and railways. During the reclamation construction, drainage systems, reclamation ditches, dams, ponds, and fire reservoirs appeared.

Mining is carried out in almost all settlements. It is mainly artisanal mining of sand and clay, in small quarries, which does not significantly affect the terrain.

Larger quarries, expressed in the scale of the map, are located near the settlements of Volodymyrets, Zhovkiny, Velyka Vedmezhka are sandy and clay quarries measuring about $100 \times 200$ and $100 \times 300$ $\mathrm{m}, 2-5 \mathrm{~m}$ deep, rarely up to $15 \mathrm{~m}$. Ivanchi are basalt quarries, up to $20 \mathrm{~m}$ deep, with heaps in the form of hills, an area of 1-2 hectares and a height of 10-18 m. flat platforms of different heights.

\section{Exploration of the field}

Rivne geological expedition in the process of deep geological mapping, search for native copper, diamonds and exploration of basalt raw materials volcanic tuffs in the Rivne region have discovered dozens of wells and several quarries. In the regional plan their petrographic, mineral, chemical composition, parameters of bodies and conditions of occurrence are studied. According to deep mapping data, volcanic tuffs can be traced under Mesozoic-Cenozoic deposits along the western slope of the Ukrainian Crystal Shield in the form of a strip 1-10 km wide at depths of 5 to $200 \mathrm{~m}$ (Fig. 2).

Of great interest as a mineral raw material are tuffs along their southeastern border of modern distribution. Here they lie shallow (meters and tens of meters) from the earth's surface and in some places are transformed by hydrochemical processes into zeolite- 
smectite raw materials, which are suitable for industrial use.

Tuffs lie in horizontal or slightly inclined (at angles of $1-5^{\circ}$ ) layers, forming thicknesses with a thickness of several meters to 140 meters. Together with basalt flows, they form the so-called trap formation (Volyn volcanic series) of the Lower Vendian.

According to the current stratigraphic scheme in the VolynPolissya depression in the section of the Volyn series there are four worlds (from bottom to top) in the section: 1 - Gorbash Gravelitesandstone with pyroclastic admixtures (up to $30 \mathrm{~m}$ ), 2 - Zabolotov basalt with layers of tuff (17-125 m), 3 - Babin tuff with separate streams of basalts $(100-220 \mathrm{~m}), 4$ - Ratne basalt with layers of lavoclastic breccias, horizons of tuffs, tuff sandstones, tuff argillites and tuff conglomerates $(30-190 \mathrm{~m})$. All the above summerstratigraphic subdivisions are composed of tuff material to a greater or lesser extent, but the most powerful layers of tuff are inherent in the Babin world, which in the context of the Volyn series in the Rivne region is most common.

On the territory of Rivne region tuffs lie under Mesozoic and Cenozoic deposits at depths from 4 to $60 \mathrm{~m}$ and stretch in the form of a strip through Volodymyrets, Sarny, Kostopil, Rivne and Goschansky administrative districts. They appear on the day surface only in the basalt quarries Berestovets, Basaltove, Politsi (Ivanchi), and outside the Rivne region, $5 \mathrm{~km}$ southeast of Slavuta, Khmelnytsky region in Tashka's career.

Volcanic tuffs of the main (basalt) composition are widespread in Volodymyrets, Sarny, and Kostopil districts. From the latitude of Rivne to the south-east in the context of the Babinka world, in addition to them, there are tuffites and tuff sandstones, which are characterized by impurities of terrigenous material from 10 to $25 \%$, rounded and semi-rolled forms of fragments of volcanic origin. The ash material here is significantly changed to complete conversion into clay products. According to textural features, among the pyroclastic rocks of the Babinian world in the Rivne region, massive varieties of tuffs, layered, thin- and obliquely layered, with cross-layered and vaguely layered tuffs are distinguished. These textures are due to the intermittency of tuffs of different shades and sizes of fragments. Change of layers and lenses happens sharp or gradual and vague. Sometimes the stratification is due to the oriented arrangement of 
elongated and flattened fragments. According to the size of the pyroclastic (fragmentary) material - medium- and small-fragmentary (psammitic) and ash fine-fragmented (siltstone) varieties, which form separate layers or often overlap with each other. Among them are sometimes found layers and layers of coarse-grained (psammitic) tuffs.

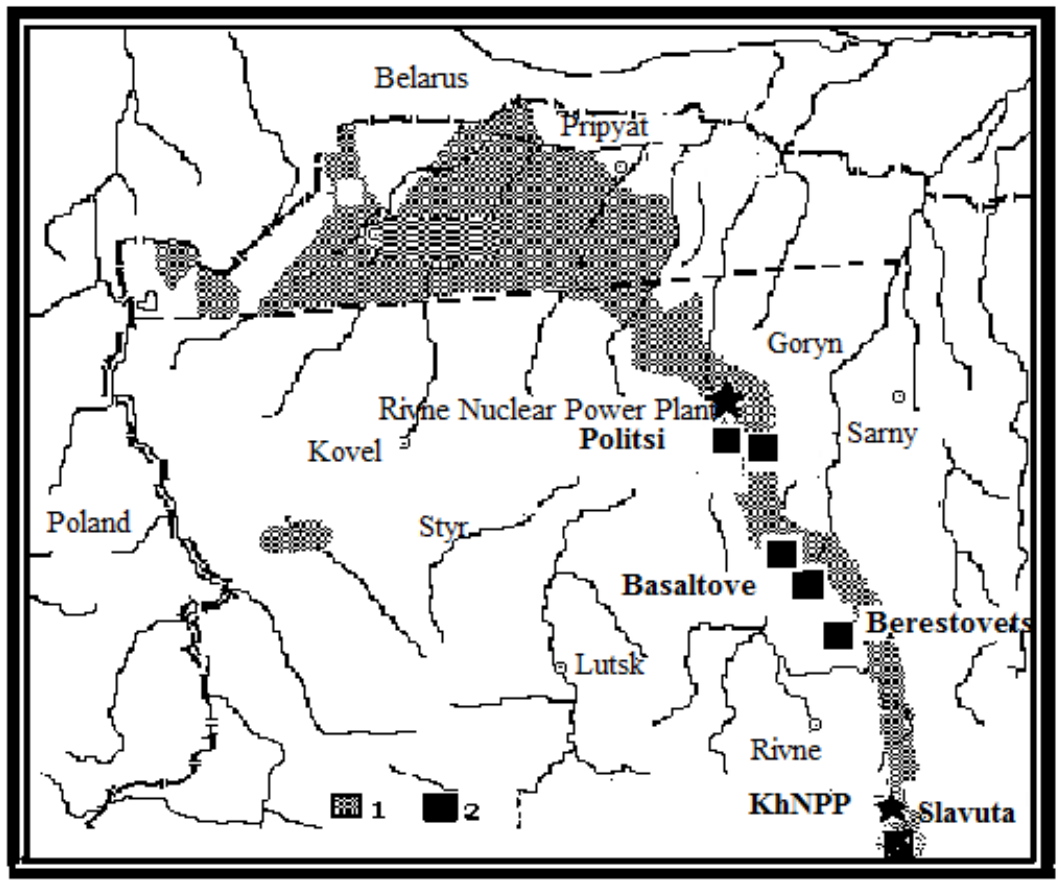

Fig. 2. Tuff outcrops on the pre-Mesozoic-Cenozoic surface (1) and in quarries (2)

Visually, it is greenish gray and chocolate brown, relatively soft rocks with a grainy structure and striped texture. When viewed under a polarizing microscope, they are composed of cemented fragments ranging in size from $0.01 \mathrm{~mm}$ to several $\mathrm{mm}$ in diameter of bubble slag, various in structure and composition of basalts, volcanic glass, occasionally intrusive types of ladders, and clastogenic minerals: plagioclase, liquid pyroxene quartz and potassium feldspar.

The fragments are bonded with cementing minerals: mainly 
analzyme, zeolites and smectites, to a lesser extent chlorite, chalcedony and calcite. Dominant in tuffs volcanic glass is largely replaced by smectites - clay minerals of the montmorillonite-saponite group.

\section{Geological characteristics of the deposit and material compo- sition}

These tuffs were studied in the most detail $2-3 \mathrm{~km}$ southwest of the village Ivanchi, where during the preliminary exploration of basalt raw materials it was drilled by 30 wells [10-13]. Here the following horizons of effusive rocks (bottom up) take part in the structure of the cover: 1 - lavaclastic breccias, 2 - almond-basalts, 3 - massive aphanite and plywood basalts, 4 - almond-stone basalts, 5 - lavoclastic basalts, 5 - lavoclastic breccias, volcanic tuffs composition. Effusive are underlain and covered with summer-wind-clastic, mainly psammitic tuffs and basalts. For direct observation, tuffs are available only on the outskirts of the village Ivanchi, where they form the bottom, as well as the base of the southern and eastern walls of the basalt quarry. In the southern wall and bottom of the quarry tuffs form a continuous horizon with an apparent length of up to $180 \mathrm{~m}$ and an open thickness of 0.3-1.7 m, which is sporadically observed within the quarry in an area of about $0.5 \mathrm{~km}^{2}$, varying from 0.1 to 7 $\mathrm{m}$, and is fixed around the quarry in the wells.

The tufa of the Rafalivsky quarry (near the village of Ivanchi) is represented mainly by medium- and small-fragmented psammitic varieties. They lie under the basalts in a thick (up to $100 \mathrm{~m}$ ) layer, which after the extraction of basalts is revealed in the bottom and walls of the quarry. In tuffs discovered by wells near the quarry, in the area of the Ivanchi basalt deposit ( $2 \mathrm{~km}$ southwest), a complete mineralogical analysis revealed high levels of zeolites, smectites and ferrous dispersed minerals, which are probably also smectites.

\section{Characteristics of the material composition of tuff raw mate- rials}

Freshly mined tuffs are well-cemented, semi-rocky rocks, but with prolonged exposure to moisture, they decompose easily to form a loose mass. After grinding these rocks on a jaw mill, the obtained tuff flour by granulometric composition corresponds to hard sand: contains particles with a size> $2 \mathrm{~mm}-25 \% ; 1-2 \mathrm{~mm}-32 \%$; 0.5-1.0 mm - $9 \%$; 0.25-0.5 mm - $14 \%$; 0.1-0.25 mm - $11 \%$; $0.1 \mathrm{~mm}-9 \%$ of the total mass of air-dry material. After grinding in a ball mill, the 
tuff material contains about $50 \%$ physical sand, 33\% dusty fraction and $17 \%$ clay matter, has a plasticity number of 5-7 and according to these parameters corresponds to low-plastic dusty sand. The bulk density of crushed tuff is in the range of $0.96-1.22 \cdot 10^{3} \mathrm{~kg} / \mathrm{m}^{3}$, and the specific surface area is $120-150 \mathrm{~m}^{2} / \mathrm{kg}$. The total porosity of the dispersed tuff material reaches about $30 \%$; swelling in water $-36 \%$, and in the presence of coagulant - $62 \%$. Water absorption is about $18 \%$ by weight and $33 \%$ by volume.

According to spectral analyzes, the average contents of microelements, including environmentally hazardous ones, in shelf tuffs generally correspond to the Clark values calculated for the main lithosphere rocks and the maximum allowable concentrations (MPC) in soils (Table 1).

Table 1 Average contents of microelements in tuffs of the Rafilovske deposit (42 samples) in $1 \cdot 10^{-4} \%$

\begin{tabular}{c|c|c|c|c|c|c|c|c|c|c|c|c|c|c}
\hline $\begin{array}{c}\text { Ele- } \\
\text { ments }\end{array}$ & $\mathrm{P}$ & $\mathrm{Pb}$ & $\mathrm{Ba}$ & $\mathrm{Mo}$ & $\mathrm{Sn}$ & $\mathrm{Cu}$ & $\mathrm{Zn}$ & $\mathrm{Ni}$ & $\mathrm{Zr}$ & $\mathrm{Co}$ & $\mathrm{Cr}$ & $\mathrm{V}$ & $\mathrm{Mn}$ & $\mathrm{Ti}$ \\
\hline $\begin{array}{c}\text { Aver- } \\
\text { age }\end{array}$ & 670 & 5 & 350 & 0,8 & 5 & 103 & 46 & 34 & 140 & 31 & 47 & 116 & 1240 & 5480 \\
\hline Clark & 1500 & 6 & 330 & 1,5 & 6 & 87 & 105 & 130 & 110 & 48 & 170 & 250 & 1200 & 8000 \\
\hline GDK & - & 30 & - & - & - & 100 & 100 & 100 & - & - & 100 & 150 & 1500 & - \\
\hline
\end{tabular}

Samples of tuffs extracted from other wells near the quarry, according to X-ray diffraction and thermal analyzes (6 determinations) contain on average $65.0(+16.0 ;-13.0) \%$ smectites of trioctahedral structure of a number of hectorite-saponite and 28, 17 (+14.83; $14.17) \%$ analcym. Tuffs were taken in samples (37 samples) at the Ivanchi basalt deposit, on average they contain: $\mathrm{SiO}_{2}-47.2 \% ; \mathrm{TiO}_{2}$ - $1.98 \% ; \mathrm{Al}_{2} \mathrm{O}_{3}-13.9 \% ; \mathrm{Fe}_{2} \mathrm{O}_{3}-11.9 \% ; \mathrm{FeO}-1.7 \% ; \mathrm{MnO}-0.17$ $\% ; \mathrm{MgO}-7.0 \% ; \mathrm{CaO}-2.79 \% ; \mathrm{Na}_{2} \mathrm{O}-4.87 \% ; \mathrm{K}_{2} \mathrm{O}-1.48 \% ; \mathrm{P}_{2} \mathrm{O}_{5}$ $-0.14 \% ; \mathrm{SO}_{3}-0.03 \%$; the rest $-6.65 \%$.

Ivanovo basalt deposit is located in Volodymyrets district of Rivne region and partly in Manevychi district of Volyn region of Ukraine. Geographical coordinates of the field:

$26^{\circ} 01^{\prime}-26^{\circ} 03$ '- east longitude

$51^{\circ} 12^{\prime}-51^{\circ} 13$ '- north latitude

The area of the field is $6.4 \mathrm{~km}^{2}$, including the area of preliminary 
exploration $-1.2 \mathrm{~km}^{2}$, has no natural boundaries.

According to the physical and geographical zoning, the area of the deposit is located on the Eastern European plain and belongs to the zone of mixed forests, to the subzone of Volyn Polissya [11-13]. Most of the area of the field is covered with forest, which belongs to the second group. The area of the deposit is characterized by accumulative types of relief - alluvial, glacial and water-glacial plains.

The deposit is located on a swampy plain with absolute marks of 168.8-173.8 m, adjacent to the watershed of the rivers Styr and Goryn. The modern surface has a general slope to the north, in the direction of the right tributaries of the Pripyat River. The area is characterized by wide sandy plains formed from sands of glacial origin. Formations of this origin include slopes and shafts, kami, as well as moraine plains. There are also ridges, shafts and slopes, which are unique forms of eolian relief. Forest species do not occupy large areas; they are blurred by water and survived only by individual islands on the sub-highlands. The lowest areas are occupied by swamps, peat deposits and wetlands.

This subzone (Volyn Polissya) has a climate of mixed forest zone, characterized by mild winters with thaws, warm and relatively humid summers, and gloomy rainy autumn with fog. Spring is always cooler than autumn. In winter, the southwest is dominated by relatively warm humid winds, which often come with thaws. In summer, westerly winds prevail. Dates of the first frost: the earliest - 14.09, The late - 07.11, The average - 06.10. Dates of the last frost: the earliest 04.04, the latest - 27.05, The average - 28.04. Duration without frosty period in days: maximum - 207, minimum - 124 , average 160. Dates of snow cover: the earliest - 02.10, Late - 23.12, Average 17.11. Dates of snow cover rise: the earliest - 17.02., The late 05.04, The middle - 19.03. The greatest average thickness of snow cover (in February) is $20-30 \mathrm{~cm}$.

Sod-slightly podzolic, sod-medium-podzolic gley soils are located in the area of works. River valleys are characterized by meadow, meadow-swamp soils and peat deposits. The average thickness of peat is $1.5 \mathrm{~m}$.

The main waterway of the district is the river Styr with the right tributaries Karmin and Stubla. Within the described area, the Styr River has a well-developed valley; the width of the river (up to $50 \mathrm{~m}$ ) 
allows the passage of small displacement vessels upstream to the village falcon in Rozhysche district of Volyn region.

The nearest settlement is Ivanchi is $2.8 \mathrm{~km}$ north of the field, Rafalivka railway station - $10.2 \mathrm{~km}$ north-west of it. $2.5 \mathrm{~km}$ northeast of the field is the Rafalivka Basalt Quarry, connected by a railway branch to the Rafalivka station. The capacity of the Rafalivka railway station (along the Rafalivka quarry) is up to 100 cars per day. A 10 $\mathrm{kV}$ transmission line is connected to the Rafalivsky quarry.

The population of the district is employed mainly in agriculture and forestry, as well as in fireplaces. Agricultural specialization: flax growing, dairy and meat cattle breeding, growing potatoes, grain, hemp and hops.

The set of labor in the area of the field is insignificant; there are no premises for rent. Water supply of the district is carried out at the expense of surface and underground waters (aquifers of quarter deposits).

\section{Physico-mechanical properties of tuffs}

Tuffs are characterized by thermal stability, resistance to aggressive environments and ionizing radiation, sufficient mechanical strength, the absence or presence of only trace amounts of toxic compounds, the absence of infection of the mineral by microorganisms.

According to their chemical composition, physical structure and properties, zeolites have much in common with bentonites and other fatty clays, alumina and similar mineral complexes, which determines the biological characteristics, targeted use of these compounds in various sectors of the economy, including livestock. However, the mechanisms of biological action of silicon-aluminum mineral complexes, the features of their use to improve the efficiency of livestock and crop production have not been studied enough. Due to the ability of these minerals at a temperature above $500{ }^{\circ} \mathrm{C}$ to emit water and allegedly boil, they were called "zeolites", "boiling stones". With careful heating (up to $+300-400{ }^{\circ} \mathrm{C}$ ) zeolite water can be removed without destroying the crystal lattice. At a temperature of 1000-1200 ${ }^{\circ} \mathrm{C}$ the edges of the zeolite melt quickly, so the water in the inner parts of the mineral cannot come out, resulting in swelling of the zeolite. Partially or completely dehydrated zeolites can reabsorb water and other gaseous and liquid substances. This is one of the main properties of zeolites. Ease of cation exchange is the second im- 
portant property of zeolites. It occurs without disturbing the crystal structure. The release of water from zeolites in most cases is the reverse process. The temperature of even partial dehydration and possible re-hydration varies greatly from sample to sample.

Table 2

Mineral composition of tuffs near the quarry Shelves (wt. \%)

\begin{tabular}{l|c|c|c|c|c|c|c}
\hline № well & 19 & 17 & 8 & 20 & 13 & 14 & $\begin{array}{c}\text { Aver- } \\
\text { age }\end{array}$ \\
\hline Depth of selection, $\mathrm{m}$ & 54,5 & 58,4 & 60,0 & 61,0 & 62,0 & 62,0 & \\
\hline Zeolites & 39,15 & 46,23 & 33,50 & 45,40 & 47,51 & 47,35 & 43,19 \\
\hline Smectite & 23,24 & 19,12 & 0,09 & 18,28 & 4,8 & 31,2 & 16,20 \\
\hline Iron dispersed minerals & 36,38 & 23,71 & 31,45 & 36,50 & 46,03 & 19,88 & 32,33 \\
\hline Feldspars & 0,92 & 9,13 & 13,73 & 1,6 & 0,89 & found & 5,25 \\
\hline Magnetite & 0,30 & 1,49 & found & 0,22 & 0,77 & 1,57 & 0,87 \\
\hline Martite & 0 & 0 & 3,52 & 0 & 0 & 0 & 0,59 \\
\hline Quartz & found & found & found & 0 & 0 & found & found \\
\hline Chlorite & found & found & found & 0 & found & found & found \\
\hline Pyroxene & 0 & 0,22 & 0 & 0 & found & found & 0,06 \\
\hline Mud & 0 & 0 & 17,66 & 0 & 0 & 0 & 2,94 \\
\hline Sum & 99,99 & 99,90 & 99,95 & 102,00 & 100,00 & 100,00 & 100,31 \\
\hline
\end{tabular}

Structural changes in zeolites that occurred during dehydration are studied using X-ray diffraction analysis, differential thermal analysis (DTA), thermogravimetric analysis (TGA), infrared spectroscopy (IR), nuclear magnetic resonance (NMR), mass spectrometry, and mass spectrometers. These structural changes range from the simple thermal expansion found in mordenite and the complex movement of cations, as in shabavit, fozhavit, mazzite, etc., to phase transformations into more dehydrated structures. There are three main models (types) of zeolite dehydration.

Type.1. Rapid dehydration in a relatively narrow temperature range, characterized by one narrow endothermic peak, abrupt weight loss on the TGA curve, marked changes in unit cell parameters and (or) phase transition. This behavior is characteristic of gismondin, natrolite, phillipsite, gmelinite, gaylandite and stilbit.

Type.2. Gradual dehydration in a wide range of temperatures, 
which consists of successive stages of dehydration, which is manifested in clear DTA and TGA reactions and which is accompanied by a gradual adjustment of the structure. This behavior is characteristic of edigonite, and is also found in lion's disease, gonarditis and lomontitis.

Type.3a. Multistage dehydration, consisting of the initial main reaction, followed by another, but weaker; thus, this type is a combination of 1 and 2 types. The adaptation of the structure occurs after the main reaction. This behavior is characteristic of Shabazite, Offretite, Erionite, Yugavaralite and Brewsterite.

Type. $3 \mathrm{~b}$. In fact, similar to type 3 a behavior when heated, but with the absolute predominance of the first clear endothermic peak and the absence of structural changes (mordenitis) or very minor structural changes (faujasite and clinoptilolite).

The different nature of dehydration when heated corresponds to different forms of water molecules in the structure. In type 1 dehydration, water is a necessary component of the structure, similar to hydrates. Type 2 dehydration is characterized by the presence of water in the appropriate position, but its presence is not required for the stability of the structure; it is held mainly by absorption forces inside the channels and cavities of the frame. The same applies to types 3 .

The complexity of this situation is determined by the interaction between large out-of-frame cations, water molecules and aluminosilicate frame. These cations are solvated (surrounded by water molecules) in the hydrated state; during dehydration they behave differently, depending on the degree of polarization and electrostatic energy. In the case of highly polarizing cations, water molecules are divided into a cation-bound hydroxyl and a proton, which is attracted to the oxygen of the framework. Weakly polarizing cations lose the surrounding water and reduce free energy by joining the oxygen of the framework. These two phenomena cause different deformations of the frame, which neutralize the existing electrostatic fields. Dehydrated and partially dehydrated zeolites are in the "activated" state and rehydrate very quickly, absorbing water from the atmosphere when in the air. Sorption properties of zeolites are not limited to water absorption; other molecules, polar and nonpolar (carbohydrates), can penetrate into the structure of zeolites. The "free diameter" of the channels is the main controlling factor for the entry of "external 
units", but the cations already present in the cavities can also limit the entry of insufficiently polar and active units. Moreover, the temperature affects the sorption properties not only qualitatively but also quantitatively, changing the effective size of the cavities.

High selectivity of adsorption and ion exchange on zeolites can lead to the accumulation of scattered chemical elements in them after the formation of minerals. The results of numerous chemical analyzes of zeolites known from the literature show that they contain almost all known chemical elements, including rare earths.

Due to the unique and diverse physicochemical properties of zeolites and other natural sorbents are beginning to play an increasingly important role in various industries and agriculture of developed countries. Ukraine has recently developed an interesting scientific field for the use of zeolites and other complex inorganic formations that have sorbing properties, as mineral additives in the production of feed and as fillers in premixes for animals.

Discovered more than two hundred years ago, natural zeolite minerals in recent decades have attracted the attention of agricultural scientists and practitioners in many countries. Japanese scientists were the first in the mid-1960s to show the possibility of using cheap zeolite tuff as a feed additive for animals, as well as for manure disposal and application to the soil along with fertilizers. The "zeolite boom" that began later in the 1970s was accompanied by an intensive search for zeolite tuff deposits in all parts of the globe. By the end of the twentieth century, about 1,000 deposits were already known in about 40 countries, including in Japan, USA, Italy, Bulgaria, Hungary, Cuba, China, Poland, Mongolia, Russia, Georgia, and Ukraine. The total explored reserves of zeolite deposits in the world are billions of tons.

According to Japanese researchers, the beneficial effect of zeolite in crop production is positive for 10 years after its introduction into the soil. From an economic point of view, zeolite justifies itself in two or three years, and in four years provides a stable income.

The difficult environmental situation in Ukraine encourages many domestic scientists and practitioners to find effective means by which to increase the efficiency of crop production, as well as at the lowest cost to improve the health of animals and get from them sound and environmentally friendly products. New technologies, ma- 
terials and means are needed for the general improvement of the ecological situation in the country, reclamation of lands affected by man-made pollution. The place and importance of these natural minerals such as zeolites have not yet been fully studied. In our opinion, it is interesting that in the presence of zeolites under the action of electric discharge from methane biologically active amino acids are formed, which may indicate the important role of alumina in the prebiotic formation of life on Earth. Zeolites have been used as a medicine in ancient Tibetan medicine. It has also long been known that they are well eaten by wild animals, especially in winter and spring, when changing feeds, disorders of the gastrointestinal tract and so on. The use of zeolites in medicine is rediscovered today. The use of zeolites as enterosorbents for the binding and excretion of radionuclides, toxic products of bacterial activity in the intestine, various kinds of intoxication of the body, etc. is promising.

In animal husbandry, zeolites began to be used as feed additives about twenty years ago in order to increase the daily weight gain of animals and poultry, under stress, to reduce the radiological load. Zeolites are especially useful in feeding animals low-quality feed, which usually leads to the development of dyspepsia, food poisoning, dysbacteriosis. A number of publications testify to the positive effect of natural zeolites as adsorbents in the removal (binding) of heavy metals from animals.

Contamination of a large area of land and water bodies of Ukraine with heavy metals and radionuclides creates an unfavorable environmental situation, which is being improved by scientists and practitioners from many sectors of the economy. They offer a large arsenal of drugs and other drugs that cause the excretion or binding of toxic compounds in the body. At the same time, there is an active search for such reagents that could block the negative effects of heavy metals on the approach of the latter to the animal or human body: preventive treatment of water, soil, green fodder, vegetables and more.

Given the fact that large-scale and large-scale areas require preventive treatment, the question of introducing such antitoxicants, which would be easily available in extraction and production, cheap and effective, arises in a timely manner. In this regard, the most promising is the use of natural zeolites. 


\section{Calculation of balance reserves of minerals}

The calculation of the balance reserves of minerals performed by specialists of the Rivne Geological Party in accordance with the approved regulations and is presented in table 3.

Table 3

Table of calculation of mineral reserves

\begin{tabular}{|c|c|c|c|c|c|c|c|c|c|}
\hline \multirow[b]{2}{*}{$\begin{array}{c}\text { Cat } \\
\text { ego } \\
\text { ry } \\
\text { of } \\
\text { sto } \\
\text { cks } \\
\end{array}$} & \multirow{2}{*}{$\begin{array}{l}\text { № } \\
\text { blo } \\
\text { cks }\end{array}$} & \multirow{2}{*}{$\begin{array}{c}\text { Area, } \\
\mathrm{m}^{2}\end{array}$} & \multirow{2}{*}{$\begin{array}{l}\text { Aver- } \\
\text { age } \\
\text { pow- } \\
\text { er, } m\end{array}$} & \multirow{2}{*}{$\begin{array}{l}\text { Volume, } \\
\mathrm{m}^{3}\end{array}$} & \multicolumn{2}{|c|}{ Including } & \multirow{2}{*}{$\begin{array}{c}\text { Volume, } \\
\mathrm{m}^{3}\end{array}$} & \multirow{2}{*}{$\begin{array}{c}\begin{array}{c}\text { Volu- } \\
\text { metric } \\
\text { weight, } \mathrm{t} \\
/ \mathrm{m}^{3}\end{array} \\
\end{array}$} & \multirow[t]{2}{*}{ Stocks, t } \\
\hline & & & & & $\begin{array}{l}\text { Industrial } \\
\text { purpose of } \\
\text { breeds }\end{array}$ & $\%$ & & & \\
\hline 1 & 2 & 3 & 4 & 5 & 6 & 7 & 8 & 9 & 10 \\
\hline \multirow{2}{*}{$\mathrm{C}_{1}$} & 1 & 977862 & 3,75 & 3666983 & $\begin{array}{l}\text { for tufa } \\
\text { smectite }\end{array}$ & 100 & 3666983 & 2,11 & 7737334 \\
\hline & 2 & 192928 & 8,45 & 1630242 & $\begin{array}{l}\text { for tufa } \\
\text { smectite }\end{array}$ & 100 & 1630242 & 2,10 & 3423508 \\
\hline \multirow{6}{*}{$\mathrm{C}_{2}$} & \multirow{3}{*}{4} & \multirow{3}{*}{473376} & \multirow{3}{*}{1,40} & \multirow{3}{*}{662726} & for rubble & 42,9 & 284309 & 2,67 & 759105 \\
\hline & & & & & $\begin{array}{l}\text { for tufa } \\
\text { smectite }\end{array}$ & 57,1 & 378417 & 2,09 & 790891 \\
\hline & & & & & total & 100 & 662726 & 2,34 & 1549996 \\
\hline & 5 & 1373933 & 15,50 & 21295961 & $\begin{array}{l}\text { for tufa } \\
\text { smectite }\end{array}$ & 100 & 2129561 & 2,09 & 44508558 \\
\hline & 6 & 1625156 & 6,72 & 10921048 & $\begin{array}{l}\text { for tufa } \\
\text { smectite }\end{array}$ & 100 & 10921048 & 2,09 & 22824990 \\
\hline & 7 & 1653017 & 27,42 & 45325726 & $\begin{array}{l}\text { for tufa } \\
\text { smectite }\end{array}$ & 100 & 45325726 & 2,09 & 94730767 \\
\hline
\end{tabular}

\section{Tuff extraction technology}

\section{Application of down hole hydraulic production of tuffs}

Well hydraulic extraction is a method of underground extraction of solid minerals, based on bringing tuff at the place of occurrence into a mobile state by hydromechanical influence and its release in the form of a hydraulic mixture on the surface. Well hydraulic production - one of the geotechnological methods of production - is the most effective for the development of deposits of loose, weakly cemented tuffs. The extraction of the useful component is carried out through special equipment and well preparation, and the production well is an opening, preparatory and threaded product, from which the purification of tuff is carried out. Methods of destruction of the tuff massif mainly depend on its strength. The separation of loose and weakly cemented permeable tuffs can be carried out by creating a filtration flow with the required value of the hydraulic gradient in the formation. It is most rational to destroy cohesive rocks with a hydro 
monitor jet of water. Intensification of the destruction process is possible due to vibration, explosion, and chemical or microbiological decomposition of the cementations substance. The destroyed tuff is fed to the suction of the dispensing device either by gravity (with a sufficient inclination of the sole of the chamber), or by pressure flows of water. Dispensing of the hydraulic mixture to the surface is carried out by means of a hydroelectric elevator, airlift, and submerged dredger or by creating back pressure, injection into the water or air deposit. A distinctive feature of down hole equipment is the harsh conditions to the transverse dimensions due to the need to work in the well. Hydraulic unit is a set of down hole hydraulic monitor and dispensing mechanism with a lifting and transport part and installation for transporting pulp from the unit. A production site is a part of the field prepared for operation, ie an area perturbed by production wells and which has access roads and communications for the supply of water, air, electricity to the production units, as well as a pipeline for transporting the hydraulic mixture. The extraction process is controlled from the surface by changing the use and pressure of the working agents, as well as the places of influence of the working agent and the selection of useful components. The choice of parameters of the technological process of down hole hydraulic production is determined by the geotechnological properties of the useful component and the physical - geological situation. Test work on the extraction of deep water-saturated sands, covered with clay rocks, was carried out in 1973 by the Institute of Foundations and Foundations Gersevanova together with the oil and gas management of Nizhnevar - Tovsknafta. The hydroelevator with a diameter of 490 $\mathrm{mm}$ was lowered into a well with a diameter of $510 \mathrm{~mm}$ at a pressure of $210 \mathrm{~m}$ of water developing pump. At a flow rate of $150 \mathrm{~m}^{3} / \mathrm{h}$ and a $37 \mathrm{~mm}$ nozzle, $40 \mathrm{~m}^{3}$ of sand per hour was extracted from a depth of $23 \mathrm{~m}$. Thus, the possibility of developing sands and gravel in the harsh conditions of Siberia and solving the important problem of providing building materials for areas of development of new oil and gas fields, where everywhere at a depth of 20-80 m there are sand deposits with a thickness of 5 to $40 \mathrm{~m}$.

\section{Development of deposits by SGV method in Poland.}

At the humidified phosphorite deposit in Buzhenin in 1965-1967, seven wells were drilled in $30 \times 30$ and $40 \times 40$ grids with 16 "pipes 
lined up to the tuff layer. Mining was carried out by one airlift. To prevent jamming of the airlift by collapsed large pieces of rock, it was placed in a movable pipe 12 ", which moved in a layer after the suction of the airlift.

When designing these works, it was assumed that if its angle of natural slope is $30^{\circ}$, the volume of production from one chamber will be about 1000 tons of tuff. However, in practice, production from one chamber did not exceed 100 tons: the main reason - the presence of layers that prevented the approach of tuff to the beginning of the well, and therefore the volume of the chamber did not reach the required size. In addition, there were difficulties such as jamming of the airlift in the well due to the fact that clogged the suction and discharge pipes of the airlift and hydraulic pipes of the surface.

In 1964-1965 in Tarnobrzeg experiments were conducted on the extraction of quartz sands for the glass industry. A layer of sand up to 30$60 \mathrm{~m}$ thick lies at a depth of $40 \mathrm{~m}$. The deposit is very moist. Mining was carried out by one airlift without hydromonitor destruction. Four wells were drilled and produced. The maximum production from one chamber was $900 \mathrm{~m}^{3}$ with a layer thickness of $30 \mathrm{~m}$. During the development of the next chamber, the surface collapsed a crater with a diameter of $14 \mathrm{~m}$ and a depth of 8-10 m was formed. After that, the experiments were stopped. The main reason for the negative results was that the development system did not take into account the influence of technology parameters on surface deformation.

\section{Development of dry deposits.}

Moscow Geological Survey named after S. Ordzhonikidze conducts research and industrial works on SGV sedimentary deposit, represented by sandy-clay deposits with a thickness of 0.5 to $2.0 \mathrm{~m}$. Overlying rocks - dense tertiary clays, depth of occurrence from 10 to $150 \mathrm{~m}$. For the destruction of tuffs (strength on the scale of M.M. Protodeacon $f=1.0-1.5$ ) required a water pressure of $5.6 \mathrm{MPa}$ at a flow rate of $150 \mathrm{~m}^{3} / \mathrm{h}$. At the same time productivity of $30-40 \mathrm{~m}^{3} / \mathrm{h}$ on rock weight is reached. Promising method of SGV and for working out of the cassiterite placers buried under the seabed. The complexity of the usual mining of these placers by dredgers is associated with significant losses in the process of gross excavation of placers covered with loose hollow rocks, with long (up to 10 months) winter and sea turbulence. 
Employees of the Institute of Physical and Technical Problems of the North of the YaF SB USSR Academy of Sciences proposed to develop these placers by the method of SGV from ice by artificial freezing of sea water and the thickness of the cover rocks. It is proposed to conduct mining without hydromonitor destruction by one hydroelevator. Experience shows that to ensure the profitability of development, it is advisable to use hydromonitoring destruction of tuff and its construction in the suction zone, and for pumping - airlift. Application of the SGV method in the USA.

This method was used in the experimental development of a uranium deposit from a depth of 61-107 $\mathrm{m}$. A hydromonitor with two nozzles was used to destroy the tuff: the water flow through them was $110 \mathrm{~m}^{3} / \mathrm{h}$ at a water pressure of $5.6 \mathrm{MPa}$. In addition, water was fed to the nozzle of the hydroelectric elevator $\left(134 \mathrm{~m}^{3} / \mathrm{h}\right)$ and to the drill bit $\left(27 \mathrm{~m}^{3} / \mathrm{h}\right)$ to destroy large particles of tuff reflected by the hydromonitor. Then the tuff through the lattice enters the suction of the elevator. The average productivity of the hydroelevator is $46 \mathrm{~m}^{3}$ / $\mathrm{h}$ for ore $\left(136 \mathrm{~m}^{3} / \mathrm{h}\right.$ for the hydraulic mixture). The concentration of solids in the pulp is $60 \%$ by weight. The level of the pulp in the chamber was maintained so that the jet acted in the air. It was found that with a layer thickness of $1.8 \mathrm{~m}$, the production will be 720 tons of tuff from each meter of the well with a chamber radius of $9.15 \mathrm{~m}$. Based on this development, it is planned to further develop deeper deposits. It is calculated that the joint operation of the elevator with the airlift is possible to extract from a depth of $460 \mathrm{~m}$. In addition, the possibility of pumping air into a sealed chamber to reduce energy consumption for lifting the pulp. It is estimated that, using the hydroelectric elevator together with the airlift and pumping air into the chamber, you can count on successful downhole hydraulic production from a depth of $2290 \mathrm{~m}$. The main characteristics of the field when choosing the parameters of development are the physical and mechanical properties of tuffs and rocks that contain them, the angle of incidence and thickness of the tuff layer, the thickness of the overlying rocks, hydrogeological conditions.

Physics-mechanical properties of tuff determine the most important parameters of SGV: specific consumption and required water pressure for destruction and flushing, parameters of hydrotransportation of rocks, the size of the alluvium map. The same properties 
largely determine the choice of basic equipment (pumps, hydromonitor, and output mechanism). Finally, the physical and mechanical properties of tuff depend on the loss and consistency during extraction, under-grinding during hydrotransportation, caking and drainage during storage. Physics-mechanical properties of roof rocks determine their resistance to exposure during the extraction of the tuff layer. According to the degree of stability of the roof rock can be divided into unstable (roof rocks collapse after tuff mining), stable (allowing tuff mining in chambers with a bare area up to 100-500 $\mathrm{m}^{2}$ ) and monolithic (allowing bare areas up to $500-1000 \mathrm{~m}^{2}$ ). The stability of the roof determines the parameters of the development system, the size of the chamber and the order of its extraction. The shape and elements of tuff bodies have a great influence on the effective use of SGV. The contact conditions of the rocks that accommodate them on the roof and sole determine the loss of tuff and methods of delivery (flushing) into the chamber. The thickness of the tuff layer largely determines the amount of production from one chamber and thus the economic efficiency of the method. However, the value of minerals plays an important role here. It may turn out that the high value of tuff allows you to effectively develop low-capacity tuff deposits. Under the conditions of treatment, tuff bodies should be divided into thin (up to $0.8 \mathrm{~m})$, low-power $(0.8-2 \mathrm{~m})$, powerful (2-15 $\mathrm{m}$ ) and very powerful (more than $15 \mathrm{~m}$ ). At the angle of incidence, the layers are horizontal $\left(0-5^{\circ}\right)$, sloping $\left(5-15^{\circ}\right)$, inclined $\left(15-45^{\circ}\right)$, and steep (more than $45^{\circ}$ ). The angle of incidence of the layer determines the method of delivery of the destroyed tuff to the suction of the dispensing mechanism, the greater the angle of incidence of the layer, the better the conditions of delivery to the chamber.

The depth of occurrence determines the design of mining equipment and affects the economic efficiency of the method. As the depth of occurrence increases, the cost of tuff extraction by the SGV method increases slightly. This allows you to effectively work out tuff bodies that lie at great depths or under bodies of water, the development of which in traditional ways is unprofitable or impossible.

Requirements for the quality of tuff, losses and consistency largely determine the parameters of the technology and equipment of SGV. Hydrogeological conditions affect the choice of mining equipment and the scheme of mining the tuff layer. If the water in- 
flow is low, the water can be pumped directly from the chamber and production is carried out in an unflooded bottom. With a large influx of water production can be carried out in a flooded face, but this significantly complicates the processes of destruction and delivery of tuff.

Wetness or complexity of the surface relief above the tuff body affects the design and type of equipment used for mechanization of mining operations, drilling rig, pipe layer and vehicles. The made equipment can be of general industrial purpose, in bog execution or with use of floating means (ship, pontoon, barge).

\section{Determination of design parameters of the airlift}

Usually when calculating the airlift are set: hourly productivity $Q$, the height of the rise $H s$ static or relative water level in the well $h_{\mathrm{st}}\left(\alpha=\frac{H}{h_{s t}+H}\right)$. Then the purpose of the calculation is to determine the parameters of compressed air and the choice of the compressor, the diameters of the air and slurry pipes, the design parameters of the nozzle. The following calculation procedure is used for this case.

1. Consumption of compressed air

$$
V_{0}=\frac{Q \cdot H \cdot \gamma_{g}^{\prime}}{23 \cdot 60 \eta_{i z} \lg \left(\frac{h}{w \cdot 10}+1\right)}
$$

where $\gamma_{\mathrm{g}}^{\prime}$ is the relative density of the hydraulic mixture, $\mathrm{kg} / \mathrm{m}^{3}$ : $\gamma_{\mathrm{g}}^{\prime}=\frac{\gamma_{v}}{\gamma_{g}} ; \gamma_{v}, \gamma_{g}$ - density of water and hydraulic mixture, $\mathrm{kg} / \mathrm{m}^{3}$, respectively; $h$ - dynamic level in the well, m; $\eta_{i z}$ - isothermal efficiency of the airlift

$$
\eta_{i z}=\frac{H \cdot \gamma_{g}^{\prime}}{23 \cdot q \cdot \lg \cdot\left(\frac{h}{w \cdot 10}+1\right)},
$$

where $q$ is the specific consumption of compressed air for the rise of $1 \mathrm{~m}^{3}$ of hydraulic mixture, $\mathrm{m}^{3} / \mathrm{m}^{3}$.

At $Q=50-300 \mathrm{~m}^{3} / \mathrm{h}$ and $H=80-300 \mathrm{~m}$, the optimal value of can be taken depending on the values of a
a 0,10-0,15
$0,15-0,25$
$0,25-0,35$
$0,35-0,50$ 

$\eta_{i z} \quad 0,25$
0,32
0,36
0,40

2. Determine the diameter of the air tube, $\mathrm{mm}$

$$
d_{\text {air }}=\frac{0,000125 \cdot \beta \cdot R \cdot T \cdot G^{2} \cdot l}{\Delta p p_{m}},
$$

where $p_{m^{-}}$the average pressure of compressed air in the pipe, $\mathrm{MPa}$;

$\Delta p$ - pressure loss, taken $5 \%$ of mercury; $R$ is the universal gas constant: $R=29.27 \mathrm{kgm} / \mathrm{kg} \mathrm{C}{ }^{\circ}(R=0.08211 \mathrm{~atm} / \mathrm{mol}, \mathrm{deg}) ; T$ is the average absolute temperature in this section of the pipe $T=\mathrm{t}{ }^{\circ} \mathrm{C}+273$ ${ }^{\circ} \mathrm{K}$; 1 is the length of the air network, $\mathrm{m}$, the length consisting of the actual length plus the length equivalent to the pressure loss on the local supports.

The value of $\beta$, which depends on the mass flow rate of compressed air, is determined by the formula

$$
\beta=\frac{2,86}{G^{0.148}},
$$

where $G$ - the amount of compressed air flowing, $\mathrm{kg} / \mathrm{h} ; \gamma$ - air density, $\mathrm{kg} / \mathrm{m}^{3}, V$ - air volume at manometric pressure, $V=\frac{V_{0}}{\rho_{m}+1}$; $\mathrm{m} /$ hour; $V_{o}$ - brought to normal conditions air flow, $\mathrm{m}^{3} / \mathrm{h}\left(r_{0}=\right.$ $0.10393 \mathrm{MPa}$ and $T_{o}=273 \mathrm{~K}$ ).

Usually at given values of $G, r_{t}, l_{n}$, taking the value of $\Delta p$, the diameter of the air tube is determined by known nomograms. You can use the formula to determine the diameter of the air tube $<\mathrm{mm}$.

$$
d_{\text {air }}=20 \sqrt{V} \text {, }
$$

3. The diameter of the slurry pipe can be determined by the formula of V.G. Geer, sm

$$
d_{e}=\sqrt[2,5]{\frac{Q}{k \cdot \alpha}}
$$

where $\alpha=\frac{h}{H+h}$ - the relative coefficient of immersion of the nozzle under the water level; $k$ is a coefficient that depends on the parameters of the airlift. 
Within the limits of the change of airlift productivity $Q=50-300$ $\mathrm{m}^{3} / \mathrm{h}$, lifting height $H=100-300 \mathrm{~m}$ and at values $\alpha=0.20-0.45$ the value of $k$ is equal to 0.24 , sm.

$$
\text { Then } d_{e}=1,77\left(\frac{Q}{\alpha}\right)^{0,4}
$$

4. Compressed air operating pressure $\mathrm{MPa}$,

$$
P_{w}=0,01\left(h_{D}+p_{1}\right) \text {, }
$$

where $p_{1}$ - air pressure losses in the air tube of the airlift and nozzle; usually take $p_{1}=0.03-0.05 \mathrm{MPa}$.

5. Starting pressure of compressed air

$$
p_{\text {starting }}=0,01\left(h_{\mathrm{st}}+p_{1}\right), \mathrm{MPa} \text {. }
$$

6. The compressor pressure is equal to the starting plus losses in the airlift $p_{1}$ and on the route $p, \mathrm{MPa}$

where $\Sigma p=p_{1}+p_{2}$.

$$
p_{\mathrm{K}}=p_{\text {starting }}+\Sigma p \text {, }
$$

7. Compressor performance is based on the number of airlift units and gives a margin of $20 \%$ for the unevenness of their work, $\mathrm{m}^{3} /$ minutes

$$
V_{\mathrm{K}}=1,2 \cdot \Sigma \cdot V_{0}, .
$$

Stocks of tuff raw materials in the Volyn region allow them to conduct long-term industrial production. First of all, they attract with their availability and wide possibilities for use. The presence of a rich microelement composition allows conducting research on complex industrial processing of tuffs, a deeper study of their properties and on this basis - to improve the technology of extraction and expand the field of use.

The existing experience of using tuffs in agriculture, animal husbandry, construction practically does not provide for deep technological processing of them in order to extract the most valuable components.

Intensive studies of tuff composition over the last decade have shown that its mineral composition requires an integrated approach to processing, as it is a source of valuable raw materials for industry. The presence of native copper, titanium, iron in quantities of industrial interest, requires improvement of mining and processing technology.

The main experience in the extraction of tuff raw materials is focused on the geotechnological method in the form of down hole hydraulic production. In Ukraine, quarry tuff mining is carried out in no more than three quarries with low productivity. However, tuffs asso- 
ciated with the development of basalt quarries are usually dumped, despite their rich micronutrient composition.

In the field of tuff research, the main focus is on down hole hydraulic technology, while it is indisputable that the use of dump tuffs is economically feasible, at the same time insufficiently studied the causes of technological difficulties, the properties of tuffs as a source of rock mass for further processing by existing methods in the mining industry. The issues of selective excavation, softening of tuffs, crushing and separation to the size required for processing are insufficiently studied.

One of the main economic problems that arise in the development of deposits is the choice of the most efficient way to develop them, and is the distribution of capital, which provides maximum mining, reducing construction time and return on investment, as well as minimum cost of minerals. Technical and economic indicators of the used method of development are determined by the initial mininggeological and hydrogeological conditions of the field and the adopted technical and technological decisions. As a rule, as a result of economic calculations, the optimal term of field development, enterprise capacity, current production volume, organization of works, operating costs, etc. are determined. A detailed comparison of different methods is possible only at the stage of technical design, so below we will consider only some aspects of the effectiveness of field development by the method of down hole hydraulic technology.

Significant differences between geotechnological methods and methods of open and underground development, as well as their novelty, determine a certain specificity of the methods of comparative economic evaluation of these methods. In open or underground mining, as a rule, rock mass is obtained, and in geotechnological methods - the finished product. Naturally, a comparison of different types of development technology should be made on the sum of the costs of obtaining the final product, including extraction, enrichment, etc. Therefore, in order to obtain comparative results when considering options, it is necessary to take into account the entire redistribution of tuff to obtain the final product. The efficiency of development is assessed by three main indicators - specific capital investment, cost and productivity. In addition, the evaluation of options should take into account profitability, payback period, construction time, return 
on investment, annual economic effect, as well as reducing the need for scarce equipment and materials. It is also necessary to take into account social factors - working conditions of workers. In this respect, geotechnological methods are more promising than other methods, because they usually do not require the presence of people in the recesses.

The construction of new mining enterprises operating on the old technology is inefficient, because such enterprises do not provide high economic performance, and the dynamics of their return on investment, as studies have shown in recent years, is clearly unsatisfactory. This is due to the high complexity of mining production and the high share of passive funds of the enterprise (mining, etc.). In general, the extraction of minerals by conventional methods is a very capital-intensive and capital-intensive industry (mainly due to mining). In addition, during the entire period of operation of the mining enterprise it is necessary to regularly (at the expense of capital costs) to prepare more and more new sites for mining. In geotechnological methods, enterprises are characterized by small passive and increased active assets, because geotechnological methods do not require mining (in the usual sense of the word), and the whole production process is reduced to drilling wells, their equipment and preparation for operation. Geotechnical mining technology does not require a huge amount (performed volume) of mining work. Due to this, the complexity of production and capital costs in geotechnological methods are less than in other methods. Thus, the cost of construction of an underground sulfur smelting plant with a capacity of 500 thousand tons/year is 5-10 times less than the cost of construction of the enterprise by conventional technology.

\section{Experience in using raw materials}

Mineral and petrographic characteristics of tuffs, their mineral composition, and structural features have been studied in sufficient detail, data on geological conditions of occurrence, chemical and mineralogical composition, favorable conditions of occurrence allow considering tuffs as a new type of mineral multipurpose raw materials. At the same time, this raw material, despite the availability of opencast mining, is almost not exploited today, but remains at the bottom of the worked-out areas of basalt quarries and is stored in dumps. As minerals, the volcanic tuffs of the Rivne region have not 
been sufficiently studied by specialized geological prospecting works and organizations. However, technological experiments and a number of studies of agrochemical, bioactive, environmental and sorbent properties of tuffs have shown their suitability for use in many sectors of the economy, in particular, in animal husbandry, poultry farming, plant growing, medicine, for the manufacture of sorbents for various types of intoxication.

The main areas in which tuffs are already used are as follows: 1). Agriculture - as a mineral fertilizer, preservation of seeds, additives to feed for animals and birds, a stabilizer for plant feeding. 2). Environmental - reclamation of radioactive contamination of soils, underground disposal of toxic substances, wastewater treatment. 3). Construction - production of building materials (bricks, tiles, ceramic tiles), production of cement and expanded clay, pigments for paints and colored concrete. 4). Binding materials - ore pelletizing, fertilizer pelletizing.

An increase in crop yields when using zeolite tuffs has been shown by studies of the National University of Water Management and Environmental Management, the Institute of Forage of the UAAN (Vinnitsa) and the State Control Research Institute of Veterinary Preparations and Feed Additives (Lviv). They developed the technical conditions Technical conditions of Ukraine 46.15.GO-0262001 for the use of tuffs of the quarries of the Rivne region. The Institute of Epizootology of the UAAS has developed technical conditions for the production of tuff flour from the Polytsi-2 deposit for use in veterinary medicine.

As noted by a number of researchers, in the Rivne region, 1.2 million hectares are exposed to radionuclide contamination as a result of the Chernobyl nuclear power plant accident, including 290 thousand hectares of agricultural land, while the pollution density exceeds the permissible norms by several times. According to the State Department of Ecology and Natural Resources, on the territory of Rivne region, due to the imperfection of the existing systems for the treatment of industrial effluents, gases, and other industrial waste products, man-made anomalies of strontium, lead, arsenic, nitrates, nitrites, organic harmful compounds are formed, usually located in close proximity to settlements and livestock facilities. Their concentrations are from 3-5 to 10 maximum permissible concentrations. 
Radionuclides and pollutants migrate by water and air, creating new man-made anomalies in places remote from pollution sources.

The presence of zeolite-smectite tuffs in the Rivne region can radically change the ecological situation and compensate for the lack of many elements in the surrounding space, since tuffs contain many useful micro- and macro elements and can additionally neutralize any harmful organic compounds, thereby improving the region's ecosystem.

The study of the geochemical situation of the Western region of Ukraine, which includes the territory of the Rivne region, showed that the soil and water lacked such biogenic trace elements as zinc, iodine, copper, cobalt, manganese, iron, selenium. This led to the lack of their content in plants, which contributed to their lack in humans and animals. This is especially true due to the lack of hematopoietic microelements in the synthesis of hemoglobin. Therefore, since the zeolite-smectite tuffs of this region contain a sufficient amount of all the listed elements, the area of their use can be significantly expanded. To date, the Rivne Regional State Administration for the past 10 years has been implementing a program for using tuffs to improve the environmental situation, reclamation of lands affected by the Chernobyl disaster in animal husbandry. Within the framework of this program, a team of scientists has developed a method of waste disposal using tuff. The aim was to increase the accumulating capacity of the layer of insulating waste coating with the simultaneous possibility of safe removal of moisture from the array of waste dumps by cleaning the infiltrate containing harmful substances with a layer of tuff. In this case, the deodorization of the environment is carried out. This method has been tested and proposed for widespread use.

The growth of the population in cities and the development of industry are associated with an increase in the amount of household and industrial waste, which, if untimely neutralized, worsen the ecological situation, polluting the air, soil, reservoirs of small, medium and large rivers, groundwater, as well as increasing the area of such territories that are in further cannot be used without special work on their restoration (reclamation). The number of landfills, which are a source of danger to all living things and have exhausted their capabilities, is growing. Landfills overloaded with landfills are a source 
of infection. In pound waters and bottom sediments near such landfills, the concentration of lead exceeds the norm by 4-36 times, zinc 2-14 times, copper - 2-8 times, mercury - 950 times, bismuth - 180 times. In addition, a greenhouse effect is created by gases $\left(\mathrm{CH}_{4}\right.$, $\mathrm{CO}_{2}$ ), which poison the atmosphere and cause spontaneous combustion in hot weather. At the same time, methane causes poisoning and death of vegetation.

The release of methane at landfills of municipal solid waste ranges from 5 to 20 percent of its global emissions and reaches an alarming level. Therefore, there is a need to design waste landfills as engineering and environmental structures in the system of a natural and technogenic complex.

The design method is based on the idea of increasing the sorption capacity of the insulating layer over the landfill of garbage and local pollutants with the simultaneous possibility of protecting the soil, safely removing moisture from the array of solid waste dumps by cleaning the infiltrate that contains harmful substances, and deodorizing the surrounding atmosphere.

The solution to this problem is achieved by implementing a method for storing waste at landfills by layering an insulating material and creating absorber trenches with an insulating material. For these purposes, zeolite tuff is used with high efficiency as a powerful natural sorbent and a by-product of basalt mining.

In addition, zeolite tuff has a high selectivity of absorption and the ability to separate the ions and molecules of different substances by size, and a sufficiently high mechanical and chemical resistance. High porosity, in comparison with quartz sand, provides an increase in the capacity of harmful substances; therefore it has higher ionexchange selectivity in comparison with a number of chemical elements, the content of which is strictly standardized.

References

1. Melnichuk V.G. Mineral resources of the Volyn trap formation. Proceedings of the scientific conference "Natural Resources of Volyn. Results of basic research (1993-2003)". Scientific Bulletin of Volyn State University. (2004) - №1. - R. 90-92. 
2. Melnichuk V.G., Mateyuk V.V. Tuffs of VolynPodillya as a new type of mineral resources. Problems of rational use, protection and reproduction of natural resource potential of Ukraine. Abstracts of the report of the 2nd AllUkrainian Scientific and Methodological Conference. - Chernivtsi, (2000). - R. 133-134.

3. Skakun L., Tkachuk A., Melnychuk V. Types of zeolite associations in hydrothermal formations of the Volyn series. Mineralogical collection. LNU, (2003) - № 53. Issue 1-2. - R. 4-13.

4. Melnichuk V.G., Novosad Ya.O. Basalt tuffs of VolynPodillya are a potential object of radioactive waste (RW) disposal. Geological science and education in Ukraine at the turn of the millennium: state, problems, prospects. - Proceedings of the scientific conference dedicated to the 55th anniversary of the Faculty of Geology of Lviv National University. LNU Publishing House. - Lviv, (2000). - R. 141-142.

5. Malanchuk Z.R. Scientific bases of well hydraulic technology. Exactly, (2002). - R. 204.

6. Tsilmag O. Mineral composition and formation of palagonite aggregates in the Vendian basalts of Volhynia. Mineralogical collection. LNU, (2005).

7. Cherney E.I., Malanchuk Z.R. Methods of selection and calculation of hydroelevator lifting of pulp of large hydraulic size. Bulletin of the UGUVHP. Sat scientific tr. - Exactly: UGUVHP, (2002). - Issue. №16. - R. 297-308.

8. Malanchuk Z.R. Modeling of hydromechanical processes of hydro-erosion of placer deposits. Sat scientific tr. "Geotechnical Mechanics". - Dnepropetrovsk: IGTM NAS of Ukraine, (2003). - Issue. №34. -R. 164-172.

9. Malanchuk Z.R. Methods for establishing rational parameters of erosion of minerals and underlying rocks. Bulletin of the UGUVHP. Sat scientific tr.- Rovno: UGUVHP, (2002). - Issue. №17. - R. 356-367. 
10. Malanchuk Z.R. Theoretical bases of calculation of pipelines of systems of borehole hydraulic extraction of minerals. Sat scientific tr. "Geotechnical Mechanics". - Dnepropetrovsk: IGTM NAS of Ukraine, (2002). - Issue №36. - R. 218224.

11. Malanchuk Z.R. Clarification of theoretical dependences of calculation of distribution pipelines of systems of a well of hydraulic mining. Sat scientific tr. "Geotechnical Mechanics". Dnepropetrovsk: IGTM NAS of Ukraine, (2002). Issue №34. - R. 393-401.

12. Naduty V., Malanchuk Z., Kurilov V. The development of works on complex recycling of raw materials of basalt open-pit minesfor the removal of aluminum concentrate. 3rd International scientific and technical conference. Innovative development of resource-saving technologies and sustainable use of natural resources. - Petrosani, Romania: UNIVERSITAS Publishing, (2020). - edition 3 / October 26. - P. 94-95.

13. Malanchuk Z.R. Resource-saving technologies of rawmaterial base development in mineral mining and processing. Multi-authored monograph. - Petrosani, Romania: UNIVERSITAS Publishing, (2020). - P. 514. 
https://doi.org/10.31713/m1103

\section{DEVELOPMENT OF ROOF BOLTING TECHNOLOGY FOR APPLICATION IN GAS- AND WATER-BEARING ROCKS \\ Krukovskyi O.P.}

Institute of Geotechnical Mechanics named by N. Poljakov of National Academy of Sciences of Ukraine, Corresponding member of NAS of Ukraine, Doctor of Technical Sciences, Deputy Director of the Institute, Ukraine

Krukovska V.V.

Institute of Geotechnical Mechanics named by N. Poljakov of National Academy of Sciences of Ukraine, Senior Researcher, Doctor of Technical Sciences, Senior Researcher in Department of Dynamic Effects of Rock Pressure Control, Ukraine

\section{Vynohradov Yu.O.}

Branch for Physics of Mining Processes of the M.S. Poliakov Institute of Geotechnical Mechanics of the National Academy of Sciences of Ukraine, Candidate of Technical Sciences, Junior Researcher in Department of Control of Rocks State, Ukraine

Abstract.

Roof bolting is traditionally used only to ensure the stability of mine workings and it is not considered as a means of influencing filtration processes in the host rocks. The purpose of this work is to substantiate the use of roof bolting as a technological method to reduce gas emission and water inflows into mine workings. To achieve this goal the mathematical model of coupled processes of deformation of layered coal-rock mass around the mine working with roof bolting and fluids filtration in the disturbed area has been developed.

It was shown that roof bolting restrains unloading of the boundary rocks from rock pressure and keeps them in triaxially compressed stress state. The permeability value decreases by the value of its technological component. The influence of roof bolting on the processes of methane and water filtration into the mine working was investigated. Methane filtration rate in the bolted area of the mine roof is equal to zero; consequently, methane from undermined gas emission sources does not participate in the filtration process. In different areas of the intersection of tectonic disturbance, water inflow into the mine working with roof bolting is 3-8 times less than in the working with frames.

Therefore, the use of roof bolting allows not only to keep the mine working in a stable state, but also to significantly reduce fluids inflows. Roof bolting can be 
considered as the second line of defense to be applied in the presence of gas- and water-bearing rocks.

Key words: filtration processes, geomechanical processes, mine workings, numerical simulation, roof bolting technology.

\section{Introduction}

Roof bolting is a spatial system of the roof bolts fixed in boreholes. The most promising method for increasing efficiency of bolts is such their layout in the space, which would keep host rocks in a triaxially compressed state.

Researchers at the Institute of Geotechnical Mechanics analyzed results of long-term observations and laboratory, computational and mine experiments conducted in more than 30 coal mines of Ukraine and established on their basis a concept of the rock-bolt support interaction, according to which supports unite into a single construction that can resist rock pressure. Such supporting limits the destruction of the host rock throughout the whole period of mine working operation. The field of application of roof bolting has been expanded for the difficult mining and geological conditions of coal mines in Ukraine. Thus, the technology of the bearing-bolt supporting was developed [1-3]. Subject to the regulatory requirements, monitoring and operation, the technology of bearing-bolt supporting allows [4]:

- to ensure reliable and safe operation of mine workings throughout the whole period of their operation;

- to increase coal production;

- to increase the average mine working construction speed;

- to simplify the mining work organization schemes;

- significantly improve the working conditions and safety of miners, economic and production performance of coal mines.

Many complications and accidents in mine workings are associated with presence of gas and water in coal beds and sandstones. Mining operations initiate the processes of deformation, cracking, water and gas filtration. Abundant water and methane inflowing in the mine workings, as a rule, leads to accidents, lengthy downtime of longwall faces, reduced productivity and, hence, to economic losses. sed downtime of stopes, reduced productivity and economic losses.

The use of roof bolting allows us to reduce the displacement of rocks into the mine workings to the minimum values, to preserve the 
enclosing rocks in the natural, monolithic state, and, therefore, to prevent the development of cracking in the zone of mine working effect. This suggests that the permeability of the host rocks in this zone will also be preserved at the natural level. This, in turn, should significantly reduce the intensity of fluids filtration and their inflow inside the mine working. The experience of mine shows that technological operations can affect filtration processes in the disturbed zone of the rock mass. Methods of mine workings construction, the amount of stope and wall advance actively influence the dynamics of stress field redistribution [5], the configuration of filtration area, permeability inside it and, consequently, the formation and direction of fluid flows in the disturbed area.

Roof bolting is traditionally used only to ensure the stability of mine workings. It is not considered as a means of influencing filtration processes in the host rocks. The purpose of our work is to substantiate the use of roof bolting as a technological method to reduce gas emission and water inflows into mine workings.

To achieve this goal, we set the following tasks:

- to develop a mathematical model of the coupled processes of deformation of the layered coal-rock mass around the mine working with roof bolting and fluids filtration in the disturbed area;

- to perform its numerical implementation using the finite element method;

- to investigate the influence of roof bolting on the filtration permeability caused by the mine working driving;

- to investigate the influence of roof bolting on the process of methane filtration from gas-bearing rocks and coal into mine workings;

- to investigate the influence of roof bolting on the process of water filtration during the undermining of water-bearing rocks;

- to develop a method to reduce gas emission and water inflows with roof bolting.

\section{Methods}

Deformation of the coal-rock massif can be described by the equation

$$
c_{g} \frac{\partial u_{i}}{\partial t}=\sigma_{i j, j}+X_{i}(t)+P_{i}(t)
$$


where $u_{\mathrm{i}}$ is displacements, $\mathrm{m} ; c_{g}$ is damping ratio, $\mathrm{kg} /\left(\mathrm{m}^{3} \cdot \mathrm{s}\right) ; \sigma_{\mathrm{ij}, \mathrm{j}}$ are derivatives of strain tensor components in $x$ and $y, \mathrm{~Pa} / \mathrm{m} ; t$ is time, $\mathrm{s} ; X_{\mathrm{i}}(t)$ is projections of external forces acting on volume unit of solid body, $\mathrm{N} / \mathrm{m}^{3} ; P_{\mathrm{i}}(t)$ is projections of forces caused by fluid pressure in porous fractured space, $\mathrm{N} / \mathrm{m}^{3}$.

A Coulomb-Mohr criterion is used to describe mathematically a process of rock transition into a disturbed state. A stress-strain state of rocks is analyzed with the help of following geomechanical parameters characterizing a degree of variety of the stress field components $\left(Q^{*}\right)$ and geostatic pressure relief of the rocks $\left(P^{*}\right)$

$$
Q^{*}=\frac{\sigma_{1}-\sigma_{3}}{\gamma H} ; \quad P^{*}=\frac{\sigma_{3}}{\gamma H},
$$

where $\sigma_{1}, \sigma_{3}$ are maximum and minimum components of main stress tensor, $\mathrm{Pa} ; \gamma$ is average weigh of overlying rocks, $\mathrm{N} / \mathrm{m}^{3} ; H$ is mining depth, $\mathrm{m}$.

Deformation of rocks during mining operations leads to a change in their filtration permeability [6-8]. The change in the values of the permeability coefficients depending on the components of the principal stress tensor can be described as follows [8,9]

$$
k_{\mathrm{tech}}=\left\{\begin{array}{l}
0, \text { for } Q^{*}<0.4 \text { and } P^{*}>0.2 \\
k_{\min }, \text { for } 0.4<Q^{*}<0.6 \text { and } P^{*}>0.1 ; \\
\mathrm{e}^{0.26 Q^{*}-4.65}, \text { for } 0.6<Q^{*}<1.0 \text { and } P^{*}>0.1 ; \\
k_{\max }, \text { for } Q^{*}>1.0 \text { or } P^{*}<0.1,
\end{array}\right.
$$

where $k_{\text {tech }}$ is coefficient of permeability, which is formed during the mine working driving, $\mathrm{m}^{2} ; k_{\min }$ is minimal value of permeability coefficient, $\mathrm{m}^{2} ; k_{\max }$ is permeability within zone of fracturing, $\mathrm{m}^{2}$.

It means that $k_{\text {tech }}=0$ within the zone of equal-component compression and elastic deformations, $k_{\text {tech }}=k_{\min }$ within the area of initial fissuring, $k_{\mathrm{tech}}=f\left(\sigma_{i j}\right)$ within the area of intense cracking, and $k_{\mathrm{tech}}=k_{\max }$ in terms of rock fracturing.

Some rock layers are initially permeable and they have permeability $k_{\text {nat }}$. Technological permeability $k_{\text {tech, }}$ which is formed during the mine working driving and depends on the stress tensor components, is superimposed on the natural $k_{\text {nat }}$ permeability fields

$$
K=k_{\text {tech }}+k_{\text {nat }} \text {, }
$$


where $K$ is absolute permeability coefficient, $\mathrm{m}^{2}$.

The equation of plane gas filtration, in terms of the available gasbearing rocks within the filtration area, is as follows [10]

$$
\frac{\partial p}{\partial t}=\frac{K}{2 m \mu_{g}}\left(\frac{\partial^{2} p^{2}}{\partial x^{2}}+\frac{\partial^{2} p^{2}}{\partial y^{2}}\right)+q_{g}(t),
$$

where $p$ is fluid pressure, $\mathrm{Pa} ; m$ is porosity of rock; $\mu_{g}$ is gas viscosity, $\mathrm{Pa} \cdot \mathrm{s} ; x, y$ are coordinates, $\mathrm{m} ; q_{g}(t)$ is function of gas emission, $\mathrm{Pa} / \mathrm{s}$.

The process of water filtration in disturbed rocks is described by the following equation [10]

$$
\frac{\partial p}{\partial t}=\frac{K}{\beta m \mu_{w}}\left(\frac{\partial^{2} p}{\partial x^{2}}+\frac{\partial^{2} p}{\partial y^{2}}\right)+q_{w}(t),
$$

where $p$ is water pressure, $\mathrm{Pa} ; \mu_{w}$ is water viscosity, $\mathrm{Pa} \cdot \mathrm{s} ; \beta$ is water-compressibility factor, $1 / \mathrm{Pa} ; q_{w}(t)$ is water release function, $\mathrm{Pa} / \mathrm{s}$.

The initial and boundary conditions for the tasks set

$$
\begin{aligned}
& \left.\sigma_{y y}\right|_{t=0}=\gamma H ;\left.\quad \sigma_{x x}\right|_{t=0}=\lambda \gamma H ;\left.\quad u_{x}\right|_{\Omega_{1}}=0 ;\left.\quad u_{y}\right|_{\Omega_{2}}=0 ; \\
& \left.u_{x}\right|_{t=0}=0 ;\left.\quad u_{y}\right|_{t=0}=0 ;\left.\quad \quad \quad\right|_{\Omega_{1}}=p_{0} ;\left.\quad p\right|_{\Omega_{2}}=p_{0} ; \\
& \left.p\right|_{t=0}=p_{0} ;\left.\quad \quad p\right|_{\Omega_{3}(t)}=p_{0} ;\left.p\right|_{\Omega_{4}}=0.1 \mathrm{MPa} \text {, }
\end{aligned}
$$

where $\sigma_{x x}, \sigma_{y y}$ are components of stress tensor, $\mathrm{Pa} ; \lambda$ is side thrust coefficient; $u_{x}, u_{y}$ are components of displacement vector, $\mathrm{m} ; p_{0}$ is fluid pressure in undisturbed rocks, $\mathrm{Pa} ; \Omega_{1}$ is vertical outer boundaries; $\Omega_{2}$ is horizontal outer boundaries; $\Omega_{3}(t)$ is time-depending boundary of filtering area; $\Omega_{4}$ is internal contour (mine working).

In order to solve the problems associated with filtration of fluids into a rock bolted working, we applied a finite element method [11, 12]. The roof bolt was simulated by the rod finite elements. At each time iteration [13], the influence of the stress field on the formation of the filtration area, the influence of change in fluid pressure on the stress state and decrease in the strength properties of rocks during soaking (in case of water filtration) are taken into account. 


\section{Results and discussion}

\subsection{Influence of roof bolting on rock permeability}

To form a rock-bolt slab in the mine roof, from 3 to 9 (depending on the size of the cross-section of the mine working and required construction power) steel-polymer bolts $2.4 \mathrm{~m}$ long are used. Deep rope bolts can be used to strengthen the rock-bolt slab.

The number of bolts in the walls of working and the scheme of their installation depend on the height of mine working, the presence of a coal seam, the strength of the coal seam and host rocks. For supporting the rock part of the sides, steel-polymer bolts with a length of 1.5 to $2.4 \mathrm{~m}$ can be used; for supporting the coal seam, plastic and wooden bolts 1.2-1.8 $\mathrm{m}$ long are used.

To study the influence of roof bolting on the permeability of host rock, we considered the cross-section of a mine working in a homogeneous massif consisting of argillite and compared two cases:

- the mine working is supported by frames;

- the mine working is supported with roof bolting.

As a result of the calculation, we have obtained stress fields and zones of inelastic deformations for these two cases. Fig. 1 shows the distributions of $Q^{*}$ parameter values and the zones of inelastic deformations (red color) at the moment of time $t=2$ days.

In the intact massif, outside the zone of influence of the mine working (Fig. 1, white color), rocks are in conditions of triaxial compression. The different-component nature of the stress field here, as a rule, is close to zero $\left(0<Q^{*}<0.2\right)$; fluids are contained in isolated pores, there is no filtration capacity and permeability coefficients is practically zero. With elastic deformation of the rock, microcracks and pores are closed, and filtration properties of the rock change little. The zone where the rock is deformed elastically does not belong to the filtration area either. 
$a$

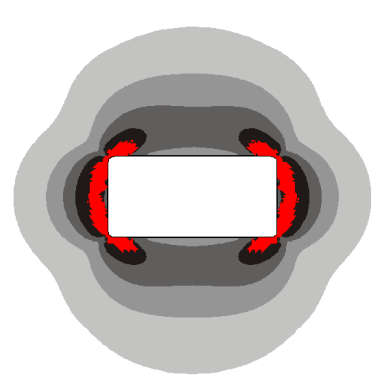

$b$

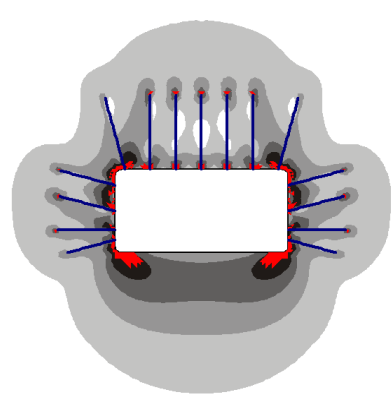

$Q^{*}>0.8$
$0.6<Q^{*}<0.8$
$0.4<Q^{*}<0.6$
$0.2<Q^{*}<0.4$
$Q^{*}<0.2$

Fig. 1. Distributions of $Q^{*}$ parameter values and zones of inelastic deformations: $a$ - the mine working with frames; $b$ the mine working with roof bolting

When constructing the mine working, the stress field around it changes: the minimum components tend to zero, and the maximum ones increase. Beyond the limits of elasticity and up to the ultimate strength, under multi-component loading, the following processes take place: the beginning of cracking $\left(0.4<Q^{*}<0.6\right)$, when the minimum permeability appears, and intense cracking $\left(0.6<Q^{*}<1.0\right)$, when the permeability coefficients increase by 2-3 orders of magnitude in various rocks. Further growth of permeability coefficients beyond ultimate strength occurs only due to the dilatation of existing fractures. In the area of destruction, which is characterized by the condition $P^{*}<0.1$, the permeability coefficients reach its maximum values.

In both cases (Fig. $1 a$ and Fig. $1 b$ ), areas of increased $Q^{*}$ parameter values are formed around the mine workings $\left(Q^{*}>0.4\right)$. The contours of mine workings surround the zones of inelastic deformation, which indicates an increase in the fracturing of the host rock, its stratification and destruction.

However, in the walls and roof of the mine working with roof bolting (Fig. 1b), the zone of inelastic deformations is much smaller than around the mine working with frames (Fig. 1a). In the mine roof, the area of increased $Q^{*}$ parameter values disappears and the undisturbed rock-bolt slab is formed, in which $Q^{*}<0.4$. Roof bolting keeps the boundary rocks in a natural, monolithic state, which ensures the stability of mine working with bolts. 
Using equations (3), we have calculated the values of filtration permeability coefficients in the study area, Fig. 2.

a
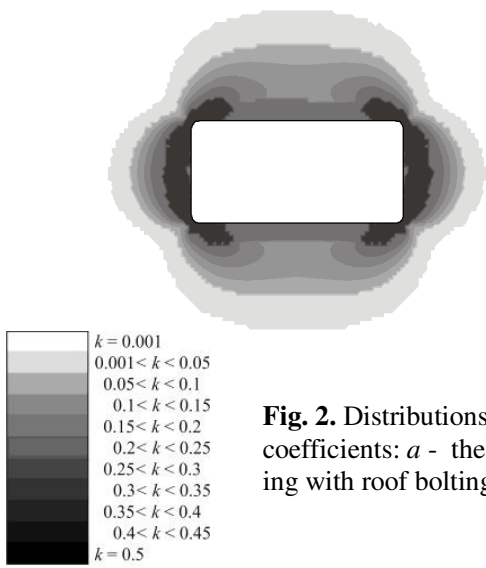
ing with roof bolting $b$

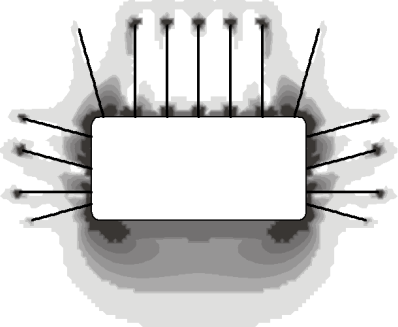

Fig. 2. Distributions of values of filtration permeability coefficients: $a$ - the mine working with frames; $b$ - the mine work-

It can be seen that a filtration area with non-zero permeability coefficients is formed around the working with frames (Fig. 2a). Within this area, fluids can freely move in the direction from the fluids emission source (gas- or water-bearing coal beds and rocks) into the mine working space.

The contours of the filtration area change if bolts are installed in the roof and walls of the mine working, Fig. $2 b$. In this case, the zone impermeable to fluids is formed in the mine roof. The rock from which it is formed, thanks to the bolts system, is preserved in its natural monolithic state. The high degree of integrity can be judged by the well-preserved traces of the executive body of the combine on the surface of the argillite, Fig. 3. Filtration of fluids through such a rock-bolt slab from fluids emission sources located in the mine roof is impossible.

The permeability in the walls of mine working with roof bolts is also significantly lower than in the walls of mine working with frames, Fig. $2 b$. 


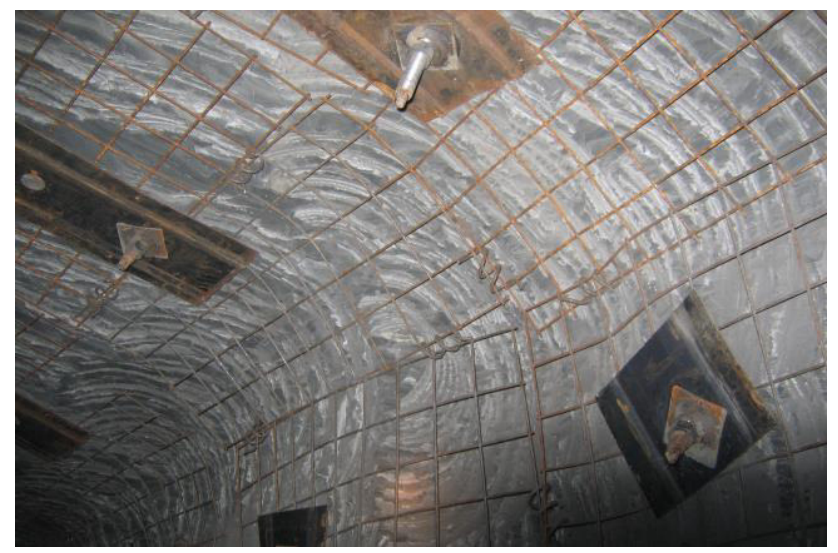

Fig. 3. Surface condition in the mine working with roof bolting

Roof bolting restrains the process of cracking in the zone of working influence. In this case, the size of filtration area is significantly reduced, the permeability inside it decreases, which leads to a decrease in the intensity of filtration movement, to the prevention or reduction of fluids inflow into the mine working with roof bolting.

Through a series of numerical experiments, we have investigated how each individual bolt affects the permeability value. After performing the calculations, we obtained the distributions of $Q^{*}$ parameter values, the zones of inelastic deformations and the fields of permeability coefficients for the cases when 1,3,5,7 and 9 bolts are installed in the mine roof, Fig. 4.

It can be seen that an impermeable region is formed around each bolt, where $k<0.001 \mathrm{mD}$ (shown in white in Fig. 4). When the number of bolts increases, these areas intersect, Fig. $4 d$ and $4 e$, and form an impermeable rock-bolt slab that protects the mine working from fluids inflows from the undermined roof rocks.

When bolts are used, $Q^{*}$ parameter values in the mine roof is reduced. Installation of each additional bolt increases the area of undisturbed rocks where $Q^{*<0.4}$ (Fig. 4) and reduces the size of the zones in which the roof rocks are unloaded from the rock pressure and $P^{*}<0.1$. Thus, the development of the process of cracking in the host rocks is not allowed, their natural solidity is preserved.Calculations showed that each wall bolt WB reduces the area of inelastic deformation zone in the walls of mine working, Fig. 5. 


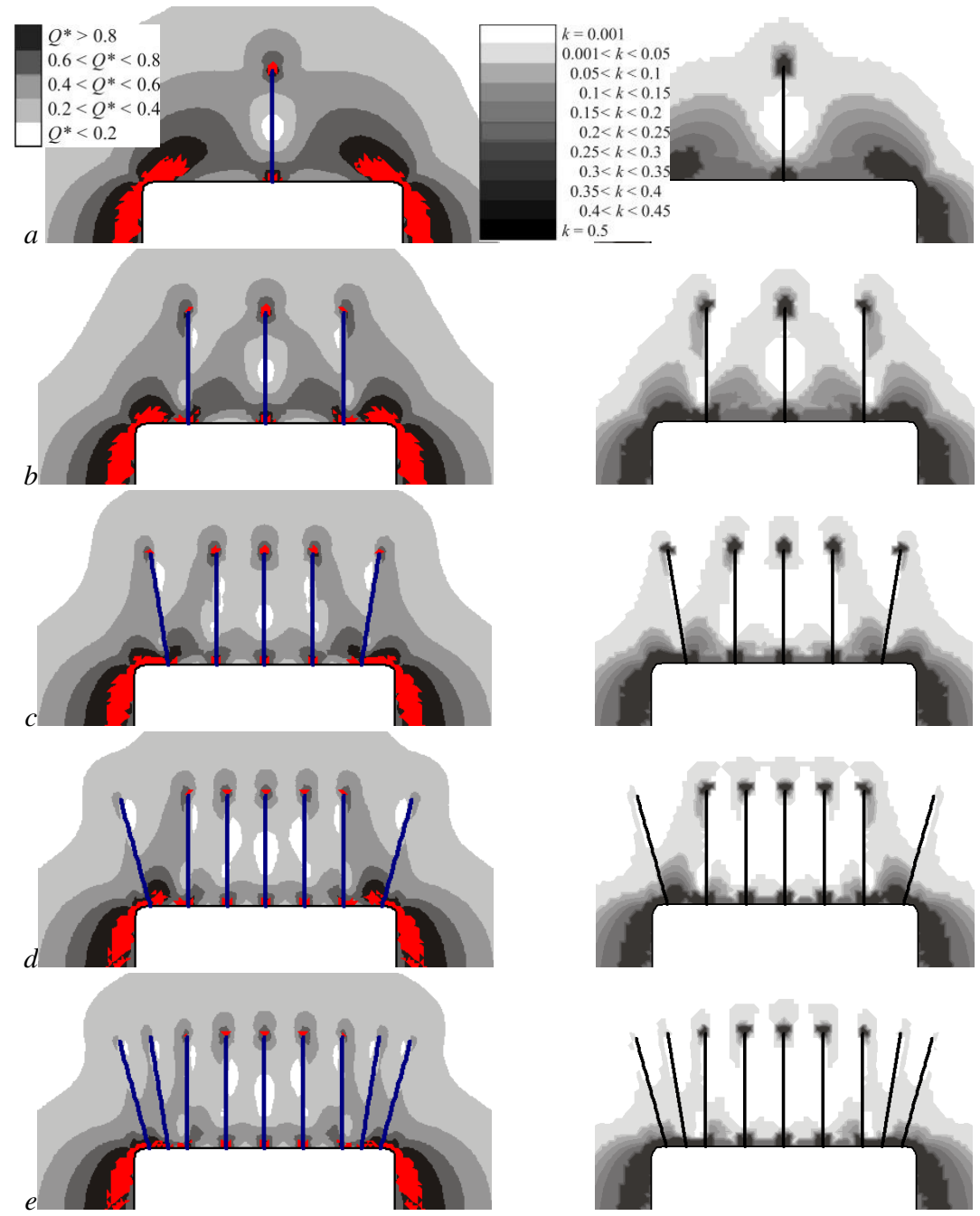

Fig. 4. Distributions of $Q^{*}$ parameter values (left side) and permeability coefficients $k$ (right side) in the mine roof with: $a-1$ roof bolt; $b-3$ bolts; $c$ - 5 bolts; $d-7$ bolts; $e-9$ bolts 


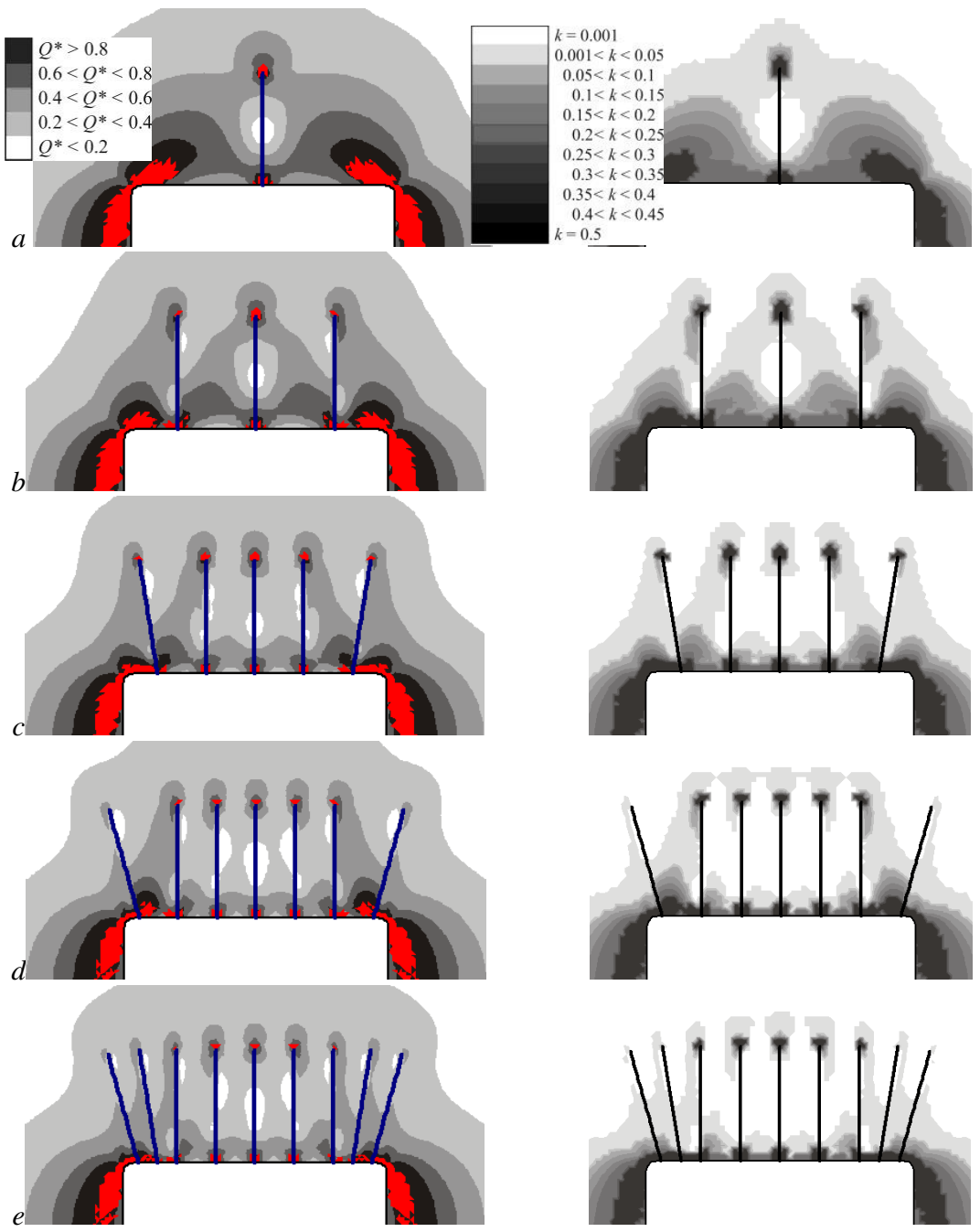

Fig. 5. Distributions of $Q^{*}$ parameter values (left side) and permeability coefficients (right side) in the wall of mine working: $a$ - no bolts; $b$ - with 1 bolt; $c$ - with 2 bolts; $d$ - with 3 bolts; $e$ - with 4 bolts 
The area where $Q^{*}$ parameter values are increased is also reduced. $P^{*}$ parameter values near the contour of mine working increase and become close to 0.2 . This means that the walls of mine working are kept in a stable state, the processes of cracking and coal squeezing are stopped and filtration permeability of this part of the boundary rocks decreases.

The graphs of changes in the values of $k$ in the roof and walls of mine working along the lines $a$ and $b$ (Fig. 6) are shown in Fig. 7.

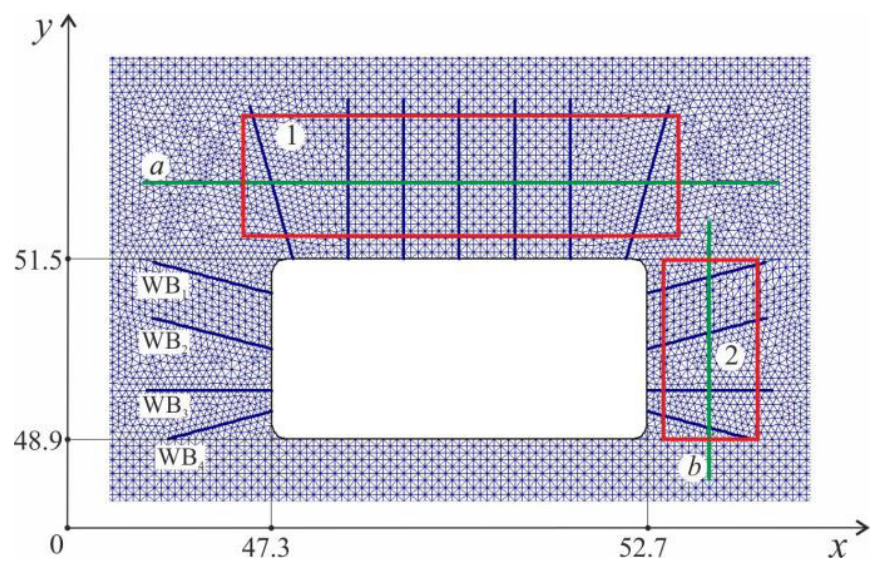

Fig. 6. Central fragment of the finite element mesh: 1 - the bolted area of roof rocks; 2 - the bolted area of wall rocks

Fig. $7 a$ shows if 5 or more bolts are installed in the mine roof, and 4 bolts are installed in the each wall of the mine working, then the permeability coefficients of the host rocks do not exceed $0.001 \mathrm{mDa}$ (for the above-described initial, boundary, mining and geological conditions and bolts location scheme).

The performed calculations show that wall bolts reduce filtration permeability coefficients in the walls of mine working to a level of $0.001 \mathrm{mDa}$ and below:

- bolt $\mathrm{WB}_{1}$ by $35 \%$;

- bolts $\mathrm{WB}_{1}$ and $\mathrm{WB}_{2}$ by $46 \%$;

- $\mathrm{WB}_{1}, \mathrm{WB}_{2}$ and $\mathrm{WB}_{3}$ by $77 \%$;

- $\mathrm{WB}_{1}, \mathrm{WB}_{2}, \mathrm{WB}_{3}$ and $\mathrm{WB}_{4}$ by $100 \%$. 

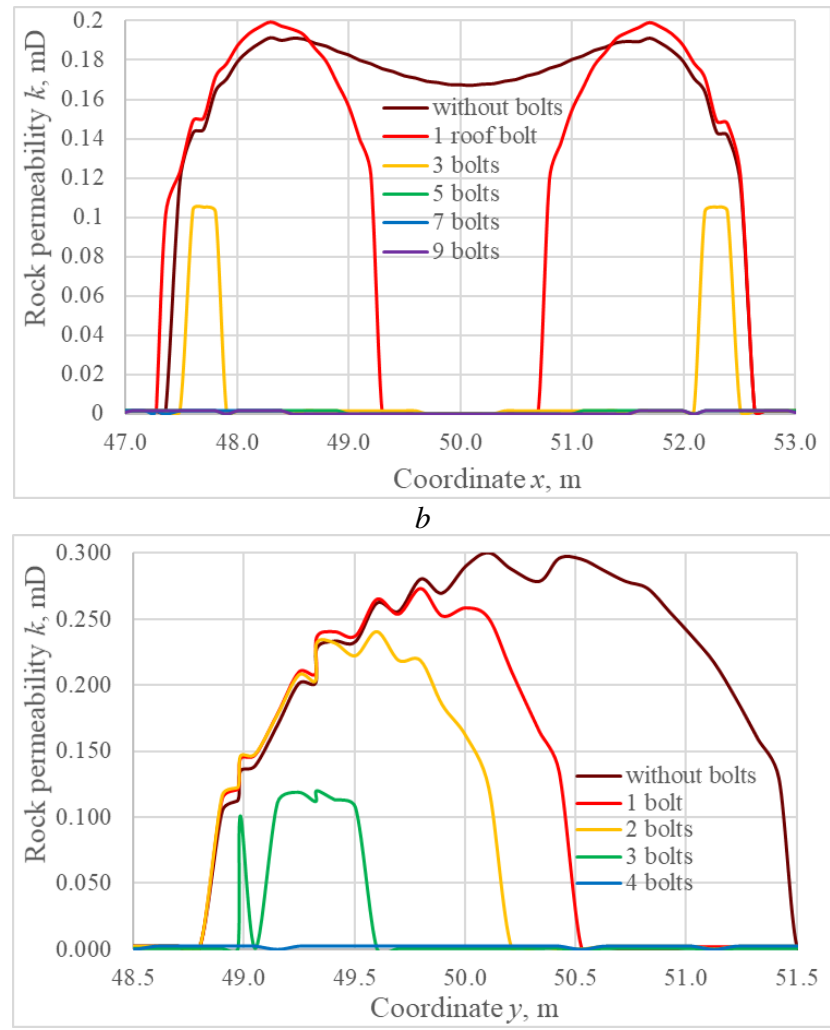

Fig. 7. Rock permeability: $a$ - in the mine roof; $b$ - in the walls of mine working

The change in the average permeability coefficients value in the bolted areas (Fig. 6) of the mine roof and walls is shown in Fig. 8.

Each bolt installed in the roof of mine working (if their number is less than 7) reduces the average permeability of the roof rocks by 10$40 \%$. However, a further increase in the number of bolts does not lead to any significant change in the average permeability in the bolted area of the mine roof.

Each of the bolts installed in the wall of the mine working reduces the average value of the permeability coefficients in the bolted area by $8-38 \%$. 


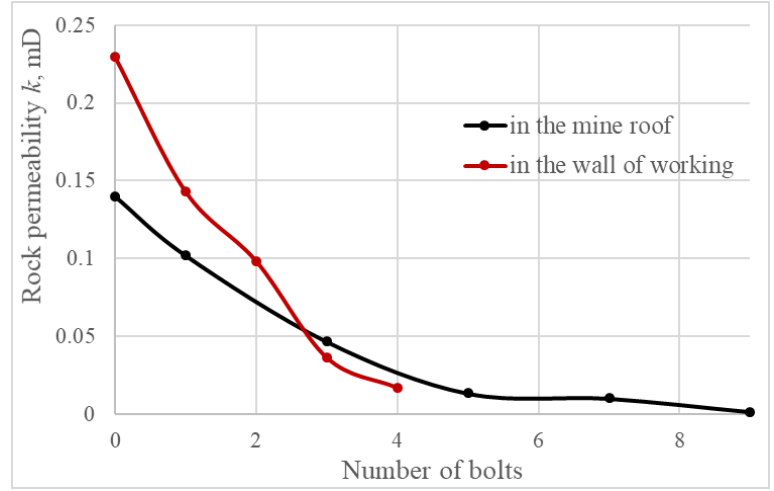

Fig. 8. Average rock permeability in the mine roof and walls

Roof bolting reduces the average filtration permeability caused by the redistribution of the stress field during excavation by 15 times or more, Fig. 8.

\subsection{Methane filtration into mine workings with roof bolting}

Mining operations in coal mines initiate the processes of rock deformation and filtration of methane, which is contained in the fractured-pore space of coal and gas-bearing sandstones. Increased methane inflow from the coal bed and undermined rocks, methane breakthroughs and blowers, gas-dynamic phenomena are the result of two closely coupled processes occurring together in time: stress redistribution and gas filtration.

In many cases, methane released into the atmosphere of mine workings impedes efficient coal production and becomes a threat to the safety of miners. On the other hand, coal bed methane is a quality gas that requires minimal processing. It is environmentally friendly and efficient fuel than coal. Methane can be extracted as an independent fossil and as a by-product obtained in the process of degassing. In both cases, the study of the methane filtration process is of scientific and practical interest.

Using the above mathematical model of the coupled processes of changing the stress state of the gas-bearing rocks and methane filtration, we investigated how the roof bolting affects filtration parameters. As an example, the conditions for Western flank ventilation en- 
try №23, coal seam $i_{3}$ of the Sukhodolskaya-Vostochnaya mine of Krasnodonugol PJSC were considered.

This rectangular mine working was constructed at a depth of $915 \mathrm{~m}$ by drilling-and-blasting way along a gas-bearing coal seam with a thickness of $1.9 \mathrm{~m}$ and a strength of $15 \mathrm{MPa}$. The seam roof is mainly represented by siltstone with a thickness of $3.0 \mathrm{~m}$, which is unstable in its lower part. This can provoke collapses to a height of $1.0 \mathrm{~m}$. Further, a gas-bearing sandstone with a thickness of $10 \mathrm{~m}$ occurs in the seam roof. The gas content of coal is $22.5 \mathrm{~m}^{3} / \mathrm{t}$, the gas content of sandstone is $1.5 \mathrm{~m}^{3} / \mathrm{t}$.

The bolts location scheme for Western flank ventilation entry №23 is shown in Fig. 9.

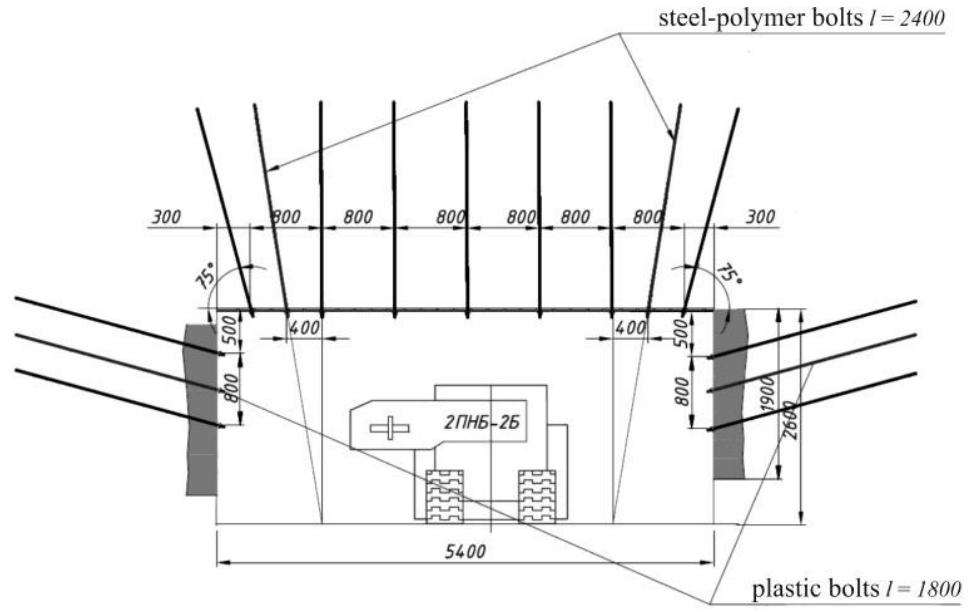

Fig. 9. The bolts location scheme

Fig. 10 shows distributions of $Q^{*}$ parameter values and the areas of inelastic deformations calculated for the mining and geological conditions of Western flank ventilation entry No.23. For comparison, the calculation results are presented in the cases of using frame support and roof bolting according to the scheme shown in Fig. 9.

Over time, in the host rocks, $Q^{*}$ parameter values increase and the zone of inelastic deformations grows. It can be seen that the presence of more durable sandstone in the mine roof leaves an imprint on distribution of $Q^{*}$ parameter values. 


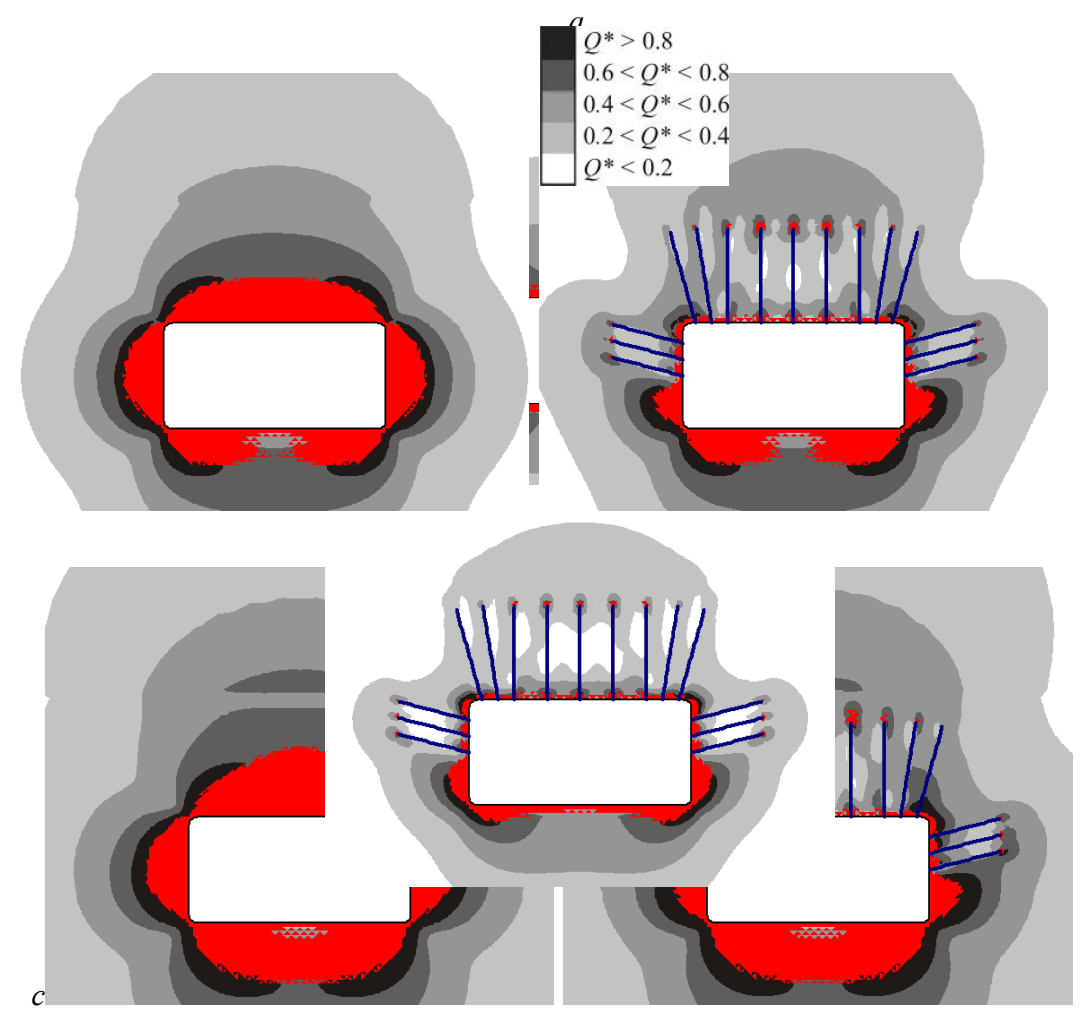

Fig. 10. Distributions of $Q^{*}$ parameter values around the mine working with frames (left side) and roof bolting (right side): $a-t=$ day; $b-t=3$ days; $c-t=15$ days

A rock-bolt slab is formed in the mine roof with bolts, the siltstone in this area is preserved in its natural, monolithic state and $Q^{*}<0.4$. In the bolted areas of the roof and walls of the mine working, the zone of inelastic deformations practically disappears; with the installation of bolts, the process of cracking in the mine roof mine does not develop, Fig. 10.

Based on the results of calculating geomechanical parameters, the field of permeability coefficients was calculated, Fig. 11. 


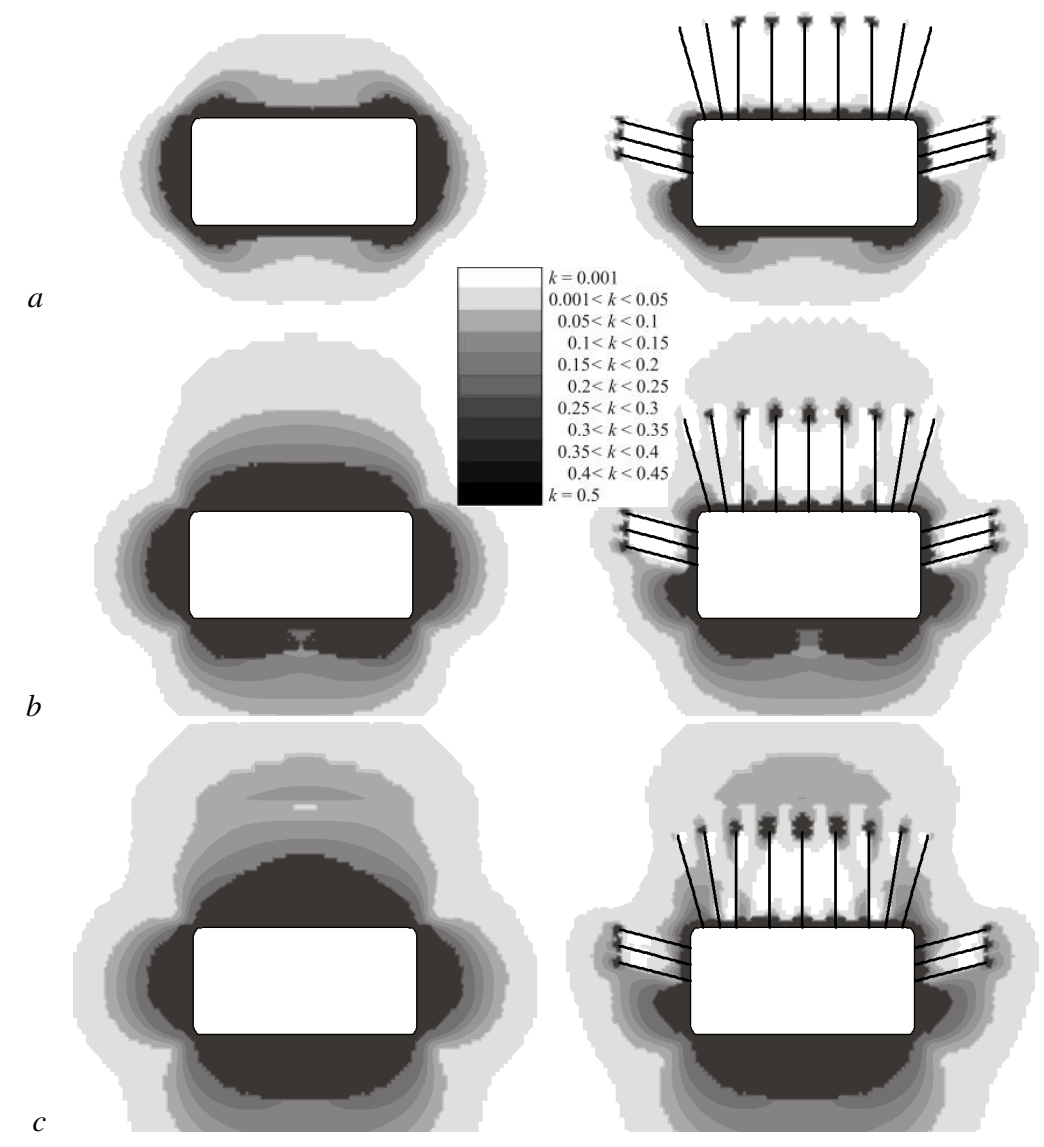

Fig. 11. Distributions of permeability coefficients values around the mine working with frames (left side) and roof bolting (right side): $a-t=1$ day; $b-t=3$ days; $c$ $t=15$ days

In the case of frame support, the filtration area, where $k>0$, includes the coal seam in the walls of mine working and the lower part of the gas-bearing sandstone located in the roof. Inside this filtration area, methane can freely move in the direction from the gas emission sources into the mine working atmosphere, the pressure of which $(0.1 \mathrm{MPa})$ is much lower than the methane pressure in the undisturbed massif (up to 8-12 MPa). 
On the left side of Fig. 11, you can see how the contours of filtration area change if the mine working is supported with roof bolts. In this case, both in the coal seam, in the walls of mine working, and in its roof, between the sandstone and the mine working, there are areas impermeable to gas. The bolts keep the siltstone in these areas in its natural monolithic state. Methane filtration through such an area is impossible.

Fig. 12 shows the isobars of relative methane pressure $p / p_{0}\left(p_{0}\right.$ is methane pressure in the undisturbed massif) in the host rocks around the mine workings with frames and roof bolting.

Over time, methane pressure drops in those parts of the coal seam that are adjacent to the mine working with frame support, Fig. 12, on the left side. This indicates that the coal seam is degassed; methane moves from it into the mine atmosphere. After 2 weeks, the area of low methane pressure captures the lower part of the gas-bearing sandstone, Fig. $12 c$, on the left side. Around the mine working with bearer frame support, the process of methane filtration is actively taking place.

In Fig. 12c, on the right side, you can see that the low pressure area does not reach the gas-bearing sandstone as a result of formation of the impermeable rock-bolt slab in the mine roof. That is, methane from this gas emission source does not enter the mine working with roof bolting, which will significantly reduce methane content in its atmosphere. Due to the influence of the wall bolts, the volume of the degassed part of the coal seam also decreases.

The graphs of the change in time of the relative gas pressure along the vertical line passing through the center of mine working and along the horizontal line passing through the center of coal seam are shown in Figures 13 and 14. Coordinate $y=51.5 \mathrm{~m}$ is the roof of mine working; coordinate $y=54.5 \mathrm{~m}$ is the lower boundary of sandstone; coordinate $x=52.7 \mathrm{~m}$ is the right wall of mine working. 


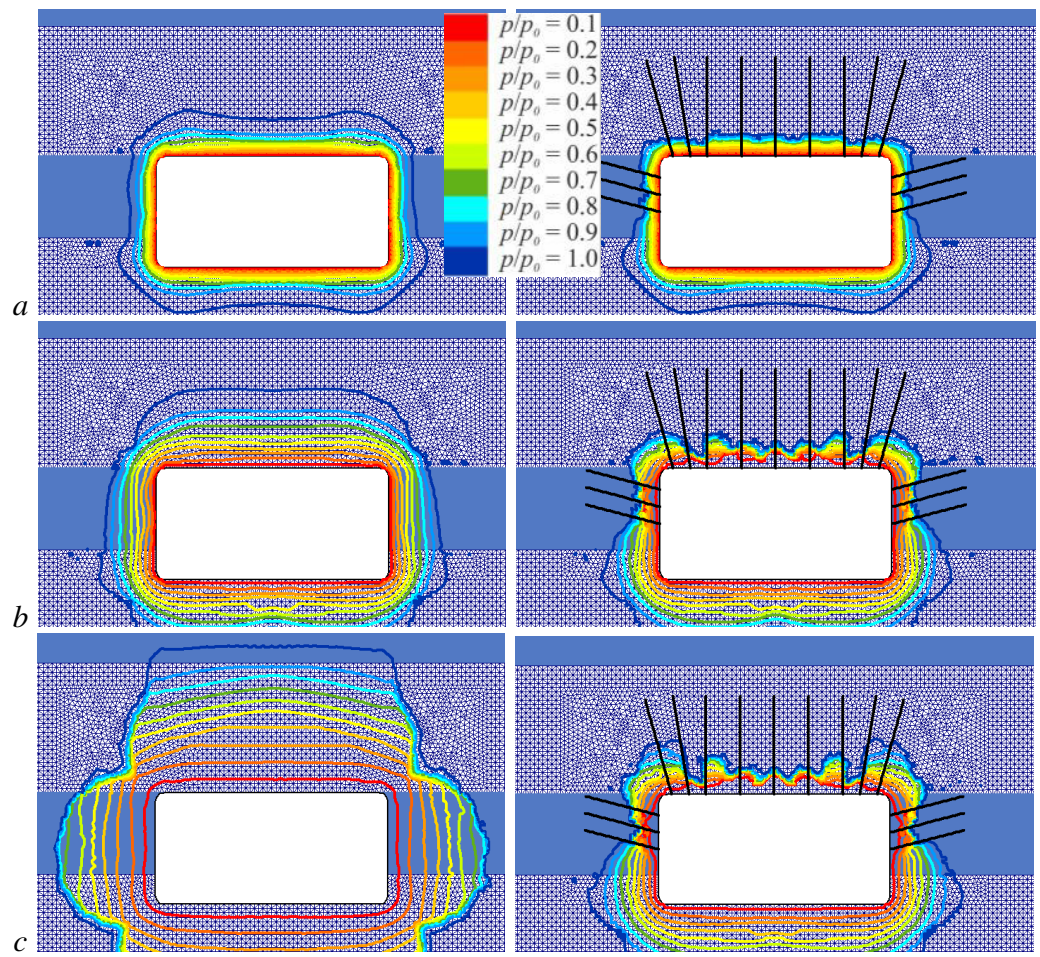

Fig. 12. Isobars of relative methane pressure around the mine working with frames (left side) and roof bolting (right side): a - $t=1$ day; $b-t=3$ days; $c-t=15$ days
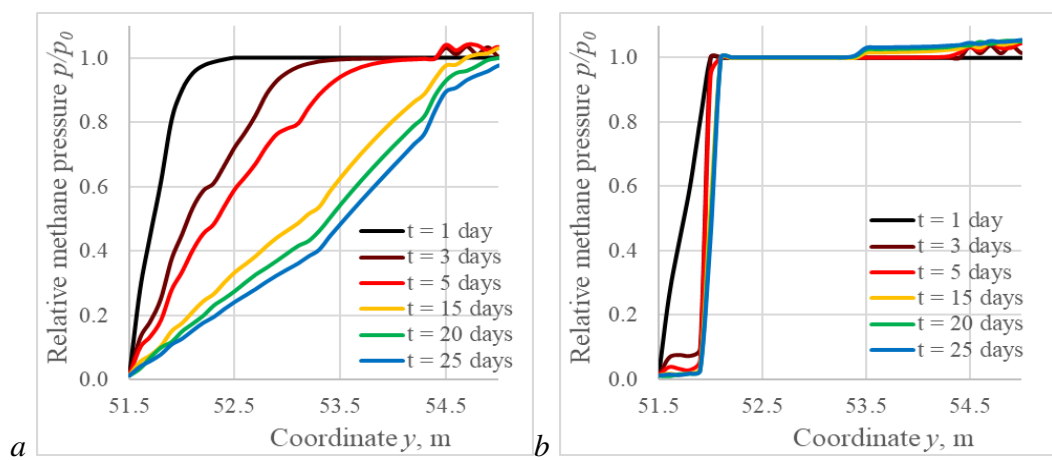

Fig. 13. Relative methane pressure in the mine roof: $a$ - mine working with frames; $b$ - with roof bolting 
In the mine roof with frame support, methane pressure gradually decreases over time. After 15 days, methane pressure begins to decrease in the lower part of the gas-bearing sandstone, Fig. 13a. In the mine roof with roof bolting, the area of low methane pressure does not extend into the depth of massif for more than $0.5 \mathrm{~m}$, Fig. 13a,b
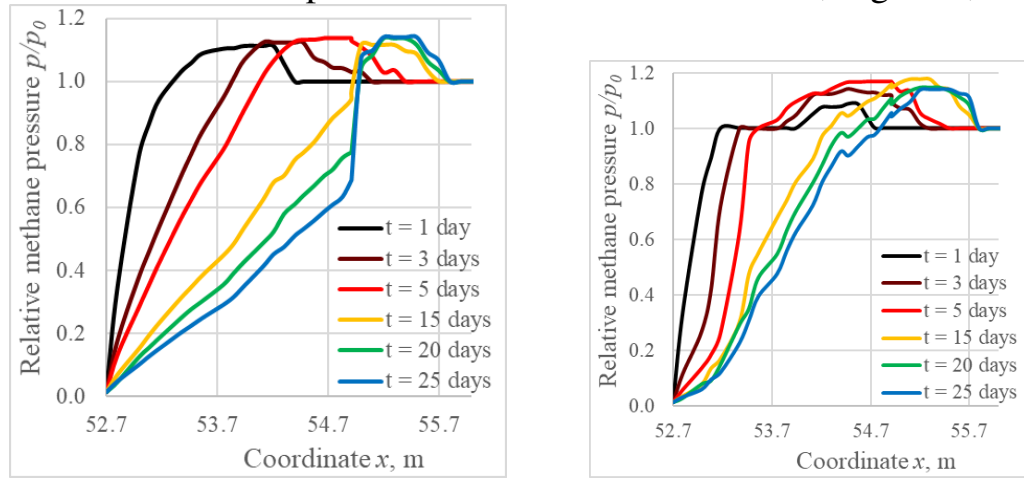

Fig. 14. Relative methane pressure in the wall of mine working: $a$-with frames; $b$ - with bolts

As you can see in Fig. 14, in the walls of the mine, in the area of bearing pressure, methane pressure in the coal seam exceeds initial seam pressure. The effect of increasing seam pressure in the bearing pressure zone is mentioned in [14-16]. This occurs as a result of mechanical compression of rocks and a reduction in the volume of fractured-pore space. You can see also that the pressure drop in the coal seam occurs more slowly if the walls of the mine working are bolted.

The methane filtration rate in the bolted area of the mine roof (Fig. 15b) for $1.5 \mathrm{~m}$ is equal to zero, which confirms the absence of gas filtration through the rock-bolt slab. In the walls of mine working (Fig. 16b), the modulus of filtration rate in the bolted area is reduced by an average of 9 times in comparison with the mine working, which is supported by frames.

At the same mine (Sukhodolskaya-Vostochnaya mine), the Group ventilation entry in block No.1 was constructed along a coal seam with a thickness of $1.8 \mathrm{~m}$ and a natural gas content of $22.5 \mathrm{~m}^{3} / \mathrm{t}$. Sandstone with a thickness of $20-30 \mathrm{~m}$ and a natural gas content of $1.5 \mathrm{~m}^{3} / \mathrm{t}$ lies in the mine roof, which is supported with bolts. The $12^{\text {th }}$ eastern conveyor drift was constructed nearby, in the same mining and geological conditions, using frame support. According to the 
ventilation and safety service, whose task is to control underground air, the methane content of the Group ventilation entry during the construction time and before the approach of the longwall was significantly less than that of the $12^{\text {th }}$ eastern conveyor drift.

a

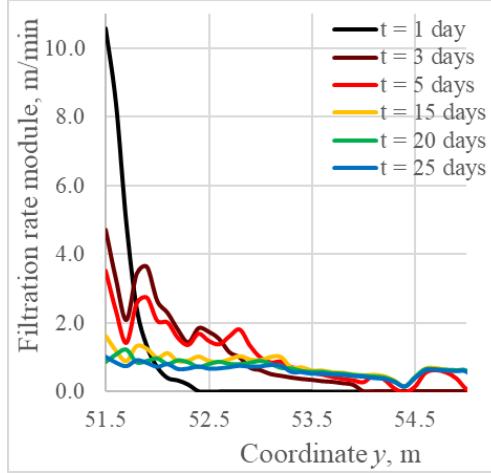

b

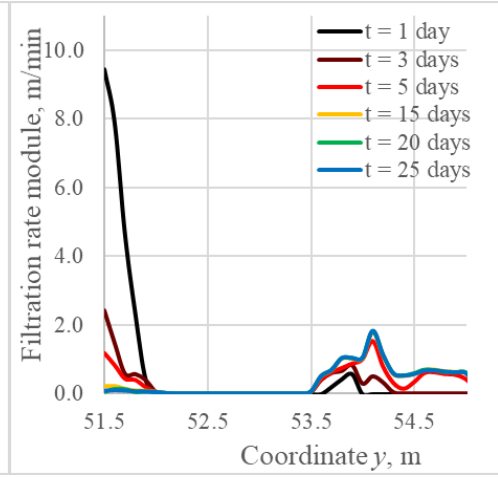

Fig. 15. Module of methane filtration rate in the mine roof: $a$ - mine working with frames; $b$ - mine working with roof bolting
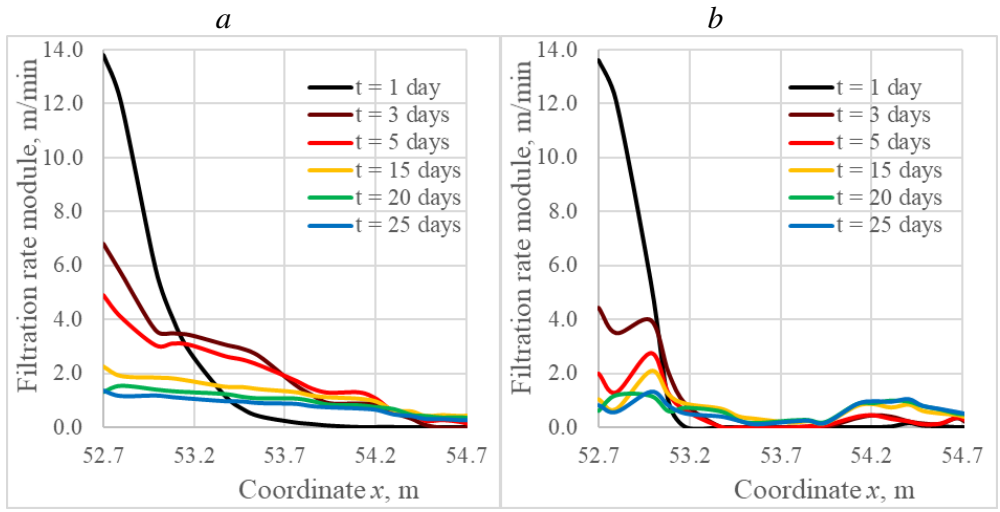

Fig. 16. Module of methane filtration rate in the wall of mine working: $a$ - with frames; $b$ - with bolts

Similarly, at the Samsonovskaya-Zapadnaya mine, PJSC Krasnodonugol, in the same mining and geological conditions, Ventilation drift of the 8th eastern inclined longwall, which was supported with bolts, and the 8th eastern conveyor slope, which was supported 
with frames, were constructed along the coal seam $k_{2}^{b}$. At the seam $k_{2}^{b}$ roof there is coal seam $k_{2}^{t}$ with a thickness of $0.2-0.35 \mathrm{~m}$ and sandstone with a thickness of 32.6-38.9 m. Natural gas content of coal seams is $20-25 \mathrm{~m}^{3} / \mathrm{t}$; natural gas content of sandstone is $5 \mathrm{~m}^{3} / \mathrm{t}$. According to the ventilation and safety service, the methane content of Ventilation drift, which was supported with bolts, was significantly less than the methane content of the $8^{\text {th }}$ eastern conveyor slope.

Such results show that roof bolting can be used as a technological method of reducing methane content in mine workings [17].

\subsection{Water filtration into mine workings with roof bolting}

Ukrainian coal mines are notable for complicated geological conditions due to the great number of tectonic disturbances and flooded rocks. Different forms of geological structures, both plicate and disjunctive, characterize Donbas. Most of the Donbas coal mines are concentrated in large synclinal folds [18]. There is a failure of rocks integrity and an increase in their permeability in zones of local folding [19]. Permeability of rocks reaches its maximum in areas with the highest concentration of tectonic stresses [20]. Type and forming conditions of the faults determine their influence on the filtration properties of rocks. If joint fissures are formed under conditions of stretching of the earth's crust (mainly faults), then they increase permeability of the coal-bearing deposits in the zone adjacent to the fault [21].

The hydrogeological structure of the Western Donbas is a system of aquifers and complexes that cover the entire sedimentary layer and the upper part of the fractured zone of crystalline rocks. The total thickness of the flooded rocks ranges from $20 \mathrm{~m}$ to $1660 \mathrm{~m}$ and more, and it increases in the direction of rocks deepening to the axis of the Dnipro-Donetsk trough [22]. Water inflow into the mine workings mainly depends on the features of the geological structure of the mine fields and particularly on the tectonic disturbance of rocks, the number of aquifers, their thickness, pressure and filtration permeability [22-24]. For example, water production in the N.I. Stashkov Mine (the most water-flooded one in the Western Donbas) is $1640 \mathrm{~m}^{3} / \mathrm{h}$. When the edge rocks are flooded, they become soaked and their strength decreases. This leads to a loss of workings stability and re- 
quires additional finance for water extraction and supporting of mine workings $[25,26]$.

We considered a possibility to use roof bolting in the mine workings in order to reduce water inflows from the undermined waterbearing rocks in the most difficult hydrogeological conditions when crossing tectonic faults.

The coal and rocks are ground and have an initial tectonic permeability on 10-20 m from both sides of the fault. Some rock layers are also initially permeable and they have permeability $k_{\text {nat }}$. Technological permeability $k_{\text {tech, }}$ which is formed during the mine working driving and depends on the stress tensor components, is superimposed on the tectonic $k_{\text {tect }}$ and natural $k_{\text {nat }}$ permeability fields. Formula (4) in this case can be written in the form

$$
K=k_{\text {tech }}+k_{\text {tect }}+k_{\text {nat }} .
$$

As an example, we considered a longitudinal section of a permanent working of $4 \mathrm{~m}$ high, which is constructed at complicated conditions, similar to the conditions of the eastern main entry of the N.I. Stashkov Mine. There is a watered fractured coal bed with a thickness of $0.4 \mathrm{~m}$ and watered sandstone with a thickness of $2.2 \mathrm{~m}$ in the mine roof. There is watered sandstone with a thickness of $0.8 \mathrm{~m}$ in the mine face. The permanent working intersects a disjunctive tectonic fault with displacement amplitude of $1 \mathrm{~m}$.

The central fragment of the finite element mesh for this problem is shown in Fig. 17.

We assumed that initial permeability of the watered sandstones is $0.002 \mathrm{mDa}$, initial permeability of the watered coal bed is $0.005 \mathrm{mDa}$; permeability in the area $l_{1}=3 \mathrm{~m}$ from displacement plane is $0.5 \mathrm{mDa}$; in the area $l_{2}=7 \mathrm{~m}$ is $0.1 \mathrm{mDa} ; p_{0}=3.5 \mathrm{MPa}$. We considered the cases when permanent working is supported by the frame support and roof bolting and its face is located at different distance $L$ (Fig. 17) from the tectonic fault:

a - $L=12 \mathrm{~m}, L>l_{1}+l_{2}$, the permanent working is outside the influence of tectonic fault;

$b-L=7 \mathrm{~m}, l_{1}<L<l_{1}+l_{2}$, the permanent working is in the slightly disturbed area;

$c-L=1 \mathrm{~m}, L<l_{1}$, the permanent working is located in the most disturbed zone of tectonic fault. 


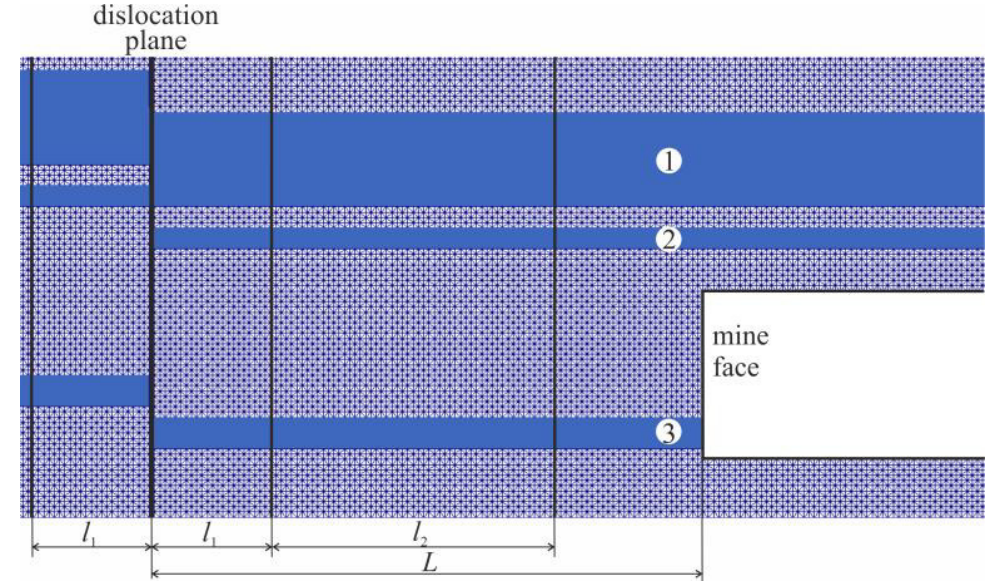

Fig. 17. The central fragment of the finite element mesh: 1,3 - watered sandstones; 2 - watered fractured coal bed

As a result of modeling, the fields of stresses and zones of inelastic deformations were obtained, Fig. 18.
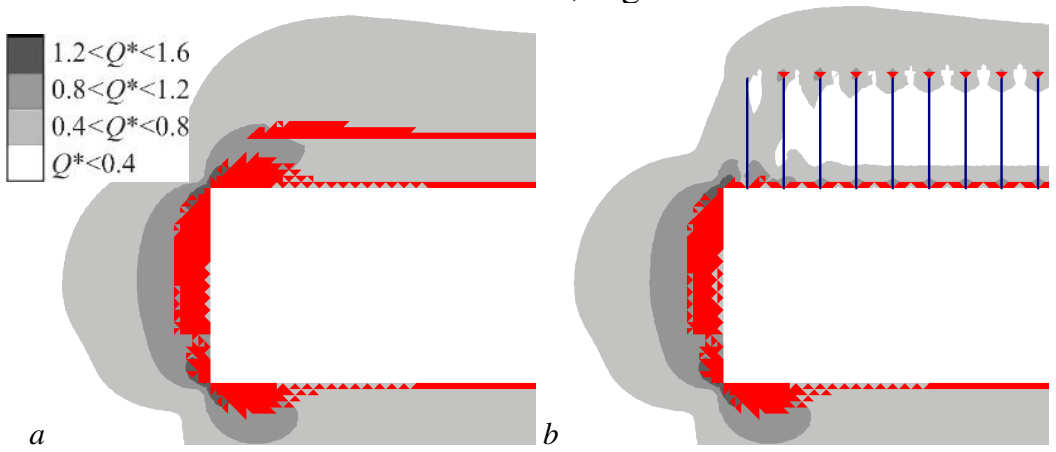

Fig. 18. Distribution of $Q^{*}$ parameter values and inelastic deformation zones: $a-$ the permanent working with frames; $b$ - the permanent working with roof bolting

Hereinafter, the calculation results are given for $t=1$ day after the mine face movement.

The Fig. 18 shows that area of increased diversity of the stress field components is formed around the mine working. Single defects, not interacting between each other, are accumulated in zone where $0.4<Q^{*}<0.8$. In areas where $0.8<Q^{*}<1.2$, the process of intense cracking develops. Here, uncontrolled growth of cracks takes place, 
and deformations rapidly increase due to the propagation of cracks and loosening of the rock [27]. Zone of inelastic deformation (is shown in red) surrounds the permanent working contour, hence, indicating the destruction of rocks.

In the mine roof with frame support (Fig. 18a), the disturbed zone includes both coal bed and sandstone. Here, weak coal bed is completely destroyed.

When using roof bolting (Fig. 18b), zone of inelastic deformations is significantly reduced in boundary rocks of the roof and completely disappears in the coal bed. In the bolted area, rocks and bolts form a slab, where $Q^{*}<0.4$. Here, both the rocks and the weak coal bed are in a triaxially compressed state that keeps them from destruction.

The results of the permeability coefficient calculation are shown in Fig. 19. In these figures, we can see dark zones of tectonic permeability and lighter zones of natural permeability in water-flooded sandstones and coal bed.

A filtration area up to $2.4 \mathrm{~m}$ deep is formed in the mine roof with frame support (left side of Fig. 19) to where the watered coal bed enters completely and sandstone enters partially. Inside this filtration area, water can move towards the contour of the mine. When the working face approaches the disjunctive disturbance, Fig. 19b and $19 c$, it moves into the zone of disturbed rocks, which stratify easily and are destructed during undermining. The bearer support is not able to suppress this process, and filtration permeability is significantly increases in this zone.

Contours of the filtration area are changed when bolts are installed in the mine roof (right side of Fig. 19). The use of roof bolting restrains the unloading of the boundary rocks from the rock pressure and keeps them in a triaxially compressed stress state. Therefore, in all cases of the mine face location relative to the tectonic fault plane, the resulting permeability $K$ decreases by the value of its technological component.

Outside of the influence of the tectonic fault (right side of Fig. $19 a$ ), depth of permeable zone in the mine roof is reduced by 7-8 times in comparison with the same zone in the left side of Fig. 19a. The impermeable rock-bolt slab is preserved between the watered 
layers and the roof of the permanent working. As a result, the process of water filtration from aquifers into the mine working is inhibited.
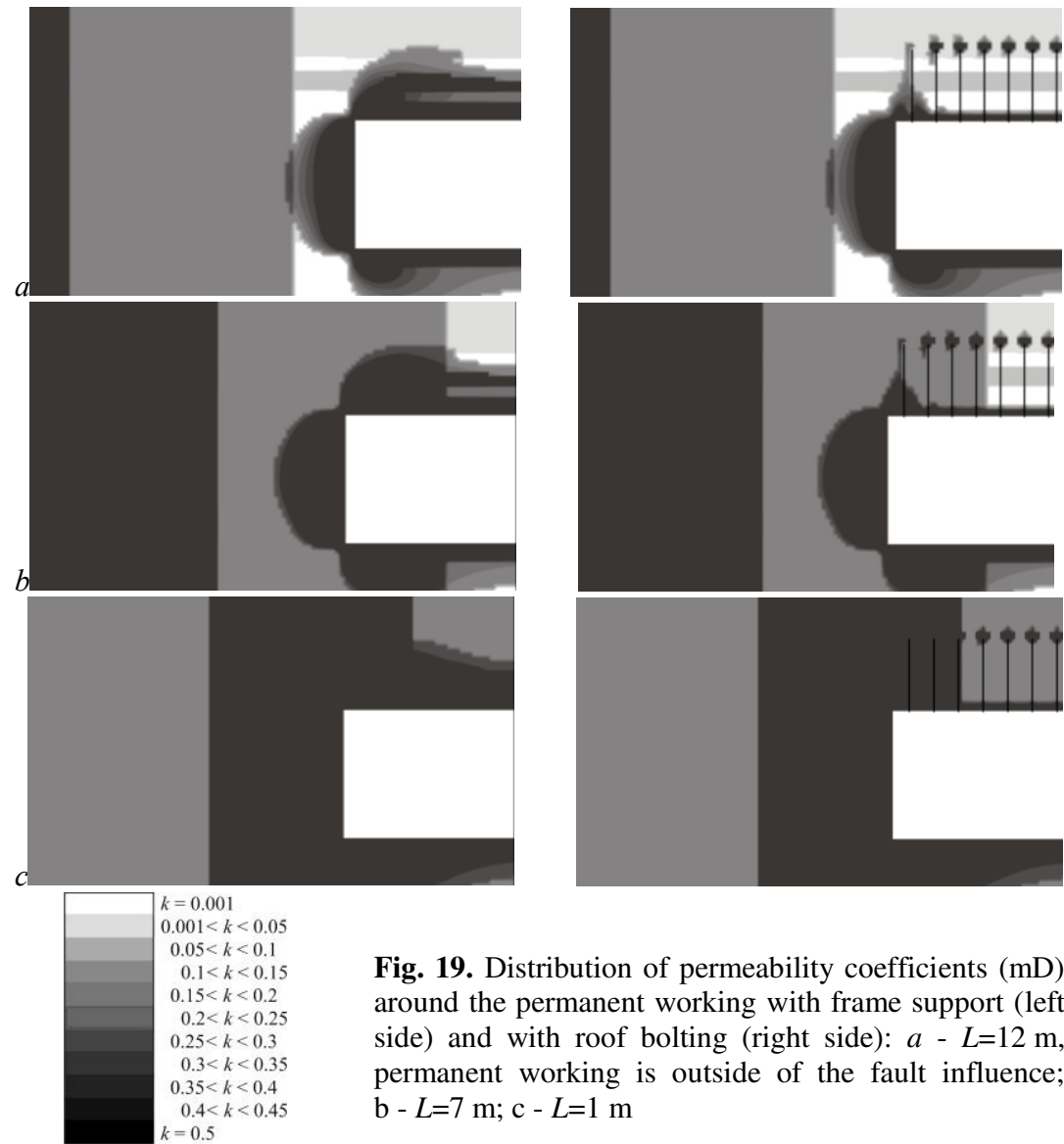

Fig. 19. Distribution of permeability coefficients $(\mathrm{mD})$ around the permanent working with frame support (left side) and with roof bolting (right side): $a-L=12 \mathrm{~m}$, permanent working is outside of the fault influence; b - $L=7 \mathrm{~m}$; c $-L=1 \mathrm{~m}$

In disturbed zone near the fault, action of the steel-polymer bolts only is not sufficient to form an impermeable slab. For this purpose, injection bolts, for example, could be used here. However, in the roof of permanent working with roof bolting (right sides of Fig. $19 b$ and $19 c)$, the permeability is significantly lower than in zone with the frame support (left sides of Fig. $19 b$ and 19c), which should reduce water inflow into the mine working in the hazardous zone.

The distribution of water pressure values are shown in Fig. 20. It can be seen that water pressure in the watered beds near the fault is 
significantly reduced as compared with formation pressure, Fig. $20 b$. As practical experience shows, the increased permeability of rocks in zones of tectonic faults causes the movement of deep pressured water along the plane of displacement in the vertical direction.
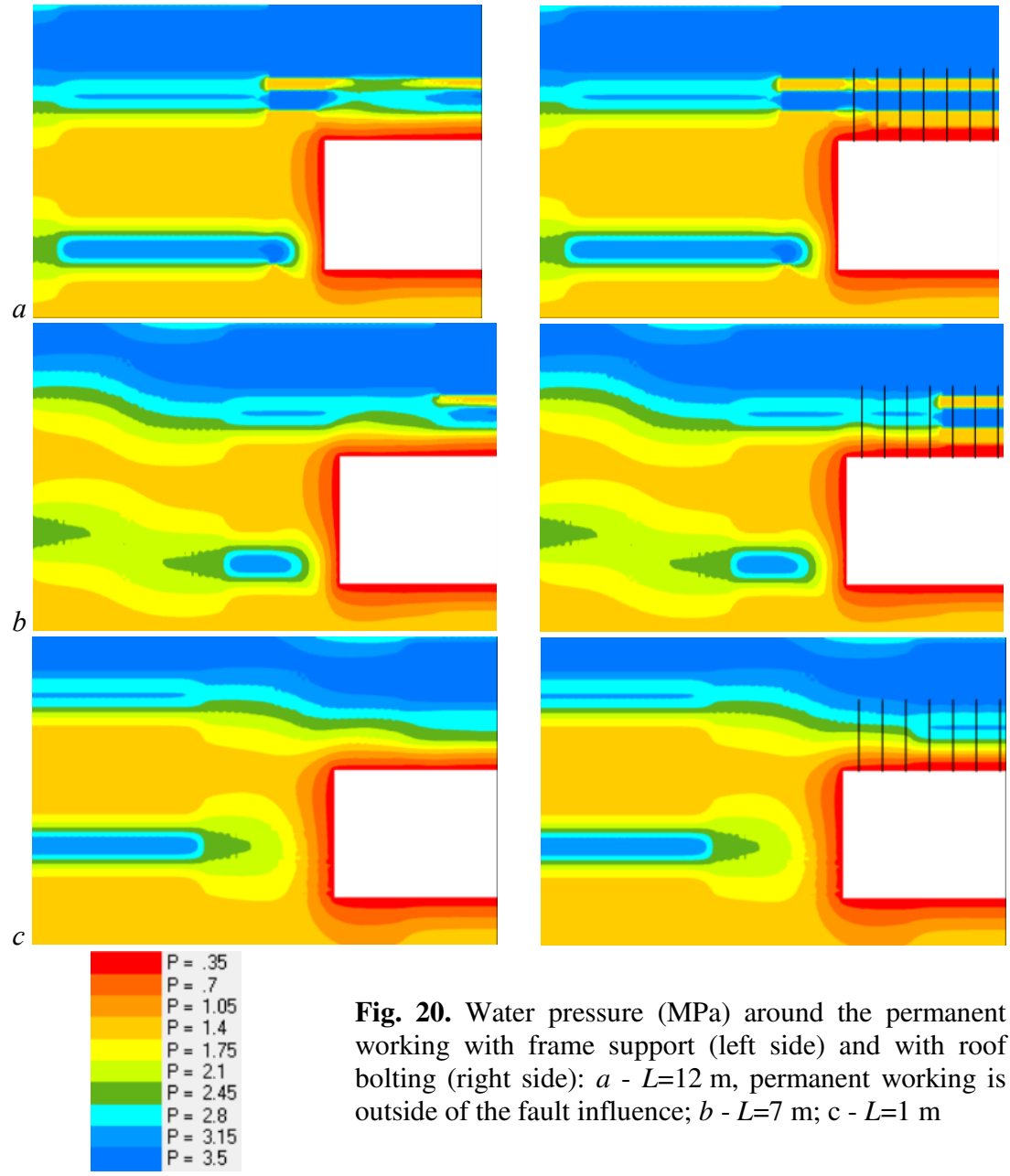

Fig. 20. Water pressure (MPa) around the permanent working with frame support (left side) and with roof bolting (right side): $a-L=12 \mathrm{~m}$, permanent working is outside of the fault influence; $b-L=7 \mathrm{~m}$; c - $L=1 \mathrm{~m}$

In the mine roof with frame support, the process of water filtration is actively taking place both outside the disturbed zone and near the tectonic fault. Water pressure in the undermined watered coal bed and in part of sandstone decreases (left side of Fig. 20). Water moves 
from areas with higher pressure to the mine working where the pressure is minimal. When the mine face approaches the fault and enters the disturbed zone, the intensity of the filtration process increases (left sides of Fig. $20 b$ and 20c). The water inflow into the permanent working from the roof is doubled, and from the watered sandstone in the mine face increases by 1.5 times, Fig. 21.

$a$

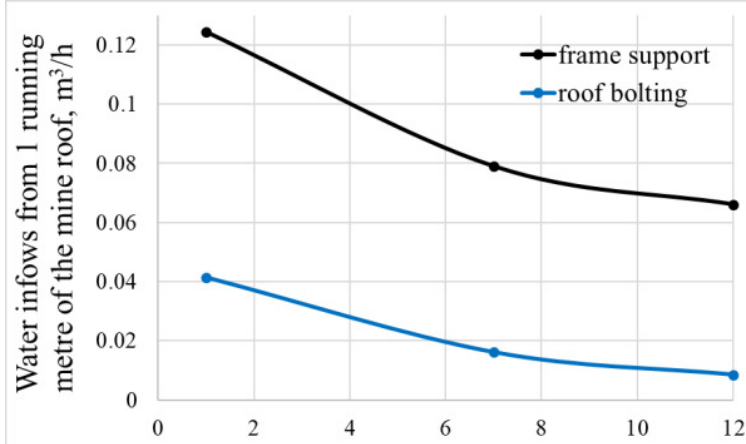

Distance from the fault to the mine face, $L, \mathrm{~m}$

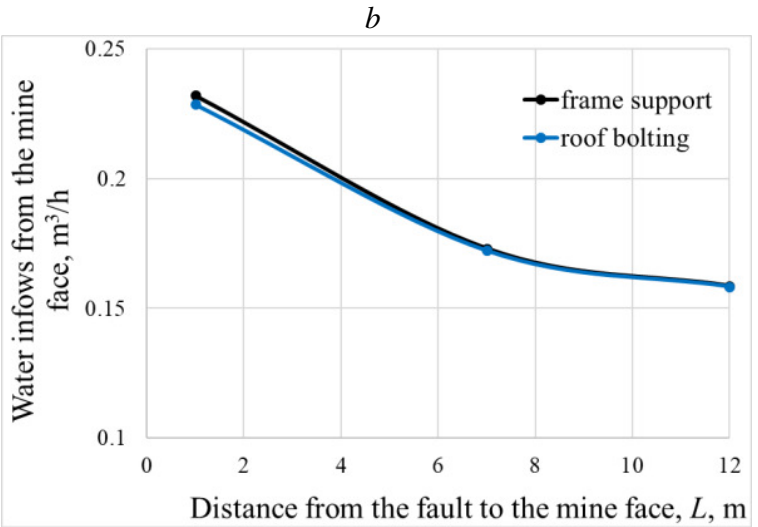

Fig. 21. Water inflow: $a$ - from undermined roof rocks (per 1 running meter of the permanent working); $b$ - from the mine face

If the roof bolting is used, the coal bed pressure and sandstone pressure practically do not change in the mine roof, in the area outside the zone of influence of tectonic disturbance (right side of Fig. 20a). This indicates a significant decrease in the intensity of the fil- 
tration process. The water inflow from the roof into the bolted mine working is almost 8 times less than into the mine working with frame supports, Fig. 21a. We can assert that outside the zone of fault influence, the impermeable rock-bolt slab in the roof reduces water inflow into the mine working to a minimum. When the mine face approaches the tectonic fault, where the roof rocks have already been disturbed as a result of tectonic impact, the roof bolts can only reduce the value of the filtration permeability by the value of $k_{\text {tech }}$. However, this is sufficient to reduce the water inflow by 5 times at $L=7 \mathrm{~m}$ and by 3 times at $L=1 \mathrm{~m}$, Fig. $21 a$.

The water flow rate from the watered sandstone in the mine working face increases by 1.5 times when it approaches the fault and does not depend on the kind of roof supporting, Fig. $21 b$.

Roof bolting in mine workings at difficult hydrogeological conditions, when they cross tectonic faults, allows to reduce permeability of tectonically disturbed host rocks, slow down the water filtration process and reduce water inflow from the undermined watered rocks into the mine workings by 3-5 times. Outside the zone of disturbance influence, an impermeable rock-bolt slab in the mine roof stops water inflow into the mine working almost completely.

Thus, the roof-bolting support can be used as a technological method for reducing the water inflow into mine workings [28, 29].

\subsection{Method of reducing fluid inflow with roof bolting}

If roof bolting is used as a technological method to reduce fluids inflows from sources located in the mine roof, additional bolts are used in the mine roof to form a powerful rock-bolt slab. Some of the additional bolts should be inclined towards the working face; the other part should be inclined in the opposite direction (Fig. 22). This contributes to a more stringent limitation of the displacement of host rocks into the mine working and preserves their natural solidity. In this case, the impermeable rockbolt slab prevents the fluids filtration into the mine working.

In fig. 22-24 the following labels are used: 1 - mine working; 2 mine face; 3 - steel-polymer bolts; 4 - steel-polymer bolts inclined at the mine face; 5 - steel-polymer bolts inclined at the mouth of mine working; 6 - gas- or water-bearing bed in the mine roof; 7 - additional wall bolts; 8 - gas- or water-bearing bed in the walls of mine working; 9 - additional bolts in the lower part of the walls; 10 - gas- or 
water-bearing bed in the floor of mine working; $a$ - distance between rows of bolts; $b$-distance between the first row of bolts and the mine face; $\alpha$ - angle of inclination of bolts to the mine face; $\beta$ - angle of inclination of bolts to the mouth of mine working.

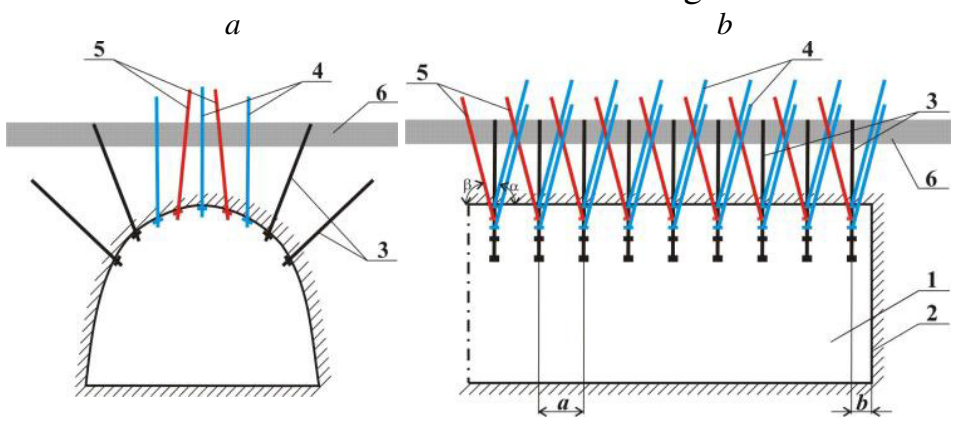

Fig. 22. The bolts location scheme in the case when fluid emission source is in the mine roof: $a$-cross-section; $b$ - longitudinal section of the mine working

If the fluid emission sources are located in the walls of the mine working, additional bolts are installed directly into the coal bed or fluid-bearing rock, Fig. 23.

$a$

$b$

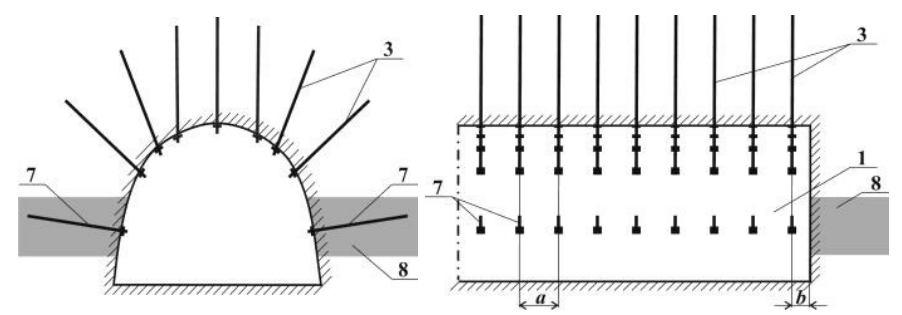

Fig. 23. The bolts location scheme in the case when fluid emission source is in the walls of mine working: $a$ - cross-section; $b$ - longitudinal section of the mine working

This prevents the onset of inelastic deformations and stratification, reduces the depth of filtration area and helps to reduce fluids inflow into the mine working.

In the case when gas- or water-bearing beds are located at the floor of working, with the help of additional bolts in the lower part of the walls of mine working and its floor, the floor heaving is limited and fluids inflow from the overworked sources is reduced. 


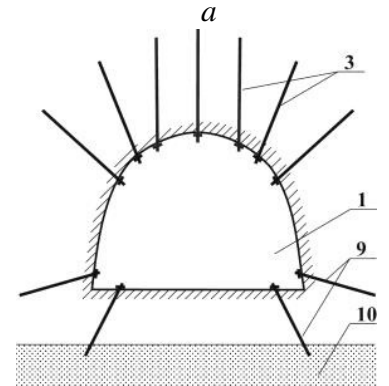

$b$

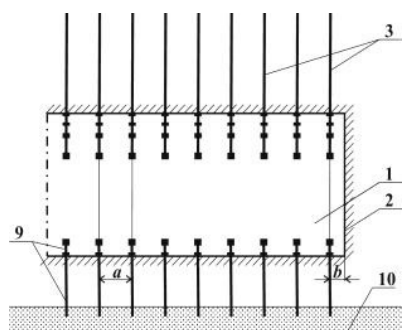

Fig. 24. The bolts location scheme in the case when fluid emission source is in the floor of mine working: $a$-cross-section; $b$ - longitudinal section of the mine working

Thus, with the help of bolts, the impermeable rock-bolt layer is created around the mine working, in which the natural solidity of the rocks is preserved. This ensures a decrease in fluids inflow into the mine working from sources in the roof, floor and walls of the mine working. Therefore, roof bolting can be used as a technological method to reduce gas emission and water inflows into mine workings [30-32], to enhance the effect of regulatory methods.

\section{Conclusions}

Roof bolting is traditionally used only to ensure the stability of mine workings and it is not considered as a means of influencing filtration processes in the host rocks. To substantiate the use of roof bolting as a technological method to reduce gas emission and water inflows into mine workings, the mathematical model of coupled processes of deformation of layered coal-rock mass and fluids filtration in the disturbed area has been developed. The cases when mine working is supported with frames and roof bolts were considered.

The investigation of influence of roof bolting on filtration permeability caused by the mine working driving has been carried out. It was shown that a filtration area with non-zero permeability coefficients is formed around the mine working with frames. Within this area, fluids can freely move in the direction from the fluids emission source into the mine working space. Roof bolting restrains the process of cracking in the zone of mine working influence. The size of filtration area is significantly reduced, the permeability inside it decreases. Roof bolting decreases the 
average filtration permeability caused by the redistribution of the stress field during excavation by 15 times or more.

The influence of roof bolting on the process of methane filtration from gas-bearing rocks and coal into the mine working has been investigated. It was shown that around the mine working with bearer frame support, the process of methane filtration is actively taking place. Methane filtration rate in the bolted area of the mine roof is equal to zero; consequently, methane from undermined gas emission sources does not participate in the filtration process. In the walls of mine working, the modulus of filtration rate in the bolted area is reduced by an average of 9 times in comparison with the mine working, which is supported by frames.

The influence of roof bolting on the process of water filtration during the undermining of water-bearing rocks has been investigated. The use of roof bolting restrains the unloading of the boundary rocks from the rock pressure and keeps them in triaxially compressed stress state. Permeability value decreases by the value of its technological component. In different areas of the intersection of tectonic disturbance, water inflow into the mine working with roof bolting is 3-8 times less than in the working with the frame supports.

Therefore, the use of roof bolting allows not only to keep the mine working in a stable state, but also to significantly reduce fluids inflows. Roof bolting can be considered as the second line of defense to be applied in the presence of gas- and water- bearing rocks. The authors have developed methods for reducing gas and water inflows using roof bolting and obtained the corresponding patents.

\section{References}

1. Bulat, A.F., \& Vinogradov, V.V. (2002). Oporno-ankernoe kreplenie gornyih vyirabotok ugolnyih shaht. Vilpo [in Russian].

2. Krukovskyi, O.P., Krukovska, V.V., Bulich, Yu.Yu., \& Zemlianaia, Yu.V. (2020). Some aspects of development and application of the bearing-bolt supporting technology. Resource-saving technologies of raw-material base development in mineral mining and processing. Universitas Publishing. https://doi.org/10.31713 $/ \mathrm{m} 901$

3. Krukovskiy, O.P., Khvorostian, V.A., \& Krukovskaia, V.V. (2013). Technology of supporting bolting of mine workings. Coal of Ukraine, 2, $13-16$ [in Russian]. 
4. SOU 10.1.05411357.010:2014. (2014). System of providing reliable and safe functioning of roof bolting mine workings. General technical requirements. Standart Ministry of Energy and Coal Mining of Ukraine [in Ukrainian].

5. Agafonov, A.V. (1998). Sposoby i sredstva obespecheniya bezopasnosti provedeniya podgotovitel'nyh vyrabotok po vybrosoopasnym plastam. Donbass [in Russian].

6. Steve Zou, D.H., Yu, Chuxin, \& Xian, Xuefu. (1999). Dynamic nature of coal permeability ahead of a longwall face. International Journal of Rock Mechanics and Mining Sciences, 36, 693-699.

7. Bai, M., Meng, F., Elsworth, D., Zaman, M., \& Roegiers, J.-C. (1997). Numerical modeling of stress-dependent permeability. International Journal of Rock Mechanics and Mining Sciences, 34:3-4, paper No. 020.

8. Krukovska, V.V. (2015). Simulation of coupled processes that occur in coalrock massif during mining operations. Geotechnical Mechanics, 121, 48-99 [in Russian].

9. Krukovskaya, V.V. (2006). Preparation method of calculation of methane filtration parameters with the account a mode of stressedly-deformed state of coalrock mass. Institute of Geotechnical Mechanics named by N.S. Polyakov NAS of Ukraine [in Russian]

10. Basniev, K., Kochina, I., \& Maksimov, V. (1993). Podzemnaya gidromehanika. Nedra [in Russian].

11. Zienkiewicz, O.C., Taylor, R.L., \& Zhu, J.Z. (2013). The Finite Element Method: Its Basis and Fundamentals, Butterworth-Heinemann.

12. de Borst, R., Crisfield, M.A., Remmers, J.J.C. \& Verhoosel, C.V. (2012). Non-linear finite element analysis of solids and structures, John Wiley \& Sons.

13. Krukovskaya, V.V. (2015). The development of the coupled processes theory in the application to geomechanics of coal-rock massif. Institute of Geotechnical Mechanics named by N.S. Polyakov NAS of Ukraine [in Russian].

14. Zhang J., \& Roegiers, J.-C. (2003). Double Porosity Finite Element Method for Borehole Modelling. International Journal of Rock Mechanics and Mining Sciences, 40, 473-483.

15. Detournay, E., \& Cheng, A. H.-D. (1993). Fundamental of poroelasticity. Comprehensive rock engineering, vol 2. Pergamon Press.

16. Chernyak, I.L., \& Yarunin, S.A. (1995). Upravlenie sostoyaniem massiva gornyh porod. Nedra [in Russian].

17. Vynohradov, V.V., Krukovskyi, O.P. \& Krukovska, V.V. (2007) Application of roof bolting constructions as technological way of the methane content decrease in the mine workings. Problems of Computational Mechanics and Strength of Structures, 11, 30-37 [in Russian].

18. Nikolin, V.I., Balinchenko, I.I., \& Simonov, A.A. (1981). Borba s vyibrosami uglya i gaza v shahtah. Nedra [in Russian].

19. Lukinov, V.V., Bezruchko, K.O., \& Prykhodchenko, O.V. (2018). Vliyanie lokal'noj skladchatosti na metanoobil'nost' gornyh vyrabotok ugol'nyh shaht. Coal of Ukraine, 1, 15-21 [in Russian].

20. Zhoglo, V.G., Grimus, S.I., \& Haletskiy, A.V. (2010). Obosnovanie modeli pronicaemosti karbonatnyh otlozhenij putem resheniya obratnyh zadach $\mathrm{s}$ 
ispol'zovaniem PK «ECLIPSE 100». Development and operation of oil and gas fields, 2, 25-30 [in Russian].

21. Bulat, A.F., Lukinov, V.V., \& Bezruchko, K.O. (2017). Umovy formuvannia hazovykh pastok u vuhlenosnykh vidkladakh. NVP «Naukova dumka» [in Ukrainian].

22. Sotskov, V.O., Zahrytsenko, A.M., \& Dereviahina, N.I. (2019). Obgruntuvannia hirnycho-heolohichnykh parametriv zastosuvannia resursozberihaiuchoi tekhnolohii selektyvnoi vidrobky vuhilnykh plastiv dlia Zakhidnoho Donbasu. Scientific notes of Taurida National V.I. Vernadsky University. Series: Technical Sciences, 6, 17-23 [in Ukrainian]. https://doi.org/10.32838/26635941/2019.6-2/04

23. Masoumi, H., Horne, J., \& Timms, W. (2017). Establishing empirical relationships for the effects of water content on the mechanical behavior of gosford sandstone. Rock Mech. \& Rock Eng., 50(8), 1-8.

24. Liu, H., Zhu, W., Yu, Y., Xu, T., Li, R., \& Liu, X. (2020). Effect of water imbibition on uniaxial compression strength of sandstone. International Journal of Rock Mechanics and Mining Sciences, 127, 104200.

25. Yang, T., Zhu, W., Yu, Q., \& Liu, H. (2011). The role of pore pressure during hydraulic fracturing and implications for groundwater outbursts in mining and tunnelling. Hydrogeol. J., 19(5), 995-1008.

26. Li, L., Yang, T., Liang, Z., Zhu, W., \& Tang, C. (2011). Numerical investigation of groundwater outbursts near faults in underground coal mines. Int. J. Coal Geol., 85(3-4), 276-288.

27. Vinogradov, V.V. (1989). Geomechanics of massif condition control near mining. Naukjva Dumka [in Russian].

28. Vynohradov, Yu.O. (2015). Analysis of the water inflow in mine working depending on the support type. Modern resource-saving technologies of mining production, 1, 89-95 [in Russian].

29. Krukovska, V. \& Vynohradov, Y. (2019). Water stability influence of host rocks on the process of water filtration into mine working with frame and roofbolting support. Essays of Mining Science and Practice 2019. E3S Web of Conferences, 109, 00041 https://doi.org/10.1051/e3sconf/201910900041

30. Vynohradov, Yu.O. (2018) Development of a method for reducing water inflow and increasing the stability of mine workings in difficult hydrogeological conditions. Institute for Physics of mining processes of NAS of Ukraine [in Ukrainian].

31. Krukovskyi, O.P., Krukovska, V.V., \& Vynohradov, Yu.O. (2016) Sposib znyzhennia vodopryplyvu u hirnychu vyrobku iz zastosuvanniam ankernoho kriplennia. Inventions (utility models) in Ukraine, 111059 [in Ukrainian]. https://base.uipv.org/searchINV/search.php?action=viewdetails\&IdClaim=228741\& chapter=description

32. Krukovska, V.V., \& Krukovskyi, O.P. (2018). Sposib znyzhennia metanovosti hirnychykh vyrobok iz zastosuvanniam ankernoho kriplennia. Inventions (utility models) in Ukraine, 124356 [in Ukrainian]. https://base.uipv.org/searchINV/search.php?action=viewdetails\&IdClaim=245815\& chapter $=$ description 
https://doi.org/10.31713/m1104

\title{
DEVELOPMENT OF GEOTECHNOLOGICAL METHODS FOR STRENGTHENING THE DISTURBED ROCK MASS
}

\author{
Demin V. F. \\ Doctor of Technical Sciences, Professor, Karaganda Technical \\ University, Karaganda, Republic of Kazakhstan
}

Kamarov R. K.

Candidate of Technical Sciences, Professor, Karaganda Technical

University, Karaganda, Republic of Kazakhstan

\section{Zhumabekova A. E.}

$\mathrm{PhD}$, Senior Lector, Karaganda Technical University, Karaganda, Republic of Kazakhstan

Extended annotation. Objectives of the research: practical usage analysis of roof bolting in coal mines; mining and geological conditions assessment of the preparatory minings; research of the stress-strain state of the rock mass around the workings; development of technological schemes of anchorage; determination of the influence of anchorage technology on the operational characteristics of mining operations. The main idea is to develop geotechnological methods and test the strengthening effect on the disturbed coal-bearing massif during man-made processes. The result of the study is to provide safe conditions for maintaining mine workings, the stability of the immediate roof, reducing rock falls and increasing the service life of the support. Subject of research: operational underground workings of coal mines. Methodology: analysis of maintenance conditions; assessment of factors that negatively affect the conduct of mining operations; determination of the manifestations of rock pressure; development of methods and means of active fastening of the broken coal-bearing array. The purpose of the work is to develop technological schemes for conducting preparatory workings of coal mines using anchoring in difficult mining and geological conditions. Research results: development of geotechnological methods for strengthening the disturbed massif. A method of two-level fixing with a complex overlap of the roof fixing zones over the workings, with the imposition of strengthening zones in the resulting rock arch, has been developed; a method for fixing the excavation in the zone of influence of cleaning works by means of stitching unstable rocks of the immediate roof and then fixing the created artificial "bridge" to the strong rocks of the main roof; mesh tightening to perceive the load from rocks in the space between the anchors and prevent the precipitation of rock mass; a method for combating soil heaving of preparatory workings by spacer blocking the disturbed rock blocks with power spacer modules. 
Introduction. The world experience of advanced coal-mining countries (USA, Australia, China, etc.) shows that effective and reliable fastening of capital and preparatory workings can be provided by using steel-polymer anchors with a bearing capacity of at least $100-130 \mathrm{kN}$. Monitoring of the use of anchor support in coal mines shows that, in accordance with existing regulatory documents, it is used both as the main and auxiliary support in combination with metal frame pliable support.

The problem of effective fastening of workings in mines is not completely solved, which is due to the fact that the currently used method of supporting excavation workings with frame metal arch supports with reinforcement posts is very labor-intensive and metalintensive.

Therefore, one of the most relevant directions in the coal mining industry is the development of a technology for fixing excavation workings, taking into account the technogenic state of the nearcontour massif in areas of increased displacement due to various types of disturbances in the occurrence of host rocks and changes in the elements of the occurrence of coal seams.

\section{Factors that negatively affect the conduct of mining opera- tions and the development of coal seams}

The rock pressure depends on the depth of the excavation, the physical and mechanical properties of the rocks in the massif (strength, collapsibility, controllability, fracturing, etc.), the angle of occurrence and thickness of the layers, the methods of coal excavation, the size of the section of the excavation, the mechanical characteristics of the support and other parameters.

The factors that complicate the conduct of treatment and preparatory work include various geological disturbances. Geological disturbances in the occurrence of coal seams are of two types, formed during the occurrence of the formation or in the formation after its occurrence.

Violations of the first type include: formation wedging - a gradual decrease in the thickness of the formation, sometimes up to its disappearance; formation swelling - a sharp increase in the thickness of the formation in a certain area. 
Violations of the second type include: upsets, offsets, displacements, folds, splits.

Upwelling is the displacement of rock along a fault associated with the uplift of one block of the earth's crust relative to another (Fig. 1).

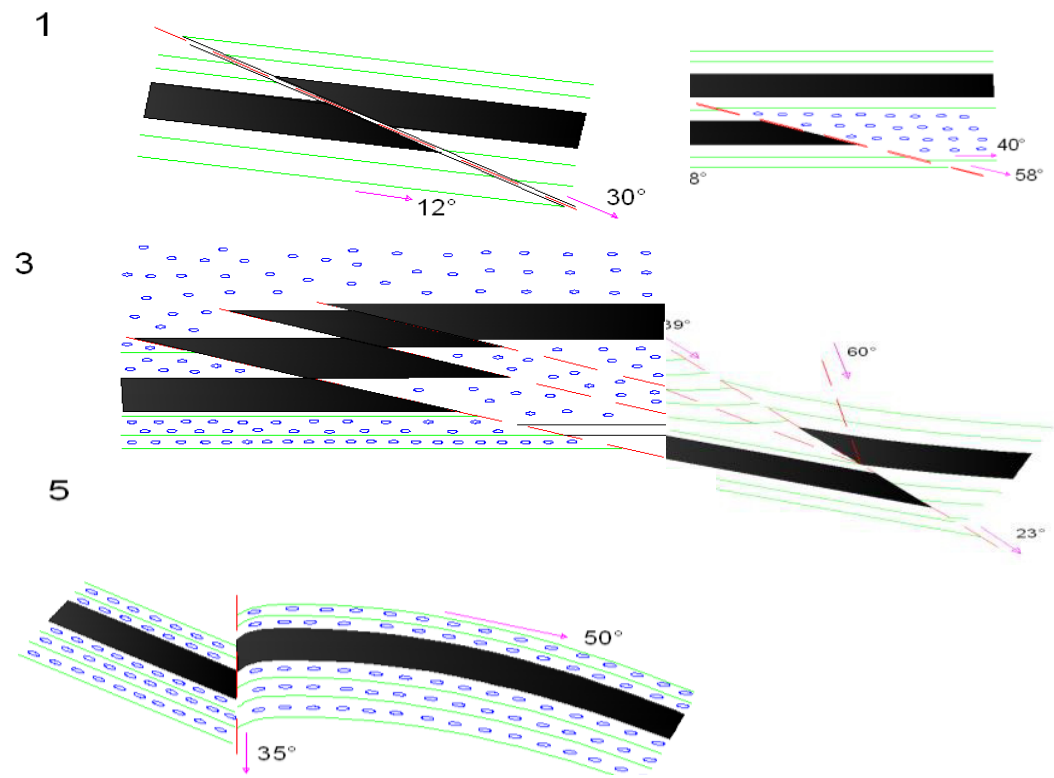

Fig. 1. Low-amplitude upswings: 1 - converging upswings on the fall; 2 - horizontal upswings; 3 - a series of horizontal upswings; 4 - diverging upswings on the fall to the flank destruction; 5 - sliding downswing

With a gentle displacement, the gap is attributed to the thrust. Usually, $45^{\circ}$ (up to $60^{\circ}$ ) is taken as the smallest angle of incidence of the reset shifter. When the angle is between 45 and $60^{\circ}$, the term "upswing" is used. In general, upsets are formed under conditions of tangential compression, often due to folding. The geometric effect of the upswing is to reduce the earth's surface [1].

Discharges - tectonic disturbances in which the surface of the fault (the displacer) is inclined towards the location of the lowered rocks (Fig. 2 and 3).

The reset is determined by the fact that its hanging wing is shifted down relative to the recumbent one. This type of dislocation is asso- 
ciated with the stretching of the rocks involved in the movement and is characterized by the absence of any compressive stresses, which are usually associated with the formation of thrusts and displacements $[2,3]$.

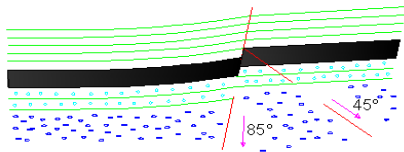

3

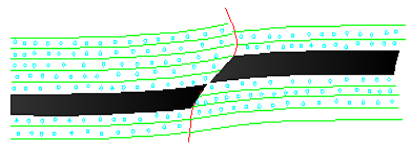

5

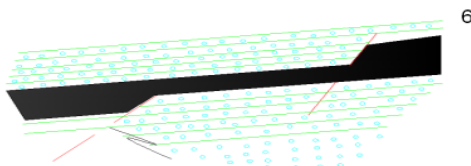

4
2
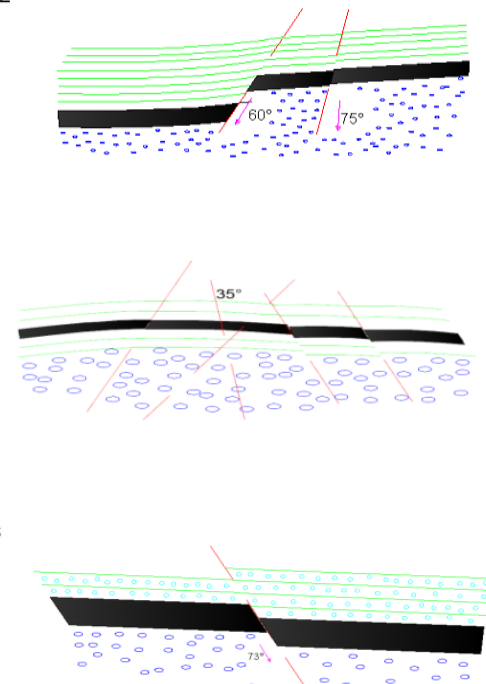

Fig. 2. Low-amplitude discharges: 1 - divergent discharges by fall; 2 - series of discharges by height; 3 - convergent diagonal discharges by fall; 4 - group of discharges by compression; 5 - convergent discharges by fall; 6 - horizontal discharges

Displacements are sub-vertical discontinuities whose displacements occur in the horizontal direction (Fig. 4). The displacements differ in the wings, the shifter, the angle of inclination of the shifter, and the displacement amplitude. In relation to the strike of disturbed rocks, displacements, as well as discharges, can be longitudinal, oblique, or diagonal and transverse [4].

1
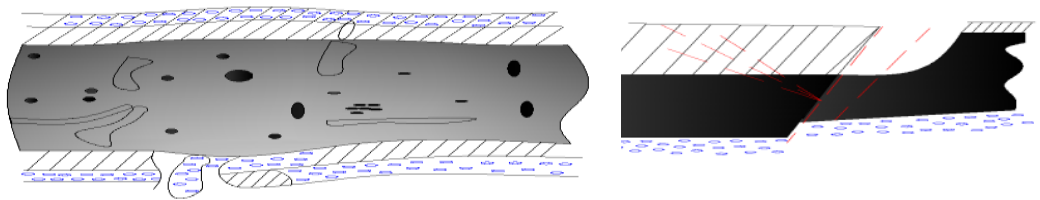
3

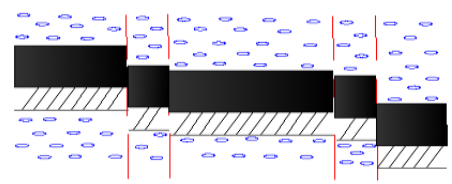

4

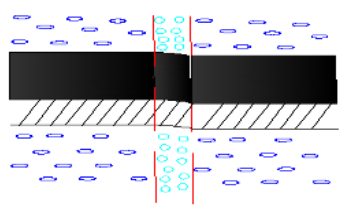

5

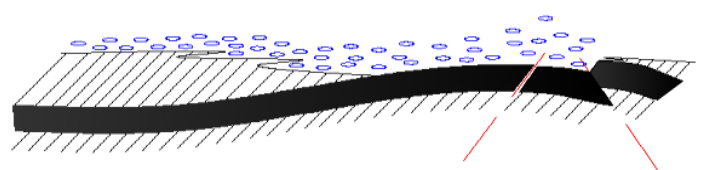

Fig. 3. Low-amplitude extended discharges: 1 - height discharges; 2 - horizontal discharges; 3 - a series of discharges; 4 - a close group of discharges; 5 - discharges and discharges that are close to each other

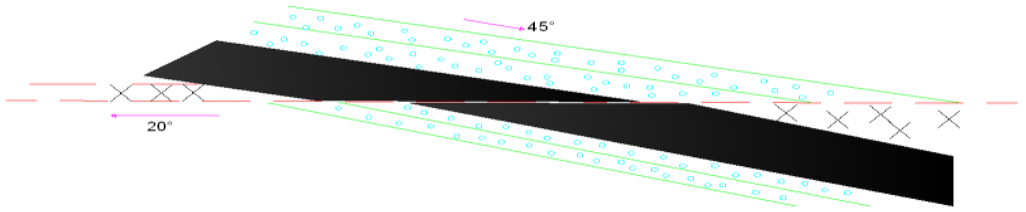

Fig. 4. Horizontal shifts in the fall

Folds - bends of rock layers usually with an alternation of convex (anticlines) and concave (synclines) forms, the most widespread and pronounced within the folded systems [5].

In the zones of influence of geological disturbances, a decrease in the rate of penetration by 2-3 times was recorded, as well as an increase in the cost of carrying out and repairing workings. This is mainly due to significant fallout with a height of up to $5 \mathrm{~m}$, associated with intense fracturing of the rock mass.

\section{Manifestations of rock pressure during mining operations}

Conducting underground workings changes the state of rocks with the formation of zones of high and low stress. The phenomena associated with the deformation, displacement, destruction of the massif, the pressure of rocks on the support, are manifestations of mountain pressure, which depend on the mining and geological conditions and technological features of the development. 
The nature of the stress distribution around the mine depends on its shape and the ratio of the cross-section dimensions. In the roof and the soil of the workings, when the lateral spacer is less than one, there are tensile forces

$$
\sigma_{\min }=k_{1} \frac{v}{1--v} \gamma H
$$

where $k_{1}$ is the coefficient of concentration of tensile stresses; $v /(1-v)$ - coefficient of lateral expansion; $v=0.1+0.4$ - Poisson's ratio; $V$ density of rocks, $\mathrm{t} / \mathrm{m}^{3}$; H-depth from the surface to the mine, $\mathrm{m}$.

As you move away from the contour of the mine deep into the massif, these stresses decrease to zero, and then turn into compressible and approach the original value

$$
\frac{v}{1-v} \gamma H
$$

There is a significant increase in compressive stresses in the sides of the mine

$$
0_{\max }=k_{2} \cdot \gamma H
$$

where $k_{2}$ is the compressive stress concentration coefficient.

As you move deeper into the array, the compressive stresses decrease to their original value $\gamma H$.

The stress concentration around the mine is limited to a certain zone, the dimensions of which are $(3+5) 1$, where 1 is the largest linear size of the mine section. Near the outcrop contour, stresses can exceed the ultimate strength of rocks, resulting in their destruction or plastic flow.

The area of influence of mining is a part of the rock mass, within which the displacement, deformation and destruction of rocks occur. The area of influence of the mine work, adjacent directly to its contour, within which the stresses are higher than in the untouched massif, is called the reference pressure zone.

The nature of the formation of the area of influence of mining, all other things being equal, depends on the physical and mechanical properties of rocks.

The rocks of the roof, sides and soles are stable. In this case, 


$$
\begin{aligned}
& k_{1 \frac{v}{1-\nu}} \gamma H<k_{c} \sigma_{p} \xi \\
& k_{2} \gamma H<k_{c} \sigma_{c \varkappa} \mathrm{E}
\end{aligned}
$$

where $E$ is the coefficient of long-term strength; $\sigma_{p}, \sigma_{c \varkappa}$ - the ultimate strength of rocks, respectively, for tension and compression under the conditions of a biaxial stress state.

If the conditions are met, no dangerous deformations are formed in the outcrops.

The rocks of the roof of the mine are unstable, and the sides and the soil are stable

$$
\begin{aligned}
& k_{1 \frac{v}{1-v}} \gamma>k_{c} \sigma_{p} \xi \\
& k_{2} \gamma H<k_{c} \sigma_{c \varkappa} \xi
\end{aligned}
$$

In this case, the roof rocks will be destroyed. With the development of fracturing in the area adjacent directly to the roof of the mine to the roof of the mine. Individual sections of the rock lose their connection with the array and fall out. The gradual collapse of the rocks continues until the formation of an irregular shape surface, which approaches the collapse arch. Outside of it, a vault of natural balance is formed.

The rocks in the roof and in the sides of the mine are unstable, in the soil they are stable

$$
k_{1} \frac{v}{1--v} \gamma H>k_{c} \sigma_{p} \xi ; \quad k_{2} \gamma H>k_{c} \sigma_{с ж} \xi
$$

Fig. 5 and 6 show, respectively, the schemes of hanging on anchors and forming using anchors of the load-bearing structure in the roof of the mine.
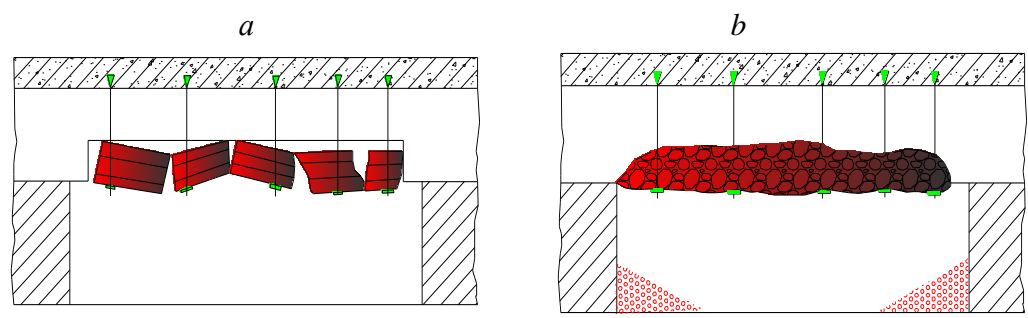

Fig. 5. The scheme of hanging on anchors: a-individual blocks; b-the disturbed layer of the immediate roof to the stable overlying rocks 
$a$

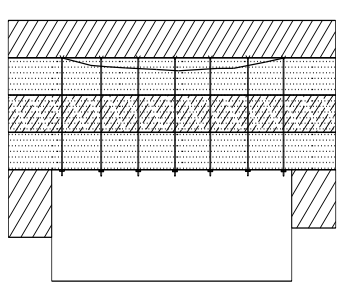

$b$

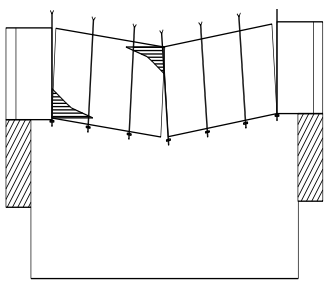

$c$

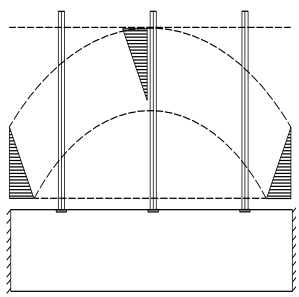

Fig. 6. The scheme of formation using anchors of the load-bearing structure in the roof of the development in various forms: a-composite beams; $\mathrm{b}$ and $\mathrm{c}$ - respectively, three articulated arches and arches

Fig. 7 shows the technological schemes for fixing the contours of mining workings.

The lower layer of the rocks of the immediate roof of the formation can have different stability both during coal excavation (separation of coal from the massif), and after a certain period of time after its exposure.

The degree of stability of the rocks of the lower layer significantly depends on the safety of labor, the efficiency of coal excavation, the choice of the type and design of the bottom-hole support, sometimes the method of roof management, etc. In the classification of the DonCSI [6], there is a typification or division of the rocks of the lower layer of the direct roof of the layers into 5 categories of stability (they are usually designated B).
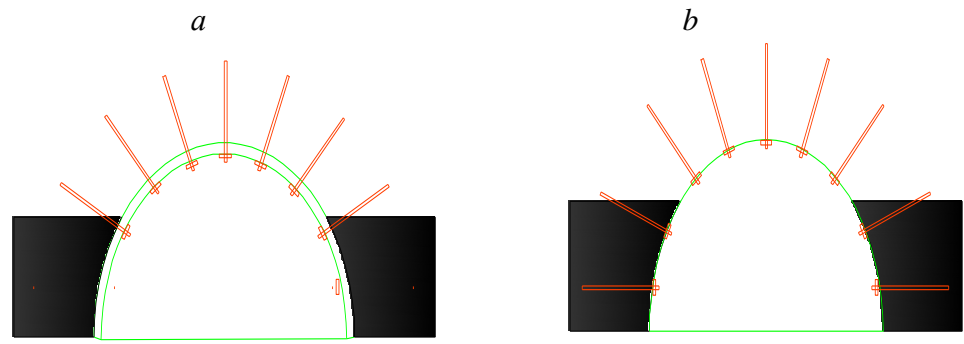

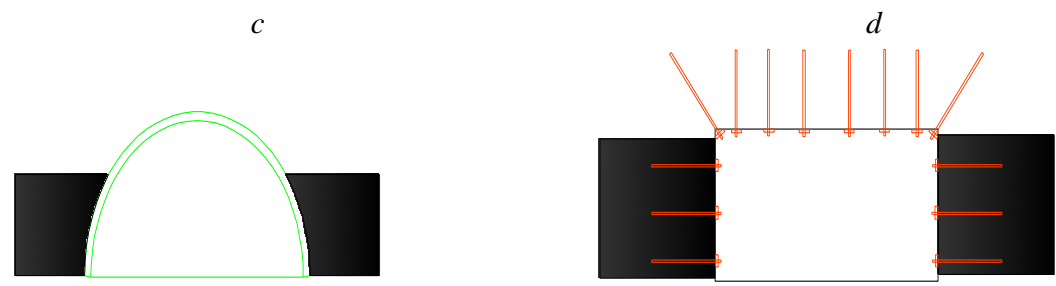

Fig. 7. Technological schemes for fixing the contours of mine workings: a-fixing the arched shape with combined support (metal-arched support with anchors in the roof); b-fixing the arched shape with combined mixed support (metal-arched support with anchors in the roof and sides); c-fixing the arched shape with metal-arched support; d-fixing the rectangular shape with anchor support

Recently, due to the increasing complexity of mining and geological conditions of development, due to the increase in the depth of mining operations and the initial development of layers with favorable conditions of occurrence, the cost of production increases; productivity in treatment and preparatory faces is at a low level, the labor intensity in conducting, maintaining and repairing mining workings increases, the ash content of extracted coal in treatment (33\% or more) and preparatory work (37-41\%) and the negative trend of their growth.

One of the limitations for the wider implementation of anchor support in the mines of the Republic of Kazakhstan, the Karaganda coal basin is the lack of a regulatory framework that allows taking into account the specific geomechanical situation, mining development schemes and experience in using anchor support, it is justified to accept the parameters of fixing mine workings. The stage for implementation in the creation of standard mining schemes is the formation of technological schemes for fixing workings using anchor support. A systematic analysis of the passports for fixing the workings of the mines of the Karaganda coal basin using anchor supports allowed us to form some of the following passports for fixing the workings with anchors for various schemes of mining development and their purpose.

Technological schemes for conducting and securing mining workings largely depend on the complexity of the mining and geological conditions of development and the emerging mining and 
technical factors in the conditions of the mines of the Karaganda coal basin.

Below are a number of passports for fixing mine workings, depending on the conditions of their operation.

The technology of working out with the use of metal-welding pliable support is shown in Fig. 8. These workings are subject to intense deformations and therefore are often re-anchored and the soil rocks are undermined.

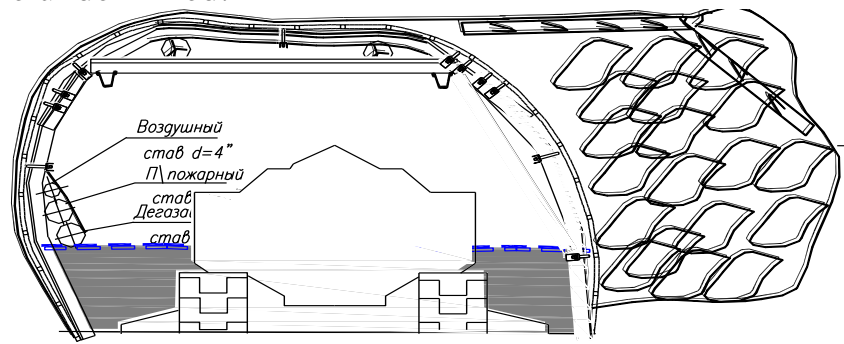

Fig. 8. Operational passport of carrying out, fastening and undermining during operation of the conveyor drift $33 \mathrm{k} 8-7-1 \mathrm{z}$ in the conditions of the mine named after Kuzembayev of the Karaganda coal basin

Due to the fact that during the operation of the workings there are disturbed and unstable zones of the mountain enclosing near-contour rocks, passports of workings with a combined attachment are used (Fig. 9).

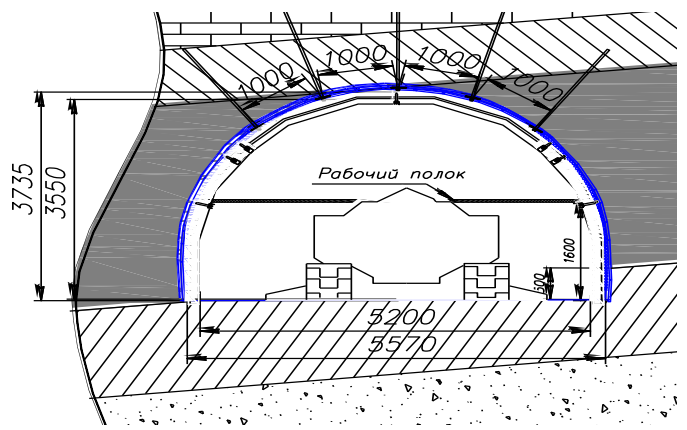

Fig. 9. The passport of the fastening of the conveyor drift $34 \mathrm{k} 8-7-\mathrm{z}$ in the conditions of the mine. Kuzembayev of the Karaganda coal basin 
Based on the general state of this problem, theoretical and experimental studies in the field of anchor anchoring of preparatory workings were carried out to solve the following tasks: analysis and evaluation of the effectiveness of existing equipment and technology of anchor fastening for various mining and technological conditions, justification of the prospects and conditions for the use of this technology; development and implementation of steel-polymer anchors of a new technological level, assessment of their effectiveness in improving the stability, reliability and safety of preparatory workings; justification of technological schemes for the installation of steelpolymer anchorage with the inclusion of the process in the tunneling cycle in order to prevent the stratification of rocks; development of a methodological approach to assessing the economic efficiency of the use of new types of anchorage created.

The method of two-level fixing with overlapping of the roof fixing zones above the workings

The maintenance of the roof for the entire duration of the mining operation is achieved by drilling and installing two levels of anchors. Anchors of the first level are steel-polymer anchors 5 (for example, 2-3 m). Second-level anchors rope anchors 4 (for example, 3-7 m). In the area of the immediate roof of the mine, in each area of the anchorage (more precisely, steel-polymer and rope), zones of strengthening of the roof are created. The anchors of the two levels are installed at such a distance from each other that the strengthening zone of the first level 1 is fixed with the strengthening zone of the second level 2 in the joint zone of strengthening zones 1 and 2 of zones 3 . Thereby creating a large area of the direct roof connected to each other by less and stronger rocks, and we achieve a large load-bearing capacity of the roof in time-Fig. 10.

\section{Method of fixing the excavation in the zone of influence of cleaning works}

The objective of the technical proposal is to increase the stability of the immediate roof on strategically important mining sites, to increase the safety of work on deep horizons by stitching unstable rocks of the immediate roof and then fixing the created artificial "bridge" to the strong rocks of the main roof.

Technical result: improvement of the technical condition of the anchor support, creation of conditions for maintaining a constant 
cross-section of the workings, ensuring the greatest stability of the immediate roof, reducing rock falls and increasing the service life of the support.

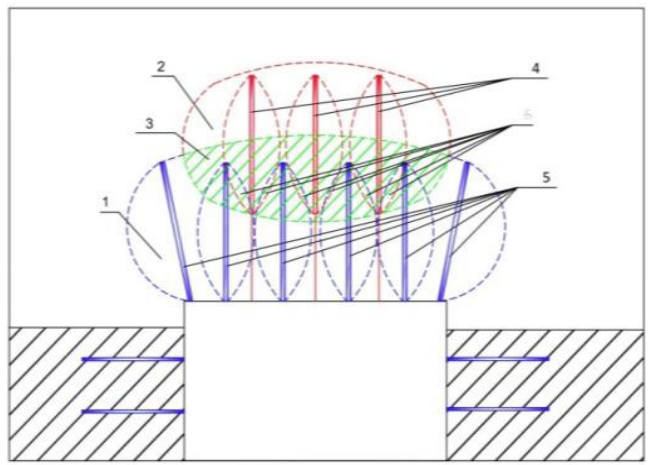

Fig. 10. The method of two-level overlapping of the roof fixing zones over the development: 1 - zone 1 (zone strengthening of the roof with steel-polymer anchors); 2 - zone 2 (zone strengthening of the roof with rope anchors); 3 - zone strengthening of the connection of zone 1 (zone strengthening of the roof with steel-polymer anchors) and zone 2 (zone strengthening of the roof with rope anchors); 4 - rope anchors; 5 - steel-polymer anchors; 6 - zone of maximum strengthening of the connection of zone 1 and zone 2

The technical result is achieved due to the fact that, when an artificially direct roof gets a certain additional margin of safety in the reference pressure zone, the rock mass created in this way is fixed with the help of rope anchors deep lying to the stronger rocks of the main roof. This creates the effect of contouring and strengthening the working plane and reduces the pressure on the support-Fig. 11.

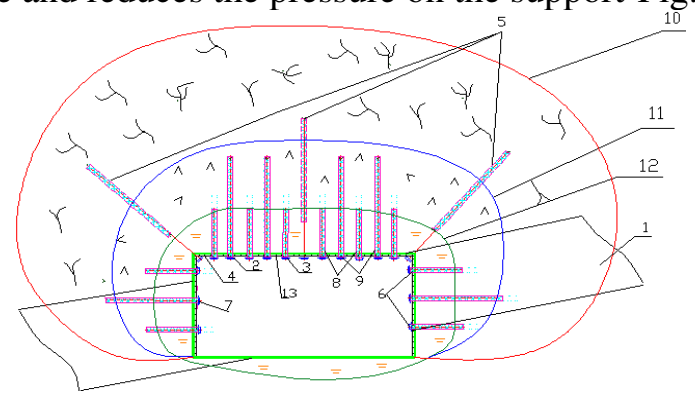

Fig. 11. Method of fixing the excavation in the zone of influence of cleaning works 
This method of fixing is based on creating a connection between the immediate roof, which is unstable rocks, with the main roof, which is represented by stable strong rocks, such as mudstone or sandstone, to which the immediate roof is attached.

This connection is made by laying 3 levels of anchors: shallow anchors of the 1st level $(6,8)$ (fasten the immediate roof), deep anchors of the $2^{\text {nd }}$ level $(7,9)$ (create a connection between the immediate roof anchored by the 1st level anchors and the main roof) and deep-lying anchors. Deep-lying anchors are usually rope anchors with a length of at least 5-7 m. For fixing the first level, steelpolymer anchors with a length of $2.4 \mathrm{~m}$ are used, and for fixing the second level, steel-polymer anchors with a length of $3.5 \mathrm{~m}$ are used.

Three zones are created around the workings: reference pressure (12), elastic deformations (10) and plastic deformations (11), surrounding the workings with the anchors of the $1^{\text {st }}, 2^{\text {nd }}$ and $3^{\text {rd }}$ levels in relation to each other and to the workings.

Fixing begins with the frill of the face, namely the roof and sides of the workings. Then the roof anchors of the first level (8) are installed with full filling. After that, the roof anchors of the secondary level (9) and the side anchors are also installed with full filling. Next, deep-laid rope anchors (5) with incomplete filling of the hole are installed. All anchors are fixed in the hole with a solution obtained when the anchor breaks the capsules that are deliberately introduced into the hole. The number of holes in each hole is determined by the passport of the face mounting.

After the solution has solidified, a pressure plate is put on the anchor, which is fixed with a nut and tensioned.

Between the strip and the plate (2) with the tension nut (3), a cone-shaped spacer is installed, which, when the load is perceived, ensures the pliability of the support due to its deformation.

\section{Mesh puff}

The technical result consists in the reliable fixing of the array of enclosing rocks, improving the design, due to the reliable connection between the sheets of mesh tightening by means of a metal rod (Fig. 12).

The task is achieved by the fact that the mesh tightening for fixing mining workings, made in the form of sheets with diamondshaped openings directed towards each other, characterized in that the last row of diamond-shaped openings, has spherical cavities 
made under the diameter of the metal connecting rod, for connecting and fixing the sheets of mesh tightening among themselves.

$a$

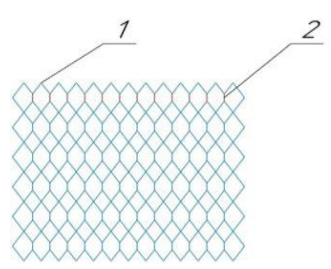

$b$

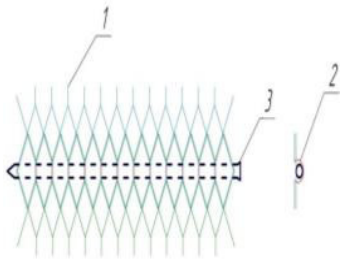

Fig. 12. Mesh tightening

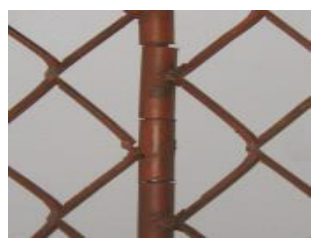

All existing types of anchors are divided into two categories according to the purposes for which they are used: first-level anchors (up to $2.5 \mathrm{~m}$ in length) for fixing the contours of mine workings, and second - level anchors (3-5 $\mathrm{m}$ in length or more) for fixing the joints and in special mining conditions (stress, overhanging coal massifs, etc.).

In order to increase the efficiency of fastening and ensure the long-term stability of preparatory workings with the use of steelpolymer anchors, it is necessary to continue research and theoretical justification of methods for calculating the parameters of fastening and checking the results in different mining conditions of coal mines.

It is possible to use various types of threaded surface of anchors, both metric and rolled, which makes it possible to increase the manufacturability of their manufacture and the load-bearing capacity of the anchor support - Fig. 13.

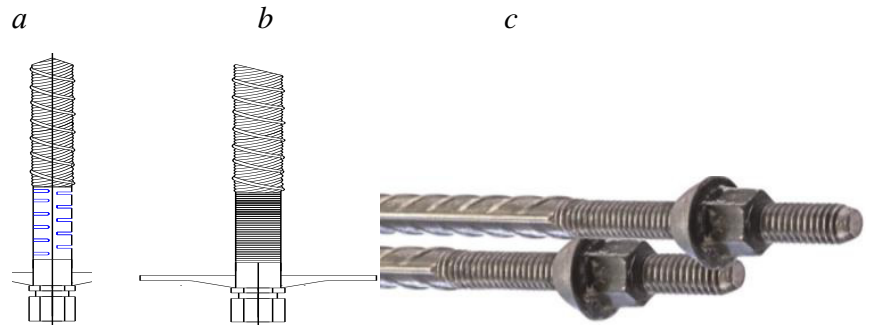

Fig 13. Anchors with an internal thread $(a)$ with a chisel end $(b)$, an external metric

(at the mouth) with a beveled end and its photo (c)

\section{Soil heaving and process flow diagrams to prevent soil rock blowing}

The stability of the soil of mine workings depends on a number of mining-geological and mining-technical factors, the most important of which are: the depth of work, the power and angle of fall of the 
formation, the moisture content of coal and the host rocks, the disturbance of the deposit, the physical and mechanical properties of the side rocks, as well as their combination in the array, the adopted development system, the length and speed of movement of the treatment face, the methods of protection of the workings, the parameters of the accepted support of the workings, the quality of its fastening, etc.

\section{Method of combating soil heaving in preparatory work}

In workings that are not affected by cleaning operations (the first type of deformation), the deformations of the rocks of the soil layers consist in a slight expansion, which is smaller in magnitude than the relative longitudinal deformation of the rock $\left(15 \cdot 10^{-3} \mathrm{~m}\right)$. Complete attenuation of deformations is observed after 150-300 days.

In the second type of deformation, a zone of destroyed rocks is located near the contour of the soil.

The coefficient of destruction of rocks in it increases with time, but this increase has a decaying character. The size of the destroyed zone reaches 2-3 m, and the expansion coefficient of rocks is 1.02-1.03. Further beyond the fracture zone to a depth of 5-6 $\mathrm{m}$ is the zone of creep deformations (elastic-viscous deformations).

The nature of rock deformation in this zone is also decaying. The relative deformations of the layers are $(10-15) \cdot 10^{-3} \mathrm{~m}$, i.e. 2 times and not less than the deformations in the fracture zone.

A comparison of the displacements along the width of the excavation shows that the intensity of deformation of soil rocks in the center of the excavation is slightly higher than on the sides [7-14].

Fig. 14 shows the relative deformations of the soil rock layers over time from the contour deep into the massif.

\section{Conclusion}

The development of geotechnological methods and testing of the strengthening effect on the disturbed coal-rock mass during manmade processes were carried out. 


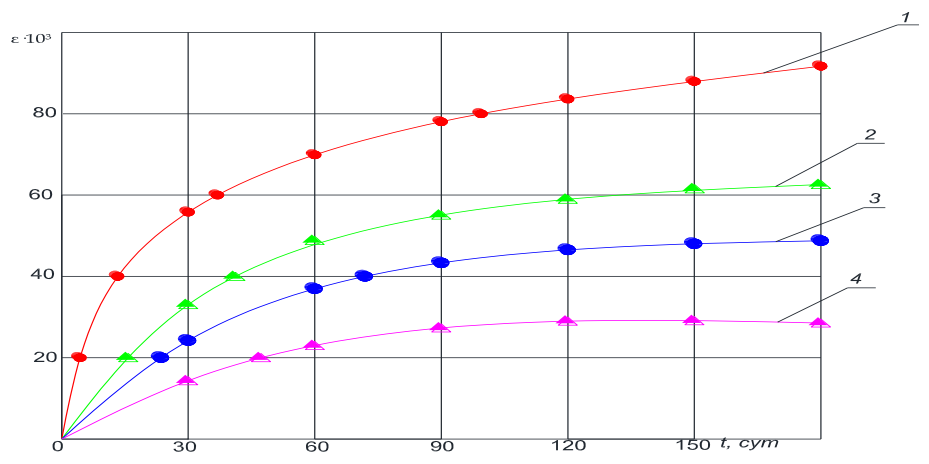

Fig. 14. Relative deformations of soil rock layers in time from the contour deep into the massif: 1 - $1 \mathrm{~m} ; 2$ - from 1 to $2 \mathrm{~m}, 3$-from 2 to $3 \mathrm{~m} ; 4$-from 3 to $4.5 \mathrm{~m}$

The factors that negatively affect the conduct of mining operations and the development of coal seams are analyzed. The manifestations of rock pressure during the preparatory workings are investigated.

The complex of factors affecting the stability of the workings fixed with anchor support, the schemes of hanging on anchors and forming a load-bearing structure in the roof of the workings using anchors, and the technological schemes of fastening the contours of the workings are evaluated.

The technology of conducting treatment works is considered. Usually, in a complex and in a relationship, the geomechanics of conducting work, the possibility of using the most advanced technical means (machines and equipment) and the rational alignment and sequence of all operations are taken into account.

When conducting mining operations on unstable subsurface rocks, the formation of cracks, splits, deformations and destructions of the weakest layers of the roof is observed, which requires additional technological measures to strengthen the lower layers of the roof of the development and reduces the pace of its implementation.

In this regard, a method of two-level fastening with a complex overlap of the roof fixing zones above the excavation, with the imposition of hardening zones in the resulting rock formation; a method 
of fixing the excavation in the zone of influence of cleaning operations by stitching unstable rocks of the immediate roof and then fixing the created artificial "bridge" to the strong rocks of the main roof; mesh tightening to perceive the load from rocks in the space between the anchors and prevent the precipitation of rock mass; a method for combating soil heaving in preparatory workings by spreading the broken rock blocks with power spacer modules.

\section{References}

1. Industry instruction on the use of frame and rock bolts in the development workings of coal and shale mines. - M .: IGD im. A.A. Skochinsky, 1985.- 64 p.

2. Shevyakov L. D. On the problems of studying rock pressure in connection with the demands of industry // Coal. - № 1, 2. 1997. - S. 34-37.

3. Carr F. Recent innovations in rock anchoring in the mines of the Government of the United Kingdom // Reports at the anchoring symposium. - London, 1984.- S. 268-281.

4. Ulrich L. Design basis for rock pressure control with combined support in stratal drifts. Gluckauf. - 2002, March. - S. 16-20.

5. Shemyakin I.I., Fomin E.V., Fedorov E.V. Improvement of the technology of conducting and securing mine workings at the Instinskaya mine // Coal. 2001.№. 2. - P. 6-10.

6. Kulasek M. Program for calculating rock pressure and convergence "Conversys". Commercial offer (Germany). - Karaganda, 2011.- 1 p.

7. Dontsul N.F. Some questions of the mechanics of a layered medium. - SPb .: ZAO Print-Express; St. Petersburg Mining Institute, 2009. - 379 p.

8. Altonian $\mathbf{P}$. Anchor fastening in the mines of the Karaganda basin. Presentation - 55 slides / ArcelorMittal. AC-R03. 2008.- 35 p.

9. Seedsman R. Review of anchoring in the mines of Karaganda / ArcelorMittal. 2010.- 35 p.

10. Instructions for the calculation and use of roof bolting in the coal mines of Kuzbass. - SPb .: JSC "VNIIMI", 2011. - 150 p.

11. Guber O. Development and delivery of digital modeling tools. Commercial offer. - Karaganda, 2011.- 10 p.

12. Katsaga T.Ya. Parametric modeling. - Karaganda: Sanat, 2004 .- 65 p.

13. Katsaga T.Ya. Modeling of the state of workings in the sinking and in the zone of influence of the cleaning work FLAC 3D. Commercial offer (USA). Karaganda, 2011.- 10 p.

14. Zabrodin A.S. On the assessment of disturbance of coal seams // In the book Geology of coal deposits.-Moscow: Nauka, T. 1, 1969. - P. 45-49. 
https://doi.org/10.31713/m1105

\title{
INVESTING THE CAUSES AND EFFECTS OF MINING INDUCED SUBSIDENCE DUE TO SINK HOLES ON THE SOUTH AND EASTERN LIMB AT LUBAMBE MINE, ZAMBIA
}

\author{
Victor Mutambo \\ University of Zambia, School of Mines, Department \\ of Mining Engineering, $\mathrm{PhD}$, Senior Lecturer and Researcher, Zambia
}

Draida Mikoloni

University of Zambia, School of Mines, Department of Mining Engineering, Research Scholar, Mining Engineer, Zambia

\begin{abstract}
Lubambe copper mine is an underground operation with a thin orebody of width ranging between approximately 5-5.5m. Between May 2020 and 2021 the mine experienced a total of six sink holes which were all sudden without giving prior indication of subsidence. The mining subsidence has led to increased mining cost and cycle times due to the closure of $182 \mathrm{ml}$ decline on the eastern limb and $175 \mathrm{ml}$ truck route on the southern limb and disturbance on surface infrastructure.

The main purpose of this study is to investigate the causes and effects of sinkholes on mining operations and surface infrastructure.

Geotechnical empirical and numerical analysis of the ground, core logging, review of rock mass characterisation and evaluation of mining practices were undertaken. The mapping data was analysed using dips, Unwedge and RS3 software.

It has been established that the east limb sinkholes were developed after a catastrophic failure at R3. $82 \mathrm{~mL}$ decline which affected a lateral stretch of approximately $50 \mathrm{~m}$. The first sinkhole on the southern limb was developed after a blast at Ramp 2.325 $\mathrm{mL}$ tips and the second was formed after a fall of ground at Ramp $2.372 \mathrm{ml}$. Empirical analysis for rock mass classification using the Q-system and RQD showed that the ground condition on the south and east limbs were poor to fair.

The sinkholes development on surface are as a result of the sill pillar failures from historical and current mining operations cascading from one level to another and creating hanging wall instability as the ground unravels to fill the voids.

Key words: sinkholes, mining induced subsidence, geotechnical assessment, mining practices

Corresponding author: vmutambo@unza.zm

\section{Introduction}

Lubambe Copper Mine is an underground mining operation situated on the Zambian Copperbelt close to the town of Chililabombwe. The Mine has been in operation since 2012. Between May 2020 and
\end{abstract}


2021 the mine experienced development of a total of six sink holes in a space of one year [1]. All six occurrences were sudden and gave no indication of subsidence in the affected areas. The only indication of subsidence formed on the eastern limb were tension cracks that formed directly above ramp 4. The first occurrence was on the eastern limb where three sinkholes developed after a catastrophic failure on Ramp 3_182 mL decline. The sinkholes formed were trough like with a conical shape, the sinkholes formed on the southern limb occurred a month apart with the first occurrence being in April, second in May and the third in October of 2021.

An empirical post stope stability analysis was conducted and a surface hazard map was developed for physical monitoring of the surface infrastructure placed in close proximity to the caving area. Other methods of monitoring employed were photogrammetry/drone technology, physical inspections and satellite monitoring.

The unexpected development of mining induced subsidence at the mine increased the costs and disrupted production by increasing the cycle times due to the closure of $182 \mathrm{ml}$ decline on the eastern limb and $175 \mathrm{ml}$ truck route on the southern limb. The additional rehabilitation cost on the two excavations was not budgeted for including the six sinkholes which have been successfully backfilled. Rehabilitation of $182 \mathrm{ml}$ decline is still underway from 2020 while $175 \mathrm{ml}$ truck route rehabilitation commenced in November 2021 on the southern limb and has since been completed.

On surface, the sinkholes on the southern limb damaged the main tarred road which was the main access to the mine and nearby community Konkola Township. Furthermore, damages resulting from subsidence led to water disruption to the mine site and community in Konkola Township following the main supply pipes ran along the road that subsidised.

\section{Ground deformation monitoring}

Ground subsidence is the lowering or collapse of the land surface, and is caused by a number of natural and human-induced activities. Natural subsidence occurs when the ground collapses into underground cavities produced by the solution of limestone or other soluble materials by groundwater. Most current subsidence in the corridor is human induced.

Factors effecting Subsidence include [2] 
Depth of Cover,

Overlying Strata Properties,

Seam Thickness,

Panel Width,

Chain Pillar Size

Surface Topography

The need of subsidence monitoring in underground mining is multi-fold:

Legislation,

Subsidence Prediction,

Maximise Ore Extraction,

Structural Design,

Risk Management, and

Environmental Monitoring

Therefore, ground subsidence due to underground mining is of major concern for the mining industry, mining communities and other stakeholders. Subsidence is currently monitored by repeated ground survey using automatic/digital levels (in line levelling), total stations (in EDM height traversing) and GPS receivers (in static and real-time-kinematic (RTK) survey) [3]. Both digital level and total station can deliver $0.1 \mathrm{~mm}$ height change resolution while GPS $5 \mathrm{~mm}$ in static and $2-3 \mathrm{~cm}$ in RTK. On the other hand, the differential radar interferometry (D-InSAR) can deliver approximately $1 \mathrm{~cm}$ height change resolution. Since radar beam scans in range direction, the movement of the platform in azimuth direction completes the 2D imaging of the mining region. The current geodetic technologies can only measure subsidence on a point-by-point basis. Therefore, $D$ InSAR and current geodetic technologies are complementary in monitoring ground subsidence due to underground mining.

Ground subsidence can damage mine and community infrastructure including water resources. Real-time monitoring of ground movements in mining areas can provide early warning of the above problems, which can effectively reduce the occurrence of environmental geological disasters, or at least reduce their impact [4]. The Interferometric Synthetic Aperture Radar (InSAR) is a non-contact and green monitoring technology that has the advantage of being available all day and in any weather conditions. It is characterized by continuous spatial coverage, high automation and high precision. It has become one of the most rapidly developing and potential tech- 
niques for earth observation and mapping. In 1990 s, Camec et al. applied D-InSAR technology to the ground deformation monitoring of mining areas, and verified its feasibility for the first time [5]. Since then, the use of InSAR to monitor ground deformations of mining areas has been rapidly expanding, and important research results have been achieved [6], [7]. For areas with complex terrain or excessive deformation gradients, the interference fringes will be very dense. Coupled with the influence of decorrelation phenomenon, the fringe aliasing phenomenon may occur. All of the above reasons can lead to incorrect unwrapping results or even unwrapping failures, and the quality of unwrapping results directly affects the accuracy of the measurement [8]. Sub-band InSAR, which is a derivative of conventional differential InSAR (D-InSAR), was first proposed by Madsen and Zebker [9], [10]. Its principle is to increase the effective wavelength by several tens or even hundreds of times by reducing the image bandwidth. As a result, the number of interference fringes is correspondingly reduced, and the difficulty of unwrapping is reduced as well. A lot of underground mining activities occur beneath farmland area or forested region; subsequently, temporal decorrelation will make great difficulties for InSAR. Both InSAR and sub-band InSAR rely on interferometric phases to extracting deformations, thus they are usually unable to correctly map the ground deformations characterized by large magnitudes and steep gradients associated with underground mining. The offset-tracking technology is able to extract deformations based on SAR image intensity information, and is not affected by phase noise and deformation gradients. It is mostly used for monitoring of large-scale deformations, such as those related to earthquakes [11], [12], and [13].

Monitoring of large-scale deformation using sub-band InSAR

The large scale and rapid land subsidence that occurs in mining areas leads to problems, such as densely spaced interference fringes and the temporal decorrelation of interferometric synthetic aperture radar (InSAR) interferograms. All, four different bandwidth images with three sub-band bandwidth parameters are used to extract simulated mining induced subsidence with seven different deformation magnitudes. In monitoring subsidence with different deformation magnitudes using images with different bandwidths.an optimal monitoring value exists; wider image bandwidths lead to smaller optimal monitoring values and higher monitoring accuracies. Therefore, an 
appropriate sub-band bandwidth should be selected that depends upon the image bandwidth and the subsidence level to achieve optimal monitoring. The optimal sub-band width for monitoring different magnitudes in mining areas is determined through simulation experiments, and these conclusions can provide a technical basis for selecting the appropriate sub-band bandwidth for monitoring of subsidence in mining areas. Although sub-band InSAR can reduce the number of interference fringes and the difficulty of unwrapping, the simultaneous introduction of large amounts of noise leads to reduced monitoring precision, and the application of the probability integral method in the prediction of mine subsidence is more mature. The probability integral method is used to perform noise peeling on the interferometric phases of the sub-bands to improve the monitoring accuracy of sub-band interferometry.

\section{Rock Quality Designation (RQD)}

$\mathrm{RQD}$ is a measure of the degree of fracturing of the rock mass and is aimed to represent the in situ rock mass quality. RQD calculation can be determined using equation1. Table 1 shows rock mass quality classification according to RQD.

$$
R Q D=\frac{\sum \text { lenqth of core pieces }>10 \mathrm{~cm}}{\text { total lenqth of the core }}
$$

Table 1

Rock mass classification based on RQD

\begin{tabular}{l|l|l}
\hline 1 & Rock Quality Designation & RGD \\
\hline A & Very Poor & $0-25$ \\
\hline B & Poor & $25-50$ \\
\hline C & Fair & $50-75$ \\
\hline D & Good & $75-90$ \\
\hline E & Exellent & $90-100$ \\
\hline
\end{tabular}

When no cores are available, RQD can be estimated from Joint spacing [22].

Rock Mass Rating (RMR) System or the Geomechanics Classification was developed by Bieniawski during 1972-1973 in South Africa to assess the stability and support requirements of tunnels [14]. Since then it has been successively refined and improved as more case histories have been examined. 
The uniaxial compressive strength of the intact rock $(\sigma c)$ : for rocks of moderate to high strength, point load index is also acceptable [15].

Rock Quality Designation (RQD)

Discontinuity spacing

Condition of discontinuity surfaces

Groundwater conditions

Orientation of discontinuities relative to the engineered structure It does not include in-situ stress conditions.

Bieniawski [16] has developed the following correlation between the $Q$-index and the

$\mathrm{RMR}$ in the form of a semi-log equation given by;

$$
R M R=9 \log Q+A
$$

Where $A$ varies between 26 and 62, and the average of $\mathrm{A}$ is 44 (derived from 111 case histories in tunneling).

Rock Tunneling Quality Index ( $Q$-System) was developed in 1974 by Barton, Lien, and Lunde at the Norwegian Geotechnical Institute, Norway for the determination of rock mass characteristics and tunnel support requirements [17], [18]. RMR and $Q$-Systems use essentially the same approach but different log-scale ratings, as $Q$ value is the product of the ratio of parameters while RMR is the sum of parameters [19]. The $Q$-rating is developed by assigning values to six parameters that are grouped into three quotients. The numerical value of the index $Q$ ranges from 0.001 to a maximum of 1,000 on a logarithmic scale [15]. Value of Q is defined and is calculated as

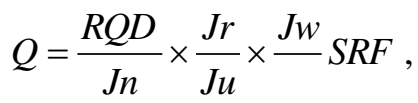

where $R Q D$ (Rock quality designation)>10 (measuring the

$R Q D$ (Rock quality designation) > 10 (measuring the degree of fracturing);

$J n$, Joint set number (number of discontinuity sets);

$J r$, Joint roughness number for critically oriented joint set (roughness of discontinuity surfaces);

$J u$, Joint alteration number for critically oriented joint set (degree of alteration or weathering and filling of discontinuity surfaces);

$J w$, Joint water reduction number (pressure and inflow rates of water within discontinuities); 
$S R F$, Stress reduction factor (presence of shear zones, stress concentrations, squeezing or swelling rocks).

\section{Mining practices}

Ore extraction in underground mines involves the generation of different type of excavations. The standup time of different types of ore source hereby referred to as stopes depend on the methods of extract and the duration of active ore extraction. The particular method chosen for the exploitation of an orebody is determined by such factors as its size, shape and geometric disposition, the distribution of values within the orebody, and the geotechnical environment [20]. Irrespective of the mining technique adopted for ore extraction are four common rock mechanics which are:

(a) To ensure the overall stability of the complete mine structure,

(b) To protect the major service openings throughout their designed duty life;

(c) To provide secure access to safe working places in and around the centres of ore

Production; and to $(d)$ to preserve the mineable condition of unmined ore reserves [20]

\section{Mining sequence}

Mining sequence must be designed by taking into account long term benefits and not short term factors because capital recovery is a long process. Practice of not following the mining sequence may, result in the creation of high stress blocks within the orebody. Kalunga and Mutambo [21] applied numerical modelling using PHASE2 software at $985 \mathrm{~mL}, 2110 \mathrm{mN}$ stope to evaluate stope hanging wall behaviour. They found that in most cases the stope hangingwall are located in a zone of relaxation or low tensile induced stress. The relaxation zones leads to unclamping of the key blocks and subsequent failure of some stopes. Additionally, poor ground conditions as well as poor drilling and blasting practices are precursor to ground failures. This position is supported by [22] reported that when a fractured rock mass is in a relaxed state stress zone, the rock blocks separated by discontinuities and the opening walls can unravel. Hangingwall sloughage occurs when the confinement of the minor principle stress is below or equal to zero [23]. When induced stress is higher than the shear strength of the rock mass around the stope, localized failures will occur following discontinuities or direct 
through intact rock resulting into [24]. According to Villaescusa, [24] the larger the stope opening the larger the more deformations that are expected at the stope walls hence making the walls more prone to damage due to blasting or stress redistribution. The magnitude and orientation of the in situ stresses greatly influences the relaxation zone [25. For instance, for similar geometries, the greater the stress regime is, the deeper the relaxation zone extends into the surrounding rock mass [25]. Henning and Mitri [23] proposed that the zone of stress relaxation reduces the clamping forces which are supposed to prevent sloughing or unravelling of the stope walls. The behaviour of stope walls is dependent on the strength of the surrounding rock mass which also depend on the geometrical nature and strength of the geological discontinuities and rock material [24]. Hughes [22], points out that rock mechanics properties such as strength of the rockmass and geological characteristics such as RQD, joint structures all influence the stability of stope walls. Therefore, the stability of underground excavations must be assessed d by taking into account geotechnical environment and the standup time for the excavation.

This study was undertaken to investigate the causes and effects of mining induced subsidence at Lubambe copper mine and provide mitigation mechanisms for reducing the likeliness of re-occurrence of undetected subsidence. Application of these mitigation factors will also allow the mine to prepare for contingency plans in an event of re-occurrence of subsidence, thereby reducing the impact on daily production, the surrounding infrastructure and the nearby community.

\section{Materials and Methods}

Underground physical inspections were conducted regularly for Geotechnical assessment of the ground condition, mining practices (mining sequence, stoping and firing) and the hydrogeology of the mine. During these inspections scanline and window mapping was conducted to determine the dip, dip direction and persistence of discontinuities in all the ramps across the mine. The mapping data was entered in the mapping database in Microsoft office excel and analysed using dips, Unwedge and RS3 software. Some of the instrumentation used to conduct these inspections and assessments includ- 
ed; flash light, distometer, geological compass, measuring tape, geological hammer, note book, clip board and pens.

On surface, core logging was done from the core yard where raw data was logged onto the logging sheets in intervals of $1 \mathrm{~m}$. Once logging of an entire bore hole was completed, the logged data was then entered into the core logging data base in Microsoft excel for empirical and numerical geotechnical analysis and interpretation using (Bieniawski's and Barton) rock mass classification criteria and GEM 4D software respectively. Extensive literature review was done on the geotechnical data available onsite which included; core logging and mapping databases, ground control management plan (GCMP), consultancy reports and, online review of published papers written on mining induced subsidence and other scholars literature in mining pertaining to this case study.

\section{Results and discussion}

Results of the study indicate that, the first subsidence occurrence on the east limb resulted in development of three sink holes. From the geotechnical analysis conducted using the empirical and numerical approach, it was discovered that the east limb sinkholes developed after a catastrophic failure was recorded underground at R3_182 mL decline which affected a lateral stretch of approximately $50 \mathrm{~m}$. Figures 1-6 show the stress analysis from $113 \mathrm{ml}$ to $182 \mathrm{ml}$.

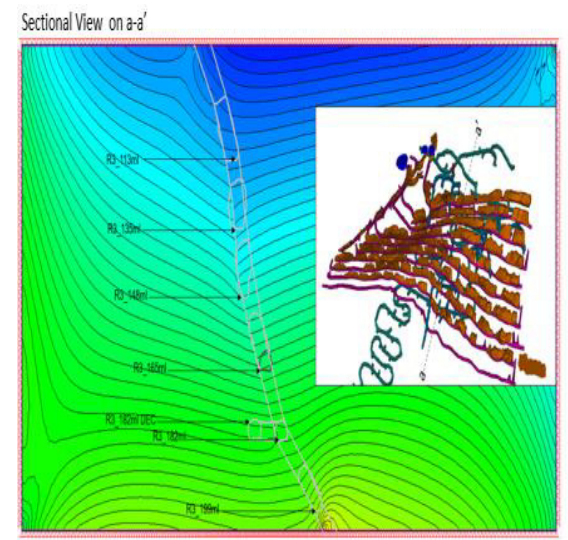

Fig. 1. Pre-mining insitu stress state (Phase 1) 


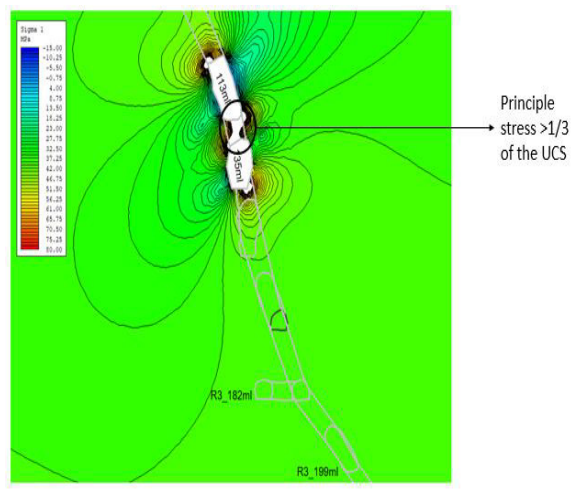

Fig. 2. Mining $113 \mathrm{ml}$ and $135 \mathrm{ml}$ (Phase 2)

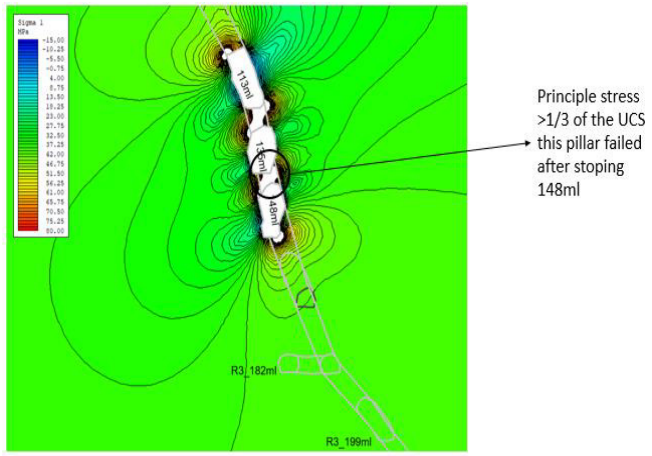

Fig. 3. Mining $135 \mathrm{ml}$ and $148 \mathrm{ml}$ (Phase 3)

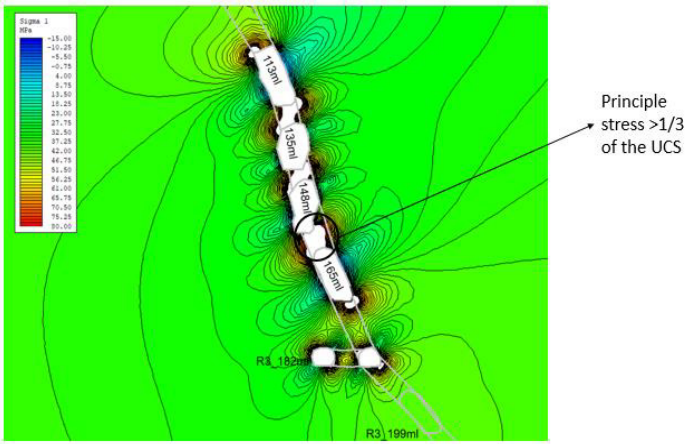

Fig. 4. Mining $148 \mathrm{ml}$ and $165 \mathrm{ml}$ (Phase 4) 


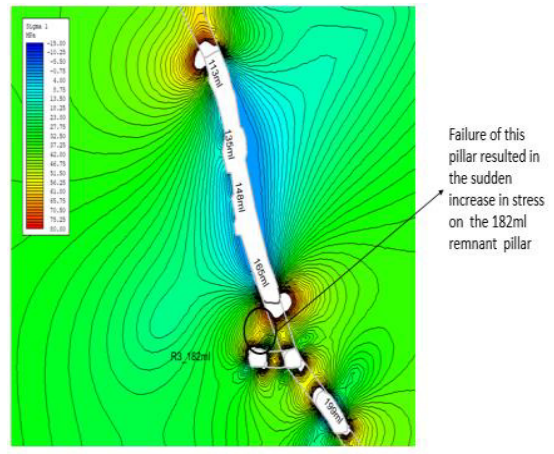

Fig. 5. Mining $182 \mathrm{ml}$ (Phase 5)

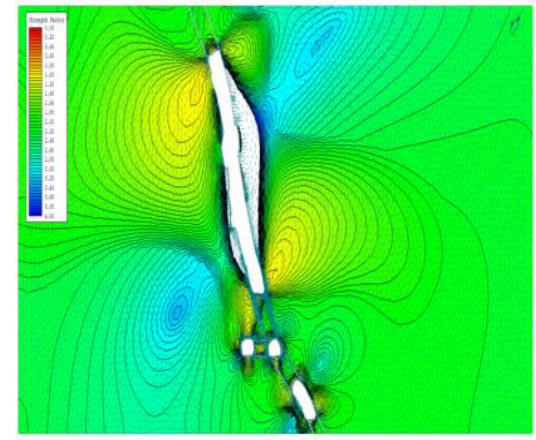

Fig. 6. Strength factor variation at $182 \mathrm{ml}$ Decline

From the numerical model done it was interpreted that, failure of the decline underground was

Caused by the following reasons listed below;

Stopes from $113 \mathrm{ml}$ to $182 \mathrm{ml}$ were designed to hole with $4 \mathrm{~m}$ sill/chain pillars. The design check shows that the minimum sill pillar should have been at least $5 \mathrm{~m}$ and the stopes should not have been designed to hole into each other.

The stope spans on $165 \mathrm{ml}$ were designed at approximately $74 \mathrm{~m}$ - $120 \mathrm{~m}$ long, and in cases where the rib pillar failed the stopes were $126 \mathrm{~m}$ long. This approach gave a very low factor of safety on the regional stability of this level with respect to $148 \mathrm{ml}$ the above.

The decline proximity analysis indicates that the location of the decline was designed within the stress redistribution zone with respect to the $182 \mathrm{ml}$ wrecking stope. The middling between the de- 
cline and $182 \mathrm{~mL}$ ore drive was approximately $6-7 \mathrm{~m}$ which was not sufficient for a $5 \times 5$ excavation. The effect on the excavation is as a result of induced stress acting perpendicular to the principle stress direction damaging the top and bottom shoulder of the drive.

The sinkholes on surface are as a result of the sill pillar failures on $165 \mathrm{ml}$ cascading through to $148 \mathrm{ml}, 135 \mathrm{ml}$ hereby creating hanging wall instability as the ground unravels to fill the voids.

On the southern limb the first two sink holes also developed as a result of subsidence, this occurred after a blast was conducted underground at R2_325 mL and a fall of ground in R2_372 mL respectively. So far, a total of three sinkholes have been recorded on the south limb bringing the total number of sink holes across the mine to six. Aside production related factors the additional factor that contributed to the expedition of subsidence on the south limb was the ponding water that was caused by uncontrolled leakages and the lowest point on the hanging wall were rain water accumulated in the wet season hereby highly saturating the area.

Table 2 shows the rock mass classification of the ground condition from the south and east limbs separately based on equation 1 .

Table 2

Shows the rock mass classification of the ground condition

\begin{tabular}{|c|c|c|c|}
\hline Year & Rock Type & Ramp & RQD \\
\hline $2018-2021$ & Arkose & 1 & $33 \%$ \\
\hline $2018-2021$ & Shale & 1 & $30 \%$ \\
\hline $2018-2021$ & Conglomerate & 1 & $25 \%$ \\
\hline \multicolumn{3}{|c|}{ Average } & $30 \%$ \\
\hline $2018-2021$ & Arkose & 2 & $31 \%$ \\
\hline $2018-2021$ & Shale & 2 & $28 \%$ \\
\hline $2018-2021$ & Conglomerate & 2 & $26 \%$ \\
\hline \multicolumn{3}{|c|}{ Average } & $29 \%$ \\
\hline $2018-2021$ & Arkose & 3 & $36 \%$ \\
\hline $2018-2021$ & Shale & 3 & $38 \%$ \\
\hline $2018-2021$ & Conglomerate & 3 & $39 \%$ \\
\hline \multicolumn{3}{|c|}{ Average } & $40 \%$ \\
\hline $2018-2021$ & Arkose & 4 & $36 \%$ \\
\hline $2018-2021$ & Shale & 4 & $38 \%$ \\
\hline $2018-2021$ & Conglomerate & 4 & $39 \%$ \\
\hline \multicolumn{3}{|c|}{ Average } & $44 \%$ \\
\hline $2018-2021$ & Arkose & 5 & $48 \%$ \\
\hline $2018-2021$ & Shale & 5 & $38 \%$ \\
\hline $2018-2021$ & Conglomerate & 5 & $52 \%$ \\
\hline \multicolumn{3}{|c|}{ Average } & $45 \%$ \\
\hline
\end{tabular}


Empirical analysis of the core logged data for rock mass classification using the RMR,Q-system and RQD results showed that the ground condition on the south and east limb can be classified as poor to fair ground as shown in Table 3.

Table 3

Empirical analysis of the core logged data for rock mass classification using the RMR, Q- system and RQD

\begin{tabular}{cccc}
\hline Limb & Criteria & Value & Classification \\
\hline South & RQD & $29.2 \%$ & Poor \\
South & RMR & $46.7 \%$ & Fair \\
South & Q-System & 2 & Poor \\
& & & \\
East & RQD & $43 \%$ & Poor \\
East & RMR & $51.2 \%$ & Fair \\
East & Q-System & 7.3 & Fair \\
\hline
\end{tabular}

The subsidence that resulted into sink hole development on both limbs can be mainly attributed to historical and current mining operations. From the historical data available it shows that the mining method practiced was a non-supported method which left behind open stopes. Information from historical mining conducted in the $1950 \mathrm{~s}$ shows production at Lubambe started on the southern limb at $100 \mathrm{~mL}$, some of their stopes were as close as $54 \mathrm{~m}$ from surface. With stopes this close to surface accompanied by an open stoping method and large stopes in weathered ground due to mining at shallow depth caving/subsidence is bound to occur.

The current mining method employed is a variant of room and pillar 'modified room and pillar' which also falls under open stoping methods(unsupported underground mining methods).This method has stope designs of $20-25 \mathrm{~m}$ with $6 \mathrm{~m}$ rib pillars and $5 \mathrm{~m}$ sill pillars that are not designed to hole.

The mining sequence of modified room and pillar is as follows;

The excavation is mined to completion for ore development with primary support installed.

\section{Thereafter secondary support is installed.}

Production drilling commences

And, lastly stoping is conducted.

The firing sequence used has the following sequence;

Ring 1 is fired 
Rings 2 and 3 are taken together

Ring 4 to the last ring in the panel are fired in a mass blast.

This firing sequence is adopted for the whole mine but subject to change upon geotechnical recommendation if there are ground condition issues in the area.

The average water discharged from underground on a monthly basis for the year 2021 was $300,000 \mathrm{~m}^{3}$ which translates to $10,000 \mathrm{~m}^{3} /$ day. The water bearing rock or aquifer is the conglomerate also known as the "kafufya' which lies on the footwall side of the ore body. Most of the water pumped from underground is from the eastern limb which comprises of Ramps 3,4 and 5. Most of the water from the east limb comes from a neighbouring mine in DRC which is currently flooded and has no operations taking place. Operations have gone deeper than this mine therefore the water accumulating from this flooded mine is seeping into Lubambe development as they mine deeper hereby dewatering the flood from the neighbouring mine.

On the southern limb, there isn't much water and can be described as fairly dry because Konkola copper mine in Chililabombwe has dewatered most of the water in the levels Lubambe is currently mining from due to the fact that $\mathrm{KCM}$ operations are way deeper than that of Lubambe.

\section{Conclusion}

This study sought to investigate the causes and effects of mining induced subsidence at Lubambe copper mine. From the investigations done, the major cause of mining induced subsidence at Lubambe can be attributed to historical and current mining operations. The historical and current mining method employed at the mine falls under non-supported underground methods which leaves open stopes behind upon completion of stoping. The current method allows for development to be completed followed by production drilling and stoping, the stoping sequence starts from the limit of the ore drive retreating towards the level access.

Subsidence due to sinkhole formation has had profound effects on both mining operations and community infrastructure such as the road and water pipelines in close proximity to the cave line. This has resulted in additional costs due to re-routing of the water pipes, construction of emergency road to the mine and community and construction of a new tarred road. 


\section{Recommendation}

In addition to INSAR satellite monitoring system the mine should consider installing surface and underground movement monitoring instrumentation. Currently the only instruments in use underground are roctails which have not been placed in all active excavations.

\section{Acknowledgement}

The authors would like to thank Lubambe mine for providing valuable data for this study. We would also like to extend our thanks to the Dean, School of Mines at the University of Zambia for providing logistical support in form of transport to and from the mine site.

\section{Funding Source}

This study was not funded by any external supporters, all the costs associated with the study were covered by the principle investigator of the study.

Potential conflict

There is no potential conflict of interest.

\section{References}

1. Longwe, P. (2020). Draft - Lubambe Ground Control Management Plan. Copperbelt, Zambia: Un-Published.

2. Nestbitt, A., 2003. Subsidence Monitoring West Cliff Colliery Longwall 5A4, APAS (Association of Public Authority Surveyors) 2003 Conference, Wollongong, Australia, 1-4.

3. Schofield, W., 1993. Engineering Surveying, Laxton's, Oxford, UK, 554pp

4. Zhang, Z., Wang, C., Tang, Y., Fu, Q., Zhang, H., 2015. Subsidence monitoring in coal area using time-series insar combining persistent scatterers and distributed scatterers. Int.J. Appl. Earth Obs. Geoinf. 39, 49-55. https://doi.org/10.1016/j.jag.2015.02.007.

5. Carnec, C., Massonnet, D., and King, C. (1996). Two Examples of the Use of SAR Interferometry on Displacement fields of Small Spatial Extent. Geophys. Res. Lett. 23, 3579-3582. doi:10.1029/96GL03042

6. Carnec and Delacourt, (20000. Three years of mining subsidence monitored by SAR interferometry, near Gardanne, France. DOI:10.1016/S09269851(99)00032-4 Corpus ID: 15825685

7. Baek, J., Kim, S.W., Park, H.J., Jung, H.S., Kim, K.D., Kim, J.W., 2008. Analysis of ground subsidence in coal mining area using sar interferometry. Geosci. J. $12,277-284$.

8. https://doi.org/10.1007/s12303-008-0028-3

9. Yu, H. W., Lan, Y., Yuan, Z. H., Xu, J. Y., and Lee, H. (2019). Phase Unwrapping in InSAR : A Review. IEEE Geosci. Remote Sens. Mag. 7, 40-58. doi:10.1109/MGRS.2018.2873644 
10. Madsen and Zebker (1992. Automated Absolute Phase Retrieval in AcrossTrack Interferometry. DOI:10.1109/IGARSS.1992.578639. Corpus ID: 62291773

11. Zebker, H.A., Villasenor, J., 1992. Decorrelation in interferometric radar echoes. IEEE Trans. Geosci. Remote Sens. 30, 950-959. https://doi.org/10.1109/36.175330.

12. Raucoules, D., Ristori, B., De Michele, M., Briole, P., 2010. Surface displacement of the mw 7 machaze earthquake (mozambique): complementary use of multiband insar and radar amplitude image correlation with elastic modelling. Remote Sens. Environ.114, 2211-2218. https://doi.org/10.1016/j.rse.2010.04.023

13. Huang, J., Deng, K., Fan, H., Yan, S., 2016. An improved pixel-tracking method for monitoring mining subsidence. Remote Sens. Lett. 7, 731-740. https://doi.org/10.1080/2150704x.2016.1183177

14. Zhao, C., Lu, Z., Zhang, Q., 2013. Time-series deformation monitoring over mining regions with sar intensity-based offset measurements. Remote Sens. Lett. 4, 436-445.https://doi.org/10.1080/2150704X.2012.746482.

15. Bieniawski, Z.T., 1993, Classification of rock masses for engineering: The RMR system and future trends, In: Hudson, J.A., ed., Comprehensive Rock Engineering, Volume 3: Oxford; New York, Pergamon Press, p. 553-573.

16. Bieniawski, Z.T., 1989, Engineering rock mass classifications: a complete manual for engineers and geologists in mining, civil, and petroleum engineering: New York, Wiley, xii, 251 Pp..

17. Bieniawski, Z.T., 1976, Rock Mass Classification in Rock Engineering, in Bieniawski, Z.T., ed., Symposium on exploration for rock engineering, Balkema: Rotterdam, p. 97-106.

18. Barton, N.R., R. Lien and J. Lunde, 1974. Engineering classification of rock masses for the design of tunnel support. Rock Mech., 6: 189-239. DOI: 10.1007/BF01239496

19. Barton, N., 1988, Rock mass classification and tunnel reinforcement selection using the Q-System, Rock classification for engineering purpose, Volume 984: ASTM Special Technical Publication: Philadelphia, p. 59-88.

20. E. Hoek (2007). Rock mass properties Practical rock, engineering.w.rocscience.com/learning/hoek-s-corner

21. Brady B.H.G and Brown E.T (1985). Rock Mechanics for underground ground Mining. London. Chapman and Hall. ISNB: 0-412-475-50-2

22. Kalunga Ngoma, Victor Mutambo (2020). Factors Influencing Ore Recovery and Unplanned Dilution in Sublevel Open Stopes. Case Study of Shaft No.4 at Konkola Mine, Zambia. World Current Journal, Special Issue on Mining. Pp 3446 DOI: http://dx.doi.org/10.12944/CWE15

23. Hughes, R., 2011. Factors influencing overbreak in narrow vein longitudinal retreat mining, s.1.: Mc.Gill University.

24. Henning, J, and Mitri, H, 2007. Mine Planning for Ore dilution Villaescusa, E. 1995. Sources of external dilution in underground sublevel and bench stoping, Procc. AusIMM Explo Conference, Brisbane Australia, pp 217-223

25. Clark, L. M., 1998. Minimizing dilution in open stope mining with a focus on stope design and narrow vein longhole blasting. MSc. Thesis, University of British Columbia. 
https://doi.org/10.31713/m1106

\title{
SOLUTIONS OF POLYMERS IN THE OIL AND GAS TECHNOLOGIES
}

\author{
Pogrebnyak V. G.
}

Ivano-Frankivsk National Technical University of Oil and Gas, Professor, Doctor of Technical Sciences, Head of the Department of Technogenic and Environmental Safety, Ukreine

\section{Chudyk I. I.}

Ivano-Frankivsk National Technical University of Oil and Gas, Professor, Doctor of Technical Sciences, Vice-Rector for Research, Ukreine

Perkun I. V.

Ivano-Frankivsk National Technical University of Oil and Gas, $\mathrm{PhD}$ (Engineeuing), Associate Professor of the Department of Technogenic and Environmental Safety, Ukreine

\begin{abstract}
There has been carried out a complex study of polymer solution reaction under hydrodynamic effect. Integrated approach turned out to be a necessary condition for successful solving of the set tasks of scientific and technical character (from fundamental studies to concrete technological process). This allowed to formulate a new structural concept with a "common denominator" such as strong deformation effect on the part of a hydrodynamic field on macromolecules that immediately generates the so called rubber-like high elasticity. The technologies of production oil and gas is based on utilization of rubberlike properties of a polymer solution that arise under definite conditions while going through porous media, nozzles and slotes. There have been obtained eco-technological criteria and practical recommendations as to practical implementation of technologies of production oil and gas.

\section{Introduction}

Last years in connection with the ripening ecological crisis there has grown practical interest to creating new nature protection technologies or ecological technologies called so. One of the most perspective directions to solve nature protection problems is a wide usage of "abnormal" phenomena revealed in the conditions of complex hydrodynamic influence on liquids with additives of soluble flexiblechain high-molecular polymers. Here it is necessary to recollect the following "abnormal" phenomena.
\end{abstract}


It is more convenient to start with the decrease of turbulent friction due to small polymeric additives. Let's take advantage of analogy with speed-boats and in general, so to say, with cigar-shaped floating bodies - dolphins or high-speed fish. On border of any body moving quickly in water when Reynolds' critical number is being in excess there appears wall-adjacent turbulence bringing resistance to movement in addition to a common viscous friction. The turbulent contribution to resistance makes tens of percent from the overall resistance. Dolphins, other cetacean as well as high-speed fish in the course of biological evolution have developed the mechanisms that relieve if not all, but a considerable part of turbulent resistance. In case of dolphins it is a kind of surface "counter-waves", reducing wall-adjacent turbulence with mucous excreta. It is characteristic that Toms' effect is being revealed at insignificant additives (million mass fractions) of very high-molecular polymers (a $10^{7}$ order of molecular weight).

Despite the application of modern knowledge and methods, yet it was not possible to describe precisely the mechanism used by fish to produce motive power, and in many respects it is still unknown. At the same time it is known that slime of fish can function as effective high-molecular substance reducing turbulent friction. Polymeric substance in the form of slime can be one of means used by fish to reduce their turbulent friction (valid in case of other high-speed floating animals).

On the basis of the proved strong deformation influence of walladjacent turbulence on macromolecules, and also using data of modeling research of features of turbulence in a frontier layer, one of the authors of the given scientific work has offered the following mechanism of Toms' effect. The mechanism of Toms' effect consists in occurrence of a self-oscillatory mode of reversible processes of macromolecule uncoiling under effect of quasi-regular longitudinal velosity gradients in a turbulent frontier layer and influence of uncoiling macromolecules both on molecular (when $C<C_{\text {opt }}$ ) and supermolecular (when $C>C_{\text {opt }}$ ) levels on the structure of wall-adjacent turbulence. All this leads to increase in the period of liquid emissions in an external part of an interface and, as consequence, to a thickening of a viscous intermediate layer. As a result generation of primary turbulence decreases and the general level of turbulent dissipation in a 
stream goes down. When molecular weights and concentrations are big enough viscosity growth caused by both "usual" intermolecular interaction and dynamic structurization leads to sharp reduction of Toms' effect $[1,2]$.

It is also necessary to stress that modeling experiments have confirmed validity of applying results obtained while studying macromolecule dynamics in non-turbulent flows with stretching to jet flows of wall-adjacent emissions of a turbulent stream, and it means that turbulent (in macroscopic scale) flow is treated as laminar (in microscale) under interaction of a hydrodynamic field with polymer molecules.

There is a possibility of Toms' effect practical application, namely when developing energy-saving technologies, after the nature of turbulent friction decrease with small polymeric additives has been determined.

Another "abnormal" phenomenon, abnormal only from the point of view of classical hydrodynamics, occurs in polymer solutions flowing in porous media. Given "anomaly" is connected with nonlinearity of polymer solutions filtration current and becomes apparent when dissipation energy, hence resistance to a current, at some threshold values of filtration speed starts to increase, and the process is more drastic the higher polymer concentration and molecular weight. Absence of resistance growth to a current of pure solvent with growth of feed velocity testifies to the fact that the effect specified is not connected with inertial turbulence.

Movement of liquids through porous materials serves as the major object for a number of areas of engineering activity. The knowledge of laws of this movement is necessary in oil industry and in soil mechanics, in hydrology and engineering ecology. Non-trivial physical effects lie at the heart of underground hydrodynamics of polymer solutions. In this connection, it is important to know the nature of these effects. Therefore determination of the physical mechanism of displaying effects of sharp increase of hydrodynamic resistance and "abnormally" high degree of porous layer coverage at its filling with a polymer solution was one of the primary goals successfully solved by the authors of this scientific work.

The approach based on deformation influence of a hydrodynamic field on macromolecules in conditions of a filtration current occupies 
special place among attempts to explain the nature of deviations from Darcy's law. To substantiate this approach it is necessary to prove experimentally the presence of strong deformation effect of a hydrodynamic field on molecular coils. Mistrust to the given idea sharply decreased after rather fundamental measurements of a double refraction factor under super-critical flow modes that allowed to prove the possibility of almost full uncoiling of macromolecules and, as consequence of this, phase transition from coil to unfolded chain in a longitudinal hydrodynamic field*.

In brief the problem essence is reduced to the fact that any state of a polymer on a phase plane or in phase space is defined by independent, though interdependent contributions of separate macromolecules (small systems after Hill) and a combination of these macromolecules (big system). In general this approach is substantiated in works by de Gennes, Prigozhin and his followers, and in Keller's works as well.

Meanwhile the whole problem of polymer solutions flow in porous media, nozzles and slotes is brought to the following main principle. Elongation degree (or convolution degree) of a flexible macromolecule can be characterized with the parametre $\beta$, equal to the ratio of distance between the ends of a macromolecule $h$ to its contour length $\mathrm{L}$. In based systems there exists rather simple correlation between the most probable value $\beta \equiv\langle\beta\rangle$ ( $\beta$ is distributed due to Maxwell's law) and Flory's parametre $f$.

However, as it was shown by S. Ya. Frenkel [3] with colleagues and independently by de Gennes, the parametre $\beta$ has more fundamental value than $f$ from the point view of thermodynamics and physical kinetics: the matter is that here we witness the theory of dissipative structures and Prigozhin's bifurcation on reaching some critical value $\beta^{*}$. Bifurcation specifically means transition from a stationary decision to a non-stationary one, for example, as in case of turbulence occurrence in the general problem on flow. And it is absolutely unimportant, in what way $\beta^{*}$ is reached, even an isolated macromolecule loses stability in relation to distribution of rotatory isomers and becomes uncoiled (i.e. gets trans-conformation).

\footnotetext{
${ }^{*}$ Hereinafter we deliberately abstain from references to information sources as all of them appear in the bibliographic list.
} 
Hence, if in a system of flexible-chain macromolecules somehow, for example, under the influence of a flow with stretching there have been reached super-critical values $\beta>\beta^{*}$, then in solutions of crystallizing polymers there can appear super-molecular formations according to nucleation mechanism, and in solutions of non-crystallizing polymers according to spinodal mechanism. In terms of Prigozhin's theory at $\beta^{*}$ the system undergoes bifurcation and passes from thermodynamic to non-thermodynamic branch where super-molecular formations acquire steady form.

The above said allowed to offer a new approach to the nature of nonlinearity of filtration flows of polymer solutions. The deviation mechanism from the Darsi's law consists in occurrence of a selfoscillatory mode of reversible processes of macromolecule uncoiling under effect of quasi-regular longitudinal velosity gradients in a porous medium and influence of uncoiling macromolecular chains both on molecular and supermolecular levels on the structure of a filtration flow, i.e. as a result of oscillations of deformations of macromolecules and dynamic supermolecular structures, formed under the influence of stretching flows, there occurs higher energy dissipation and nonlinearity of a filtration flow.

Nonlinearity in a filtration flow of polymer solutions ensures alignment of front for advancement and filling layered non-uniform and cracked-porous beds with a polymer liquid, and consequently, provides a wide coverage of a bed.

The designed approach to explain the mechanism of filtration nonlinearity in polymer solutions flow well keeps within the general scheme of self-regulated processes where negative feedback dominates. It is characteristic of systems, capable to change their properties under the influence of external physical effects, in this case under the influence of longitudinal velocity gradients locally arising in pores, i.e. flows with stretching.

Nonlinearity observed at polymer solutions flow through porous media does not allow to use the linear law of filtration - Darcy's law to forecast technological indicators of feeding polymer solution in an underground layer.

Such project studies are in need of a filtration law that would describe the flow of both Newtonian and non-Newtonian fluids with 
difficult rheology in conditions of flow with stretching. In monography [2] gained a generalised filtration law to be true for polymer solutions and common Newtonian fluids. The generalised filtration law takes into account manifestation of elastic deformation effects at $\dot{\varepsilon}>\dot{\varepsilon}_{\text {кр }}$ and, hence, is true both for shift flows and for polymer solution flows with stretching.

Everything said allows to carry out complete analysis of the problems related to "abnorma" effects, arising under conditions of polymer solution flows with stretching and their use when designing corresponding of technologies of production oil and gas.

The approach designed to explain the mechanism of filtration flow nonlinearity allowed to substantiate technological variants of filling various porous media with polymer solutions which was assumed as a basis of technologyfor increasing oil production based on oil ejection from layers with polymer solutions, as well as to work out a number of other technologies. Such technologies may serve - to increase performance efficiency and reduce power consumption in various hydraulic systems - to extinguish fire with water, to supply heat, to pump out water emergently, in hydroacoustic stations of fishery vessels and other as well as in perforation of oil and gas wells by high-velocity jet of polymer solution.

Physical-chemical and technological problems are closely bound in this work, but nevertheless the technological problem somewhat dominates over the physical-chemical one. Have studied reactions of polymer-containing systems to hydrodynamic effects not with methods of phenomenological rheology but from positions of molecular hydrodynamics. It allowed them to solve a number of special problems generated by rather difficult rheology of polymer solutions under flows with stretching. In this connection, the data presented in this work, on macromolecule dynamics in conditions of a converging flow are of separate interest as well, when the polymer solution flow in the porous-fractured reservoir.

The logics of work - from fundamental research to concrete technological process. The complex approach to studying polymer solutions reaction to hydrodynamic effects allowed to predict, and further to confirm experimentally the fact of hydrodynamic field influence on floculating ability of flexible-chain linear macromolecules. This 
new phenomenon, perspective in respect of working out and upgrading technologies of cleaning various liquids the oil and gas industry, is given a proper attention inother other works [2,4,5]. There has been offered mechanism of the given phenomenon based on conceptions about strong deformation influence of a hydrodynamic field on molecular coils.

Theoretically predicted and experimentally discovered fact of longitudinal hydrodynamic field influence on floculating ability of molecules of a linear flexible-chain polymer opens a possibility to design devices allowing to increase efficiency of floculation cleaning of liquids. This allowed to offer technical decisions to realise a method of hydrodynamic activation of polymer floculants and equipment to measure residual concentration of a polymer floculant in liquids after their clarification. This is a source of prospects to intensify cleaning processes for various liquids (sewage drinking water, lubricant oils, etc.) when using polymer floculants.

\section{Displacement of Oil from Porous Bed by the Oscillating Flow of Polymer Solution}

Experiments were conducted with the aim of elucidating the nature of the mechanism of an "anomalously" high degree displacement of oil from porous bed using the polymer solution. The most contradictory opinions as to the nonlinearity of filtration flow of polymer solutions are being stated; most researchers believe that the nonlinearity is caused by the adsorption of macromolecules onto the porousmedium walls [6-8]. There is an opinion that the deviations from Darcy's law are due to the elastic-strain effects manifesting themselves in the case of flow of solutions of flexible-chain polymers in a porous medium [2,9-10]. Below, we will be dealing with experiments on checking the mechanism of an "anomalously" high degree displacement of oil from porous bed using the polymer solutions; the basis for this mechanism is provided by the concepts of a strong strain action of the hydrodynamic field on coiled macromolecules in filtration flow [11].

The mechanism of deviations from Darcy's law lies in the selfoscillating regime of reversible processes of unrolling of macromolecules under the action of the longitudinal velocity gradients quasiregularly arising in the porous medium and in the influence of un- 
rolling macromolecules at both the molecular and supermolecular levels on the structure of the filtration flow. The oscillation of the strains of macromolecules and dynamic supermolecular formations arising under the action of stretching flows results in the higher-thanaverage energy dissipation filtration and the flow nonlinearity [2]. The latter ensures the equalization of the front of advance and filling of inhomogeneous laminar beds with polymer fluid and hence a wider coverage of the bed and hence a high degree displacement of oil.

From the above mechanism of nonlinearity of the filtration of polymer solutions and from the theory of elastic-strain effects in the case of flow with stretching of polymer solutions [9,10], it follows that the higher degree displacement of oil from porous bed must be attained in oscillating injection of a polymer solution into it. To substantiate this prediction we studied the aqueous solutions of polyethylene oxide (PEO) under the conditions of oscillating hydrodynamic field with stretching.

In realizing the model regime of injection of a solution polymer into a porous medium (bed), the solution under study was forced through a flow chamber (module) under the action of a constant pressure difference (see fig. 1.1). This is an unusual kind of viscosimeter in which the hydroresistors are short capillaries.

In the stationary regime, flow through the hydroresistors was carried out by creation of a pressure difference at the viscosimeter inlet and outlet, whereas in the oscillating regime, it was carried out by superposition of a constant pressure difference and the pulsating pressure arising in the vessel between the capillaries due to the vibrations of the membrane of an electromagnetic vibrator. The amplitude of membrane vibrations was monitored by a special device. It was constant at different frequencies in each run of experiments and was selected such that the rate of flow (caused by the membrane vibrations) of the polymer solution through the capillaries was lower than the flow rate due to the constant pressure difference. The oscillating component of the flow velocity in the capillaries that was caused by the pressure pulsations in the intercapillary volume was smaller than the flow velocity in the capillary due to the constant pressure difference in the viscosimeter. The flow-rate velocity of the polymer solution through the capillaries was higher than the critical value [11]. The diameter of the capillaries was $0.2 \cdot 10^{-3} \mathrm{~m}$. 


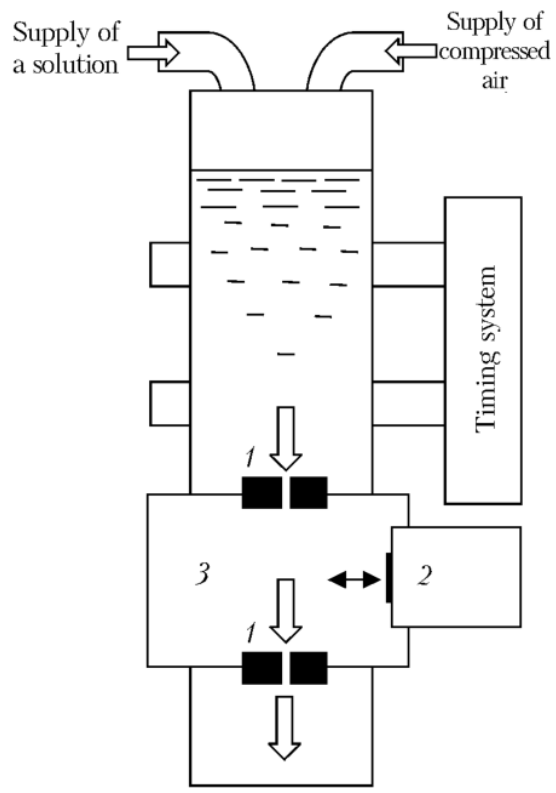

Fig. 1.1. Diagram of a viscosimetric unit: 1 - short capillary; 2 - electromagnetic vibrator; 3 - zone of action of the vibrator

The hydrodynamic efficiency of the polymer solutions under study was evaluated by the value of the efficient viscosity $\eta_{\text {ef, }}$ which was determined by comparison of the flow-rate velocities of the solution under study and calibration viscous Newtonian fluids at the same pressure difference. The entire unit was placed in a thermostat, where the temperature of the solutions under study was monitored by an electronic heat controller.

Fig.1.3 shows the experimental cell represents a layer of quartz compacted in a hermetically sealed space is filled with oil between two glass plates having inlet and outlet pipes.The inlet pipe was connected either directly to a measuring vessel, into which the aqueous polymer solution had been poured in advance, or via a module with a vibrator.The measuring vessel is equipped with a system for recording the flow-rate of the solution injected into the model of natural bed.The solution is injected due to the excess air pressure produced in the measuring vessel; the pressure is monitored by a manometer. The structure of the experimental setup enables us to visualize the process of advance of the front of the polymer solution in the porous 
bed and to qualitatively evaluate the efficiency of different regimes of oil displacement from porous bed by the flow patterns.

PEO having the viscosity-average molecular weight of $\bar{M}_{\eta}=4.5 \cdot 10^{6}$ was used as a polymeric additive in water and characteristic of a viscosity $1,72 \mathrm{~m}^{3} / \mathrm{kg}$. The aqueous solutions of polymer had concentration $C_{\mathrm{PEO}}=0.001 \div 0.050 \%$.The viscosity of the oil ranged from $10^{-2}$ to $5 \cdot 10^{-2} \mathrm{~Pa}$ sec.

The results of the experiment are presented in fig. $1.2 a$, where $\eta_{\mathrm{ef}}$ is the effective viscosity of the solution under the conditions of stationary outflow and $\Delta \eta_{\text {ef }}$ is the addition resulting under the oscillating action on the mainstream flow. The curves correspond to different velocities of mainstream flow through the capillaries. It is seen that the critical frequency of action $\omega_{\text {cr' }}$ on the stationary flow exists; beginning with this frequency, flow becomes more dissipative.

The quantity $\omega_{\text {cr' }}$ grows with average flow-rate velocity, whereas $\Delta \eta_{\mathrm{ef}}$ decreases. With lower concentrations of PEO in the solution and the same flow-rate velocity, the value of the critical frequency is higher.

When polymer systems (PEO solutions in our case) are strained, changes in the strains $\varepsilon$ and the stresses $\sigma$ occur in different phases $[12,13]$. The angle $\delta^{\prime}$ characterizing this difference is a composite function of the frequency of actions $\omega^{\prime}$. Strain in this case is carried out under the action of the stress following the law

$$
\sigma(t)=\bar{\sigma}+\sigma_{0} \exp \left(i \omega^{\prime} t\right)
$$

where $\bar{\sigma}$ - stationary tension, $t$ - time. 

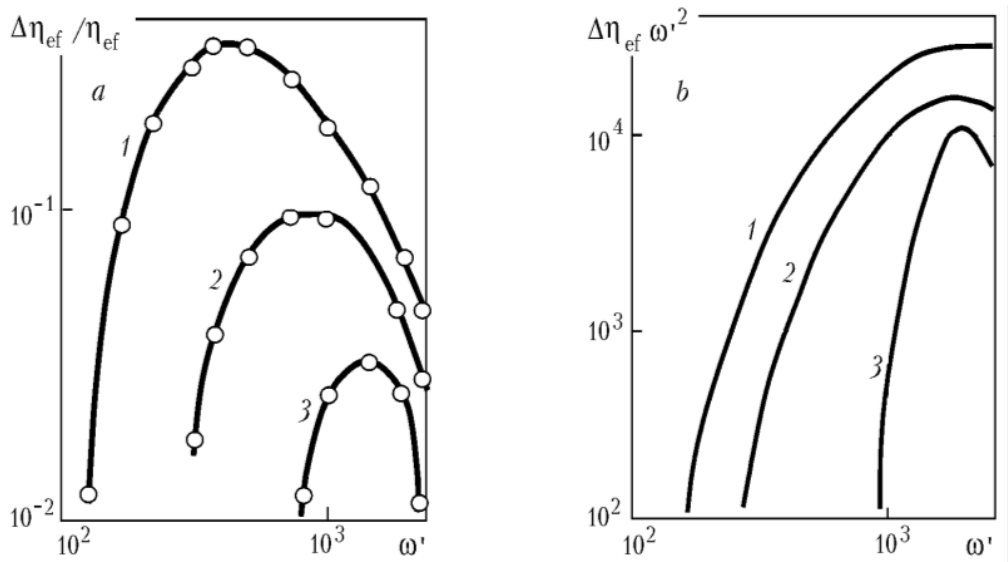

Fig. 1.2. Influence of the frequency of external action on the change in the effective viscosity (a) and the dissipative function $(b)$ in the case of flow of an aqueous PEO solution $\left(\mathrm{MPEO}=4.5 \cdot 10^{6}\right.$ and $\left.\mathrm{CPEO}=0.02 \%\right)$ through short capillaries with different average velocities: 1) 0.3 ; 2) 0.5 ; 3) $0.7 \mathrm{~m} / \mathrm{sec} . \Delta \eta_{\mathrm{ef}} \omega^{\prime 2}, \mathrm{rad}^{2} \mathrm{~Pa} / \mathrm{sec} ; \omega^{\prime}, \mathrm{rad} / \mathrm{sec}$

Taking into account that $\sigma(t)=\sigma_{0} \cos \left(\omega^{\prime} t\right)$ and $\varepsilon=\varepsilon_{0} \cos \left(\omega^{\prime} t-\delta^{\prime}\right)$, and excluding the time from these equalities we obtain the equation

$$
\left(\frac{\sigma}{\sigma_{0}}\right)^{2}+\left(\frac{\varepsilon}{\varepsilon_{0}}\right)^{2}=\varepsilon^{2} \delta^{\prime}+\left(\frac{\sigma}{\sigma_{0}}\right) \cdot\left(\frac{\varepsilon}{\varepsilon_{0}}\right) \cos \delta^{\prime}
$$

Expression (1.2) represents the equation of an ellipse whose area is equal to the work $A_{0}$ done in a cycle of harmonic vibrations and irreversibly lost (dissipating) under strain. Then the dissipation function $\mathrm{W}$ is computed as the product of $A_{0}$ and the number of cycles per unit time

$$
W=A_{0} \frac{\omega^{\prime}}{2 \pi}=\frac{\varepsilon_{0} \sigma_{0} \omega^{\prime}}{2} \sin \delta^{\prime} .
$$

From relation (1.3) it is seen that, under the same conditions of strain, the dissipative function only depends on the polymer characteristics expressed in the value of $\delta^{\prime}$. 
Changing the stresses by the harmonic law, we may track a change in the strain rate $\dot{\varepsilon}$. The latter is related to the strain $\varepsilon$ as follows

$$
\dot{\varepsilon}=\frac{d \varepsilon}{d t}=\varepsilon_{0} i \omega^{\prime} \exp \left[i\left(\omega^{\prime} t-\delta^{\prime}\right)\right]=i \omega^{\prime} \varepsilon .
$$

The value of the ratio $\sigma / \dot{\varepsilon}$ is a complex dynamic viscosity $\eta^{*}$. This quantity may be represented in the form of the real and imaginary components $\eta^{*}=\eta^{\prime} \mathrm{i} \eta^{\prime \prime}$, where $\eta^{\prime}=\left(\sigma_{0} / \varepsilon_{0} \omega^{\prime}\right) \sin \delta^{\prime}$ and $\eta^{\prime \prime}=\left(\sigma_{0}\right.$ $\left./ \varepsilon_{0} \omega^{\prime}\right) \cos \delta^{\prime}$. Introducing $\eta^{\prime}$ into relation (1.3) and performing transformations, we obtain

$$
W=\eta^{\prime} \cdot \frac{\varepsilon_{0}^{2} \omega^{\prime 2}}{2} .
$$

Dynamic viscosity manifests itself in the system under strain, and the increment of the effective viscosity $\Delta \eta_{\text {ef }}$ under the conditions of superposition of harmonic actions on mainstream flow is attributable to the appearance of $\eta^{\prime}$. Since the amplitude value of the strain $\varepsilon_{0}$ remains constant in the experiment, we may use scaling and rewrite (1.5) in the form

$$
W \approx \Delta \eta_{e f} \cdot \omega^{\prime 2} .
$$

For the experimental curves (fig. 1.2a), we have obtained dissipative-function curves (fig. 1.2b) using expression (1.6). An analysis of these curves shows that, as the average velocity of flow of the aqueous PEO solution through the capillaries increases, i.e., as the fraction of macromolecules (because of the presence of the molecularweight distribution) that have experienced unrolling $[10,11]$ and are unrolled to a higher degree, which causes the induction of rigidity in the macromolecules, increases, the dissipation of pulsating-flow energy decreases. The threshold value of the frequency, beginning from which the flow becomes distinctly dissipative, grows for less "flexible" and stretched molecules. As the induced rigidity of macromolecules increases, the dissipative curve acquires a more pronounced extremum character. 
From the data obtained it follows that oscillating filtration flow of polymer solutions must ensure a higher degree of filling and coverage of a porous bed and thus a higher degree displacement of oil from a natural bed.

Fig. 3 shows the patterns of oil displacement from of a model porous bed with a laminar in homogeneity using polymer solution. In the first version (see fig. 1.3a), displacement of oil of the porou space using polymer solutions was carried out in the stationary regime, whereas in the second version (see fig. 1.3c), it was carried out in the pulsating regime.

The structure of the experimental setup enables us to visualize the process of advance of the front of the polymer solution in the porous bed and to qualitatively evaluate the efficiency of different regimes of oil displacement from porous bed by the flow patterns.

Calculation of the injection regimes is based on the use of the Debora $(D e)$ number characterizing the beginning of the development of a higher-than-average hydrodynamic resistance: $D \mathrm{e}_{\mathrm{cr}}=\theta_{\mathrm{c}} \dot{\varepsilon}$, where $\theta_{\mathrm{c}}$, relaxation time of the solution; $\dot{\varepsilon}$, strain rate.

The relaxation time $\left(\theta_{c}\right)$ may be determined experimentally or from the known molecular characteristics of the polymer $[14,15]$

$$
\begin{array}{r}
\theta_{c}=\theta_{0} \cdot \exp (k), k<1 ; \\
\theta_{c}=\theta_{0} \cdot\left[\exp \left(k^{2 / 3}\right)\right] / k^{1 / 3}, k>1, \\
k=[\eta]_{0} \cdot C,
\end{array}
$$

where $\theta_{0}$ - relaxation time of weakly strained coiled macromolecules, $k$ - criterion of the degree of concentration of the solution, $[\eta]_{0}$ characteristic viscosity, $C$ - concentration of the polymer in the solution. 

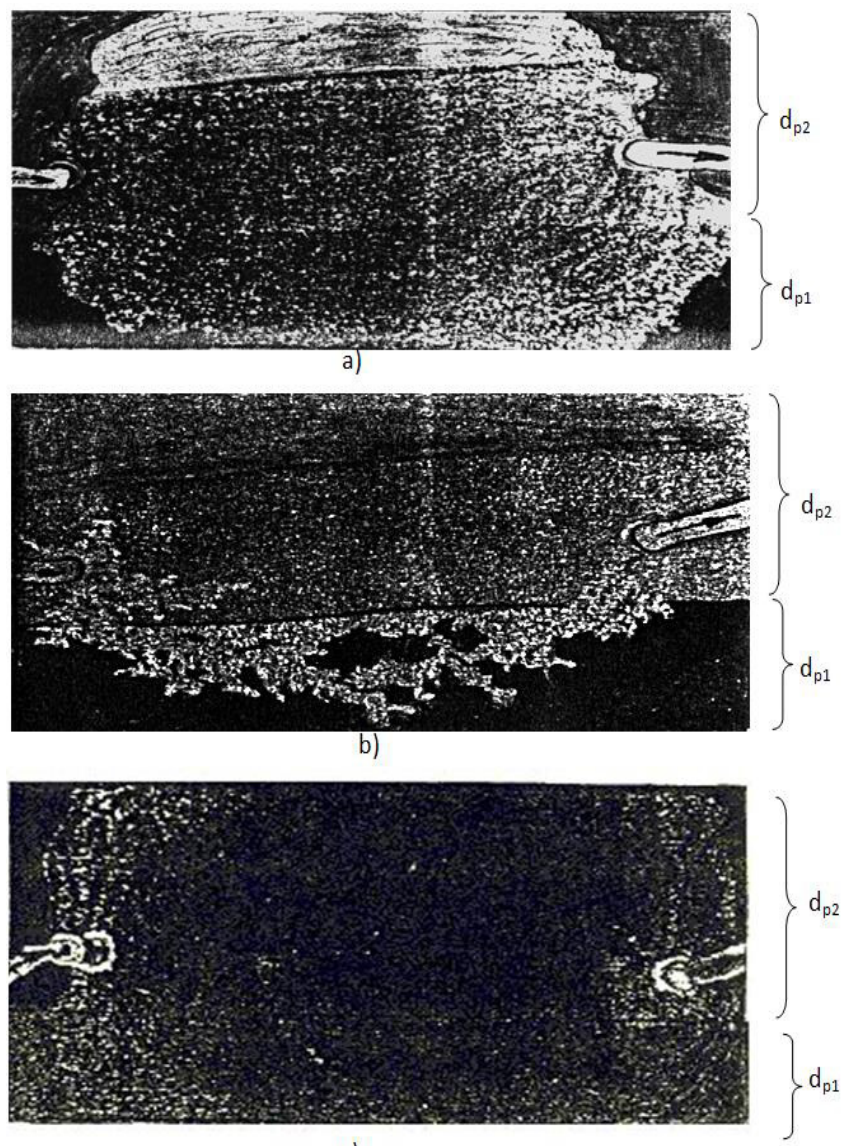

c)

Fig. 1.3. Patterns of oil displacement from porous medium with a laminar inhomogeneity $\left(d_{p} / d_{\mathrm{p} 2}=5\right)$ using PEO solution: $a$ - stationary regime of oil displacement at supercritical velocities; $b$ - the same, at subcritical velocities; c supercritical regime of oil displacement in the case of oscillating $(1000 \mathrm{rad} / \mathrm{sec})$ action on filtration flow

The longitudinal velocity gradient realized in the pore cross sections in flowing of the polymer solution defies an accurate calculation. However, we may evaluate it as a first approximation, solving the problem on flow of a Newtonian fluid in a convergent channel [2] as an element of a pore channel 


$$
\dot{\varepsilon} \approx 2 V_{f} /\left(K \cdot d_{p}\right),
$$

where $V_{f}$ - filtration rate, $K$ - coefficient of porosity of the medium, $d_{p}$ - average pore size.

For the ranges of PEO molecular weight and concentrations of practical importance, the Debora number may be assumed to be equal to unity for $k<1$ and to 2.5 for $k>1$ in accordance with experimental data.

Passing from the model to an actual filtration flow and on the basis of the results obtained, we may state that oscillating filtration flow of polymer solutions ensures a higher degree of coverage of the bed and thus a higher degree displacement of oil from a natural bed (fig. 1.3c) than stationary flow (fig. 1.3a) and stationary regime of oil displacement at supercritical velocities (fig. 1.3b).

The experiments conducted have confirmed the correctness of the prediction of the theory of elastic-strain effects in tensile flow of the higher degree of oil displacement from of a porous bed in the oscillating regime of injection of a solution polymer into a porous medium (bed) and hence the mechanism of deviations from Darcy's law the basis for which is provided by the concepts of a strong strain action of the hydrodynamic field on coiled macromolecules.

The effects causing the highly dissipative regime in oscillating flow of polymer solutions through porous media play an important role in optimization of the process of oil displacement from porous (especially with a laminar inhomogeneity) bed using polymer solutions. The injection of a solution polymer into a porous medium (bed) must occur in the oscillating regime, when elastic strains appear, and the frequency of pulsating action on the filtration flow must correspond to the maximum of the dissipative function $W(\omega) \approx \Delta \eta_{e f} \cdot \omega^{\prime 2}$.

\section{Perforation of oil and gas wells by a high-velocity jet of pol- ymer solution}

The method of hydro-sandblasting perforation (HSP) of oil and gas well casing strings is a fairly effective [16], but this method has significant disadvantages: in the process of HSP, the inner surfaces of the tubing, fittings and equipment used in the water-abrasive perforation fluidare subject to strong hydroabrasive wear; as a result of 
this hydroabrasion, the diameter and profile of the nozzle holesincreases, forming a perforation jet, which in turn leads to a gradual decrease in its velocity and to weaker perforation and longer total execution time; due to the hydroabrasive wear of the sandblasting machine nozzles, there is a need to periodically replace the nozzles, which causes additional costs for the nozzles, which are made by powder metallurgy of hard alloys, and due to an increase in the number of round-trip operations; there is intense wear on the pipes, meaning they need to be replaced; the abrasive sand particles penetrate deep into the rock in the channels which are formed, impairing the productivity of the formation. All this leads to more resourcesbeing necessary in the hydroperforation of oil and gas well casing strings.

The problem of developing a highly efficient, innovative method forhydroperforating oil and gas well casings can be approached by taking advantage of certain anomalies in the hydrodynamic behaviour of polymer solutions in longitudinal flow. That is, the cutting hydroabrasive jet in the inlet section of the hydroperforator nozzles must be replaced by a polymer solution jet [17]. The polymer must be a safe substance which is approved for use in the oil and gas industry. Such polymers include PEO, polyacrylamide (PAA) or hydrolysed polyacrylamide (HPAA). For example, PEO is a safe substance that is used as a flocculent to purify and disinfect drinking water, as a thickener in the food industry, in pharmaceuticals and more $[18,19]$.

An analysis of the literature data shows that modern ideas about the behaviour of macromolecules under the conditions of convergent flow - as in the entrance area of the jet-forming nozzle of a hydroperforator - are far from perfect. Currently, we are transitioning from an accumulation of experimental information to an understanding of its physicochemical essence and to establishing the basic patterns of its rubber-like, high-elasticity manifestation. New knowledge is needed to understand the rheophysics of several anomalies during the flow of polymer solutions through the nozzle of ahydroperforator, which would allow very efficient perforation of the casing strings of oil and gas wells with a high-velocity polymer solution to be developed. 
Of particular scientific and practical interest is the study of transitions, which result in structures that are far from equilibrium. Nonequilibrium thermodynamics proves that non-equilibrium phase transitions are possible. These transitions have only been thoroughly studied in concentrated polymer solutions, while the dynamic phase transitions in dilutepolymer solutions are only studied in a longitudinal field, which is created by the superposition of two coaxially located streams [20-22]. It has long been suggested that such transitions are impossible under the conditions of convergent flow of dilute polymer solutions. It was previously proved that convergent flow is a superposition of currents undertension and shear forces [23]. This is primarily due to the interest in work on the dynamics of polymer chains in convergent flows, because a strong deformation effect on macromolecular balls must take place in the inlet of the nozzle of the hydroperforator [24].

The most significant results in the study of the structural changes in polymer solutions under the action of a homogeneous longitudinal hydrodynamic field were obtained by Brestkin et al. [21]. The main result of this work is the proof that in the conditions of a homogeneous longitudinal hydrodynamic field, dynamic phase transitions are possible. However, this findingrefers to a homogeneous longitudinal field and not to convergent currents, which takes place in the inlet area of a drill nozzle. This indicates the relevance of research on the anomalous phenomenon of the high destructive capacity of a waterpolymer jet. According to the results of the review of convergent [23] and turbulent flows of polymer solutions [25] and the use of polymer additives in cutting materials [26,27], it has been established that the process of perforating oil and gas well casing strings with a stream of polymer solution requires further study. It becomes obvious that the development of a highly efficient process for hydroperforating oil and gas well casing strings can be approached using features ofthe hydrodynamic behaviour of polymer solutions observed in a longitudinal flow, which occurs in the inlet section of hydroperforator nozzles.

The aim of the study is to develop an efficient, innovative method of perforating oil and gas well casing strings with a high-velocity stream of polymer solution that conserves resources and energy and 
meets the requirements for environmentally friendly hydrocarbon production.

The perforation work was performed on laboratory stands. A laboratory hydraulic stand based on an URG-3020 unit - with an operating pressure of up to $500 \mathrm{MPa}$, had a jet diameter at the nozzle of $3 \cdot 10^{-3} \mathrm{~m}$ and a function for controlling both the integral and differential parameters of the process of material destruction by a waterpolymer jet - was used as the source of high-speed fluid flow. A model was created for the obstacle (target) to test the effectiveness of perforation: a kind of "sandwich" which contained a 10-mmthicksheet of steel - with a strength category of D according to GOST 632-80, which simulated a casing - a concrete layer, 20-mm-thick ring and a layer of rock (compressive strength: $600 \mathrm{~kg} / \mathrm{cm}^{2}$ ) with a total thickness of $0,8 \mathrm{~m}$.

We also used an industrial water jet, which provided $450 \mathrm{MPa}$ of pressure in the jet-forming nozzle, an average jet velocity of up to $350 \mathrm{~m} / \mathrm{s}$ and had a jet diameter at the nozzle of $1 \cdot 10^{-3} \mathrm{~m}$. A detailed description of the hydrodynamic part of the water jet, its characteristics andthe methods for determining the average speed, momentum and energy of the jet can be found in Atanov [27], Pogrebnyak et al. [28] or Brenner et al. [29]. To qualitatively assess the energy capabilities of the jet in the experiments, we studied the interaction between the jet and the obstacle installed on a physical pendulum. The barrier was made of steel (category of S3) sheets with dimensions of $220 \times 220 \times 3 \cdot 10^{-3} \mathrm{~m}$ with mounting holes. There was a gap of $5 \cdot 10^{-2} \mathrm{~m}$ between the plane of the obstacle and the body of the physical pendulum.

An optical-mechanical complex and a polarisation-optical installation [30] were used to study the peculiarities of the flow of polymer solutions under model conditions of jet-forming nozzles, as were the dynamics of polymer macromolecules in the inlet section of hydroperforator nozzles.

Solutions with a completely dissolved polymer were prepared by diluting to the desired concentration of a prepared $0.1 \%$ polymer solution. Because aqueous solutions of PEO (as well as other polymers) have significantly different properties during long-term storage, $0.05 \%$ potassium iodide is used as a stabilizer in aqueous solutions of PEO, which almost completely eliminates the ageing of PEO 
in water during storage and does not affect its hydrodynamic activity [23]. PEO solutions with intrinsic viscosities of 2.42 and $1.72 \mathrm{~m}^{3} / \mathrm{kg}$ and molecular weights of $6 \cdot 10^{6}$ and $4 \cdot 10^{6}$ were used.

The novelty in the design and components of this research is the comprehensive study of the reactions of polymer solutions to the hydrodynamic effect of tension, i.e. under the conditions of the jetforming nozzle of a hydroperforator. Complexity is a necessary condition for solving not only fundamental scientific problems, but also technical ones (from basic research to a specific technological process).

Establishing the nature of the destructive capacity of a polymer solution jet is important for the development of an efficient, innovative method of perforating oil and gas well casings with a high-speed polymer solution jet. Contradictory opinions have been put forward about the mechanism of the destructive power of a high-velocity jet of a polymer solution. Some researchers believe that the increased destructive capacity of the water jet when small polymersare added is caused by the Toms effect during the flow of the working fluid through the nozzle that forms the jet [26]. Based on this, it is argued that the jet with polymer additives has a higher speed and dynamic pressure than a jet of pure water at the same operating pressure and nozzle diameter, and therefore destroys more of the material. In other words, it is assumed that associates of polymer molecules are formed in a water-polymer jet (without experimental proof) [31]. In [27,32], the high destructive capacity of a high-velocity jet of a polymer solution is associated with the deformation effects that occur during the flow of aqueous solutions of polymers undertension. Therefore, we discuss the experiments that were set to clarify the peculiarities of a polymer solution jet's destructive capacity, which is based on the idea that a strong deformation of the hydrodynamic field occurs on macromolecular bundlesin the inlet of the nozzle.

This experiment was conducted using a hydraulic stand of industrial manufacture. The experimental data are presented in table 2.1. and fig. 2.1. It can be seen that the maximum distance from the jetforming nozzle of the hydrostand to the target obstacle, when the target obstacle puncture is still observed, is $1.5 \mathrm{~m}$ for water and $2.5 \mathrm{~m}$ for a $0.0008 \%$ aqueous polymer solution; the effectiveness of 
PEO additives was observed in concentrations starting from0.004\%; and that PEO impurities reduced the average jet velocity.

Table 2.1

The effect of PEO concentration and distancefrom the nozzle to the target obstacle on the interactionwith a jet of PEO solution

$\begin{array}{cccc}C_{\mathrm{PEO}}, \% & \begin{array}{c}\text { Distance to } \\ \text { the target, } \mathrm{m}\end{array} & \begin{array}{c}\text { Average velocity } \\ \text { of jet flow, } \mathrm{m} / \mathrm{s}\end{array} & \begin{array}{c}\text { Nature of target obstacle } \\ \text { Diameter of a hole } \\ (15-18) \cdot 10^{-3} \mathrm{~m}\end{array} \\ 0 & 1,5 & 255 & \begin{array}{c}\text { No puncture } \\ \text { No puncture }\end{array} \\ 0 & 1,75 & 250 & \begin{array}{c}\text { Diameter of a hole } \\ (15-18) \cdot 10^{-3} \mathrm{M}\end{array} \\ 0,0004 & 2,5 & 250 & \begin{array}{c}\text { No puncture } \\ 0,0004\end{array} \\ 0,0008 & 1,5 & 240 & \begin{array}{c}\text { Diameter of a hole } \\ (8-10) \cdot 10^{-3} \mathrm{M}\end{array}\end{array}$

The experimental data are fully explained by a strong deformation effect of the hydrodynamic field on molecular bundles of the polymer. In a previous study [33], the transition of the bundle-expanded chain at a convergent flow (in the model conditions of the nozzle of the hydroperforator) of aqueous solutions of PEO was experimentally revealed. It is shown that the hydrodynamic field, which arises under conditions of convergent flow, leads to a significant degree of expansion of polymer molecules (60-70\%) and to a bundle-to-chain transition.
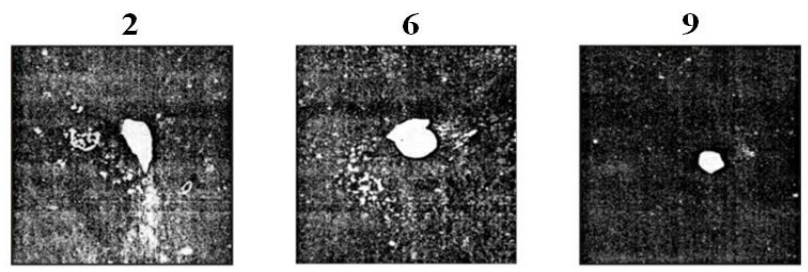

Fig. 2.1. Photos of the target obstacle after interaction with jets of water and an aqueous solution of PEO: $2-$ water; $6-M_{\mathrm{PEO}}=6 \cdot 10^{6}, C_{\mathrm{PEO}}=$ $0,0004 \% ; 9-M_{\mathrm{PEO}}=6 \cdot 10^{6}, C_{\mathrm{PEO}}=0,0008 \%$ 
The longitudinal velocity gradient, which occurs in the contraction cone nozzle of the hydrostand, can be calculated as not exceeding $2 \cdot 10^{3} \mathrm{c}^{-1}$. Therefore, despite the high speeds $(250 \mathrm{~m} / \mathrm{s})$ and resulting large shear velocity gradients, the conditions of deformation of polymer macromolecules in the conical nozzle of the water jet and in the inlet section of the model nozzle are almost the same. This indicates that during the flow of an aqueous polymer solution in the nozzle of the water jet, the PEO macromoleculesare subjected to strong deformation of the longitudinal hydrodynamic field. All this supports the claim that the high-velocity water-polymer jet is "reinforced" by highly developed macromolecular chains of the polymer, and - considering the results from Pogrebnyak et al. [34] - then supramolecular structures. Part of the energy goes to the structural adjustment of the flow [17,33], which lowers the average flow rate of the aqueous polymer solution and improves the quality of its formation, asa jet with small polymer additives is more compact (has a smaller diameter) than water (see fig. 2.1 and table 2.1). This contributes to an increase in the maximum distance from which the destruction of the steel barrier/target can occur.

The data of the experiments which are presented in table 2.1 convincingly testify that the high destructive capacity of a high-velocity water jet with small polymer additives is not due to the Toms effect. This is confirmed, first of all, by the $8-10 \%$ reduction in the average jet velocity of the aqueous PEO solution relative to the water jet's velocity at the same operating pressure and nozzle diameter. Thus, despite the lower flow rate of the polymer solution, its destructive capacity was much higher than that of the water jet.

The conclusion that the large destructive capacity of the highvelocity water jet with dissolved small polymer impurities was not due to the Toms effect also follows from the analysis of turbulent fluid flow presented below. In the case of near-wall turbulence, its structure should be affected by highly uncoiled macromolecular chains $[1,35,36]$. To do this, there must be certain conditions in the turbulent flow, namely, the longitudinal velocity gradients and the time of deformation in them must be greater than $0,5 / \theta_{\mathrm{c}}$ and $\theta_{\mathrm{s}}$, accordingly (where $\theta_{\mathrm{c}}$ is the relaxation time of the polymer solution). At some fairly high dynamic velocities, when the formation and de- 
struction of tensile zones occur at a high frequency, as follows from the work by Cantwell [37], increasing the strain rate should reduce the strain factor by increasing the strain rate should reduce the strain factor by decreasing the time of the longitudinal velocity gradient. This is due to small-scale turbulence, the percentage of which increases sharply at high velocities [37,38]. Also, the degradation of polymer solutions significantly reduces the Toms effect at high velocities [23]. Therefore, in high-velocity turbulent flows, the hydrodynamic activity of PEO should decrease due to the discrepancy between the characteristic relaxation times of the aqueous PEO solution, the time scale of the flow (emissions) and the degradation of the PEO macromolecules.

To confirm the correctness of the above approach, it is necessary to conduct a detailed study of the polymer solution's flow through the nozzles of a hydroperforator. At the same time, there are obvious advantages of using currents in the model of nozzles forming a stream in order to research the macromolecules' interaction with a hydrodynamic field in connection with thepossibility of studying experimentally the features of a polymer solution stream formingunder controlled conditions.

Before proceeding to the discussion of the experimental data, let us consider the parameters that will characterise the dissipative processes in flow model systems of jet-forming nozzles.The energy dissipated per unit of time during the flow of a liquid is equal to

$$
W=\Delta P \cdot q \text {, }
$$

where $\Delta P$ is the pressure drop in the system or in its individual sections at a given flow rate $q$. This is the work that must be spent per unit of time to push the liquid through the jet-forming nozzle. Equation (2.1) is valid for any type of flow (shear, longitudinal or the superposition of one and the other - convergent) and any shape of jetforming nozzle. Energy dissipation can be represented as

$$
W=\frac{\eta e f \cdot q^{2}}{k_{f s}},
$$

where $k_{f s}$ is the constant of the flowing system and $\eta_{e f}$ is theeffective viscosity which characterises the resistance of the continuous envi- 
ronment to irreversible changesin form at various sites ina current and is calculated by expression

$$
\eta_{e f}=k \frac{\Delta P}{f_{s}} .
$$

The constant $k_{f s}$ is determined experimentally by using Newtonian fluids with known viscosities.

From Equation (2.2) it follows that dissipation at a liquid stream can be characterised using effective viscosity. For a Newtonian fluid, it always coincides with the shear viscosity, whereas the effective viscosity of a non-Newtonian medium depends on the flow regimes and is an average characteristic. The latter is due to the fact that the viscosity of such a medium is different at points in space with different rates of deformation [39].

The data that characterise the influence of outflow velocity through a nozzle on effective the viscosity of PEO aqueous solutions of various concentrations for molecular weight $6 \cdot 10^{6}$ are given in fig. 2.2.

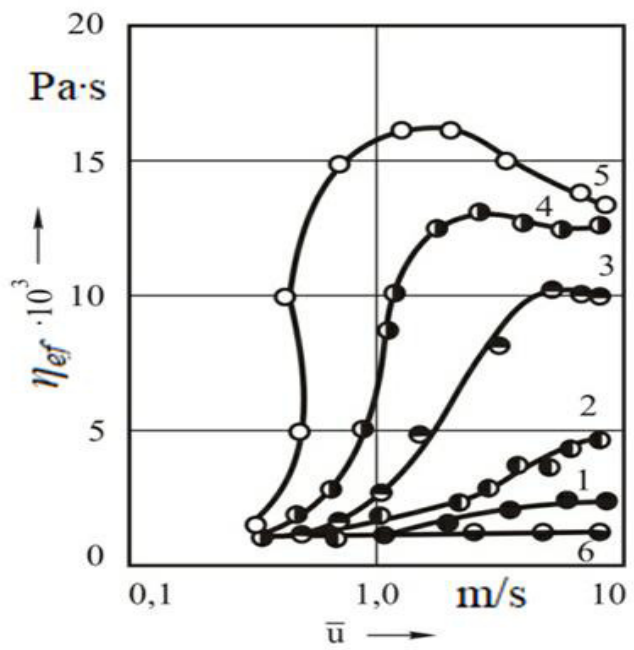

Fig. 2.2. Dependence of an aqueous $P E O$ solution's effective viscosity on its average flow through a nozzle with a square inlet $\left(d_{\mathrm{noz}}=0.12 \cdot 10^{-3} \mathrm{~m} ; \mathrm{M}_{\mathrm{PEO}}=6 \cdot 10^{6} ; \mathrm{C}_{\mathrm{PEO}}\right.$ : $1-0.0005 \% ; 2-0.001 \% ; 3-0.002 \% ; 4-0.003 \% ; 5-0.004 \% ; 6$ - water) 
The error of viscosity measurement did not exceed $2 \%$. It is seen that at relatively low velocities, the solutions behave like Newtonian fluids and their viscosities are close to the viscosity of the solvent (water). At the critical threshold value, $\bar{u}=u_{c r}$, the viscosity of the solution begins to increase; the sharper the increase, the higher the concentration of the polymer. The absence of growth of effective water viscosity with growth suggests that the specified effect is not connected with inertial turbulence. The data describing the influence of the diameter of the nozzle's aperture on the effective viscosity of PEO solutions show (fig. 2.3) that increasing the diameter of the nozzle essentially increases the critical speed.

These experimental results (fig. 2.3) allow us to assume that the observed changes of viscosity with growth $\bar{u}$ due to first of all at the expense of a difficult structure of the hydrodynamic field at the entrance section of the jet-forming nozzle (not at the expense of the macromolecules' adsorption). Studies of solutions in a stationary Kuett field have shown that they can detect a decrease in viscosity only with increasing velocity gradient [40] and only in turbulent motion do they show certain anomalies (Pilipenko, 1980). Therefore, the change in the geometry in the inlet walls of the jet-forming nozzles (i.e. the conditions of solution deformation) should change the nature of the dependence of $\eta_{e f}$ on $\bar{u}$.

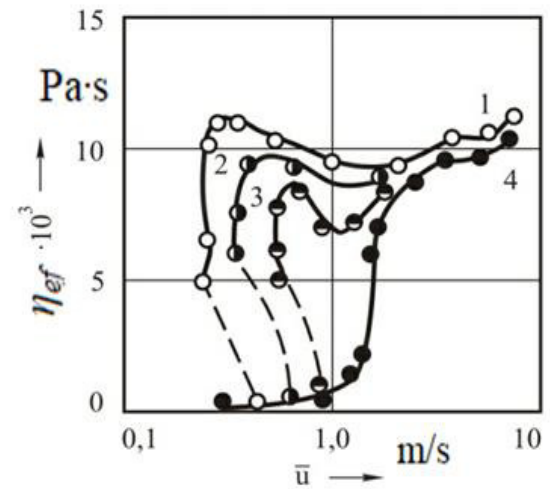

Fig. 2.3. Theinfluence of the nozzle diameter on the effective viscosity of PEO aqueous solutions $\left(\mathrm{C}_{\mathrm{PEO}}=0.02 \%\right.$; $\mathrm{MPEO}_{\mathrm{PEO}}=4 \cdot 10^{6} ; \mathrm{d}_{\mathrm{noz}}: 1-0.34 \cdot 10^{-3} \mathrm{~m} ; 2-0,42 \cdot 10^{-3}$ $\left.\mathrm{m} ; 3-0.52 \cdot 10^{-3} \mathrm{~m} ; 4-0,6 \cdot 10^{-3} \mathrm{~m}\right)$ 
Fig. 2.4 shows the curves that reflect the influence of conditions (inlet angle) of the polymer solution's flow through the jet-forming nozzle with an inlet angle of $180^{\circ}$ and $45^{\circ}$ (smooth inlet and a standard factory nozzle) on the effective viscosity. It can be seen that the flow of the PEO solution in the first case (curve 1) is highly dissipative, while in the second (curve 2) it is slightly dissipative. At the same time, for a Newtonian liquid (water), the angle of entry into the nozzles does not play a significant role. A similar conclusion follows from the analysis of the data in fig. 2.5, which shows the results of experiments to identify the effect of the angle of entry into the nozzle and the PEO concentration on the effective viscosity of polymer solutions. The experimental data characterise the peculiarities of the flow of PEO aqueous solutions through the model nozzles of a hydroperforator.

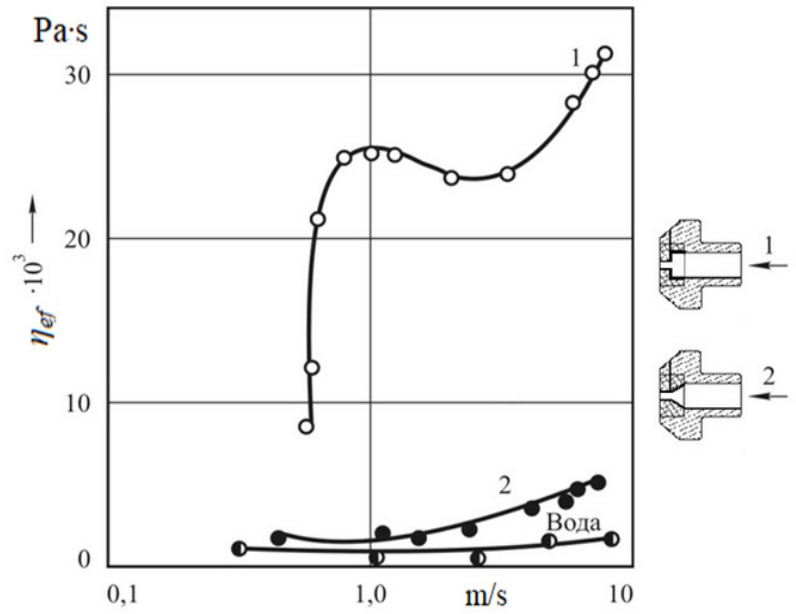

Fig. 2.4. The influence of conditions of the entry into the nozzle on effective viscosity: $\mathrm{MPEO}_{\mathrm{PEO}}=6 \cdot 10^{6}, \mathrm{C}_{\mathrm{PEO}}=0,1 \% ; d_{\min }=0,53 \cdot 10^{-3} \mathrm{~m} ; 1$ - rectangular entry $\left(180^{\circ}\right), 2$ - smooth entry $\left(45^{\circ}\right)$

From the experiments regarding the detection of the influence of the entrance angle into a nozzle on the effective viscosity of PEO solutions, it is clear that there are phenomena that are typical for such flows, yet not for purely viscous environments. At some critical values of $u_{k p}$, the effective viscosity begins to increase sharply, and the 
sharper this increase, the higher the concentration of polymer in solution and the wider the angle of entry into the nozzle. The highest value for $\eta_{e f}$ was observed for a nozzle with an inlet angle of $180^{\circ}$, i.e. when there was a sudden narrowing. Reducing the angle of entry into the hole of the nozzle leads to a decrease in $\eta_{e f}$ and displacement of the critical (threshold) speed in the direction of large values.

The ambiguity of the effective viscosity's dependence on $\bar{u}$ (one velocity can correspond to two values of viscosity, see figs. 2.3 and 2.5) testifies to the difficult nature of these currents and, naturally, studying only integral characteristics of a flows draws attention not enough to understand the observed phenomena. As mentioned above, in a previous study [33] the transition of the bundle-unfolded chain at a convergent flow (in the model conditions of the hydroperforator nozzle) of aqueous solutions of PEO was experimentally revealed.

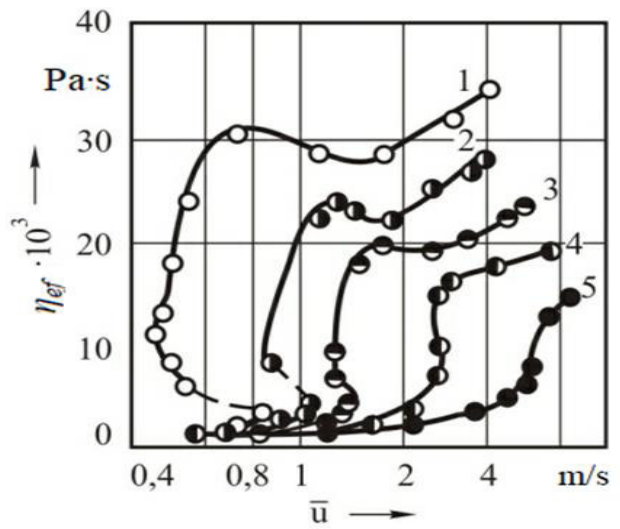

Fig. 2.5. The influence of the inlet angle on the effective viscosity when PEO aqueous solutions flow through the nozzles: $\mathrm{MPEO}_{\mathrm{PEO}}=6 \cdot 10^{6}, \mathrm{CPEO}_{\mathrm{PEO}}=0,1 \%, \beta: 1-$ $180^{\circ}, 2-150^{\circ}, 3-98^{\circ}, 4-65^{\circ}, 5-35^{\circ}$

It has been established that the water-PEO system at convergent flow under certain regimes is self-regulating with negative feedback. It has been shown that increasing longitudinal velocity gradients leads to deformation of the macromolecular coils, which in turn causes a rearrangement of the flow structure and increase the time of influence of the longitudinal velocity gradient on the macromolecular chains. The hydrodynamic field, which occurs under conditions of 
convergent flow, leads to a significant proportion of the polymer molecules unfolding, hence the peculiarities of the convergent flow of even dilute solutions due to the ability of the macromolecules to easily change the shape of these molecular balls under the action of the complex structure of the hydrodynamic field that arises in the inlet nozzle of the hydroperforator and due to the increased molecular interactions at the molecular-supramolecular level caused by these changes. Therefore, experiments proving the possibility of supramolecular structure formation during the flow of an aqueous solution of PEO in a model of jet-forming nozzles of a hydroperforator are fundamental in terms of solving the destroying of nature, which causes the destructive power of a high-speed water-polymer jet. Below we turn to such experiments.

Experimental studies [17] have demonstrated that selforganisation in space and time can be observed in aqueous solutions of PEO in the inlet section of the nozzle, which forms a jet (flow undertension). Therefore, to create a hydrodynamic field under tension, a convergent flow of water into a small hole in the plate (a model of a nozzle) with a diameterof $3 \cdot 10^{-4} \mathrm{~m}$ was used. Streams of PEO solutionwith a molecular weight of $6 \cdot 10^{6}$ were introduced into the water stream at a sufficient distance from the hole. The range of concentrations studied was $0.001 \%-0.1 \%$. The speed of the aqueous solution of PEO at the points of introduction of jets coincided with the speed of the main flow of water. Visualisation of the flow in the inlet area of the hole was carried out using admixtures of dye in the injected aqueous solutions.

At low flow rates, the coloured streams of PEO aqueous solution visualised the flow lines of the main stream (fig. 2.6). The behaviour of the streams of PEO solutions was no different from the behaviour of streams of pure water injected into the convergent stream. When a critical water flow through the outlet of the nozzle was reached, the nature of the flow of jets of aqueous solution changed dramatically. Quite thick streams of PEO aqueous solution were transformed into thin threads, the length of which changed over time (fig. 2.7). When observing the dynamics of the formation and destruction of individual threads (this is the oscillating nature of the movement of flooded streams of PEO solution) the following pattern is revealed. Initially, 
as the jets of PEO solution approached the hole, they were observed to bend smoothly towards the hole. At the same time, their velocity along these curvilinear trajectories began to increase more and more noticeably, as evidenced by the decrease in the thickness of the streams. Near the hole there was an abrupt decrease in the thickness of the streams of aqueous PEO solution, and they were transformed into a thin thread. The area of transformation of the thick stream into a thin thread began to move up the streams, which led to an increase in the length of the threads. Since the streams of the aqueous solution of PEO approached the hole at the same time, at each time the length of the threads spun by the flow from the individual streams of aqueous solution was different.

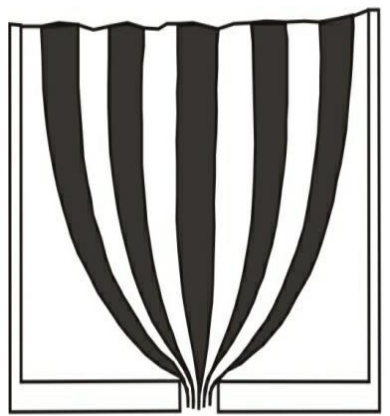

Fig. 2.6. The flow in the inlet section of themodel nozzle when the PEO aqueous solutions were injected into water (МРEO $=6 \cdot 10^{6} ;$ СРеO $=0,03 \% ; \bar{u}<u_{c r}$ )

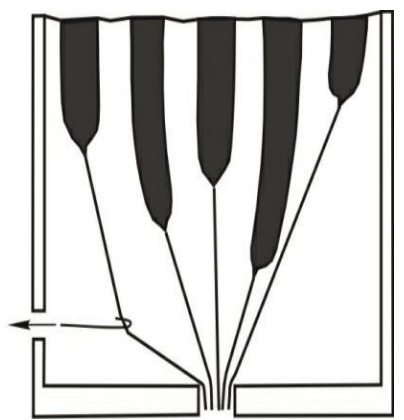

Fig. 2.7. The flow at the moment of wire probe effecting a polymer thread spun by hydrodynamic field $\left(\mathrm{MPEO}_{\mathrm{PE}}=6 \cdot 10^{6}\right.$; $\mathrm{CPEO}=0,03 \% ; \bar{u}=2,5 \mathrm{~m} / \mathrm{s}, \bar{u}>u_{c r}$ )

When acritical length was reached, the thread in the immediate vicinity of the hole broke. After that, the thread remaining at the top lost elasticity and sagged, i.e. one of the lines of the main flow of water. When the stream of aqueous PEO solution again approached the hole, everything repeated. The observed behaviour of flooded streams of aqueous PEO solution during tensile flow is due to the development of many PEO balls under the action of a hydrodynamic field. Rolling out molecular chains of PEO led to a decrease in their flexibility, which under certain conditions caused phase separation under the action of a hydrodynamic field, i.e. leading to the formation of a dynamic supramolecular structure. 
The following experiment can confirm this formation of a dynamic supramolecular structure under the action of a tensile hydrodynamic field. In the subcritical modes of main water flow leakage in the inlet area of the hole, a thin wire-probe with a device for capturing the thread of an aqueous solution of PEO was introduced. The movement of this probe wire in a plane perpendicular to the jets did not change the flow pattern, asthe jets of the aqueous PEO solution in these flow regimes are permeable to it. If the same experiment is repeated in the supercritical mode of water leakage, it is possible to capture one or more a polymer threads at the time of their growth and move aside, as shown in fig. 2.7. This is only possible in the presence of a sufficiently strong interaction between PEO molecules, i.e. in the emergence of a supramolecular structure, which is formed in this case under the action of a tensile hydrodynamic field. The minimum concentration of aqueous PEO solutions, when it was still possible to divert the aqueous solution of PEO, was $0.008 \%$, which corresponds to the region of dilute solutions when the intrinsic viscosity $[\eta]_{0}$ multiplied by the concentration of PEO $C_{\mathrm{PEO}}$ was less than 1 [40].

These results and those given above suggest that aqueous solutions of PEO can be divided into at least three regions of concentration. This is the region of dilute aqueous PEO solutions, where PEO macromolecules under the action of a hydrodynamic field are subjected to strong deformation effects (expansion of macromolecules), but still weakly interact with each other in the expanded state. The second is the region of semi-dilute aqueous PEO solutions (intermediate), when in subcritical flow regimes the solutions are diluted, and in the supercritical ones - already concentrated in the result of the formation of supramolecular structures under the action of a hydrodynamic field. These dynamic structures should be considered the type of dynamic phase transitions dealt with by the theory of dissipative structures [42]. The last region is the region of concentrated aqueous solutions of PEO $\left([\eta]_{0} \cdot C_{P E O}>1\right)$, when significant interactions between PEO molecules exist without the action of a hydrodynamic field. It should be noted that the first two areas relate to the concentrations of the manifestation of great destructive power of a high-velocity jet of an aqueous solution of PEO. Thus, when aqueous 
solutions of PEO flow through the nozzles, forming a high-velocity jet, there may be a dynamic supramolecular structure that is subject to Prigogine's principles of self-organisation [42]. These results are crucial for elucidating the nature of the great destructive capacity of a high-velocity water-polymer jet.

By elucidating the dynamics of macromolecules in the hydrodynamic field of a jet-forming nozzle and experimentally proving the formation of a dynamic supramolecular structure in the inlet section of the nozzle, we can obtain reasonable ideas to explain the mechanism behind the destructive capacity of a water-polymer jet.

Analysis of the concentration dependence of the destructive capacity of polymer solutions and the results indicating on formation of dynamic supramolecular structures in polymer solutions suggest that approaching the optimal concentration of polymer $\left(\mathrm{C} \geq \mathrm{C}_{\mathrm{opt}}\right)$, the destructive capacity of water generates anisotropic supramolecular formations that have a lifetime 10 times longer than the relaxation time of the macromolecule [33]. A further increase in the PEO concentration led to the creation of conditions for the interaction between individual molecules of PEO, even without the action of a hydrodynamic field. This leads to a sharp increase in the usual viscosity and, of course, to a relatively strong decrease in the flow rate of the aqueous solution. The consequence of this is a decrease in the destructive capacity of the water-polymer jet when reaching a relatively high concentration of PEO in aqueous solution.

To substantiate and systematise the physical laws of the fracture mechanism in the process of perforating the casing strings of oil and gas wells with a stream of polymer solution and the relationship of the individual phenomena that occur, it is important to develop schemes for calculating basic technological parameters and rational modes of a hydroperforator. The experimental data show that the process of water-polymer perforation of oil and gas well casing strings is complex and has specific features which contrast with the perforation of the water jet and hydroabrasive jet.

The subject of the work - to develop a highly efficient innovative method for perforating oil and gas well casing strings - can be achieved through a method of hydrostream perforation of the well that includes directing the jet to the place of perforation, sealing the inner cavity of the tubing and jet apparatus, actuating the ball valve located at the bottom of the jet apparatus, sealing the annulus with a self-sealing gland, and supplying the tubing pipe with cutting fluid, that is, an aqueous solution of PEO with a molecular 
weight of $M=6 \cdot 10^{6}$ at a concentration of $C_{\mathrm{PEO}}=0.003-0.007 \%$ by weight and with an operating pressure of $100-300 \mathrm{MPa}$. These parameters are the innovative technological feature in the function of this cutting fluid.

Perforation works were performed in the laboratory using a hydraulic stand based on a URG-3020 installation. The model of the obstacle (target) on which the perforation efficiency was tested is described in the experimental part. The results of the destruction of the model barrier by a waterpolymer jet with PEO concentrations of $0.0025-0.008 \%$ and a PEO molecular weight of $6 \cdot 10^{6}$, a leakage pressure of $200 \mathrm{MPa}$, a nozzle diameter of $3 \cdot 10^{-3} \mathrm{~m}$ and a perforation time of $10 \mathrm{~min}$ are provided in table 2.2.

Table 2.2

The effect of PEO concentration on the length of the channel formed in the model obstacle

\begin{tabular}{c|c|c}
\hline No of research & CPEO, $\%$ & $\begin{array}{c}\text { Length of formed channel, } \\
10^{-3} \mathrm{~m}\end{array}$ \\
\hline 1 & 0,0025 & 0,245 \\
\hline 2 & 0,003 & 0,385 \\
\hline 3 & 0,005 & 0,405 \\
\hline 5 & 0,007 & 0,430 \\
\hline 5 & 0,008 & 0,435 \\
\hline
\end{tabular}

The tests were also performed with a concentration of PEO aqueous solution of $0.005 \%$, but the pressure of the destructive fluid changed. These results are presented in table 2.3.

Table 2.3

The effect of the pressure of the destructive fluid on the length of the channel formed in the model barrier with a formed $0.005 \%$ concentration of PEO in the water-polymer stream

\begin{tabular}{c|c|c}
\hline No of research & $\begin{array}{c}\text { Pressure of cutting fluid, } \\
\text { MPa }\end{array}$ & $\begin{array}{c}\text { Length of formed channel, } \\
10^{-3} \mathrm{~m}\end{array}$ \\
\hline 6 & 75 & 225 \\
\hline 7 & 100 & 380 \\
\hline 8 & 200 & 405 \\
\hline 9 & 300 & 420 \\
\hline 10 & 350 & 425 \\
\hline
\end{tabular}

Decreasing the pressure below $100 \mathrm{MPa}$ reduced the perforation efficiency, while raising it above $300 \mathrm{MPa}$ caused a slight increase in the length of the channel; however, in a production environment there are technical difficulties in maintaining such high pressures. 
Comparative perforation works were performed on a similar model of the obstacle using HSP (sand fractional composition: 0.5-1.2 $10^{-3}$ $\mathrm{m}$; concentration: $30-50 \mathrm{~kg} / \mathrm{m}^{3}$; leakage pressure: $200 \mathrm{MPa}$. In the case of HSP, the length of the channel in the obstacle model was $320 \cdot 10^{-3} \mathrm{~m}$.

The results presented in tables 2.2 and 2.3 show that PEO additives in the selected range of concentration and flow regimes will lead to greater channel formation efficiency during the perforation of oil and gas well casings, which will allow more efficient use of oil and gas fields' potential.

Experimental and field testing of the proposed method of perforatingthe casing columns of oil and gas well casing strings- using a jet of PEO aqueous solution - which was carried out during the secondary opening of the productive reservoir at a well in the Carpathian oil-andgas-bearing region, confirmed the practical and economic feasibility of its use. The environmental friendliness of PEO additives should be noted, because this polymer is not harmful to humans and does not harm nature.

The mechanism behind the destructive power of a high-velocity jet of polymer solution has been discovered. It is not due to the Toms effect, but consists in the destructive action of the dynamic pressure of the water-polymer jet, "reinforced" by highly developed macromolecular chains and dynamic anisotropic supramolecular structures formed under the action of expanding flow in the inlet section of the hydroperforator nozzle that forms the high-velocity jet flow.

Research and field testing of the method of hydrojet perforation of well casingsthat uses aqueous solutions of PEO confirmed that the process of well perforation is more efficient, environmentally friendly and resource-saving than hydro-sandblasting perforation.

The new data on the influence that different jet-forming nozzles have on the hydrodynamic behaviour of aqueous polymer solutions during their flow through the nozzles and the established patterns of the influence that the structures have on the efficiency of well perforation - aimed at developing a highly efficient process for perforating oil and gas well casing strings with a high-velocity stream of polymer solution - are innovative, relevant and promising.

3. The nature of Hydrodynamic Drag Reduction of Oil Flow in Pipelines by Polymer Additions 
The problem of reducing the energy intensity of the oil-trunk pipelines by increasing their productivity remains one of the key problems of economic development of different countries. It is obvious that the task of improving the hydrodynamic characteristics of the oil pipelines is to find the ways to reduce the oil flow drag - fluid friction. Among the known methods of artificial influence on the boundary layer, in order to reduce the hydrodynamic drag in oil pipelines, special place is taken by a method, based on the injection of polymer solutions. This method is the only one in the development that has certain practical progress [43-46].

Laboratory and field tests of the influence of small polymer additions to reduce the drag of oil flow in pipelines began conducting since the late 70 -ies of the XX century [45,47-50]. The design development of oil pipeline by using polymeric additions for turbulent drag reduction was justified, because the actual increase of the TransAlaska oil-trunk pipeline capacity [44] has amounted 20\%. However, the resulting friction drag reduction effects by applying polymer solutions in oil pipelines are far from the theoretically predicted. Therefore, the technical task of reducing the hydrodynamic resistance of oil flow in the pipelines by applying the polymer solution into the boundary layer needs to be resolved.

This applies to all questions above regarding the nature of turbulent drag reduction by using polymer additions. Understanding the nature of reducing drag flow of oil in pipelines by small polymer additions will allow to develop recommendations on the choice of rational hydraulic regimes of oil pipelines, as well as to outline the ways for the directed synthesis of high-performance polymer additions that reduce friction in the turbulent oil pipelines.

In the hydrodynamics of polymer solutions there takes place the transition from accumulating experimental information to understanding the physical essence and establishing main regularities of manifestation of memory and elasticity effects. Toms effect revealed as an experimental fact in the late 40-ies, up to now has been causing great difficulties when interpreting it from the point of view of modern ideas of the hydrodynamics of turbulent flow.

Among the attempts to explain the nature of effect Toms', lying in drag reduction by the polymeric components, special place is taken by a hypothesis, based on strong deformation effect of a near-the- 
wall turbulence on macromolecules $[17,45]$. For the substantiation of this hypothesis experimental proofs of presence of large degrees of deformation of macromolecules in a wall-adjacent zone of a turbulent flow are necessary. The skepticism concerning strong deformation effect of wall-adjacent turbulence on macromolecules is stipulated yet by the fact that, as a rule, shift effects wall-adjacent a turbulence are analyzed, and not the, jet flows ("explosions") with a longitudinal gradient of speed which arise in the wall-adjacent area $[37,51]$. It is possible to hope, that the way to understanding and describing phenomena reduction of turbulent friction by polymer additions lies through the study of hydrodynamic effects of big reversible (as well as non-reversible) deformations of molecular coils in flows with stretching.

Therefore the experiments proving the stretching of molecules in conditions of wall-adjacent turbulence have a fundamental character not only in point of developing the mechanism of drag reduction by polymer additions but also in point of more profound insight into the nature of turbulence itself.

For polarization-optical visualization of wall-adjacent turbulence flow of polymer solutions using the experimental installation, consisting of the optical bench, the light source, a polarizing microscope, filter and a plate equal to a quarter of a wavelength. The scheme of the installation can be found in the $[2,30]$. The light source was a mercury-quartz lamp DRSh250. Transparent rectangular channel was used as hydrodynamic cells. It was made of glass and had the cross-section $(4 \times 4) \cdot 10^{-3} \mathrm{~m}$ and the length of $1 \mathrm{~m}$. It was fixed to the special coordination table and could be moved in three mutually perpendicular directions. Visualization was made in the wall-adjacent area of the channel, that was located at a distance of $0.25 \mathrm{~m}$ from its end.

Due to the significant experimental difficulties in obtaining data on the stress state of macromolecules in conditions of wall-adjacent turbulence in the oil flow, experiments were carried out with water solutions of polyethylene oxide (PEO), which were used as a model polymer solutions in oil.

PEO having the viscosity-average molecular weight of $4 \cdot 10^{6}$ was used as a polymeric additive and latent root of a The solutions of polymer had concentration $0.01-0.05 \%$. Special hydrodynamic canal a rectangular cross-section $(4 \times 4) \cdot 10^{-3} \mathrm{~m}$ and height of $1 \mathrm{~m}$ was used. 
Visualization made in wall-adjacent of area located on a distance $0.25 \mathrm{~m}$ from its extremity of the channel.

Deformation of the Molecular coils of Flexible Polymers under wall-adjacent turbulence conditions. Experiments proving macromolecule unrolling under wall-adjacent turbulence have fundamental character not only in relation to the development of the Toms' effect mechanism but as well as to the more profound insight of the nature of the wall-adjacent turbulence itself.

Such tests can be carried out due to polymer linear macromolecules having their own anisotropy and anisotropy of form. Moreover in case of full macromolecule unrolling that can be realized only in flows with stretching, there takes place rather significant (by $3 \div 4$ orders of magnitude greater than for simple shift) and quick increment of the birefringence factor with the increase of velocity gradient acting on molecular coils up to extremely possible $\Delta n_{\infty}$ [20]. The given peculiarity of birefringence dependence on the degree of macromolecule unrolling just gives hope for the occurrence of birefringence area in zones with greater longitudinal velocity gradients of a boundary layer despite the sharp sensitivity reduction of the polarization-optical method under small polymer solution concentrations.

Fig. 3.1 shows a sketch of a picture birefringence zone of a turbulent boundary layer of a current of a water solution PEO having concentration $0.05 \%$ and $\mathrm{Re}=2 \cdot 10^{4}$.

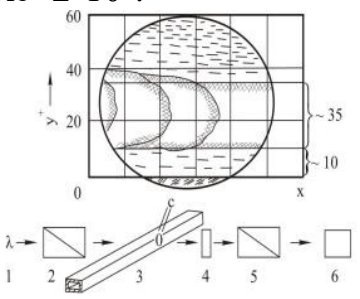

Fig. 3.1. The sketch of a picture of birefringence zone and a diagram of experimental installation 1 - mercury lamp; 2 - polarizer; 3 -hydrodynamic channel; 4 - plate a equal to a quarter of a wavelength; 5 - analyzer; 6 - camera or cine camera

Polarization and optical visualization testify, that in the field of $10 \leq y^{+} 45$, in which maximum generation of jets of fluid happens, birefringence is localized. In the immediate proximity to the wall $\left(0 \leq y^{+}<10\right)$ and in the field of the kernel $\left(y^{+}>45\right)$ birefringence is unvariable $\left(y^{+}=\mathrm{u}^{*} \cdot y / v\right.$, where: $y$ - is coordinate; $\mathrm{v}^{*}$ - is dynamic velocity; $v$ - is kinematic viscosity). 
This fundamental experiment unequivocally shows the presence of strong deformation effect on the molecular coils in certain zones of a turbulent boundary layer, having supercritical longitudinal gradients of speeds.

A mean angle of the orientation of polymer molecules with a direction of the main flow is $\sim 35^{\circ}$. The performed visualization of near-the-wall turbulent flow of water solution PEO has confirmed the conventional ideas about the structure of a turbulent boundary layer.

Adequate experimental verification of macromolecule unrolling under wall-adjacent turbulence made it obvious that using nonturbulence flows with stretching for the study of macromolecule interaction with hydrodynamic field is advantageous as giving the possibility to experimentally investigate "abnormal" effects in controlled conditions and allowing to model the main peculiarities of a turbulence boundary layer.

Dynamic structure formation in solutions of hudrodynamic active polymers. Let's examine the tests allowing to reveal the ability of hydrodynamic active polymers to dynamic structure formation effected by hydrodynamic field with stretching. To create hydrodynamic field with stretching there has been used a flow of Newtonian liquid (water, acetone, dioxan) converging to a small outlet $0.3 \cdot 10^{-3} \mathrm{~m}$ in diameter. At quite a distance from the outlet there have been injected in this flow some jets of PEO solutions or hydrolyzed polyacrylamide (HPAA) with molecular mass $6 \cdot 10^{6}$ and $4 \cdot 10^{6}$ and characteristic viscosity 2.42 and $3.70 \mathrm{~m}^{3} / \mathrm{kg}$ correspondingly. The degree of PAA hydrolysis was 5 percent. Interval of the studied concentrations was $0.001 \div 0.1 \%$. Polymer solution velocity in points of injection agreed with velocity of the main liquid flow. Visualization of the flow in the inlet area was done with the help of dye additives injected into polymer solution. Under small outflow velocities dyed jets of polymer solution visualize stream-lines of the main flow (fig. 3.2). 

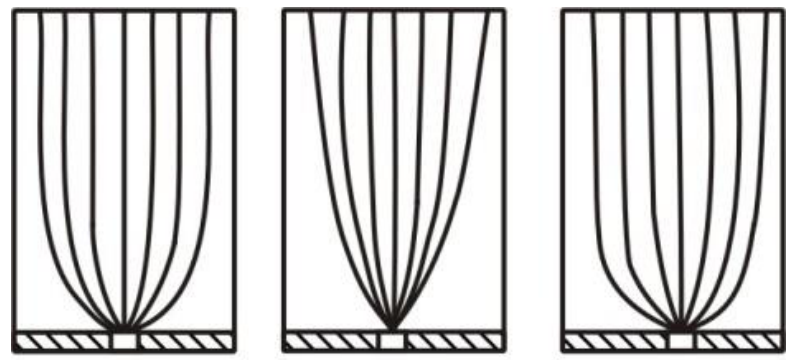

Fig. 3.2. Picture of flow in the inlet area of a capillary when injecting polymer solution into water during pre-critical mode of outflow $\mathrm{MPEO}=6 \cdot 10^{6} ; \mathrm{CPEO}=0,025 \%$; $\mathrm{M}_{\mathrm{HPAA}}=4 \cdot 10^{6}, \mathrm{C}_{\mathrm{HPAA}}=0,05 \%$. $a$ - water into water at $\dot{\varepsilon}>\dot{\varepsilon}_{c r} ; b$ - HPAA into water at $\dot{\varepsilon}>\dot{\varepsilon}_{c r} ; c$ - PEO into water at $\dot{\varepsilon}<\dot{\varepsilon}_{c r}$

In his case behaviour of PEO and HPAA solution jets doesn't differ at all from the behaviour of water jets injected into converging liquid flow. Reaching some critical flow rate of liquid through the orifice the character of jet flow of polymer solution drastically changes. Rather thick polymer jets transform into thin threads that change their length with time flow (fig. 3.3).

When observing the dynamics of forming and destructing separate threads (here lies the moving pulsation character of the flooded polymer jets) the following regularity comes to life. At the beginning when polymer jets approach the orifice there can be traced their gradual bend towards the orifice. Here their velocity growth along these curve trajectories becomes more noticeable as the jet thickness gets reduced. Near the orifice discontinuous (for PEO solutions) reduction of jets thickness takes place as they are transformed into thin threads. Transformation area of a thick jet into a thin thread starts to shift up along the jets resulting in the increase of the thread length. HPAA water solutions reveal more gradual change of jet thickness than PEO solutions. As jets approach the orifice not concurrently the length of threads spun by the flow from separate polymer jets is different at each given moment. Birefringence is observed in the area of thread emergence. 


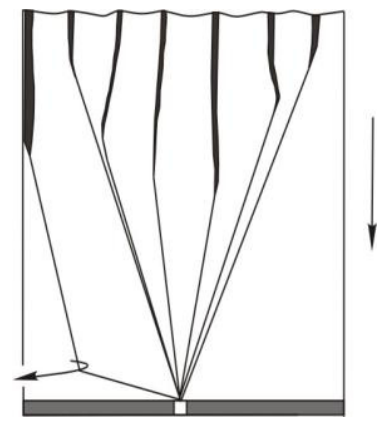

Fig. 3.3. Photo of flow at the point of wire probe effecting a polymer thread spun by hydrodynamic field $\mathrm{M}_{\mathrm{PEO}}=6 \cdot 10^{6}, \mathrm{C}_{\mathrm{PEO}}=0.03 \%, \bar{u}=2.5 \mathrm{~m} \cdot \mathrm{s}^{-1}$

When reaching some critical length a thread cuts off in close proximity to the orifice. After that the remaining at the top thread loses its elasticity and sags marking one of the stream lines of the main flow. When a polymer jet approaches the orifice again the whole thing is repeated anew. This process is resumed with time interval from fractions of a second to several seconds depending upon the outflow mode of the main flow, polymer molecular mass, polymer type, solvent quality and temperature, as well as polymer concentration in solution.

Outflow velocity growth of converging water flow as well as increase of molecular mass and polymer concentration result in the increase of thread length and reduction of their length-changing rate. Temperature growth leads to the opposite effect. Tests with acetone and dioxan (solvents with poorer thermodynamic qualities than water) showed that under the same velocities as in tests with water pulsation rate of thread length is bigger, but the amplitude of these changes is less than in case of injecting polymer solution into water. It should be also stressed that there are such ejection modes for concentrated (to Debay $[\eta]_{0} \cdot C>1$ ) polymer solutions, when the emerged polymer threads don't cut off during the whole period of observation.

There also has been studied the effect of initial (non-turbulent by hydrodynamic field) sizes of molecular coils, that in polyelectrolytes (HPAA) depend on the hydrogen measure of the surroundings, on the ejection character of HPAA solution jets injected into water flow. The experiment has shown that in case of $\mathrm{pH}$ of the 
main flow equaling 2 the length of a polymer thread decreases sharply (3-4 times for 0.05 percent concentration) while the thread lengthchanging rate increases by $1.5-2$ times. The increase of $\mathrm{pH}$ in the range between 7 and 9.5 practically doesn't influence the ejection character.

The main regularities of the polymer jets behaviour when injected into a flow with stretching, which is the main liquid flow, are similar to those in case of polymer solution outflow through short capillaries $[17,45]$. Hence, the observed behaviour peculiarities of the flooded polymer jets in flow with stretching are caused by rather strong polymer coils unrolling effected by hydrodynamic field (the degree of unrolling here reaches $\sim 60-70$ percent $[2,33]$ ). Uncoiling of macromolecule chains leads to decrease of their flexibility, which under certain conditions causes phase separation effected by hydrodynamic field, i.e. it leads to dynamic structure formation.

The following experiment may serve as a proof of dynamic structure formation effected by hydrodynamic field with stretching. A thin wire with a device for polymer thread hold-up is introduced into the inlet area of the orifice during the pre-critical mode of the main flow ejection. This wire travel in the plane perpendicular to jets doesn't change the flow picture, i.e. during these modes the polymer jets are permeable to it. If the experiment is repeated during over-critical mode of liquid outflow, then it would be possible to hold-up one or several polymer threads during their growth and divert them as it is shown in fig. 3.3. This can be done only if there is a strong interaction between polymer molecules, i.e. when sub-molecular structure is formed, in this case under the effect of stretching hydrodynamic field. The minimum concentration of PEO water solutions allowing to divert a thread spun by hydrodynamic field was 0.008 percent, which corresponds to the range of diluted solutions $\left([\eta]_{0} \cdot \mathrm{C}<1\right)$.

The given results as well as those obtained while studying converging flows of polymer solutions allow to state that hydrodynamic active polymer solutions should be divided into at least three concentration ranges. The first is the range of diluted polymer solutions when macromolecules are under strong deformation effect (unrolling) caused by hydrodynamic field, but the interaction between them is still weak. The second is the range of semi-diluted solutions (intermediate) when during pre-critical flow modes become diluted 
and during over-critical modes they become concentrated due to super-molecule structure formation caused by the shift of phase separation curves effected by hydrodynamic field. These dynamic structures should be classified as dynamic phase transitions that are studied by the theory of dissipation structures [42]. And the last range is the one of concentrated solutions $\left([\eta]_{0} \cdot C>1\right)$, when noticeable interaction between molecules do exist without hydrodynamic field. It should be stressed that the first two ranges refer to concentrations when the Toms' effect is manifested.

So, the results obtained by us show that dynamic structure formation and periodic processes subjected to Prigozhin's principles of self-organization may occur in hydrodynamic active polymer solutions in flow with stretching.

Polymer solutions in model conditions of wall-adjacent turbulence. When changing the orientation of zones with stretching generated with a help of a short capillary tube as to the wall (barrier) position it is possible to simulate ejections of polymer solution micro-jets from the wall-adjacent area.

Fig. 3.4 shows curves that characterize relationship of effective viscosity to $\mathrm{u}$ and obtained in PEO water solution flow through a short capillary tube with orientation of a single axis stretching zone along a normal to the "wall" surface. It is seen that when a stretching zone approaches a solid surface the flow becomes more dissipative, but the critical velocity is shifted to less values. The given situation may serve as a model of normal component in a blasting flow near the wall; then the data obtained testify to the decrease of probability for such "blasts" to occur in the wall-adjacent area when there is a polymer in a liquid. That's why the thickness of a viscous sub-layer in a liquid with decreasing resistance must be higher and the average (in time) intensity of lateral velocity pulsations must be less than in a liquid without a polymer. 


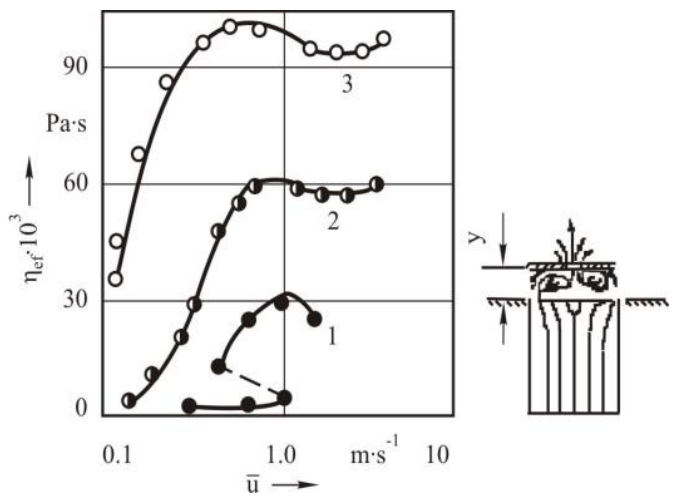

Fig. 3.4. Influence of a space the wall positioned normally to the axis of a longitudinal flow on effective viscosity in polymer solution $M_{P E O}=4 \cdot 10^{6} ; C_{P E O}=0,05 \% ; y$ : 1 - without a wall $(y \rightarrow \infty) ; 2-5 \cdot 10^{-3} \mathrm{~m} ; 3-5 \cdot 10^{-3} \mathrm{~m}$

Curves shown in fig. 3.5 meet the conditions of PEO solution outflow through a capillary tube when its axis is positioned in parallel to the "wall" surface. When surface approaches zone axis with longitudinal velocity gradient the maximum value of effective viscosity is practically unchanged while the critical velocity value is shifted to greater values.

This situation serves as a model of longitudinal component in a blasting flow near the wall. Independence of the maximum viscosity value and insufficient increase of $u_{\mathrm{cr}}$ on approaching the "wall" must testify to the fact that average (in time) intensity of longitudinal blasts and, thus, velocity pulsations near the wall are similar to those in flows without polymer additives.

In flows with stretching zones macromolecules of a dissolved polymer, when $\dot{\varepsilon}>\dot{\varepsilon}_{\mathrm{cr}}$, suppress big longitudinal gradients, and just this very feature must lead to the decrease of velocity pulsation intensity near the wall and manifestation of some threshold flow mode that gives way to the hydrodynamic activity of polymer additives to be revealed. The obtained results are in complete conformity with the known ones that prove the existence of a threshold velocity of Toms' effect manifestation [41]. 


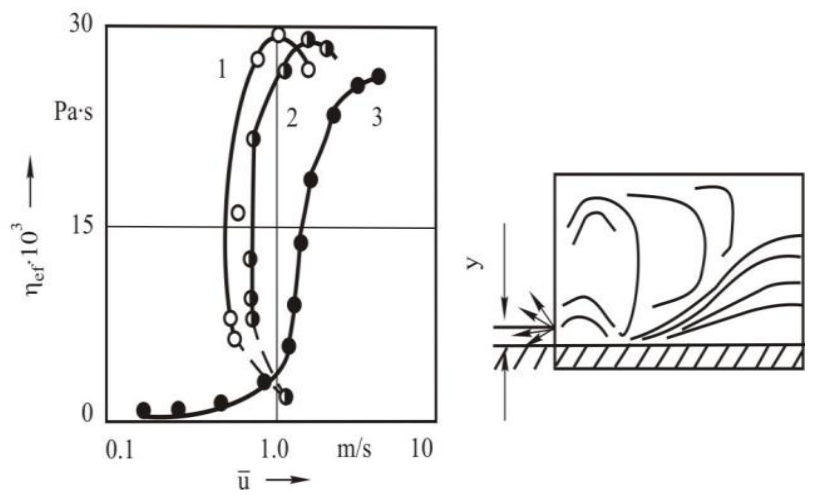

Fig. 3.5. Influence of a space to the wall positioned in parallel to the axis of a longitudinal flow on effective viscosity in polymer solution $\mathrm{M}_{\mathrm{PEO}}=4 \cdot 10^{6} ; \mathrm{C}_{\mathrm{PEO}}=0,05 \% y ; y: 1-$ without a wall $(y \rightarrow \infty)$ $2-5 \cdot 10^{-3} \mathrm{~m} ; 3-5 \cdot 10^{-4} \mathrm{~m}$

Summarizing we may say that the studied experiments and the data obtained allow to receive additional information on the structure of wall-adjacent turbulence and to come to the issue on mechanism of turbulence friction reduction effect due to polymer additives; we are to deal with it in the following section.

Mechanism of turbulence friction reduction effect due to polymer additives. The data obtained due to this work convincingly prove that the system water-polymer (polymer with flexible chains) under walladjacent turbulence in certain flow modes $\left(v^{*}>v^{*}\right.$ treshold $)$ is selfregulating with negative feedback that is manifested in the following: the growing longitudinal velocity gradients acting in the area $\left(0 \leq \mathrm{y}^{+}<10\right)$ where jet flows are generated to the maximum as a result of turbulent explosions, lead to macromolecule coil deformation which in its turn causes structure reconstruction of these flows in order to decrease longitudinal velocity gradients. The latter cannot be lower than critical values equaling $0,5 / \theta_{\mathrm{c}}$.

If they appear to be lower than $\dot{\varepsilon}_{c r}$ then macromolecules will start to form into a coil with no more effect on velocity field; velocity gradient sharply increases here leading to significant deformation of macromolecular coils and everything repeats again. It means that in auto-vibration mode the system regulates velocity gradient in jet flows making it relatively small but still sufficient enough for mac- 
romolecular coil deformation. It should be stressed here that namely this ensures Virk's asymptote and no full laminarization of walladjacent turbulence flow.

Growth of deformation velocity as a result of non-linear effects leads to insignificant further increase of deformation factor, but this turns to be enough to stabilize typical velocity gradient within a rather broad interval of flow velocities. In case of rather high $v^{*}$, as it comes out from $[43,51,41]$ deformation velocity growth leads to deformation factor decrease due to the cut of effect time for longitudinal velocity gradient. The latter is due to small-scale turbulence which share sharply increases under high $v^{*}[43,51,41]$.That's why Toms' effect dependence on velocity has extremal nature. Degradation of polymer solutions starts to contribute significantly to Toms' effect reduction at high velocities.

So, liquid ejections from the wall area into the outer area of a boundary layer that nearly periodically interrupt calm flowing, are stabilized by feedback molecule deformation (flooded jet flows with longitudinal velocity gradient). This leads to frequency decrease of these ejections and finally to suppression of normal Newtonian energy processes caused by jet ejections and, thus, to friction resistance decrease. The part of explosion cycle where gradient $\dot{\varepsilon}>\dot{\varepsilon}_{c r}=0,5 / \theta_{c}$ takes place is subjected to the greatest effect. The interaction between macromolecular coils and hydrodynamic field in auto-vibration mode takes place in any zone of a flow with stretching in a wall-adjacent area of a turbulence flow, which prevents primary turbulence development.

It is important to compare macromolecular scales describing polymer molecules in solution as well as turbulence scale near the wall. In this case linear and temporal scales must be single-valued. Analysis of experimental data shows that both typical size $\lambda_{f}$ and time $\mathrm{T}_{\mathrm{f}}$ depend on concentration, molecular mass and some other factors. On average the following factors can be accepted: $\lambda_{f} \sim 10^{-4}-10^{-5} \mathrm{~m}$, while $T_{f} \sim 10^{-3}-10^{-4} s$ [41]. Macromolecules in solution are characterized by a linear scale that depends on the degree of their stretching; contour length of a completely stretched macromolecule should 
be taken as its characteristic feature, maximum (fundamental) time for relaxation should be treated as typical time.

In case of full macromolecule stretching its contour length has a micro-scale factor of wall-adjacent turbulence. The stretching rate of approximate $60 \div 70$ percent was obtained in model conditions of wall-adjacent turbulence. This demonstrates the fact that interaction between turbulence field velocity and macromolecules may take place both on the level of individual molecules (very watered down solutions) and on the level of super-molecular formations generated by hydrodynamic field (semi-diluted and moderately concentrated solutions). The average relaxation time of polymer solutions $[1,41]$ coincides in factor with the typical time of wall-adjacent turbulence.

Comparison of concentration dependence of the Toms' effect and the data testifying to the formation of dynamic super-molecular structures in polymer solutions allows to state that in the vicinity of optimal concentration (when $C \geq C_{\text {opt }}$ ), where the Toms' effect reaches its maximum, solutions start generating anisotropic super-molecular forms having the lifetime 10-20 times longer than $\theta_{c}$ [2,45]. Further increase of concentration leads to conditions favourable for interaction between individual polymer molecules even without the hydrodynamic field effecting on them. The longitudinal hydrodynamic field effect in polymer solution gives way to the formation of dynamic super-molecular structures with lifetime significantly exceeding (in several factors) the temporal scale of the wall-adjacent turbulence. That's why unlike the super-molecular forms in semi-diluted solutions these super-molecular forms act as "stiff sticks". As an outcome of this the Toms' effect is decreased at a high polymer concentration in solution as well as at a high dynamic velocity.

On the basis of data that characterize macromolecule dynamics in non-turbulence flows with stretching and the proved evidence of strong deformation effect on macromolecules in wall-adjacent turbulence, and using data of model studies of turbulence peculiarities in a boundary layer there has been established the molecular-andsupermolecular mechanism of effect reduction for flow resistance when injecting soluble polymer additives in a turbulence flow. Mechanism of Toms' effect lies in the occurrence of auto-fluctuating mode of reversible processes of macromolecule deformation caused 
by longitudinal velocity gradients that quasi-regularly originate in turbulence boundary layer and in macromolecule deformation effect both on molecular (when $C<C_{\text {opt }}$ ) and super-molecular (when $C>C_{\text {opt }}$ ) levels on the wall-adjacent turbulence structure, i.e. as a result of macromolecule deformation oscillations and solubility of dynamic super-molecular forms brought about by the flow-with-stretching effect. All this leads to the increase of liquid ejection periods into the outer zone of the boundary layer and in consequence to the viscous sub-layer becoming thicker. As an outcome of this generation of primary turbulence gets reduced and general level of turbulence dissipation in the flow becomes lower. In case of sufficiently big molecular masses and concentrations the viscosity growth caused by both "common" intermolecular interaction and dynamic structure formation leads to sharp Toms' effect decrease.

The considered experimental data prove the substantiation to transfer outcomes obtained during the study of macromolecule dynamics in non-turbulence flows with stretching onto jet currents of wall-adjacent ejections in turbulence flow, i.e. turbulence current (to macroscopic scale) is perceived as laminar one (to microscopic scale) when hydrodynamic field interacts with polymer molecules. Macromolecules may serve as an efficient tool of getting additional information about the structure of wall-adjacent turbulence.

The developed approach of explaining the turbulent drag reduction mechanism fits well into the general scheme of self-regulatory processes, which are dominated by negative feedbacks. It is typical for systems that can change their properties under the action of external physical effects, in this case, under the influence of jet currents ("explosions") with stretching which locally occurring in the boundary layer of the oil pipeline.

Understanding the nature of reducing drag flow of oil in pipelines by small polymer additions will allow to develop recommendations on the choice of rational hydraulic regimes of oil pipelines, as well as to outline the ways for the directed synthesis of high-performance polymer additions that reduce friction in the turbulent oil pipelines.

\section{Improvement of Water Fire-Fighting Systems at Oilfield Territories}

A fire (fires) is a major ecological factor that at certain conditions leads to the strongest contamination of environment. An increase of 
work efficiency of the fire extinguishing systems is one of important engineer-technological measures that allows to decrease the influence

of the combustion products on a biosphere and to increase level of safety on oilfield territories. Reduction of hydrodynamic resistance of fire hoses and pipelines allows to improve the efficiency of waterbased fire-suppression systems which are the most widespread and feasible methods of the fire-fighting on the oilfield territories.

Among the well-known methods of the decrease in the hydrodynamic drag resistance through the artificial modification of the boundary layer of the fire hoses, the method of the introduction of the polymer solutions is almost unique, and certain practical results have been achieved in its development. The study has shown that the introduction of small amounts of polyethylene oxide (PEO) and polyacrylamide (PAA) into the fire-suppression liquids (water and water solutions of surfactants) make it possible to significantly (down to $75 \%$ ) reduce the hydrodynamic drag resistance. This reduction (when other parameters of the hydraulic system are unchanged) ensures that the capacity of the fire-fighting systems is 1.5-2 times higher, or the length of the fire hoses may be 3-5 times higher, or the pump power consumption may be decreased by $60-70 \%$, or the diameter of the fire-suppression pipes may be decreased by $15-20 \%$. Besides, it has been shown that the additions of the polymers to water or surfactant solutions considerably improve their firesuppression properties [2, 52-54].

This study relates to the hydrodynamics of the polymer solutions in the pipelines and problem of the improvement of the introduction devices. The hydrodynamics of polymer solutions at the polymer introduction into the boundary layer of the fire hoses has not been examined properly.

It is assumed that in case of the flow of polymer solutions through the slots and other elements of the introduction systems, essential "anomalies", which could considerablyaffect the Toms effect, cannot be observed. Such a conclusion is based on the analysis of the data obtained from the study of the shear laminar flows where the effects of elastic deformations are insignificant. In the introduction systems a complex flow is dominant and it consists of superposition of the shear and predominantly longitudinal (with stretching) flow. In case 
of such complex flows, the effects of elastic deformations become so significant that it may result in lessening the potential effect of the polymer additives, especially at high velocities of the flow of the firesuppressing liquids.

Water solutions of polyethylene oxide with the molecular masses $2 \cdot 10^{6}$ and $410^{6}$ were investigated. The mass fraction of polymer was varied from 0 to $0.3 \%$, temperature during experiments: $25^{\circ} \mathrm{C}$.

Solutions of fully dissolved polymer were prepared in dark vessel by dissolving the ethanol-polymer suspension in distilled water at room temperature during 2-3 days or by dilution of the previously prepared solutions of polymer $(0.1 \%, 0.2 \%$ and $0.5 \%)$ during $7-8$ days before the desired concentration. Since water solutions of PEO significantlychange properties at the upon prolonged storage, conformities to law of their aging process in water were preliminary studied and stabilizers to exclude it were chosen. The addition of $0.05 \%$ by mass potassium iodide solution in the PEO and PAA, which almost completely eliminates the aging of these polymers in water during storage and does not affect on the hydrodynamic activity, are used as such stabilizer [1,2].

We used a special hydrodynamic bench that allows achieving the exhaust velocities of the water flow through its channel of up to $35 \mathrm{~m} / \mathrm{s}$; the channel's length was $8.5 \mathrm{~m}[1,55]$. Orifices for measuring the pressure and for the sensors of friction force were placed on the lower wall of the channel. The injection system consisted of a dosing unit, underslot chamber ensuring different conditions of the deformation of the polymer solution (by changing the entrance angle) at the entrance to the slot. The angle between the injected polymer stream and the wall did not vary. The following characteristics have been variable: the angle of the opening of the slot $\beta^{\circ}$ (the angle of the entrance to the slot), concentration of the injected polymer solution, velocity of the injection, molecular mass, polymer brand, and velocity of the fire suppressing liquid (water).

This paper regularities and manifestations of the elastic deformations of the polymer flow are investigated under conditions close to that of the real flows of the fire hoses at oilfield territories.

The experiments described below were conducted in order to establish the conformities to law of manifestation of elastic deformations in the flow of polymer solutions under conditions 
typical for the internal problem in relation to the fire hoses and pipelines.

In fig. 4.1, the experimental data related to the flow of polyethylene oxide (PEO) water solutions through the underslot camera are shown. It is clear that the phenomena, unusual for purely viscous mediums, are inherent for such flows. At a certain critical (threshold) average exhaust velocity $\bar{u}$, the relative pressure differential increases sharply, and it is sharper at the higher polymer concentrations. The characteristics of the dependence $\xi=f(\bar{u})$ indicate the high dissipation of energy in the polymer solutions flow through the injector, i.e. the increased hydrodynamic drag resistance is observed at the supercritical flow rates.

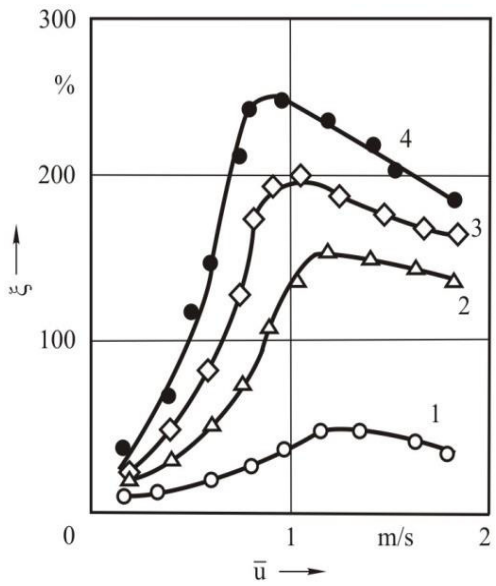

Fig. 4.1. Influence of $\bar{u}$ and angle of entrance into a slot on the relative pressure differential

Mol. mass: $4 \cdot 10^{6}, C_{\mathrm{PEO}}=0.1 \% ; \beta: 1-9^{\circ}, 2-13^{\circ}, 3-22^{\circ}, 4-34^{\circ}$

The presented experimental data are in accordance with the results obtained from the study of the flow of the polymer solutions under the simulated conditions such as through short capillary tubes and slots. These flows were thoroughly investigated in papers $[10,11,17,33,36,45]$. There should be stressed the most important moments of the elastic stress effects in the polymer solution flows with stretching. Transition to a flow mode with increased energy dissipation is accompanied by formation of so called "inlet flooded jet" as a "cord" or "fillet" enclosed by secondary flows in the shape of 
ring-shaped vortex. In case of the supercritical flow mode for polymer concentrations ranged from very diluted to moderately concentrated, the hydrodynamic field causes rather strong deformation effects on molecular chains. The uncoiled part of a polymer chain may be as large as $60-70 \%$ [33]. In half-diluted and moderately concentrated polymer solutions, the relaxation times of the fully stretched and slightly deformed individual chains differ more than by 2 orders of magnitude.

The reason for such a large time for the curling of the polymer chain is supermolecular structures formed in the hydrodynamic field. This is reflected in the decrease of turbulent friction if the lifetime of supermolecular formations in the polymer solution at the moment of its introduction to the boundary layer is comparable to the residence time in the fire hose at oil field territories.

The results of the polymer solution injection onto the lower wall of the channel through the underslot chambers with varying angles of the entrance to the slot shows (fig. 4.2), that when the polymer solution is introduced onto the inner surface of the fire hose at low angles of the entrance to the slot, the drop in the tangent stresses of friction is exhibited practically right behind the point of the introduction of the polymer to the flow.

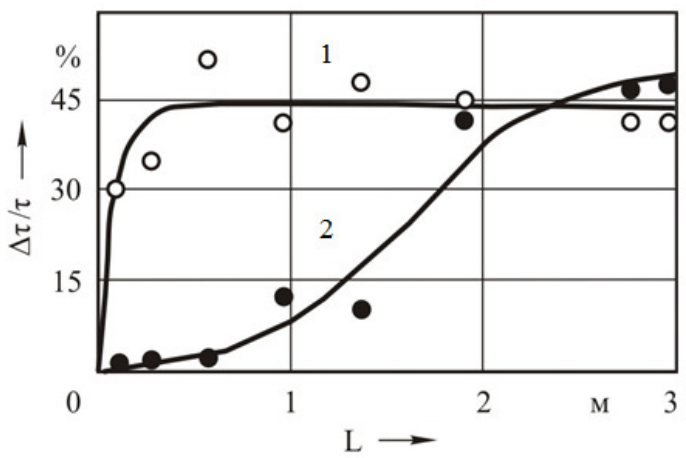

Fig. 4.2. Influence of the angle of the entrance to the slot on the distribution of the decrease in the tangent stresses along the lower wall of the channel for the injections of PEO solutions

Mol. mass: $2 \cdot 10^{6}, C_{\mathrm{PEO}}=0.3 \%, V_{0}=16.5 \mathrm{~m} / \mathrm{s}, Q=50 \mathrm{sm}^{3} / \mathrm{s} ; \beta^{\circ}: 1-7.8^{\circ}, 2-165^{\circ}$

If the polymer solution is introduced into the boundary layer through the chamber with a large angle of the entrance, there is a de- 
lay in development of hydrodynamic activity of the polymer molecules.

It should be mentioned that the distribution of the tangent stresses and relative pressure losses along the channel correlate with each other. As it follows from the results shown in fig. 4.2, the change of the mode of the polymer introduction through the underslot camera from weakly dissipative to strongly dissipative by modification of the entrance conditions results in double decrease in the drag resistance coefficient.

It should be mentioned that the distribution of the tangent stresses and relative pressure losses along the channel correlate with each other. As it follows from the results shown in fig. 4.2, the change of the mode of the polymer introduction through the underslot camera from weakly dissipative to strongly dissipative by modification of the entrance conditions results in double decrease in the drag resistance coefficient.

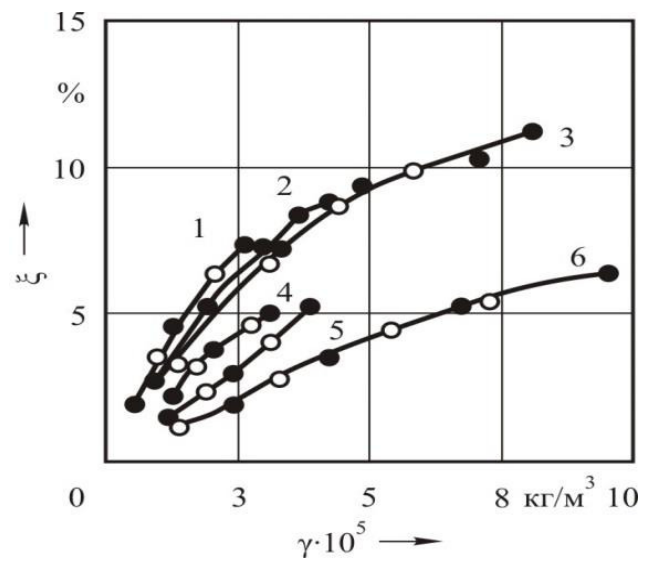

Fig. 4.3. Plot of the general pressure losses along the channel versus the specific concentration of PEO Mol. mass: $2 \cdot 10^{6}, \mathrm{~V}_{\mathrm{o}}:-16.5 \mathrm{~m} / \mathrm{s}, \mathbf{O}-25 \mathrm{~m} / \mathrm{s}$;

$\beta=7.8^{\circ}(1,2,3), \beta=165^{\circ}(4,5,6) ; C_{\mathrm{PEO}}: 1$ and $4-0.05 \%, 2$ and $5-0.1 \%, 3$ and 6 $-0.3 \%$

There has been (fig. 4.3) registered a considerably larger divergence in the plots of the drop of the resistance versus the changing concentrations of the polymer in case of the introduction of the polymer onto the inner surface of the fire hose under conditions of 
strong deformation effect of the hydrodynamic field on the injected solution, compared to the weak gradient effect.

Specific concentration was used to plot a chart (fig. 3)

$$
\gamma=Q \cdot C_{P E O} / \Omega \cdot V_{0},
$$

where $Q$ - volume flow rate of the injected liquid, $C_{P E O}$ - concentration of the injected polymer solution $\left(\mathrm{kg} / \mathrm{m}^{3}\right), \Omega$ - moistened surface, $V_{0}$ - velocity of the filling flow.

The visualization of the flows of the polymer solution in the underslot chamber shows that the conditions of the entrance render influence on the drop of hydrodynamic resistance only when there is a loss of stability of the flow caused, as was shown earlier in $[34,55]$, by the formation of the dynamic supermolecular structures which sharply increase the dissipativeness of the flow. The reduction of efficiency of the polymeric solution due to the deformation effects in the introduction system may be as large as $25 \%$ or higher at $\mathrm{V}_{0}>15$ $\mathrm{m} / \mathrm{s}$. The increase in the rate of the water flow results in the expansion of the area with the reduced hydrodynamic activity of the polymer.

The significance of the area with the reduced hydrodynamic activity of the polymer introduced into the boundary layer is the more, the less is the length of the fire hose. It may be explained by the fact that the lifetime of the derivative structures under conditions of the flow with stretching is in the order of magnitude of $0.1 \div 0.2 \mathrm{~s}$ or higher $[2,34,45,55]$. This is the time during which the polymer after leaving the slot in the fire hose has reduced activity due to its memory. Obviously, the higher is the velocity of the water flow, the larger is the area behind the slot filled with the polymer solution under this condition, and its size is defined as

$$
l_{\lambda}=\theta_{\mathrm{sw}} \cdot V_{\mathrm{o}}
$$

where $\theta_{\mathrm{sw}}$ - time of structural relaxation of the supermolecular formations, $V_{0}$ - velocity of the filling flow.

Hence, for the velocity of the water flow of $25 \mathrm{~m} / \mathrm{s}$, this area should extend downwards along the stream to $2.5 \mathrm{~m}$, if $\theta_{\mathrm{sw}}=0.1 \mathrm{~s}$. The estimated size of the area with the reduced hydrodynamic activity of the polymer is in good correlation with the experimentally obtained results. 
The results of the experiments with the introduction of the polymer solutions of the various concentration through the underslot camera with the changing angle of the entrance (fig. 4.3) show that for the given specific average concentration of the polymer in the boundary layer the efficiency of the reduction of drag resistance is decreased with the growth of the concentration of the injected polymer solution, and it is the stronger, if the angle of the entrance is higher. In [56], it was outlined a hypothesis that viscoelastic effects (swelling of the jet) near the slot strengthen the pull of the polymer solution by the external boundary layer and result in a faster decrease in the concentration of the polymer on the inner surface of the pipeline. The results obtained in $[57,58]$ make us reconsider this hypothesis because the visualization of the flow behind the slot [58] and the actual concentration of the polymer in the boundary layer have not evidenced to the increased diffusion of the polymer. Most feasible is the explanation based on the impact of the effective viscosity (taken in its broad sense) that does not contradict to the results of the studies on the hydrodynamic activity of the polymers under conditions of the introduction of the polymer solution to the fire suppression pipeline. The dynamic structures of the polymer formed in the hydrodynamic field cause its compression [34], and this, of course, should cause a decrease in the diffusion of the polymer in the boundary layer.

The detected regularities of the manifestation of elastic deformations at the introduction of the polymer solution to the firesuppression pipeline allow suggesting a method for evaluation of the flow resistance of the fire suppressant liquid with the polymer additives in it. The flow resistance of the liquid in the pipeline at the introduction of the polymer solution to the boundary layer caused by the elastic deformations can be determined as

$$
X=\int_{0}^{\ell_{\lambda}} \chi(x) \tau_{w 0} d x+\int_{\ell_{\lambda}}^{\ell_{p}-\ell_{\lambda}} \chi(x) \tau_{w c} d x,
$$

where $\chi$ is the perimeter of the pipeline cross-section, $\tau_{w l}$ and $\tau_{w o}$ tangential stresses with the introduction of the polymer to the boundary layer and without it, $L$ - length of the pipeline, $1_{\lambda}$ - length with the reduced hydrodynamic activity of the polymer.

The data obtained in this study shows that in solving the problems of drag reducing of the fire suppressing liquid in the fire hoses and pipeline by injecting the polymer solutions in the boundary layer, for 
the development of the optimum system of the introduction, it is necessary to take into account possible effects of the elastic deformations. The decrease in the effect of drag reduction at the introduction of the polymer solution into the boundary layer of the fire hose is due to the combination of the deformational effects of the longitudinal hydrodynamic field developed in the system of the injection and molecular-concentration characteristics of the polymeric solution.

Thus it is possible to improve the effective systems of the polymer introduction into the fire hoses and therefore operation of the fire suppression systems at oilfield territories using water.

This paper demonstrates the ways to improve the efficiency of the systems of input of polymers in fire hoses and pipelines, and to improve the efficiency of fire-fighting systems by water and solutions of surfactants that will help to reduce pollution by combustion products and, obviously, improve the safety of working conditions on oilfield territories.

\section{Degradation of polymer solutions in a hydrodynamic field with a longitudinal velocity gradient}

Despite the great number of investigations on studying the infl uence of various factors on the degradation of polymers in solutions, their results are ambiguous, and a number of questions are still not clearly understood [59-63]. Changes occurring in polymer solutions under the action of a hydrodynamic field have not been satisfactorily explained yet; there are no substantiated ideas of the mechanism of the phenomenon. Investigations considering the reasons why the effi ciency is lost by polymer solutions under stretching-flow conditions are very few in number. Elucidation of the causes of polymer degradation under hydrodynamic action is necessary for developing methods to control its negative impact on the effi ciency of practical use of polymers.

Flow with a longitudinal velocity gradient can be implemented when a polymer solution is flowing through capillaries with different inlet angles. In the inlet part of the capillary, flow with a predominantly longitudinal velocity gradient is implemented [11], whereas in the channel of a smooth capillary with a diameter constant along the length, flow with a transverse gradient. Therefore, in capillary liquid flow, there are both a predominantly longitudinal flow (at the capil- 
lary inlet) and a purely shear flow (in the capillary). The shorter the capillary, the larger the share of the longitudinal flow in the general hydrodynamic pattern, and the longer the capillary, the larger the share of the shear flow. The share of flow with a transverse velocity gradient can also be increased by decreasing the angle of entry into the capillary. It is important to elucidate what kind of flow is responsible for the polymer degradation in water. Also, it should be noted that many kinds of flow, e.g., turbulent or fi ltration-type, can be reduced to a superposition of two kinds of flow: shear flow and stretching one [10].

In the experiments, use was made of a flow-type viscometer with replaceable hydraulic resistors (capillaries with different inlet angles, lengths, and diameters) whose geometry enabled us to assign different velocity fi elds and residence times of macromolecules in these fields. The degree of action of hydrodynamic fields on the solutions of polyethylene oxide (PEO), polyacrylamide (PAM), and hydrolyzed polyacrylamide (HPAM) was assessed by the loss of their effi ciency in reducing turbulent friction. The relative change in the coeffi cient of hydrodynamic resistance refl ects the efficiency (hydrodynamic activity) of a polymer in reducing turbulent friction. This efficiency was calculated by using an expression of the following form [64]

$$
E=\frac{\lambda_{s l v}-\lambda_{s o l}}{\lambda_{s l v}} \equiv \frac{\Delta \lambda}{\lambda}=\left[1-\left(\frac{t_{s o l}}{t_{s l v}}\right)^{2} \frac{\Delta P_{s o l}}{\Delta P_{s l v}}\right] \cdot 100 \%
$$

In this formula, the subscript "slv" refers to the solvent and the subscript "sol," to the solution. In computing, we determined the value of the effect of reduction in the hydrodynamic resistance of a tube of length $1.02 \mathrm{~m}$ and diameter $2.17 \cdot 10^{-3} \mathrm{~m}$ in the case of flow of aqueous polymer solutions with a concentration lower than the optimum one (when $C<C_{\text {opt }}$ ), which had been prepared from the solution exposed to a hydrodynamic field. The quantity $C_{\text {opt }}$ corresponds to the maximum on the concentration dependence $E_{0}=f(C)$. The true value of the pressure difference at the channel ends was determined with account taken of the corrections for the head loss due to the removal of the kinetic energy by the outfl owing jet [65]. Other kinds of loss turned out to be minor. It was found that their value was smaller than $0.5 \%$ of the pressure indicated by the manometer at the largest flow 
rate. Therefore, they were disregarded. The error in measuring the coeffi cient of hydrodynamic resistance $\lambda$ was $1 \%$. The degradation was evaluated as

$$
D=\frac{E_{o}-E}{E_{o}} \cdot 100 \%,
$$

where $E_{0}$ and $E$ were determined at a constant Reynolds number. In some experiments, the degradation was evaluated as the ratio $E / E_{0}$ at a constant pressure difference. In most cases for PEO solutions treated by the hydrodynamic field at higheraverage temperatures or with additions of salt, the quantity $D$ was determined at $25^{\circ} \mathrm{C}$, with $C_{\text {PEO }}$ being equal to $0.0002 \%$. The additions of salt from the PEO solution were removed, on exposure to the hydrodynamic field, using a dialysis bag. This was done for the degree of action of the hydrodynamic field on the polymer system to be monitored by the solutions (control and treated), which were under identical conditions at the instant of measurement. Conversely, in other works in which the infl uence of temperature and salts on the degree of degradation of polymer solutions was studied in different hydrodynamic fields, the latter condition was violated [59-63]. Neglect of this circumstance often generates lots of mistakes and errors when experimental results on degradation of polymer solutions are interpreted.

Fig. 5.1 gives experimental results on treatment of a $0.004 \%$ PEO aqueous solution. The rate of flow through capillaries had a value of $2.6 \mathrm{~m} / \mathrm{s}$. It can be seen that a tenfold flow of the solution through a capillary of diameter $0.34 \cdot 10^{-3} \mathrm{~m}$ having a straight portion of length $0.45 \cdot 10^{-3} \mathrm{~m}$ and a convergent portion of $10^{-2} \mathrm{~m}$ with an opening angle of $20^{\circ}$ (curve 2) leaves the effi ciency of reduction in the hydrodynamic resistance unaltered, in practice, compared to the untreated solution (curve 1 ). Curves 3 and 4 correspond to the treatment of the tested solutions on capillaries of the same diameter with an inlet angle of $180^{\circ}$ and a length of $0.45 \cdot 10^{-3} \mathrm{~m}$ and $45 \cdot 10^{-3} \mathrm{~m}$, espectively. The hydrodynamic activity of the treated solutions has decreased by the same value despite the fact that the capillaries differed by two orders of magnitude in length and hence in the residence time of macromolecules in the shear flow. Since the conditions of entry into the capillaries were identical, the residence time of macromolecules in the longitudinal hydrodynamic field was identical, 
too. Increase in the number of treatment cycles to 85 (curves 5 and 6 ) caused the solution's hydrodynamic activity to degrade, but the capillary length, as previously, did not affect the value of degradation. A comparison of curves 2 and 3 shows that the increase in the degree of longitudinal action on the system leads to a greater degradation. Increase in the residence time of macromolecules in the region with a longitudinal velocity gradient, which was achieved by increasing the number of convergent-divergent cells of the hydraulic resistor [10], also caused the degradation to increase (fig. 5.1, curve 7).

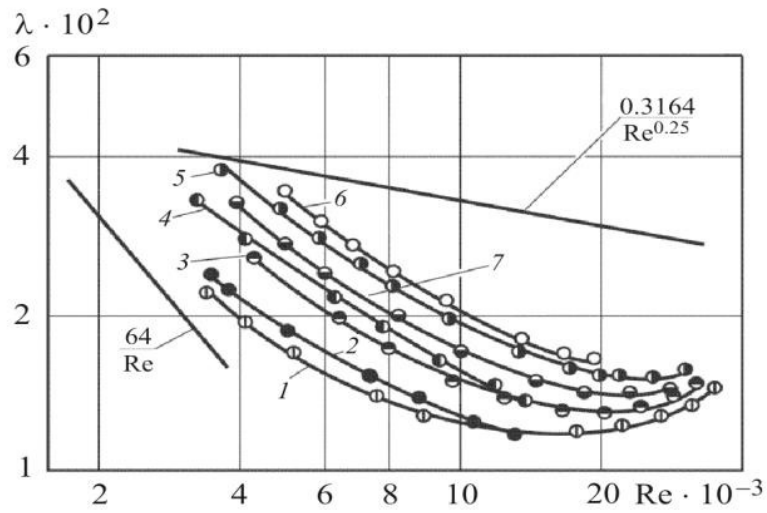

Fig. 5.1. Change in the hydrodynamic activity of PEO of mol. weight $6 \cdot 10^{6}$ on exposure to the hydrodynamic field: mic field with a predominantly transverse velocity gradient; 3 - in the hydrodynamic field with a redominantly longitudinal velocity gradient; 4 - in the superposition of shear and stretching fields; 5 and 6 - the same as 3 and 4, but with a longer time of exposure to the hydrodynamic field; 7 - in the hydrodynamic field of the hydraulic resistor with convergent-divergent cells

An analysis of the considered data shows that the degradation of polymer solutions is independent of the time of their residence in the laminar flow with a transverse velocity gradient and is fully determined by the value of the longitudinal velocity gradient and by the time of its action on the solution. Consequently, the degradation of polymer solutions in the hydrodynamic field is caused by the action of just stretching flows on macromolecules, whereas the shear component of these flows does not appreciably affect the degradation of the solutions. 

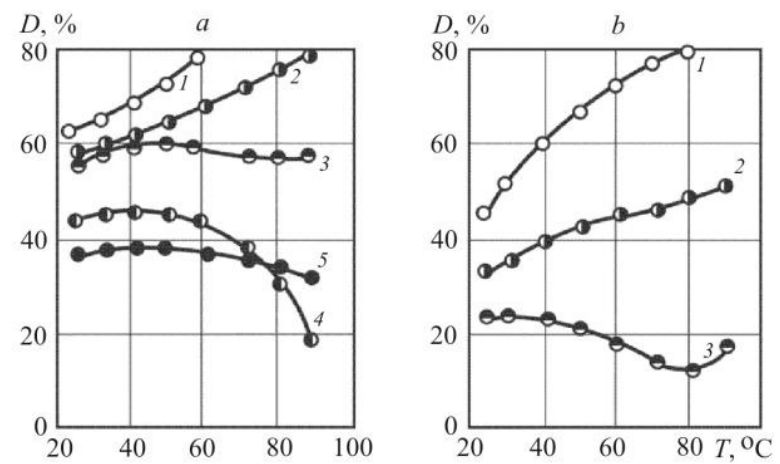

Fig. 5.2. Influence of temperature on the degradation of $P E O$ solutions on exposure to a stretching hydrodynamic field: $a$ - treatment included a 85 fold flow of a polymer solution at different temperatures through a capillary with an inlet angle at $180^{\circ}$ with a flow velocity of $2.6 \mathrm{~m} / \mathrm{s}$ at $M_{\mathrm{PEO}}=6 \cdot 10^{6}$ :

$$
\begin{gathered}
1-C_{\mathrm{PEO}}=0.0016 ; 2-0.004 ; 3-0.01 \text { and } 4-0.1 \% ; \\
M_{\mathrm{PEO}}=4 \cdot 10^{6}: 5-C_{\mathrm{PEO}}=0.1 \% ; b-M_{\mathrm{PEO}}=6 \cdot 10^{6} ; \\
\left.C_{\mathrm{PEO}}=0.0016 \%: 1\right) u=2,3-1.57 \text { and } 3-1.5 \mathrm{~m} / \mathrm{s}
\end{gathered}
$$

Increase in the molecular weight of the polymer and in the strength of the longitudinal hydrodynamic fi eld and decrease in the concentration of the polymer in the solution (increase in the concentration tends to suppress longitudinal velocity gradients) must cause the degradation to enhance. These conclusions are confi rmed by the data in fig. 5.2.

However, if the initial dimensions of macromolecules change due to the change in the temperature, the ionic force, and $\mathrm{pH}$ of the medium (figs. 5.2 and 5.3), the obtained results are not so unambiguous to interpret. It can be seen that the degradation of moderately concentrated solutions decreases with growth in the temperature, whereas that of diluted solutions increases.

Degradation decreases as the concentration of the salt in the solution grows, but if we increase the intensity of the hydrodynamic action (curve 3, fig. 5.3), degradation, at least in diluted solutions, increases. 


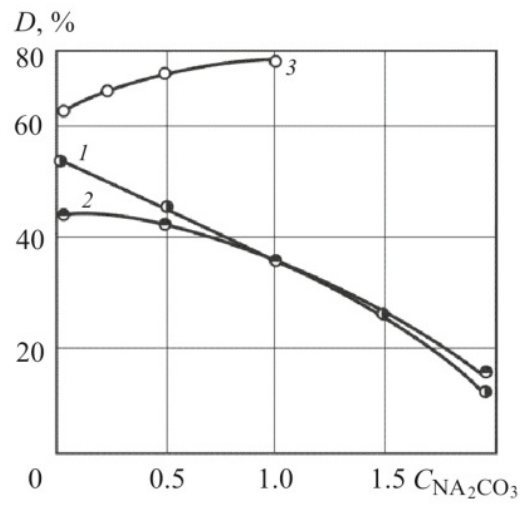

Fig. 5.3. Infl ence of the ionic force of the solution on the degradation of PEO of mol. weight $6 \cdot 10^{6}$ during the flow in a capillary with an inlet angle of $180^{\circ} ; u=2.6$ $\mathrm{m} / \mathrm{s}: 1-C_{\mathrm{PEO}}=0.004$ and $2-0.1 \% ; 3-u=8 \mathrm{~m} / \mathrm{s}$ and $C_{\mathrm{PEO}}=0.004 \%$

A comparison of the considered results and the data presented in [10] shows that if the polymer solutions are treated at velocities higher than $u_{\mathrm{cr}}$, increase in the temperature and the concentration of the salt causes the quantity $D$ to grow. The observed reduction in $D$ (figs. 5.2 and 3) is due to the treatment regime approaching a subcritical one. Analogous results have also been obtained on exposure of the polymer solutions to a hydrodynamic field implemented in the case of flow through porous media. It can be seen that the degradation of the aqueous PEO solutions grows with temperature (fig. 5.4).

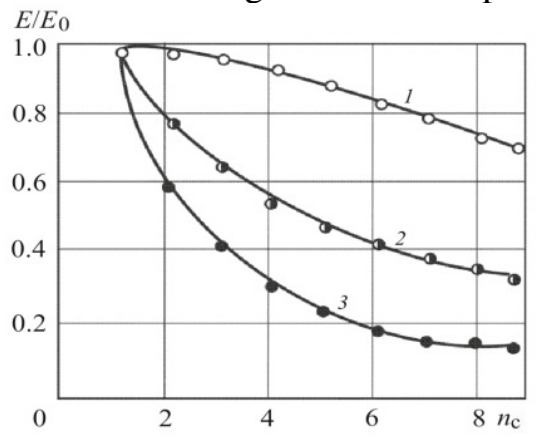

Fig. 5.4. Infl uence of temperature on the degradation PEO solutions of mol. Weight $3 \cdot 10^{6}$ during the flow through a porous tablet with a pore size of $1.6 \cdot 10^{-4} \mathrm{~m}$ at $C_{\mathrm{PEO}}=0.0002 \%$ and $\Delta P=3 \cdot 10^{5} \mathrm{~Pa}: 1-T=4 ; 2-40$ and $3-70^{\circ} \mathrm{C}$ 
In the PAM solutions, the influence of temperature is less pronounced (fig. 5.5, curves 1 and 2). Similar values of the characteristic viscosity of the PEO and PAM samples under study (1.4 and 1.1 $\mathrm{m}^{3} / \mathrm{kg}$ ) point to the nearly identical dimensions of unperturbed coiled macromolecules. Nonetheless, PAM exhibits higher stability to exposure to the hydrodynamic field than PEO. This could be due to the fact that the characteristic PEO viscosity, because of the presence of the lower critical mixing temperature in these solutions [18], and hence the dimensions of the volume occupied by the polymer coil, decreases as the temperature grows, whereas the characteristic PAM viscosity changes only slightly as the temperature grows.

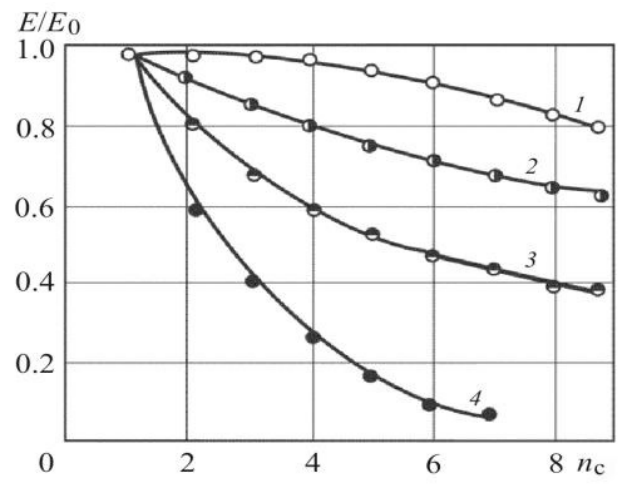

Fig. 5.5. Infl uence of temperature and $\mathrm{pH}$ of the medium on the degradation of PAM and HPAM solutions in filtration flow at $\Delta P=3 \cdot 10^{5} \mathrm{~Pa}$ and an average pore size of $1.6 \cdot 10^{-4} \mathrm{~m}$ :

$M_{\text {HPAM }}=6 \cdot 10^{6}$ and $C_{\text {PAM }}=0.0004 \%: 1-T=4$ and

$2-80^{\circ} \mathrm{C} ; M_{\mathrm{HPAM}}=6 \cdot 10^{6}$, the degree of hydrolysis is $12 \%$, $C_{\text {HPAM }}=0.0004 \%, \mathrm{pH}: 3-7$ and 4$) 3$

The conformation of HPAM molecules can be changed by varying the medium's $\mathrm{pH}$ from the dense reduced coil in the acidic medium to a loose, strongly swollen coil in the region of neutral and mildly alkaline $\mathrm{pH}$ values. The infl uence of the changes in the dimensions of the HPAM coiled macromolecules on the degradation of their solutions in filtration flow is presented in fig. 5.5 (curves 3 and 4). It can be seen from the fi gure that the highest stability of the HPAM solution is manifested in the neutral medium, despite the maximum dimensions of the polymer coils. 
The above-given results demonstrate that at a constant molecular weight, the reduction in the dimensions of polymer coils tends to enhance their degradation under the action of the hydrodynamic field with a longitudinal velocity gradient. This puts in doubt the decisive role of the reduction in the polymer's molecular weight due to the rupture of molecular chains, which has been used as the basis for the destruction mechanism of degradation [59-62].

The observed decrease in the characteristic viscosity of the polymer does not yet mean the reduction in the molecular weight and only points to the reduction in the hydrodynamic volume [66], i.e., in the equilibrium dimension of coiled macromolecules. Therefore, to confi rm the expressed assumptions, it is necessary to measure the molecular weight using absolute methods, among which are light scattering and sedimentation-diffusion analysis.

We investigated PEO of molecular weight $3 \cdot 10^{6}$ whose solution was exposed 150 times to a longitudinal hydrodynamic fi eld implemented in the capillary's inlet region in the supercritical regime of $\mathrm{fl}$ ow. Experimental data were processed by the Zimm method $[66,67]$.

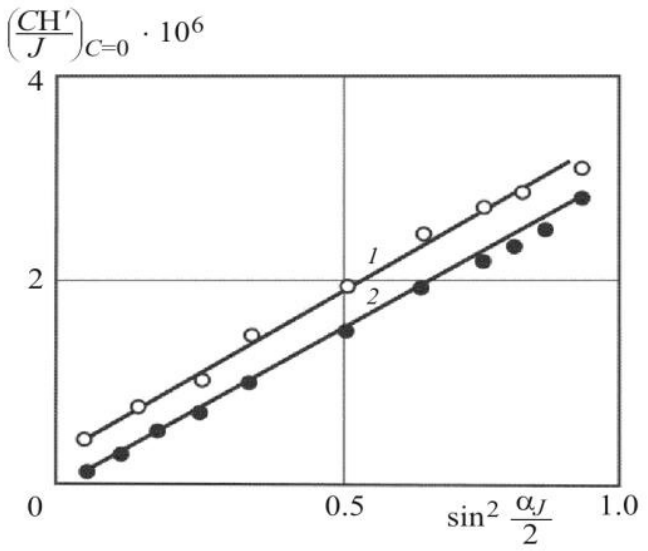

Fig. 5.6. Light-scattering indicatrix for the original and hydrodynamic-field-treated PEO solutions of mol. weight $3 \cdot 10^{6}$ at an initial concentration of the solutions of $0.1 \%$ : 1 - original polymer solution; 2 - after a 150 fold flow of the polymer solution through a capillary with an inlet angle of 180 with a flow velocity of $2.6 \mathrm{~m} / \mathrm{s}$ 
Fig. 5.6 gives the light-scattering indicatrices for the original (not treated by the hydrodynamic field) and hydrodynamic-field-treated PEO solutions. The results demonstrate the increase in the intensity of light scattering in the treated solution compared to the original one at all angles. This means that the molecular weight has grown on exposure to a stretching hydrodynamic field.

Data on determining the polymer's molecular weight by the absolute methods, which point, at least, to the absence of reduction in the molecular weight in the process of degradation of polymer solutions, can be explained, assuming the initiation of intramolecular branchings (crosslinkings) by the longitudinal hydrodynamic field. They can be of both chemical $[63,67]$ and physical [68] nature. The formation of supramolecular structures in the PEO and PAM solutions due to the change in the phase diagram under the action of stretching flows can be evidence in favor of the physical nature of the interactions.

The generation of a small amount of insoluble supramolecular particles in diluted polymer solutions [67], presumably, should fully be attributed to the formation of intermolecular cross-linkings of a chemical nature. The absence of the reduction in the PEO and PAM molecular weight, according to the data of light scattering and of the sedimentationdiffusion analysis, points to the fact that polymer cross-linkings are mainly formed between portions of one and the same strongly deformed coiled macromolecule. The formation of intramolecular cross-linkings leads to a reduction in the dimensions of coiled macromolecules and in their kinetic flexibility, i.e., to a loss of deformability in the longitudinal velocity field.

The degradation of polymer solutions is independent of the time of their residence in the flow with a transverse velocity gradient and is fully determined by the value of the longitudinal velocity gradient and by the time of its action on the solution. In the hydrodynamic field with a longitudinal velocity gradient, the highest stability of an HPAM solution to exposure to the hydrodynamic fi eld is manifested in a neutral medium despite the maximum dimensions of polymer coils.

Data on the deformation action of a convergent hydrodynamic fi eld on macromolecules with variation in their initial dimensions due to the temperature, the ionic force, and the medium's $\mathrm{pH}$ demonstrate that a necessary condition for the degradation of polymer solutions in 
the hydrodynamic field is its strong deformation action on the coiled molecules.

Experimental investigation of the degradation of PEO, PAM, and HPAM aqueous solutions under stretching-flow conditions has enabled us to state that the obtained results are unambiguously interpreted under the assumption of initiation of intra- and intermolecular branchings (cross-linkings) by the hydrodynamic field, which dominate over the rupture of macromolecules.

The established flow diagram of the process of degradation of polymer solutions enables us to formulate the physicochemical principles of the behavior of macromolecules under the conditions of composite hydrodynamic fields and to outline ways of raising the efficiency of their use in the oil and gas technologies.

\section{Specific of Polymer Solution Flow in the Sloted-Porous Reservoir}

Today, there are a lot of methods to enhance oil recovery from reservoirs, but most of them are environmentally hazardous. The most effective methods that allow extracting up to $40-45 \%$ of oil are the methods involving injection of acid, alkalis and other active chemicals into the formation [69]. But in the process of oil production contamination of the environment is taking place. Great damage is caused to it by chemical reagents during their injection into the reservoir or delivery to the field [70,71].

Because of this, the solution to the problem of improving the environmental efficiency of oil recovery methods is now relevant and timely. Among the methods of increasing oil displacement from reservoirs, the method of polymer flooding meets the most environmental requirements, but is not always highly efficient [9].

One of the main issues that needsto be solved during the development of the technology for increasing oil recovery from formations by using polymer solutions is to determine the optimal flow regime in the fractured-porous reservoir. Technological indicators when using polymer solutions to increase oil recovery from the reservoir are calculated being based on the condition of satisfying the inequality 


$$
\dot{\varepsilon} \cdot \theta_{c} \leq D e_{c r}
$$

where $\theta_{\mathrm{c}}-$ relaxation time of the polymer solution; $\dot{\varepsilon}-$ longitudinal velocity gradient.

Expression (1) is a criterion for the transition of a macromolecular coil from a hydrodynamically impermeable "segmental gel", where a significant part of the segments is screened, to a flowing "segmental solution" in which all segments already hydrodynamically interact with the solvent. When performing the above inequality in polymer solutions (polyethylene oxide, polyacrylamide, etc.) in the flow with a longitudinal velocity gradient, dynamic supramolecular structures are formed [34,72, 73]. Expression (6.1) should be interpreted as the Deborah number because the inverse value of the longitudinal gradient of velocity is nothing but the time scale of the stream [74].

Thus, the calculation covers calculating the relaxation time (characteristic time) of the polymer solution and the longitudinal velocity gradient taking place which is realized during of polymer solutions flow in the fractured-porous reservoir. According to the experimentally obtained data, the critical Deborah number for water solutions of polyethylene oxide (PEO) is 2.5 [2].

We obtained the following equation to define the characteristic relaxation time of the polymer solution (viscoelastic fluid)

$$
\theta_{c}=\left\{\begin{array}{ll}
\theta_{0} e^{k} & \text { at } k<1 \\
\theta_{0} \frac{e^{k^{2 / 3}}}{k^{1 / 3}} & \text { at } k>1
\end{array},\right.
$$

where $[\eta] 0$ - characteristic viscosity, $C$ - concentration of polymer in solution, and $[\eta] 0 \cdot C=k$. Dependence $\theta_{\mathrm{c}} / \theta_{0}$ on $[\eta] 0 \cdot C$ for PEO of two different molecular masses in the water as shown in fig. 6.1.

The solid line shows the course of the dependence obtained for equation (6.2). We can see that the points obtained during the experiments for the corresponding concentration regions lie satisfactorily on the estimated curve. 


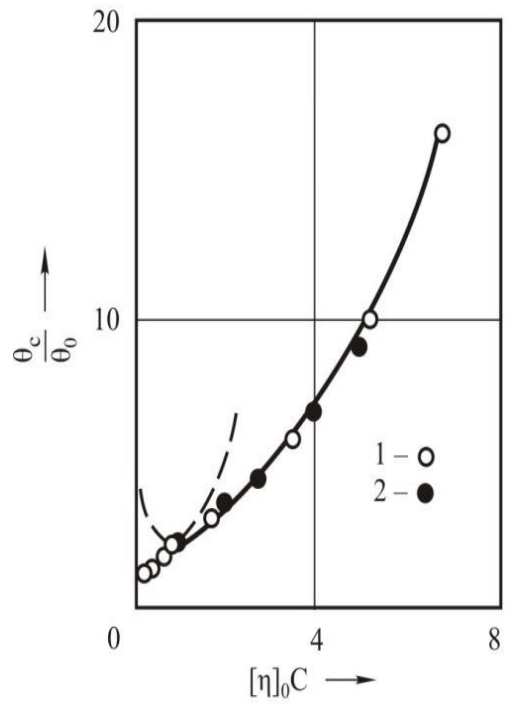

Fig. 6.1. Profiles of $\theta_{\mathrm{c}} / \theta_{\mathrm{c}}$ for varying concentration $[\eta]_{0} C$ for different PEO in solution MPEO: $1-4 \cdot 10^{6} ; 2-2,5 \cdot 10^{6}$

So, substituting the known molecular characteristics of the polymer into equation (6.2) we can calculate the relaxation time of polymer solutions. The effect of temperature in this equation is taken into account by the temperature dependence $\theta_{\mathrm{c}}$ i $k$.

At the same time, research literature to our knowledge doesn't highlight any analytical equations for calculating a longitudinal velocity gradient in the input area of the slot. To calculate the longitudinal velocity gradient of the polymer solution flow in the input area of the slot, it is necessary, taking into account its viscoelastic properties, to analyze the flow of polymer solution through the slotedporous reservoir.

Problem Statement. Polymer solutions possess viscoelastic properties [75-77]. Therefore, when polymer solution flows through the slot, to evaluate deformation characteristics of the flow (stream functions, distributions of the longitudinal velocity gradient and normal stress) resulting in manifestation of abnormal (compared with the behaviour of the ordinary fluid) effects, we can use a well-known Maxwell's fluid model 75-78] with the Jaumann derivative [79]. 
We chose this model because, according to Lodge [78], the study of non-linear, non-permanent, from the view of Lagrange, currents of viscoelastic fluids doesn't add any new information to the already obtained by studying homogeneous or quasi-homogeneous shear deformations. In his opinion, “... the only reason for detailed calculations of different types of non-linear currents is to make sure that they are practically implemented." This Lodge's statement can be interpreted in such a way, that there is no need for new rheological equations to describe convergent flows (in the input area of the slot); it's enough to use the equations of a steady Couette flow [75], or, at least, to determine whether they can explain the specific of polymer solution convergent flow in the sloted-porous reservoir.

Solution. To describe steady streamflow in the incompressible environments, we use the following classical equations [74,79]

- the continuity equation

$$
\mathcal{V}_{, i}^{i}=0,
$$

- the Cauchy motion equation

$$
\rho \mathcal{V}^{k} \mathcal{V}_{, k}^{i}=-g^{i k} P_{\cdot k}+T_{, k}^{i j},
$$

where $g^{\text {ik }}-$ metric tensor, and $T_{k}^{i j}$ is determined by covariant differentiation $T^{i j}$

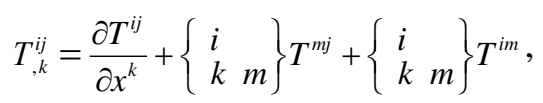

where $\left\{{ }_{k}^{i} m\right\}$ are the Christoffel symbols expressed by the dependence

$$
\left\{{ }_{k}^{i} m\right\}=\frac{1}{2} g^{i \ell}\left(\frac{\partial g_{k \ell}}{\partial x^{m}}+\frac{\partial g_{m \ell}}{\partial x^{k}}-\frac{\partial g_{k n}}{\partial x^{\ell}}\right) .
$$

Having designated $\theta_{\mathrm{c}}$ to relaxation time and $\eta_{\mathrm{c}}-$ to viscosity, we can write the structural rheological equation of the Maxwell's fluid model [75-80]

$$
T^{i j}+\theta_{c} \frac{D_{j} T^{i j}}{D t}=2 \eta_{c} D^{i j},
$$

where $D_{j} / D_{t}$ - the Jaumann derivative described by the equation

$$
\frac{D_{j} T^{i j}}{D t}=\frac{\partial T^{i j}}{\partial t}+V^{k} T_{k}^{i j}-W_{k}^{i} T^{k j}-T^{i k} W_{k}^{j},
$$

in which 


$$
\begin{aligned}
& D_{k m}=\frac{1}{2}\left(\mathcal{V}_{k, m}+\mathcal{V}_{m, k}\right), \\
& W_{k m}=\frac{1}{2}\left(\mathcal{V}_{k, m}-\mathcal{V}_{m, k}\right) .
\end{aligned}
$$

Analyze the case, where the incompressible fluid moves between two parallel planes and flows through the slot which length is considerably longer than width. The flow is flat and stationary. Fig. 6.2 shows the shape of the slot of the the sloted-porous reservoir and Cartesian coordinates.

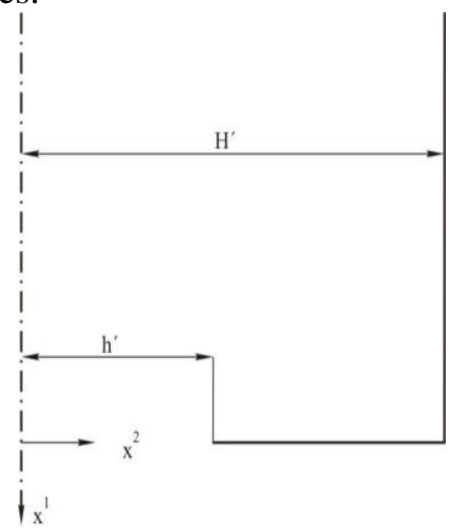

Fig. 6.2. The shape of the slot and Cartesian coordinates

The components of the metric tensor in Cartesian coordinates are

$$
\begin{aligned}
& g_{11}=g_{22}=1, \\
& g_{12}=g_{21}=0 .
\end{aligned}
$$

The Christoffel symbols $\left\{\begin{array}{l}i \\ k\end{array} \quad \begin{array}{l}m\end{array}\right\}$ equal zero since the components of the metric tensor $g_{\text {ik }}$ are not coordinate-dependent. Let us express this in a dimensionless form, introducing the following quantities into equations (6.3), (6.4) and (6.5)

$$
\begin{array}{rlrl}
x_{1}^{*} & =\frac{x^{1}}{H^{\prime}}, & x_{2}^{*} & =\frac{x^{2}}{H^{\prime}}, \\
V_{1}^{*} & =\frac{V^{l}}{\bar{u}}, & V_{2}^{*}=\frac{\mathcal{V}^{2}}{\bar{u}},
\end{array}
$$




$$
\begin{array}{rlrl}
T_{11}^{*} & =\frac{H^{\prime}}{\eta_{c} \bar{u}} T^{l l}, & T_{22}^{*}=\frac{H^{\prime}}{\eta_{c} \bar{u}} T^{22}, \\
T_{12}^{*}=\frac{H^{\prime}}{\eta_{c} \bar{u}} T^{12}, & T_{21}^{*}=\frac{H^{\prime}}{\eta_{c} \bar{u}} T^{21}, \\
P^{*}=\frac{H^{\prime}}{\eta_{c} \bar{u}} P, &
\end{array}
$$

where $\overline{\mathrm{u}}$-average flow velocity; $2 \mathrm{H}^{\prime}$ - slot width. Considering transformations (3), (4), (5), they are reduced to

$$
\begin{aligned}
& \frac{\partial v_{1}^{*}}{\partial \mathrm{x}_{1}^{*}}+\frac{\partial \mathcal{V}_{2}^{*}}{\partial \mathrm{x}_{2}^{*}}=0 \\
& \operatorname{Re}\left(\mathcal{V}_{1}^{*} \frac{\partial \mathcal{V}_{1}^{*}}{\partial \mathrm{x}_{1}^{*}}+\mathcal{V}_{2}^{*} \frac{\partial \mathcal{V}_{1}^{*}}{\partial \mathrm{x}_{2}^{*}}\right)=-\frac{\partial \mathbf{P}^{*}}{\partial \mathrm{x}_{1}^{*}}+\frac{\partial \mathrm{T}_{11}^{*}}{\partial \mathrm{x}_{1}^{*}}+\frac{\partial \mathrm{T}_{12}^{*}}{\partial \mathrm{x}_{2}^{*}} \\
& \operatorname{Re}\left(\mathcal{V}_{1}^{*} \frac{\partial \mathcal{V}_{2}^{*}}{\partial \mathbf{x}_{1}^{*}}+\mathcal{V}_{2}^{*} \frac{\partial \mathcal{V}_{2}^{*}}{\partial \mathbf{x}_{2}^{*}}\right)=-\frac{\partial \mathbf{P}^{*}}{\partial \mathbf{x}_{2}^{*}}+\frac{\partial \mathbf{T}_{21}^{*}}{\partial \mathbf{x}_{1}^{*}}+\frac{\partial \mathbf{T}_{22}^{*}}{\partial \mathbf{x}_{2}^{*}},(6.8 b) \\
& T_{11}^{*}+W e\left\{\begin{array}{l}
\mathcal{V}_{1}^{*} \frac{\partial T_{11}^{*}}{\partial x_{1}^{*}}+\mathcal{V}_{2}^{*} \frac{\partial T_{11}^{*}}{\partial x_{2}^{*}}- \\
-\frac{1}{2}\left(\frac{\partial \mathcal{V}_{1}^{*}}{\partial x_{2}^{*}}-\frac{\partial \mathcal{V}_{2}^{*}}{\partial x_{1}^{*}}\right)\left(T_{12}^{*}+T_{21}^{*}\right)
\end{array}\right\}=2 \frac{\partial \mathcal{V}_{1}^{*}}{\partial x_{1}^{*}}, \\
& T_{22}^{*}+W e\left\{\begin{array}{l}
\mathcal{V}_{1}^{*} \frac{\partial T_{22}^{*}}{\partial x_{1}^{*}}+v_{2}^{*} \frac{\partial T_{22}^{*}}{\partial x_{2}^{*}}+ \\
+\frac{1}{2}\left(\frac{\partial \mathcal{V}_{1}^{*}}{\partial x_{2}^{*}}-\frac{\partial \mathcal{V}_{2}^{*}}{\partial x_{1}^{*}}\right)\left(T_{12}^{*}+T_{21}^{*}\right)
\end{array}\right\}=2 \frac{\partial \mathcal{V}_{2}^{*}}{\partial x_{2}^{*}},
\end{aligned}
$$




$$
\begin{gathered}
\left.T_{12}^{*}+W e\left\{\begin{array}{l}
\mathcal{V}_{1}^{*} \frac{\partial T_{12}^{*}}{\partial x_{1}^{*}}+\mathcal{V}_{2}^{*} \frac{\partial T_{12}^{*}}{\partial x_{2}^{*}}+ \\
\frac{1}{2}\left(\frac{\partial \mathcal{V}_{1}^{*}}{\partial x_{2}^{*}}-\frac{\partial \mathcal{V}_{2}^{*}}{\partial x_{1}^{*}}\right)\left(T_{11}^{*}-T_{22}^{*}\right)
\end{array}\right)\right\}=\frac{\partial \mathcal{V}_{1}^{*}}{\partial x_{2}^{*}}+\frac{\partial \mathcal{V}_{2}^{*}}{\partial x_{1}^{*}}, \\
T_{21}^{*}+W e\left\{\begin{array}{l}
\mathcal{V}_{1}^{*} \frac{\partial T_{21}^{*}}{\partial x_{1}^{*}}+\mathcal{V}_{2}^{*} \frac{\partial T_{21}^{*}}{\partial x_{2}^{*}}+ \\
+\frac{1}{2}\left(\frac{\partial V_{1}^{*}}{\partial x_{2}^{*}}-\frac{\partial \mathcal{V}_{2}^{*}}{\partial x_{1}^{*}}\right)\left(T_{11}^{*}-T_{22}^{*}\right)
\end{array}\right)=\frac{\partial \mathcal{V}_{1}^{*}}{\partial x_{2}^{*}}+\frac{\partial \mathcal{V}_{2}^{*}}{\partial x_{1}^{*}},
\end{gathered}
$$

where $\operatorname{Re}=\frac{\rho \bar{u} H^{\prime}}{\eta_{c}}$ - the Reynolds number; $W e=\frac{\theta_{c} \bar{u}}{H^{\prime}}$ - the Weissenberg number.

If we restrict ourselves to a flow in which the inertial terms can be neglected, then the left side of equation (6.8) will equal zero. Applying the continuity equation (6.7), we introduce the stream function

$$
v_{1}^{*}=\frac{\partial \psi}{\partial \mathrm{x}_{2}^{*}}, v_{2}^{*}=-\frac{\partial \psi}{\partial \mathrm{x}_{1}^{*}}
$$

If we assume that the fluid flow at the slot input area of the oil sloted-porous reservoir has the Poiseuille velocity profile, the velocity on the surface of the solid wall (adhesion condition) equals zero, and the flow velocity is constant, the boundary conditions will take the following form

$$
\begin{gathered}
x_{1}^{*}=-\infty, \quad \mathcal{V}_{1}^{*}=\frac{3}{2}\left(1-\mathrm{x}_{2}^{* 2}\right), \quad V_{2}^{*}=0, \\
x_{1}^{*}=0, \quad 0 \leq \mathrm{x}_{2}^{*} \leq \mathrm{h}^{*}, \quad V_{1}^{*}=V_{0}^{*} \quad V_{2}^{*}=0, \\
x_{1}^{*}=0, \quad \mathrm{~h}^{*} \leq \mathrm{x}_{2}^{*} \leq 1, \quad \mathcal{V}_{1}^{*}=V_{2}^{*}=0, \\
x_{2}^{*}=0, \quad \frac{\partial \mathcal{V}_{1}^{*}}{\partial \mathrm{x}_{2}^{*}}=V_{2}^{*}=0,
\end{gathered}
$$




$$
x_{2}^{*}=1, \quad V_{1}^{*}=V_{2}^{*}=0,
$$

where $v_{0}^{*}=$ const, determined by the expendable velocity; $h^{*}$ dimensionless value, equals $\mathrm{h}^{\prime} / \mathrm{H}^{\prime} ; 2 \mathrm{H}^{\prime}$ - slot width.

It is necessary to solve equations (6.7), (6.8), and (6.9), according to the boundary conditions (6.11), to determine the flow and stress fields, according to the boundary conditions (6.11). It is not possible to solve these equations in a general form; therefore, we restrict ourselves to slow flows. In this case, we can not only neglect the inertial terms but also assume that the Weisenberg number is less than one.

Let's recall that the Weissenberg number characterizes the rate of the viscoelastic properties of the fluid in a shear flow. In the case under consideration, we have a complex flow with both shear and longitudinal velocity gradients. As the velocity of the outflow through the slot increases, as proven in [23], the proportion of the longitudinal (stretching) flow increases, and the shear decreases. Therefore, it is more appropriate, instead of the Weissenberg number, to use a Deborah number, which characterizes the rate of viscoelastic properties in a stretching flow [74]. Nevertheless, for stationary flows, the ratio is $D e / W e=\operatorname{Re}^{0,75}[74,81]$, which means that both criteria, $W e$ and $D e$, are interconnected within geometrically similar flows.

Therefore, for restrictions, imposed on this flow, in the same way as in [79], we can write the velocities, stress, and stream functions as the decomposition by number $W e$

$$
\begin{aligned}
& \mathcal{V}_{i}^{*}=\mathcal{V}_{i}^{(0)}+W e \mathcal{V}_{i}^{(1)}+W e^{2} \mathcal{V}_{i}^{(2)}+\ldots, \\
& P^{*}=P^{(0)}+W e P^{(1)}+W e^{2} P^{(2)}+\ldots, \\
& T_{i j}^{*}=T_{i j}^{(0)}+W e T_{i j}^{(1)}+W e^{2} T_{i j}^{(2)}+\ldots, \\
& \psi^{*}=\psi^{(0)}+W e \psi^{(1)}+W e^{2} \psi^{(2)}+\ldots .
\end{aligned}
$$

Substituting (6.12) into equations (6.7), (6.8), (6.9), and the boundary conditions (6.11), we will put the equation in order with respect to the Weissenberg number. Now we can write down the terms of equations that do not include the Weissenberg number: 


$$
\begin{gathered}
\frac{\partial \mathcal{V}_{1}^{(0)}}{\partial \mathrm{x}_{1}^{*}}+\frac{\partial \mathcal{V}_{2}^{(0)}}{\partial \mathrm{x}_{2}^{*}}=0, \\
\frac{\partial \mathrm{T}_{11}^{(0)}}{\partial \mathrm{x}_{1}^{*}}+\frac{\partial \mathrm{T}_{12}^{(0)}}{\partial \mathrm{x}_{2}^{*}}=\frac{\partial \mathrm{P}^{(0)}}{\partial \mathrm{x}_{1}^{*}}, \\
\frac{\partial \mathrm{T}_{21}^{(0)}}{\partial \mathrm{x}_{1}^{*}}+\frac{\partial \mathrm{T}_{22}^{(0)}}{\partial \mathrm{x}_{2}^{*}}=\frac{\partial \mathrm{P}^{(0)}}{\partial \mathrm{x}_{2}^{*}}, \\
\mathrm{~T}_{11}^{(0)}=2 \frac{\partial \mathcal{V}_{1}^{(0)}}{\partial \mathrm{x}_{1}^{*}}, \quad \mathrm{~T}_{22}^{(0)}=2 \frac{\partial \mathcal{V}_{2}^{(0)}}{\partial \mathrm{x}_{2}^{*}}, \\
\mathrm{~T}_{12}^{(0)}=\frac{\partial \mathcal{V}_{1}^{(0)}}{\partial \mathrm{x}_{1}^{*}}+\frac{\partial \mathcal{V}_{2}^{(0)}}{\partial \mathrm{x}_{1}^{*}}, \\
\mathrm{~T}_{21}^{(0)}=\frac{\partial \mathcal{V}_{1}^{(0)}}{\partial \mathrm{x}_{1}^{*}}+\frac{\partial \mathcal{V}_{2}^{(0)}}{\partial \mathrm{x}_{1}^{*}}, \\
\frac{\partial \psi^{(0)}}{\partial \mathrm{x}_{2}^{*}}, \quad \mathcal{V}_{2}^{(0)}=-\frac{\partial \psi^{(0)}}{\partial \mathrm{x}_{1}^{*}}
\end{gathered}
$$

Boundary conditions

$$
\begin{array}{ll}
x_{1}^{*}=-\infty, & V_{1}^{(0)}=\frac{3}{2}\left(1-x_{2}^{* 2}\right), \quad V_{2}^{(0)}=0, \\
x_{1}^{*}=0, \quad 0 \leq x_{2}^{*} \leq h^{*}, \quad & V_{1}^{(0)}=V_{0}^{*}, \quad v_{2}^{(0)}=0, \\
x_{1}^{*}=0, \quad h^{*} \leq x_{2}^{*} \leq 1, \quad v_{1}^{(0)}=V_{2}^{(0)}=0, \\
x_{2}^{*}=0, \quad \frac{\partial V_{1}^{(0)}}{\partial x_{2}^{*}}=v_{2}^{(0)}=0, \\
x_{2}^{*}=1, \quad v_{1}^{(0)}=v_{2}^{(0)}=0 .
\end{array}
$$

Considering equation (6.13), by expressing $\frac{\partial \mathrm{P}^{(0)}}{\partial \mathrm{x}_{1}^{*}}, \frac{\partial \mathrm{P}^{(0)}}{\partial \mathrm{x}_{2}^{*}}$ through $\psi^{(1)}=0$ and its derivatives and excluding $\mathrm{P}^{(0)}$, we obtain

$$
\left(\frac{\partial^{2}}{\partial x_{1}^{* 2}}+\frac{\partial^{2}}{\partial x_{2}^{* 2}}\right) \psi^{(0)}=0
$$

For boundary conditions (14) the solution of the equation (6.15) 
describes the flow of the ordinary fluid.

$$
\psi^{(0)}=\psi^{(0)}\left(x_{1}^{*}, x_{2}^{*}\right)
$$

By substituting equation (6.12) into equation (6.9) and grouping the terms with the Weissenberg number in the first power, we obtain

$$
\begin{aligned}
& T_{11}^{(1)}=\frac{1}{2}\left(\frac{\partial \mathcal{V}_{1}^{(0)}}{\partial x_{2}^{*}}-\frac{\partial \mathcal{V}_{2}^{(0)}}{\partial x_{1}^{*}}\right)\left(T_{12}^{(0)}+T_{21}^{(0)}\right)+ \\
& +2 \frac{\partial \mathcal{V}_{1}^{(1)}}{\partial x_{1}^{*}}-\mathcal{V}_{1}^{(0)} \frac{\partial T_{1}^{(0)}}{\partial x_{1}^{*}}-\mathcal{V}_{2}^{(0)} \frac{\partial T_{11}^{(0)}}{\partial x_{2}^{*}}, \\
& T_{22}^{(1)}=2 \frac{\partial \mathcal{V}_{2}^{(1)}}{\partial x_{2}^{*}}-\frac{1}{2}\left(\frac{\partial \mathcal{V}_{1}^{(0)}}{\partial x_{2}^{*}}-\frac{\partial \mathcal{V}_{2}^{(0)}}{\partial x_{1}^{*}}\right)\left(T_{12}^{(0)}+T_{21}^{(0)}\right) V_{1}^{(0)} \frac{\partial T_{22}^{(0)}}{\partial x_{1}^{*}}-\mathcal{V}_{2}^{(0)} \frac{\partial T_{22}^{(0)}}{\partial x_{2}^{*}} \text {, } \\
& T_{12}^{(1)}=\frac{\partial V_{1}^{(1)}}{\partial x_{2}^{*}}+\frac{\partial \gamma_{2}^{(1)}}{\partial x_{1}^{*}}-\frac{1}{2}\left(\frac{\partial \mathcal{V}_{1}^{(0)}}{\partial x_{2}^{*}}-\frac{\partial \mathcal{V}_{2}^{(0)}}{\partial x_{1}^{*}}\right)\left(T_{11}^{(0)}-T_{22}^{(0)}\right)-\gamma_{1}^{(0)} \frac{\partial T_{12}^{(0)}}{\partial x_{1}^{*}}-\mathcal{V}_{2}^{(0)} \frac{\partial T_{12}^{(0)}}{\partial x_{2}^{*}},(6 \\
& T_{21}^{(1)}=\frac{\partial \gamma_{1}^{(1)}}{\partial x_{2}^{*}}+\frac{\partial \gamma_{2}^{(1)}}{\partial x_{1}^{*}}-\frac{1}{2}\left(\frac{\partial \gamma_{1}^{(0)}}{\partial x_{2}^{*}}-\frac{\partial \gamma_{2}^{(0)}}{\partial x_{1}^{*}}\right)\left(T_{11}^{(0)}-T_{22}^{(0)}\right)-\gamma_{1}^{(0)} \frac{\partial T_{21}^{(0)}}{\partial x_{1}^{*}}-\gamma_{2}^{(0)} \frac{\partial T_{21}^{(0)}}{\partial x_{2}^{*}},
\end{aligned}
$$

where $\mathcal{V}_{i}^{(0)}, T_{i j}^{(0)}$ - the velocity and stress components of the terms of equations having the Weissenberg number in a zero power, respectively; they are known.

In the similar way, converting the continuity equation, the equation of motion and the boundary conditions, we obtain

$$
\begin{aligned}
& \frac{\partial \mathcal{V}_{1}^{(1)}}{\partial \mathrm{x}_{1}^{*}}+\frac{\partial \mathcal{V}_{2}^{(1)}}{\partial \mathrm{x}_{2}^{*}}=0, \\
& \frac{\partial \mathrm{T}_{11}^{(1)}}{\partial \mathrm{x}_{1}^{*}}+\frac{\partial \mathrm{T}_{12}^{(1)}}{\partial \mathrm{x}_{2}^{*}}=\frac{\partial \mathrm{P}^{(1)}}{\partial \mathrm{x}_{1}^{*}}, \\
& \frac{\partial \mathrm{T}_{21}^{(1)}}{\partial \mathrm{x}_{1}^{*}}+\frac{\partial \mathrm{T}_{22}^{(1)}}{\partial \mathrm{x}_{2}^{*}}=\frac{\partial \mathrm{P}^{(1)}}{\partial \mathrm{x}_{2}^{*}} .
\end{aligned}
$$

Boundary conditions 


$$
\begin{array}{ll}
x_{1}^{*}=-\infty, & \mathcal{V}_{1}^{(1)}=\mathcal{V}_{2}^{(1)}=0, \\
x_{1}^{*}=0, & \mathcal{V}_{1}^{(1)}=V_{2}^{(1)}=0, \\
x_{2}^{*}=1, & \mathcal{V}_{1}^{(1)}=V_{2}^{(1)}=0, \\
x_{2}^{*}=0, & \mathcal{V}_{1}^{(1)}=V_{2}^{(1)}=0 .
\end{array}
$$

The stream function (6.10) takes the following form

$$
v_{1}^{(1)}=\frac{\partial \psi^{(1)}}{\partial x_{2}{ }^{*}}, \quad v_{2}^{(1)}=-\frac{\partial \psi^{(1)}}{\partial x_{1}^{*}}
$$

Considering(6.19) and excluding equation (6.17), we obtain this equation

$$
\left(\frac{\partial^{2}}{\partial x_{1}^{* 2}}+\frac{\partial^{2}}{\partial x_{2}^{* 2}}\right)^{2} \psi^{(1)}=0 .
$$

The solution of equation (6.20) with boundary conditions (6.18) has the form $\psi^{(1)}=0$, consequently, the terms of the equation with the Weissenberg number in the first power do not affect the velocity distribution. However, as we can see from equation (6.16), stress $T_{11}^{(1)}, T_{22}^{(1)}, T_{12}^{(1)}, T_{21}^{(1)}$ prove the influence of the elasticity of the terms of the equation with the Weissenberg number in the first power. By substituting equation (6.12) into equation (6.19), taking into account that $\mathcal{V}_{1}^{(1)}=\mathcal{V}_{2}^{(1)}=0$, and grouping the terms containing the Weissenberg number in the second power, we obtain

$$
\begin{aligned}
& T_{11}^{(2)}=2 \frac{\partial \mathcal{V}_{1}^{(2)}}{\partial x_{1}^{*}}+\frac{1}{2}\left(\frac{\partial \mathcal{V}_{1}^{(0)}}{\partial x_{2}^{*}}-\frac{\partial \mathcal{V}_{2}^{(0)}}{\partial x_{1}^{*}}\right)\left(T_{12}^{(1)}+T_{21}^{(1)}\right)-\mathcal{V}_{1}^{(0)} \frac{\partial T_{11}^{(1)}}{\partial x_{1}^{*}}-\mathcal{V}_{2}^{(0)} \frac{\partial T_{11}^{(1)}}{\partial x_{2}^{*}}, \\
& T_{22}^{(2)}=2 \frac{\partial V_{2}^{(2)}}{\partial x_{2}^{*}}-\frac{1}{2}\left(\frac{\partial V_{1}^{(0)}}{\partial x_{2}^{*}}-\frac{\partial V_{2}^{(0)}}{\partial x_{1}^{*}}\right)\left(T_{12}^{(1)}+T_{21}^{(1)}\right)-\mathcal{V}_{1}^{(0)} \frac{\partial T_{22}^{(1)}}{\partial x_{1}^{*}}-V_{2}^{(0)} \frac{\partial T_{22}^{(1)}}{\partial x_{2}^{*}}, \\
& T_{12}^{(2)}=\frac{\partial V_{1}^{(2)}}{\partial x_{2}^{*}}+\frac{\partial V_{2}^{(2)}}{\partial x_{1}^{*}}-\frac{1}{2}\left(\frac{\partial V_{1}^{(0)}}{\partial x_{2}^{*}}-\frac{\partial V_{2}^{(0)}}{\partial x_{1}^{*}}\right)\left(T_{11}^{(1)}-T_{22}^{(1)}\right)-V_{1}^{(0)} \frac{\partial T_{12}^{(1)}}{\partial x_{1}^{*}}-V_{2}^{(0)} \frac{\partial T_{12}^{(1)}}{\partial x_{2}^{*}} \text {, } \\
& T_{21}^{(2)}=\frac{\partial V_{1}^{(2)}}{\partial x_{2}^{*}}+\frac{\partial V_{2}^{(2)}}{\partial x_{1}^{*}}-\frac{1}{2}\left(\frac{\partial V_{1}^{(0)}}{\partial x_{2}^{*}}-\frac{\partial V_{2}^{(0)}}{\partial x_{1}^{*}}\right)\left(T_{11}^{(1)}-T_{22}^{(1)}\right)-V_{1}^{(0)} \frac{\partial T_{21}^{(1)}}{\partial x_{1}^{*}}-V_{2}^{(0)} \frac{\partial T_{21}^{(1)}}{\partial x_{2}^{*}} \text {. }
\end{aligned}
$$


Once in equations (6.17), (6.18) and (6.19) index (1) was substituted by (2), the continuity equations, the equations of motion, the boundary conditions and the stream function took the same form.

Therefore, excluding $\mathrm{P}^{(2)}$, we'll get

$$
\begin{aligned}
& \left(\frac{\partial^{2}}{\partial x_{1}^{* 2}}+\frac{\partial^{2}}{\partial x_{2}^{* 2}}\right)^{2} \psi^{(2)}=\frac{\partial^{2} V_{1}^{(0)}}{\partial x_{2}^{*} \partial x_{1}^{*}}\left(\frac{\partial A}{\partial x_{1}^{*}}+\frac{\partial A}{\partial x_{2}^{*}}\right)+ \\
& +\frac{\partial \mathcal{V}_{1}^{(0)}}{\partial x_{2}^{*}}\left(\frac{\partial^{2} A}{\partial x_{1}^{* 2}}+2 \frac{\partial^{2} T_{12}^{(l)}}{\partial x_{2}^{*} \partial x_{1}^{*}}\right)+\frac{\partial \mathcal{V}_{2}^{(0)}}{\partial x_{1}^{*}}\left(\frac{\partial^{2} A}{\partial x_{2}^{* 2}}-2 \frac{\partial^{2} T_{12}^{(l)}}{\partial x_{1}^{*} \partial x_{2}^{*}}\right)- \\
& -C \frac{\partial^{2} B}{\partial x_{1}^{*} \partial x_{2}^{*}}-\frac{B}{2}\left(2 \frac{\partial^{2} C}{\partial x_{1}^{*} \partial x_{2}^{*}}-\frac{\partial^{2} A}{\partial x_{2}^{* 2}}+\frac{\partial^{2} A}{\partial x_{1}^{* 2}}\right)- \\
& -\frac{\partial B}{\partial x_{1}^{*}}\left(\frac{\partial C}{\partial x_{2}^{*}}+\frac{\partial A}{\partial x_{1}^{*}}\right)+\frac{\partial B}{\partial x_{2}^{*}}\left(\frac{\partial A}{\partial x_{2}^{*}}-\frac{\partial C}{\partial x_{1}^{*}}\right)+\frac{\partial^{2} V_{1}^{(0)}}{\partial x_{2}^{* 2}} \cdot \frac{\partial T_{12}^{(l)}}{\partial x_{1}^{*}}+ \\
& +\frac{\partial^{2} V_{2}^{(0)}}{\partial x_{2}^{* 2}} \cdot \frac{\partial T_{12}^{(1)}}{\partial x_{2}^{*}}-\frac{\partial^{2} \mathcal{V}_{1}^{(0)}}{\partial x_{1}^{* 2}} \cdot \frac{\partial T_{12}^{(1)}}{\partial x_{1}^{*}}-\frac{\partial^{2} \mathcal{V}_{2}^{(0)}}{\partial x_{1}^{* 2}} \cdot \frac{\partial T_{21}^{(1)}}{\partial x_{2}^{*}}+ \\
& +2 \frac{\partial \mathcal{V}_{2}^{(0)}}{\partial x_{2}^{* 2}}\left(\frac{\partial^{2} T_{12}^{(1)}}{\partial x_{2}^{* 2}}+\frac{\partial^{2} T_{12}^{(1)}}{\partial x_{1}^{* 2}}\right)+\frac{A}{2}\left(\frac{\partial^{2} B}{\partial x_{2}^{* 2}}-\frac{\partial^{2} B}{\partial x_{1}^{* 2}}\right)+ \\
& +\mathcal{V}_{1}^{(0)}\left(\frac{\partial^{3} T_{12}^{(1)}}{\partial x_{2}^{* 2} \partial x_{1}^{*}}-\frac{\partial^{3} T_{12}^{(1)}}{\partial x_{1}^{* 3}}+\frac{\partial^{3} A}{\partial x_{1}^{* 2} \partial x_{2}^{*}}\right)+ \\
& +\mathcal{V}_{2}^{(0)}\left(\frac{\partial^{3} T_{12}^{(1)}}{\partial x_{2}^{* 3}}-\frac{\partial^{3} T_{12}^{(1)}}{\partial x_{2}^{* 2} \partial x_{2}^{*}}+\frac{\partial^{3} A}{\partial x_{2}^{* 2} \partial x_{1}^{*}}\right) \cdot
\end{aligned}
$$

where $A=T_{11}^{(1)}-T_{22}^{(1)} ; \quad B=\frac{\partial \mathcal{V}_{1}^{(0)}}{\partial x_{2}^{*}}-\frac{\partial \mathcal{V}_{2}^{(0)}}{\partial x_{1}^{*}} ; \quad C=T_{12}^{(1)}+T_{21}^{(1)}$.

Since the right-hand side of equation (6.22) is known, so by solving equation (6.22) that comprises the boundary conditions, we will obtain the terms of the equation with the Weissenberg number in the second power. These terms characterize the distribution of velocities and stresses. It should be noted that, in contrast to [79], the righthand side of equation (6.22) contains derivatives of the order that is higher than in [79].

Results of the numerical simulation of the Maxwell fluid flow through the slot. Figs. 6.3 and 6.4 visualise the stream function when 
ordinary $(W e=0)$ and Maxwell $(W e=0.1)$ fluids flow through the slot. Obviously, as the channel compression ratio decreases, the stream function experiences an increasing impact at the inlet slot.

When the Maxwell fluid flows through a simulated slotted chamber, there arises the circulation zone (fig. $3 b$ ) which extends from the right corner of the channel to the slot and occupies a triangular area. The flow lines form the inlet flow. Consequently, a decrease in the channel compression ratio (as well as an increase in $W e$ ) results in the input flooded jet.
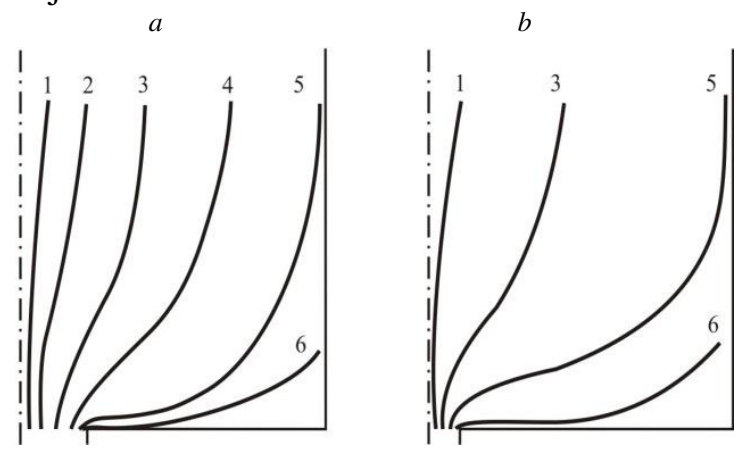

Fig. 6.3. Thestream function, when flowingt hroughthe slot of the Newtonianfluid $\mathrm{We}=0, \Psi: 1-0,125,2-0,375,3-0,625$, $4-0,875,5-0,9715,6-1,0$ $a-\mathrm{h}^{\prime} / \mathrm{H}^{\prime}-0,2 ; b-\mathrm{h}^{\prime} / \mathrm{H}^{\prime}-0,07$

$c$
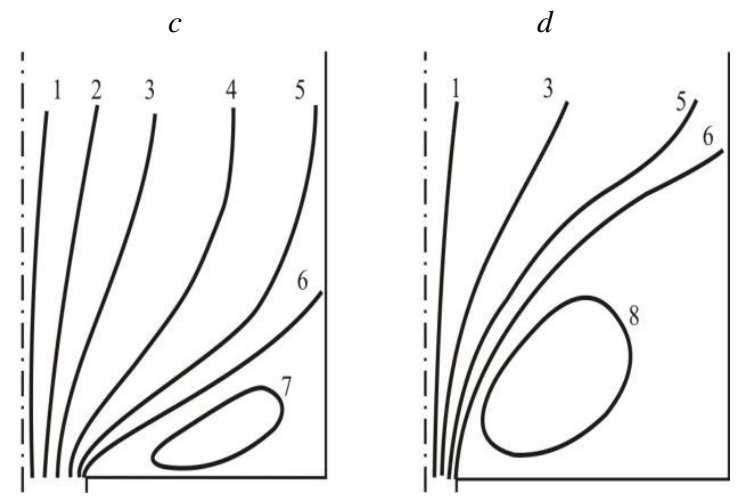

Fig. 6.4. The stream function, whenflowingthroughtheslot of the Newtonianfluid $\mathrm{We}=0,1, \Psi: 1-0,125,2-0,375,3-0,625$, $4-0,875,5-0,9715,6-1,0,7-1,01,8-1,1 ; a-\mathrm{h}^{\prime} / \mathrm{H}^{\prime}-0,2 ; b-\mathrm{h}^{\prime} / \mathrm{H}^{\prime}-0,07$ 
Fig. 6.5 shows the distribution of the dimensionless longitudinal velocity gradient along the flow axis when ordinary (curves 1 and 2) and Maxwell (curve 3) fluids flow into the slot. We can see that the maximum value of the velocity gradient in the flow of an ordinary fluid is reached at the distance $3 h^{\prime}$ i $\left(x_{1}^{*}=1,5\right)$ from the slot for the compression ratios of 0.2 and 0.07 , respectively. The flowing fluid acquires the viscoelastic properties what shifts the maximum on the curve $\dot{\varepsilon}^{*}=f\left(x_{1}^{*}\right)$ to the region of large $X^{*}$ and decreases the value of $\dot{\varepsilon}_{\text {max }}^{*}$.

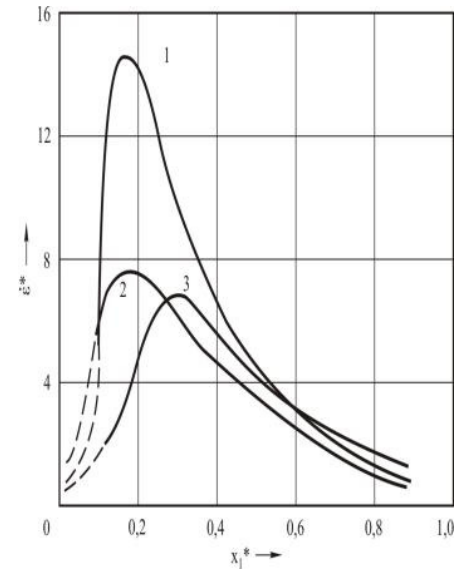

Fig. 6.5. The distribution of the dimensionless longitudinal velocity gradient along the axis of the fluid flowing into the slot

$1: \mathrm{h}^{\prime} / \mathrm{H}^{\prime}=0,07, \mathrm{We}=0$;

$2: \mathrm{h}^{\prime} / \mathrm{H}^{\prime}=0,2, \mathrm{We}=0$

$3: \mathrm{h}^{\prime} / \mathrm{H}^{\prime}=0,2, \mathrm{We}=0,1$

A comparison of the experimental data obtained in $[2,23,33,79]$ with the results of the numerical simulations shows that the simulated flow lines and the distribution of the velocity gradient correspond to the experimentally obtained results for relatively low velocities.

The distribution of dimensionless

normal stress for the channel compression ratio of 0.07 and the Weissenberg number 0.1 is shown in fig. 6.6.

The results properly visualise the experimental data on the distribution of isochromes in the input area of the slot (fig. 6.6b and [82]).

As in the polystyrene-bromoform system under consideration both the polymer and the solvent had the same refractive indices, the obtained lines of equal birefringence value (isochromes) inside the input flooded jet are proportional to the first difference of normal stresses. 

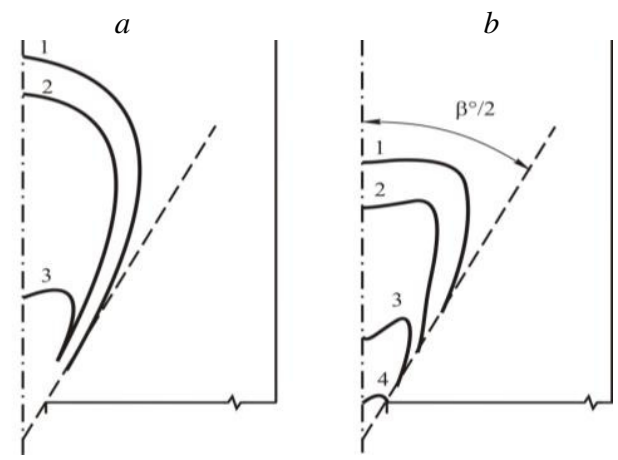

Fig. 6.6. The distribution of dimensionless normal stresses $(a)$ and isochromes (b) in the input area of a slot The angular half-width of the stream $\left(\beta^{\circ} / 2\right)-30^{\circ}$;

$$
\begin{gathered}
a-\mathrm{We}=0,1, h^{\prime} / H^{\prime}=0,07 ; \mathrm{T}^{*}: 1-5,2-7,3-45 ; \\
\quad b-\Delta \mathrm{n}: 1-10^{-4} 2-7 \cdot 10^{-4} 3-15 \cdot 10^{-4} 4-62 \cdot 10^{-4}
\end{gathered}
$$

The obtained results indicate that the numerical method of the convergent flow analysis of Maxwell's highly viscoelastic fluid can be used to calculate the longitudinal velocity gradients realized in the inlet area of cracks during the flow of polymer solutions in the porous-fractured reservoirs. It should be noted, however, that in the general case it is necessary to take into account the influence of the entryangle into the crack, which can be done by considering the problem in rectilinear inclined or curvilinear coordinates. At the same time, the analysis of the viscoelastic fluid flow in the porousfracturedreservoir is sharply complicated.

The conducted analysis of the viscoelastic fluid leakage through the fissure has defining value, first of all, for confirming the interpretation of experimental data proposed in $[11,33,83]$, which characterize special aspects of the convergent flow of aqueous polymer solutions in the inlet area of the hole or fracture.

The calculation results verify the ideas obtained from the experimental solution of this problem about the strain-stress state of polymer macromolecules (liquid elements) during polymer flow in the inlet area of the fissure in the oil reservoir and confirm the possibility of using numerical analysis of convergent polymer flow for calculating longitudinal velocity gradients in the inlet area of the fissure, and can also serve as additional substantiation of the proposed in $[10,86]$ mechanism for increasing oil recovery from reservoirs by using polymer solutions. 


\section{Conclusion}

Starting to summarize this work it is necessary to notice that polymers need to be used namely as polymers, i.e. not there where they replace something, but where they are irreplaceable. Such statement does not exclude application of polymers as materials in the usual meaning of this word. In popular articles authors still are biased to treat polymers as "materials of the future". The word "materials" dominates as though the only application of polymers is to be materials for engineering and machine designs, fibres, organic glasses, etc.

Such approach has immediate consequences leading to two extremes. The first of them reduces physics of polymers to physical materials technology at best, and chemistry - to the helper of chemical technology. The second extreme, which in some research circles turned to be a reaction on the first one, is characterized by "flight" into molecular biology, since polymeric molecules (macromolecules of DNA, RNA, etc.) are a basis of all alive.

All this leads to the situation when important technical (technological) problems to be solved due to polymers specific place among other substances remain unsettled.

We should note [84] that the fundamental property of polymers as a special form of substance condensation is their, i.e. ability in corresponding conditions to a limited (technology) or unlimited (evolution) entropy fall in some local system. Act of polymerization is something more fundamental than usual phase transition as starting from this point the system in principle may acquire ability to spontaneous self-complication and self-improvement.

Anti-entropability particularly has ties with individualization, or macromolecules distinctness, their ability to be carriers or transmitters (or transformers) of information and at last their ability for dynamic realization of information recorded on them, in particular, is connected. "Tomorrow" of polymer systems is connected with implementation of these properties in technics, medicine, genetics and other areas.

Polymers also differ from other substances by the fact that macromolecules are very big and are capable to change their form. This variety of molecular and super-molecular morphological forms in polymers and their solutions can be used widely in technics. 
Description of all possible applications of polymer systems would withdraw us too far aside from the main objective of this work. We'll enumerate only those applications that are most important for technics today. First of all they are new technological principles of system preparation for polymerization and transition from "usual" materials to anisotropic systems.

Polyfoams have big internal surface and consequently can be used for linking considerable quantities of substances possessing certain effect - effectors. For example, one of such effectors is haemoglobin that connects and transports oxygen. Haemoglobin is immobilized in foam-polyurethane that catches oxygen like fish gills. Using such haemo-sponge a diver can stay under water much longer than with a usual aqualung. There's also a possibility for a more attractive variant: decomposition of water takes place in polyfoam resulting in oxygen release. In both variants it is not an aqualung any more, i.e. "a water lung" (lat. aqua - water and Engl. lung - a lung), but "artificial gills".

Immobilization of haemoglobin in foam-polyurethane is only one of numerous examples showing possibilities of linkage, transportation and delivery of effectors by means of polymers. Effectors can be tied physically or chemically with a polymer surface, be grasped by polymeric particles, encapsulated by polymers or chemically sewed with them. The type of immobilization defines quantity and speed of effector release.

Microencapsulation is probably the most important process. It was discovered in 1953 by a scientific worker of "National Cash Register Company" who managed to cover small droplets of oil with a thin layer of water-containing-gelatin with its further hardening. Thus received gelatin microcapsules had diameter from 1 micron and above.

Other polymers can be used instead of gelatin. Not only oil droplets, but also many other liquid and solid materials can be encapsulated, for example, dyes, vitamins, bleaching agents, aromatic additives, herbicides, insecticides, medicines, fertilizers, adhesive materials, etc. Microcapsules are also used for manufacturing "carbon-free paper". Appearance of such paper made unnecessary the usage of carbon paper. Microcapsules are pasted to the underside of the original copy. When writing on the face side of any form capsules break with ink release to the duplicate. 
The encapsulated material can be released from a polymer cover not only under mechanical effect, but in other ways too. Capsules can resolve with the help either physical or chemical processes.

In the past well soluble fertilizers were applied after definite time intervals. However these fertilizers are easily washed off with rains into lakes and rivers causing eutrophication. Any plot of land should be treated with fertilizers during the whole period of vegetation Microencapsulation is likely to become very useful under these circumstances. If a polymer capsule is slightly permeable for water, fertilizer is used up during the whole period of vegetation. Similar processes take place in so-called bioorganic fertilizers. Inorganic effectors are encapsulated by means of organic materials that yield in slow decay with inorganic compounds release.

Encapsulation plays especially important role in pharmacology. First of all encapsulating materials ensure dosed medicine supply into the human body protecting it from overdosing. Similarly, application of microencapsulation to prolong dissolution period for special sewing agents in polymer solution was offered by us as one of the stages to implement technology of creating waterproof screens in the oil and gas technologies $[2,86]$.

The problem to decrease of hydrodynamic drag reduction of oil flow in pipelines by polymer additions and improvement of important technological methods when cleaning liquids from colloiddisperse impurities may also be settled with the use of polymers.

Therefore we proceed from the thesis that polymers need to be used namely as polymers when settling technical problems. This allowed us design a technological decisions for use of solutions of polymers in the oil and gas technologies.

References

1. Pogrebnyak V. G., Voloshin V. S. (2017) Enerhozberezhennia i efekt Tomsa: za redaktsiieiu Yu. F. Ivanyuta. Monografiya. Kiev, Ukraine: Osvita Ukrainy. $440 \mathrm{~s}$.

2. Pogrebnyak V. G., Voloshin V. S. (2010) Ecological Technology of Creating Waterproof Screens. Monografia. Donetsk, Ukraine: Knowledge. 482 p.

3. El'yashevich G. K., Frenkel'S. Ya. (1980) Thermodynamics of orientation of polymer solutions and melts, in: A. Ya. Malkin and S. P. Papkov (Eds.), Orientation Phenomena in Polymer Solutions and Melts. Moscow: Khimiya.Pp. 9-90. 
4. Pogrebnyak V. G., Perkun I. V., Naumchuk M.V. (2011) Sposib osvitlennia harchovykh ridyn polimernymy flokuliantamy. Pat. 57600 Ukraine, MPK C12H 1/02 (2006.01). № U2010 08323, Biul. 5.

5. Pogrebnyak V.G., Perkun I.V., Pogrebnyak A.V. (2013) Parametry flokuliatsiinoho protsesu, shcho zabezpechuiut pidvyshchennia spozhyvnykh vlastyvostei ta yakist yabluchnoho soku pid chas osvitlennia. Tovaroznavchyi vistnyk.Zb. nauk. prats. Lutsk: LTU. Vyp. 6. Ss. 205-212.

6. Jones W. H. and Ho S. P. (1979) The flow of dilute aqueous solutions of macromolecules in various geometries. VII. Mechanisms of resistance in porous media. J. Phys.Vol. 12, No. 3. Pp. 383-393.

7.Boyko V. S., Kondrat R. M., Yaremchuk R. C. (1996) Handbook of oil and gas science. L'viv: Svit. 620 p.

8. Korsakova N. K., Penkovsky V. I., Altuninaand L. K., Kuvshinov V. A. (2016) Redistribution of filtration flows by thermo gel at boundary water flooding of oil reservoirs. AIP Conf. Proc. Tomsk. Pp. 1783-1784.

9. Malkin A. Y., Arinstein A., Kulichikhin V. G. (2014) Polymer extension flows and instabilities. Progress in Polymer Science. Vol. 39, No. 5. Pp. 959-978.

10. Pogrebnyak V. G., Pisarenko A. A. (1999) Deformation effects in case of a flow with stretching of polymer solutions. Turbulence and Shear flow phenomena, Santa Barbara, California, Banerjee S., Eaton J. K. editors. New York. Pp. 13451350.

11. Pogrebnyak V. G., Ivanyuta Yu. F. and Frenkel S. Y. (1992) The structure of the hydrodynamic field and distortions of the molecular shape of flexible polymers under free-converging flow conditions. Polymer Sci. USSR. Vol. 34,No. 3. Pp. 270-273.

12. Ferry J. D. (1980) Viscoelastic properties ofpolymers. John Wiley \& Sons.641 p.

13. Malkin A. Y. (2009) Status of Polymer Rheology: achievements and problems series. Polymer Sci. ser. A. Vol. 51, No. 1. Pp. 106-136.

14. Baranov V. G., BrestkinYu. V., Agranova S. A., Pinkevich V. N. (1986) The behavior of macromolecules polystyrene in "viscosities" of a good solvent. Polymer Sci. ser. B. Vol. 28, No. 11. Pp. 841-843.

15.Bazelevich A. V., Entov V. M., Karpov A. V. et al. (1991) The Relaxation Time of Polymer Solutions: Methods of Measurement and Some ofIts Applications. Moscow: Instit. of Appl. Mech. of the Russian Academy of Sciences. 42 p.

16. Chornyy M. I., Chornyy O. M., Metoshop I. M., Kuzin I. M. (2013) Heolohichni osnovy rozkrittia i viprobuvannia produktyvnykh plastiv.Navchalnyjiposibnyk. Ivano-Frankivsk: Wydawnictwa IFNTUNG. $306 \mathrm{~s}$.

17. Ivanyuta Yu. F., Naumchuk N. V., Pogrebnyak V. G.,Frenkel' S. Ya. (1985) Flow structure of aqueous solutions of polyethylene oxide in the inlet region of short capillaries. Journal of Engineering Physics. Vol. 49,No.4. Pp. 1192-1197.

18. Diment O. N., Kazanskii K. S., Miroshnikov A. M. (1976) Glikoli i drugiye proizvodnye okisey etilena i propilena. Monografiya. Moscow: Khimiya. $374 \mathrm{~s}$.

19. Salyanov V. I., Skuridin S. G., Lortkipanidze G. B. et al. (1978) Relation between molekular-strukture of aqueous-solutions of polyethylene-glycol and 
comhaction of double-standed DNK-molecules.Molekulyarnaya Biologiya. Vol.12, No. 3. Pp. 485-495.

20.Brestkin Yu. V., Ahranova S. F., D'iakova N. E. et al. (1989) Birefringence effects ofpolymer-solutions in hydrodynamic fields. Vysokomolekulyarnye Soedineniya. Ser. B. Vol. 31, No.11. Pp. 844-846.

21. Brestkin Yu. V. (1987) Dynamic coil-extended chain phase transition in the longitudinal field. Acta Polymerica. Vol. 38, No.8. Pp. 470-477.

22. Keller A., Odell J. A. (1985) The extensibility of macromolecules in solutions, a new focus for macromolecular science. Colloid. Polym. Sci. Vol. 263, No. 3. Pp. 181-201.

23. PogrebnyakA. V., PerkunI. V., PogrebnyakV. G. (2017) Degradation of Polymer Solutions in a Hydrodynamic Field with a Longitudinal Velocity Gradient. Journal of Engineering Physics and Thermophysics. Vol. 90, No. 5.Pp. 1219-1224. DOI: $10.1007 / \mathrm{s} 10891-017-1677-8$.

24. Pogrebnyak A. V., Perkun I. V., Pogrebnyak V.G., Shimanskii V. Y. (2021) Thermal Effects in the Flow of a Polymer Aqueous Solution Through a Hydrocutting Jet-Forming Head. Journal of Engineering Physics and Thermophysics. Vol. 94, No.1. Pp. 137-142. DOI:10.1007/s10891-021-02281-1.

25. Povkh I. L., Pogrebnyak V. G., Toryanik A. I. (1979) Relation between molecular structure of polyethyleneoxideand drag reduction.Journal of Engineering Physics. Vol. 37, No.4. Pp. 1131-1136.

26. Kuzmin R. A., Tihomirov R. A.,Kravchenko D. V.(2002) O preimushchestvakh gidrorezaniya materialov struey zhidkosti s dobavkami vodorastvorimykh polimerov. Aerokosmicheskie tekhnologiii obrazovanie narubezhe vekov: Materialy Vserossiyskoy nauchno-tekhnicheskoy konferenczii. Rybinsk:Wydawnictwa RGATA. Chast` 2. Ss. 53-54.

27. Pogrebnyak V. G., Naumchik N. V. (1995) On the hydrodynamic activity of polymers in high-velocity flows. Inzhenerno-FizicheskiiZhurnal. Vol. 68, No. 1.Pp. 146-148.

28. Atanov H. A. (1987) Gidroimpulsnye ustanovki dliya razrusheniiy. Monografiya. Kiev: Wydawnictwa Vyshcha shkola. 152 s.

29. Brenner V. A., Jabin A. B., Pushkarev A. E., Sycheholev M. M. (2000) Gidrostrujny`e tekhnologii v promyshlennosti. Gidromekhanicheskoe razrushenie gornykh porod. Monografiya. Moskva: Wydawnictwa Akad. Gornykh nauk. 343 s.

30. Azzari P., Rjanova A. B., Svitasheva K. K. (1981) Ellipsometriya i polyarizovannyj svet.Monografiya. Moskva: WydawnictwaMir. $583 \mathrm{~s}$.

31. Kudin A. M. (1972) On the sizes of associates in solutions of polymers that reduce the hydrodynamic resistance. Hydromekhanika. Kiev: Wydawnictwa Science Dumka. Is. 20. Ss.82-87.

32. Pogrebnyak V. G., Chudyk I. I., Perkun I. V. (2021) High-efficiency Casing Perforation Oil and Gas Wells. SOCAR Proceedings. Reservoir and Petroleum Engineering. No. 2. Pp. $112-120$.

http://dx.doi.org/10.5510/OGP2021SI200578.

33. Pogrebnyak A., Chudyk I., Pogrebnyak V., PerkunI. (2019) Coiluncoiled chain transition of polyethylene oxide solutions under convergent flow. Chemistry and Chemical Technology. Vol. 13, No.4. Pp. 465-470. 
DOI:10.23939/chcht13.04.465.

34. Pogrebnyak V. G., Naumchik N. V. (1992)Dynamic structurization in solutions of hydrodynamically active polymers. Journal of Engineering Physics and Thermophysics.Vol. 63, No. 2. Pp. 763-765.DOI: 10.1007/BF00861695

35. Kryvenko G., Perkun I.,Pogrebnyak V. G. (2017) The nature of Hydrodynamic Drag Reduction of Oil Flow in Pipelines by Polymer Additions. Petroleum Science and Engineering. Vol. 2, No.3. Pp. 79-85.

DOI: $10.11648 /$ j.pse.20170102.12.

36. PogrebnyakV. G., IvanyutaYu. F., Naumchuk I. V. (1991) Unrolling of macromolecules under wall turbulence conditions. Inzhenerno-FizicheskiiZhurnal. Vol.61, No.6. Pp. 925-927.

37. Cantwell B. I. (1981) Organized motion in turbulent flow. Ann. Rev. Fluid. Mech. No.13. p. 457-519.

38. Bredshou P. (1974) Vvedenie v turbulentnostieeizmerenie. Monografiya. Moskva: Wydawnictwa Mir. 278 s.

39. Pogrebnyak V. G., PogrebnyakA. V., PerkunI. V. (2021) Maxwell fluid flow in system supplying hydrodynamically active polymer to boundary layer of streamlined object.Mathematical Modeling and Computing. Vol. 8, No. 1. Pp. 5868. DOI:10.23939/mmc2021.01.058.

40. Frenkel'S. Ya., El'iashevich H. K., Panov Yu. N. (1970) Kontsentrirovannyerastvorypolimerov Uspekhi khimii i fiziki polimerov. Moskva: Khimiya. Pp. 87-138.

41. Pilipenko V. N. (1980) Vliyanie dobavok na pristennye turbulentnye techeniya. Itogi nauki I tekhniki. Ser. Mekhanikazhidkostiigaza. Moskva: Wydawnictwa VINITI. No.15. Pp. 156-257.

42. Hlesdorf P., Prigojin I. (2003) Termodinamicheskaya teoriya struktury, ustoychivosti i fluktuatsii. Monografiya. Moskva: WydawnictwaURSS. 280 p.

43. Abdalla A. Y., Japper-Jaafar A., Mohd Fakrul Radzi Mohd Radzi (2016) Effects of Polymer Addition to a Newtonian Solvent in Horizontal Pipe Flow. Journal of Applied Sciences. No 16. Pp. 271-278.

44. Motier I. F., Prilutski P. I. (1985) Gase histories of polymer draq reduction in crude oil lines. Pipe lines industry. Vol. 62, No 6. Pp. 33, 34, 37.

45. Pogrebnyak V. G., Ivanyuta Yu. F. (1998) Experimental research of the influence of conditions of polymer admission to the boundary layer on a drop of turbulent friction. Proc. of the Intern. Symp. on Seawater Drag Reduction. Newport, Rhade Island USA, S. 1. Pp. 295-297.

46. Polimer expands crude line capacity. (1985) Pipe line industry. Vol. 63, No.1. Pp. 71-72.

47. Al-Yaaria M., Soleimanib A., Abu-Sharkha B., Al- Mubaiyedha U., Alsarkhic A. (2009) Effect of drag reducing polymers on oil-water flow in a horizontal pipe. International Journal of Multiphase Flow. No 35. Pp. 516-524.

48. Durst F., Ray S., Unsal B.and Bayoumi O. A. (2005) The development lengths of laminar pipe and channel flows. J. Fluids Eng. No 127. Pp. 1154-1160.

49. Beaty W. K., Ionston R. L., Rramer R. L., Warnack L. G., Wheeler G. R (1984) Offshore crude oil production increased by drag reducers. Drag Reduct. 3 rd int. Conf. Bristol. F1 -F14. 
50. Nesyn G. V., Manzhai V. N., Suleimanov Yu. V., Stankevych V. S., Konovalov K. V.(2012) Mechanism of action, evaluation of efficiency and features of obtaining polymeric anti-turbulent additives for transport of hydrocarbon liquids. Polymer Science, Ser. A. Vol. 54, No 1. Pp. 65-72.

51. Nikulin V. A. (2014) About one model of heat transfer in wall- adjacent turbulence. Ser. 1. Mechanics and Physics: Fundamental and applied research. Vol.1, No. 43. Pp. 4-12.

52.Stupin O. B., Symonenko O. P., Aslanov P. V. (2013)Hydrodynamic activity of water- soluble polymer compositions and perspectives of their application in energy saving and ecology. Visnyk of National University "Lviv Polytechnic": Thermal power. Engineering environment. Automation. No. 758. Pp. 85-96.

53. Symonenko A. P. (2012) Improving the efficiency of firefighting equipment by applying the hydrodynamic activity of water - soluble polymer compositions. Compilation of scientific works of the National Civil Protection University of Ukraine: Problems of Fire Safety. Is.32. Pp. 195-206.

54.Liberanore M. W., Pollauf E. J., McHungh A. J. J. (2003) Shear - induced structure formation is solutions of drag reducing polymers. Non-Newton. Fluid Mech. Vol. 113, No. 2-3. Pp. 193-208.

55. Pogrebnyak V. G., Pisarenko A. A.(2002) Solutions of Polymers under the Conditions of Wall Turbulence. Mechanism of Drag Reduction. Intern. J. of Fluid Mech. Research.Vol. 29, No. 6. Pp. 130-138.

56. Wu J., Fruman D. H., Tulin M. P. (1978) Drag reduction by polymer diffusion at high Reynolds numbers. J. ofHydronautics.Vol. 12, July. Pp. 134-136.

57. Fruman D. H.and Galivel P. (1979) Anomalous effects connected with ejection of polymer, reducing resistance, in turbulent boundary layers of pure water. Technical papers from the Symposium on Viscous Drag Reduction, Ed. By Gary R. Hough, Vought Advanced Technology Center, Dallas, Texas. Vol.72. Pp. 12331241 .

58. Vdovin A. V. and Smolyakov A. V. (1978) Diffusion of solutions in a turbulent boundary layer. Zh. Prikl. meh. iteh. Fiz. No. 2. Pp. 66-73.

59. Casale A.and Porter R. S. (1978-1979) Polymer Stress Reactions. Vols. 12, Academic Press, New York. 269 s.

60.Henmann T. J. Polymer degradation and stabilization. Polym. News. Vol.9, No.10. Pp. 309-311.

61. Soules D., Fernando R. H. and Glass J. (1986) Mechanical stability of water-soluble carbohydrate polymers. Polym. Mater. Sci. Eng. Div. No. 53. Pp. 555559.

62. Brestkin Yu. V. et al. Destruction of polystyrene macromolecules in a strong longitudinal hydrodynamic field. Vysomol. Soedin. Ser. B.Vol. 31, No.7. Pp. 506-510.

63. Vyshkina T. V. (1988) Chemical Transformations of Polyacrylamide in the Hydrodynamic Field. Candidate's Dissertation in Chemical Sciences. Kiev: NU named after T. Shevchenko. $110 \mathrm{~s}$.

64. Povkh I. L.(1976) Technical Hydromechanics. Leningrad: Mashinostroenie. $502 \mathrm{~s}$. 
65.Smol'skii B. M., Shul'man Z. P. and Gorislavets V. M. (1970) Rheodynamics and Heat Transfer of Nonlinearly Viscoelastic Materials. Minsk: Nauka i Tekhnika. $466 \mathrm{~s}$.

65. Tsvetkov V. N., Éskin V. E. and Frenkel' S. Ya. (1964) Structure of Macromolecules in Solutions. Moscow: Nauka.719 s.

67. Klenin V. I. (1995) Thermodynamics of Systems with Flexible Polymers. Monografiya. Saratov: Saratovskii Univ. 736 s.

68. El'yashevich G. K.andFrenkel' S. Ya. (1980) Thermodynamics of orientation of polymer solutions and melts, in: A. Ya. Malkin and S. P. Papkov (Eds.), Orientation Phenomena in Polymer Solutions and Melts.Moscow: Khimiya, Pp. 9-90.

69. Boiko V. S., Kondrat R. M., Yaremiichuk Z. S. (1996)Dovidnyk z naftohazovoispravy. Lviv: IFNTUNH. $620 \mathrm{~s}$.

70.Kachurin A., Sattarov R., AyupovaD., GabdullinaA.(2011) Improvement of the technology of strata oil recoveryenhancementusingSoftPusher Polyacrylamide in the fields of LUKOIL -Western Siberia OOO. Oil Industry. No. 8. Pp. 126-128.

71. Bondarenko A. V., Kudryashova D. A. (2015) The application of hydrodynamic modeling for predictive effectiveness assessment of polymer floodingtechnologyonMoskudinskoyefield. Oil Industry. No.10.Pp. 102-105.

72. Pogrebnyak V. G. (2005) Polymer Macromolecules as a Tool for Studying Wall-Adjacent Turbulence Flow. Proceedings of the 2nd International Symposium on Seawater Drag Reduction. Busan, Korea: ASERC. Pp. 79-90.

73. De Gennes P. G.(1974) Coil-stretch thransition of dilute flexible polymers under ultrahigh velocity gradients. J. Chem. Phys.Vol. 60, No 12. Pp. 5030-5042.

74.Astarita J., Marucci J. (1978) Osnovyi gidromehaniki nenyutonovskih zhidkostey. Moscow: Mir. 309 s.

75. Vinogradov G. V., Malkin A. Ya. (1977) Reologiya polimerov. Moscow: Khimiya. $438 \mathrm{~s}$.

76. Ferri J. (1963) Vyazkouprugiesvoystva polimerov.Moscow: Inostr. lit. 535 s.

77. Kristensen R. (1974) Vvedenie v teoriyu vyazkouprugosti. Moscow: Mir. $338 \mathrm{~s}$.

78. Lodge A. S. (1969) Elastichnyie zhidkosti. Vvedenie v reologiyu konechnodeformiruemyih polimerov. Moscow: Nauka. $463 \mathrm{~s}$.

79. Nakamura K. (1978) Medlennoe istechenie vyazkouprugoy zhidkosti po konicheskomu kanalu. Senk'i kikay gakkaysi. Vol. 31, No.8. P. 49-55.

80. Voytkunskiy Ya. I., Amfilohiev V. V., Pavlovskiy V. A. (1970) Uravnenie dvizheniya zhidkosti s uchetom ee relaksacionnykh svojstv. Sb. Nauch. tr. Leningr. korablestr. ins-t. No. 69, Ss.19-25.

81. Hintse I. O. (1963) Turbulentnost. Mehanizm i teoriya. Moscow: Phiz.-mat. Izdat. $680 \mathrm{~s}$.

82. Brestkin Yu. V., Amribakhshov A. A., Kholmuminov A. A., Frenkel S.Y. (1988) Razvorachivanie makromolekul pri shodyaschemsya techenii. Izv. AN UzSSR. Seriya phiz.-mat. nauk. No. 6. Pp. 80-84.

83. Pogrebnyak A. (2017) The Elastic Deformations and Anomalously High Cutting Ability of a Polymer Solution Jet. Scientific journal of the Ternopil Ivan Puluj National Technical University. Vol. 1, No.85. Pp. 89-94. 
84. Frenkel' S. Ya. (1973) Polimeryi. Problemyi, perspektivyi i prognozyi. Fizika segodnya i zavtra: za redaktsiieiu V. M.Tuchkevicha. Leningrad: Nauka. Ss.176-270.

85. Feynman R. P. (1966) The Development of the Space-Time View of Quantum Electrodynamics. Science. Vol. 153, No. 3737. Pp. 699-708.

86. Pogrebnyak V.G., Perkun I. V., Pogrebnyak A. V. (2016)Displacement of Oil from Porous Bed by the Oscillating Flow of Polymer Solution. American Journal of Science. Engineering and Technology. Vol. 1, No 2. Pp. 53-57.

https://doi.org/10.31713/m1107

\title{
TECHNOLOGY OF RAW MATERIAL ENRICHMENT OF INHOMOGENEOUS CARBONATE DEPOSITS AND EVALUATION OF ITS ENERGY EFFICIENCY
}

\section{Dreshpak O. S.}

Dnipro University of Technology, $\mathrm{PhD}$, associate professor, Department of Technological Engineering of Materials Processing, Ukraine

\section{Dreshpak N. S.}

Dnipro University of Technology, $\mathrm{PhD}$, associate professor, Department of Electrical Engineering, Ukraine

\section{Vypanasenko S. I.}

Dnipro University of Technology, DSc (Engineering), professor, Department of Power Engineering, Ukraine

\begin{abstract}
The article presents the results of solving the urgent scientific and practical problem of establishing regularities connecting the indicators of the efficiency of enrichment and classification of raw materials of heterogeneous limestone deposits with its initial characteristics, technological and design parameters of the classification equipment, substantiating rational screening modes on this basis. An assessment of the energy efficiency of the proposed technical solutions is given. The research was carried out at Dnipro University of Technology (Ukraine, Dnipro).

Technological lines for dry processing of limestone raw materials, which are used in quarries, ensure the production of marketable products of acceptable quality only for large grades of crushed stone in low humidity conditions. Small grades of crushed stone are not used and are sent to the dump. There is a need to improve the existing process of classification and enrichment of raw materials in order to improve the quality of the final product and expand, on this basis, the fractional com-
\end{abstract}


position of commercial crushed stone, which complies with the requirements of state standards.

The proposed concept of enrichment of raw materials of heterogeneous carbonate deposits consists in the forced separation of clay coatings from pieces of rock, followed by highly efficient screening of limestone in quarry conditions. The implementation of the concept provides for the use of a roller-finger screen, which provides high performance indicators at high material moisture. New analytical dependencies have been obtained linking the indicators of the efficiency of limestone concentration with the results of the granulometric and chemical analyses of the feedstock, the efficiency of its screening. On their basis, a mathematical model has been created that allows, with a limited amount of experimental data, to predict the achieved enrichment efficiency indicators, taking into account the characteristics of the classification devices used.

It is shown that the dependence of the indicator of the efficiency of enrichment of raw materials on the size of the separation of particles by screening devices has an extremum, and the value of the size corresponding to the maximum of the indicator does not depend on the efficiency of screening. This makes it possible to use a screening mode with an optimal particle size separation, while ensuring high enrichment efficiency, reducing waste from the processing process, and improving the ecological situation in the region.

A method for calculating the optimal size of the separation of the material to be classified has been developed. On its basis, an algorithm for calculating the indicators of the concentration efficiency was created, which allows obtaining expanded information on the nature of changes in certain parameters with a variation in the size of the separation of particles and screening efficiency.

The use of a roller-finger screen as a combined device, which carries out both the separation of clay coatings from pieces of limestone, and the separation of particles by size (including conditions of high humidity of the feedstock), improves the screening efficiency. Based on the study of the dynamics of the particle of the material, the determination of the forces acting on the particle, the obtained analytical dependence determines the condition for excluding the mode of its infringement. It is proved that such a regime does not depend on the levels of forces acting on the particle, but is determined exclusively by the values of the angles characterizing the position of the points of contact of the particle with parts of adjacent rolls.

To study the enrichment and classification processes of the feedstock, linear regression multifactor models were created, where the values of the limestone content in the feedstock and the moisture content of the material were used as factors, and the values of the indicators of the efficiency of enrichment and screening of limestone were used as the response functions. The models allow the comparing of the efficiency of screening and beneficiation processes in classification options with and without a roller-finger screen.

The presence of a roller-finger screen is manifested in its stabilizing effect on the classification process, which is accompanied by an increase in the beneficiation efficiency by $10-20 \%$.

Along with the tasks of increasing the efficiency of enrichment of raw materials from carbonate deposits, the indicators of the energy efficiency of the technological 
process are considered. A methodology for assessing the energy intensity of the existing and proposed raw material enrichment technology has been developed. The structure of the regression model for standardizing the indicator of specific electricity consumption is proposed and a list of measures that are advisable to use in order to improve energy efficiency is determined.

Key words: enrichment efficiency, raw material classification, finger-feller screen, limestone, raw material moisture.

\section{Introduction}

The metallurgical and construction industries are the main consumers of limestone. Requirements for commercial limestones are set out in regulations and are sufficiently meaningful and complex to implement. The content of clay particles in the commodity product is normalized. In different classes of carbonate rocks, the maximum allowable values of clay additives are different, but should not exceed $20 \%$. Upper calcite levels in standard size classes are not limited. In the process of enrichment of raw lime deposits, it is important not to reach the lower limit of calcite content. The presence of clay particles in the form of films, and primers significantly worsens the conditions for obtaining a high quality product. Grinding and grading operations are used to process raw materials. The low efficiency of the classification process is the reason for the continuous growth of tailings. There is a need to improve the existing technological lines of enrichment of raw materials in order to improve the quality of the product, expanding its fractional composition. In conditions of high humidity of raw materials clay additives create problems with the classification of limestone. Increasing the moisture content of the raw material to be sieved leads to clumping of the clay during processing, its adhesion to the surface of the sieves, which reduces the efficiency of classification, and in some cases the process can not be implemented. At the same time, the company incurs significant losses associated with reduced production.

Outstanding scientists of Ukraine and abroad havedealt with scientific problems of dry classification of raw materials: Andreev S.E., Bardovsky A.D., Berdus V.V., Blekhman I.I., Weisberg L.A., Kartaviy N.G., Levendell E. E., Levenson L.B., Liandov K.K., Inflated V.P., Nepomnyashchy E.A., Olevsky V.A., Olyunin V.V., Pilov P.I., Poturaev V.N. ., Rundqvist K.A., Teacher A.D., Franchuk V.P., Chervonenko A.G., Shlain B.I. and others. Wet processing of 
inhomogeneous carbonate rocks in the quarry is practically impossible, as in most cases there is no ability to provide the process with water in the required amounts; it is not possible to dispose of production sludge. Dry methods of processing raw materials, accompanied by the separation of its clay particles, are not effective enough and need improvement. In the conditions of dry processing of raw materials it is necessary to focus on the expanded operational modes characterized by high indicators of efficiency of screening, in the direction of increase of values of humidity of material acceptable for this process. This will reduce the dependence of equipment modes on weather and seasonal conditions, and reduce interruptions in the operation of production lines.

It is shown that theoretical research in the field of enrichment and classification of materials focuses mainly on establishing the links between known indicators of enrichment efficiency, classification of raw materials and technological, design parameters of the equipment that performs these processes. Methods of probability theory and mathematical statistics are widely used.

Recently, much attention has been paid to ensuring high energy efficiency of mineral beneficiation processes. Such processes are usually energy intensive. Indicators of specific energy consumption are units, and often tens of $\mathrm{kW} \cdot \mathrm{g} / \mathrm{ton}$. With significant volumes of raw material processing, energy costs are significant, which determines the relevance of research aimed at improving energy efficiency of processes. The application of operating regimes with high efficiency of screening of limestone raw materials should be accompanied by an assessment of energy efficiency of decisions taken before implementation. It is expedient to compare the energy efficiency indicators of the existing and the proposed enrichment technologies. The indicator of energy efficiency largely depends on the control of its importance in the process of enrichment of raw materials and the timely application of measures to improve it. To carry out such control, it is necessary to determine the normalized values of energy consumption, which fully meets the requirements of the current standard ISO50001.

\section{Research methods and results}

The problem is one of determining the relationship between the efficiency of enrichment of limestone raw materials with the results 
of its particle size and chemical analysis and the efficiency of classification. On this basis, a mathematical model for forecasting this indicator was developed, rational screening regimes were substantiated, and a method for calculating indicators of the enrichment process was created. The accepted concept of limestone enrichment of inhomogeneous deposits is determined. It is shown that with increasing the size of raw materials, the content of calcite increases, and clay additives - decreases. At the same time, the results of the analysis show that even large classes do not contain enough limestone to classify them as a marketable product. Uneven distribution of calcite content in different size classes is a prerequisite for solving the problem of limestone enrichment by classifying the raw materials of the deposit. But obtaining a marketable product only by classifying raw materials is not always possible (for example, in the absence of sufficient calcite in large fractions). It is known that the increase in moisture content of raw materials is accompanied by a decrease in the efficiency of screening and even a possible shutdown of the production line. Therefore, in the technological line of raw material processing it is necessary to introduce an additional element that eliminates the negative consequences. The heterogeneity of raw materials of carbonate deposits introduces uncertainty into the results of its enrichment with existing technological lines. Therefore, it is important to predict the efficiency of enrichment, the quality of the obtained product, based on chemical and particle size analysis of raw materials for a particular field, and the modes of operation of technological equipment. It should be noted that the existing technologies of enrichment of raw materials and the proposed concept of enrichment provide for the implementation of the final classification operation, which determines the achieved level of enrichment. Therefore, the paper focuses on creating a mathematical model for predicting the efficiency of enrichment by classifying raw materials. The acceptability of the use of power functions in regression dependencies reflecting the results of chemical and granulometric analysis of raw materials of inhomogeneous carbonate deposits is confirmed.

$$
m_{2 d} / m=a_{1} d^{n_{1}}+b_{1} ; m_{u 2 d} / m=a_{2} d^{n_{2}}+b_{2},
$$

where $m_{2 d}$ - the mass of the particles of the lower size class in the product to be classified; $m_{u 2 d}$ - mass of limestone in the lower size 
classes of this product; $m$ - the mass of the product; $a_{1}, a_{2}, b_{1}, b_{2}, n_{1}$, $n_{2}$ - coefficients of degree regression dependence (for raw materials of Zapadno-Tyaginsky deposit $a_{1}=22,403 ; a_{2}=7,962 ; b_{1}=-0,675 ; b_{2}=-$ 0,$\left.271 ; n_{1}=0,347 ; n_{2}=0,448\right) ; \mathrm{d}$ is the size of the separation of raw material particles in the screening process.

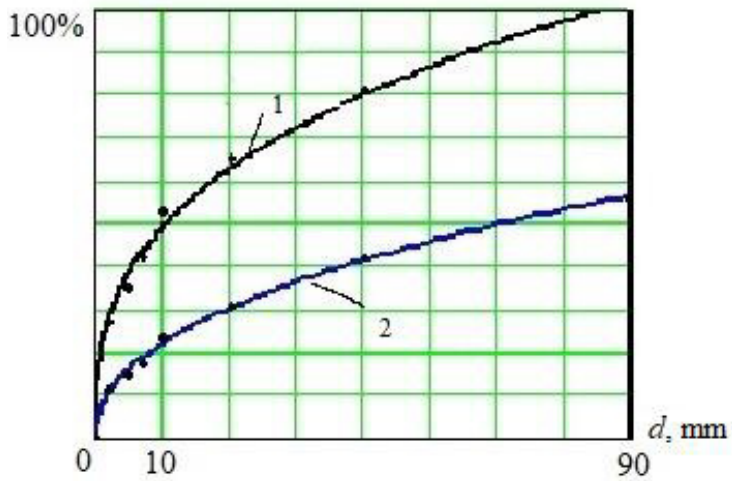

Fig. 1. Dependences between output $m_{2 d} / m(d)=\gamma$ and $m_{u 2 d} / m(d)=\alpha$ limestone content in the total sample $\left(m_{2 d} / m(d)\right.$ - curve 1 and $m_{u 2 d} d m(d)$ - curve 2)

The calculated values of the correlation relations $r$ for the considered models were: for curve $1-r=0,997$, curve $2-r=0,998$. The experimental points shown in Fig. 1 practically coincide with curves 1 and 2. High levels of correlation relations allow us to consider the dependences (1) with appropriate assumptions that reflect the functional relationships between parameters and use them in the developed model, to calculate the determined values of enrichment efficiency indicators.

Taking into account the dependence $m_{2 d}(d)$ we obtain

$$
\frac{m_{1 d}}{m}(d)=1-\frac{m_{2 d}}{m}(d),
$$

where $m_{1 d}$ - the mass of particles of the upper size class in the product to be classified.

Mass of oversized product $m_{1}$ :

$$
m_{1}=m_{1 d}+m_{2 d}\left(1-E_{s}\right)
$$

where $E_{s}=m_{2 /} m_{2 d}\left(E_{s}-\right.$ screening efficiency); $m_{2}-$ the mass of the sub-sieve product.

Output of over sieve $\left(\gamma_{1}\right)$ and sub-sieve $\left(\gamma_{2}\right)$ products 


$$
\gamma_{1}=\frac{m_{1 d}}{m}+\frac{m_{2 d}}{m}\left(1-E_{s}\right) ; \quad \gamma_{2}=1-\gamma_{1}
$$

The use in equations (3), (4) of the variable $E_{s}$, which can vary within $0 \leq E_{s} \leq 1$ depending on the achieved level of screening efficiency, allows in the following analysis to consider the dependence of parameters characterizing the enrichment process, not only on the variable $d$, but also from the value of $E_{s}$.

The content of limestone in the over sieve $\left(\beta_{1}\right)$ and sub-sieve $\left(\beta_{2}\right)$ products is calculated by the formulas

$$
\begin{gathered}
\beta_{1}=\frac{m_{u 1}}{m_{1}}=\frac{m_{u 1 d}+m_{u 2 d}\left(1-E_{s}\right)}{m_{1 d}+m_{2 d}\left(1-E_{s}\right)}=\frac{\frac{m_{u 1 d}}{m}+\left(\alpha-\frac{m_{u 1 d}}{m}\right)\left(1-E_{s}\right)}{\gamma_{1}}, \\
\beta_{2}=\frac{m_{u 2}}{m_{2}}=\frac{\alpha-\left(\frac{m_{u 1 d}}{m}+\left(\alpha-\frac{m_{u 1 d}}{m}\right)\left(1-E_{s}\right)\right)}{1-\gamma_{1}}
\end{gathered}
$$

where $m_{u 1}, m_{u 2}$, - the mass of limestone in the super-lattice and sub-lattice products; $\alpha$ - lime content in the product to be sieved; $m_{u l d}$-the mass of limestone in the upper grades of the size of the product to be sieved.

Equations (4), (5) allow determining the indicators of limestone extraction in superscreen $(\varepsilon 1)$ and subsieving $\left(\varepsilon_{2}\right)$ products.

In addition to the enrichment index $E$, the model allows to calculate the values of parameters $\gamma_{1}, \gamma_{2}, \beta_{1}, \beta_{2}, \varepsilon_{1}, \varepsilon_{2}$ which are also important characteristics of the process.

We use a mathematical model to predict the efficiency of limestone beneficiation of the Zapadno-Tyaginsky deposit and consider the dependence $E\left(E_{s}, d\right)$ obtained by calculation, where models (1) are used. The family of characteristics $E(d)$ at different values of $E_{s}$ illustrates Fig.2. The analysis shows that the increase in $E_{s}$ is accompanied by an increase in E. These curves have extremes. The maximum values of $E$ for different curves $(1,2,3)$ correspond to the same values of the size $d$ (about $7 \mathrm{~mm}$ ). Assuming the value of $d=7 \mathrm{~mm}$ as a rational value of the size of the separation of raw materials $\left(d_{o p t}\right)$, we conclude that $d_{\text {opt }}$ does not depend on $E_{s}$, i.e. for arbitrary values of $E_{s}$ at $d=d_{\text {onm }}$ the maximum level of enrichment is provided. The use of this mode is important for the practical implementation of the screening device, as the size of the sieve gaps should be set equal to $d_{\text {opt }}$. 
Calculations show that the nature of the dependences $E(d)$ shown in Fig. 2 is preserved at different values of the limestone content in the raw material $\alpha$. Variation $\alpha$ leads only to a change in the value of $d_{\text {opt }}$, which provides the extremes of the family of functions. The second important conclusion, which follows from Fig. 2, is that even effective screening modes $\left(E_{s}=0,9-\right.$ $1,0)$ are not able to provide high rates of enrichment efficiency (maximum value of $\left.E_{s}=0,2\right)$. Therefore, the raw materials of the Zapadno-Tyaginsky deposit need additional processing, for example, within the framework of the concept of enrichment proposed by the authors.

The practical use of the developed model to predict the effectiveness of enrichment involves the implementation of a certain sequence of actions. This sequence is presented in the form of a method of calculating the rational value $d_{\text {opt }}$. The following sequence of actions is defined:

1. Perform particle size and chemical analysis of raw materials to be classified.

2. Get the regression dependences $m_{2 d} / m(d), m_{u 2 d} / m(d)$.

3 . Construct the dependence $E(d)$ and find the value $d_{o n m}$ corresponding to the maximum level $E$.

4. For the mode of operation of the screen $d=d_{\text {opt }}$ to determine the corresponding indicators $\gamma_{1}, \gamma_{2}, \beta_{1}, \beta_{2}, \varepsilon_{1}, \varepsilon_{2}$.

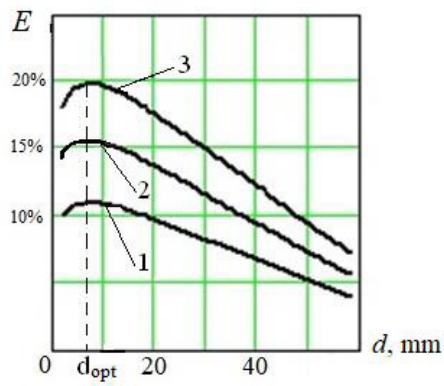

Fig. 2. Dependence between enrichment efficiency $E$ and separation size $d$ at different values of screening efficiency $E_{s}$ (curve $1-0,7$; curve 2-0,8; curve $3-0,9$ )

To simplify the procedure of using the proposed technique developed an algorithm for calculating the indicators listed in paragraphs $2,3,4$. The algorithm is implemented in MathCAD and allows to obtain advanced information about the nature of changes in the calculated parameters for variations $d$ and $E_{s}$. 
To determine the parameters of power dependences (1) it is possible to use the method of interpolation of the function, which will allow in the conditions of rapid analysis to abandon a series of experiments (to build a regression dependence) and limit their number to two. This is important to reduce the amount of work, as well as the time required to perform calculations. The accuracy of the forecast when using the proposed model depends on the values of correlation relations in equations (1). This allows the researcher to independently assess the accuracy of the calculation results and decide on its acceptability. To assess the reliability of the calculation results, a comparison of the calculated and experimental data obtained in the laboratory was performed. The discrepancy between these data did not exceed $7 \%$.

The universality of the developed technique is that it uses the developed mathematical model and can be used to analyze the raw materials of any inhomogeneous carbonate deposit. The practical significance of the proposed method is that it allows to determine the optimal screening regimes, to assess the levels of enrichment efficiency that can be achieved by classifying raw materials.

The use of traditional sieves with sieving surfaces for the classification of raw materials does not ensure the stability of the enrichment results as a result of the adhesion of fine particles of raw materials at high humidity. Based on this, in the practice of screening, the process is transferred to the mode of operation of the screen, where the adhesion of particles is manifested to a small extent. Practical experience in the processing of raw materials shows that this mode is characteristic of the particle size separation $d \geq 20 \mathrm{~mm}$. In the practice of classification of raw materials to increase the efficiency of enrichment E usually implement the lower limit $(d=20 \mathrm{~mm})$. The analysis shows that significant volumes of processed raw materials with a high content of limestone end up in the dump. Accumulation of material in the tailings leads to environmental problems.

In the current situation, it is advisable to change the mode of operation of the screen in such a way as to achieve the maximum value of limestone extraction (Fig. 2). It is necessary to ensure in the mode $d=d_{\text {opt }}$ high screening efficiency $E_{s}$. In conditions of high humidity of raw materials such efficiency is provided by roller screens where openings are continuously cleared of sticking. Increasing humidity helps to reduce the strength 
of clay coatings. There are favorable conditions for their separation by applying to the surfaces of solid parts of raw materials little effort, which is achieved by the use of roll-finger screens.

To exclude the possibility of limestone clamping modes, it is necessary to study the dynamics of material particles. The forces acting on the spherical particle are determined (Fig. 3) and the analytical dependence is obtained, which determines the condition of excluding the mode of its clamping

$$
\frac{\cos \beta \cdot \sin \frac{\alpha}{2}+\cos \gamma \cdot \sin \frac{\alpha}{2}-\cos \left[\beta-\left(\frac{\pi}{2}-\frac{\alpha}{2}\right)\right]}{\cos \beta \cdot \cos \frac{\alpha}{2}-\cos \gamma \cdot \cos \frac{\alpha}{2}}>f,
$$

It is shown that this mode does not the grip angle $\alpha$ and the angle $\beta$, which characterizes the position of the point of contact of the particle material to the finger. The analysis of the functional dependence shows that when the angle $\beta$ increases, the range of acceptable (in terms of eliminating the clamping of particles) values of $\alpha$ is shifted to the zone of decrease in the numerical values of the angle $\alpha$. Changing the coefficient of friction to a small extent does not lead to a significant change in the areas corresponding to the mode of ejection of particles from the danger zone. Determining the functional dependence allows the designers of the screens to check the design to exclude the mode of clamping particles.

In determining the design parameters of the screen, it is advisable to implement the division at the level of $d=d_{\text {opt }}$. It is shown that in the design of a disk with two fingers it is rational to provide the height of the finger $h=d_{\text {opt }}$. In the four-finger design, the size of the hole, which provides a given size of the separation of particles $d$, exceeds the same size in the two-finger design. The value of this excess depends on the design parameters of the disk and should be taken into account when designing screens.

Let's estimate efficiency of use of a screen of a new design in the conditions of change of humidity of initial raw materials. For this purpose, regression mathematical models have been developed to calculate the efficiency of enrichment and classification of the material. 


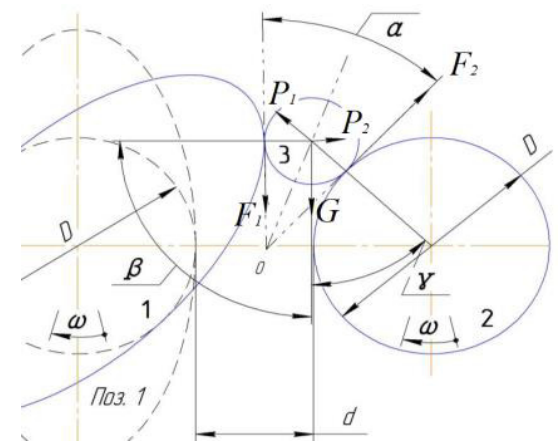

Fig.3. Forces acting on a particle of material

The difficulty of determining the functional relationships between variables that reflect the effectiveness of the processes of classification and enrichment, as well as the parameters that determine them, is the multifactorial nature of the problem, the complexity of the mathematical description of dependencies. Therefore, it is advisable to investigate stochastic relationships between variables, in particular to use regression analysis.

The hypothesis of the adequacy of nonlinear one-factor models is confirmed (1). To do this, the variance of adequacy $S_{a d}^{2}$, the variance of reproducibility of the experiment in parallel experiments $S_{r e p}^{2}$ is determined. The homogeneity of the variances in the experiments was confirmed by applying the Cochren test. The calculated $F_{\mathrm{p}}$ and tabular $F_{\mathrm{t}}$ values of the Fisher test are compared.

To confirm the feasibility of using roller-finger screen in the technological line of raw material beneficiation, it is necessary to create mathematical models to calculate the efficiency of beneficiation $E$ and screening $E_{s}$ in the presence and absence of such screen in the technological line. The formation of models takes into account factors that change significantly in the conditions of production, such as: limestone content $\alpha$ (factor $X_{1}$ ) and moisture $W$ of raw materials (factor $X_{2}$ ). The limits of change of factors $X_{1}$ and $X_{2}$ are determined.

Other factors influencing the values of $E, E_{s}$, in the conditions of experiments remained unchanged. Thus, four regression models have been developed 


$$
\begin{array}{ll}
\hat{Y}_{E C}=b_{03}+b_{11} X_{1}+b_{21} X_{2}, & \hat{Y}_{E S C}=b_{03}+b_{13} X_{1}+b_{23} X_{2} \\
\hat{Y}_{E H}=b_{02}+b_{12} X_{1}+b_{22} X_{2}, & \hat{Y}_{E S H}=b_{04}+b_{14} X_{1}+b_{24} X_{2} .
\end{array},
$$

Here $\hat{Y}_{E C}, \hat{Y}_{E H}, \hat{Y}_{E S C}, \hat{Y}_{E S H}$ - estimates of mathematical expectations of parameters: $\hat{Y}_{E C}$ - parameter $E$ without the use of roller-finger screen; $\hat{Y}_{E H}$ - parameter $E$ in terms of its use; $\hat{Y}_{E S C}$ - parameter $E_{s}$ in the absence of a screen; $\hat{Y}_{E S H}$ - parameter $E_{s}$ in its presence; $b_{i j}$ - regression coefficients.

The matrix method of calculating the coefficients of regression dependences is used. To assess the adequacy of multifactor models (7), the values of adequacy variances $S_{a d}^{2}$ and reproducibility variances $S_{\text {rep }}^{2}$ were determined, and the homogeneity of variances in the experiments was confirmed. The significance of the coefficients $b_{i j}$ in the regression equations (7) is estimated. The application of Fisher's criterion confirmed the adequacy of the developed models.

A factorial experiment of type $\left\langle 2^{2} »\right.$ was performed. Using orthogonal planning, an experimental plan is drawn up.

Table 1

Experiment plan

\begin{tabular}{c|c|c|c|c|c|c|c}
\hline $\begin{array}{c}\text { № } \\
\text { eperiment }\end{array}$ & $X_{0}^{*}$ & $X_{1}^{*}$ & $X_{2}^{*}$ & $\hat{Y}_{E C}$ & $\hat{Y}_{E H}$ & $\hat{Y}_{E S C}$ & $\hat{Y}_{E S H}$ \\
\hline 1 & + & - & - & $Y_{E C 1}$ & $Y_{E H 1}$ & $\hat{Y}_{E S C 1}$ & $\hat{Y}_{E S H 1}$ \\
\hline 2 & + & + & - & $Y_{E C 2}$ & $Y_{E H 2}$ & $\hat{Y}_{E S C 2}$ & $\hat{Y}_{E S H 2}$ \\
\hline 3 & + & - & + & $Y_{E C 3}$ & $Y_{E H 3}$ & $\hat{Y}_{E S C 3}$ & $\hat{Y}_{E S H 3}$ \\
\hline 4 & + & + & + & $Y_{E C 4}$ & $Y_{E H 4}$ & $\hat{Y}_{E S C 4}$ & $\hat{Y}_{E S H 4}$ \\
\hline
\end{tabular}

Modeling of the process of raw material enrichment using dependences (7) shows that $1 \%$ change in moisture content of raw material $W$ leads to a greater change in $E, E_{s}$, than $1 \%$ change in limestone content in raw materials, i.e. the degree of influence of model factors on function feedback is different. The screening efficiency of the parameter $E_{s}$ depends to a small extent on the limestone content $\alpha$. There is a significant dependence of the parameter $E_{s}$ on the mois- 
ture content of raw materials. At increase of humidity of raw materials to $12 \%$ efficiency of parameter $E_{s}$ with use of a roller-finger screen exceeds the existing indicator in 2 times that promotes stabilization of value of this indicator in the course of change of humidity of raw materials (Fig. 4). The increase in the parameter $E_{s}$ is accompanied by an increase in the efficiency of enrichment of the parameter $E$ by $10-20 \%$ (compared to the option without a screen).
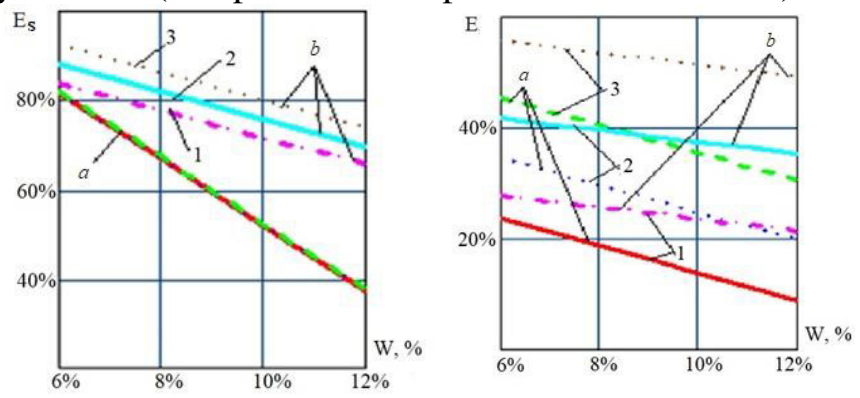

Fig.4. Dependence between screening efficiency $E_{s}$ and enrichment $E$ on limestone content $\alpha$ and humidity $W$ ( $a$-without roll-finger screen; $b$-with screen; $1-\alpha=51 \% ; 2-\alpha=65 \% ; 3-\alpha=79 \%)$

The above confirms the feasibility of using roller-finger screens in the technological lines of enrichment of raw materials of heterogeneous carbonate deposits. The experimental sample developed in laboratory conditions finger screen (Fig. 5) implements the results of theoretical studies performed in terms of its design, modes of operation of screens of this type.

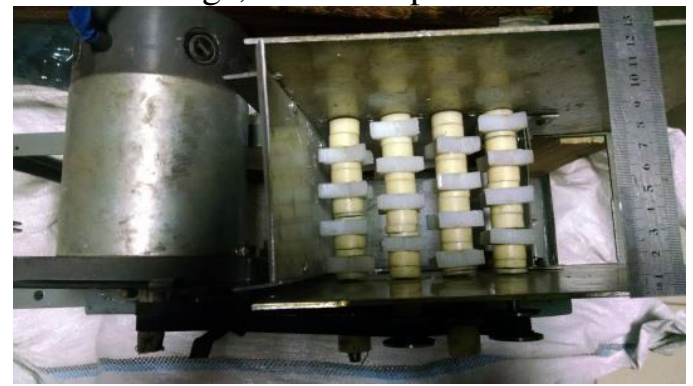

Fig.5. Photo of an experimental sample of the screen

The procedure of sampling for granulometric and chemical analyzes of raw materials is revealed. The results of particle size analysis indicate that the weights of large classes in the raw material are predominant. Chemical analysis confirms the increase in the mass of 
related elements in small size classes. A number of experimental studies were conducted in accordance with the above methods of experiment planning.

During their implementation, the values of the limestone content in the original product and the moisture content of the sample material varied. Modes of classification of materials both with the use of roller-finger screen and without its use were studied. Execution of granulometric and chemical analyzes of sieve and sub-sieve products allowed to determine the achieved indicators of screening and enrichment efficiency, to build on this basis multifactor regression models (7), to perform a comparative analysis of the considered approaches to raw material enrichment (Fig. 4).

The results of the experiments indicate that when using a rollerfinger screen there is an increase in the mass of the sub-sieve product. The mass of clay additives and small particles of limestone increases, and in the case of high humidity (12\%) of the original product, this increase is more noticeable (1.5-2 times), which indicates the feasibility of using roll-finger screens in technological lines of enrichment. It is proposed at the early stage of the process of processing limestone raw materials to classify the material with a rollerfinger screen, ensuring the separation of alumina small particles from larger ones with high limestone content (Fig. 6).

This will allow at an early stage of the processing process to increase the degree of purification of raw materials, improve the working conditions of commercial screens due to the absence of small alumina particles, improve the quality of the resulting gravel. The constructive decisions of rolls and disks of a roll-finger screen are offered and protected by patents. The solution is to place the fingers of the disk relative to the adjacent screen of the screen, using the original mounting fingers on the disk. They ensure the efficiency of the screen, reduce the time of repair work.

Let us turn to the analysis of the efficiency of electricity use by the technological line shown in Fig.6. 


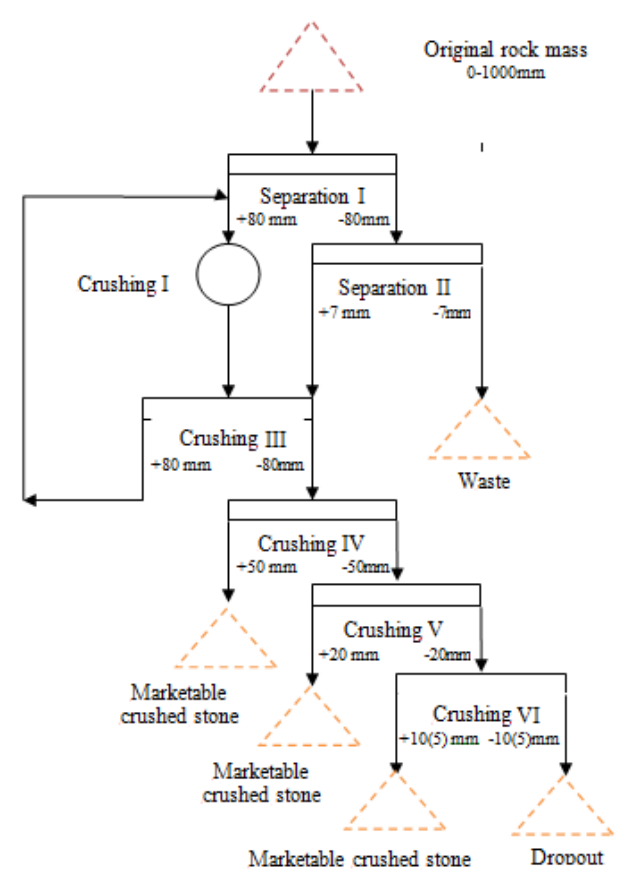

Fig.6. Technological scheme of enrichment with the use of roller-finger screen (separation II)

This scheme of enrichment involves the use in the traditional line of enrichment of an additional element (roll-finger screen). The change in the electrical load of the power supply network of the technological complex is due to the presence of this additional element. The ratio of the average values of power $\left(P^{*}\right)$ of electricity consumed by technological lines with an additional element $\left(P_{\text {add }}\right)$ and without it $\left(P_{\mathrm{abs}}\right)$, determines the quantitative characteristics of such a change. It should be noted that the value of $P^{*}=P_{\text {add }} / P_{\text {abs }}$ can be both smaller and larger than one. It depends on the characteristics of the electrical equipment used. It should also be borne in mind that the presence of a roller-finger screen changes the modes of operation of other elements of the system, reducing the weight of the material to be classified with the release of the product. The energy intensity of the enrichment process must take into account the duration of processing of raw materials. As can be seen from Fig. 4, at the same values of limestone content and its humidity, the value of $E_{s}$ in the 
presence of an additional element $E_{\text {s.add }}$ exceeds the value corresponding to its absence $\left(E_{s . a b s}\right)$. That is, in the presence of a rollerfinger screen, the set value of $E_{s}$ is reached in a shorter period of time. We will assume that the degree of reduction of the time of the classification process is determined by the ratio $T^{*}=E_{s . a b s} / E_{s . a d d}$, which is less than one. Then the relative value of the energy intensity of the process $V^{*}$ (the ratio of energy consumption in the presence and absence of roll-finger screen) is obtained from the dependence

$$
V^{*}=P^{*} \cdot T^{*}
$$

Determination of $V^{*}$ allows to make an approximate assessment of the effectiveness of the introduction of new technology for processing raw materials in terms of its energy efficiency. If the value of $V^{*}$ exceeds one, then the application of new technology requires an increase in energy consumption. If the value of $V^{*}$ is less than one, you should expect a reduction in costs. The proposed method takes into account structural changes in the technological line of enrichment. The implementation of new technology, which involves the use of roller-finger screen, will provide a sustainable change in energy efficiency of the enrichment process. However, there are other components that significantly affect the value of energy intensity of the technological process. Influential factors include the peculiarities of the management of the classification process. Important actions of service personnel (primarily grinding, screening operators) in the process of managing the production line. Usually the control is reduced to the choice of the degree of loading of the line, determining the moments of switching on and off the equipment, the procedure for technological stops. Management should be such as to ensure high efficiency of raw material enrichment with minimum values of specific energy consumption. To do this, operators must reduce the duration of idling modes of the production line, eliminate overload modes, reduce the duration of technological stops. The degree of fulfillment of these requirements depends on the qualifications of service personnel, their motivation to implement the formulated actions. The expediency of introducing control actions to determine the effectiveness of management is obvious.

The task of controlling energy efficiency is not new. The control is carried out by comparing the actual indicators of specific energy 
consumption with the planned ones. Existing differences are subject to analysis and on their basis form actions for process management. There are a number of methods for normalizing the indicators of specific energy consumption. In the conditions of transient changes in the values of specific energy consumption, which is characteristic of the technology of enrichment of limestone raw materials with the implementation of the function of manual process control, it is advisable to use the statistical method of rationing. This method provides sufficient accuracy of the forecast, which allows you to assess the effectiveness of control actions of process operators in a short period of time (per shift, per day). Operational control involves measuring the values of electricity consumed per shift (or day), moisture content of raw materials to be processed, as well as the mass of the resulting product. The values of these parameters, obtained in a volume sufficient for statistical evaluation, are used to construct a regression dependence that determines the planned indicators of energy consumption. It should be noted that the measurement of these parameters with sufficient accuracy is not a time-consuming process and is carried out when collecting statistical information.

It is proposed to use regression dependence to estimate the amount of energy consumed during the change or day of $E_{n}$.

$$
E_{n}=A_{1}+A_{2}(W \cdot N),
$$

where $A_{1}, A_{2}$ - coefficients of regression dependence, $N$ - mass of the product obtained in a given period of time.

The product of $W \cdot N$ takes into account the interaction of two factors influencing (raw material moisture and product weight) on the value of energy consumed. From (9) it is easy to obtain a predicted estimate of the value of specific energy consumption $E_{n}^{*}=E_{n} / N$. In the process of collecting statistical information, it is important to ensure the synchronicity of measuring the values of the dependence parameters (9). Control of energy efficiency allows to assess the contribution of service personnel of the technological complex in the implementation of energy saving tasks. 


\section{Conclusions}

The main scientific and practical results of the work are as follows:

1. Technological lines of dry processing of raw limestone, which are used in quarries, ensure the receipt of marketable products of acceptable quality only for large classes of gravel in conditions of low humidity. Small classes of crushed stone are not used and are sent to the dump. There is a need to improve the existing process of classification and enrichment of raw materials in order to improve the quality of the final product and expand on this basis the fractional composition of commercial gravel that meets the requirements of state standards.

2. The concept of enrichment of raw materials of heterogeneous carbonate deposits is defined, which consists in separation of clay coverings from pieces of rock with the subsequent highly effective screening of a product in quarry conditions. Implementation of the concept involves the use of roller-finger screen, which provides high efficiency at high humidity.

3. New analytical dependences are obtained, which connect the indicators of limestone beneficiation efficiency with the results of granulometric and chemical analyses of raw materials, and the efficiency of its screening. Based on these, a mathematical model was created that allows, with a limited amount of experimental data, the prediction of the achieved indicators of enrichment efficiency, taking into account the characteristics of the applied classification devices.

4. It is shown that the dependence of the raw material enrichment efficiency indicator on the particle size separation by screening devices has an extremum, and the size value corresponding to the maximum of the indicator does not depend on the screening efficiency. This allows you to use the screening mode with the optimal size of the separation of particles, to ensure high efficiency of enrichment, reduce waste from the processing process, and improve the environmental situation in the region.

5. A method for calculating the optimal value of the size of the separation of the material to be classified has been developed. Based on this, an algorithm for calculating the efficiency of beneficiation was created, which allows the obtaining of expanded information 
about the nature of changes in certain parameters with variations in the size of particle separation and screening efficiency.

6 . The use of a roller-finger screen as a combined device that separates clay coatings from pieces of rock and the separation of particles by size (including conditions of high humidity of raw materials), improves the efficiency of screening. Based on the study of the dynamics of the material particle, the determination of the forces acting on the particle, an analytical dependence is obtained, which determines the condition of excluding the mode of its clamping. It is proved that this mode does not depend on the levels of forces acting on the particle, but is determined exclusively by the values of the angles that characterize the positions of the points of contact of the particle to the finger and the lining shaft.

7. Linear regression multifactor models have been created to study the processes of enrichment and classification of raw materials, where the values of limestone content in raw materials and material moisture are used as factors, and the values of enrichment and screening efficiency indicators are used as response functions. The models allow comparison of the efficiency of screening and enrichment processes in the classification variants with and without the use of a roller-finger screen.

8. The application of Fisher's test confirmed the hypotheses about the adequacy of the developed nonlinear one-factor and linear multifactor regression models. This determines the high reliability of the results of modeling the processes of enrichment and screening of limestone.

9. With an increase of humidity of raw materials to $12 \%$ efficiency of screening of a roller-finger screen exceeds the similar indicator without its use by $30-35 \%$. The presence of a roller-finger screen is manifested in its stabilizing effect on the classification process, accompanied by an increase in the efficiency of enrichment by 10 $20 \%$. Thus, the expediency of using roll-finger screens in technological lines of enrichment of raw materials of carbonate deposits is proved.

10. A method is available for estimating the ratio of energy consumption of existing and proposed technologies for enrichment of raw materials, which allows to determine the feasibility (in terms of 
energy efficiency of the process) of introduction into the technological line of enrichment of a roll-finger screen.

11. The structure of the regression model for normalization of the indicator of specific energy consumption by the technological line of enrichment of limestone raw materials is offered. Operational control of energy efficiency by the technological line allows evaluation of the actions of operators of the process of enrichment of raw materials in the direction of reducing specific energy consumption.

\section{References}

1. Dreshpak, O. (2015). Analysis of limestone processing technology from inhomogeneous carbonate deposits, International scientific-practical conference on Problems of energy efficiency and automation in industry and agriculture. Kirovograd, Ukraine.

2. Dreshpak, O. (2016). Determination of dependences of limestone raw materials of Zapadno-Tyaginsky inhomogeneous carbonate deposit, $5^{\text {th }}$ International scientific-practical conference for young scientists and students on Actual problems of modern technologies. Ternopil, Ukraine.

3. Dreshpak, O. (2017). The features of methodology for predicting limestone dressing efficiency.International scientific-practical conference on Energy efficiency and energy saving. Dnipro, Ukraine.

4. Dreshpak, O. (2018). Mathematical model for calculating enrichment efficiency. Forum of students and young scientists "Widening our horizons". Dnipro, Ukraine.

5. Dreshpak, O. S. (2015). Determination of the degree of impoverishment of limestones of the Zapadno-Tyaginskoye deposit. Enrichment of minerals, 61(102), 56-58.

6. Dreshpak, O. S. (2018). Features of the design of the shaped disks of the roller-finger screen. Enrichment of minerals, 70(111), 6-17.

7. Dreshpak, O. S. (2018). Efficiency of beneficiation and classification of raw materials from a heterogeneous carbonate deposit. Collection of scientific works of the National Mining University, 56, 175-183.

8. Pilov, P.I., \& Dreshpak, O.S. (2019). Mathematical model for predicting limestone enrichment indicators. Journal of energy for a clean environment, 18(4), 319-333.

9. Dreshpak, N.S., Vypanasenko, S.I., \& Dreshpak, O.S. (2021). Accounting for electricity in control systems for the efficiency of its use. Mining electromechanics and automation, 103, 20-25.

10. Dreshpak, N.S., \& Vypanasenko, S.I. (2015). Informational and methodological support for energy efficiency control. Power Engineering, Control and Information Technologies in Geotechnical Systems, 1, 53-59.

11. Dreshpak, N.S., \& Vypanasenko, S.I. (2015). Algorithm for forecasting energy efficiency of steel production. Mining electromechanics and automation, 97, 108-112. 
12. Vypanasenko, S.I., \& Dreshpak, N.S. (2013). The features of energy efficiency measurement and control of production processes. Energy Efficiency Improvement of Geotechnical Systems, 1, 71-78.

13. Dreshpak, N.S., Dreshpak, O.S., \& Vypanasenko, S.I. (2021). Specific norms of energy consumption in the task of controlling the efficiency of its use. "Electrical engineering and electric power engineering", 3, 31-39.

https://doi.org/10.31713/m1108

\section{DESIGN-INDUCED OPERATIONAL CHANGES OF STRESS-STRAIN STATE IN FLAT RUBBER-CABLE TRACTIVE ELEMENT OF HOISTING AND TRANSPORTING MACHINE}

Kolosov D.L.

Dnipro University of Technology, Dnipro, Dr. Sc. (Tech.), Associate Prof., Head of Department of Structural, Theoretical and Applied Mechanics, Ukraine

Samusia V.I.

Dnipro University of Technology, Dnipro, Dr. Sc. (Tech.), Associate Prof., Head of Department of Mining Mechanics, Ukraine

\section{Bilous O.I.}

Dniprovsk State Technical University, Kamianske, Cand. Sc. (Tech.), Associate Prof., Associate Prof. of Department of Mechanical Engineering, Ukraine

\section{Tantsura H.I.}

Dniprovsk State Technical University, Kamianske, Cand. Sc. (Tech.), Associate Prof., Associate Prof. of Department of Mechanical Engineering, Ukraine

\section{Onyshchenko S.V.}

Dnipro University of Technology, Dnipro, Cand. Sc. (Tech.), Associate Prof. of Department of Structural, Theoretical and Applied Mechanics, Ukraine

Abstract.

Main indicators of a stress-strain state (SSS) of a rubber-cable belt, the rubbercable rope for a random placement pattern and the size of the part with broken cables, including partially removed cables, with cable breakages and their random 
amount, different conditions of belt interaction in its cross-sections of connection to structural elements of a conveyor and a lifting machine to ensure control of its tractive ability during the life cycle. Performed researches clarify the idea of the interaction mechanism of reinforcing elements in composite materials of layered structure with hard and soft layers. Obtained results can be used for development and justification of a unified technology of creation and engineering support of operation of lifting and transporting machines with flat tractive-bearing elements with increased life-span, level of efficiency and operational safety in systems of extraction, transportation and processing of minerals.

\section{Introduction}

Lifting and transporting complexes are the most important link in the chain of mineral extraction. The economic efficiency and social stability of a mining complex $[1,2]$ as a whole depend on an uninterrupted and safe operation of lifting and transporting complexes [3]. Effective and trouble-free operation of lifting and transporting machines, including ones with flat tractive-bearing elements, can be provided by creation and realization of bases of scientifically justified engineering support throughout the life cycle their operation.

Rubber-cable flat belts (RCB) are used in lifting and transporting engineering. They perform the function of tensile force transmission. Transported material is on the conveyor belt. Conveyor belts have a closed form. Rubber-cable and rubber-fabric flat belts have a system of tractive elements located along its longitudinal axis. Reinforcing elements are placed with the same spacing along the belt width. An elastic shell provides the structural integrity of tractive elements into which they are packed. Tractive elements are broken during operation. Belts can be used in sifting machines, in conveyors for partial water discharge during the transportation of moist lumpy mass. To do this, it is enough to make holes in a belt.

Formation of artificial holes and breakage of tractive elements during the belt operation lead to a change in their structure. Changing the structure leads to a change in a mechanism of interaction of reinforcing elements. This change leads to a redistribution of loads between the reinforcing elements, occurrence of tangential stresses in a belt shell and, eventually, to a reduction of tractive ability of a flat belt (rope).

Reduction of a tractive ability can lead to unpredictable consequences. The variety of possible patterns of changing the structure of a belt reinforcement due to a need to adapt the belt to the needs of technological process, design features of the machine, the breakage 
of its elements during the operation process requires the solution of the actual task - the development of a single method for determining the stress-strain state of a flat elastic belt reinforced with longitudinal tractive elements.

\section{State of Question and Statement of Research Problem}

Conveyors of various designs, including steeply inclined [4], with a suspending belt [5, 6], tubular [7], are designed for transportation of considerable amounts of material. They are mostly equipped with rubber-cable belts. Belt cables can have ruptures of continuity. So the continuity of tractive elements is ruptured in butt-joint connections. The connections are performed in order to obtain a belt of considerable length, to provide it with a closed form on the conveyor. The ruptures of continuity of cables lead to a decrease in endurance and strength of belts [8,9], in particular in butt-joint connections [10]. Properties of butt-joint connections of rubber-cable conveyor belts that were in operation are investigated in [11]. The holes can be made in belts [12]. Cables can break during operation of belts. Tractive ability and operational reliability of belts [13] and their butt-joint connections [14] are reduced during operation.

Reduction of a tractive ability of ropes and belts can lead to unpredictable consequences. Failure of conveyors due to a failure of belts and support rollers in the air-salt medium reaches $47 \%$ [15]. The method for determining the value of a safe load on a belt with defects is justified in [16]. It is based on empirical dependency and does not involve the case of removal of cable parts. The issue of determining the reduced mechanical characteristics of composite materials reinforced by a system of regularly arranged, parallel reinforcing elements of nonsignificant rigidity is depicted in [17]. The effect of the geometric parameters of the rubber-cable belt on its stress-strain state in the interaction with clamping elements on the driving drum winder is investigated in [18].

Paper [19] suggests an algorithm for determining the stress-strain state of a flat rubber-cable rope with one broken cable, considering the deviation of a drum generatrix from a straight line. The possibility of consideration of design parameters of a machine by means of assigning certain boundary conditions of loading of a rubber belt (rope) is displayed.

Known algorithms for determining a stress-strain state of a flat rubber-cable conveyor belt, a rope of a lifting machine can't be used to determine a tractive ability of a belt with various cable disturb- 
ances, including belts with systematically located holes.

Rubber-cable belts consist of a system of parallel cables, located along the belt in the same plane. Rubber-fabric belts have a system of parallel threads located in several planes. In a case of longitudinal loading, including the case of formation of through holes, the threads are located in parallel planes and deform in the same manner. Mechanisms of deformation of rubber-cable and rubber-fabric belts can be considered close. Consider a rubber-cable belt, which is used as a flat rope. Along the belt width, the cables are located with a constant spacing and packed into an elastic shell. Longitudinal deformations of cables are much larger than their deformations in the plane of a belt. The elastic shell takes almost only shear stress. Deformations of cables are insignificant in the plane of a belt. Neglect the influence of a difference between the twisting angles of adjacent cables in the plane of a belt to the values of tangent stresses in the elastic material. The specified allows considering rubber-cable belt as a composite material of regular layered structure with rigid and soft layers.

Breakages of a tractive core of the belt, made artificially or those that occurred during the operation rupture the regular structure of the belt. Belts with random breakages of reinforcing elements partially lose a regularity of placement of reinforcing elements. The latter case can be considered as a separate case of a regular change in the belt structure. Belts interact with elements of conveyors of various designs.

Mechanical properties of the belt, including its strength, depend on the amount, relative placement, mechanical properties of reinforcing elements and shell material, and the character of distribution of forces between tractive elements. The task of determining the distribution of forces between tractive elements is statically indeterminate. The distribution of forces depends on a character of interaction of the belt with individual structural elements of the conveyor. The formation of holes in such belts is connected to the partial removal of reinforcing elements and the reduction of its tractive ability.

The task is to create an algorithm for determining the main indicators of the stress-strain state of a rubber-cable belt and a rubber-cable rope for a random placement pattern and the size of the part with broken cables, including partially removed cables, with cable breakages and their random amount, different conditions of belt interaction in its cross-sections of connection to structural elements of a conveyor and 
a lifting machine to ensure control of its tractive ability during the life cycle.

\section{Belt with Regular Ruptures of Continuity of Cable Groups}

The main tractive elements of a belt and a rope are cables. A rubber-cable rope of the lifting machine and a rubber-cable belt are called a belt henceforth. Belt cables consist of strands. Strands consist of wires. Wires in strands as well as strands in cables are twisted. This structure leads to a twisting moment of a cable when it is loaded with longitudinal force. In order to balance the twisting, the belt structure has an even number of cables. Correspondingly, the number of removed tractive elements in a special hole in the belt should be even. The number of broken cables in a general case can be random.

The lengths of conveyors on which rubber-cable belts are installed are significant. This allows disregarding the circular (closed) shape of a belt. Consider a belt in which two opposite edges are attached to structural elements of a conveyor. The load character of a belt on the conveyor is determined by its structure. Features of interaction of a belt with conveyor drums can be defined by boundary conditions.

Considering the upper-mentioned and in order to obtain a solution for a general case, consider the rubber-cable belt with a length $l_{1}+l_{2}$. The belt has $M+N$ cables. Broken (removed) group of $N$ cables out of these $M+N$ cables is located on the part of a belt with length $l_{2}$. The group is located at the edge of the belt. It is loaded with a tensile force $P$ at random boundary conditions. Cables have a considerable tensile rigidity. The main deformation of the elastic shell is its shear between the cables.

Cable displacements in a belt, as a layered structure with hard and soft layers can be determined by dependency [19], which is obtained from the condition of cables equilibrium on a belt part of a constant regular structure

$$
u(i, x)=\sum_{n=1}^{M-1}\left(\frac{A_{n} e^{\beta_{n} x}+B_{n} e^{-\beta_{n} x}}{\beta_{n}}\right) \cos \left(\mu_{n}(i-0.5)\right)+\frac{P x}{Z E F}+c,
$$

where $u(i, x)$ - displacement of a cable $i(1 \leq i \leq Z)$ in a crosssection $x ; A_{n}, B_{n}, c$ - unknown constants;

$$
\mu_{n}=\frac{\pi n}{Z} ; \beta_{n}=\sqrt{\frac{2 G k_{G}}{(t-d) E F}\left(1-\cos \left(\mu_{n}(i-0.5)\right)\right)} ; Z, d, t \text { - amount, }
$$


diameter and spacing of cable placement in a belt; $E, F$ - reduced tensile rigidity of a cable and its cross-sectional area; $G$ - reduced shear modulus of an elastic shell of the belt; $k_{G}$ - the coefficient that considers the influence of the elastic shell material shape located between the cables.

Rupture of integrity of cables leads to a rupture of a belt structure and eliminates the possibility of using (1). Use the method of crosssections. Cut the belt into two parts along the location of a crosssection of cable breakage (along the cross-section of their amount change in parts of a belt). Within each of these parts of a belt its structure is unchanged. Expression (1) is applicable for each part. For the first part the amount of cables $Z$ equals $M+N$. For the second one $Z=M$. The stress-strain state of the entire belt can be determined if the condition of joint deformation of both parts and the condition of loading of belt boundaries is ensured.

Give belt parts numbers 1 and 2 . The numbers are written in the indexes of parameters related to the first and second parts of the belt. The beginning of the $x$-axis is located on the common boundary of both parts. Formulate boundary conditions and condition of joint deformation of belt parts.

Assume that deformations at the belt edges are defined by func$f_{1}(i)=\sum_{n=1}^{M+N} F_{1, n} \cos \left(\mu_{1, n}(i-0.5)\right)$
$f_{2}(i) \sum_{n=1}^{M} F_{2, n} \cos \left(\mu_{2, n}(i-0.5)\right)$. Formulate boundary conditions: in a cross-section

$$
x=-l_{2} \quad u_{2, i}=f_{2}(i), \sum_{i=1}^{M} p_{i}=P
$$

and when

$$
x=l_{1} \quad u_{1, i}=f_{1}(i), \quad \sum_{i=1}^{M+N} p_{i}=P,
$$

where $p_{i}$ - tensile force of cable $i$.

Conditions of joint deformation of parts (in a cross-section $x=0$ ) 


$$
\begin{gathered}
u_{1, i}=u_{2, i}(1 \leq i \leq M), \\
p_{1, i}=p_{2, i} \quad(1 \leq i \leq M), \\
p_{1, i}=0(M<i \leq N+M) .
\end{gathered}
$$

From the boundary conditions the following dependencies are formulated

$$
\begin{aligned}
& A_{1, n}=\left(F_{1, n}-B_{1, n} e^{-\beta_{1, n} l_{1}}\right) e^{-\beta_{1, n} l_{1}}, \\
& A_{2, n}=\left(F_{2, n}-B_{2, n} e^{\beta_{2, n} l_{2}}\right) e^{\beta_{2, n} l_{2}} .
\end{aligned}
$$

The obtained ratios allow reducing the amount of unknowns in expressions for displacements and internal loads of cables in a belt

$$
\begin{gathered}
u_{1}(i, x)=\sum_{n=1}^{M+N-1}\left(F_{1, n} e^{-\beta_{1, n} l_{1}} e^{\beta_{1, n} x}+B_{1, n}\left(e^{-\beta_{1, n} x}-e^{-2 \beta_{1, n} l_{1}} e^{\beta_{1, n} x}\right)\right) \times \\
\quad \times \frac{\cos \left(\mu_{1, n}(i-0.5)\right)}{\beta_{1, n}}+\frac{P x}{(M+N) E F}+c_{1}, \\
u_{2}(i, x)=\sum_{n=1}^{M-1}\left(F_{2, n} e^{\left.\beta_{2, n} l_{2} e^{\beta_{2, n} x}+B_{2, n}\left(e^{-\beta_{2, n} x}-e^{2 \beta_{2, n} l_{2}} e^{\beta_{2, n} x}\right)\right) \times}\right. \\
\times \frac{\cos \left(\mu_{2, n}(i-0.5)\right)}{\beta_{2, n}}+\frac{P x}{M E F}+c_{2} .
\end{gathered}
$$

Coefficient $c_{1}$ is assumed zero. Then $c_{2}=u_{1}(i, 0),(1 \leq i \leq M)$

Expressions of displacement (6), (7) include unknown vectors of displacements with values $N+M-1$ and $M-1$. In order to reduce the number of vectors of unknown constants, the first $(M-1)$ constants of a vector $B_{1, m}$ are expressed through unknown constant $B_{2, n}$. The numbers of cables are considered as a discrete coordinate axis. Internal forces occurring in cables of the first part are written in a form of Fourier series on a segment $(0<i<M+N+1)$ 


$$
\begin{aligned}
& p_{1}(i, x)=\frac{2 E F}{M+N} \times \\
& \times \sum_{m=1}^{M+N-1}\left[\begin{array}{l}
\sum_{n=1}^{M-1}\left(\times \sum_{j=1}^{M} \cos \left(\mu_{2, n}(j-0.5)\right) \cos \left(\mu_{1, m}(j-0.5)\right)\right. \\
\beta_{2, n} l_{2}+B_{2, n}\left(1-e^{2 \beta_{2, n} l_{2}}\right) \times \\
+\sum_{j=M+1}^{M+N} B_{1, j} \cos \left(\mu_{1, m}(j-0.5)\right)
\end{array}\right] \times \\
& \times\left(\frac{e^{-\beta_{1, m} l_{1}} e^{\beta_{1, m} x}+e^{-\beta_{1, m} x}}{e^{-\beta_{1, m} l_{1}}-1}\right) \cos \left(\mu_{1, m}(i-0.5)\right)+\frac{P}{M+N} .
\end{aligned}
$$

In the resulting expression, the sum of members with unknown values of a vector of constant $B_{2, n}$, reproduces the condition of equality of loads of cables belonging to the first and second parts in the cross-section $x=0$. The sum of members of an unknown vector $B_{1, j}(M \leq j \leq M+N-1)$ describes the distribution of forces between cables of the first part, the ends of which are located in the same cross-section.

The internal loading forces of cables of the second part are determined from (7) by Hooke's law

$$
\begin{gathered}
p_{2}(i, x)= \\
=\sum_{n=1}^{M-1}\left(F_{2, n} e^{\beta_{2, n} l_{2}} e^{\beta_{2, n} x}-B_{2, n}\left(e^{-\beta_{2, n} x}-e^{2 \beta_{2, n} l_{2}} e^{\beta_{2, n} x}\right)\right) \times \\
\times \cos \left(\mu_{2, n}(i-0.5)\right) E F+\frac{P}{M} .
\end{gathered}
$$

Accepted forms of solutions ensure the implementation of condition of equality of forces in terms of joint deformation of parts of an unbroken cable belonging to both parts of the belt (4). The condition of equality of displacements of cables with numbers $1 \leq i \leq M$ in a cross-section $x=0$ and the condition where internal forces in cables are equal to zero, that were determined in conditions of joint deformation of belt parts (4), allow creating a system of algebraic equations of order $M+N-1$. The belt has $M+N$ cables in the first part. 
Note that the expressions of internal forces (8) and (9) have two components. The first depends on a cable number and a value of coordinate $x$. The second is a constant value. The sum of forces defined only by the first components equals zero. This allows not defining the condition of load absence for one of the cables with a number greater than $M$. The specified condition is executed automatically. Order of the system of equations $M+N-1$ is sufficient to determine all unknown constants.

Known values of constants allow determining the distribution of forces between cables and their displacements. The displacements allow determining the tangential forces transmitted by the elastic shell located between the cables. Tangential forces are proportional to displacement angles of elastic shell material. Tangents of displacement angles are determined by the difference in displacements of adjacent cables related to the distance between them.

Belt strength is determined by maximum loads of cables and forces transmitted by an elastic shell between them. The maximum loaded cable is adjacent to the broken one in the breakage crosssection. Expression (8) makes it possible to find this maximum force

$$
\begin{aligned}
p_{\max }= & \sum_{n=1}^{M-1}\left(F_{2, n} e^{\beta_{2, n} l_{2}}-B_{2, n}\left(1-e^{2 \beta_{2, n} l_{2}}\right)\right) \times \\
& \times \cos \left(\frac{\pi n}{2 M}\right)(-1)^{n} E F+\frac{P}{M} .
\end{aligned}
$$

The maximum tangential forces are transmitted by an elastic shell in the part at the end of a broken cable adjacent to the unbroken one. They correspond to the maximum displacement angle. The tangent of maximum displacement angle is determined by the dependency

$$
\begin{gathered}
\alpha_{\max }=\sum_{n=1}^{M+N-1}\left(F_{1, n} e^{-\beta_{1, n} l_{1}}+B_{1, n}\left(1-e^{-2 \beta_{1, n} l_{1}}\right)\right) \times \\
\times \frac{\cos \left(\mu_{1, n}\left(M-\frac{1}{2}\right)\right)-\cos \left(\mu_{1, n}\left(M+\frac{1}{2}\right)\right)}{\beta_{1, n}} .
\end{gathered}
$$

A condition, that the group of adjacent cables at the edge of the belt is broken (removed) is accepted above. The results obtained are also acceptable in a case when a group of broken cables is symmetrically 
located along the longitudinal axis of the belt. This is due to the fact that in the symmetry plane there are no tangential stresses in a rubber shell, as they do not occur on the belt side. The difference is in the fact that in a case of breakage of a group of cables in the middle of the belt the number of broken $N$ and unbroken $M$ cables in the expressions above should be taken twice as small as the actual ones. Thus, (10) and (11) are also acceptable for the case when broken cables are located in the middle of a belt. Locations of breakages at the edge of a belt and symmetrically to its axis are extreme cases. Correspondingly, indicators of a stress-strain state for other cases do not exceed the indicators specified for two cases.

Obtained expressions of maximum internal forces taken by cables and the maximum values of tangents of displacement angles determine the maximum values of indicators of a stressstrained state of a rubber-cable belt.

Consider using the offered method on an example of a belt type RCB-3150. In order to remove moisture from washed agricultural products, holes are made in a conveyor belt with a removal of parts of longitudinal tractive elements. Tractive elements, in general, may not be metallic. But their longitudinal deformations greatly exceed their normal displacements in the belt plane. Elastic shell transfers shear stresses. Uniform moisture drainage, regardless of the location of holes in a belt, that moves and has a closed form, can be provided with a uniform hole placement along the length and width of the belt.

Assume that the holes have dimensions $l_{2} \times b$. Place $x$-axis along the belt. The start of axis is on the boundary of a random row of holes (Fig. 1).

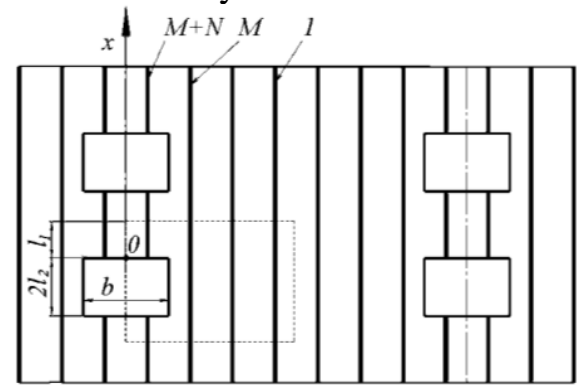

Fig. 1. Diagram of placement of tractive elements and holes with dimensions $l_{2} \times b$ on a belt

Give numbers to cables from one to $M+N$. Value $M+N$ deter- 
mines the amount of cables in a symmetrical part of a repeating element of the belt. Value of the amount of cables $N$ depends on a hole width and a cable placement spacing and is determined by the formula $N=b / 2 t$. Cables are shown with thickened lines. Show the symmetrical part of a repeating belt element with a system of holes arranged with a constant spacing, along the belt and along its width using dash lines. The symmetry of the specified element leads to the following features of its deformation. Cross-sections in planes of symmetry, located normally to $x$-axis, don't curve. Displacements of reinforcing elements located symmetrically to the edge of the hole of parallel axis are equal. Tangential stresses do not occur in the rubber between specified tractive elements during the belt loading with tensile forces. There are no tangential stresses in the area near a hole.

In a part $x>0$ the amount of tractive elements is $M+N$. In a part $x<0-M$. As performed before, split the belt into two parts by a cross-section $x=0$. Indicate them with numbers 1 and 2 . The numbers are used as indexes to indicate the values of the corresponding belt part.

Formulate boundary conditions

a) in a cross-section

$$
x=l_{1} \quad u_{2 i}=u_{1, i \pm 1}, p_{1, i}=\frac{P}{M+N},
$$

b) in a cross-section

$$
x=\frac{l_{2}}{2} \quad u_{2 i}=u_{2, i \pm 1} .
$$

At boundary (12) we have $F_{1, n}=0(1 \leq n \leq M+N)$. From condition (13) $-A_{2, n}=0(1 \leq n \leq M)$.

Displacements and internal loading forces of cables are determined from (6)-(9) and appear as shown in (14)-(17).

Using Hooke's law in (8), determine displacements of cables of the first belt part.

Use the conditions of joint deformation of belt parts (4). Construct a system of algebraic equations of order $M+N-1$ (18). 


$$
\begin{aligned}
& u_{1}(i, x)=\sum_{n=1}^{M+N-1} B_{1, n}\left(e^{-\beta_{1, n} x}-e^{-2 \beta_{1, n} l_{1}} e^{\beta_{1, n} x}\right) \times \\
& \times \frac{\cos \left(\mu_{1, n}(i-0.5)\right)}{\beta_{1, n}}+\frac{P x}{(M+N) E F}, \\
& u_{2}(i, x)=\sum_{n=1}^{M-1} B_{2, n}\left(e^{-\beta_{2, n} x}-e^{2 \beta_{2, n} l_{2}} e^{\beta_{2, n} x}\right) \times \\
& \times \frac{\cos \left(\mu_{2, n}(i-0.5)\right)}{\beta_{2, n}}+\frac{P x}{M E F}+c_{2}, \\
& p_{1}(i, x)=\sum_{m=1}^{M+N-1}\left[\begin{array}{l}
\sum_{n=1}^{M} B_{2, n}\left(\frac{e^{-\beta_{2, n} l_{2}}-1}{\beta_{2, n}}\right) \times \\
\left.\times \sum_{j=1}^{M} \cos \left(\mu_{2, n}(j-0.5)\right) \cos \left(\mu_{1, m}(j-0.5)\right)+\right] \times \\
+\sum_{j=M+1}^{M+N} B_{1, j} \cos \left(\mu_{1, m}(j-0.5)\right)
\end{array}\right] \\
& \times\left(\frac{e^{-\beta_{1, m} l_{1}} e^{\beta_{1, m} x}+e^{-\beta_{1, m} x}}{e^{-\beta_{1, m} l_{1}}-1}\right) \beta_{1, m} \cos \left(\mu_{1, m}(i-0.5)\right) \frac{2 E F}{M+N}+\frac{P}{M+N} \text {, } \\
& p_{2}(i, x)=\sum_{n=1}^{M} B_{2, n}\left(e^{-\beta_{2, n} l_{1}} e^{\beta_{2, n} x}+e^{-\beta_{2, n} x}\right) \times \\
& \times \cos \left(\mu_{2, n}(i-0.5)\right) E F+\frac{P}{M} .
\end{aligned}
$$




$$
\left\{\begin{array}{c}
\sum_{n=1}^{M-1} B_{2, n}\left(\frac{e^{-\beta_{2, n} l_{2}}-1}{\beta_{2, n}}\right)\left(\begin{array}{l}
\sum_{j=1}^{M} \cos \left(\mu_{2, n}(j-0.5)\right) \sum_{m=1}^{M+N-1} \frac{2 \cos \left(\mu_{1, m}(i-0.5)\right)}{M+N} \times \\
\times \cos \left(\mu_{1, m}(j-0.5)\right)-\cos \left(\mu_{2, n}(i-0.5)\right)
\end{array}\right)+ \\
+\sum_{j=M+1}^{M+N} B_{1, j} \sum_{m=1}^{M+N-1} \cos \left(\mu_{1, m}(i-0.5)\right) \frac{2}{M+N} \cos \left(\mu_{1, m}(j-0.5)\right)=0, \\
\quad \sum_{n=1}^{M} B_{2, n}\left(\frac{e^{-\beta_{2, n} l_{2}}-1}{\beta_{2, n}}\right) \sum_{j=1}^{M} \cos \left(\mu_{2, n}(j-0.5)\right) \times \\
+\sum_{m=1}^{M+N-1} \cos \left(\mu_{1, m}(j-0.5)\right)\left(\frac{e^{-2 \beta_{1, m} l_{1}}+1}{e^{-2 \beta_{1, m} l_{1}}-1}\right) \beta_{1, m} \cos \left(\mu_{1, m}(i-0.5)\right)+ \\
+\sum_{j=M+1}^{M+N} B_{1, j} \sum_{m=1}^{M+N-1} \cos \left(\mu_{1, m}(j-0.5)\right)\left(\frac{e^{-2 \beta_{1, m} l_{1}}+1}{e^{-2 \beta_{1, m} l_{1}}-1}\right) \beta_{1, m} \cos \left(\mu_{1, m}(i-0.5)\right)= \\
(M+1 \leq i \leq M+N-1) .
\end{array}\right.
$$

The width of holes $b$ is proportional to the amount of tractive elements. Set their amount equal to two and four. Solve the system of equations for these conditions. Find unknown constants. Determine the internal tensile forces of belt cables, their displacements, tangents of displacement angles of elastic material of a belt shell.

The concept of stress concentration factor is used in engineering practice. Analogically, define the tensile load concentration factor of tractive elements. The load concentration factor is the internal tensile force of a tractive element related to their average value on a belt part with $M+N$ cables. The load concentration factor depends on a change of the amount of cables in the belt part and a character of redistribution of forces between them. Considering the specified, the value of load concentration factor is considered a product of a relative load concentration factor $k_{r}$ and the coefficient of change of the amount of cables in the belt part with a reduced amount of cables, namely

$$
k_{n}=\frac{M+N}{M} \text {. }
$$

Then 


$$
k=k_{r} k_{n} .
$$

Similarly, values of cable displacements, values of tangents of displacement angles are considered as products of relative displacements, relative tangents of shear angles of the elastic layer and the coefficient of change in the number of cables in the belt part with a reduced amount of them, namely:

$$
\begin{aligned}
& u=u_{r} k_{n}, \\
& \alpha=\alpha_{r} k_{n} .
\end{aligned}
$$

Fig. 2 shows the distribution of relative load concentration factors, displacements and tangents of shear angles for the case $l_{1}=1 \mathrm{~m}$, $l_{2}=1 \mathrm{~m}, M=7, N=3$, in the cross-section $x=0$.

According to the graphs, the load concentration factors, and the shear angles achieve maximum values for cables adjacent to the broken cables and in the elastic shell between the continuous and broken cables. This is a consequence of the maximum gradient of displacements of adjacent unbroken and broken cables. The value of the relative load concentration factor is 1.17 , and the load concentration factor is 1.671 .

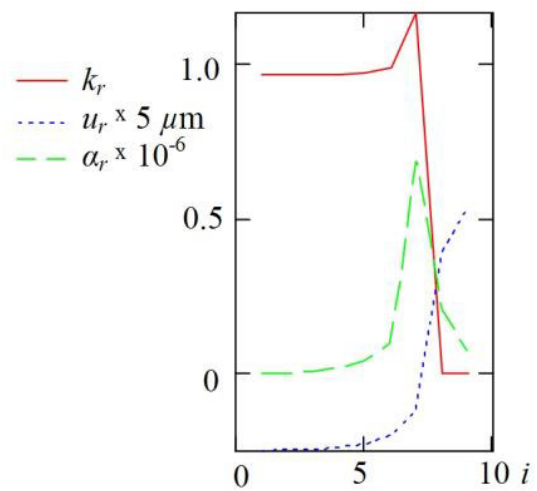

Fig. 2. Distribution of relative load concentration factors $\left(k_{r}\right)$, that occur in cables with numbers $i$, relative displacements $\left(u_{r}\right)$ and tangent of shear angles of elastic inter-cable layer $\left(\alpha_{r}\right)$ in a cross-section $x=0$

The stress-strain state of the belt under given boundary conditions depends on a number of factors such as size of belt parts, the amount of cables, including the broken. Fig. 3 shows the graphs of dependencies of maximum values of relative load concentration factors and relative shear angles tangents for the case $l_{2}=1 \mathrm{~mm}$. The length of the first one is $1 \mathrm{~mm}, 1,2,3, \ldots, 10 \mathrm{~m}$. The amount of cables $M=7, N=3$. 
Fig. 3 shows an increase in the load concentration factors and shears with increasing length of the first belt part if the length of the latter does not exceed $10 \mathrm{~m}$. This character of change of these parameters is a consequence of a joint effect of a local change in a belt structure and a limited belt deformation in the cross-section $x=l_{1}$.

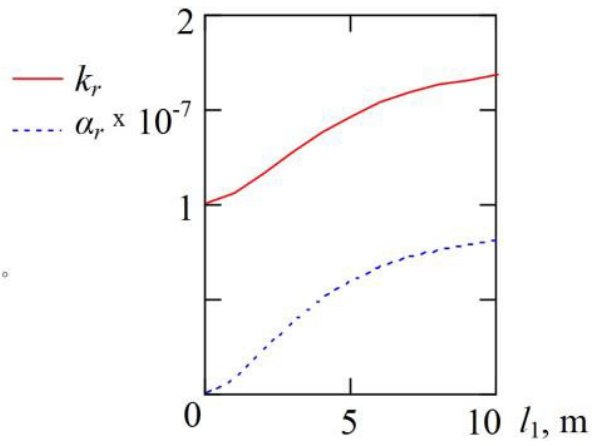

Fig. 3. Dependency of maximum values of relative internal load concentration factors $\left(k_{r}\right)$, that occur in cables and maximum shear angles tangents of elastic intercable layer $\left(\alpha_{r}\right)$ in a cross-section $x=0$ on the length of the first belt part and the length of the second part of $1 \mathrm{~mm}$

Consider the case of a constant length of the first part $l_{1}=10 \mathrm{~m}$. The length of the second one is $1 \mathrm{~mm}, 1,2,3, \ldots, 10 \mathrm{~m}$. According to St. Venant's principle, with increasing distance from the place of local perturbation of the stress-strain state, the latter approaches the uniform state. Belt cross-section that passes through the middle of the second part is the most distant from a cross-section of cable amount change. Considering this fact, determine the values of load concentration factors in the cross-sections $x=0$ and $x=l_{2}$, and maximum values of coefficients and shear (Fig. 4).

Shown calculation results indicate that the values of maximum stresses in the belt decrease with increasing length of the part where cables are partially removed. Maximum shears and load concentration factors decrease provided that the length of the belt part with removed cables does not exceed $5 \mathrm{~m}$. Maximum load concentration factors in the middle part are smaller than the corresponding concentration factors in the cross-section $x=0$. They decrease provided that the length of the belt part with removed cables does not exceed $11 \mathrm{~m}$. Tangential stresses in the middle section of the second belt part are absent. 


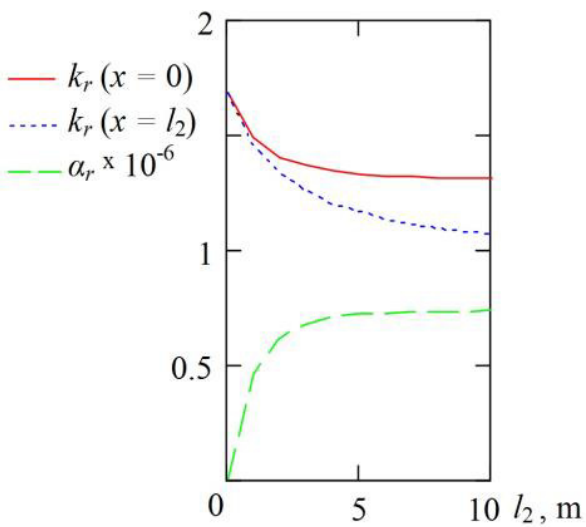

Fig. 4. Dependency of values of relative internal load concentration factors $\left(k_{r}=0\right)$ that occur in cables in a cross-section $x=0, k_{r}\left(x=l_{2}\right)$ in a cross-section $x=l_{2}$ and maximum shear angle tangents of elastic inter-cable layer $\left(\alpha_{r}\right)$ on the length of the second belt part and the length of the first part of $10 \mathrm{~m}$

The influence of the amount of partially removed cables on the stress state of the belt is shown in the Fig. 5.

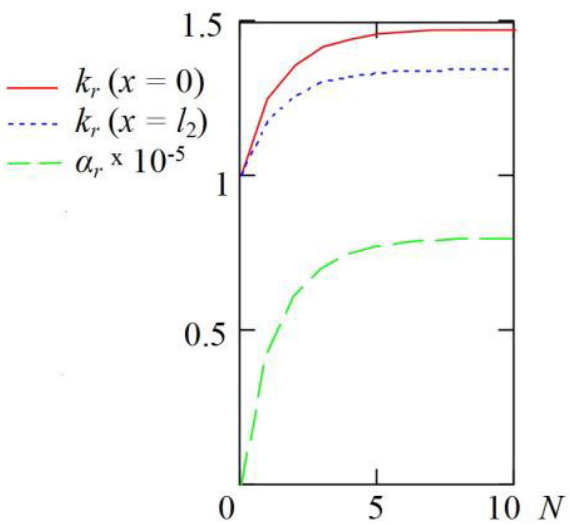

Fig. 5. Dependency of values of relative internal load concentration factors $k_{r}(x=0)$ that occur in cables in a cross-section $x=0, k_{r}\left(x=l_{2}\right)$ in a cross-section $x=l_{2}$ and maximum shear angle tangents of elastic inter-cable layer $\left(\alpha_{r}\right)$ on the amount of broken cables $N$

Fig. 5 shows the calculated values of concentration factors with the length of the second part of $3 \mathrm{~m}$, the first one $-10 \mathrm{~m}$. The amount of broken cables was chosen within the range from zero to 10 , and 
unbroken - 10. The graphs show that, in the absence of partially removed cables, the load concentration factors are equal to 1 . The mutual shear of cables is absent. The increase of the amount of partially removed cables leads to a nonlinear increase in the relative load concentration factors and shears, provided that the amount of partially removed cables does not exceed the number of unbroken. Absolute values of the load concentration factors and shear values in the case of quantitative excess of partially removed cables over the amount of unbroken cables practically linearly increase with an increase of the amount of partially removed cables.

Fig. 6 shows the values of concentration factors with the length of the second part of $3 \mathrm{~m}$, the first one - $10 \mathrm{~m}$. The amount of partially removed cables is 5, and unbroken - from 10 to 30 .

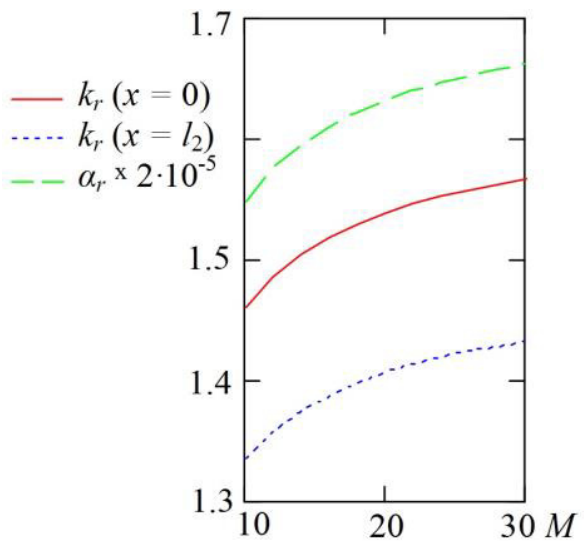

Fig. 6. Dependency of values of relative internal load concentration factors $k_{r}(x=0)$ that occur in cables in a cross-section $x=0, k_{r}\left(x=l_{2}\right)$ in a cross-section $x=l_{2}$ and maximum shear angle tangents of elastic inter-cable layer $\left(\alpha_{r}\right)$ on the amount of unbroken cables $M$

Graphs show that the increase of the amount of unbroken cables, like in the previous case, with the increase of the amount of partially removed cables, leads to a nonlinear increase of relative load concentration factors and shears. At the same time, the absolute values of the load concentration factors and shear values nonlinearly reduce with the increase of the amount of unbroken cables.

Compare the results for a belt with limited boundary deformations, if there are two parts in which the belt has unbroken cables 
and on a given length partially removed cables under different conditions. The most unevenly distributed forces between cables and the greatest tangential stresses in the elastic layers between cables occur when a length of the part with partially removed cables is approaching zero. The increase of a ratio of the amount of unbroken cables to their amount, which is removed on some length, leads to a nonlinear decrease in maximum tensile forces of cables and maximum shear of elastic layers located between cables.

The case of limited boundary deformations of a belt allows determining its stress state when it has a regularly variable structure. In the operation process of belts, there may be local, non-regular cases of belt breakage. Consider the case of a load of infinitely long belt, in the middle of which several cables are partially removed on a limited length. From (4)

$$
F_{1, n}=0
$$

Fig. 7 shows the distribution of relative load concentration factors, deformations and tangents of shear angles in the cross-section $x=0$ for a case similar to (Fig. 2), but for $l_{1} \rightarrow \infty$

According to the graphs in Fig. 7, the load concentration factors and the shear angles reach the maximum values for cables adjacent to broken cables and in the elastic shell between the unbroken and broken cables. This is a consequence of the maximum gradient of displacements of adjacent unbroken and broken cables. The value of the relative load concentration factor is 1.387 , and the load concentration factor is 1.982 .

Consider the dependency of the stress state of the belt on a length of the second belt part. The results are shown in Fig. 8 .

The given calculation results allow drawing the following conclusions. The values of maximum stresses in a belt with cables partially removed on a limited length depend on the amount of cables in the belt, the amount of partially removed cables, and the length of a part of their removal. So the minimum values of the load concentration factors are obtained in the case of removal of 3 cables from 10 in the belt with a length of the cable removal part of $1 \mathrm{~m}$. Minimum tangential stresses are realized for the length of the specified part of $0.5 \mathrm{~m}$. The presence of a minimum of maximum tensile forces and shear angles is the result of overlapping edge effects due to the change of 
the amount of cables on boundaries of the part of partial cable removal. This effect occurs with any amount of removed cables and their total amount in the belt.
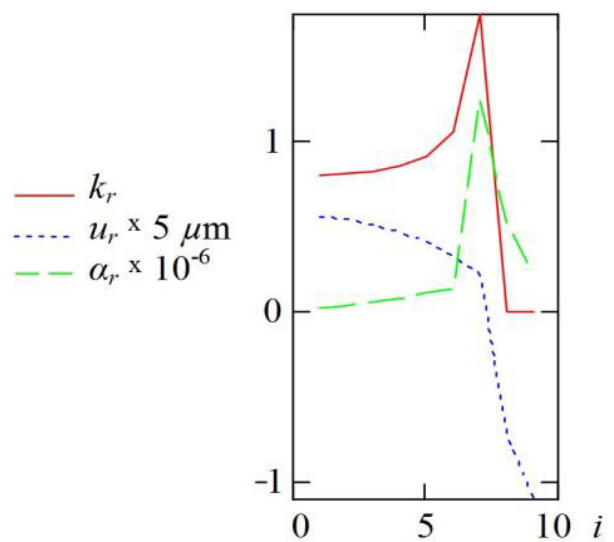

Fig. 7. Distribution of relative load concentration factors $\left(k_{r}\right)$, that occur in cables with numbers $i$, relative displacements $\left(u_{r}\right)$ and tangent of shear angles of elastic inter-cable layer $\left(\alpha_{r}\right)$ in a cross-section $x=0$ for $l_{1} \rightarrow \infty$

The effect of reduction of maximum tensile load concentration factors of cables is also observed in the case of breakage of the same cable in two cross-sections [20]. This effect can be used to increase the tractive ability of the belt with broken cables. For this, it is appropriate to artificially cut broken cables at a certain distance, or partially remove them. The latter may allow the removal of parts of cables in which the strings and wires lost their mutual connection, the connection formed by their twisting.

Note that the length used in studies above corresponds to mechanical characteristics of the belt RCB-3150. Indicators for this belt are indexed $b$. Indicate mechanical characteristics without a corresponding index. Considering the indicated designations, the obtained results can be extended to belts with other mechanical characteristics provided that they are proportional to the coefficient

$$
k=\sqrt{\frac{G k_{G}}{(t-d) E F} \frac{\left(t_{b}-d_{b}\right) E_{b} F_{b}}{G_{b} k_{G_{b}}}} .
$$

This is a consequence of the fact that the values of forces, displacements (1) are proportional to exponential functions. The argu- 
ments of functions are the product of values of a characteristic index $\beta_{n}$ and linear dimensions.

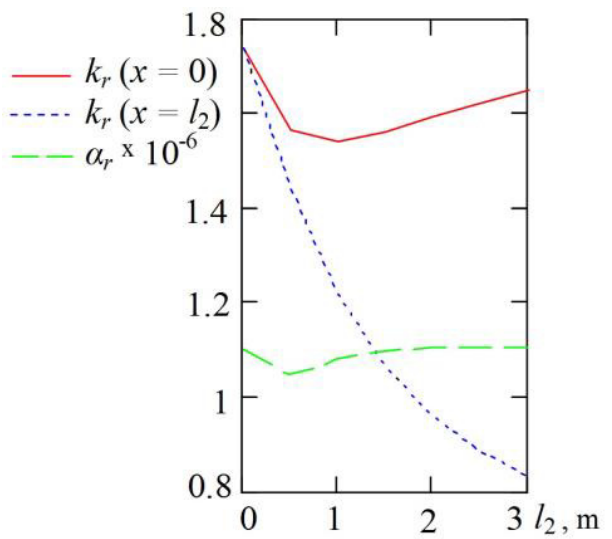

Fig. 8. Dependency of values of relative internal load concentration factors $k_{r}$ $(x=0)$ that occur in cables in a cross-section $x=0, k_{r}\left(x=l_{2}\right)$ in a cross-section $x=l_{2}$ and maximum shear angle tangents of elastic inter-cable layer $\left(\alpha_{r}\right)$ on the length of the second belt part when $l_{1} \rightarrow \infty$

\section{Belt with Irregularly Located Ruptures of Continuity of Cables}

Above we have considered the stress-strain state of a rope (belt) with regularly spaced cable breakages. During operation, the possible occurrence of a significant number of breakages of cables is possible. Their complex impact cannot be predicted. It must be determined considering the discrete values of numbers of broken cables and the location along the rope length. The number of breakages may be less than or equal to the number of cables in the rope. The most common case is the case of breakage of all cables. It corresponds to one of the possible schemes of butt-joint connection of rubber-cable belts. We will determine the displacements of cables, and the forces that occur in them using the expressions [19].

First, construct a model for the case of rupture of continuity of an arbitrary $j$-th rope (belt) of infinite length. Let the cross-section of the break have the coordinate $x=0$. Cut the rope into two parts. Give the parts numbers $1(x \leq 0)$ and $2(x \geq 0)$. As in previous cases, the part numbers are included in the indexes of quantities. The following conditions must be met in the cross-section $x=0$ 


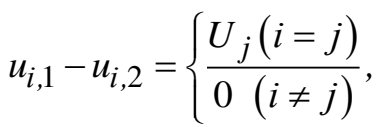

$$
\begin{aligned}
& p_{i, 1}-p_{i, 2}=0, \wedge p_{j, 1}=0 .
\end{aligned}
$$

When $x \rightarrow \pm \infty$

$$
\begin{aligned}
& u_{i, 1}-u_{i, 2} \rightarrow 0, \\
& p_{i, 1}=p_{i, 2} \rightarrow P .
\end{aligned}
$$

Consider the location symmetry of the cable breakage. Consider the part of the rope (belt) where $x \geq 0$ From condition (26) we have $A_{m}=0$.

The difference of displacements of edges of a broken cable is formulated as a sum of Fourier series

$$
u_{i, 1}-u_{i, 2}=\frac{2}{M} U_{j} \sum_{m=1}^{M-1} \cos \left(\mu_{m}(j-0.5)\right) \cos \left(\mu_{m}(i-0.5)\right)+\frac{1}{M} U_{j} \text {. }
$$

Displacements and internal loading forces on cables of the sample in accordance with [19] with arbitrary breakage will take the form

$$
\begin{gathered}
u_{i}=\frac{2}{M} U_{j} \sum_{m=1}^{M-1} \cos \left(\mu_{m}(j-0.5)\right) \cos \left(\mu_{m}(i-0.5)\right) e^{-\beta_{m} x}+\frac{1}{M} U_{j}+\frac{P}{E F} x, \\
p_{i}=\frac{2 E F}{M} U_{j} \sum_{m=1}^{M-1} \cos \left(\mu_{m}(j-0.5)\right) \cos \left(\mu_{m}(i-0.5)\right) e^{-\beta_{m} x_{3}} \beta_{m}+P .
\end{gathered}
$$

From (25) and (29) we determine the coefficient of proportionality and the expression for determining the distribution of forces between the cables

$$
U_{j}=-\frac{P M}{2 \sum_{m=1}^{M-1} \cos \left(\mu_{m}(j-0.5)\right)^{2} \beta_{m}} .
$$

The numbers of broken cables, the distances between the crosssections of gaps are combined into two sets $J$ and $L$. The crosssections with breakages are given the numbers $i$. We combine them into the set $I$. From the expression of the distribution of forces between the cables (29) we find the formula for the distribution of forces in the cross-sections of breakages of the cables 


$$
\begin{gathered}
p_{i, i \in I}=P \times \\
\left.\times \sum_{j \in J} \vartheta_{j} \frac{\sum_{m=1}^{M-1} \cos \left(\mu_{m}(j-0.5)\right) \cos \left(\mu_{m}(i-0.5)\right) e^{-\beta_{m}\left|l_{i}-l_{j}\right|_{\beta_{m}}}}{\sum_{m=1}^{M-1} \cos \left(\mu_{m}(j-0.5)\right)^{2} \beta_{m}}+1\right],
\end{gathered}
$$

where $\vartheta_{j}$ is the vector of proportionality coefficients.

The vector of proportionality coefficients is determined from the condition of absence of cable loads in the cross-sections of their breakages. Expression (27) in its expanded form is an algebraic system of equations. The solution of the system allows determining the vector of proportionality coefficients. Note that for an infinite distance between cable breakages, the components of the vector are equal to ones.

From expression (31) the displacements of cables in the crosssections of their breakages

$$
\begin{gathered}
u_{i, i \in I}= \\
=P \sum_{j \in J} \frac{\vartheta_{j}}{E F} \frac{\sum_{m=1}^{M-1} \cos \left(\mu_{m}(j-0.5)\right) \cos \left(\mu_{m}(i-0.5)\right) e^{-\beta_{m}\left|l_{i}-l_{j}\right|}}{\sum_{m=1}^{M-1} \cos ^{2}\left(\mu_{m}(j-0.5)\right) \beta_{m}} .
\end{gathered}
$$

Displacements of the cables (32) allow finding the maximum values of the tangents of shear angles of elastic material of rope shell in the local part, where the distance between points belonging to two adjacent cables in one cross-section is minimal.

Expressions (31) and (32) allow determining the SSS of a rope with any number of cables $M$ in the cross-sections of cable breakage. For example, consider a rope with five cables. All cables have gaps. The placement spacing of cross-sections with gaps is equal to $l$. The rope is loaded with a force that creates a single average load of cables (Fig. 9). 


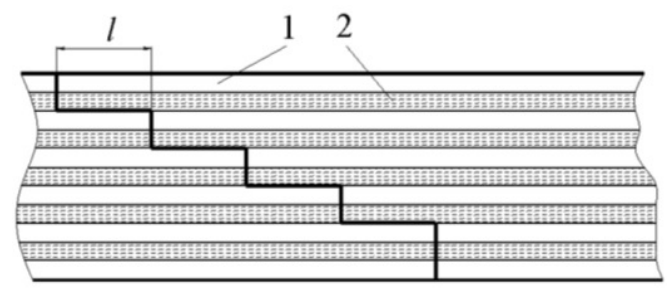

Fig. 9. Scheme of breakages of cables: 1 - layers of rubber, 2 - cables

Displacements, as well as loads of cables, are symmetrical with regard to the middle of a sample. The plane of symmetry of the belt coincides with the plane of symmetry of the middle cable when the number of cables is odd. The middle cable with an odd number of them will be considered the first one. In a rope with an even number of cables, the cables that are the closest to the middle of the rope are considered the first ones. Fig. 10 shows the ratios of coefficients of non-uniformity of force distribution in the extreme and middle cables for distances between the planes of breakages of $0.4 \mathrm{~m}, 0.5 \mathrm{~m}$ and $0.6 \mathrm{~m}$ and the variable number of cables in the sample.

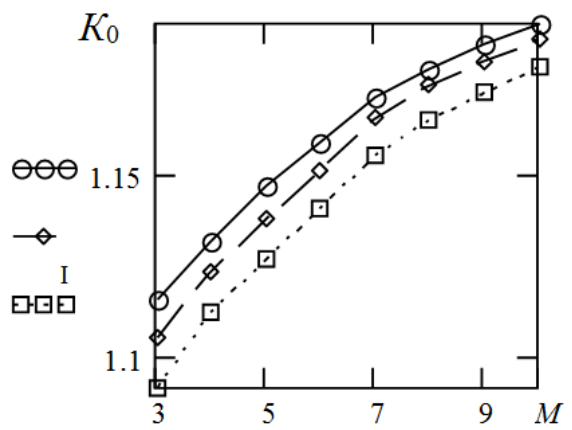

Fig. 10. Distribution of the ratio of the coefficients of non-uniformity of force distribution in the extreme and middle cables $K_{0}$ for the distances between the breakages $0.4 \mathrm{~m}, 0.5 \mathrm{~m}$ and $0.6 \mathrm{~m}$ and different numbers of cables $M$ : the upper curve is for $600 \mathrm{~mm}$, middle curve $-500 \mathrm{~mm}$, the lower curve - $400 \mathrm{~mm}$

The obtained dependencies show that the reduction of distances between the planes of discontinuities of cables leads to a decrease in the limits of changes in the coefficients of uneven distribution of forces between the cables. The outermost cables remain the most loaded. The coefficient of non-uniformity of force distribution for these cables is much higher than such coefficients for adjacent ca- 
bles. Further, consider the equal distances between the planes of the discontinuities of cables to be basic. Fig. 11 shows the ratios of the coefficients of non-uniformity of force distribution similar to the above for the case of reducing the lengths of the first and last crosssections of the sample relative to the basic by 20 and $30 \%$.

In the sample with an odd number of cables, the cross-section of the breakage of the middle cable coincides with the plane of symmetry. The sample of three cables has two areas located between the cross-sectional planes of the damaged cables. Changing the lengths of these areas is equal to changing the basic lengths. This case was from consideration. The graphical dependencies show that the reduction of lengths of the extreme areas leads to a decrease in the coefficients of unevenness of the loads of the extreme cables relative to the average. At the same time, it is even possible to exceed the maximum loads of the middle cables over the extreme ones. This pattern can be used to reduce the extreme loads of the cables of composite material with damage, such as in the butt-joints of the belts.

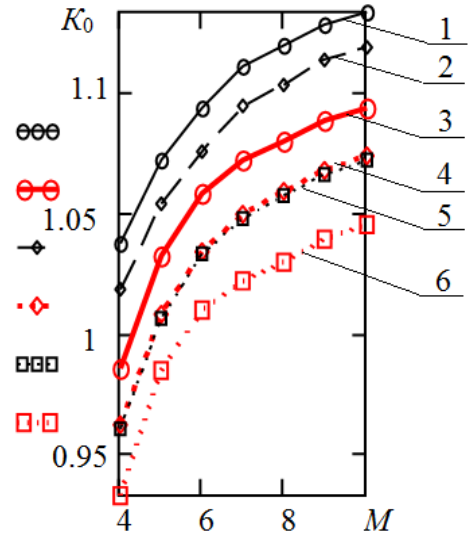

Fig. 11. Graph of the ratios of the coefficients of uneven force distribution in the extreme and middle cables $K_{0}$ for the base distances between the planes of the location of the gaps $400 \mathrm{~mm}, 500 \mathrm{~mm}$ and $600 \mathrm{~mm}$ and the different number of cables in the sample $M$. Denotations: $1-600 \mathrm{~mm}, 20 \%$ (black curve with circles); $2-500 \mathrm{~mm}, 20 \%$ (black dashed curve with rhombi); $3-600 \mathrm{~mm}, 30 \%$ (thicker red curve with circles); $4-500 \mathrm{~mm}, 30 \%$ (red dotted curve with rhombi); $5-400 \mathrm{~mm}, 20 \%$ (black dotted curve with squares); $6-400 \mathrm{~mm}, 30 \%$ (red dotted curve with squares)

According to the graphical dependencies of the displacement of 
the cables in the sample with breakages are different. Different displacements of cables lead to shear stresses in the inter-layers of elastic material. They are proportional to the tangents of the shear angles of elastic material between the cables. Expression (32) allows defining them in cross-sections of damage of cables

$$
=P \sum_{j \in J}\left(\begin{array}{c}
\gamma_{k, i \in I}= \\
\frac{\vartheta_{j}}{E F} \times \\
\times \frac{\sum_{m=1}^{M-1} \cos \left(\mu_{m}(j-0.5)\right)\left(\cos \left(\mu_{m}(k-0.5)\right)-\cos \left(\mu_{m}(k+0.5)\right)\right) e^{-\beta_{m}\left|l_{i}-l_{j}\right|}}{h \sum_{m=1}^{M-1} \cos ^{2}\left(\mu_{m}(j-0.5)\right) \beta_{m}}
\end{array}\right),
$$

$(1 \leq k<M)$.

Expressions of forces, displacements are the product of functions dependent on the cable number and the value of the $x$ coordinate. The last function in the obtained solution has decreased. The parameters of stress-strain state for cross-sections that do not coincide with the cross-sections of the damage are less important. The strength of the material is determined by the strength of the most loaded elements. In our case, these are the cables adjacent to the broken cable. Strength conditions of rubber-cable belt with random location of broken cables

$$
P\left[\sum_{j \in J} \vartheta_{j} \frac{\sum_{m=1}^{M-1} \cos \left(\mu_{m}(j-0.5)\right) \cos \left(\mu_{m}(j \pm 1-0.5)\right) e^{-\beta_{m}\left|l_{i}-l_{j}\right|_{\beta_{m}}}}{\sum_{m=1}^{M-1} \cos ^{2}\left(\mu_{m}(j-0.5)\right) \beta_{m}}+1\right] \leq[P],
$$

$$
\frac{G P}{t-d} \times
$$

$\times \sum_{j \in J}\left(\frac{\sum_{m=1}^{M-1}\left(\cos ^{2}\left(\mu_{m}(j-0,5)\right)-\cos \left(\mu_{m}(j \pm 1-0,5)\right) \cos \left(\mu_{m}(j-0,5)\right)\right) e^{-\beta_{m}\left|l_{i}-l_{j}\right|}}{h \sum_{m=1}^{M-1} \cos ^{2}\left(\mu_{m}(j-0,5)\right) \beta_{m}}\right) \leq[\tau]$.

Strength conditions must be fulfilled for both adjacent cables in all cross-sections of their breakage. In the general case, the total 
number of such conditions is four times the number of damages. Extreme cables have only one adjacent cable. The left parts of the strength conditions are given by symmetric functions. They are zero for $j=1 \wedge j=M$. In the case of damage to the extreme cables, the total number of conditions is less than twice the number of damaged extreme cables.

Fulfillment of the established conditions of strength allows making the reasonable decisions concerning conditions and admissibility of use of composite materials, in particular rubber-cable conveyor belts with the cables damaged in the course of operation, what provides safety of their use and utilizing their full resource.

\section{Conclusion}

Performed researches clarify the idea of the interaction mechanism of reinforcing elements in composite materials of layered structure with hard and soft layers. Boundary conditions significantly affect the stress-strain state of the belt.

An increase of the amount of partially removed cables leads to a nonlinear increase of relative load concentration factors and shears, provided that the amount of partially removed cables does not exceed the amount of unbroken cables. Absolute values of load concentration factors and shear values in the case of quantitative excess of partially removed cables over the amount of unbroken cables practically linearly increase with an increase of the amount of partially removed cables.

An increase of the amount of unbroken cables with the increase of a partially removed amount leads to a nonlinear increase of relative load concentration factors and shears. Absolute values of load concentration factors and shear values are nonlinearly reduced with an increasing amount of unbroken cables.

Values of maximum stresses in the belt with cables partially removed on a limited length depend on the amount of cables in the belt, the amount of partially removed cables, and the length of cable removal part.

The developed method allows determining the stress-strain state of the flat, reinforced with longitudinal tractive elements, belt of elastic material with various breakages of tractive elements, including the rupture of continuity and in the case of partial removal of elements under various boundary conditions. Method can be used in a control system of the conveyor belt during the belt life cycle. 
Further researches should be directed to a development of a method for determining the stress-strain state of the belt with damage, considering the design features of the conveyor base.

Using the methods of composite mechanics, a mathematical model of interaction of any number of soft and hard layers with the system of breakages to the latter is solved.

Analytical expressions of stress-strain state indicators of layered composite material with a given number of layers and local defects are obtained in a closed form.

The following is established by the analysis of the obtained solutions. The rupture of continuity of a cable leads to distortion of cross-sections of a belt. Damaged cable has larger displacements than the other ones. The uniform distribution of external loads between the cables is disturbed. The disturbance of the stress-strain state is localized both along the sample and along its thickness. Damage to the extreme cable leads to an increase in the tensile forces of the adjacent cable over $60 \%$ of the average load. The two cables closest to the damaged one are loaded with a force that exceeds their average total load by almost $80 \%$. The breakage of the middle cable leads to less disturbance.

The character of local stress disturbances also depends on the number of cables in the belt. As the total number of cables increases, the extreme forces occurring in the sample with the damaged cable decrease to almost constant values if the number of cables in a belt is not less than ten.

The linear formulation of the problem and the principle of superposition allows using the obtained dependencies in the case of applying force to one cable and fixing others.

The obtained solutions allow determining a stress-strain state of a rubber-cable belt and create conditions for making reasonable decisions regarding the conditions and admissibility of using rubber-cable belts with broken cables during operation, which ensures their operation safety and maximum utilization of their resource.

References

1. Dychkovskyi, R.O., Avdiushchenko, A.S., Falshtynskyi, V.S., \& Saik, P.B. (2013). On the issue of estimation of the coal mine extraction area economic efficiency. Naukovyi Visnyk Natsionalnoho Hirnychoho Universytetu, (4), 107-114.

2. Pivnyak, G., Dychkovskyi, R., Smirnov, A., \& Cherednichenko, Yu. (2013). Some aspects on the software simulation implementation in thin coal seams mining. Energy Efficiency Improvement of Geotechnical Systems, 1-11. 
3. Ilin, S.R., Samusia, V.I., Ilina, I.S., \& Ilina, S.S. (2016). Influence of dynamic processes in mine hoists on safety exploitation of shafts with broken geometry. Naukovyi Visnyk Natsionalnoho Hirnychoho Universitetu, (3), 42-47.

4. Kartavy, A.N., (2000). Justification of main parameters of steeply inclined conveyor with a clamping belt for quarries with large mineral extraction rate: PhD dissertation: 05.05.06.

5. Averchenkov, V.I., Davydov, S.V., Dunaev, V.P., \& Ivchenko, V.N. (2004). Conveyors with a suspended belt. Moskow.: Machine-building.

6. Pedchenko, O.S. (2007). Computational model of a suspended conveyor belt on a conveyor with a trajectory bended in a vertical plane. Mining informational and analytical bulletin, (1), 322-324.

7. Belmas, I.V., Kolosov, D.L., \& Kolosov, A.L. (2014). Study of stresseddeformed state of rubber-rope cable in the area of tubular transformation. Bulletin of PNRPU. Geology. Oil \& Gas Engineering \& Mining, (12), 48-55.

8. Kolosov, L.V., \& Bel'mas, I.V. (1981). Use of electrical models for investigating composites. Mechanics of Composite Materials, 17(1), 115-119.

9. Bel'mas, I.V. (1993). Stress state of rubber-rope tapes during their random damages. Problemy Prochnosti i Nadezhnos'ti Mashin, (6), 45-48.

10. Prushak, V.Ya. (2008). Numerical estimation of durability of connections of rubber-cable conveyor belt. Bulletin of BNTU, (1), 35-38.

11. Golikov, G.F., \& Ryabov, D.V. (2007). Criterions of estimation of operational quality of rubber-fabric conveyor belt and butt-joint connections. Mining informational and analytical bulletin, (10), 328-330.

12. Belmas, I.V., Perfilyeva, Yu.M., Daniyarov, N.A., \& Karsakova, A.Zh. (2013). Determination of stress-strain state of rubber-fabric belt with holes. Enbekteri university. University proceedings, (4), 60-64.

13. Gerasimov, G.K. (2006). Increase of operation reliability of rubber-cable belts of conveyor types 2LU120 and 2LTU120. Ugol, (9), 28-29.

14. Levchenya, Zh.B. (2004). Increase of reliability of butt-joint connections of conveyor belts at mining enterprises: $\mathrm{PhD}$ dissertation: 05.05.06.

15. Ishchenko R.V. (2013). Increase of reliability of high-wear parts of conveyor belts in air-salt mediums: PhD dissertation: 05.05.06.

16. Volohovskiy, V.Yu., Radin, V.P., \& Rudyak, M.B. (2010). Concentration of loads in cables and a bearing ability of rubber-cable conveyor belts with breakages. MPEI Vestnik, (5), 5-12.

17. Daria Zade S. (2013). Numerical method of determining effective characteristics of unidirectional reinforced composites. Bulletin NTU "KhPI", (58), 71-77.

18. Kolosov, D., Dolgov, O., \& Kolosov, A. (2013). The stress-strain state of the belt on a drum under compression by flat plates. Annual Scientific-Technical Collection - Mining of Mineral Deposits, 351-357.

19. Belmas, I.V., \& Kolosov, D.L. (2017). The stress-strain state of the flat rope caused by breaks of tractive elements and design of hoisting engine drum. Collection of research papers of national mining university, (50), 163-170.

20. Belmas, I.V., \& Bobylyova, I.T. (2012). Influence of cable breakages on a strength of a flat tractive element. Collection of the presentations of the participants of the 6th International Scientific and Methodical Conference, 88-91. 
https://doi.org/10.31713/m1109

\section{A CASE STUDY OF DETERMINING THE INTENSITY OF VIBRATION ACCELERATIONS AND THE POTENTIAL IMPACT ON STRUCTURES}

\section{Krzysztof TOMICZEK ${ }^{1}$}

Ph.D. Eng. Krzysztof Tomiczek, Department of Geoengineering and Resources Extraction, Faculty of Mining, Safety Engineering and Industrial Automation, Silesian University of Technology, Gliwice, Poland

\section{Summary.}

Assessment of vibrations caused by tremors accompanying by exploitation of useful minerals, both by opencast and underground methods, on surface structures consists in checking whether the analysed building object can take over, without damage, ground vibrations caused by underground tremors. It is the dynamic resistance of the object to vibrations caused by tremors in the rock mass. After the theoretical introduction, two simplified analyses of the assessment of the resistance of ground structures are presented.

Keywords: rock mass seismicity, tremors induced by mining, dynamic resistance of buildings, threat to building stability, safety of structures

\section{Introduction}

Ground vibrations related to high-energy tremors induced by the exploitation of useful minerals, both by opencast and underground methods, may pose a threat to structures on the surface. Vibrations may cause discomfort for residents. Therefore, regardless of the continuous observations of rock mass stability and seismological observations carried out by the geophysical services of mines plants; surface measurements of ground vibration accelerations are often performed. Vibration measurements are the most appropriate way to assess the dynamic impact of rock tremors on the elements of the land surface infrastructure. Vibration measurements also allow to determine the maximum, instantaneous component amplitudes, horizontal and vertical, vibration accelerations, dominant frequency and amplitude values for this frequency, and the duration of vibrations with a specific level of acceleration amplitude.

1Krzysztof.Tomiczek@polsl.pl,k.tomiczek@yahoo.co.uk , https://orcid.org/0000-0001-9227-310X Researchgate: Krzysztof_Tomiczek 


\section{Acceleration of ground vibrations and the amplification factor}

The intensity of ground vibrations depends on many factors that are more or less measurable or predictable. Therefore, the prediction of the expected intensity of vibrations is extremely difficult.

The obvious and most important factors are:

- the size of the seismic phenomenon measured by magnitude, seismic energy, seismic moment or epicentre size as well as the size of the fracture in the rock mass,

- epicentre depth and distance of the observation site and medium damping properties,

- direction of seismic propagation.

What is also important, as shown by the results of many years of seismometric research, are the local soil and rock conditions at the observation site, including the type of soils and rocks, quality and thickness of loose overburden, their waterlogging, and topography.

In the absence of measurement data, it is possible to estimate, with some approximation and claims, the acceleration of ground surface vibrations on the basis of empirical formulas relating to a given area. Even in the absence of knowledge of the vibration duration, amplitude of the dominant frequency, etc.

These formulas allow to estimate the vibration accelerations on the basis of the knowledge of the tremor energy and the distance of the epicentral location of the tremor at the given point on the ground surface.

For example, for strong phenomena with energies in the range $2 \times 10^{5} \mathrm{~J}<\mathrm{E}<1 \times 10^{8} \mathrm{~J}$ and epicentral distances up to $10 \mathrm{~km}$, the acceleration of rockground vibrations can be estimated by the empirical formula proposed by Prof. Mutke (e.g., 1991)

$$
a_{M D}=\left[1.33 \cdot 10^{-3} \cdot(\log E)^{2.66}-0.089\right]\left[1.53 \cdot R^{0.155} \exp (-0.65 R)+0.14\right]
$$

where $a_{M D}$ - amplitude of acceleration of subrock vibrations, $\mathrm{m} / \mathrm{s}^{2}$,

$E$ - seismic energy, $J$,

$R$ - epicentral distance, $\mathrm{km}$; object - the epicentre of the tremor.

Empirical relationships are determined on the basis of research and measurements.

The area around the epicentre, which is the near-wave field boundary on the surface, can be treated as the epicentre. For strong 
tremors induced by mining in the Upper Silesian Coal Basin (USCB), phenomena with a magnitude of $M \geq 1.7$ or seismic energy $E \geq 210^{5} \mathrm{~J}$, the radius of such a zone is about $1000 \mathrm{~m}$.

The research was conducted in Poland, incl. by the Central Mining Institute, Cracow University of Technology, AGH University of Science and Technology, and the Rock Mass Mechanics Institute of the Polish Academy of Sciences in Cracow. Based on the measurements made on subrock at different distances from the tremors, it follows that the amplitudes of velocity and acceleration of subrock vibrations decrease with increasing epicentral distance. The phenomenon is less strong in the epicentral zone, while the phenomenon is strong outside of its. The physical justification is that absorption damping dominates in the near-wave field, whereas in the far-wave field the influence of geometric damping is much stronger. In practice, it means that the global damping function in the epicentral zone shows a flattening effect, while outside the epicentral zone it is a monotonically decreasing function. Assuming that only strong mining tremors can in practice be damaging to buildings, the standardized vibration damping function for high-energy phenomena is described (see, e.g., Mutke 1992).

The relationship describing the normalized decrease of the horizontal components of the $V_{D}$ velocity of the vibrations of the bedrock in the USCB for tremors with energy $510^{8} \geq E \geq 210^{5} \mathrm{~J}$, as a function of the epicentral distance $D$ (up to $10 \mathrm{~km}$ from the epicentre), for accelerations $a_{D}$

where $R^{2}=D^{2}+0.5^{2}$

$$
a_{D}=1.53 R^{0.155} \exp (-0.65 R)+0.014
$$

$D$ - epicentral distance, $\mathrm{km}$.

The coefficient of 0.5 in the formula for $R$ corresponds to the average depth of tremor centre, equal to $0.5 \mathrm{~km}$.

Apart from the maximum acceleration amplitudes or the vibration velocity of the ground of building structures, an important parameter is also the dominant frequency of vibrations with maximum amplitudes. The dynamic responses of structures in particular ranges of vibration frequencies are not the same.

The dominant frequency intervals are obtained by targeting the accelerograms in the frequency domain. Their essence is, for example, a Fourier Transformation (FT) and on this basis determining the 
minimum $F_{\min }$ and maximum $F_{\max }$ values for which the level of the spectral amplitude decreased twice in relation to its maximum value.

The determined equations of the regression curves, limiting the range of occurrence of dominant frequencies at the bottom and top, may have the following form (e.g., Chudek after Mutke, 2008)

$$
\begin{aligned}
& F_{\text {max }}=[99 \exp (-0,49 \log E)]+1.27 \\
& F_{\text {min }}=[91 \exp (-0,78 \log E)]+1.79
\end{aligned}
$$

where $E$ - seismic energy, $J$.

The frequency range determined by the equations is for the vibration accelerations of the subrocks in the epicentral zone.

In order to calculate the subrock coefficient, it is important to know the dominant frequencies of vibrations reaching the overburden layers. If there is no database of tremors from a given area at a rock site, this frequency can be determined from the abovementioned relationships.

The frequency range of the dominant vibrations with the highest velocities and accelerations is important in determining the base coefficient of tremor amplification. This coefficient depends on the frequency of the dominant vibrations. On the other hand, the occurring tremors of a short input, e.g., 1 peak, are not a big threat to buildings, even at a high value of velocity or acceleration expressed by this peak (see the GSI-GZW scale).

Measurement premises and theoretical solutions for the passage of a seismic wave through a multilayer rock mass are characterized by a change in vibration amplitudes when the wave passes through each layer.

The following factors influence the change of vibration amplitudes:

- incident wavelength $\gamma$, or its frequency $f$,

- thickness of layer $H$,

- layer density $\rho$,

- wave velocity $v$, as well as wave type and wave incidence angle.

Practice shows that if the rock layer is less stiff, more cracked and the velocity of the seismic wave is lower in it, then it is easier to increase the vibration amplitudes with the appropriate incident wavelength.

The measurement data prove that, depending on the structure of the subsurface layers, the maximum values of the ground surface 
vibration acceleration caused by mining tremors may be both partially damped and/or strengthened. The parameter quantifying this phenomenon is the substrate factor, also known as the amplification factor.

The maximum values of the amplitudes of the surface vibration accelerations

$$
\begin{gathered}
V=V_{M D} W_{f} \\
a_{M S K}=a_{M D} W_{f}
\end{gathered}
$$

where $W_{f}$ - substrate factor, vibration amplification.

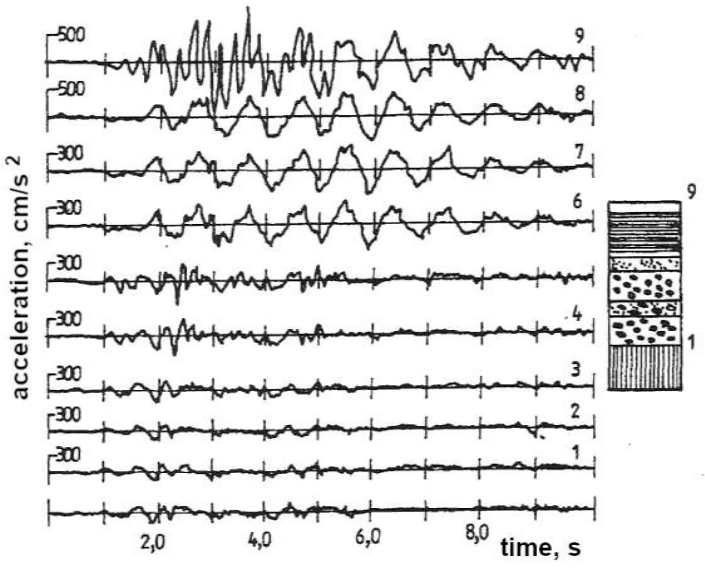

Fig. 1. Examples of vibration accelerograms recorded in a multilayer medium at the boundary of each layer (after Okamoto, 1954, 1984).

Many cases of damage of buildings, often at large distances from the epicentre of the tremor, have their source in the phenomenon of local vibration amplification. The vibrations are amplified by the overburden made of loose layers. An example of the influence of a stratified medium, and especially of the weakly coherent layers of this medium, on the change in the magnitude of the vibration acceleration amplitudes is shown in Fig. 1 (see Okamoto, 1954, 1984).

The highest values of vibration accelerations in USCB are related to direct waves. In particular, they relate to horizontally polarized lateral waves, i.e., "SH" waves. This wave, when passing through horizontal boundaries, does not create other types of waves.

For waves "SH" that fall on the ground at any angle $\square$ and for 
vertically falling " $P$ " longitudinal waves, the vibration amplitude is doubled. This is due to the boundary conditions that the wave encounters at the layer-air interface. If these waves propagate through the flat horizontal boundary of the layer separation $(z=0)$, then they are partially reflected and partially refracted. The substrate factor calculation algorithm was based on the solution in an elastic medium with damping and rock mass described by the Kelvin rheological model.

In practice, the vibration recordings on the same overburden layer will be significantly different from each other and only some of them will show the maximum value of the substrate factor, vibration amplification. The reason for this is the simultaneous influence of several seismogeological factors on the surface effect. Seismic waves are, in fact, non-harmonic, and the resultant amplitude is determined by the composition of harmonic waves. The frequency range of the maximum vibrations is different for tremors with different seismic energies, epicentral distances, etc. As a result, the recorded amplification result refers to certain averaged amplification in the range of dominant vibration frequency. Moreover, a slight change in the wavelength incident on the layer or the angle of incidence of the wave is sufficient for the gain in $W_{f}$ to change. When assessing the vibrations for the development of the surface and the safety of people, the possibility of the strongest vibrations i.e., the occurrence of the highest value of the substrate factor for the vibrations recorded in a given area, should always be taken into account.

In fact, in many situations the wave is incident at an angle and the recorded gains will be less than the maximum. However, it should be assumed that, in practice, we must take into account the occurrence of the least favourable situation.

\section{Examples of a simplified assessment of the dynamic re- sistance of objects}

The problems of the dynamics of buildings based on computational models with a limited number of degrees of freedom, described in detail with harmonic equations, lead to very complex analytical solutions describing structures that exist in reality. Due to the difficulties in determining the seismic wave characteristics caused by mining tremors and the high complexity of the computational model of real 
building, the search for solutions to complex problems is carried out using simplified calculation models. Empirically correlated data are used from many years of observation of the behaviour of buildings subject to dynamic influences, with simultaneous theoretical analysis of the phenomenon.

This sub-chapter presents examples of a simplified assessment of the underground mining dynamic impact on two selected structures:

- primary school building,

- the building of the sports hall.

The method of assessing the harmfulness of surface vibrations on buildings was used in accordance with the applicable PN-85/B02170 standard (the standard was updated in 2016) based on, inter alia, on the dynamic impact scale (SWD).

\subsection{Primary school building}

The characteristics of the primary school building:

- building height (including cellars, approximately $3.30 \mathrm{~m}$ and attic approx. $3.0 \mathrm{~m}) \times$ approx. $18.75 \mathrm{~m}$,

- total length of the building (without the outhouse) - approx. $23.45 \mathrm{~m}$,

- width - approx. $18.76 \mathrm{~m}$,

- usable area of $1320 \mathrm{~m}^{2}$,

- cubature - approx. $7265 \mathrm{~m}^{3}$.

General building characteristics: brick building, Klein ceilings on steel beams, reinforced concrete stairs, wooden roof, covered with tar paper. Flat window and door lintels.

The building was kept in relatively good condition. The roof is covered with tar paper on the boarding without visible damage. The walls of the overground, made of solid brick, 2 bricks thick, showed no visible damage. The ceiling in the basement was in good condition and was made of hollow ceramic bricks. Basement walls, made of brick, with no visible damage. Window lintels were changed as a result of renovation in 1984, combined with the replacement of window frames. Door lintels unrecognized. Foundations not recognized. Reinforced concrete staircase, no damage. The building was secured against mining damage in the form of anchoring, with all external corners secured with steel angles. The condition of the facade after renovation did not raise any objections. From a technical point of view, the essential elements of the building were in good condition. 
The building had a partial basement. On the ground floor, $1^{\text {st }}$ and $2^{\text {nd }}$ floor, there were 12 classrooms with a secretary's office and auxiliary rooms.

\section{Threats of underground exploitation}

The seams located at various depths were continuously exploited throughout practically the entire area of the city district. For the expected effects on the surface of the site, the IIIrd category of land surface protection was adopted, with the risk of tremors with an energy $E$ of up to $10^{8} \mathrm{~J}$.

Current technical condition and visible damage to the building.

There were clear diagonal cracks in the gable wall of the building, significant cracks in the terrazzo floor, and cracks in the walls in the basement part.

Assessment of dynamic resistance to mining tremors.

The proper vibration of the building.

To determine the frequency of natural vibrations of the building, the approximate method included in the PN-85/B-02170 (and 201612) and PN-77/B-02011 standards was used, as shown in Table 1.

Table 1

Scheme of determining the approximate values of the basic periods of horizontal proper vibrations $T_{l}$ for typical multi-storey residential and public buildings according to $\mathrm{PN}-85 / \mathrm{B}-02170$

\begin{tabular}{|c|c|c|}
\hline Scheme of the building & $\begin{array}{c}\text { Frequency } \\
\text { of vibrations } T_{1}, \mathrm{~s}\end{array}$ & $\begin{array}{c}\text { Building type and height } H, \\
\text { m }\end{array}$ \\
\hline & $T_{l}=0.015 \mathrm{H}$ & $\begin{array}{c}\text { monolithic, brick or con- } \\
\text { crete, } H<30 \mathrm{~m}\end{array}$ \\
\hline & $T_{l}=0.02 \mathrm{H}$ & $\begin{array}{c}\text { reinforced concrete large- } \\
\text { panel } H<30 \mathrm{~m}\end{array}$ \\
\hline$I$ & $T_{1}=0,09 \frac{H}{\sqrt{B}}$ & $\begin{array}{l}\text { reinforced concrete skeleton } \\
\qquad H<50 \mathrm{~m}\end{array}$ \\
\hline$\left|-n^{B}\right|$ & $T_{1}=0,10 \frac{H}{\sqrt{B}}$ & steel skeleton $H<50 \mathrm{~m}$ \\
\hline \multicolumn{3}{|c|}{$\begin{array}{l}H \text { - building height, } \mathrm{m} \text {, } \\
B \text { - lateral width of the building, } \mathrm{m} \text {. } \\
\text { Comments: } \\
\text { 1. If the walls of the load-bearing are significantly weakened by } 40-50 \% \text { of the } \\
\text { openings, the vibration period } T_{1} \text { should be increase by } 10 \div 20 \% \text {, respectively. } \\
2 \text {. In the case of the foundation of the building on soils with high deformability, } \\
\text { e.g., silty sands, the vibration period } T_{1} \text { should be increased by } 10 \% \text {. }\end{array}$} \\
\hline
\end{tabular}

The following values were taken:

for $H=18.75 \mathrm{~m} \rightarrow T_{1}=0.28 \mathrm{~s}$

Due to the existing window and door openings in the walls of the school and the fact that the structure of the structure (walls) was sub- 
ject to the effects of previously conducted mining, the value of the vibration period $T_{1}$ was increased by $20 \%$.

$$
T_{1}=0.336 \mathrm{~s} \quad \rightarrow \quad \text { the proper frequency } n=2.98 \mathrm{~Hz}
$$

After analysing the existing geological and mining conditions, 3 variants of the subsoil acceleration prediction were considered:

- $1^{\text {st }}$ variant based on the "Provisions on the expansion of the school building of the District Mining Office"; assumed the IIIrd category of land suitability for development, maximum shocks with energy $E=10^{8} \mathrm{~J}$ and acceleration $a_{M D} \leq 300 \mathrm{~mm} / \mathrm{s}^{2}$,

- $2^{\text {nd }}$ variant based on the "Provisions on agreeing the conditions of development and land development for the construction of a sports hall" of the District Mining Office assumed: Ind category of land suitability for development, tremors with energy $E=10^{8} \mathrm{~J}$ and acceleration $a_{M D} \leq 300 \mathrm{~mm} / \mathrm{s}^{2}$,

- $3^{\text {rd }}$ variant based on the information and situational maps of the mine's surface with information on the predictioned deformations and accelerations of surface vibrations under the impact of mining. The forecasts assumed: the energy of the recorded tremors $E=10^{3} \div 10^{6} \mathrm{~J}$, in the absence, weak and medium degree of stress increase and seismic hazard, ground acceleration $120 \mathrm{~mm} / \mathrm{s}^{2} \leq a_{M D} \leq 200$ $\mathrm{mm} / \mathrm{s}^{2}$, acceleration for $E=110^{7}-510^{7}$, based on the Mutke's equation

$$
a_{M D}=1.33 \cdot 10^{-3} \cdot(\log \mathrm{E})^{2.66}-0.089
$$

where $a_{M D}$ - amplitude of acceleration of rock vibrations, $\mathrm{m} / \mathrm{s}^{2}$,

$E$ - seismic energy, $J$.

$a_{M D} \approx 145-215 \mathrm{~mm} / \mathrm{s}^{2}$

It was assumed that the expected ground surface vibration accelerations in the range of up to $10 \mathrm{~Hz}$, caused by mining tremors for all analysed objects, should be in the range from $145-300 \mathrm{~mm} / \mathrm{s}^{2}$.

With regard to the assessment of the dynamic impact of tremors induced by underground mining on the terrain surface, it is used, inter alia, the SWD scale (Scale of Dynamic Influences), which is the basis of the Polish standard PN-85/B-02170 (and 2016-12) - "Assessment of the harmfulness of vibrations transmitted through the ground onto buildings". It was developed in 1984, and after 2016 updates it can be used. 
The PN-85/B-02170 (and 2016-12) standard allows the use of dynamic impact scales (SWD) as an approximate method of verifying dynamic effects on buildings. The SWD scales were developed in 1984 for the needs of the Polish Standard. SWD scales can be used for buildings made of masonry elements and for buildings made of large blocks. It was assumed that they apply only to the most common types of building in practice. Based on analyses of selected buildings considered model buildings, dynamic influences calculations were performed, which were used to construct the SWD scales. The calculations included, inter alia, type of structure, various types of ground on which the building is erected and the technical condition of the building. The criteria for selecting individual degrees of harmfulness were based on checking that the conditions of stiffness, strength, and stability were met. The SWD scales were defined with the assumption of long-term harmonic vibrations e.g., several hours a day.

The SWD-I scale applies to compact buildings with small dimensions in the horizontal direction, not exceeding $15 \mathrm{~m}$, one or two-storey buildings and with a height not exceeding any of the dimensions of the horizontal direction. The indications of the SWD-I scale apply to brick buildings, hollow blocks, , slag concrete blocks or similar.

The SWD-II scale is used in the case of multi-storey buildings, up to 5 storeys, with masonry or mixed construction, the height of which is less than twice the smallest building width, and in the case of low-rise buildings, up to 2 storeys, but not meeting the conditions specified for the SWD-I scale.

The SWD scales have five zones (I, II, III, IV and V) separated by four boundary lines (A, B, C and D). The axes of the figures are: vibration frequency $f(\mathrm{~Hz})$ and acceleration $a\left(\mathrm{~m} / \mathrm{s}^{2}\right)$. Both axes are logarithmic. Continuous boundary lines marked with A, B, C and D (lower lines) are used for old buildings with damage. High (dashed) lines A ', B', C' and D' are used for undamaged buildings. In engineering practice, the most common vibrations qualify for the first three of the above-mentioned zones, known as harmful zones.

The following criteria for the division into damage zones were adopted:

- zone I vibrations imperceptible by the building;

boundary $A$ - the lower boundary of vibration perception by the building and the lower boundary of taking into account dynamic in- 
fluences; when vibrations below this boundary, dynamic influences may not be taken into account,

- zone II - vibrations felt by the building, but not damaging to the structure; there is only accelerated wear of the building and the first scratches in mortars, plasters, etc.;

boundary $B$ - boundary of building stiffness, lower boundary of the formation of scratches and cracks in structural elements; many years of research and observation of buildings conducted at the Institute of Structural Mechanics of the Cracow University of Technology show that usually no scratches in mortars and plasters appear then,

- zone III - damaging vibrations for the building; they cause local scratches and cracks, thus weakening the building structure and reducing its load-bearing capacity and resistance to dynamic influences. Mortars and plasters may loosen.

Assessment of the harmfulness of the analysed vibrations

For the described primary school building, dynamic resistance was assessed on the basis of the SWD-II scale of the PN-85/B-02170 standard (Fig. 2).

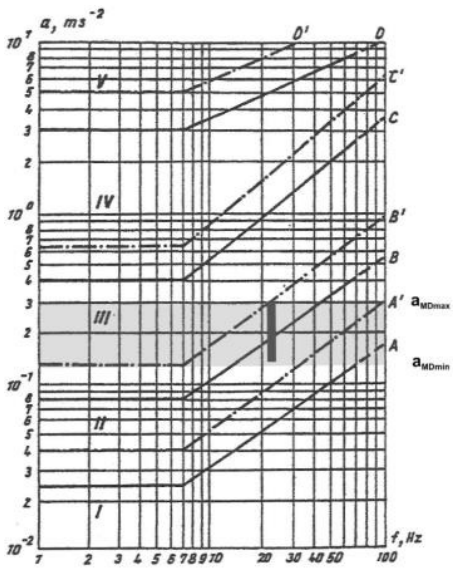

Fig. 2. Example of interpretation of the SWD-II scale (since 1985, after PN-85/B02170, and 2016-12)

To assess the harmfulness, the value of the proper frequency of the building was adopted, $\mathrm{Hz}$ $n=2.98$ 
and the predicted acceleration that the ground will reach at the foundation level, $\mathrm{mm} / \mathrm{s}^{2}$

$$
a_{M D}=145 \div 300
$$

The nomogram in Fig. 3 shows that the acceleration amplitude corresponding to the median frequency of $2.98 \mathrm{~Hz}$ is above the boundary line B' in the third zone of the SWD-II scale. From the information provided in point $\mathrm{D}$, it would appear that vibrations, the parameters of which are within zone IIIrd of the scale, should be damaging to the building structure and cause damage to its structural elements. And this would be the case if the vibrations had a longlasting effect on the structure of the analysed building i.e., several hours a day. The running time of the mining parasiteismic vibrations is very short and lasts on average about $8.0 \mathrm{~s}$, and especially the most intense phase of vibrations lasts about 0.5 seconds after activation of the structure; after this time the vibrations are damped. Therefore, the vibration waveforms with the characteristics shown in Figure 2 above will certainly be damaged by the building, but should not be damaged to its structural elements. There is only accelerated wear of the building structure; local scratches and cracks, as well as cracks in plaster mortars may appear. Prolonged stay in the zone of these vibrations may weaken the building structure and reduce its loadbearing capacity and resistance to dynamic influences.

\subsection{Sports hall building}

The characteristics of the sports hall building:

- building height - approx. $12.21 \mathrm{~m}$,

- total length of the building - approx. $34.50 \mathrm{~m}$,

- width - approx. $16.25 \mathrm{~m}$,

- usable area - approx. $757 \mathrm{~m}^{2}$,

- cubic capacity - approx. $4626 \mathrm{~m}^{3}$.

The sports hall building was located on the west side of the existing school. The hall is connected with the school directly by a corridor. The main entrance is located on the eastern side of the room, with the front to the existing school and the entrance to the school surface. The entrance to the warehouses is on the south side of the sports hall. The building was designed in a rectangular shape. Thanks to this arrangement, the maximum use of the land area was ensured. The connecting corridor allows for convenient connection with the school premises by internal communication. The main body 
of the building is a room with a height of $8.80 \mathrm{~m}$, covered with a gable roof. The building is located on the boundary of the lot according to the regulations.

Access to the sports hall is from three sides:

- from the south, through the layout of the designed sidewalks the main access to the warehouse,

- from the west side - emergency exit,

- on the eastern side, the main entrance from the pedestrian path leading to the entrance to the school premises, and with internal communication routes from the premises of the existing school.

The sports hall has been designed in a way that enables its multifunctionality, including: conducting physical education classes included in the curriculum, classes with young people and conducting volleyball and basketball games.

The sports hall has an entrance for spectators from the side of the existing school and the street. The sports arena with dimensions of $28.25 \times 16.00 \mathrm{~m}$ allows you to play basketball and volleyball; has been extended to include a seat belt for spectators. There is a trainer's room with a sanitary facility and a medical office next to the sports arena. The corridor and the hall provide communication between the coaches' room, the medical room, cloakroom, and sanitary complexes and the arena.

In the sports hall there is also a gym and a room for corrective exercises accessible directly from the corridor, indirectly from the sports arena. The facility has a warehouse for sports equipment and chairs available directly from the arena.

Accessibility of the building for disabled people is ensured by using external ramps and doors with appropriate parameters. For people with disabilities, a generally accessible toilet and a toilet in cloakrooms are provided.

According to the attached geotechnical documentation, there are fine sands and sandy loams at the foundation level. No groundwater was found up to the foundation level. For these ground conditions, the limit resistance of the subsoil is approximately $150 \mathrm{kN} / \mathrm{m}^{2}$.

On the basis of the decision of the mining experts, the area is subject to mining damage, defined for the IInd category of land suitability for development. 
The sports hall has a skeleton structure - wooden girders based on reinforced concrete columns. On the eastern and southern sides, the outbuildings were designed in traditional technology.

The building of the sports hall is situated on an area with a slope towards the west with a level difference of about $1.80 \mathrm{~m}$. The area is covered with greenery and a dozen or so trees of different ages. In addition, there are elements of small architecture in the area - terrain stairs and retaining walls up to about $1.0 \mathrm{~m}$ high. In the western part, there is a land drainage system.

Due to the mining damage, the footings of the pillars, strip footings, and bowstrings were placed at one depth, on a $30 \mathrm{~cm}$ thick layer of compacted sand. On this layer, a $10 \mathrm{~cm}$-thick lean concrete base was made.

The reinforced concrete structures of foundations, columns, and binders are made of B20 gravel concrete, the main reinforcement of AII18G2 steel and steel stirrups AISt3SX.

The foundation walls with a thickness of $30 \mathrm{~cm}$ are made of concrete blocks on a cement mortar of $10 \mathrm{MPa}$ brand. In the gable walls there are posts that stiffen the wall $25 \times 20 \mathrm{~cm}$, reinforced with steel bars $4 \times 16 \mathrm{~mm}$.

Reinforced concrete pillars of the hall structure, $25 \times 45 \mathrm{~cm}$ in size, are fixed in the foundation. Reinforcement at $3 \times 18$ on both narrower sides.

The outer walls of $25 \mathrm{~cm}$ thickness are made of megaterm blocks on a $5 \mathrm{MPa}$ brand cement-lime mortar. There are $20 \times 25 \mathrm{~cm}$ poles on the walls of the gable.

At the level of ceilings and windows, reinforced concrete wreaths $25 \times 25 \mathrm{~cm}, 4 \times 16 \mathrm{~mm}$.

The internal walls are made of $25 \mathrm{~cm}$ thick megaterm hollow bricks. Partition walls, 6.5 and $12 \mathrm{~cm}$ thick, made of $3 \mathrm{MPa}$ cementlime mortar.

Lintels made of prefabricated L-19 beams. Over the windows on the long walls of the hall, reinforced concrete lintels, which also act as a wreath. Cross-section $25 \times 25$, reinforcement $4 \times 16 \mathrm{~mm}$. The lintels above the openings between the hall and the back room were made of $25 \times 30 \mathrm{~cm}$ reinforced concrete beams, the reinforcement at the bottom $5 \times 16$ and the top $2 \times 16$. 
Filigran type ceiling with a construction height of $25 \mathrm{~cm}$. In places where the ceiling rests on the walls, reinforced concrete wreaths $25 \times 25 \mathrm{~cm}$. In the place where the AHU rests on the roof of the back room, in the ceiling, two $2 \times 16 \mathrm{~mm}$ reinforced ribs with a width of 10 $\mathrm{cm}$.

The supporting structure of the flat roof consists of doubletrapezoidal glued wooden girders with dimensions of 125/65 and a thickness of $12 \mathrm{~cm}$, made of K27 class wood. The girders are based on reinforced concrete columns with the use of anchored steel elements.

Wooden $10 \times 24 \mathrm{~cm}$ panels are based on the girders, on which the remaining layers of the flat roof, i.e., $20 \mathrm{~cm}$ thick mineral wool and two layers of heat-welded roof felt, are laid.

The structure of the connector is separated from the structure of the sports hall and the existing school building $5 \mathrm{~cm}$ dilatation width.

Foundation benches, $40 \mathrm{~cm}$ wide, made on a ballast of compacted sand, $30 \mathrm{~cm}$ thick. Foundation level minimum $1.0 \mathrm{~m}$ below ground level. The foundation walls of the ground floor and the flat roof are made as in the back room of the room.

The floor is on a $12 \mathrm{~cm}$ thick reinforced concrete slab supported by foundation walls. Similarly, the flat roof. In the level of support of the ceiling slab, a reinforced concrete beam $20 \times 20 \mathrm{~cm}$, reinforced $4 \times 16 \mathrm{~mm}$.

\section{Current technical condition and visible damage to the building}

Visible detachment of the ceiling slab from the walls. Horizontal cracks in window and door lintels. Few vertical cracks in the walls, mainly above reinforced concrete columns.

The proper frequency of the building

To determine the frequency of proper vibrations of the building, the approximate method included in the PN-85/B-02170 (and 201612) and PN-77/B-02011 standards was used, as shown in Table 1.

Adopted:

for $H=12.2 \mathrm{~m} \quad \rightarrow \quad T_{1}=0.183 \mathrm{~s}$

Due to the appearance of window openings in the walls of the sports hall and taking into account the fact that the structure was already under the influence of previous mining, the value of the vibration period $T_{1}$ was increased by $20 \%$. 


\section{$T_{1}=0.22 \mathrm{~s} \quad \rightarrow \quad$ the proper frequency $n=4.55 \mathrm{~Hz}$}

Acceleration of the substrata

The same values were adopted as in the case of the primary school.

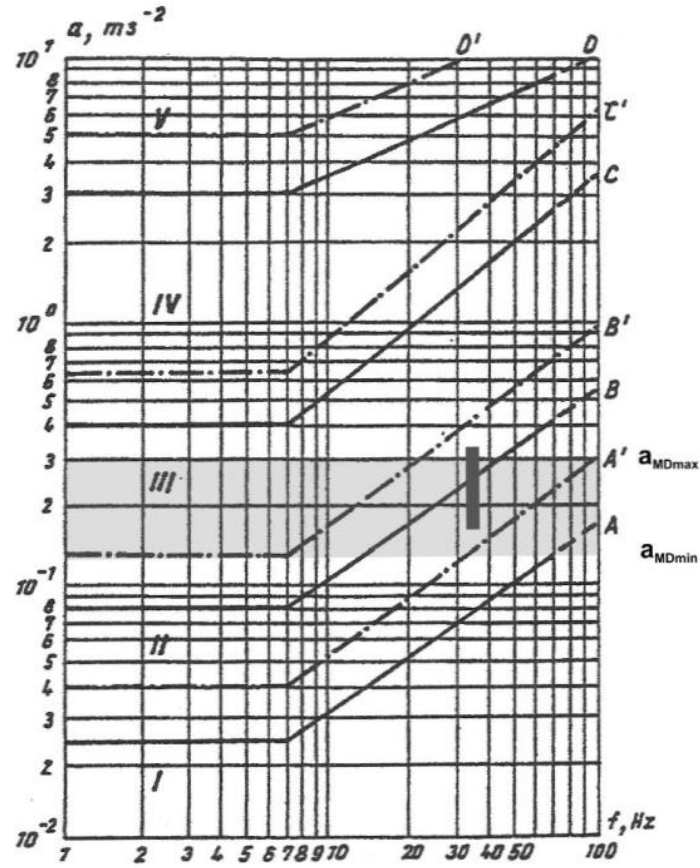

Fig. 3. Example of the interpretation of SWD-II scale (after PN-85/B-02170)

Evaluation of the damaging of the analysed vibration waveforms

As in the case of the Primary School, the PN-85/B-02170 (and 2016-12) standard and the SWD dynamic impact scale included in it were used to assess the dynamic effects on buildings.

To assess the damaging, the value of the natural frequency of the building was adopted

$$
n=4.55 \mathrm{~Hz}
$$

and the predicted amount of acceleration that the ground will achieve at the foundation level, $\mathrm{mm} / \mathrm{s}^{2}$

$$
a_{M D}=145-300
$$

The nomogram in Fig. 3 shows that the acceleration amplitude corresponding to the frequency in the central part of $4.55 \mathrm{~Hz}$ is located near the borderline B in the IIIrd zone of the SWD-II scale. 
From the information provided in the previous section:

- zone III - vibrations damaging the building, causing local scratches and cracks, thus weakening the building structure and reducing its load-bearing capacity and resistance to dynamic influences; mortars and plasters may fall off.

It should be assumed that vibrations caused by mining exploitation, due to their short-term nature, will be felt by the building, but generally not damaging its structural elements. On the other hand, the wear of the building structure will be faster, which in turn will lead to the appearance of cracks in mortars and plasters.

\section{Summary and commentary to the simplified assessment of the dynamic resistance of buildings}

Two buildings: a primary school and a sports hall were subjected to the effects of acceleration of ground surface vibrations in the range of up to $10 \mathrm{~Hz}$ with the values of $a_{M D}=145-300 \mathrm{~mm} / \mathrm{s}^{2}$, according to the presented analysis.

The vibrations induced by mining were damaging to buildings and caused local scratches and cracks in walls and mortars. As the running time of the mining-related parasiteismic vibrations is very short and lasts about $8 \mathrm{~s}$, and the most intense phase of vibrations lasts about 0.5 seconds after excitation; these vibrations were not damaging to the load-bearing elements of the structure. However, these vibrations certainly caused an accelerated wear of the building structure.

The analysis was carried out based on the assumed and forecast values of seismic energy in the area in question.

The potential occurrence of long-term vibrations could weaken the building structure and reduce its load-bearing capacity and resistance to dynamic influences.

Despite the simplicity of the solutions used to analyse this and similar problems related to the assessment of the dynamic resistance of a building 15 years after the implementation of these and other analyses, it can be concluded that all forecasts have been positively verified with the actual real state of structures. 


\section{Sources (selected)}

1. Bańka P. i Lier E.: Opis drgań powierzchni terenu wywołanych wstrząsami górotworu uwzględniający kierunkowość tłumienia drgań. Description of the Surface Vibrations Caused by Rockmass Tremors Taking Into Account the Directivity of Vibrations' Attenuation. Górnictwo - perspektywy i zagrożenia, 7(1), 241-255, 2018

2. Chudek M., Kraviec W. i Wowk A.: Wpływ oddziaływania tąpań i wstrząsów masywu skalnego na obiekty powierzchniowe. Influence of rockbursts and rock-mass tremors on surface buildings]. Wiadomości Górnicze, nr 9/2000, Katowice 2000

3. Chudek M., Krawiec W., Samedow A., Wowk A., Strzałkowski P., Kleta H., Duży S., Ścigala R., Pęciak A. i Pleskot M.: Kompleksowa metoda prognozowania oddziaływania wpływu podziemnej eksploatacji złóż oraz wstrząsów górotworu na chronione obiekty powierzchniowe w brzeżnym obszarze niecki obniżeniowej. [A comprehensive method for prediction the impact of underground mining and rock mass tremors on protected surface objects in the marginal part of a subsidence basin]. Praca zbiorowa, red. Chudek M., Wydawnictwo Politechniki Śląskiej, Gliwice 2003

4. Drzęźla B.: Cele i sposoby wspólnej (grupowej) lokalizacji hipocentrów wstrząsów górniczych na przykładzie metody $\mathrm{P}$ i wzorów dla ośrodka jednorodnego $\mathrm{i}$ izotropowego. [Aims and methods of joint group location of mining tremors hypocenters on the example of the $\mathrm{P}$ method and formulas for a homogeneous and isotropic medium]. ZN PŚ, z. 188, s.: Górnictwo, s. 9-29, Gliwice 1990

5. Jaśkiewicz-Proć I.: Analiza charakterystyk drgań gruntu wraz z funkcją przejścia drgań na budynki. The analysis of ground vibration with transfer function of vibration on the building. CUPRUM - Czasopismo Naukowo-Techniczne Górnictwa Rud, nr 1 (70), s. 21-35, 2014

6. Kawecki J. i Stypuła K.: Błędy w prognozowaniu i diagnostyce wpływów dynamicznych na budynki. Errors in vibration forecasts and diagnoses concerning evaluation of dynamic influences on buildings. Czasopismo Techniczne, Wydawnictwo Politechniki Krakowskiej, z. 1-M/2008, Kraków 2008

7. Kuzienko A.A., Worobew W.D. i in.: Sejsmiczeskoje dejstwiewzrywa w gornych porodach. [Seismic phenomena in rock masses resource deposits]. Izdatelstwo „Nedra”, Moskwa 1971

8. Kuźniar K., Maciąg E. i Tatara T.: Unormowane spektra odpowiedzi od drgań powierzchniowych wzbudzanych wstrząsami górniczymi. Normalized response spectra from surface vibrations induced by mining tremors. Journal of Civil Engineering, Environment and Architecture. JCEEA, t. XXXI, z. 61 (2/14), s. 69-80, 04-06.2014

9. Lan J., Liu J. and Song X.: Study on the influence of the seafloor soft soil layer on seismic ground motion. Natural Hazards Earth Syst. Sci., 21, 577-585, 2021

10. Mutke G.: Metoda prognozowania parametrów drgań podłoża generowanych wstrząsami górniczymi w obszarze GZW. [The method of prediction of the 
ground vibrations parameters generated by mining tremors in the Upper Silesian Coal Basin (USCB)]. Praca doktorska, GIG, Katowice 1991

11. Mutke G. i Dworak J.: Czynniki warunkujące efekt sejsmiczny wstrząsów górniczych na powierzchniowe obiekty budowlane w obszarze GZW. [Factors determining the seismic effect of mining tremors on surface construction objects in the Upper Silesian Coal Basin (USCB)]. Publikacje Instytutu Geofizyki Polskiej Akademii Nauk, M-16, Kraków 1992

12. Miedwiediew S.V., Sponhauer W. i Karnik V.: Skala MSK-64. [MSK-64 scale]. Materiały Konferencji UNESCO, Paryż 1964

13. Olszewska D.: Ocena efektów lokalnych i struktury częstotliwościowej sygnałów sejsmometrycznych dla poprawy dokładności prognozy rozprzestrzeniania drgań wzbudzanych wstrząsami górniczymi w Legnicko-Głogowskim Okręgu Miedziowym. Assessment of local effects and the frequency structure of seismometric signals to improve the accuracy of the prediction of the vibration propagations induced by mining tremors in the Legnica-Glogow Copper District. Rozprawa doktorska, Akademia Górniczo-Hutnicza im. Stanisława Staszica, Wydział Geologii Geofizyki i Ochrony Środowiska, Katedra Geofizyki, Kraków 2008

14. Typuła K.: Ocena wpływu drgań drogowych na budynek i ludzi w budynku. [Assessment of the impact of road vibrations on the building and people in the building]. Politechnika Krakowska, https://slidetodoc.com/wpyw-drga-na-budynki-iludzi-w-budynkach/ (03.12.2021)

15. Yasuhiro Kojima, Tatsuo Ohmachi and Shusaku Inoue: Vibration characteristics and earthquake response of a fill dam having a semi-circular dam axis. The 14th World Conference on Earthquake Engineering, October 12-17, 2008, Beijing, China

16. Lewandowski R.: Redukcja drgań konstrukcji budowlanych. Wprowadzenie. [Reduction of vibrations in building structures. Introduction]. 2002/2003 https://silo.tips/download/redukcja-drga-konstrukcji-budowlanych-wprowadzenie (05.12.2021)

17. Maciąg E.: Interakcja układu budynek - podłoże podlegającego działaniom sejsmicznym i parasejsmicznym. [The interaction of the building - substrate system subject to seismic and parseismic activities]. Mechanika Teoretyczna i Stosowana 4/17, Kraków 1979

18. Okamoto S.: Antiseismic Design of Civil Engineering Structures. Tokyo, Japan 1954

19. Okamoto S.: Introduction to Earthquake Engineering. University of Tokyo Press, 1984

20. Polish Standard PN-85/B-02170 (PN-85/B-02170:2016-12)

21. Polish Standard PN-77/B-02011

22. Piwowarski W. i Zych J.: Analiza trajektorii dynamiki procesu przemieszczeń pogórniczych. [Analysis of the trajectory of the dynamics of the postmining displacement proces]. ZN Politechniki Śląskikej, seria: Górnictwo i Geologia, t. 6 z. 1 s. 189-202, 2011 
https://doi.org/10.31713/m1110

\title{
PROSPECTS FOR SURFACE MINING OF IRON ORE DEPOSITS IN UKRAINE
}

\author{
Slobodyanyuk V.K. \\ The National University of Kryvyi Rih, PhD (Engineering), \\ Associate Professor, the Department of Open Pit Mining Operations, \\ Ukraine
}

\begin{abstract}
At present, new iron ore deposits with much more favorable mining and geological conditions than in Ukraine are being commissioned abroad. Factors that currently complicate the operation of iron ore pits in Ukraine are the significant amount of stripping operations and the need to alienate large areas of agricultural land to place waste dumps.

The purpose of this study was to determine the parameters of the most typical iron ore deposits, surface mining of which is possible in the future. The geometric dimensions and depositional conditions of iron ore deposits largely determine the main parameters of the open pit, its production capacity, development system, the method of opening-up and the key performance indicators.

It was found that the stratified deposits are $82.5 \%$ of reserves of ferruginous quartzite and $83.3 \%$ of the total number of deposits, synclinal deposits $-3.3 \%$ of reserves and $8.3 \%$ of deposits, anticlinal - about $14 \%$ of the balance reserves and $8.3 \%$ of the number of deposits. $50 \%$ of ferruginous quartzite reserves are represented by deposits with a horizontal thickness of over $200 \mathrm{~m}$.

The performed mining and geometric analysis of iron ore deposits is the basis for the development of new surface mining technologies, which will ensure the costefficient development of ferruginous quartzite deposits with complex mining and geological conditions.
\end{abstract}

\section{Introduction}

\section{A track record in systematization of iron ore deposits and ge- ometric analysis of open pit fields in iron ore open pit mines.}

It is known that the geometrical dimensions and conditions of occurrence of iron ore deposits largely predetermine the main parameters of the open pit, its production capacity, the development system, the method of opening-up and the key performance indicators.

In the surface mining theory, there are several examples of systematization of iron ore deposits according to mining and geological conditions in order to determine common approaches to the development [1-5].

Depending on the mining and technical conditions of iron ore de- 
posits in Ukraine, it was proposed [5] to identify six typical open pits with a surface length of one to six kilometers and a width of 300 to $800 \mathrm{~m}$ (Table 1). In [5], in reliance on the proposed classification of typical deposits, the potential of the raw material base of Ukrainian mining and processing companies (GOKs) were studied.

Open pits of the first, third and sixth types have a rounded shape and develop synclinal deposits, open pits of the second, fourth and fifth types develop steeply dipping stratified deposits. The output capacities of typical open pits are determined depending on the area of ore bodies. The open pits of the $1^{\text {st }}$ type include Pit No. 1 of AMKR, Pits No. 2 and No. 4 of Central GOK. Type 2 is represented by Pit No. 2 of AMKR, pits of InGOK, Mikhailovsky and Lebedinsky GOKs. Pit No. 3 of AMKR, the pit of YuGOK, Pervomaisky pit of SevGOK, Pit No. 3 of Central GOK are included in type 3. Pit No. 1 of Central GOK, Stoilensky and Sokolovsky pits of SSGOK belong to the $4^{\text {th }}$ type. The pit of Poltavsky GOK, Annovsky pit of SevGOK and Sarbaisky pit of SSGOK are characteristic for type 5. The $6^{\text {th }}$ type is the United pit of YuGOK and Pit No.3 of AMKR (promising open pit).

Table 1

Key parameters of typical iron ore open pits [5]

\begin{tabular}{l|c|c|c|c|c|c}
\hline \multirow{2}{*}{ Indicator } & \multicolumn{5}{|c}{ Type of an open pit field } \\
\cline { 2 - 6 } & 1 & 2 & 3 & 4 & 5 & 6 \\
\hline Dimensions of a deposit, m: & & & & & & \\
$\quad$ - horizontal thickness & 370 & 300 & 875 & 300 & 350 & 1300 \\
- mining depth & 300 & 400 & 500 & 500 & 600 & 800 \\
- length on the level of ulti- & & & & & & \\
mate mining depth & 150 & 900 & 1600 & 2680 & 4350 & 3800 \\
Dimensions of a pit field, m: & & & & & & \\
- surface length & 1000 & 2000 & 3000 & 4000 & 5000 & 6000 \\
- surface width & 1000 & 1200 & 2000 & 1200 & 2500 & 3000 \\
- area, ha & 82.6 & 194.6 & 487.2 & 476.2 & 826.3 & 1509 \\
Rock volume in the pit, mln $\mathrm{m}^{3}:$ & & & & & & \\
- rock mass & 108.5 & 374.7 & 1392.7 & 1192.5 & 2730 & 7139 \\
- iron ore & 58.2 & 152.9 & 890.9 & 451.7 & 1013.6 & 4573 \\
$\quad$ - overburden & 50.3 & 221.8 & 501.8 & 740.8 & 1716.4 & 2565 \\
- area of dump fields, ha & 90.6 & 399.2 & 903.2 & 1333.5 & 3089.5 & 4617 \\
Average stripping ratio, $\mathrm{m}^{3} / \mathrm{m}^{3}$ & 0.86 & 1.45 & 0.56 & 1.64 & 1.69 & 0.56 \\
Total area under mining, ha & 312.8 & 960.6 & 3528.4 & 2893.7 & 6348.6 & 17101.2 \\
Annual output capacity, $\mathrm{mln} \mathrm{m}^{3}:$ & & & & & & \\
$\quad$ - raw ore & 2.6 & 4.0 & 6.8 & 6.0 & 9.0 & 12.4 \\
- overburden & 2.2 & 5.8 & 3.8 & 9.84 & 15.2 & 6.95 \\
\hline
\end{tabular}


This approach to the classification of iron ore deposits and open pits has a number of disadvantages.

Firstly, the typical open pits reflect the mining and geological conditions of the best Ukrainian open pits. Currently, most of the unique and large iron ore deposits and several medium-sized deposits are involved in development. Such favorable conditions for surface mining will not be repeated in the future. Deposits with difficult mining and geological conditions will be involved in development. At the same time, the sixth type of open pit is designed to simulate the development of a unique synclinal deposit with favorable mining and geological conditions.

Secondly, the proposed classification does not provide for open pits that develop anticlinal deposits. A number of operating and projected iron ore open pits develop anticlinal deposits.

Thirdly, the classification does not give an answer as to how the proposed open pits and deposits are typical for the conditions of Ukraine. Knowing what types of deposits and geological environment will prevail in the future will allow giving a long-term outlook to the importance of the iron ore industry for the Ukrainian economy and directions of development of theory and practice of surface mining of iron ore deposits.

The main provisions of classification, typification and parameterization of iron ore deposits

The need to group iron ore deposits is extremely relevant, since it allows identifying the types of deposits with similar features. However, the approaches to different types of classifications may vary from the point of view of different specialists. As noted by G.A.Gross, "one of the difficulties in creating such a classification is the difference in the interests of an exploration geologist, mining engineer, metallurgist and economist. A single classification is not able to satisfy all these interests." [6]. And yet, iron ore deposits of one or several formations in terms of genesis have many similarities, among which we can highlight the most important in the context of surface mining operations.

The most general classification is based on geological and genetic criteria. Relying on geotectonic and metallogenic zoning within the Ukrainian Shield, five large iron-bearing zones have been identified: Odessko-Belotserkovskaya;

Krivorozhsko-Kremenchugskaya; 
Pridneprovskaya; Belozersko-Orekhovskaya; Priazovskaya.

Another most important parameter is the value of indicated reserves of iron ore in the subsurface. The classification given in [7], with some alterations, may be considered the most optimum. It was calculated taking into account the statistical distribution of occurring natural types of iron ore deposits over a larger area of the ex-USSR (Table 2).

According to their industrial importance, mineral reserves are divided into balance and off-balance reserves. The balance reserves meet the specifications for calculation of reserves in the subsurface and their use is currently economically viable. The off-balance reserves are reserves that are currently economically inexpedient to exploit due to their small number, small deposit size, low content and special complexity of operating conditions, and the need to apply complex processing, but which may become the subject of industrial development in the future.

Table 2

Classification of the USSR iron ore mineral resource base by deposit size [7]

\begin{tabular}{l|c|c|l|l}
\hline Deposit size & $\begin{array}{l}\text { Number of } \\
\text { deposits, \% }\end{array}$ & $\begin{array}{l}\text { Metal reserves, } \\
\text { mln tons }\end{array}$ & $\begin{array}{l}\text { Percentage of } \\
\text { metal in re- } \\
\text { serves, \% as of } \\
1986\end{array}$ & $\begin{array}{l}\text { Percentage of } \\
\text { metal in ore } \\
\text { mined, \% as of } \\
1986\end{array}$ \\
\hline Unique & 1.5 & $>3000$ & 32 & 6 \\
\hline Rather large & 1.5 & $1500-3000$ & 13 & 20 \\
\hline Large & 10 & $350-1500$ & 36 & 47 \\
\hline Medium & 27 & $50-350$ & 15 & 21 \\
\hline Small & 37 & $5-50$ & 3.8 & 5.2 \\
\hline Ore occurrence & 23 & $<5$ & 0.2 & 0.8 \\
\hline
\end{tabular}

Each ore deposit is characterized by a peculiar, unique structure. However, there are some groups of deposits, united by a common genesis, with similar structure-forming conditions, which show very similar structural features. The greatest degree of similarity is found in the iron ore deposits composed of ferruginous quartzite: both large basins, such as Krivorozhsky and Kremenchugsky, as well as individual deposits.

When dividing deposits into categories and types, the basis was those features of the structure that significantly affect its development, namely the structure of the productive stratum and its main parameters. In addition, the structure of the host rocks to be excavat- 
ed on the way was taken into account.

Attempts to systematize the ore-bearing structures were made long ago. Here we should note the work entitled "Structure of Ore Fields of Krivorozhsky Iron Ore Deposits" by N.P. Semenenko (1946). It extensively provides both data on the ore-bearing structures of rich iron ores and data on the tectonics of iron ore strata. Numerous works by E.N. Belevtsev (1946, 1952, 1955, 1957, 1962, 1989), G.V. Tokhtuev (1955, 1989), D.I. Ischenko (1955), A.P. Karshenbaum (1959), V.P. Maksimovich (1955), M.I. Chernovsky $(1962,1989)$ have been devoted to tectonics and structural analysis of iron ore strata, and a series of monographs - "Iron Ore Formations of Pre-Cambrian".

The types of ferruginous quartzite deposits in the Krivoy Rog region was systematized by A.V. Plotnikov and M.I. Chernovsky [8]. They identify the structural types of deposits as follows: monoclinal, flexural, synclinal, anticlinal and blocky. It should be noted that the authors based the division of the selected types on the different types of large folds (synclines, anticlines, flexures) or their fragments monoclines, as well as deposits with a predominantly block structure.

If we consider the systematization of ferruginous quartzite deposits more broadly, taking into account other ore provinces, it is worth noting that both folded deformations and discontinuous ones that break the ore sequence into differently-sized blocks are widely represented in any deposit of the Precambrian ferruginous-siliceous formation. Therefore, almost every deposit is characterized by a foldblock structure. The question rests on the size of geological formations and their consistency within the area of proposed mining. In view of this, while systemizing one may emphasize those basic features of structural iron ore deposits, which play a decisive role in the development of the deposit.

Considering the above and the previous track record in systematization of iron ore deposits, it is proposed to divide their structures into two large categories such as predominantly folded and blocky. In the category of folded deposits, folded deformations play the main role, with a relatively small degree of block influence. The category of block deposits, in turn, is characterized by the development of block structures, and the role of folds is relatively minor.

The main structural types of Precambrian iron ore deposits 


\section{in Ukraine}

The category of folded depositsDeposits in the closures of large synclines (Skelevatsky type)

This type of deposits is characterized by the largest reserves of iron ore, large size, favorable mining conditions and high ore output capacity of open pits.

The synclinal folds are entirely composed by iron-bearing sequence. Productive levels are interspersed partially with nonproductive ones. These deposits are very convenient for large open pits. The dip of rocks in the pit walls $\left(50-70^{\circ}\right)$ coincides with the slopes of non-mining pit walls ensuring their sufficient stability in case of significant deepening. The large size of open pits creates normal conditions to locate transport communications on their walls.

The peculiarity of the geological structure of these deposits is their location in the area of the southern centriclinal closure of large linearly elongated synclinal folds.

Among these deposits we can distinguish several groups, differing by certain features of the structure and size.

Deposits of the first group are located in folds with a gentle plunge of the hinge. These deposits include the Skelevatskoye Magnetite deposit, which is located in the central part of ZapadnoInguletskaya syncline of the Krivbass, and the Belanovskoye deposit, located within the closure of Galeshchinskaya syncline in the Kremenchugsky basin.

Deposits of the second group are located in the cup-shaped closures. The deposit proper encompasses this entire structure, which expands in the area of closing, and the structure becomes dropshaped in plan. The Inguletskoye and Gorishne-Plavninskoye deposits belong to this group.

A somewhat special position is held by the group of Zheltorechenskiye deposits, the structure of which differs from the first two groups by many structural features.

The first group of deposits represents the most well-studied Skelevatskoye Magnetite deposit, which has been in operation since 1955. The peculiarity of its structure is a very gentle plunge of the hinge from south to north. Within the deposit, an angle of plunge averages $15^{\circ}$. This hinge position contributes to an increase in the 
horizontal thickness of the most productive levels, especially in the area of the centroclinal closure, despite complications caused by discontinuous tectonic faults. The greatest depth of plunging the IV main productive ferruginous level is about $800 \mathrm{~m}$ in the northern part of the deposit. Further north, the ore body is overlain by oxidized quartzite of the fifth and sixth ferruginous levels.

\section{Deposits in the closure of relatively small faulted synclines.}

A subtype of Skelevatsky type of iron ore deposits are smaller iron ore deposits of the synclinal type (Petrovskoye, Artemovskoye, Proletarskoye and others).

Deposits of Petrovsky subtype are located within narrow, appressed synclinal ore fields or represented by their fragments. In contrast to the basic type, these deposits are characterized by a much greater diversity.

Along with appressed and subparallel limbs of synclinal folds (Petrovskoye deposit), among these deposits, there are centroclinal closures with diverging limbs (Artemovskoye and Proletarskoye deposits). The hinges of synclinal folds slope both to the north and to the south (Artemovskoye deposit).

The peculiarities of deposits of this subtype are numerous discontinuous tectonic faults, often dividing the ore body into separate, different in size geological blocks.

The Artemovskoye deposit is located within the synclinal fold of the same name (Skelevatsky type). The surface length of the fold is about $3 \mathrm{~km}$, and the wavelength of limbs in the southern part is up to $1 \mathrm{~km}$. The fold has undergone complex deformations. Its closure faces to the north and opens to the south. The entire fold is complicated by discontinuities. The axis of the fold in the area of closing has a submeridional strike, then, in the middle part, it acquires a southeastern direction SE $155-160^{\circ}$, and in the southernmost part it again takes a submeridional orientation SE $175-178^{\circ}$, NS $0-180^{\circ}$. The extension of the axial plane is also characterized accordingly. Its dip from north to south also changes. In the northern and southern parts it is subvertical, in the central part - steep western. The hinge of the fold plunges southward at angles of $20-30^{\circ}$ (average $25^{\circ}$ ), causing the closure to plunge southward to depths of over $600 \mathrm{~m}$. The angle at the apex (in the horizontal plane) is $25-28^{\circ}$, indicating a great compression of the fold. 
The Petrovskoye deposit is located to the southwest of the Artemovskoye deposit. It is an appressed synclinal fold, facing south with a closure and being open to the north. The fold hinge plunges northeastward at a steep angle of $75-80^{\circ}$, flattening and undulating thereafter. The total length of the deposit is about $4 \mathrm{~km}$. The dip of limbs is westerly. The eastern limb dips at an angle of $45-75^{\circ}$, while the western limb slopes more steeply at $60-85^{\circ}$. The syncline is complicated by numerous discontinuous tectonic faults that break the deposit into blocks.

The iron ore sequence is represented by a single stratum. The greatest thickness of the iron ore stratum is determined in the fold closure, and then it very sharply decreases in the limbs. There is also heterogeneity in the structure of iron ore sequence and within the limbs.

The western limb is characterized by a fairly steep decline in the thickness of ore sequence from the closure to the northeast, with very minor variations. The eastern limb differs from the western one in the greater average thickness of the ferruginous bench, its sharper variations, and greater tectonic fragmentation.

The transcurrent tectonic faults split the eastern limb into a series of blocks, which shift relative to each other, therewith, the thickness of iron ore sequence also changing, both upward and downward.

\section{The structural peculiarities of iron ore deposits located in clo- sures of synclines}

The group of fields considered above, located in closures of synclines is characterized by a number of important common features, which should be paid attention to, given that this group of deposits is the most favorable for surface mining.

All mentioned deposits, as well as other deposits of similar type, are favorable by their structure for priority surface mining (taking into account, of course, their size and thickness of overlying sedimentary rocks). The deposits of greatest practical interest are those with the greatest ore sequence directly in the area of closing, i.e. the pit shell itself is located within the closure and insignificantly covers the fold limbs.

Structurally, the increase in horizontal and true thickness within a closure may be due to several reasons: 
$a$ - one of the important reasons is an intensively appressed fold, as a result of which we have a doubling of the horizontal thickness due to the convergence or contact of fold limbs (Skelevatskoye, Artemovskoye, Petrovskoye, etc.);

$b$ - an equally important factor is the gentle plunge of the hinge in the closing area. In this case, the ore formation has a large horizontal development area. Flattening of the ferruginous stratum occurrence within the deposit and a sharp plunge of the hinge outside of it is observed at a number of deposits (for example, Skelevatsky, partly Inguletsky, Zheltorechensky, etc.);

$c$ - increase in the horizontal thickness of ore sequence is caused by the presence of special structural conditions that contribute to the formation of cauldron-shaped basins in the area of fold closures (Inguletskoye and Gorishne-Plavninskoye deposits). These conditions are probably caused by block movements (subsidence) of the sedimentation basement, or by subsidence being similar to cauldron-forming processes in the final stages of the general volcanogenic cycle;

$d$ - as remarked by many researchers [7-10], there is a significant increase in the thickness of ore interlayers in the closing area of some iron ore deposits as compared to the thickness in the limbs. This may be due to the injection of mobile ore material during folding processes (layer-by-layer injection, features of metamorphism, etc.); a possible factor behind this process can also be considered as the features of primary sedimentation in conditions of inclined drift surfaces, where the closing area will be characterized by an increased inflow of material.

The mentioned structural features of deposits located in closures of synclines show that the presence of similar common structural features in the horizontal plane (general shape, character of the closure and limbs, etc.) is not always confirmed by the same deep structure. Particularly important is the angle of hinge plunge.

For example, with a very similar position in the structure of the Skelevatsky and Belanovsky (eastern) deposits, the different position of the hinge - in one case gentle, in the other - steep, determines their different commercial value. Another important feature should be considered the increased ore-bearing capacity of synclinal fold closures.

\section{Deposits in slightly disturbed synforms}

A representative of this subtype is the Gulyaypolskoye deposit, 
located in the Priazovskaya iron ore zone. It is believed that the deposit composes a large synform $(3 \times 9 \mathrm{~km})$ of oval shape, the axis of which is oriented in the northwestern direction.

he iron ore bed completely outlines the fold, undergoing discontinuities and compressions, as well as displacements along the systems of transcurrent fault dislocations. The horizontal thickness at the surface of the crystalline basement varies from $30-50 \mathrm{~m}$ in the central part of the fold up to $300-450 \mathrm{~m}$ in the northwestern and western parts. The dip of rock in the closures and on the limbs is steep - 75$80^{\circ}$, in some cases it is close to vertical. The lower boundary of ferruginous rock is $2.5-3 \mathrm{~km}$ in the northwestern part of the deposit, 1.5 $\mathrm{km}$ in the center, and $0.8-0.9 \mathrm{~km}$ in the southeastern part. Analyzing the distribution of ore sequence within the deposit, we can note that in the northwestern part, the most powerful thickness prevails (on average, over $100-120 \mathrm{~m}$ ), and in the southeastern part, it is relatively small (30-70 m).

Typical volcanogenic complex of the host and interbedded with the iron ore stratum metamorphosed rocks, the nature of the fold itself, provide an opportunity to reasonably suggest that Gulyaypolskaya synform is also an eroded ancient (Proterozoic) caldera of collapse type.

\section{Deposits in anticlinal folds (Tarapakovsky type)}

Deposits of this type are much less common than deposits of other types. Anticlinal folds, depending on the conditions of formation, can be divided into two large groups - appressed (squeezed) and open. The appressed folds at the vertical position of the axial plane are characterized by steep pitches. In this case, if the limbs are composed by ore sequence, then in the central part of the fold in the closure it doubles due to their convergence, as well as due to additional folding. In some anticlines, there is a process of injecting ore material into the area of closing.

The open folds have gentle angles of limb inclination when the axial plane is vertical. In the central part, in the core, non-metallic strata often emerge. As a result, the configuration of the open pit may acquire a complex shape that inherits the ore sequence.

Deposits of this type may include the Severny and Yuzhny Tarapaki, the Inguletskaya anticline deposit (Pit of 2-bis AMKR).

The deposit of Inguletskaya anticline is the most studied. The 
hinge of Inguletskaya anticline plunges gently in a northerly direction at angles of $15-18^{\circ}$. The inclination of limbs is different. On the eastern limb it is $40-60^{\circ}$ to the east, south-east, on the western limb it is $60-80^{\circ}$ to vertical with a west, north-west dip.

The presence of different inclination of anticlinal fold beds, as well as the presence of discontinuities creates certain difficulties during mining operations, determining a different approach to the excavation of ore strata on the eastern and western pit wall. Differences in geological environment also result in varying degrees of their stability.

Deposits in anticlinal folds tend to change the qualitative composition and thickness of the ore sequence in different parts of the fold. Thus, in particular, the Tarapakovsky deposits are characterized by significant variability in the composition of the main ore bed $\mathrm{K}_{2}{ }^{4 \mathrm{f}}$. In contrast to neighboring synclinal-type deposits, the ore bed here has lower and more variable total iron and magnetic iron values. There are significant differences in the thickness of the eastern and western pit walls. The western strata (west dips) in TarapakovskoLikhmanovskaya anticline tend to decrease in total thickness.

A number of iron ore deposits of anticlinal character are caused by the formation of granitoid domes of various sizes. Metamorphic rocks, including ferruginous quartzite strata, encircle these domes completely or partially, being located in the limbs of these structures. This type of deposits includes Zapadno-Zelenorechenskoye, Kamchatka group of deposits, as well as a number of deposits and iron ore occurrences, intensely granitized, which are currently represented by separate, often spatially separated remnants, fringing granitoid massifs (domes). Such deposits and ore occurrences may include Chkalovskoye and Chervonoshakhtarskoye ore occurrences, Leninskoye, Orekhovskoye, Proletarskoye and Lozovatskoye deposits within the area of the Pravoberezhny Magnetic Anomalies, the Secretarskoye deposit at Pobuzhye, the Vostochny Novodanilovsk site within the OrekhovoPavlohradsky iron ore zone and others.

The most typical structures of these deposits may be observed on the example of the structure of the Zapadno-Zelenorechenskoye deposit and the group of Kamchatka deposits.

The Zapadno-Zelenorechenskoye deposit is located $4 \mathrm{~km}$ north of Artemovskoye one. Here there is a well-defined granitoid dome, consisting of plagioclase granites. It is bordered by a rock stratum 
containing a layer of silicate-magnetite ferruginous quartzite, forming a brachiatic anticlinal fold. The upper part of the fold is eroded and granitoids emerge on the surface of the crystalline basement. The thickness of the ore bed is 40-60 m. The occurrence of iron ore in the uneroded northwestern part of the dome is gentle to horizontal in the center and steeper on the limbs (from 30 to $60^{\circ}$ ). The eastern limb when dipping becomes steep, almost vertical up to reverse.

The hinge of the general anticline, the south-eastern reflection of which is the Zapadno-Zelenorechensky dome, gently plunges in a north-westerly direction. The upper apical part of the fold, composed by iron ore strata, is located within the crystalline basement surface along $800-900 \mathrm{~m}$, and further to the north-west it is overlapped by the overlying gneiss sequence.

\section{Monoclinal deposits (Saksagan type)}

Deposits of this type are the most common in quantitative terms. The banded, monoclinically dipping ore zones are most common in ore fields composed of iron-siliceous formations.

Linearly elongated zones composed of ferruginous quartzite are characteristic of all ore belts of the Ukrainian Shield: Belotserkovsko-Odessky, Krivorozhsko-Kremenchugsky, OrekhovoPavlogradsky, and Priazovsky.

Monoclinal deposits may be located in one ore field, being an extension of each other (Saksaganskoye, Annovskoye, Inguletskoye (Likhmanovskoye) ore fields), or articulated with deposits located in the area of synclinal fold closure (for example, GorishnePlavninskoye and Lavrikovskoye deposits). As noted above, we will refer to this type of deposits as a group of fields that have a synclinal overall structure, in which the fold closure is strongly plunged, and only monoclinically plunging limbs are located in the area of accessible mining.

Such deposits include: "Bolshaya Gleyevatka" (Pit No.1 of Central GOK), southern Annovskoye (Annovsky pit of SevGOK), northern Annovskoye deposit, Zheltyanskaya group - western and northeastern, Popelnastovskoye, Nikolaevskoye, Mlynkovskoye, Uspenovskoye, Lavrikovskoye, Eristovskoye, areas of Saksaganskoye ore field, Zelenovsky area of Likhmanovskaya (Inguletskaya) strip, etc.

For deposits of this type, the internal structure and thickness of 
the ore strata, the consistency of quality and thickness, both along the strike and down dip are of great importance.

Most monoclinal deposits belong to the second tectonotype, which is characterized by the intercalation of iron ore levels with shale ones. Therewith, their thickness plays a big role. The large thickness of non-metallic shale separating the iron ore strata makes it necessary to mine selectively each ore bed. The relatively low thickness (usually less than $10 \mathrm{~m}$ ) of non-metallic beds is mined together with ore levels, reducing the overall quality. In this regard, monoclinically built iron ore deposits are divided by the quality of individual ore beds into one-, two-, three-, and four-layer, as well as multi-layer deposits, which contain a greater number of layers.

The one-layer ore formation is characterized by a single ore layer, which may include one or more technological varieties, as well as minor in thickness (less than $10 \mathrm{~m}$ ) non-metallic layers, veins or lenticular inclusions.

The two-layer ore formation consists of two sub-parallel layers of ferruginous quartzite, which are separated by a non-metallic formation of similar thickness or greater than the thickness of a single ore layer, usually exceeding $10 \mathrm{~m}$. Formations may be of equal thickness and technological characteristics, or slightly different. With large differences in thickness and quality, joint development may be partial or concentrated on a single layer only.

Accordingly, the three-layer productive formation consists of three equivalent or slightly different in thickness ore beds, separated by two non-metallic (usually shale or gneiss) strata with thickness exceeding $10 \mathrm{~m}$.

The four-layer iron ore formation consists of four beds of ferruginous quartzite separated by three strata of non-metallic rocks. It is often noted that two or three layers converge, and sometimes merge to form a single stratum, when the ore sequence is four-layered.

The multi-layer iron ore sequence consists of many (more than 4) strata separated by non-metallic beds.

Often, such strata are represented by relatively thin iron ore layers, also separated by thin non-metallic beds.

Such zones are generally difficult to mine selectively and often the total thickness of the ore strata does not meet the requirements of the conditions. In such cases, individual sections of the ore layer that 
meet the condition requirements are selected for further mining.

When assessing monoclinal deposits, the length of iron ore layers, their total thickness and thickness of individual layers, both along the strike and down dip, their stability within the deposit, as well as parameters characterizing the quality of raw materials play a great role.

The length of the ore beds determines the total reserves of raw materials.

A number of deposits with monoclinal occurrence are characterized by the sustained extent of the main ore strata. However, there are also fields where, in the presence of one or two stable main strata, there are phenomena of wedging in neighboring strata, cutting by tectonic faults, combining two strata into one, and also phenomena of splitting of one thick bed into several thin beds.

The thickness of ore sequence determines the main parameters of the open pit; the presence of two or more sub-parallel ore strata affects the configuration of the bottom and walls of the open pit.

Monoclinal ore beds in deposits of this type usually dip steeply, almost vertically. This allows for a clearer distinction when mining the conditioned, substandard and non-metallic rock strata over long distances along the strike.

The stability of the thickness and quality of ore raw material along the strike and dip may be disturbed by the presence of folding (vertical flexures), as well as by diagonal and transverse tectonic faults. Folded deformations in the form of vertical flexures (a vertical hinge, the Saksaganskoye ore field) and less frequently horizontal flexures (horizontal fold hinge, the Annovskoye ore field) are noted in deposits of this type. The amplitude of these deformations plays a major role. Insignificant amplitudes (not exceeding 0.5 thickness of the ore sequence) have relatively little effect on the overall mining plan. Large amplitudes of flexures have a significant impact on the configuration of the open pit and on technological solutions for the location of openings (the location of pit roads, crushing and reloading points, conveyors) [11]. The presence of flexural bends also affects the quality of ore raw material. Within these bends, an increased degree of oxidation of ferruginous quartzite is noted, up to the oxidized rich iron ores, and the physical and mechanical properties change.

Discontinuous tectonic faults also lead either to an increase or to a reduction in the thickness of ore strata. This phenomenon is charac- 
teristic of diagonal shear deformation, both in plan and in section (Pit 1 of CGOK).

Transverse discontinuous tectonic faults also disturb the occurrence of the ore sequence, shifting it in one or another direction relative to the middle strike line. The magnitude of these shifts is also very influential on the formation of the open pit, if it reaches values greater than 0.5 thickness of the ore strata.

Qualitative indicators and the complex of physical and mechanical properties in the zone of the influence of tectonic faults behave differently. In a number of faults and their zone of influence, there is a very sharp difference of these parameters from the main thickness. This is due to the presence of numerous fault seams, increased fracturing of the adjacent rocks, the presence of superimposed hydrothermal and hypergenic processes that significantly change the original rocks. The spatial parameters of the zone of influence caused by tectonic movements along faults and superimposed processes are often very difficult to estimate, due to their great unconformity along the fault. At the same time, there are a number of discontinuous tectonic faults (most often transverse) along the zones of which, despite significant displacement of the strata, there are almost no changes in the surrounding rocks (Annovsky open pit). The zone itself is represented in this case by a narrow strip (first $\mathrm{cm}$, tens of $\mathrm{cm}$ ), grinded and cemented by the surrounding rock.

\section{Consideration of structural types of iron ore deposits in the design of open pits}

Typification of iron ore deposits by structural features is extremely important when designing the mining companies. It allows us to take into account the features of the geological structure as early as the design stage, to provide for the development of mining operations at different depths, to anticipate the required set of mining and geological researches and capital works. On the other hand, the typification of deposits will enable us to take advantage of the experience in development of similar types of previously stripped or exhausted deposits.

In view of the above, much attention should be paid to the issues as follows: a) types of deposits, their sizes and reserves of raw materials; b) type of the deposit and the projected configuration of the open pit in plan and section, the capacity of proven reserves to be 
extracted; c) the stability of pit walls when mining deposits of different types; d) opportunities for development of small deposits and deposits with variable overburden thickness; e) clarification of the relationship of structural types of deposits and their degree of profitability.

a) types of deposits and proven reserves

The above data on the typification of deposits makes it possible to highlight the parameters and characteristics of deposits, which should be considered when designing and developing by the surface mining method. One of the key indicators is the size of proven reserves.

The most favorable for surface mining is Skelevatsky (synclinal) type of deposits, characterized by large reserves and a synclinal structure being optimum for mining: the core and limbs of the syncline are ore sequence. The structure of the deposit contributes to the full development of reserves, as the parameters of the open pit in the area and in the section coincide with the ore sequence.

For Tarapakovsky (anticlinal) type deposits, the most favorable for mining is the closing part of the fold. Plunging limbs may only be of interest up to a certain depth. The reserves in the limbs cannot be fully extracted by the surface mining method.

Also favorable for surface mining is Pervomaisky (concentrated block) type of deposit, within which the ore body, although broken into separate blocks, but in general the pit shell is located within the ore body, despite the shifts of ore blocks.

Among the deposits of Saksagansky (monoclinal) type, only deposits with large reserves, which have a large horizontal thickness and high quality of ore strata, being capable of overlapping the costs of excavation, haulage and storage of waste and host waste rocks are favorable for surface mining.

Deposits with a complex structure and low thickness of ore beds are classified as problematic for surface mining. The decision on the possibility of surface mining is made on the basis of simulation of the optimum boundaries and mode of mining operations.

b) types of deposits and configuration of open pits in plan and section

The structure of the deposit determines possible degree of completeness of its development. The considered types of iron ore depos- 
its allow us mainly to determine the position of the open pit in plan and in section. However, if for Skelevatsky type the issue of the spatial position of the open pit within the field does not cause special difficulties, for other types of this issue is very relevant. For Tarapakovsky and Shimanovsky types of deposits, not only the position of the open pit in plan, but especially the vertical section of the pit is important. The uneven thickness and quality of the western and eastern limbs of the anticline (Severny Tarapak and Yuzhny Tarapak deposits) makes us lean toward the idea of developing an asymmetric cross-sectional profile of the open pit. With the progress in mining operations, the fold limbs will be developed first, leaving for a later period the central, elevated part of the deposit, represented by poorer varieties of ferruginous quartzite and a thicker mass of the shale level (shale 3-4).

A complex configuration, both in plan and cross section, will have pits opening anticlinal deposits, being similar in structure to Zapadno-Zelenorechenskoye or Kamchatka deposits. Here, the ore sequence is thickest in the periclinal sections, where the hinge of the anticline slopes downward, forming gentle synclinal bends. The structure of these bends is very complex; it is identical to the foldedblock deposits, where both folds and blocks offset one another are noted. If it is possible to develop the ore stratum on the limbs, the open pit will bifurcate, inheriting their configuration.

Features of the geological structure of deposits of Pervomaisky type should also be taken into account in the design of open pits. Large shifts in the horizontal and vertical planes make adjustments to the optimum pit wall design. It is necessary to take into account the position, directions of shift and rotation angles of the structural blocks of the deposit when planning the mining operations.

In the deposits of Saksagansky type, the open pits extend in the direction of ore stratum strike. Here, folded flexure-type dislocations with horizontal and vertical hinges, as well as thrust and strike-slip faults will play a major role. The presence of such dislocations leads to a change in the configuration of the open pit in plan and in section (Annovsky open pit).

The increase and decrease in the amount of extracted iron ore raw materials as compared with the proven reserves may be explained by technological (dilution and losses) and geological (rare exploration 
network) factors, as well as the uniqueness of the deposit structure, which cannot be accounted for by the existing methods of exploration. The presence of mesofaulting, low- and medium-amplitude block dislocations introduces certain corrections to the estimation of total deposit reserves. These corrections may be taken into account when comparing geological exploration data and actual iron ore production volumes with a correction for a certain deposit type. No such work has been done. However, given the existing data, it can be noted that these divergences will increase from simple structures of deposits (Skelevatsky type) to more complex ones (folded-block type of deposits).

c) Stability of pit walls when mining the different types of deposits

The degree of pit wall stability is greatly influenced by the dip angles of their host rocks, as well as the presence and spatial location of major faults.

The direction of the dip in synclinal folds is oriented toward the center. A dip of 60-75 is considered most favorable for good pit wall stability. Such a dip corresponds to the parameters of the bench slopes. The stability of pit walls is sufficient, even in the presence of interbedded tectonic faults. At sub-vertical dip (80-90) there is also a fairly high stability of pit walls.

More gentle dip (30-50), which does not coincide with the technological rules determining the value of the bench slope (70-75), is unfavorable for the pit wall stability. A very gentle occurrence $(\sim 0$ $20^{\circ}$ ) also creates a more reliable stability.

More favorable conditions for pit wall stability are created by simple anticlinal folds, stipulating the reverse dip of rocks, which provide sufficient stability at various angles of rock dipping.

Similar to the dip of rocks, the pit wall stability is affected by tectonic faults, causing fractured unstable zones. Water often seeps through them, creating additional instability. Complicating mesofaulting and shallow blockiness create additional factors that weaken the pit wall stability.

For deposits of complex structure, where the location of rock dips and faults is not reliable, the pit wall stability requires constant attention during the entire deposit development process.

d) peculiarities of development of small deposits with large overburden thickness 
Along with large deposits, the raw material base of ferrous metallurgy in Ukraine is represented by a large group of small deposits, much of which can be developed by surface mining method. There are such deposits in the Pobuzhye, in the Pravoberezhny area, in the Priazoviye. Small open pits will ensure the extraction of high quality ore in a short time with relatively small capital expenditures. As an example, in the past, iron ore mining in the Krivbass began with the development of small deposits.

With a large thickness of overburden and the use of a set of mining equipment being standard for the iron ore open pits in Ukraine (electric rope shovels with a 10-12 cub m bucket and 130 ton dump trucks), involving in the development of small deposits will require a large amount of capital and stripping operations. This problem manifested itself during the commissioning of deposits such as Artemovskoye and Petrovskoye (Pravoberezhny Magnetic Anomalies, the Kirovograd region), where, along with loose overlying rocks, the ore body is overlain by Precambrian rocks represented by shale.

Since the share of small deposits is large, the justification and development of new methods of opening up and development of such fields are an urgent task [11]. It is possible to reduce the volume of capital and stripping operations by means of dump trucks, which require a smaller width of transport berms, and overcoming large longitudinal slopes (up to 15-20 degrees). The use of skip hoists and inclined conveyors, including those located in underground mine workings, may be effective. The combined surface-underground method of deposit development will also be effective. At the first stage, the open pit mines the most favorable part of the deposit for surface mining (the closing part of the syncline, the bed section with the maximum thickness, etc.). At the second stage, adits are used to open the reserves of the deposit located outside the pit. Transportation of ore extracted by underground mining method from the adits to the day surface is carried out by haulage berms on the pit wall.

e) the role of deposit structure in the degree of profitability of mining.

In [8] it is noted that the structure of the deposit affects the technical and economic performance of the open pit and its profitability. A comparative analysis of mining and geological conditions and technical and economic indicators of deposits under operation, 
showed [8] the dependence of the efficiency of field development on its geometric parameters and reserves. Mining efficiency is affected by the shape of the ore body, its thickness, and the thickness of overburden. As the thickness of the ore body increases, the operational stripping ratio decreases and the maximum output capacity of the open pit increases; as the thickness of overburden increases, the operational stripping ratio and the amount of mining and capital operations increase.

\section{Statistical and geometric analysis of deposits}

Deposits of synclinal and anticlinal types are characterized by the set of parameters as follows: an angle of the hinge plunge; number of ferruginous levels; total thickness of ferruginous levels in each fold limb; a dip angle of fold limbs; an azimuth of fold limbs; a length of fold limbs; reserves of ferruginous quartzite; thickness of sedimentary mantle; average content of iron in ore and in concentrate. Stratified deposits are characterized by the set of parameters as follows: an azimuth of the stratum strike; stratum dip angle; thickness and length of each stratum; total thickness of the strata; total thickness of waste rock separating the mineral strata; reserves of ferruginous quartzite; thickness of the sedimentary mantle; average iron content in ore and in concentrate. The selected indicators allow geometrically describing the simplified productive strata of promising deposits.

The deposits de facto are much more complex than the simplified scheme used to represent the field through its main parameters. Various sources of information (monographs, articles, dissertations, research reports, exploration reports) were used to collect deposit parameters. The simplified, skeleton models of deposits were created based on the selected and averaged parameters. Ore reserves calculated by simplified models were compared with the deposit reserves given in the geological literature. In case of a significant discrepancy, the deposit parameters were rechecked and corrected on the basis of cartographic materials. For a number of deposits, inferred resources (usually category $P_{1}$ ) are used as reserve data.

In the process of collecting information on iron ore deposits in Ukraine, 133 deposits were analyzed (including Krivorozhsky iron ore district and Pravoberezhny anomalies - 58, Kremenchugsky district - 27, Pridneprovsky - 11, Belozersko-Orekhovsky - 20, Odessko-Belotserkovsky - 5, Priazovsky - 12). 42 deposits were selected in 
order to further study and generalize the parameters of iron ore deposits that are promising in terms of surface mining. The main criterion for the selection of deposits was the thickness of the sedimentary mantle of no more than $100 \mathrm{~m}$.

The main classification feature is the structure and morphology of a part of the ore sequence in the depth interval being available for surface mining (up to 500-700 m). For example, a synclinal field with a deep hinge and a low thickness $(10-20 \mathrm{~m})$ of one of the limbs was considered as a stratified deposit. The parameters characterizing its structure in terms of the possibility of surface mining were specified for each deposit.

A number of deposits (Orekhovskoye, Proletarskoye, Krasnofedorovskoye, Zheltyanskoye, Nikolaevskoye, Severo-Tersianskoye, Vasinovskoye, Novoukrainskoye, Kuksungurskoye, Korsakskoye) are characterized by a very complex structure that makes it impossible to characterize them as a whole. Moreover, individual sections of the deposits are located from each other at a considerable distance, measured in hundreds of meters, which allows us to conclude that until a certain stage of development or even until its completion, these ore bodies will be developed by separate open pits. Each of these deposits was divided into separate sections and these sections were subsequently treated as separate productive strata.

Thus, on the basis of 42 iron ore deposits, 60 separate productive strata were identified, which were analyzed and further considered as separate deposits. The total reserve of ferruginous quartzite in the deposits selected for analysis is more than 20 billion tons.

When analyzing the scope of deposits as a whole, we proceeded from the categories determined by the classification of the iron ore mineral resource base in the USSR according to the size of deposits. In accordance with this, the totality of deposits by reserves was conditionally divided into 6 categories. Unique deposits are characterized by ore reserves over $3000 \mathrm{mln}$ tons, rather large (RL) 1500-3000 mln tons, very large (VL) 750-1500 mln tons, large (L) 350-750 mln tons, medium (M) 50-350 mln tons and small (S) 5-50 mln tons.

Analysis of the collected information shows that 50 deposits are classified in terms of surface mining as stratified (S), 5 - as synclinal (S) and 5 - as anticlinal (A) fields.

Fig. 1-2 show the distribution of reserves and the number of iron 
ore deposits by size and morphological structure. The stratified deposits are associated with $82.5 \%$ of ferruginous quartzite reserves and $83.3 \%$ of the total number of deposits, with synclinal deposits $3.3 \%$ of reserves and $8.3 \%$ of the deposits, with anticlinal - about $14 \%$ of the balance reserves and $8.3 \%$ of the number of deposits. Thus, the existing opinion about the predominance of stratified fields among iron ore deposits being suitable for surface mining is confirmed.

$40 \%$ of reserves are concentrated in very large fields, which represent $13 \%$ of the total number of deposits. They are followed by large and medium-sized fields, which represent 26.1 and 22.6 percent of reserves, respectively, and 21.7 and 53.3 percent of the number of deposits. Small fields account for less than $1.5 \%$ of total reserves and $10 \%$ of total number. In turn, rather large fields account for $10.4 \%$ of reserves and $1.7 \%$ of the number of deposits.

Very large stratified fields represent $30.3 \%$ of total reserves, large ones $-22.0 \%$, medium ones $-18.8 \%$, rather large stratified fields $10.4 \%$.

The participation of classic synclinal deposits in the balance of reserves is insignificant - about 3\%, while anticlinal deposits represent $13 \%$ of reserves. The shares of synclinal and anticlinal deposits in the total number of deposits are approximately equal (about $8 \%$ ). There are no synclinal deposits with reserves over $350 \mathrm{mln}$ tons. Anticlinal deposits represent $10 \%$ of very large deposits and about $5 \%$ of large deposits (Fig. 1a). Among the small deposits, the share of anticlinal deposits in the distribution by reserves and number of deposits is insignificant.

The iron ore deposits is analyzed by the length of ore bodies (Fig. $3,4)$ with distribution into five categories: up to $1000 \mathrm{~m}, 1000-2000$ $\mathrm{m}, 2000-3000 \mathrm{~m}, 3000-4000 \mathrm{~m}$ and $4000-5000 \mathrm{~m} .37 \%$ of reserves and $43 \%$ of deposits of their total number are characterized by the length of ore bodies from 1000 to $2000 \mathrm{~m} .25 \%$ of reserves are associated with the length of ore bodies along the strike of over $3000 \mathrm{~m}$. The length of ore bodies less than $1000 \mathrm{~m}$ is characterized by $8 \%$ of reserves and $28 \%$ of the total number of deposits. The range from 2000 to $3000 \mathrm{~m}$ is representative $-31 \%$ of the reserves and $17 \%$ of the number of deposits.

The iron ore deposits is analyzed by the total horizontal thickness 
of ore bodies (Fig. 5, 6) with distribution into seven categories: up to $50 \mathrm{~m}, 50-100 \mathrm{~m}, 100-150 \mathrm{~m}, 150-200 \mathrm{~m}, 200-300 \mathrm{~m}, 300-500 \mathrm{~m}$ and over $500 \mathrm{~m}$. More than $50 \%$ of the total deposits reserves (Fig. 5) are represented by ore bodies with horizontal thickness over $200 \mathrm{~m}$ (Fig. $5 \mathrm{~b}$ ): $30 \%$ of reserves are characterized by horizontal thickness of $200-300 \mathrm{~m}, 17 \%$ - 300-500 m and 6\% - over $500 \mathrm{~m}$. Over $50 \%$ of the total number of deposits (Fig. 6) have a horizontal thickness of less than $100 \mathrm{~m}, 18 \%$ more than $200 \mathrm{~m}$.

In the process of designing the surface mining a number of strategic tasks are solved: determining the boundaries of the open pit, the choice and justification of opening-up methods and development system, the choice of direction of mining development in the open pit area and provision of ore, overburden and rock output capacities.

In projects for the deposit development, it is obligatory to calculate the maximum possible production capacity in terms of mining and technical factors and to analyze the dynamics of its development from the beginning up to the final open pit. The production capacity determined in this way is the upper limit of production capacity in its search area.
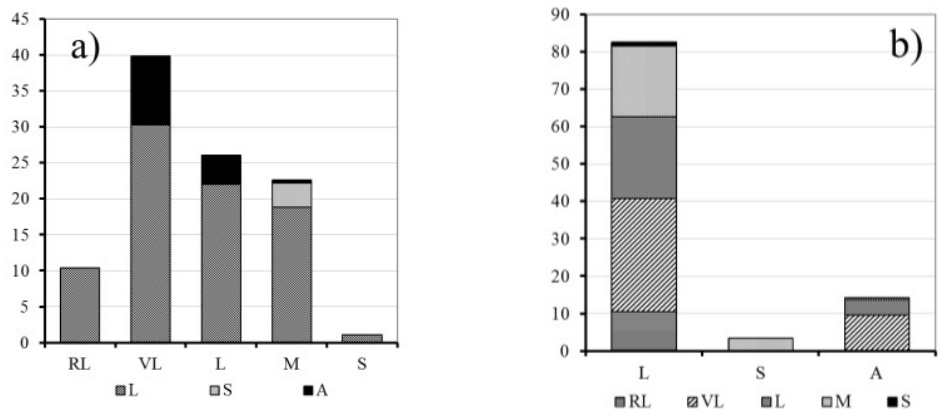

Fig. 1. Distribution of reserves of iron ore deposits by grain size categories (a) and by deposit morphology (b) 

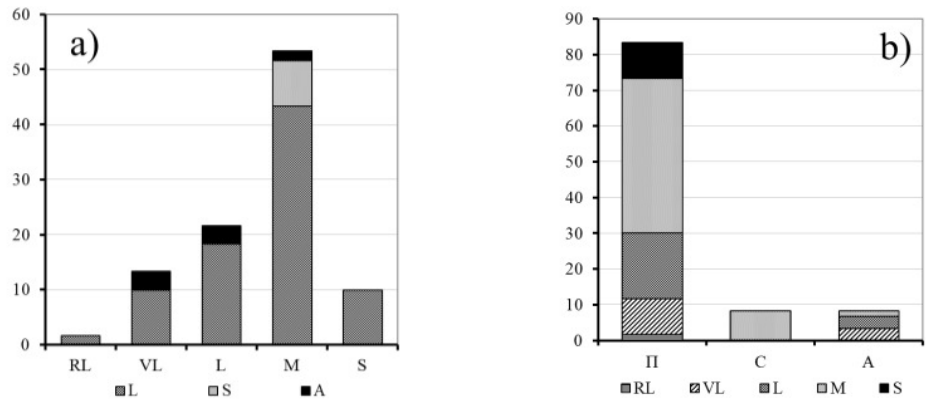

Fig. 2. Distribution of the number of iron ore deposits by grain-size categories (a) and by deposit morphology (b)
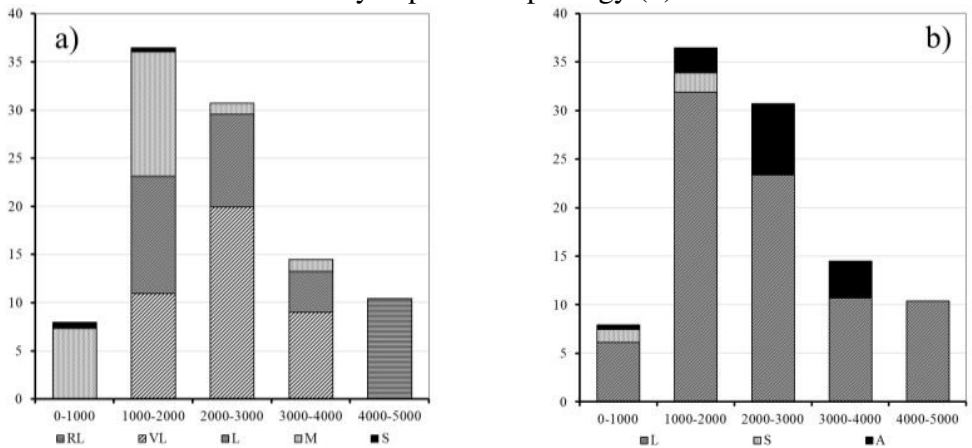

Fig. 3. Distribution of reserves of iron ore deposits of different size (a) and different morphology (b) depending on the extent of ore bodies along the strike
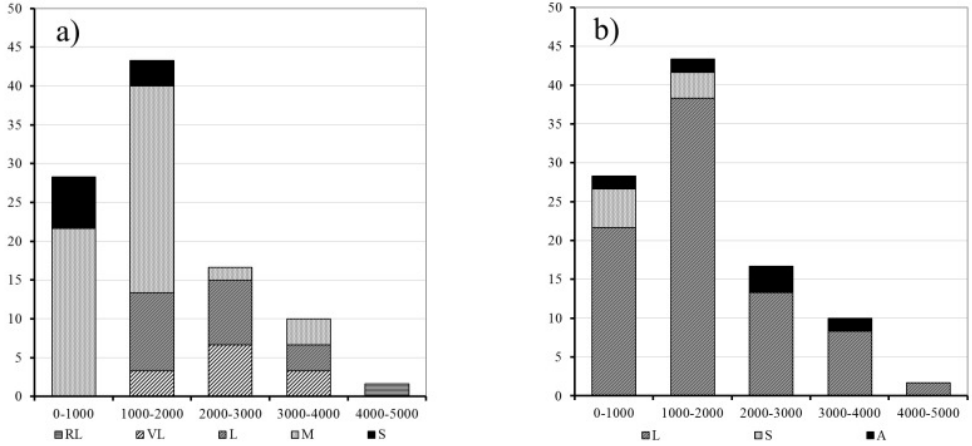

Fig. 4. Distribution of the number of iron ore deposits of different size (a) and different morphology (b) depending on the extent of ore bodies along the strike 

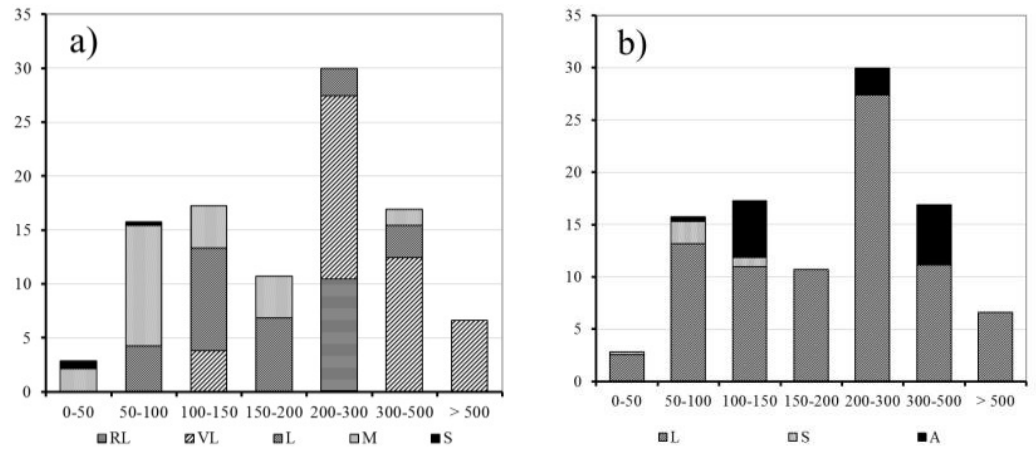

Fig. 5. Distribution of reserves of iron ore deposits of different size (a) and different morphology (b) depending on the horizontal thickness of ore bodies
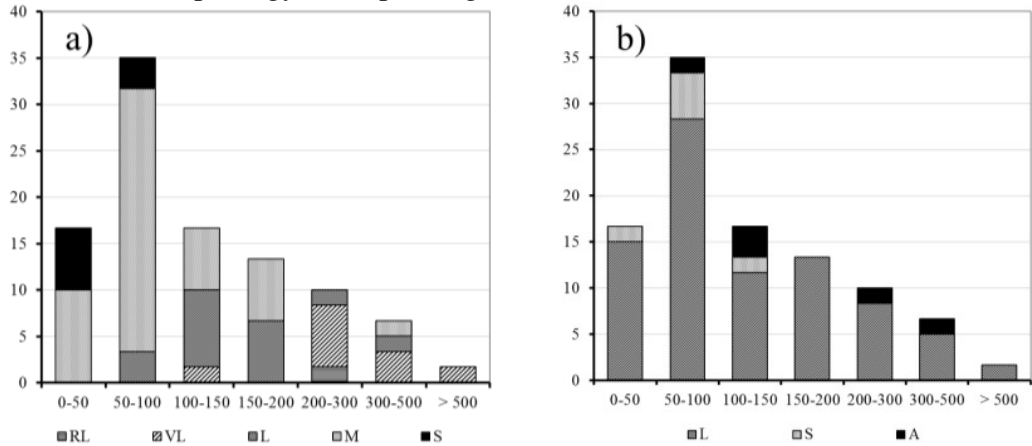

Fig. 6. Distribution of the number of iron ore deposits of different size (a) and different morphology (b) depending on the horizontal thickness of ore bodies

According to the standards of technological design, the possible ore production is determined by the formula

$$
A_{\mathrm{p}}=h_{\Gamma} S_{P} \rho \frac{1-r}{1-v}, \mathrm{t},
$$

where $h_{\Gamma}$ is the rate of vertical mining, m/year; $S_{\mathrm{P}}$ - ore body area, within which the mining operations deepen, $\mathrm{m}^{2} ; \rho$ - ore density in the subsurface, $\mathrm{t} / \mathrm{m}^{3} ; r$ - operational ore losses, unit fractions; $v-$ weight dilution factor, unit fractions.

In specific geological and technical conditions, the determining parameter for calculating the possible production capacity of the open pit is an indicator of the intensity of the development of steeply dipping deposits - the rate of vertical mining. In design practice, at the stage of feasibility studies, as well as in approximate calculations, 
the rate of deepening the open pit is taken by analogy. At open pits that use rail transport, the annual deepening of mining operations is on average 6-10 m/year, and with road transport 10-15 m/year.

Thus, the technically possible production capacity of the open pit is a function of the ore zone area, which in first approximation is equal to the product of the length of the ore body by the horizontal thickness. Using the collected information about iron ore deposits, you can make a preliminary prediction about the possible production capacity of the open pit and the degree of favorability of mining and geological environment. The main factors influencing the degree of the deposit favorability for surface mining are the thickness of overlying rocks and the total horizontal thickness of ore bodies. It is known that with an equal ore body area, more favorable mining conditions will be characterized by an open pit, which develops the ore body of greater horizontal thickness and shorter length along the strike.

The distribution of ferruginous quartzite reserves depending on the total thickness and strike of ore bodies for promising and operating deposits is shown in Fig. 7. The figure also shows graphs (hyperboles) defining the set of values of ore body thickness and extent along the strike, the product of which is equal to the area of 5,10,15, $20,30,40,50$ and 100 ha. Assuming the rate of deepening of a conventional open pit to be equal to $7.5 \mathrm{~m} /$ year, we obtain that the ore body area, being equal to $100 \times 100 \mathrm{~m}$ ( $1 \mathrm{ha})$, provides production of about $0.25 \mathrm{mln}$ tons/year of ferruginous quartzite. The obtained value is overestimated, let's take it as the maximum possible production capacity. Accordingly, the ore area of 5 ha provides annual production of $1.25 \mathrm{mln} \mathrm{t}, 10 \mathrm{ha}-2.5 \mathrm{mln} \mathrm{t}, 20 \mathrm{ha}-5 \mathrm{mln} \mathrm{t}$ and $100 \mathrm{ha}-$ $25 \mathrm{mln}$ t. Focusing on the position of promising deposits relative to the hyperbolas, which determine the possible production capacity of the open pit at the corresponding values of thickness and strike, we can estimate the industrial potential of the deposits.

Analysis of the position on the graph of deposits under operation correlates with the known data on mining and geological conditions in the pits that develop them.

Over $80 \%$ of reserves are characterized by deposits with a level of maximum possible production capacity exceeding $5 \mathrm{mln}$ t/year. These are mostly fields with reserves of more than $350 \mathrm{mln} \mathrm{t}$ (40\% of the total 
number of analyzed deposits). About $36 \%$ of the total number of deposits is characterized by a possible production capacity of less than $2.5 \mathrm{mln}$ t/year, and $7 \%$ of reserves are associated with these fields.

The influence of the thickness and character of occurrence of the ore body on the main technical and economic indicators of deposit development was investigated on the example of a stratified-type deposit. For this purpose, calculations were made of the volume of extracted ore and overburden removed from the pit for different options of the final pit, developing a deposit with given parameters. A mining and geometric analysis of a typical series of deposits characterized by the general parameter - the strike of $2000 \mathrm{~m}$ and a variable parameter - the horizontal thickness of the ore body from $50 \mathrm{~m}$ to $250 \mathrm{~m}$ were performed for the stratified type. The depth of occurrence of the ore body is $500 \mathrm{~m}$, the thickness of the overlying rocks is $0 \mathrm{~m}$. The obtained dependences of the overburden volumes from the ore reserves in the open pit are shown in Fig. 8 (dashed lines). Analysis of the calculation results shows that the horizontal thickness of the ore body has a decisive influence on the technical and economic indicators of development.

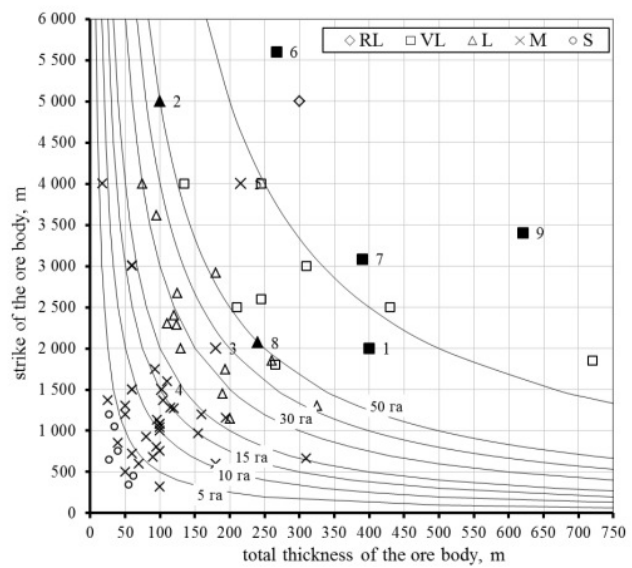

a) distribution of deposits by reserves 


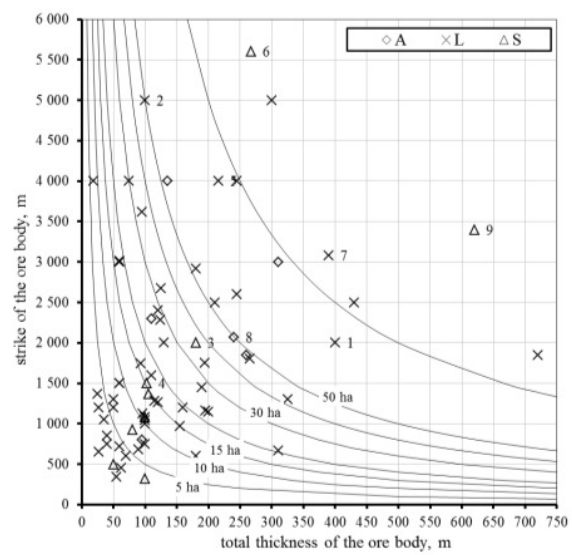

b) distribution of deposits by morphology

Fig. 7. Distribution of deposits depending on the total thickness and strike of ore bodies for promising and operating deposits (1 - Pervomaiskoye, 2 -

Annovskoye, 3 - Petrovskoye, 4 - Artemovskoye, 5 - Bolshaya Gleevatka, 6 Skelevatskoye, 7-Valyavkinskoye, 8-Novovokrivorozhskoye, 9 - Inguletskoye)

In order to analyze the technical and economic indicators of surface mining, the lines of equal specific operating costs $(\$ / t)$ were plotted in Fig. 8. The lines of equal specific costs connect the points characterizing the volumes of ore and overburden in the final pit shell, developing deposits of the type series, where the specific operating costs became equal to the specified level. In Fig. 8, the lines of specific operating costs in the range of possible values are plotted in increments of $\$ 1 / \mathrm{t}$. The lines of equal costs are represented by a bundle of straight lines, the greater the slope of which is the higher the specific operating costs of the pit in question. The straight line on the graph of increasing volumes corresponds to the same value of the stripping ratio.

Analysis of a number of stratified deposits with the ore body thickness varying from $50 \mathrm{~m}$ to $250 \mathrm{~m}$ shows that as the thickness of the ore body increases, the technical and economic performance of open pit development improves. This allows us to conclude that, along with the thickness of the ore body, the ratio of the horizontal area of the ore body to its perimeter is an important parameter that affects the technical and economic performance. The greater this value, the more favorable conditions for development of the deposit we have. 


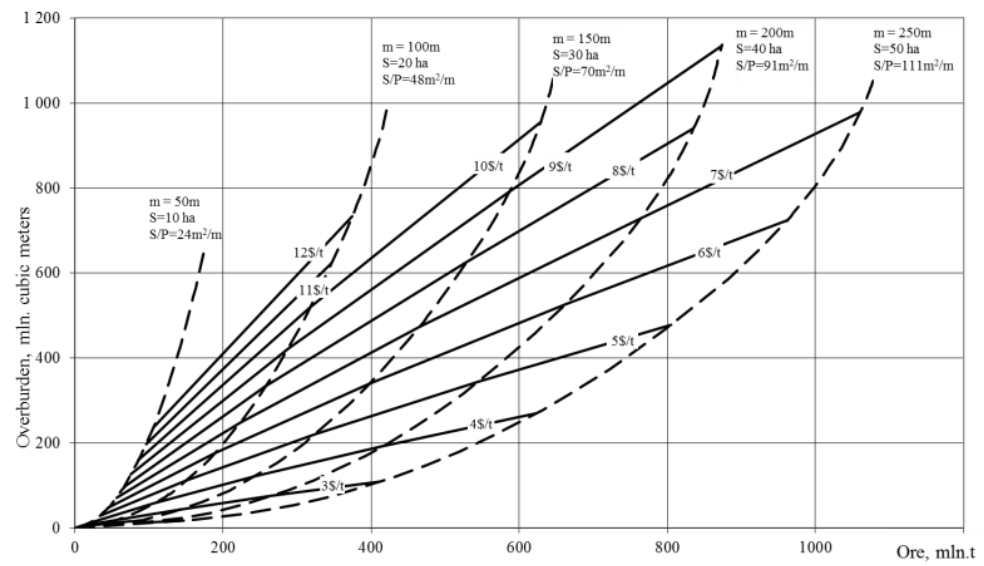

Fig. 8. Dependences of overburden volumes on ore reserves within the pit shells developing stratified deposits with different horizontal thickness of the ore body

Conclusions and directions for further research. It was found that the stratified deposits are $82.5 \%$ of reserves of ferruginous quartzite and $83.3 \%$ of the total number of deposits, synclinal deposits $-3.3 \%$ of reserves and $8.3 \%$ of deposits, anticlinal - about $14 \%$ of the balance reserves and $8.3 \%$ of the number of deposits. $50 \%$ of ferruginous quartzite reserves are represented by deposits with a horizontal thickness of over $200 \mathrm{~m}$ (18\% of the total number of deposits). The performed mining and geometric analysis allows us to determine as a priority the further development of the surface mining theory of stratified steeply dipping deposits.

Typification and parameterization of structural types of iron ore deposits systematizes approaches to the assessment of different types of deposits, which will improve the efficiency of evaluation and preproject work on the development of new deposits. A systematic approach to the analysis of iron ore deposits will allow for a more detailed assessment of proven reserves of iron ore raw materials, to determine rational parameters of open pits and mining technology, to determine the basic principles of rational development of small and medium-sized deposits.

In further studies, it is necessary to analyze the impact of the thickness and nature of the ore body occurrence on the mining tech- 
nology, the method of opening and the main technical and economic indicators of surface mining.

\section{References}

1. Rzhevskiy V.V. (1975). Tekhnologiya i kompleksnaya mekhanizatsiya otkrytykh gornykh rabot [Technology and complex mechanization of open pit mining]. Moscow: Nedra [in Russian].

2. Sheshko Ye.F.(1951). Otkrytaya razrabotka mestorozhdeniy poleznykh iskopayemykh [Open pit mining of mineral deposits].

Moscow: Ugletechizdat [in Russian].

3. Arsent'yev A.I.(1981). Vskrytiye i sistemy razrabotki kar'yernykh poley [Opening and quarry field development systems]. Moscow: Nedra [in Russian].

4. Drizhenko A.Yu., Martynenko V.P., Simonenko V.I.(1994). Vskrytiye glubokikh gorizontov kar'yerov [Opening of deep horizons of open pit mines]. Moscow: Nedra [in Russian].

5. Martynenko V.P.(1999). Nauchnoye obosnovaniye i razrabotka ekologicheski oriyentirovannykh tekhnologiy gornykh rabot na zhelezorudnykh gorno-obogatitel'nykh kombinatakh [Scientific substantiation and development of environmentally oriented mining technologies at iron ore mining and processing plants]. Thesis of Doctor of Technical Sciences. Dnepropetrovsk [in Russian].

6. Gross G.A.(1969). Geologo-ekonomicheskaya otsenka zhelezorudnykh mestorozhdeniy [Geological and economic assessment of iron ore deposits]. Moscow: Mir [in Russian].

7. Verigin M.I., Epatko Yu.M., Orlov V.P. (1990). Zhelezisto-kremnistyye formatsii dokembriya yevropeyskoy chasti SSSR. Prognoznaya otsenka zhelezorudnykh mestorozhdeniy [Ferro-siliceous formations of the Precambrian of the European part of the USSR. Predictive assessment of iron ore deposits]. Kiev: Naukova dumka [in Russian].

8. Kulish E.A., Plotnikov A.V. (2005). Geologicheskiye faktory ekonomicheskoy tsennosti zhelezorudnykh mestorozhdeniy

[Geological factors of the economic value of iron ore deposits]. Kiev: Logos [in Russian].

9. Belevtsev Ya.N., Epatko Yu.M., Verigin M.I. (1981). Zhelezorudnyye mestorozhdeniya dokembriya Ukrainy i ikh prognoznaya otsenka [Precambrian iron ore deposits of Ukraine and their predictive assessment]. Kiev: Naukova dumka [in Russian].

10. Semenenko N.P. (1959). Geologiya zhelezisto-kremnistykh formatsiy Ukrainy [Geology of ferruginous-siliceous formations of Ukraine]. Kiev: Academy of Sciences of the Ukrainian SSR [in Russian].

11. Vilkul Yu., Slobodyanyuk V., Maximov I. (2021). Optimisation of location and performance parameters for the crushing and transfer stations in the deep open pit mines. Sustainable Extraction and Processing of Raw Materials Journal. №2. 
https://doi.org/10.31713/m1111

\title{
SIMPLIFIED MODEL FOR DETERMINING ROCK MASS OSCILLATION VELOCITY AT LIMESTONE DEPOSIT
}

\author{
S. Lutovac \\ $\mathrm{PhD}$ (Engineering), Associate Professor, Faculty of Mining \\ and Geology, University of Belgrade, Serbia
}

B. Gluščević

PhD (Engineering), Full Professor, Faculty of Mining and Geology, University of Belgrade, Serbia

\section{Gligorić}

$\mathrm{PhD}$ (Engineering), Assistant Professor, Faculty of Mining and Geology, University of Belgrade, Serbia

\author{
J. Majstorović \\ $\mathrm{PhD}$ (Engineering), Research Associate, Faculty \\ of Mining and Geology, University of Belgrade, Serbia
}

R. Tokalić

PhD (Engineering), Full Professor, Faculty of Mining and Geology, University of Belgrade, Serbia

\begin{abstract}
As a way of exploitation in mining operation, mass blasting has the more application. However, usage the large amount of explosives leads to increasing the negative blasting effects. By the negative blasting effects, we mean seismic effect of blasting, sound effect, scattering of blasted rock mass, etc. In order to protect environment from shock when performing blasting it is necessary to define rock mass oscillation equation for each working site. This paper offers the analysis of the method for defining parameters of the oscillation equation. To define parameters in the rock mass oscillation equation, we have used five models. The first model represents a usual model - method of Least Squares. The second model is based on the quotient of the value of the equal number of experimental data of oscillation velocity and corresponding reduced distances. The third model is based on defining parameters of oscillation equation by applying Lagrange's theorem. The fourth model is based on defining parameters for oscillation equation by applying the quotient of relative oscillation velocity increments and reduced distances. As the result of numerous measuring's there has been noted that the value of one of the parameters in the oscillation equation is within the limits from 1 to 3 , however most frequently from 1 to 2 . On the basis of this as well as on the basis of oscillation equation characteristic, the value of one parameter was adopted. Thus, we got a new rock mass
\end{abstract}


oscillation equation which is now simpler, and we designated it as the fifth model. On the basis of calculation on concrete example of mass blasting, it has been stated that all mentioned models may be used in order to calculate rock mass oscillation velocity.

Key words: working environment, blasting, oscillation velocity, rock mass oscillation equation.

\section{Introduction}

Explosion caused by detonation of explosive is accompanied by liberation of a great quantity of energy. On that occasion, a part of that energy is used for the destruction of the rock. The other part of energy in the form of a seismic wave is lost in the massive, causing elastic deformations in the rock mass. These deformations at the site are manifested as impact. The impact may cause damage to the objects as well an unpleasant feelings and fear in people. Many authors have studied and proved that sensitivity of the human body to the blasting effects is more than 10 times greater than of sensitivity of the buildings [1-2]. By knowing the rock mass characteristics, status and type of potentially endangered structure, and blasting parameters, blasting works can be executed in a safe and secure way [3-5]. Controlling the seismic effects of blasting and reducing the negative effects are of great importance for the work safety and maintaining the regular production in open-pit mines [6-8]. Parameter for estimating of the seismic action of blasting, that is commonly used, represents the rock mass oscillation velocity.

As the relation between rock mass oscillation velocity and the basic parameters that influence its magnitude, most often is used the M.A. Sadovskii equation where oscillation velocity $v$ is given in the form o

$$
v=K \cdot R^{-n},
$$

where $R$ is reduced distance, that represents distance from the blasting site to monitoring site $r$, reduced to the total quantity of the explosive $Q$ i.e. $R=r / \sqrt[3]{Q}$. Parameters $K$ and $\mathrm{n}$ are conditioned by characteristics of the rock mass and blasting conditions. Thus, $v$ is a decreasing and convex function of the variable $R$.

\section{Recording rock mass oscillation velocity}


Intensity of the shock is measured by instruments - seismographs. Measuring of the rock mass oscillation velocity needed for this paper has been done by the instrument type Vibraloc, produced by the Swedish firm ABEM. From seismograph, maximum values for three oscillation velocity components can be recorded in directions $X, Y$ and $\mathrm{Z}$ from the rectangular coordination system, as follows:

$v_{\mathrm{t}}$ - rock mass oscillation velocity horizontal transversal component,

$v_{\mathrm{v}}$ - rock mass oscillation velocity vertical component,

$v_{1}$ - rock mass oscillation velocity horizontal longitudinal component.

Based on that, maximum, i.e. resulting rock mass oscillation velocity $v_{r}$ can be determined using following equation

$$
v r=\sqrt{v_{t}^{2}+v_{v}^{2}+v_{l}^{2}}
$$

In Fig. 1, the recording of oscillation velocity of the ground intended for blasting IV - measuring point 3 at Drenovac open pit is shown.

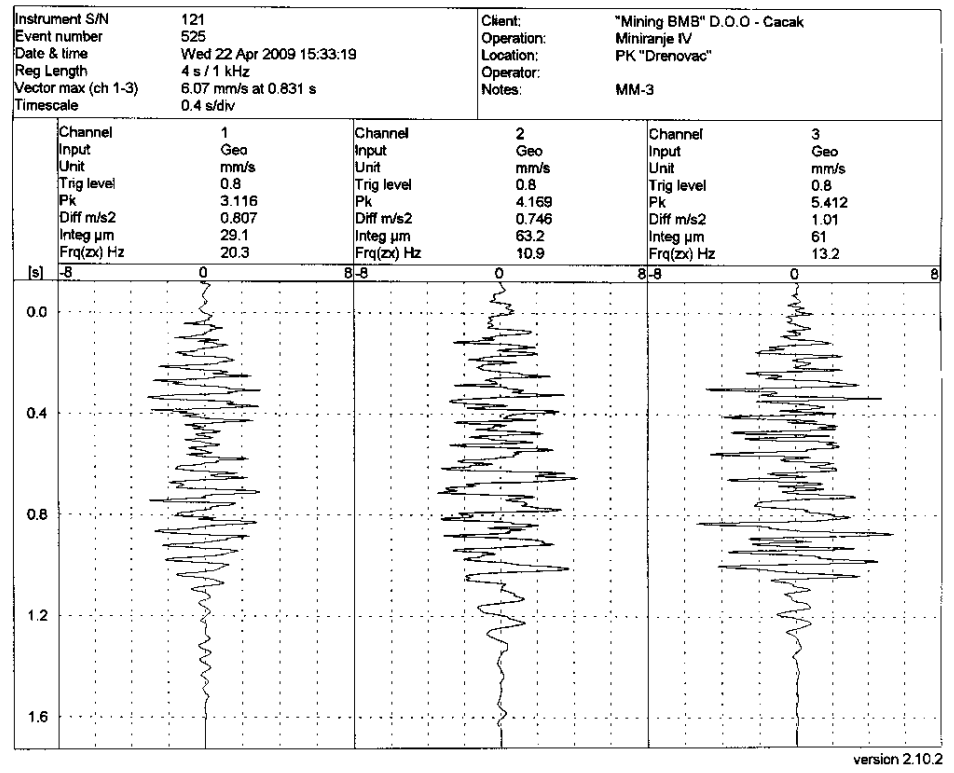

Fig. 1. Record of oscillation velocity of the ground intended for blasting IV - MP 3 


\section{Rock mass oscillation velocity equation}

Rock mass oscillation velocity equation defines velocity alteration of rock mass oscillation depending on distance, explosive amount, properties of rock material and blasting method. The equation, defined in this way, offers the possibility to determine the seismic effect of blasting towards a structure, whereby the connection, between the rock mass oscillation velocity and consequences that can affect facilities, is used.

The equation of M.A Sadovskii [9] is given in the form

$$
v=K \cdot R^{-n}=K \cdot(r / \sqrt[3]{Q})^{-n}
$$

where there are

$v$ - rock mass oscillation velocity $(\mathrm{cm} / \mathrm{s})$

$K$ - coefficient conditioned by rock mass characteristics and blasting conditions,

$n$ - exponent conditioned by characteristics of rock mass and blasting conditions,

$r$ - distance from the blasting site to the monitoring point (m),

$Q$ - total amount of explosive $(\mathrm{kg})$.

$R$ - the reduced distance, given in the form $R=r / \sqrt[3]{Q}$.

The Sadovskii equation is determined based on test blasting for the concrete working environment.

\subsection{Derivation the rock mass oscillation velocity equation}

The equation of Sadovskii was derived from the condition: if the radius of charge $r_{0}$ and distance from the blasting site to the monitoring point $\mathrm{r}$ increase in the same or approximately the same ratio, the rock mass oscillation velocity $\mathrm{v}$ remains the same [9-10].

Here we cite another manner of rock mass oscillation velocity equation derivation. If, in blasting in the specific environment, the relative increment in rock mass oscillation velocity and relative increment of reduced distance are monitored, then it can be seen that their relations at various levels have approximately the same value which will be marked $-n$ meaning that

$$
(\Delta v / v) /(\Delta R / R) \approx-n
$$

Thereby, it can be considered that 
$\lim _{\Delta R \rightarrow 0} \frac{\frac{d v}{v}}{\frac{d R}{R}}=-n$, which means that is $: \frac{\frac{d v}{v}}{\frac{d R}{R}}=-n$

Equation (5) can be written in the form: $\frac{d v}{v}=-n \cdot \frac{d R}{R}$, whereby integration, it is obtained

where $C$ is a constant of integration.

Equation (6) can be written in the form

$$
\log v=\log C \cdot R^{-n}
$$

If in the previous equation we use $C=K$, we arrive at M.A. Sadovskii rock mass oscillation equation.

\subsection{The property of the rock mass oscillation equation}

The rock mass oscillation equation, given in the Equation (1) may be written in the form

$$
v \cdot(R)=K \cdot R^{-n}
$$

Then from the Equation (8) for the derivation $v(R)$ we obtain

$$
v \cdot(R)=-n \cdot K \cdot R^{-n-1}
$$

which may be written in the form

$$
v \cdot(R)=-\frac{n}{R} \cdot K \cdot R^{-n}
$$

Having in mind Equation (8), from the Equation (10) we obtain

$$
v \cdot(R)=-n \cdot \frac{v(R)}{R}
$$

If Lagrange's equation is applied to the function $v(R)$ from (8) in the final growth increment, we obtain

$$
\mathrm{v}(R+h) \approx v(R)+h \cdot v(R+\theta \cdot h), 0<\theta<1
$$

or small absolute values $h$, from (12), we obtain the relation

$$
v(R+h) \approx v(R)+h \cdot v(R)
$$

Having (11) in mind, relation (13) becomes

$$
v(R+h) \approx v(R)-n \cdot h \cdot \frac{v(R)}{R}
$$

A significant property of the equation of rock mass oscillation velocity depending on the reduced distance which is obtained from the relation (14) is as follows: if the reduced distance $R$ from any level is increased (decreased) by $1 \%$, the rock mass oscillation velocity $v$ will decrease (increase) by approximately $n \%$ [11]. 
Indeed, for $h= \pm \frac{R}{100}= \pm 1 \% R$, from (13) we obtain

$$
\begin{aligned}
& v\left(R \pm \frac{R}{100}\right) \approx v(R) \mp n \cdot \frac{R}{100} \cdot \frac{v(R)}{R} \\
& v\left(R \pm \frac{R}{100}\right) \approx v(R) \mp n \cdot \frac{v(R)}{100} \\
& v(R \pm 1 \% R) \approx v(R) \mp n \% \cdot v(R)
\end{aligned}
$$

\section{Models for determining parameters for rock mass oscilla- tion equation}

In the Equation (1) two parameters appear, $K$ and $n$, which need to be determined for a specific work environment and specific blasting conditions. It is possible to determine the parameters $K$ and $n$ in many ways, i.e., models, using the values obtained by experimental measurements.

4.1. Model 1 - Determining the parameters by applying the least square method

The Least Square Method is mainly used to obtain the parameters $K$ and $n$ which represents a common model [12].

4.2. Model 2 - Determining the parameters through the application of quotient of products of the same number of reduced distances and oscillation velocities

According to this model, determination of the parameter $n$ is based on the quotient of the product of equal number of experimental data of the rock mass oscillation velocity $v$, using the oscillation velocity equation. In this way, first, we determine the parameter $n$, and then with parameter $n$ found, we determine the parameter $K$ from the rock mass oscillation equation [11]. theorem

4.3. Model 3 - determining parameters by applying Lagrange's

In the rock mass oscillation velocity equation (1), parameter $n$ may be determined by consecutive approximations with applying Lagrange's theorem [12].

4.4. Model 4 - determining parameters by applying quotient of relative increments oscillation velocity and reduced distances

Beginning with the rock mass oscillation velocity equation (1), which is derived in a different manner (Chapter 3.1), where parame- 
ter $K$, that appeared as the integration constant, we can determine from the conditions (initial condition) that for $R=R_{1}$ we get $v=v_{1}$.

Parameters and will be determined by applying experimental data of pairs $\left(R_{i}, v_{i}\right), i=1,2, \ldots, N$, provided that the curve of the rock mass oscillation velocity passes through the point $M_{1}\left(R_{1}, v_{1}\right)$. In that case out of Equation (1) for $R=R_{1}$ and $v=v_{1}$, we obtain

$$
v_{1}=K \cdot R_{1}^{-n} \rightarrow K=v_{1} \cdot R_{1}^{n}
$$

By the replacement of values for $K$ from (16) in the equation (1) we obtain the equation

$$
v=v_{1} \cdot\left(\frac{R_{1}}{R}\right)
$$

From the equation (17) for $R=R_{1}$ there is obtained $v=v_{1}$ or any $\mathrm{n}$, in our case $n>0$. For $R=R_{i}, i=2,3, \ldots, N$, from the equation (17) we can take that: $v_{i}=v_{1}\left(\frac{R_{1}}{R_{i}}\right)^{n},=2,3, \ldots, N$, from where the relation is obtained

$$
v_{1} \cdot v_{2} \cdot \ldots \cdot v_{1}^{N}\left(\frac{R_{1}^{N}}{R_{1} \cdot R_{2} \cdot \ldots \cdot R_{N}}\right)
$$

From the relation (18) we can determine parameter $n$. By logarithm operation of relation (18) we obtain

$$
n \log \left(\frac{R_{1}^{N}}{R_{1} \cdot R_{2} \cdot \ldots \cdot R_{N}}\right)=\log \left(\frac{v_{1} v_{2} \cdot \ldots \cdot v_{N}}{v_{1}^{N}}\right) ; \frac{\log \left(\frac{v_{1} v_{2} \cdot \ldots \cdot v_{N}}{v_{2}^{N}}\right)}{\log \left(\frac{R_{2}^{N}}{R_{1} \cdot R_{2} \cdot \ldots \cdot R_{N}}\right)}
$$

By the replacement of the value for the parameter $n$ in the equation (17), found in this way, we obtain the relation for the rock mass oscillation velocity in the monitored environment: $v=v_{1} \cdot\left(\frac{R_{1}}{R}\right)^{n}$. Thus, to determine the parameter $n$, all experimental data were taken into account.

4.5. Model 5 - defining parameters adopting the values of parameter $n$

Earlier numerous explorations have shown that that value of parameter $\mathrm{n}$ ranges mostly in the interval from 1 to 3 , most frequently in the interval from 1 to 2 . Taking into consideration the characteris- 
tic of the rock mass oscillation equation (Chapter 3.2.) as well as the values of parameter $n$, which is mostly in the interval from 1 to 2 , we can accept that it is $n=1,5$, which means that rock mass oscillation equation is reduced to the relation

$$
v=K \cdot R^{-1,5}
$$

From equation (20) for $K$ we get

$$
K=v \cdot R^{-1,5}
$$

For finding parameter $K$ are used data for pairs $\left(R_{m}, v_{m}\right)$, $m=1,2, \ldots, N$, from the table of experimental data, thus we arrive at

$$
K_{1}=v_{1} \cdot R_{1}^{1,5} ; \quad K_{2}=v_{2} \cdot R_{2}^{1,5} ; \ldots ; K_{N}=v_{N} \cdot R_{N}^{1,5}
$$

however, for parameter $K$ we take its arithmetical mean value.

In this way the model for solving rock mass oscillation equation has been simplified by adopting the value of parameter ${ }_{n}$.

On the basis of the calculated rock mass oscillation equation using formula (1), using various earlier mentioned models, we are able to construct the approximate curve. This curve correlates the received results of the oscillated velocities depending on applied quantity of explosive, distance from the blasting site to the monitoring place, characteristics of the working environment and conditions of blasting.

\section{Defining statistical criteria}

For the above-mentioned models 1-5, on the basis of experimental data, we can get equations that can give us the rock mass oscillation velocities $\mathrm{v}$ depending on the reduced distance $R$.

In order to evaluate the degree of connection between the registered (measured) and calculated rock mass oscillation velocities in this paper we used the coefficient of linear correlation $r[13,15]$ between the logarithms of reduced distances $R$ and logarithms of oscillation velocities $v$. Coefficient of linear correlation $r$ is also used in order to evaluate the degree of connection between values of obtained parameters $\mathrm{n}$ and $K$ for models $1-5$.

Besides, in order to evaluate the degree of connection between the reduced distances $R$ and oscillation velocities $\mathrm{v}$ we used index of the curved dependency $\rho[14,16]$.

As a convenience measure of the obtained functional relationship for the given experimental data, the criterion „3S" was also used 
[12]. This criterion uses squares of differences between the obtained experimental data and the calculated ones for oscillation velocities of $\mathrm{v}$. If those differences are one after another $\varepsilon_{1}, \varepsilon_{2}, \ldots \varepsilon_{N}$, then it is

$$
S=\sqrt{\frac{\varepsilon_{1}^{2}+\varepsilon_{2}^{2}+\ldots+\varepsilon_{N}^{2}}{N}}
$$

According to this criterion, for the evaluation of convenience of the obtained functional correlation, the following relations are valid:

- if it is $\left|\varepsilon_{\max }\right| \geq 3 S$, the obtained functional correlation is rejected as unfavorable,

- if it is $\left|\varepsilon_{\operatorname{mxx}}\right|<3 S$, the functional correlation is accepted as a good one.

\section{Review of mass blasting at the drenovac open pit \\ 6.1. General characteristics of the Drenovac open pit}

This paper includes examinations carried out during mass blasting at the Drenovac open pit, Kolubara region, central part of West Serbia. Measurements are performed at the mass or stratified limestone [17]. The physical - mechanical characteristics of the working environment are:

volume mass $\gamma=2,68 \mathrm{kN} / \mathrm{m}^{3}$,

porosity $p=0,7-1,5 \%$,

cohesion $C=0,25 \mathrm{MPa}$,

compressive strength (in dry state $\sigma_{p d}=120-134 \mathrm{MPa}$, in water saturated state $\sigma_{p w}=83-129 \mathrm{MPa}$ ),

angle of internal friction $\varphi=41^{\circ}$

\subsection{Manner of blasting operations at the Drenovac open pit}

Measurements of seismic shock waves at the Drenovac open pit carried out during blasting were conducted in order to exploit the deposit. Eight blasting operations were carried out.

The AMONEX-1 28/200, AMONEX-1 60/1000, AMONEX 60/1000, ANFO $J$ in bags of $25 \mathrm{~kg}$ and ANFEX PP 70/1500 were used as explosives. The explosive was activated in boreholes by NONEL detonators, marked $N-25 / 500$ and $K$-42 connectors while initiation is performed using electronic detonators. Basic data related to the number of boreholes, the overall explosive amount, the explo- 
sive amount by deceleration interval, overall borehole depth and average stemming length, are presented in Table 1.

Table 1

Review of blasting parameters at the Drenovac open pit

\begin{tabular}{c|c|c|c|c|c}
\hline Blasning & $N_{b}$ & $Q_{u k}[\mathrm{~kg}]$ & $Q_{i}[\mathrm{~kg}]$ & $L_{u k}[\mathrm{~m}]$ & $L_{\mathrm{c}}[\mathrm{m}]$ \\
\hline I & 27 & 661.4 & 36.2 & 211.0 & $2.8-3.0$ \\
\hline II & 28 & 1980.6 & 71.2 & 488.0 & $2.8-3.0$ \\
\hline III & 15 & 915.3 & 66.2 & 213.0 & $2.8-3.0$ \\
\hline IV & 16 & 745.0 & 47.0 & 175.0 & $3.0-3.2$ \\
\hline V & 40 & 1895.0 & 60.5 & 453.0 & $3.0-3.2$ \\
\hline VI & 22 & 1774.4 & 85.2 & 402.0 & $3.0-3.2$ \\
\hline VII & 43 & 1988.6 & 54.2 & 518.0 & $3.0-3.2$ \\
\hline VIII & 20 & 600 & 32.0 & 273.0 & $3.0-3.5$ \\
\hline
\end{tabular}

\subsection{Calculation of rock mass oscillation equation parameters at the Drenovac open pit}

Values of distance from the blasting site to the place of observation, total quantity of explosive, calculated values of reduced distances, registered values of rock mass oscillation velocities per components $v_{v}, v_{t}, v_{1}$ and resulted rock mass oscillation velocities $v_{r}$ for blastings I-VIII, at the total of seven measured points MP, are presented in Table 2.

Table 2

Review of blasting parameters and measurement results

\begin{tabular}{c|c|c|c|c|c|c|c|c|c}
\hline № & Blast & MP & $r(\mathrm{~m})$ & $Q(\mathrm{~kg})$ & $R$ & $v_{v}(\mathrm{~cm} / \mathrm{q})$ & $v_{1}(\mathrm{~cm} / \mathrm{s})$ & $v_{2}(\mathrm{~cm} / \mathrm{s})$ & $v_{v}(\mathrm{~cm} / \mathrm{s})$ \\
\hline 1 & I & MP2 & 383.87 & 661.4 & 44.0585 & 0.070 & 0.100 & 0.110 & 0.1643 \\
\hline 2 & I & MP3 & 250.49 & 661.4 & 28.7499 & 0.260 & 0.470 & 0.540 & 0.7616 \\
\hline 3 & I & MP5 & 647.42 & 661.4 & 74.3073 & 0.080 & 0.090 & 0.080 & 0.1446 \\
\hline 4 & II & MP1 & 605.54 & 1980.6 & 48.2182 & 0.060 & 0.060 & 0.070 & 0.1100 \\
\hline 5 & II & MP2 & 334.15 & 1980.6 & 26.6078 & 0.080 & 0.120 & 0.150 & 0.2081 \\
\hline 6 & II & MP3 & 256.71 & 1980.6 & 28.4042 & 0.510 & 0.500 & 1.090 & 1.3031 \\
\hline 7 & II & MP6 & 527.05 & 1980.6 & 41.9681 & 0.090 & 0.230 & 0.160 & 0.2943 \\
\hline 8 & III & MP1 & 616.35 & 915.3 & 63.4804 & 0.091 & 0.083 & 0.082 & 0.1482 \\
\hline 9 & III & MP2 & 250.14 & 915.3 & 25.7629 & 0.192 & 0.573 & 0.719 & 0.9392 \\
\hline 10 & III & MP3 & 412.66 & 915.3 & 42.5015 & 0.380 & 0.605 & 0.412 & 0.8247 \\
\hline 11 & III & MP5 & 714.10 & 915.3 & 73.5481 & 0.138 & 0.096 & 0.116 & 0.2045 \\
\hline 12 & III & MP6 & 541.13 & 915.3 & 55.7332 & 0.170 & 0.241 & 0.177 & 0.3454 \\
\hline 13 & III & MP7 & 530.89 & 915.3 & 54.6785 & 0.133 & 0.236 & 0.193 & 0.3326 \\
\hline
\end{tabular}




\begin{tabular}{c|c|c|c|c|c|c|c|c|c}
\hline № & Blast & MP & $r(\mathrm{~m})$ & $Q(\mathrm{~kg})$ & $R$ & $v_{v}(\mathrm{~cm} / \mathrm{q})$ & $v_{1}(\mathrm{~cm} / \mathrm{s})$ & $v_{2}(\mathrm{~cm} / \mathrm{s})$ & $v_{v}(\mathrm{~cm} / \mathrm{s})$ \\
\hline 14 & IV & MP1 & 723.77 & 745.0 & 79.8390 & 0.060 & 0.080 & 0.070 & 0.1221 \\
\hline 15 & IV & MP2 & 410.33 & 745.0 & 45.2635 & 0.140 & 0.170 & 0.180 & 0.2844 \\
\hline 16 & IV & MP3 & 223.89 & 745.0 & 24.6973 & 0.310 & 0.420 & 0.540 & 0.7511 \\
\hline 17 & IV & MP5 & 644.64 & 745.0 & 71.1102 & 0.110 & 0.200 & 0.200 & 0.3035 \\
\hline 18 & IV & MP7 & 426.38 & 745.0 & 47.0339 & 0.200 & 0.230 & 0.210 & 0.3701 \\
\hline 19 & V & MP1 & 737.38 & 1895.0 & 60.0667 & 0.050 & 0.070 & 0.040 & 0.0948 \\
\hline 20 & V & MP3 & 210.96 & 1895.0 & 17.1847 & 0.550 & 0.790 & 1.150 & 1.4996 \\
\hline 21 & V & MP7 & 422.53 & 1895.0 & 34.4192 & 0.210 & 0.360 & 0.320 & 0.5254 \\
\hline 22 & VI & MP3 & 231.44 & 1774.4 & 19.1171 & 0.577 & 1.160 & 0.709 & 1.4768 \\
\hline 23 & VI & MP5 & 650.53 & 1774.4 & 53.7341 & 0.055 & 0.071 & 0.077 & 0.1165 \\
\hline 24 & VI & MP6 & 640.06 & 1774.4 & 52.8693 & 0.081 & 0.150 & 0.168 & 0.2393 \\
\hline 25 & VI & MP7 & 425.36 & 1774.4 & 35.1350 & 0.340 & 0.465 & 0.259 & 0.6316 \\
\hline 26 & VII & MP3 & 333.13 & 1988.6 & 26.4910 & 0.534 & 0.460 & 0.602 & 0.9268 \\
\hline 27 & VII & MP6 & 530.48 & 1988.6 & 42.1845 & 0.101 & 0.190 & 0.150 & 0.2623 \\
\hline 28 & VII & MP7 & 415.31 & 1988.6 & 33.0260 & 0.284 & 0.525 & 0.286 & 0.6618 \\
\hline 29 & VIII & MP1 & 609.20 & 600.0 & 72.2286 & 0.030 & 0.070 & 0.070 & 0.1034 \\
\hline 30 & VIII & MP3 & 387.35 & 600.0 & 45.9254 & 0.339 & 0.527 & 0.629 & 0.8878 \\
\hline 31 & VIII & MP6 & 532.35 & 600.0 & 63.1171 & 0.067 & 0.112 & 0.079 & 0.1607 \\
\hline 32 & VIII & MP7 & 493.85 & 600.0 & 58.5524 & 0.072 & 0.157 & 0.156 & 0.2327 \\
\hline
\end{tabular}

Based on data given in Table 2 , the rock mass oscillation equation is calculated by the formula (1) - for the models 1 and 2 .

The calculation of the curve was carried out for values of reduced distances from $R=17,1847$ to $R=79,8390$. Thus, curve parameters were calculated enabling us to determine the equation of rock mass oscillation for models $1-5$ in the form of

$$
\text { Model } 1 \quad v_{1}=166,3916 \cdot R^{-1,6433}
$$

thus between $\log v_{\mathrm{r}}$ and $\log R$ we get linear dependency that is expressed by equation (24) with the coefficient of linear dependency $r_{\log }$ which is: $r_{\log }=-0,8003$.

Graphic review of the rock mass oscillation equation is shown in fig. 2 . 


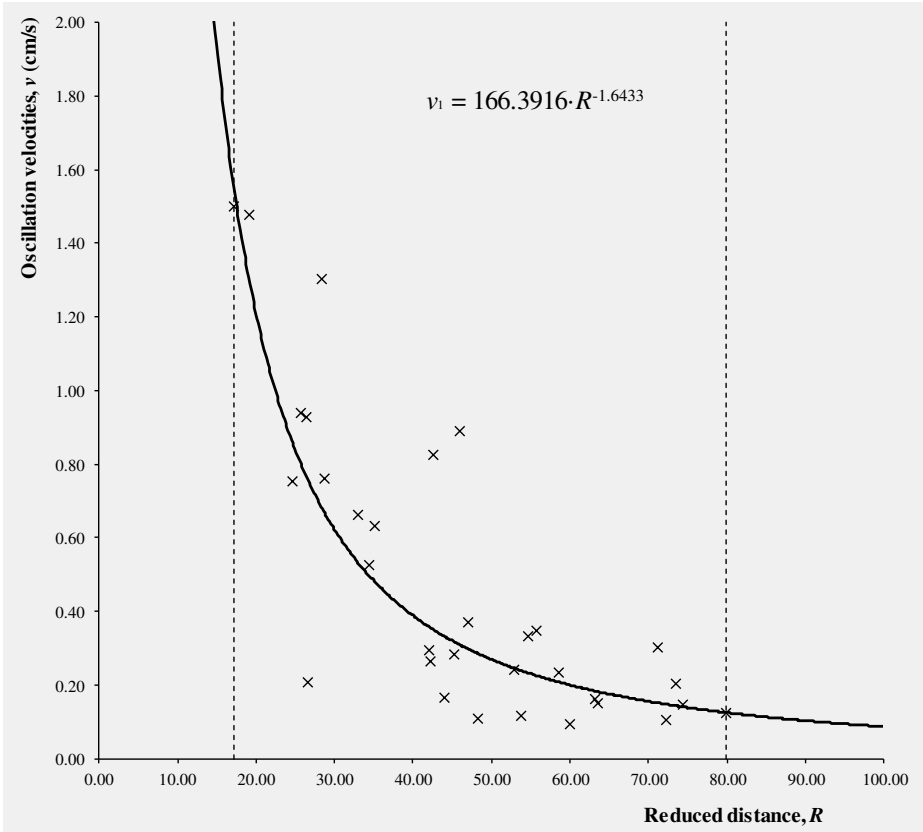

Fig. 2. Graphic review of oscillation velocity and reduced distance at the Drenovac open pit

Model 2

$$
\begin{aligned}
& v_{2}=172,4630 \cdot R^{-1,6214} \\
& v_{3}=58,2539 \cdot R^{-1,3311} \\
& v_{4}=143,2699 \cdot R^{-1,6032} \\
& v_{5}=109,3704 \cdot R^{-1,5}
\end{aligned}
$$

On the basis of the obtained equations for rock mass oscillation (24), (25), (26), (27) and (28) it is possible to calculate values of rock mass oscillation velocities for the corresponding reduced distances for models 1-5.

In table 3, the review of reduced distances $R$, registered rock mass oscillation velocities $v_{r}$ is given, as well as calculated rock mass oscillation velocities from $v_{i 1}$ to $v_{i s}$, for models 1-5. 
Table 3

Review of registered and calculated rock mass oscillation velocities for models 1-5

\begin{tabular}{|c|c|c|c|c|c|c|c|}
\hline № & $R$ & $v_{r}(\mathrm{~cm} / \mathrm{s})$ & $v_{i 2}(\mathrm{~cm} / \mathrm{s})$ & $v_{i 2}(\mathrm{~cm} / \mathrm{s})$ & $v_{i 3}(\mathrm{~cm} / \mathrm{s})$ & $v_{i 4}(\mathrm{~cm} / \mathrm{s})$ & $v_{i 5}(\mathrm{~cm} / \mathrm{s})$ \\
\hline 1 & 17.1847 & 1.4996 & 1.5539 & 1.7141 & 1.3220 & 1.4996 & 1.5353 \\
\hline 2 & 19.1171 & 1.4768 & 1.3043 & 1.4421 & 1.1472 & 1.2641 & 1.3085 \\
\hline 3 & 24.6973 & 0.7511 & 0.8562 & 0.9520 & 0.8158 & 0.8384 & 0.8911 \\
\hline 4 & 25.7629 & 0.9392 & 0.7988 & 0.8890 & 0.7712 & 0.7835 & 0.8364 \\
\hline 5 & 26.4910 & 0.9268 & 0.7631 & 0.8497 & 0.7431 & 0.7493 & 0.8021 \\
\hline 6 & 26.6078 & 0.2081 & 0.7576 & 0.8437 & 0.7387 & 0.7440 & 0.7969 \\
\hline 7 & 28.4042 & 1.3031 & 0.6804 & 0.7589 & 0.6772 & 0.6700 & 0.7225 \\
\hline 8 & 28.7499 & 0.7616 & 0.6670 & 0.7442 & 0.6664 & 0.6572 & 0.7095 \\
\hline 9 & 33.0260 & 0.6618 & 0.5311 & 0.5943 & 0.5541 & 0.5262 & 0.5763 \\
\hline 10 & 34.4192 & 0.5254 & 0.4963 & 0.5558 & 0.5244 & 0.4924 & 0.5416 \\
\hline 11 & 35.1350 & 0.6316 & 0.4798 & 0.5376 & 0.5103 & 0.4765 & 0.5252 \\
\hline 12 & 41.9681 & 0.2943 & 0.3583 & 0.4030 & 0.4028 & 0.3583 & 0.4023 \\
\hline 13 & 42.1845 & 0.2623 & 0.3552 & 0.3996 & 0.4000 & 0.3554 & 0.3992 \\
\hline 14 & 42.5015 & 0.8247 & 0.3509 & 0.3948 & 0.3961 & 0.3512 & 0.3947 \\
\hline 15 & 44.0585 & 0.1643 & 0.3307 & 0.3724 & 0.3775 & 0.3315 & 0.3740 \\
\hline 16 & 45.2635 & 0.2844 & 0.3164 & 0.3565 & 0.3642 & 0.3174 & 0.3592 \\
\hline 17 & 45.9254 & 0.8878 & 0.3089 & 0.3482 & 0.3572 & 0.3101 & 0.3514 \\
\hline 18 & 47.0339 & 0.3701 & 0.2971 & 0.3350 & 0.3461 & 0.2985 & 0.3391 \\
\hline 19 & 48.2182 & 0.1100 & 0.2852 & 0.3218 & 0.3348 & 0.2868 & 0.3267 \\
\hline 20 & 52.8693 & 0.2393 & 0.2451 & 0.2771 & 0.2962 & 0.2475 & 0.2845 \\
\hline 21 & 53.7341 & 0.1165 & 0.2387 & 0.2699 & 0.2899 & 0.2411 & 0.2777 \\
\hline 22 & 54.6785 & 0.3326 & 0.2319 & 0.2624 & 0.2832 & 0.2345 & 0.2705 \\
\hline 23 & 55.7332 & 0.3454 & 0.2248 & 0.2544 & 0.2761 & 0.2274 & 0.2629 \\
\hline 24 & 58.5524 & 0.2327 & 0.2073 & 0.2349 & 0.2586 & 0.2101 & 0.2441 \\
\hline 25 & 60.0667 & 0.0948 & 0.1987 & 0.2253 & 0.2499 & 0.2017 & 0.2349 \\
\hline 26 & 63.1171 & 0.1607 & 0.1832 & 0.2079 & 0.2340 & 0.1863 & 0.2181 \\
\hline 27 & 63.4804 & 0.1482 & 0.1815 & 0.2060 & 0.2322 & 0.1846 & 0.2162 \\
\hline 28 & 71.1102 & 0.3035 & 0.1506 & 0.1714 & 0.1966 & 0.1539 & 0.1824 \\
\hline 29 & 72.2286 & 0.1034 & 0.1468 & 0.1671 & 0.1955 & 0.1501 & 0.1782 \\
\hline 30 & 73.5481 & 0.2045 & 0.1425 & 0.1623 & 0.1909 & 0.1458 & 0.1734 \\
\hline 31 & 74.3073 & 0.1446 & 0.1401 & 0.1596 & 0.1833 & 0.1434 & 0.1707 \\
\hline 32 & 79.8390 & 0.1221 & 0.1245 & 0.1421 & 0.1711 & 0.1278 & 0.1533 \\
\hline
\end{tabular}

Fig. 3 shows a graphic review of the coefficients of the linear dependency between registered and calculated rock mass oscillation velocities for models $1-5$. 


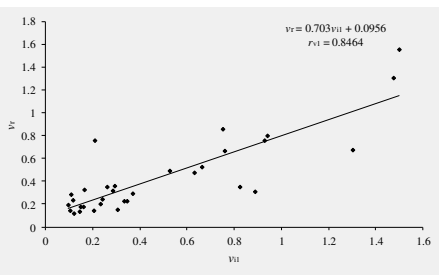

a)

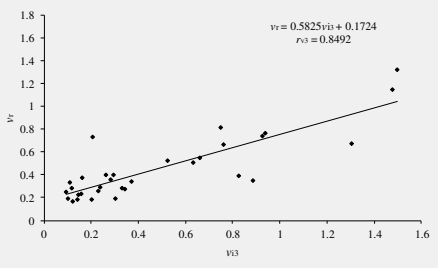

c)

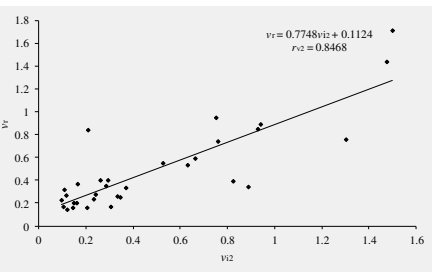

b)

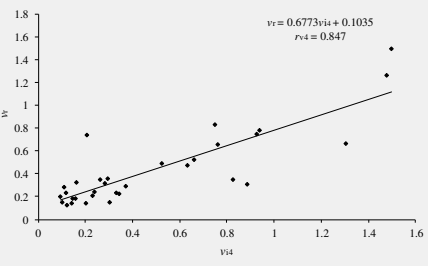

d)

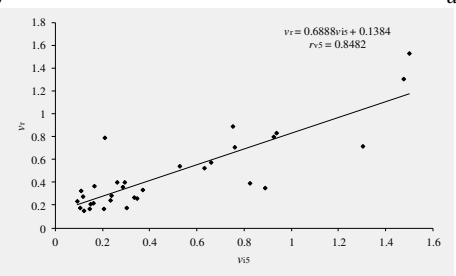

e)

Fig. 3. Graphic review of the coefficients of the linear dependency between registered and calculated oscillation velocities for: $a$ ) model $1, b$ ) model $2, c)$ model 3 , d) model 4 and $e$ ) model 5

In table 4, review of reduced distances $R$, registered rock mass oscillation velocities $v_{r}$ is given as well as the differences between registered and calculated oscillation velocities for models 1-5.

Table 4

Review of differences between registered and calculated rock mass oscillation velocities for models 1-5

\begin{tabular}{c|c|c|c|c|c|c|c}
\hline № & $R$ & $v_{r}(\mathrm{~cm} / \mathrm{s})$ & $v_{r}-v_{i 1}$ & $v_{r}-v_{i 2}$ & $v_{r}-v_{i 3}$ & $v_{r}-v_{i 4}$ & $v_{\mathrm{r}}-v_{i 5}$ \\
\hline 1 & 17.1847 & 1.4996 & -0.0543 & -0.2145 & 0.1776 & 0.0000 & -0.0357 \\
\hline 2 & 19.1171 & 1.4768 & 0.1725 & 0.0347 & 0.3296 & 0.2127 & 0.1683 \\
\hline$\ldots$ & $\ldots$ & $\ldots$ & $\ldots$ & $\ldots$ & $\ldots$ & $\ldots$ & $\ldots$ \\
\hline 3 & 79.8390 & 0.1221 & -0.0024 & -0.0200 & -0.0490 & -0.0057 & -0.0312 \\
\hline
\end{tabular}


Based on data from table 4, a statistical analysis has been done and following values have been obtained:

\section{for Model 1:}

The curved line dependency index $\rho_{1}$ between the reduced distance $R$ and rock mass oscillation velocity $v$, is:

$\rho_{1}=0,8380$ (there is a strong correlation between $R$ and $v$, given in the Equation (24)).

Maximal difference between registered and calculated rock mass oscillation velocities $\left(\varepsilon_{\max 1}\right)=\max \left|\varepsilon_{1}\right|$, is:

$$
\left(\varepsilon_{\max 1}\right)=0,6227, \mathrm{~S}_{1}-0,2200,3 S_{1}=0,6600,
$$

Since $\left(\varepsilon_{\max 1}<3 S_{1}\right.$, this supposed functional relation is accepted as a correct one.

\section{for Model 2:}

$\rho_{2}=0,8439$ ((there is a strong correlation between $R$ and $v$, given in the Equation (25)).

$$
\left(\varepsilon_{\max 2}\right)=0,6356, \mathrm{~S}_{2}-0,2163,3 \mathrm{~S}_{2}=0,6488 .
$$

$\left(\varepsilon_{\max 2}<3 S_{2}\right.$ (supposed functional relation is accepted as a correct one).

\section{for Model 3:}

$\rho_{3}=0,8303$ ((there is a strong correlation between $R$ and $v$, given in the Equation (26)).

$$
\left(\varepsilon_{\max 3}\right)=0,6259, S_{3}-0,2247,3 S_{3}=0,6741 \text {. }
$$

$\left(\varepsilon_{\max 3}<3 S_{3}\right.$ (supposed functional relation is accepted as a correct one).

\section{for Model 4:}

$\rho_{4}=0,8357$ (there is a strong correlation between $R$ and $v$, given in the Equation (27)).

$$
\left(\varepsilon_{\max 4}\right)=0,6331, S_{4}-0,2214,3 S_{4}=0,6642 .
$$

( $\varepsilon_{\max 4}<3 S_{4}$ (supposed functional relation is accepted as a correct one).

\section{for Model 5:}

$\rho_{5}=0,8469$ (there is a strong correlation between $R$ and $v$, given in the Equation (28)).

$$
\left(\varepsilon_{\max 5}\right)=0,5888, S_{5}-0,2144,3 S_{5}=0,6431 .
$$

$\left(\varepsilon_{\max 4}<3 \mathrm{~S}_{5}\right.$ (supposed functional relation is accepted as a correct one). 
Based on the obtained values for parameters $n$ and $K$ in the rock mass oscillation equations, by application of the mentioned five models, the linear dependency between $n$ and $K$ form has been determined.

$$
K=358,7443 \cdot n-422,4447
$$

With coefficient of the linear dependency which is: $r_{p}=0,982$

Based on the values of the coefficient of linear dependency $r_{p}$ between parameters $n$ and $K$ for all five models, we can say that there is a strong correlation between parameters $n$ and $K$.

\section{Conclusion}

To establish the relationship between the rock mass oscillation velocity of the and basic parameters affecting its magnitude, being: the quantity of explosive, the distance from the blasting site, characteristics of the rock mass and the type of blasting, it is the equation of M. A. Sadovskii that is used most commonly. In this paper, parameters $n$ and $K$ from Sadovskii's equation were determined in five ways - models in the given work environment. Their corresponding functions have been obtained presenting rock mass oscillation velocities of the depending on a reduced distance. The calculated corresponding indexes of the curved line correlation point out that there is a rather strong curved line relationship between a reduced distance and the rock mass oscillation velocity expressed in the obtained functions.

The relation between parameters $K$ and $n$ has been obtained in this study. This relation made it possible to find the value of the second parameter for the given determined value of one parameter. In practice it is simpler to determine the value of the parameter $K$ in advance for an adopted value of the parameter $n$ in the interval from $1-2$, as has been applied in model 5 . In this way, a new simplified formula has been obtained for determining the rock mass oscillation velocity equation in which only parameter $K$ is calculated.

Comparing values of the recorded oscillation velocities of the rock mass with the corresponding calculated ones, it can be seen that they are approximately the same. Linear dependency with highly strong correlation has been obtained between registered and calculated values of rock mass oscillation velocities. On the basis of the obtained coefficients of the linear dependency, we can conclude that all five models can be used for calculating the rock mass oscillation velocity. 
From the obtained formulas for determining rock mass oscillation velocity by models $1-5$, we can see that at higher values of parameter $n$ they get higher values of parameter $K$ and vice versa, whereby we established that there is a highly strong linear dependency between them. These facts confirm once again that all models mentioned above can be used for calculating the rock mass oscillation velocity.

\section{References}

[1] Yao Q., Yang X., Li H. (2017); Development of Absorbed Blasting Vibration Energy Index for the Evaluation of Human Comfort in Multistorey Buildings, Shock and Vibration, 2017, Article ID 9567657, 12 pages, DOI: https://doi.org/10.1155/2017/9567657

[2] Zhang Z. Y., Zhang W. X., Wu X. X. (2003); Modern Hydraulic Engineering Blasting, China Water Power Press, Beijing, China

[3] Stanković S., Dobrilović M., Bohanek V. (2017); A Practical Approach to the Ground Oscillation Velocity Measurement Method, The Mining-GeologyPetroleum Engineering Bulletin, DOI: 10.17794/rgn.2017.4.6

[4] Qiang Y., Xingguo Y., Hongtao L. (2017); A Method for Evaluating the Comfort During Blasting Vibration Based on Energy Absorbing Principle, Journal of Vibration and Control, DOI: https://doi.org/10.1177/1077546316685680

[5] Yu L. (2015); Safety Influence of Blasting Vibration on Multistory Building, Journal of Railway Engineering Society, 32 (3), 86-89

[6] Ma L., Li K., Xiao S., Ding X., Chinyanta S. (2016); Research on Effects of Blast Casting Vibration and Vibration Absorption of Presplitting Blasting in Open Cast Mine, Shock and Vibration, Article ID 4091732, 9 pages, (2016), DOI: https://doi.org/10.1155/2016/4091732

[7] Kuzu C., Guclu E. (2009); The Problem of Human Response to Blast Induced Vibrations in Tunnel Construction and Mitigation of Vibration Effects Using Cautious Blasting in Half-Face Blasting Rounds, Tunnelling and Underground Space Technology, 24 (1), 53-61, DOI: 10.1016/j.tust.2008.02.001

[8] Li D. D., Deng Z. D. (2012); Evaluation of the Effects of Blasting Vibration on Humans in the Excavation of CMICT Dock, Engineering Blasting, 12 (2), 82-85

[9] Medvedev S.V. (1964); Seismics of Mountainous Explosions, Nedra, Moscow, Russia, 42-43,

[10] Lutovac S., Vidanović N., Beljić Č., Gligorić Z. (2015); Soil Oscillation Law Parameter Determination with the Application of Lagrange's Theorem at the "Kovilovača" Open Pit, Mining Metallurgy Engineering Bor, 3, 53-62, DOI: $10.5937 / \mathrm{mmeb} 15030531$

[11] Lutovac S., Gluščević B., Tokalić R., Majstorović J., Beljić Č. (2018); Models of Determining the Parameters of Rock Mass Oscillation Equation with Experimental and Mass Blastings, Minerals, 8 (2), 70, DOI: https://doi.org/10.3390/min8020070

[12] Simeunović D. (1985); Mathematics, Faculty of Mining and Geology, Mining Department, Belgrade, Serbia, 101-103 
[13] Mukaka M., (2012); A Guide to Appropriate Use of Correlation Coefficient in Medical Research, Malawi Med. J., 24 (3), 69-71

[14] Wang T., Zhang S. (2011); Study on Linear Correlation Coefficient and Nonlinear Correlation Coefficient in Mathematical Statistics, Studies in Mathematical Sciences, 3 (1), 58-63, DOI: 10.3968/j.sms.1923845220110301.4Z483

[15] Smith R. (2015); A Mutual Information Approach to Calculating Nonlinearity, Stat, 4, 291-303, DOI: 10.100X/sta.0000

[16] Guerard J. (2013); Introduction to Financial Forecasting in Investment Analysis, Springer, New York, DOI:10.1007/978-1-4614-5239-3

[17] Trajković S., Lutovac S., Katona O. (2009); Study of Seismic and Air Impacts on the Surrounding Building Structures as the Result of Blasting at the Open Pit "Drenovac" Near Mionica, Faculty of Mining and Geology, Belgrade, 34(A), 15-51(B) (in Serbian).

https://doi.org/10.31713/m1112

\section{BITUMEN EXTRACTION TECHNOLOGY FROM BITUMINOUS SAND DEPOSITS}

Yelchenko-Lobovska A.S.

National University «Yuri Kondratyuk Poltava Polytechnic»,

PhD Student, Ukraine

\section{Lavryk I.O.}

National University «Yuri Kondratyuk Poltava Polytechnic»,

PhD Student, Ukraine

Liashenko A.V.

National University «Yuri Kondratyuk Poltava Polytechnic», senior lecturer, Ukraine

Pedchenko L.O.

National University «Yuri Kondratyuk Poltava Polytechnic», $\mathrm{PhD}$, Ukraine

\section{Pedchenko M.M.}

National University «Yuri Kondratyuk Poltava Polytechnic», $\mathrm{PhD}$, Ukraine

\footnotetext{
Abstract

Today considerable experience in the development of tar sands is accumulated. However, well-known mining technologies do not cover the entire depth range of natural bitumen deposits. In addition, there are significant energy-intensive technol-
} 
ogies and negative environmental impacts. In view of this, the purpose of this work is to improve the method of extracting natural bitumen in site for a deposit interval of 75-200 $\mathrm{m}$ and to substantiate the basic technological scheme of this method. The proposed method of extracting bitumen from poorly cemented reservoirs in the depth range of $50-400 \mathrm{~m}$ provides: creation of artificial production; the transfer of the rock into the water mixture composition under the action of high pressure jets of a heated mixture of water, a hydrocarbon solvent and a flotation agent; separation from the rock and concentration of bitumen in the production as a result of its heating, dissolution and flotation; selection of depleted bitum slurry from the production by gas lift. The proposed method of extracting bitumen is the transfer of the rock at the its occurrence site to the suspension condition on the excavation created by the hydraulic production method, separation and concentration of bitumen by dissolving it with a heated hydrocarbon solvent and a flotation agent (hydrocarbon reagents) and extraction in composition of the depleted rock slurry to the surface by the gas lift method. As the preliminary calculations show, the proposed method will allow the efficient extraction of bitumen and highly viscous oil from weakly cemented reservoirs in the depth range of 50-400 $\mathrm{m}$. Also, the proposed technology creates the preconditions for the development of oil sands at a depth of 75-200 m since there is currently no effective technology for the interval. In addition, it can significantly reduce energy costs, environmental pollution and greenhouse gas emissions.

\section{Introduction}

The depletion of traditional deposits and the rise in energy prices have led to considerable interest in exploring unconventional hydrocarbon fields. Heavy oil and natural bitumen are one of the strategic hydrocarbon reserves for oil companies around the world. Their reserves are many times higher than those of traditional oil and gas.

Approximately 1.7 trillion barrels of crude bitumen are in the oil sands [1,2] but predicts that only $19 \%$ of this total (315 billion barrels), will ultimately be recovered. A smaller amount, 174 billion barrels, could be recovered using today's technology and under current and anticipated economic conditions [1]. (For comparison, crude oil reserves in Saudi Arabia are estimated at 264 billion barrels.)

The development of natural bitumen reserves is being successfully implemented in Canada, the USA and other countries in the world [3].

Thus, oil sands production in Alberta increased from about 1 million barrels/day in 2004 to 2.4 million barrels/day in 2014. This is equivalent to an annual increase of $8 \%$.

All geological preconditions for the formation of large industrial clusters of high-viscosity oil and natural bitumen are in Ukraine as 
well. However, targeted search and exploration work to identify them in Ukraine is not being conducted. All known deposits were discovered incidentally during oil and gas exploration [4].

Bituminous sands contain 9-13\% bitumen, 3-7\% water and 80$85 \%$ rock. Small particles, preferably clay, with a diameter of less than 44 microns are from $15 \%$ to $30 \%$ of the rock. The task is to separate the bitumen not only from the sand grains, but also particles of micron and submicron size clay.

In addition, bituminous oil has a high density $\left(0.965-1.22 \mathrm{~g} / \mathrm{cm}^{3}\right)$ and anomalous viscosity (over $104 \mathrm{MPa} \cdot \mathrm{s}$ ). Sulfur and metals, especially vanadium and nickel in concentrations comparable to their content in ore deposits, are also part of it.

Thus, natural bitumen is significantly different from traditional oil in chemical composition, physicochemical properties, the degree of interaction with the host rocks and the nature of the saturation of the pore environment. Therefore, the methods and approaches used in the extraction of traditional oil cannot be directly implemented for the development of high-viscosity oil deposits and natural bitumen [4].

In this regard, a number of methods for the bitumen extraction from tar sands have been developed. A number of methods are receiving refinement and improvement.

\section{Methods of oil sands development}

Oil sands are mainly developed in two ways: the extraction of bitumen by the quarry method and the methods of its extraction in site [5]. The choice of method depends mainly on the depth of the reservoir. Deposits at depths of up to $50 \mathrm{~m}$ and subject to surface mining account for about $20 \%$ of Canada's bitumen deposits. The remaining $80 \%$ of the oil sands that can be mined at the site.

A quarrary method involves two major steps: the removal of the rock from the quarry and the extraction of bitumen in industrial installations. After the rock is extracted, bitumen is separated from the sand by a process of hot water extraction, patented in 1928 by Dr. Carl Clark (bitumen is separated from sand and clay particles by a combination of mechanical energy, heat, and the presence of surfactants). Currently modifications of this method are applied [6].

Pieces of petroleum sandy ore are ground and mixed with warm water containing $\mathrm{NaOH}$ to form an aqueous slurry at the mining 
sites. The slurry is then conditioned at elevated temperatures to help release bitumen. Traditionally, extraction drums are used to extract bitumen at $80{ }^{\circ} \mathrm{C}$. Recently, pipelines leading to the primary separation unit at $35-50^{\circ} \mathrm{C}$ have been used to facilitate separation.

In hydraulic pipelines and drums, the pieces of rock left in the slurry are displaced and reduced in size. In drums or in hydraulic pipelines, bitumen is «released» from the grains of sand. Phase separation is enhanced by mechanical displacement and breaking pressure. At a temperature of $35-50{ }^{\circ} \mathrm{C}$ and the $\mathrm{pH}$ of the suspension within 8-8.5 bitumen is separated, forming droplets that are released from the grains with stirring of the suspension.

Because bitumen and water have similar densities, the flotation method is used to separate them. For this, bitumen is gradually aerated at a rate of about $30 \%$ by volume of gas to the mixture volume. However, it is very difficult to organize the supply of the optimum amount of air for quality aeration and to avoid excessive air supply [5].

In [7] it was shown that the aeration stage is the most critical and this has the effect of bitumen loss.

Thus, during conditioning, the liquid suspension is aerated and ideally the bitumen is separated from the sand, attached and distributed to air bubbles. The bituminous foam collected in the gravity separation vessel contains about $10 \%$ solids and $30 \%$ water. The foam air bubbles are easily removed by heating or gravity drainage, but the viscous bitumen is not easily cleaned of small clay particles and drops water emulsified. Dilution of bitumen with a solvent reduces its viscosity and density and accelerates the settle of denser solids. However, emulsified droplets of water and clay particles have tiny diameters, so they settle very slowly [8-9].

The process is carried out using inclined plates of sedimentation tanks, cyclones and centrifuges. For this operation, Syncrude and Suncor use a light fraction of oil (mainly hexane) as the solvent for foaming. When the solvent is used in a sufficiently high amount, the bitumen asphaltene is partially precipitated. This results in the formation of composite aggregates that catche water and solids from diluted bitumen foam. This method significantly improves the gravitational separation, thus eliminating the need for cyclones or centrifuges.

The successful application of water-based technologies for the extraction of bitumen from the Athabasca oil sands lies in the key fact 
that the sand in the oil sands is hydrophilic. Also, it is believed that a thin layer of water surrounds the individual grains of sand (about 10 $\mathrm{nm}$ thick), separating them from bitumen [10]. The most characteristic feature of the Alberta oil sands is that the grains are moist or hydrophilic. This hydrophilic tendency of the sands is successful because the process of extracting bitumen with hot water would not work if the grains were not moistened.

It is assumed that the water film is stabilized by electrostatic forces resulting from the formation of a double electric layer at the boundary of the phase separation of «oil - water» and «water - sand» [11-14].

Quartz sand absorbs most of the bitumen and water mixture, forming a continuous phase. The water film separates bitumen from sandy and clay surfaces.

Thus, the removal of bitumen from the oil sands using the processes of water-based extraction includes the following steps:

- grinding of rock that occurs in bunkers or hydraulic pipelines in the process of heating its surface and gradual erosion;

- separation of bitumen from sand grains. (The speed of this step depends on the balance between the forces of bitumen separation the from the sand grain and the force of attraction (sticking) of the bitumen to these grains.) The processes of this stage are affected by the rate of heat transfer, mechanical mixing, chemical additives and interfacial properties;

- the bitumen droplet released from the sand is attached to the air bubble. Depending on the process temperature, the bitumen either attaches to the air bubble at a low temperature process $\left(<35^{\circ} \mathrm{C}\right)$ or absorbs the bubble in «hot» $\left(75-80{ }^{\circ} \mathrm{C}\right)$ or «warm» (about $45^{\circ} \mathrm{C}$ ) processes. As a result of aeration, the bitumen floats to the top of the gravity separation vessel. As a result, a layer of bitumen foam is formed.

For any production method, the extracted bitumen for quality improvement is subjected to primary processing for synthetic oil. In this case, residual of the rock (mainly clay fraction) and water are also removed from the bitumen. (Before distillation, the diluted bitumen product typically contains approximately $2 \%$ water and $0.5 \%$ fine solids.)

This processing is similar to ordinary crude oil treatment using cracking and hydrotreating processes. The synthetic crude oil is then sent to an oil refinery for further physical and chemical processing. 
Unfortunately, the quarrying method cannot be used for deeper tar sands. In this case, in-situ well production technologies are applied. In this case, methods that minimize their viscosity is the most rational [15].

Among such methods, thermal and thermochemical occupy a special place. These include different combinations of steam or solvent injection through horizontal or vertical wells. Currently, two main types of in-site methods are made and widely implemented: Cyclic Steam Stimulation (CSS) and Steam-Assisted Gravity Drainage (SAGD) [16].

Both methods include the injection of hot steam into a reservoir for heating oil sands in order to reduce the viscosity of the bitumen and to stimulate its production. The CSS method was the first to be used in the production of bitumen in site. It includes the injection of water vapor into the well at a temperature of $250{ }^{\circ} \mathrm{C}$ to $400{ }^{\circ} \mathrm{C}$. Water vapor advancing the layer heats the bitumen, reducing its viscosity. The wells are allowed to settle for several days or weeks and then the hot oil mixed with condensed water is pumped out for weeks or months. Then the method is repeated. However, in addition to the high cost of pumping water vapor, the CSS method generally results in bitumen extraction not exceeding 20-25\%.

Another in-site method (currently most widely used) is SteamAssisted Gravity Drainage. The method includes the drilling of two horizontal wells - one at the bottom of the formation and the other five meters above it. Water vapor is injected into the upper well, melting the bitumen, which then flows into the lower well.

The degree of water conversion to steam is about $75 \%$, i.e. $1 \mathrm{~kg}$ of feed water generates $0.75 \mathrm{~kg}$ of steam, and $0.25 \mathrm{~kg}$ remains in the liquid form [17].

The process of steam gravity begins with the stage of preheating, during which (several months) the steam is circulated in both wells. However, due to the conductive heat transfer, the zone of the reservoir between the extraction and injection wells is heated, the bitumen viscosity in this zone is reduced and thus the hydrodynamic connection between the wells is provided. At the main stage of extraction, steam is already pumped into the injection well.

The resulting liquid oil mixed with condensed water vapor is pumped to the surface. The level of bitumen extraction by the SAGD method reaches 40-60 percent. However, this method is most effective for the extraction of oil sands located at a depth of more than $200 \mathrm{~m} \mathrm{[18].}$ 
The above methods have many problems related to the level of costs and the negative impact on the environment. For example, the use of large amounts of water vapor requires high energy consumption and the use (and placement) of large amounts of water. Currently, the extraction and processing of tar sands requires several barrels of water per barrel of oil obtained [19].

Open field development and further processing results in significant sand volumes that is not fully cleared. It requires further processing before being returned to the environment. In addition, the use of large quantities of caustic soda for extraction by the quarry method improves the stability of fine clay particles in waste, the removal which is a major problem of the influence on the environmental.

Calculations show that energy consumption to increase the temperature of 1 ton of oil sand by $1{ }^{\circ} \mathrm{C}$ is about $5 \mathrm{MJ}$. Such an energyintensive process inevitably releases greenhouse gases that pose a threat to the environment. Therefore, for the development of natural bitumen deposits with the achievement of acceptable values of extraction coefficients, new methods are needed that are superior to the efficiency of traditional steam-boiling technologies.

Solvent extraction is one possible alternative. Here, the introduction of thermal energy at the beginning of the extraction process can be minimized (the process can be carried out even at ambient temperature) by adding solvents that reduce the viscosity of the bitumen.

In this regard, methods the bitumen extraction by the solvent (eg, VAPEX, N-Solv) are being developed.

Thus, in the VAPEX - VAPor EXtraction method (using solvents in a vaporous state) a mixture of solvents (propane, butane, oil and methane) is pumped into the reservoir in the form of steam into the upper horizontal well (Fig. 1). The solvent is mixed with bitumen to reduce its viscosity.

The extraction process is carried out through the lower horizontal well. The process uses no water and produces no $\mathrm{CO}_{2}$. But the project has not yet found widespread implementation as a number of important technical issues have not been resolved (the process of dissolution is very slow). 


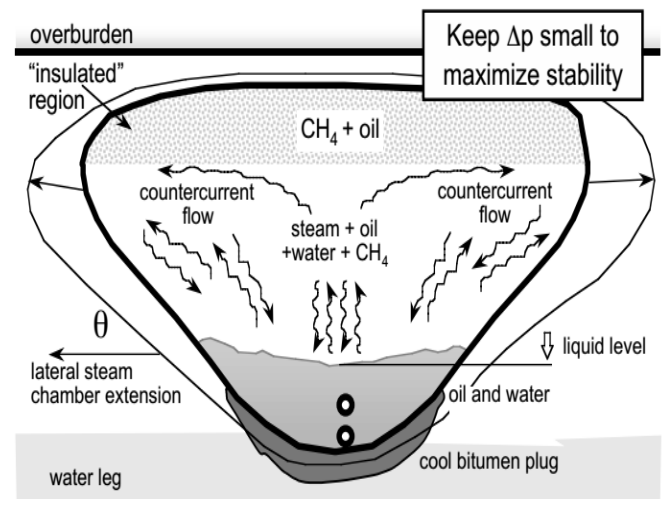

Fig. 1. Basic elements of SAGD (\& VAPEX)

New technology of N-Solv (Fig. 2), includes pumping into the reservoir of solvent (propane) heated to a temperature of $\sim 50{ }^{\circ} \mathrm{C}$. Propane dissolves bitumen, its most heavy components remain underground. Lighter oil and solvent, which is able to restore, are lifted to the surface. In addition, the mass is less viscous than in the traditional underground method, so it can be immediately transported by pipeline.

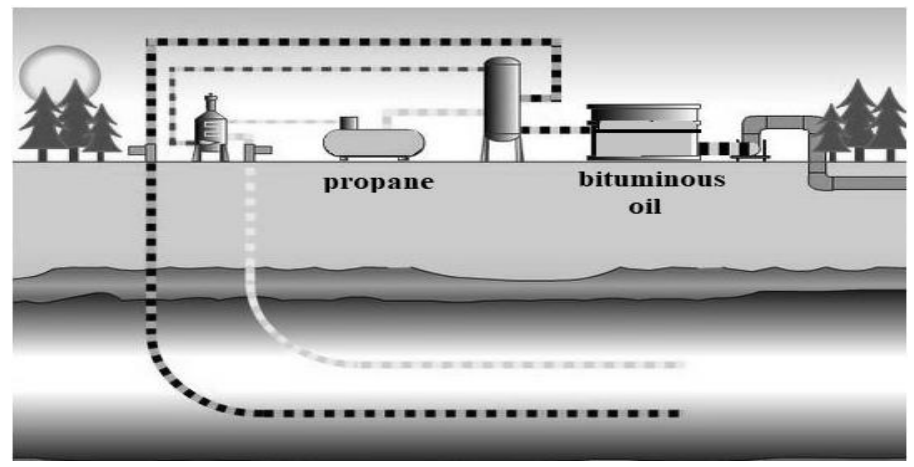

Fig. 2. Technology of oil extraction from tar sands

(N-Solv technology)

Moreover, the improvement of the N-solv technology itself by heating the solvent, as well as cleaning it from methane admixture made it possible to significantly increase the efficiency of the pro- 
cess. (It was found that the methane presence in the formation significantly worses the process of heat exchange at the interface of solvent - bitumen).

As a result, greenhouse gas emissions are reduced by $80 \%$ compared to traditional methods of production. In addition, the heavy admixtures present in bitumen - such as sulfur, asphaltenes, heavy metals and the heaviest hydrocarbon fractions - remain underground.

However, known methods that include the injection of water vapor or hydrocarbon solvents have a significant disadvantage associated with the heterogeneity of the rock productive layers. This inevitably leads to their breaking in the production wells and the need to apply flow diversion technologies (blocking gels, sediment-forming compositions).

Because of this, most horizontal sections of SAGD wells are laid at a depth of more than $200 \mathrm{~m}$ (due to the danger of the agent breaking into the surface). In the article [18] analyzes 28 SAGD wells. They are drilled in the range $212-425 \mathrm{~m}$, with an average of $303 \mathrm{~m}$.

As the lower boundary of the quarry development is $75 \mathrm{~m}$ depth, there is a considerable interval of natural bitumen bedding (at least $125 \mathrm{~m}$ capacity (in the range $75-200 \mathrm{~m}$ ) for which there is no acceptable extraction technology.

Thus, today there is a need for efficient, safe and economical ways of removing bitumen from tar sands. In addition, an important task is to develop an effective method for the deposit interval of tar sands.

\section{Justification of technology parameters}

An analysis of the accumulated experience in the development of tar sands showed that one of the ways in-site technology development (for this interval) could be the technology proposed by the authors. It would allow processes to be carried out directly in the area of the bituminous rock occurrence. The processes are similar to those occurring in above-ground technological equipments (bituminous sand processing) by the Clark method [6].

Moreover, the area of implementation of these processes, considering the need to reduce energy consumption and environmental impact, should be local, controlled and as isolated as possible. 
The latter condition, taking into account the properties of the bituminous rock, can be fulfilled provided that the pressure in the limited working area is not at the level of formation.

These requirements, in our opinion, can be fulfilled provided the consistent implementation by the technology of the following operations:

- formation in the productive layer of mountain excavation, which will be an area for geotechnological processes, according to the Clark method [6];

- the bring of the necessary amount of heat and reagents for reduce the bitumen viscosity and its separation from the rock;

- formation of conditions for efficient bitumen extraction and its extraction in the most concentrated form.

In addition, the technology must have minimal impact on the environment, provide maximum heat recovery, have a minimum period from the beginning of the project to the receipt of products and output to the design capacity.

Analysis of known technological solutions today showed that the above requirements can correspond the technology developed on the basis of elements of well production technology [20].

This technology includes the opening of a well, the rock's breaching at the place of its occurrence with the help of a jet stream, the transfer of the rock into the hydraulic mixture composition and extraction to the surface [20].

The mechanism of hydraulic rocks fracturing is a complex process caused by the simultaneous action of a number of factors. These include normal and tangential stresses when the jet influence to an array, dynamic shock action, filtration pressure, abrasive action, etc. [21].

An added advantage of the technology is that it allows the mining of disconnected ore bodies in flooded wells in high water inflows, as well as under water and offshore.

However, the rapid decay of the jet energy occurs in the conditions of bottom well flooded. This requires the use of hosepipes or telescopic monitors that lengthen as the motion of the bottom well. As a result, the extraction of the rock mass and the unit construction are complicated, as well as the risk of the roof collapse and clogging of equipment.Therefore, this technology requires improvement and adaptation to the features of the tar sands deposits development. 
Significant susceptibility to bituminous sand disintegration (especially after reducing the bitumen viscosity as resultate heating or solvent action) is a positive factor to the protection of this method.

Taking into account the above requirements for bitumen and high-viscosity oil extraction technology at the site of their precipitation, as well as the features (and disadvantages) of the technology well hydraulic extraction of the minerals in works [22, 23], a method (Fig. 3) is proposed, which includes:

- disclosure of the productive layer horizontal well 8 heated working fluid - water with surfactants;

- transfer of the rock (from the bottom of the well) to the slurry as a result of the action of high-pressure working fluid streams (stream III) $(5-20 \mathrm{MPa})$ at a temperature above $100{ }^{\circ} \mathrm{C}$ (stream III). Moreover, the rods of hydromonitors 7 with nozzles in the working position occupy perpendicular to the axis of the well position. In the process, they rotate around the well axis and gradually move along in the direction of contact with the fracture front. Mountain excavation gradually forms, which develops in the direction of the wellhead;

- increment of the destructive action of the working fluid jets due to the abrasive action of the rock 2 particles, which are captured by the hydromonitore jets 7 together with part of the pulp in the interval from the nozzle slice to the front of destruction;

- carry into the excavation with the working fluid flow of thermal energy to reduce the bitumen viscosity;

- the gravitational compartment at some distance beyond the hydromonitors 7 (where turbulent mixing is extinguished) from the formed pulp of the main part of the rock 2, (except the clay fraction). As a result, the pulp is enriched with bitumen and pushed back to the vaulted excavation;

- withdrawal from the production of bitumen-enriched pulp (stream II) through the slurry tank 5, located in the vaulted part of the production to the separator 12;

- separation from the pulp in the separator 12 of the solid phase remainder (stream $\mathbf{I})$;

- the selection of the bitumen concentrate (stream $\boldsymbol{I V}$ ) and sending it for further processing. 


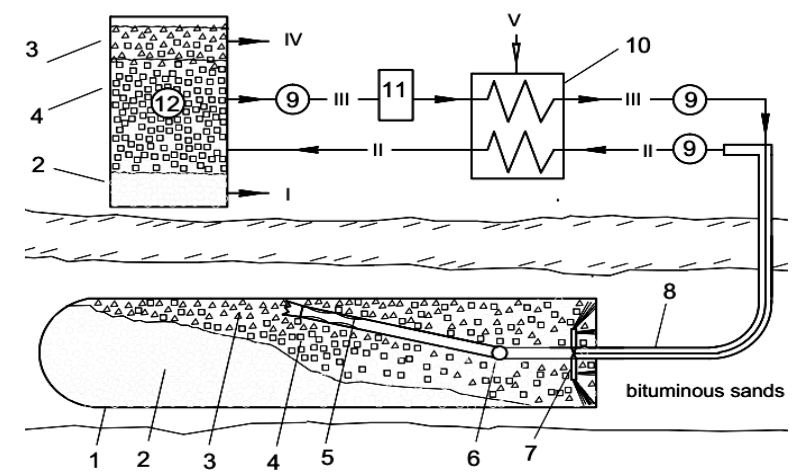

Fig. 3. Scheme of the bitumen's extracting method from the tar sands deposits: 1 production; 2 - sediment of sand; 3 - pulp enriched with bitumen; 4 - water with a clay fraction; 5 - a shank with a chisel and a pulp gathering; 6 - the hinge; 7 - hydromonitor device; 8 - well; 9 - pump; 10 - block of heating; 11 - a block of partial separation of the solid phase; 12 - separator; streams: I - sand precipitate; II - pulp enriched with bitumen; III - clay solution; IV - bitumen; V - a coolant

It is also assumed that outside the hydraulic system where the pressure corresponds to a reservoir, the level of superheating of the fluid in the fracture zone will be sufficient to boil it. The formation of water vapor bubbles in the rock pores the will increase the process of its disintegration. Then, in the resulting water mixture, the bitumen drops are attached to the bubbles. Similarly to the processes carried out in the extraction plants, the process of bitumen flotation to its vaulted will take place in the mountain excavation.

However, the technology proposed in [22, 23] is based on thermal processes of bitumen extraction and therefore cannot be perfect in terms of energy efficiency, environmental impact through $\mathrm{CO}_{2}$ emissions. Therefore, there are reserves for its improvement and competitiveness.

Heating (even in the localized zone) of the productive layer, based on the bitumen low content, heat capacity and thermal conductivity of the rock, without the prospect of heat recovery is unjustified. 
It is known that a positive result can be achieved by using solvent bitumen to reduce the viscosity. (The positive experience of moderate heating (eg up to $50{ }^{\circ} \mathrm{C}, \mathrm{N}$-Solv method) should also be used). It is also expedient to use the liquid solvent as part of the working fluid of the hydromonitors when making it into excavation.

In addition, instead of the bitumen flotation with water vapor bubbles, it should be provided to introduce into the excavation a flotation agent which, under thermobaric conditions of production, was in a gaseous state and in the supply line in a liquid state. (Therefore, it was fed into the well of the working fluid for monitors).

Also, to maximize bitumen extraction and reduce solvent losses, the following should be considered.

It is estimated that about $70-80 \%$ of the rock (mainly sand), based on the composition of bituminous sand, will separate as a result of gravitational deposition from the pulp in the production. As a result, mountain excavation approximately $4 / 5$ of the cross section will be filled with sediment. Its porosity will be about $30 \%$. On this basis, ideally the process should be organized in such a way that the pore space of the sediment was filled with a slurry of water and clay fraction of the rock. In this case, all the bitumen, together with the flotation agent, will be displaced from the sludge to the vaulted excavation.

After taking into account (and agreeing) the above positions, a method (geotechnology) and a schematic diagram (Fig. 4) of «cold» hydropower in-site bitumen from deposits located at a depth of 50 to $400 \mathrm{~m}$ are proposed.

The method provides:

- disclosure the reservoir with horizontal wells; 


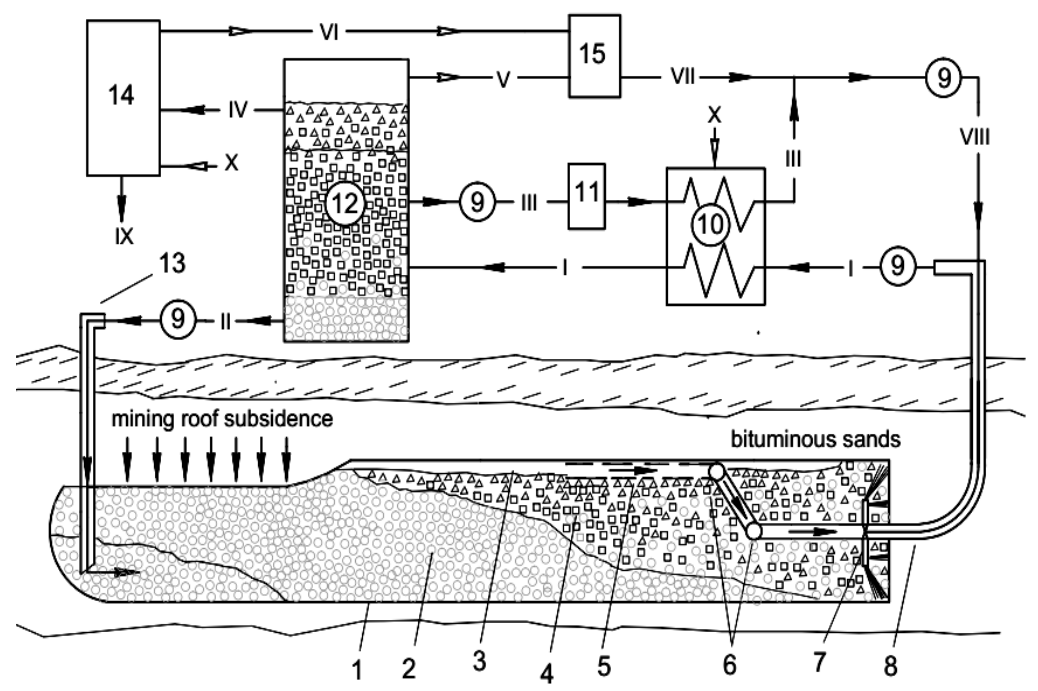

Fig. 4. Schematic diagram of an improved method of extracting bitumen from tar sands: 1 excavation; 2 - sediment of the rock; 3 - gas cap; 4 - water mixture, enriched with bitumen; 5 - intake device; 6 - swivel connection; 7 -hydromonitors; 8 - horizontal section of the well; 9 - pump; 10 - the heater; 11 - a filter; 12 - separator; 13 - injection well; 14 - evaporation column; 15 - the liquefaction unit; flows: I - mixture of bitumen, solvent, water, clay fraction of rock and flotation agent; II - rocks; III - water; IV - a mixture of bitumen, solvent and flotation agent; V - a gaseous flotation agent; VI - gaseous solvent and flotation agent; VII liquefied solvent and flotation agent; VIII - a mixture of water, solvent and flotation agent; IX - bitumen; $\mathbf{X}$ - supply of thermal energy

- transfer of the rock (starting from the bottom well) to the slurry as a result of the action of jets working fluid (stream VIII) of high pressure $(5-20 \mathrm{MPa})$ at a temperature of about $50{ }^{\circ} \mathrm{C}$. Moreover, the rods of hydraulic monitors 7 with nozzles in the working position occupy perpendicular to the axis of the well position. In the process, they rotate around the well axis and gradually move in the direction of contact with the fracture front. Mountain excavation (mining) is gradually forming, which develops in the direction of the wellhead. Disintegration of the rock of the productive layer is carried out by high-pressure working fluid jets, which include water, flotation agent and bitumen solvent. In this case, the flotation agent in the thermobaric conditions of the flow line of the working fluid and until the nozzles slice hydromonitors is in a condensed state, and in the 
production - evaporates. After that, its part in the form of bubbles is attached to the bitumen drops and the rest - accumulates in the vault;

- magnification of the destructive action of the working fluid jets due to the abrasive action of the particles of the rock 2, which are captured by the hydromonitor jets 7 together with part of the pulp in the interval from the nozzle slice to the front of destruction;

- the separation of natural bitumen from the rock occurs as a result of reducing its viscosity under the action of solvent;

- at some distance along the hydromonitors 7 (where turbulent mixing goes off) the gravitational separation of the hydraulic mixture into the sediment layer (rocks 2 and water in the pores), the gas cap 3 of the flotation agent vapor in the vault, and the target product layer between them - hydraulic mixture enriched with rhe bitumen 4 (bitumen, solvent, water, clay fraction of rock and flotation agent);

- selection from the excavation excavation (stream $I$ ) of hydraulic mixture enriched with bitumen 4 is carried out by gas lift method due to the excess pressure formed by the working fluid (stream VIII) and the flotation agent in the gas cap 3;

- the selection of the target product (stream $\boldsymbol{I}$ ) to the separator 12 is carried out through the intake device 5, which in the working position floats to the pulp concentrate area and its end, to capture gas to form the gas lift effect, is located on the border of the pulp - gas cap. In this case, the intensity of selection of the enriched pulp will be regulated by the flow rate of the hydromonitors working fluid and its composition;

- separation in the separator 12 selected from the production of the hydraulic mixture to the working fluid (stream $\boldsymbol{I I I}$ ), which under pressure is fed to the hydraulic monitors 7, a bitumen mixture, flotation agent and solvent (stream $\boldsymbol{I} \boldsymbol{V}$ ) and rock (stream $\boldsymbol{I}$ ).

As a flotation agent propane gas mixture is proposed to be used. Moreover, the ratio of these components in the mixture will depend on the technological parameters of the particular object of development (depth of occurrence and temperature in the production).

A wide fraction of light hydrocarbons obtained from the destruction of the produced bitumen in the process of its preliminary preparation is proposed to be used as a solvent. Its component 
composition will also be determined by the specific conditions of the development object.

The mixture of bitumen, solvent and flotation agent (stream $\boldsymbol{I V}$ ) in the evaporator 14 is divided into bitumen (stream $\boldsymbol{I X}$ ) and a pair of flotation agent and solvent (stream $\boldsymbol{V I}$ ). Separated in the separator 12 flotation agent (stream $\boldsymbol{V}$ ) and vapor mixture of flotation agent and solvent from the evaporation column 14 (stream $\boldsymbol{V I}$ ) are liquefied in block 15 . The water from the separator 12 (stream $\boldsymbol{I I I}$ ), if necessary, is additional purified from the clay admixtures in the filter 11 , heated to a temperature of $50-60{ }^{\circ} \mathrm{C}$, connects with the flow of liquefied solvent and flotation agent (stream $\boldsymbol{V I I I}$ ) and high pressure pumps 9 is fed to the hydromonitors (as a working fluid). Water, flotation agent and solvent to the hydromonitors (given the small diameter of the pipeline, high pressure and flow rate) come in a enough dispersed and homogeneous mixture.

The precipitate from the separator 12 and other waste through the injection well 13 in the form of flow $\boldsymbol{I I}$ is pumped into the lower part of the spent excavation (production) interval (to prevent a breakthrough into the production area).

One of the parameters that is proposed to take into account when choosing the diameter of the formed excavation is its mechanical resistance to fracture. The best option will be when in the interval of the working area the vault will be stable. But at some distance, the production will gradually deform, while pushing pulp and gas cap enriched with bitumen to the working zone.

The pressure in excavation (production) 1 will be insignificant and will exceed the hydrostatic only by the amount necessary for the organization of the gas-lift of the hydraulic mixture. Therefore, the pulp breakthrough to the surface is excluded. Therefore, there will be no limitations on the characteristics of the rock in the productive layer roof.

Based on the processes that will take place in the production, the bitumen extraction coefficient of this technology can compete with the coefficient for the career mode. The method will allow for easy extraction of bitumen (highly viscous oil) at the site at any depth, starting from the minimum. 
The profitability of in-situ oil sands development technologies is primarily determined by the bitumen extraction coefficient and specific energy consumption. With the recent fall in oil prices, the development of oil sands has faced difficulties. However, with the recent fall in oil prices, the development of oil sands has faced difficulties. In this regard, the presented technology has a number of advantages. It will be the most energy efficient because it does not provide a period of long pre-heating of the rock. In addition, thermal energy is introduced directly into the zone of the rock destruction. As a result, energy losses to the surrounding rock will be minimal. It is assumed that the bitumen extraction coefficient is at the level of the quarry method.

\section{Conclusions}

1. A method of extracting bitumen from weakly cemented reservoirs is proposed and scientifically substantiated, which includes: formation of artificial excavation (production); the transfer of the rock into the composition of the water mixture under the action of high pressure jets of a heated mixture of water, a hydrocarbon solvent and a flotation agent; separation from the rock and concentration of bitumen in production as a result of its heating, dissolution and flotation; selection of the depleted by the rock of suspension from excavation (production) due the gas-lift method.

2. The proposed method allows the extraction of bitumen from weakly cemented reservoirs at the place of occurrence for a depth interval of 75-400 m.

3. The proposed method does not require preliminary drainage of the site, and therefore shortens the start of production.

4. The pressure in the production will be around to the hydrostatic one, so the pulp breakthrough to the surface is excluded. There will also be no limitations on the characteristics of the rock in the roof of the productive formation.

5. The duration of preparatory operations will be insignificant. The selection of products will begin almost immediately after the inflow of the working fluid on the hydraulic monitors. 
References

1. Alberta Energy \& Utilities Board, Alberta's Reserves 2004 and Supply/Demand Outlook/Overview (2005), Statistical Series (ST) 2005-98, 2.

2. Kraemer, D., Bajpayee, A, Muto, A., Berube, V., \& Chiesa, M. (2009). Solar assisted method for recovery of bitumen from oil sand. Appl Energy, 86, 1437-41.

3. Lukin O.Y. (2008). Vuhkevodnevyi potentsial nadr Ukrainy ta osnovni napriamky yoho osvoyennia. Visnyk Nationalnoi Akademii Nauk Ukrainy, (4), 5667.

4. Stebel'ska H.Y. (2015). Heolohichni umovy rozvidky ta rozrobky pokladiv vysokoviazkykh naft ta pryrodnyh bitumiv. Visnyk Kharkivs'koho natsional'noho universytetu, (1157), 53-57.

5. Masliyah1, J., Zhou, Z., Xu, Z., Czarnecki, J., \& Hamza, H. (2004). Understanding Water-Based Bitumen Extraction from Athabasca Oil Sands. Canadian Journal of Chemical Engineering, 82, 628-654.

6. Kasperski, K.L. (2001). Review of research on aqueous extraction of bitumen from mined oil sands. Report.CANMET Energy Technology Centre, Natural Resources Canada, Devon, report CWRC 01-17 (CF).

7. Liu, J., Xu, Z., \& Masliyah, J. (2005). Processability of Oil Sand Ores in Alberta. Energy Fuels, 19(5), 2056-2063. https://doi.org/10.1021/ef050091r

8. Romanova, U.G., Valinasab, M., Stasiuk, E.N., Yarranton, H.W., Schramm, L.L., \& Shelfantook, W.E. (2006). The Effect of Oil Sands Bitumen Extraction Conditions on Froth Treatment Performance. Journal of Canadian Petroleum Technology, 45(9), 36-45. https://doi.org/10.2118/06-09-03

9. Schramm, L.L., Stasiuk, E.N., Yarranton, H., Maini, B.B., \& Shelfantook, B. (2003). Temperature Effects in the Conditioning and Flotation of Bitumen From Oil Sands in Terms of Oil Recovery and Physical Properties. Journal of Canadian Petroleum Technology, 42(8), 55-61. https://doi.org/10.2118/03-08-05

10. Czarnecki, J., Radoev, B., Schramm, L.L., \& Slavchev, R. (2005). On the nature of Athabasca oil sands. Adv. Colloid Interface Sci., 114-115, 53-60. https://doi.org/10.1016/j.cis.2004.09.009.

11. Czarnecki, J., \& Moran, K. (2005). On the Stabilization Mechanism of Water-In-Oil Emulsions in Petroleum Systems. Energy Fuels 19(5), 2074-2079. https://doi.org/10.1021/ef0501400

12. Czarnecki, J., Moran, K., \& Yang, X. (2007). On the "Rag Layer" and Diluted Bitumen Froth Dewatering. Can J Chem Eng 85(5), 748-755. https://doi.org/10.1002/cjce.5450850520

13. Taylor, S.E. (2018). Interfacial Chemistry in Steam-Based Thermal Recovery of Oil Sands Bitumen with Emphasis on Steam-Assisted Gravity Drainage 
and the Role of Chemical Additives Colloids Interfaces, 2, 16; https://doi.org/10.3390/colloids2020016

14. Drelich, J. (2008). Wetting phenomena in oil sand systems and their impact on the water-based bitumen extraction process. Mining, Metallurgy \& Exploration, 25, 1-12. https://doi.org/10.1007/BF03403379

15. Shah, A., Fishwick, R., Wood, J., Leeke, G., Rigby, S., \& Greaves M. (2020). A review of novel techniques for heavy oil and bitumen extraction and

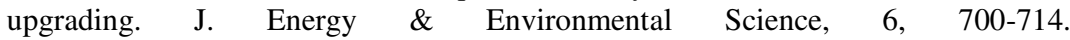
ttps://doi.org/10.1039/B918960B

16. Lazzaroni, E.F., Elsholkami, M., Arbiv, I., Martelli, E., Elkamela, A., \& Flowler, M. (2016). Energy infrastructure modeling for the oil sands industry: current situation. Appl Energy, 181, 435-445. https://doi.org/10.1016/j.apenergy. 2016.08.072

17. Hofmann, H., Babadagli, T., \& Zimmermann, G. (2014). Hot water generation for oil sands processing from enhanced geothermal system: process simulation for different hydraulic fracturing scenarios. Appl Energy, 113, 524-547. https://doi.org/10.1016/j.apenergy.2013.07.060

18. Rui, Z., Wang, X., Zhang, Z., Lu, J., Chen, G., Zhou, X., \& Patil S. (2018). A realistic and integrated model for evaluating oil sands development with Steam Assisted Gravity Drainage technology in Canada. Applied Energy. 213, 7691. https://doi.org/10.1016/j.apenergy.2018.01.015

19. Allen, E.W. (2008). Process water treatment in Canada's oil sands industry: I. Target pollutants and treatment objectives. Journal of Environmental Engineering and Science, 7(2), 123-138. https://doi.org/10.1139/S07-038

20. Bondarchuk, I.B., \& Shenderova, I.V. (2015). Classification of hydraulic borehole mining technological processes during pay zone development. IOP Conf. Ser.: Earth Environ. Sci. 24 012004. https://doi.org/10.1088/1755-1315/24/1/012004

21. Rehbinder, G. (1980). A Theory about Cutting Rock with Water Jet. Rock Mechanics, 12(3-4), 247-257. http://dx.doi.org/10.1007/bf01251028

22. Pedchenko, L., Pedchenko, N., Manhura, A., \& Pedchenko, M. (2019). Development of natural bitumen (bituminous sands) deposits based on the borehole hydro-extraction technology. E3S Web of Conference. (123), 301036 https://doi.org/10.1051/e3sconf /201912301036

23. Pedchenko, M., \& Pedchenko, L. (2018). Expanding of spheres the application of borehole hydro-production technology to develop deposits of nontraditional hydrocarbons. E3S Web of Conference. (60), 00018. https://doi.org/10.1051/e3sconf/20186000018 
https://doi.org/10.31713/m1113

\title{
SUBSTANTIATION OF RATIONAL PARAMETERS OF THE EXPLOSIVE BREAKOUT TECHNOLOGY IN A STRUCTURAL BLOCK ARRAY
}

Yelzhanov Yerbol Abdrakhmanovich

International Educational Corporation LLP (Kazakh Main Architectural and Construction Academy), Candidate of Technical Sciences, Associate Professor, Republic of Kazakhstan Deputy Dean for External Relations and Student Affairs

\section{Yussupova Saltanat Abenovna}

Almaty University of Power Engineering and Telecommunications named after Gumarbek Daukeyev, Candidate of Technical Sciences, associate professor, Republic of Kazakhstan

\author{
Aben Yerbolat Khalidillaevich \\ Candidate of Technical Sciences, associate professor of Mining \\ department, Satbayev University, Republic of Kazakhstan
}

\section{Annotation}

The idea of this work is to choose a technological scheme of drilling and blasting, which provides spacer pinching of the separateness released along the natural surfaces of the weakening of the ore massif and thereby increases the duration and efficiency of explosive crushing of the structural block array as a whole, the object of research of which is the technological process of drilling and blasting of ore during underground mining of powerful and medium-capacity deposits represented by strong ores.

The authors in this robot investigated the parameters of fracturing and structural blockiness of the ore-containing massif of the Yubileynoye deposit and conducted experimental work to establish the quality of breaking of the fractured structural block ore array, and also developed recommendations for choosing a rational scheme and calculating the parameters of drilling and blasting operations in a structurally heterogeneous array.

Keywords: Ore extraction, Drilling and blasting, Underground mining of deposits

\section{Introduction}

Currently, the annual volume of world mining has exceeded 10 billion tons, of which about $64 \%$ are solid minerals. An analysis of the dynamics of production volumes over the past 20 years shows that the specific increase in the gross output of the mining industry in the Asian economy is the largest today and during this time it has 
increased almost one and a half times, while in European countries and in North America this indicator is noticeably decreasing. It should be noted that the volume of mining operations in Africa, Australia and South America is also characterized by significant growth.

The demand for mineral raw materials and metals in the world due to scientific and technological progress is constantly growing. At the same time, the explored balance reserves of ore deposits are rapidly decreasing, the mining and geological conditions of the remaining reserves and the mining conditions of their development are deteriorating, the content of useful components is noticeably decreasing.

The development of mineral resources in a market economy requires the creation of new efficient development systems, the use of machines and mechanisms with high productivity, reliability, energy conservation, as well as their equipment with advanced mechanization and automation systems.

Integrated use of mineral resources, reduction of costs during sinking and cleaning operations, reduction of mineral losses, as well as ensuring the safety of people require rational mining operations in full compliance with the mining and geological and mining engineering conditions for the development of mineral deposits.

When drawing up mining schedules and passports of drilling and blasting operations, along with the results of standard laboratory studies of the physical and technical properties of rock samples, it is necessary to study the structure of the massif in detail. This is due to the fact that the consumption of explosives in an array disturbed by crack systems can be noticeably reduced. In addition, the incorrect orientation of the charges of boreholes and boreholes relative to the position of the dominant system of cracks leads to dislocations associated with the violation of rocks in the legal zone of mining. Therefore, along with the structural attenuation coefficient, traditionally taken into account in calculations, it is necessary to pay attention to the orientation of crack systems in the face.

The degree and nature of fracturing of rocks in the massif, the orientation and level of the main natural stresses, the choice of the optimal layout of blast wells and their blasting mode have a significant impact on the results of the explosion.

In connection with the above, the choice of an effective technology 


\section{Investigation of the structure of the ore massif and assess-}

ment of its impact on the technology and parameters of drilling and blasting operations

\subsection{Determination of fracturing parameters of the ore- containing array}

To assess the structural structure of the array using the amplitude parameters of passing elastic waves, experimental observations were carried out in underground conditions according to the scheme shown in Fig. 1.

Calibrated charges of ammonite № 6 weighing $125 \mathrm{~g}$ were used as a pulse source, the detonation of which was initiated by electric detonators. The charges were placed in holes drilled at various distances from the sensor installation site, as shown in Figure 1. The recording equipment was the SMV, VIB-A seismic receivers and the P-700 oscilloscope. The seismic receivers were mounted on the wall of the mine using a solution of fast-hardening cement and recorded the horizontal component of the vibration velocity of the free surface, which is associated with the mass velocity of particles at the wave front passing through the array.

Calibration of VIB-A vibrographs was carried out in accordance with the instructions set out in the instrument passport; SMV seismic receivers were calibrated on a vibration stand according to the VNIMI methodology given in [1].

In the monograph by E.F. Savarensky and D.P. Kirnos, it is shown that when choosing sensors to obtain undistorted signal recording, two fundamentally different approaches are possible, which follow from the solution of the differential equation describing the operation of the seismograph.

1 The natural oscillation frequency of the moving part of the device should be much less than the frequency of the recorded process. In this mode, vibragraphs work to record the amplitudes and velocities of vibrations.

2 The natural oscillation frequency of the moving part of the device should be much higher than the natural frequency of the recorded process. In this mode, sensors work to record the accelerations of vibrations.

Calibration of the sensors determined that the natural oscillation frequency of the moving part of the VIB-A seismic receiver is $2 \mathrm{~Hz}$, 
and for the CMV device - $20 \mathrm{~Hz}$, and the sensitivity is $10.8 \mathrm{mV} *$ $\mathrm{s} / \mathrm{cm}$ and $31.2 \mathrm{mV} / \mathrm{cm}$, respectively. The sensitivity of the seismic receivers was determined at frequencies of $300-500 \mathrm{~Hz}$.

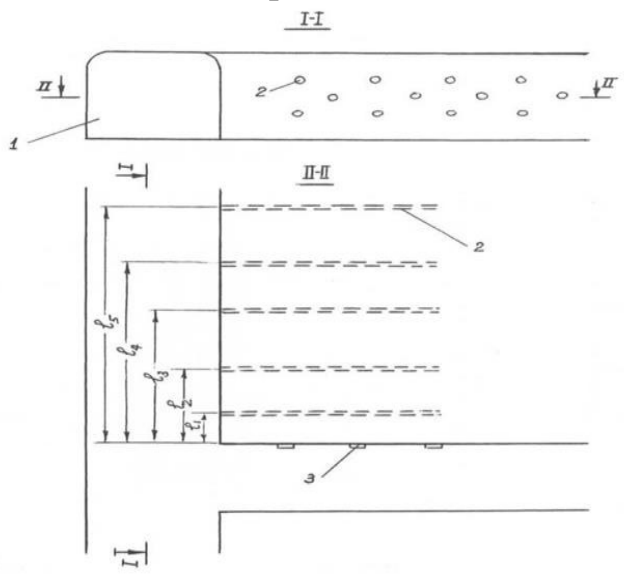

Fig. 1. Layout of calibrated explosive charges and seismic receivers for measuring the velocities of longitudinal waves in a structural block array: 1 - sub - storey drift; 2 - holes with calibrated explosive charges; 3 - seismic receivers

By analyzing the frequency of vibrations of the rock mass received by the seismic receiver, it was found that the predominant frequency of the voltage wave pulse excited by the explosion based on measurements of $0.25-7.05 \mathrm{~m}$ or at relative distances $(12-352) \cdot r_{0}$, where $r_{0}$ is the radius of the explosive charge used, was exactly $300-500 \mathrm{~Hz}$.

The seismic sensors used high-frequency galvanometers M 001.5 with an operating frequency band from 0 to $1700 \mathrm{~Hz}$. As indicated in [2], when using a high-frequency galvanometer, the frequency of free oscillations of which is much higher than the frequency of the recorded process, the deflection of the beam to the seismic receiver will be proportional to the magnitude of the current flowing through the coil. Thus, in our conditions, a low-frequency sensor paired with a broadband galvanometer is able to give an undistorted diagram of the speed of the observed oscillations.

In the course of experimental work, 25 experimental explosions were made. A well - known dependency was used to decipher the received signals

$$
v=\frac{A \cdot R_{о б}}{j_{r} \cdot j_{c}},
$$


where $v$ - displacement velocity, $\mathrm{m} / \mathrm{s}$;

$A$ - the amplitude of the displacement on the oscillogram, mm;

$R_{o \sigma}$ - the resistance of the circuit, which consists of the resistance of the seismic receiver, the resistance of the wires and the internal resistance of the galvanometers, ohms;

$j_{r}$ - galvanometer sensitivity, $\mathrm{mm} / \mathrm{mA}$;

$j_{c}$ - sensitivity of the seismic receiver, $\mathrm{MB} \cdot \mathrm{c} / \mathrm{cm}$.

The values of the displacement velocities were taken according to the amplitude of the first entry, which was the maximum in all records. In the studied range of changes in the distances from the explosion source to the signal registration point, the first entry on the seismic receivers is the result of the passage of a direct voltage wave.

Table 1 shows the results of measurements of the displacement rates of the outcrop surface of the rock mass at various distances from the source of the explosion and the results of calculations of the amplitude parameters of fracturing.

The data were processed by methods of mathematical statistics, the boundaries of confidence intervals were found for the distributions, standard deviations and coefficients of variation were calculated [3-5]. The standard deviation for the amplitude fracture indices was 0.09 , and the coefficient of variation was $25 \%$.

The study of the effect of fracturing on the parameters of elastic waves was carried out within the sub-storey workings at the horizons of 345 and $331 \mathrm{~m}$, where rocks are mainly granite porphyry. Before the start of the explosions, a sketch was carried out of all visible traces of cracks on the outcrops of the massif with the measurement of their width, azimuths of strike and angles of incidence. Visual observations and measurements have established that the rocks in the studied areas are characterized by intense fracturing. The width of the cracks varies from 0.5 to $2 \mathrm{~mm}$. When processing the data, the total number of cracks along the measurement lines was calculated and the average size of the natural separations composing the array was determined. The average size of natural isolation on mountains. $345 \mathrm{~m}$ is 25 $\mathrm{cm}$, and on mountains. $331 \mathrm{~m}-32 \mathrm{~cm}$. At the same time, the nature of the cracks - their length and width on both horizons remain the same.

The amplitude index of fracturing is equal to the ratio of the amplitude of the wave passing in the fractured array to the amplitude of the wave in the monolith at the same distance. The values of the amplitudes $A_{1}$ and $A_{2}$ were determined experimentally by detonating calibrated charges weigh- 
ing $125 \mathrm{~g}$ in natural separations of different lengths. The absorption coefficient for monolithic rocks turned out to be equal.

Table 1

Results of measurement of elastic wave parameters in fractured rocks

\begin{tabular}{|c|c|c|c|c|c|c|c|c|c|c|}
\hline \multirow{2}{*}{ № } & \multirow{2}{*}{$\begin{array}{l}\text { Distance } \\
\text { to the } \\
\text { explo- } \\
\text { sion } \\
\text { point, } \\
\mathrm{cm}\end{array}$} & \multirow{2}{*}{$\begin{array}{c}\text { Measured } \\
\text { displace- } \\
\text { ment } \\
\text { velocity, } \\
\mathrm{cm} / \mathrm{s}\end{array}$} & \multirow{2}{*}{$\begin{array}{l}\text { Estimated } \\
\text { displace- } \\
\text { ment } \\
\text { velocity for } \\
\text { monolithic } \\
\text { rock, } \mathrm{cm} / \mathrm{s}\end{array}$} & \multirow{2}{*}{$\begin{array}{l}\text { The } \\
\text { ampli- } \\
\text { tude } \\
\text { index of } \\
\text { fractur- } \\
\text { ing, the } \\
\text { fraction } \\
\text { is one. }\end{array}$} & \multicolumn{2}{|c|}{$\begin{array}{l}\text { The number of } \\
\text { cracks in the } \\
\text { measurement } \\
\text { interval, pcs. }\end{array}$} & \multicolumn{2}{|c|}{$\begin{array}{l}\text { The size of the natural } \\
\text { part, } \mathrm{cm}\end{array}$} & \multicolumn{2}{|c|}{$\begin{array}{c}\text { Deviatio } \\
\mathrm{n}\end{array}$} \\
\hline & & & & & $\begin{array}{c}\text { actua } \\
1\end{array}$ & $\begin{array}{c}\text { Settleme } \\
\mathrm{nt}\end{array}$ & $\begin{array}{c}\text { Measure } \\
\mathrm{d}\end{array}$ & $\begin{array}{c}\text { calculate } \\
\text { d }\end{array}$ & $\begin{array}{l}\mathrm{c} \\
\mathrm{m}\end{array}$ & $\%$ \\
\hline 1 & 2 & 3 & 4 & 5 & 6 & 7 & 8 & 9 & 10 & $\begin{array}{l}1 \\
1\end{array}$ \\
\hline \multicolumn{11}{|c|}{ horizon $345 \mathrm{~m}$} \\
\hline 1 & 45 & 130,0 & 158,4 & 0,82 & 2 & 2 & 22 & 20 & 2 & 9 \\
\hline 2 & 60 & 115,4 & 116,0 & 0,99 & 2 & 2 & 25 & 26 & 1 & 4 \\
\hline 3 & 90 & 70,8 & 78,3 & 0,90 & 4 & 4 & 20 & 24 & 4 & 20 \\
\hline 4 & 108 & 52,3 & 63,8 & 0,82 & 4 & 4 & 25 & 22 & 3 & 12 \\
\hline 5 & 118 & 52,0 & 58,7 & 0,88 & 5 & 5 & 20 & 15 & 5 & 25 \\
\hline 6 & 128 & 40,9 & 53,6 & 0,76 & 5 & 5 & 26 & 22 & 4 & 15 \\
\hline 7 & 152 & 38,3 & 50,4 & 0,76 & 6 & 6 & 21 & 18 & 3 & 14 \\
\hline 8 & 162 & 23,8 & 40,2 & 0,57 & 6 & 6 & 23 & 19 & 4 & 17 \\
\hline 9 & 165 & 26,4 & 38,3 & 0,69 & 7 & 6 & 26 & 24 & 2 & 8 \\
\hline 10 & 181 & 23,2 & 34,5 & 0,67 & 7 & 7 & 28 & 24 & 4 & 14 \\
\hline 11 & 180 & 23,6 & 34,5 & 0,68 & 7 & 7 & 28 & 24 & 4 & 14 \\
\hline 12 & 188 & 20,0 & 33,0 & 0,60 & 7 & 8 & 27 & 25 & 3 & 11 \\
\hline
\end{tabular}

horizon $331 \mathrm{~m}$

\begin{tabular}{l|l|l|l|l|l|l|l|l|l|l}
\hline 1 & 50 & 127,9 & 130,5 & 0,98 & 1 & 1 & 25 & 25 & 0 & 0 \\
2 & 65 & 106,6 & 107,8 & 0,99 & 2 & 1 & 27 & 31 & 4 & 15 \\
3 & 158 & 30,6 & 40,2 & 0,76 & 6 & 6 & 20 & 22 & 2 & 10 \\
4 & 169 & 24,0 & 38,2 & 0,63 & 6 & 9 & 24 & 17 & 7 & 29 \\
5 & 180 & 23,5 & 34,0 & 0,69 & 6 & 7 & 25 & 22 & 3 & 12 \\
6 & 305 & 8,9 & 13,2 & 0,67 & 9 & 8 & 31 & 34 & 3 & 10 \\
7 & 312 & 8,0 & 13,0 & 0,62 & 9 & 9 & 30 & 31 & 1 & 3 \\
8 & 320 & 7,2 & 11,9 & 0,61 & 9 & 9 & 32 & 32 & 0 & 0 \\
9 & 540 & 1,4 & 2,8 & 0,50 & 13 & 13 & 36 & 38 & 2 & 5 \\
10 & 550 & 1,2 & 2,7 & 0,44 & 13 & 14 & 39 & 36 & 3 & 8 \\
11 & 685 & 0,6 & 1,2 & 0,50 & 15 & 13 & 43 & 49 & 6 & 14 \\
12 & 703 & 0,4 & 1,0 & 0,40 & 15 & 16 & 44 & 42 & 2 & 4 \\
13 & 705 & 0,4 & 1,0 & 0,40 & 15 & 16 & 44 & 42 & 2 \\
\hline
\end{tabular}

Fig. 2 shows a graph of the dependence of the amplitude index of fracturing on the number of cracks in the path of the wave, based on 
the results of measurements on both horizons. This dependence is approximated by the following equation

$$
\frac{A_{i}}{A_{M}}=\frac{1}{1+Q N}=\frac{1}{1+0,08 N} .
$$

It is noteworthy that the values of the ratios of the amplitude indices of fracturing $-A_{i} / A_{M}$, obtained at sites with different sizes of "natural separations and at different distances from the explosion point are described by one equation. This confirms the conclusions made as a result of laboratory experiments about the fundamental possibility of assessing the structural state of the array by the ratio $A_{i} / A_{M}$.

In general, the dependence $\left(A_{i} / A_{M}\right)=f(a, N)$ can be represented by a family of curves of the form $1 /(1+a N)$ with different coefficient values $a$, which indirectly characterizes the qualitative characteristics of cracks - their width and type of filler. The greater the width of the cracks and the difference in wave resistances when passing through the cracks and "separately", the greater the value $a$ and steeper than a parabola.

Based on formula (2), using the values of the amplitudes $\mathrm{Ai}$ measured at a certain distance $r$ from the explosion point, it is possible to calculate the number of cracks at this distance and then calculate the average size of the "natural" separation.

Table 2

Categories of fracturing and explosivity of pyroxenites depending on the average diameter of the individual and the specific consumption of Explosives

\begin{tabular}{|c|c|c|c|c|c|}
\hline \multicolumn{2}{|c|}{ Category } & \multicolumn{2}{|c|}{$\begin{array}{c}\text { Average diameter of } \\
\text { the individual, } m\end{array}$} & \multirow{2}{*}{$\begin{array}{c}\text { Compressive } \\
\text { strength of rock, } \\
\mathrm{MPa}\end{array}$} & \multirow{2}{*}{$\begin{array}{c}\text { Specific consump- } \\
\text { tion of Explosives, } \\
\mathrm{kg} / \mathrm{m} 3\end{array}$} \\
\hline fractures & Explosivity & $\begin{array}{l}\text { in the } \\
\text { array }\end{array}$ & $\begin{array}{c}\text { in the } \\
\text { mountain } \\
\text { mass }\end{array}$ & & \\
\hline I-II & $\begin{array}{l}\text { easily } \\
\text { exploding }\end{array}$ & $\leq 0,5$ & $0,15-0,20$ & $30-60$ & $0,5-0,7$ \\
\hline III & $\begin{array}{l}\text { average } \\
\text { explosive }\end{array}$ & $\begin{array}{c}0,5- \\
1,0 \\
\end{array}$ & $0,20-0,25$ & $50-100$ & $0,7-1,0$ \\
\hline IV & $\begin{array}{l}\text { hard - to - } \\
\text { explode }\end{array}$ & $\begin{array}{l}1,0- \\
1,5\end{array}$ & $0,25-0,35$ & $90-150$ & $1,0-1,4$ \\
\hline V & $\begin{array}{l}\text { very difficult } \\
\text { to explode }\end{array}$ & $\geq 1,5$ & $\geq 0,35$ & $150-210$ & $1,4-1,8$ \\
\hline
\end{tabular}

In Table 2, a comparison of the rocks measured by outcrops and calculated according to the dependence (2) of the sizes of "natural" separations in the massif is carried out. The magnitude of the devia- 
tions of the calculated dimensions in absolute units varies within 3-5 $\mathrm{cm}$ or in percentage terms $-12-15 \%$. This indicates the sufficient reliability of the proposed fracture assessment methodology [22].

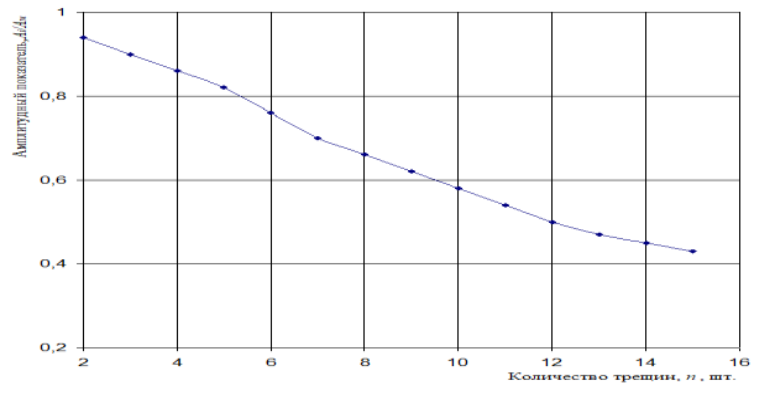

Fig. 2. Dependence of the amplitude index of fracturing $\left(A_{i} / A_{m}\right)$ on the number of cracks $(n)$

Thus, the determination of the fracturing intensity of the rock mass using amplitude indicators should be performed in the following sequence.

1. The absorption coefficient of the energy of the passing wave in the monolith ("natural" separations) is determined. To do this, explosions of charges of the same weight are produced, isolated in an array of natural separations of different lengths with fixation of the amplitudes of voltage waves at different measurement bases.

2. In a section with a known degree of fracturing of the array, measurements are made of the actual amplitudes of elastic waves excited by charges of the same weight. According to these data, the value of the coefficient a is calculated, which characterizes the crack parameters.

3. The average size of natural separations in any other part of the array is calculated from the measured value of the amplitudes Ai using the obtained ratio (2).

So, the proposed fracturing assessment technique has been tested in underground conditions and has shown sufficient reliability in determining the fracturing intensity of a rock mass. The advantage of this technique is that with the help of amplitude indicators, it is possible to determine the average size of the "natural" individual composing the array, which is extremely important to know for calculating the parameters of drilling and blasting operations in fractured rocks. 
As a result of the study of the fracturing of the deposit, it was found that the most disturbed cracks are the ore arrays of sections "1" and "2". The maximum dimensions of the ribs of the structural units in them are approximately the same and equal to $600 \mathrm{~mm}$, however, the nature of the cracks and the material of their filling are different. The site " 1 " of the deposit is characterized by a large crack opening. The ores of site "2" are brittle, the cracks are mostly closed and "healed". The section " 3 " is the least disturbed by cracks, it is characterized by the presence of a large number of quartered rocks. The maximum size of the natural part in it is $1000 \mathrm{~mm}$.

\subsection{Determination of the parameters of destruction of the structural block array on the contour of the mining}

The destruction of the structural block array on the contour of the mining takes place when the stress concentration leads to an excess of the strength of the rock. The parameters of the destruction zone are related to natural factors (the natural stress field, the properties of rocks in the array) and technological (the cross section of the workings, the layout of the holes, the flow rate of explosives and the mode of exploding charges, etc.).

The structure of the rock mass has a great influence on the efficiency of drilling and blasting operations during the excavation and during the treatment of ore. The strength of a rock in a monolithic sample and in an array broken by cracks may differ by orders of magnitude.

When the hole is located in close proximity to the plane weakening the crack array, most of the explosion energy is dissipated in the pore space of the latter. This significantly reduces the effectiveness of the explosion, increases the output of the oversized, and also leads to the destruction of the contour zone if the crack extends beyond the production contour.

All of the above points to the importance of knowing the structure of the massif in the vicinity of mining workings when drafting BVR projects. The degree of influence of cracks in some cases is taken into account by lowering the structural strength of the rock, and in others - through adhesion and the angle of internal friction, which are indicators of mechanical coupling between individual blocks of rock in a state of extreme equilibrium. Naturally, depending on the ac- 
cepted estimated strength characteristics, the structure of the proposed calculation formulas also changes and, in many cases, they differ significantly from each other. Therefore, it would be extremely imprudent to take as a basis any recommendation without preliminary verification for a specific deposit. Taking this into account, we studied the issues of determining the degree of influence of cracks on the strength of rocks in the roof of the mine in relation to the Yubileynoye deposit.

Below is a description of studies of the effect of cracks oriented parallel and normal to the direction of action.

Samples with a normal layering arrangement to the direction of the destructive load also consisted of three layers. The nature of the destruction of the extreme layers is the same as that of monolithic samples and the shear surfaces extend to the boundaries of the middle layer. At the boundary with the middle layer, the destruction occurs with a shift along the surface of the cracks. After that, the middle layer begins to collapse with the formation of shear surfaces similar to Luders sliding surfaces under shear deformations in brittle metals [6].

The effect of horizontal layering on the compressive strength of samples is less pronounced. For example, the strength of tested samples with one horizontal crack almost exactly coincides with the strength of a monolithic sample. And the strength of the sample with two horizontal cracks turned out to be less than the strength of the monolithic sample by only $3 \%$.

In the dissertation of E.S. Radenko [7], a dependence is given for determining the fracturing coefficient of $C_{t}$, taking into account the weakening of a massive ore column with a height of hc due to the presence of $V_{b l}$ volume separations formed by the intersection of three main systems of cracks in it

$$
K_{m}=\left(\frac{h_{u}}{\sqrt[3]{V_{\text {бл }}}}\right)^{-0,6},
$$

The presence of weak interlayers in the body of the whole is recommended to be taken into account by the coefficient of heterogeneity $K_{n}$, determined by the dependence 


$$
K_{H}=1-\sqrt{\frac{h_{c l}}{h_{0}}} \cdot(1-\eta),
$$

where $h_{c л}$ - the power of the weak interlayer in the body of the whole, m;

$h_{0}$ - total height of the whole, m;

$\eta$ - the ratio of the cubic strengths of the interlayer rock and ore.

In the monograph by V.I. Borsch-Companietz [8], the dependence of the influence of the fracture intensity $(H / h)$ on the value of the structural attenuation coefficient (the ratio of rock adhesion in the $K_{m}$ array to adhesion in the $K_{k}$ piece) is presented. This curve is approximated by an analytical dependence of the form

$$
K_{M}=K_{\kappa}\left(\frac{H}{h}\right)^{-0,6},
$$

where $H$ - the characteristic size of the considered area of the array, m;

$h$ - the average size of individual rocks in this zone, $\mathrm{m}$.

For surfaces that do not coincide with the attenuation surfaces, according to the results of field tests of samples with normally secant layering by G.L. Fisenko [9], the dependence between the adhesion of rock in a piece and an array was established

$$
K_{\mu}=\frac{K_{\kappa}}{1+a \cdot \ln \frac{L}{l}},
$$

where $K_{\kappa}$ - coupling in a piece of rock, $\mathrm{Pa}$;

$a$ - coefficient depending on the strength of the rock in the piece and the nature of fracturing;

$L$ - the length of the considered section of the array, m;

$l$ - the size of the rock block in the array, $\mathrm{m}$.

If we use an expression that is defined by the Mora stress circle,

$$
K=\frac{\sigma_{\kappa}}{2} \operatorname{tg}\left(\frac{\pi}{4}-\frac{\rho}{2}\right),
$$

then you can imagine this dependence in the form of

$$
K_{\mu}=\frac{\sigma_{\kappa}}{2} K \operatorname{ctg} \theta
$$


For an array weakened by slanting cracks, the following relation is given

$$
K_{\mu}=K^{\prime}+\frac{K_{\kappa}-K^{\prime}}{1+a \cdot \ln \left(\frac{L}{l}\right)}
$$

where $K^{\prime}$ - coupling between individual blocks in the array, Pa;

$L$ - the length of the considered section of the array, m;

$l$ - the size of the rock block in the array, $\mathrm{m}$.

Considering the features of the physico-mechanical properties and structure of the ores of the Talnakh deposit (Russia), D.M. Bronnikov, N.F. Zamesov and G.I. Bogdanov [21] note that in genetically and mineralogically homogeneous ores, strength is closely related to the size of the natural separation. Thus, with the size of the natural separation in the range of 200-300 mm, the strength limit of the ore for uniaxial compression is in the range of $80-160 \mathrm{MPa}$ (average $110 \mathrm{MPa}$ ), with a decrease in the size of the separations to $100-200 \mathrm{~mm}$, the observed strength of the ore decreased to 50-130 MPa (average $80 \mathrm{MPa}$ ) and, finally, in ore with a size of 50-100 $\mathrm{mm}$ separations, the strength of the ore reached the level of 15-65 MPa (average $35 \mathrm{MPa}$ ).

I.V. Baklashov and K.V. Ruppeneit [10] proposed a dependence for determining the stress concentration on the production circuit due to its technogenic roughness

$$
K_{\sigma}=1+\frac{h_{g n}\left(n_{s n}-1\right)}{2 R} / 1-\frac{h_{g n}\left(n_{s n}-1\right)}{2 R},
$$

where $h_{\mathrm{Bп}}$ - depth of depressions on the contour of the mining, $\mathrm{m}$;

$R$ - the radius of the zero contour dividing the areas of depressions and protrusions equally, $\mathrm{m}$;

$n_{\text {вп }}$ - the number of depressions on the zero production circuit, pcs.

Measurements made by VNMI employees at the mines of Gornaya Shoria (Russia) showed that the stress concentration in the roof depressions reaches $5.5 y H$, which is why even in strong rocks dynamic forms of mountain pressure are observed. Calculations show that the use of smooth blasting reduces stresses on the contour of production about 1.7-1.8 times.

Y.M. Kartashov, V.B. Matveev, G.V. Mikheev and A.B. Fadeev [11], considering the uniaxial compression of the layered structure along the strata, came to the conclusion that the resistance of the 
structure is determined by the longitudinal stability of the layers when the ratio $h / b>16$, and at a lower relationship strength does not depend on $h / b$ and equal to the strength of the monolith.

However, in fact, the stability of the layers depends on this ratio even at $h / b<16$, due to the inevitable non-parallelism of the layers, uneven load distribution between the layers, and, most importantly, due to the eccentricity of the load application on each layer.

If there is a connectedness between the layers of the structure characterized by tensile strength $\sigma \mathrm{p}$, then a compression stress equal to

$$
\sigma_{c} \geq \sigma \geq \sigma_{c} \frac{\sigma_{p}^{\prime}}{\sigma_{p}},
$$

where $\sigma_{\mathrm{c}}$ и $\sigma_{\mathrm{p}}$ - compressive and tensile strength of the rock, $\mathrm{MPa}$.

Consider the resistance to uniaxial compression of a structural medium such as brickwork. If there is no adhesion along the cracks, then a load 2 times less will be required to break the sample along the vertical plane than for the formation of such a gap in a monolithic sample, since there is already a gap in the form of initial cracks at half the distance [11].

After the formation of a series of longitudinal breaks, the frequency of which will be determined by the size of the structural block b, the columns may immediately lose stability and collapse if their height significantly exceeds the thickness. If the columns are wide enough, that is, with a small $\mathrm{b} / \mathrm{h}$ ratio, they can resist stress growth up to the strength level of a monolithic sample.

D.M. Kim conducted a series of experiments in the laboratory to assess the strength of prefabricated prisms of a similar structure. He found that for the compressive strength of the material of cubesblocks of $8 \mathrm{MPa}$, as $h / b$ increases, the strength of the prefabricated structure decreases to the level of $40 \%$ of the strength of the monolith, and after reaching $b / h=14$ or more remains constant [12].

Analysis of the stability of fractured structures allows us to establish the reason for the dependence of strength on the ratio of the size of the loaded zone and the elementary structural block - one of the forms of manifestation of the large-scale effect.

The amount of compressive strength is significantly affected by the orientation of the attenuation surface in the array with respect to 
the direction of action of the compressive load. The greatest decrease in strength occurs when the secant cracks are located at an angle $\alpha=\frac{\pi}{2}-\frac{\rho}{2}$ in the direction of the compressive load. The compression resistance of the structure along the layers, taking into account the orientation of the slanting cracks, can be determined analytically for each layer separately according to the following formula

$$
\sigma_{M}=\frac{K_{M} \cos \rho_{M}}{\cos \rho \sin \left(\beta-\rho^{1}\right)}
$$

where $K_{M}, \rho_{M}$ - accordingly, the adhesion and the angle of internal friction in the monolithic rock, $\mathrm{Pa}$ and degrees;

$\beta$ - the angle between the normal to the layering and the crack trace;

$\rho^{\prime}$ - the angle of friction on the crack surface, degrees;

At the angle $\beta \leq \rho_{M}$, and also close to $\rho_{M}$, the compressive resistance of the rock in the massif becomes equal to the compressive strength of high monolithic samples.

The natural massif is always divided into cracks, which cause a sharp decrease in the connections between natural separations. Since a single sample cannot characterize the state of the rock mass as a whole, it is desirable to determine the strength of rocks in natural conditions, directly in the places of their occurrence, for an adequate assessment of the strength of the array.

The main strength characteristics of a fractured rock mass are: compression resistance, adhesion and the angle of internal friction.

The magnitude of the internal friction angle $p$ depends on the roughness of the shear surfaces of the rock and is usually determined by the granulometric composition of the rock composing individuals.

The larger the size of the separations and the smaller the cementing substance per unit volume, the more pronounced the roughness of the sliding surfaces, hence the higher the coefficient of internal friction $\operatorname{tg} \rho$.

In the monograph [11], the authors give the following analytical expression for determining the resistance limit for a layered fractured medium 


$$
\sigma_{1}=\min \left\{\begin{array}{c}
2 C t g\left(\frac{\pi}{4}+\frac{\varphi}{2}\right)+\sigma_{3} \operatorname{tg}^{2}\left(\frac{\pi}{4}+\frac{\varphi}{2}\right) ; \\
\frac{C^{\prime} \cos \varphi^{\prime}+\sigma_{3} \cdot \sin \alpha \cdot \cos \left(\alpha-\varphi^{\prime}\right)}{\cos \alpha \cdot \sin \left(\alpha-\varphi^{\prime}\right)},
\end{array}\right.
$$

where $C$ и $\varphi$ - coupling and internal friction angle for a monolithic rock sample, $\mathrm{Pa}$ and degrees;

$C^{\prime}$ и $\varphi^{\prime}$ - coupling and the angle of internal friction on the contacts of layering, $\mathrm{Pa}$ and degrees.

If the medium has not one, but several directions of fracturing (structural blockiness), then the previous condition is somewhat modified

$$
\sigma_{1}=\min \left\{\begin{array}{c}
2 C \cdot \operatorname{tg}\left(\frac{\pi}{4}+\frac{\varphi}{2}\right)+\sigma_{3} \operatorname{tg}^{2}\left(\frac{\pi}{4}+\frac{\varphi}{2}\right) ; \\
\frac{C_{i}^{\prime} \cos \varphi_{i}^{\prime}+\sigma_{3} \cdot \sin \alpha_{i} \cdot \cos \left(\alpha_{i}-\varphi_{i}^{\prime}\right)}{\cos \alpha_{i} \cdot \sin \left(\alpha_{i}-\varphi_{i}^{\prime}\right)}, i=1,2,3
\end{array}\right.
$$

I.A. Turchaninov et al. the authors in the monograph [14] note that the influence of dynamic loads from blasting operations in a wide range of mining and geological conditions is almost the same and leads to additional weakening of rocks around the mine at a distance of $20-40 \mathrm{~cm}$ from the contour. Due to the block structure of rock arrays, their resistance to tensile stresses is very small, so that in engineering calculations, the tensile strength of rocks in the array can be assumed to be zero. In such cases, the area of rock destruction around the mine will coincide with the area of tangential stresses. At the same time, it is convenient to characterize the strength of rocks by the values of adhesion $\tau_{0}$ and the angle of internal friction $\varphi$. The form of destruction in this case is the relative displacement (shift) of individual parts of the rock.

The area of tensile stresses in the roof of the workings with a rectangular cross-sectional shape is limited by a vaulted curve.

When only compressive stresses are applied in the massif around the production, rock destruction may occur by crushing structural blocks at high stresses or by chipping along the surface of natural cracks, that is, destruction only in the area of contacts between structural blocks. 
According to the theory of limiting equilibrium, the condition of non-destruction over the shear surface is determined by the inequality, $\mathrm{Pa}$

$$
\tau_{x, y}<\tau_{0}+\sigma_{n} \cdot \operatorname{tg} \varphi
$$

where $\tau_{x, y}$ - effective tangential stress, Pa;

$\sigma_{n}$ - the normal component of the compressive stress acting on the slip pad, Pa.

In turn, the normal and tangential components on the sliding surface are determined by the dependencies

$$
\left.\begin{array}{rl}
\tau_{x y} & =\frac{\sigma_{y}}{2} \sin 2 \alpha ; \\
\sigma_{n} & =\sigma_{y} \cdot \cos ^{2} \alpha+\sigma_{x} \sin ^{2} \alpha,
\end{array}\right\}
$$

where $\sigma_{y}$. и $\sigma_{x}$. - accordingly, the maximum and minimum main voltages, $\mathrm{Pa}$;

$\alpha$ - the angle of inclination of the sliding surface to the line of action of the minimum main voltage $\sigma_{x}$.

Taking into account the dependencies (16), the limit equilibrium condition takes the following form

$$
\frac{\sigma_{y}-\sigma_{x}}{2} \cdot \sin 2 \alpha<\tau_{0}+\left(\sigma_{y} \cdot \cos ^{2} \alpha+\sigma_{x} \cdot \sin ^{2} \alpha\right) \cdot \operatorname{tg} \varphi
$$

or after converting the expression in parentheses

$$
\frac{\sigma_{y}-\sigma_{x}}{2} \cdot \cos 2 \alpha(\operatorname{tg} 2 \alpha-\operatorname{tg} \varphi)<\tau_{0}+\frac{\sigma_{y}+\sigma_{x}}{2} \cdot \operatorname{tg} \varphi \text {. }
$$

The collapse of the structural separation on the contour of the mining is possible only in the case of simultaneous implementation of the cleavage on the surfaces of the I, II, III crack systems, while on the upper horizontal face of the separation, the block must be detached from the overlying part of the array. Of course, this is the case when the size of the individual is significantly smaller than the span of the mining.

In [14] it is noted that for the condition of non-destruction of sections of the rock mass weakened by differently oriented cracks, the provision of three inequalities is necessary 


$$
\left.\begin{array}{l}
\frac{\sigma_{y}-\sigma_{x}}{2} \cdot \cos 2 \alpha\left(\operatorname{tg} 2 \alpha-\operatorname{tg} \varphi_{m p}\right)<\tau_{m p}+\frac{\sigma_{y}+\sigma_{x}}{2} \cdot \operatorname{tg} \varphi_{m p} \\
\frac{\sigma_{z}-\sigma_{x}}{2} \cdot \cos 2 \alpha\left(\operatorname{tg} 2 \alpha-\operatorname{tg} \varphi_{m p}\right)<\tau_{m p}+\frac{\sigma_{z}+\sigma_{x}}{2} \cdot \operatorname{tg} \varphi_{m p} \\
\frac{\sigma_{y}-\sigma_{z}}{2} \cdot \cos 2 \alpha\left(\operatorname{tg} 2 \alpha-\operatorname{tg} \varphi_{m p}\right)<\tau_{m p}+\frac{\sigma_{y}+\sigma_{z}}{2} \cdot \operatorname{tg} \varphi_{m p}
\end{array}\right\}
$$

where $\tau_{m p}$ и $\varphi_{m p}$ - adhesion and the angle of internal friction on the surfaces of natural cracks, $\mathrm{Pa}$ and degrees.

The conditions for the implementation of chipping on the surfaces of natural cracks allow us to estimate the size of the zone of possible falls from the walls and roof of the workings.

I.A. Turchaninov offers a dependence for determining the stability of structural blocks to fall into the workings

$$
\frac{\gamma}{2 f_{\mathrm{o}} P}>\frac{1}{a}+\frac{1}{b},
$$

where $a$ and $b$ - transverse dimensions (in plan) structural blocks, m;

$P$ - strut of structural blocks, MPa;

$f_{0}$ - coefficient of friction on the surfaces of cracks of separations;

$\gamma$ - volume weight of the rock, $\mathrm{MN} / \mathrm{m} 3$.

V.M. Mostkov [16] recommends determining the depth of the zone of disturbed rocks around the mine by the formula, $\mathrm{M}$

$$
h_{H}=K \cdot{ }_{0},
$$

where $B_{0}$ - production span, m;

$K$ - a dimensionless coefficient, depending on the strength of the rocks, for $f=10$ and higher, $K=0,05-1$.

The angle of internal friction and adhesion of the rock is established by testing rock samples for a cut and drawing up a strength passport. Research by Y.M. Kartashev et al. the authors found that the values of the angle of internal friction determined on the surface between the banks of the crack and in a monolithic piece are values of the same order. If the crack surfaces are sanded or filled with abrasion products, the value of the internal friction angle is reduced by $5-10 \%$ [11].

The calculation of the parameters of drilling and blasting operations during the sinking of underground workings requires taking into account all mining-geological and mining-technical characteristics of the rock mass. In addition to the physical and mechanical 
properties and fracturing, it is necessary to take into account the directions of the main stresses in the array. It is possible to get an idea of the main stresses $\left(\sigma_{1}, \sigma_{2}\right)$ in the rock mass using the deformation ellipsoid [15].

The deformation ellipse can be constructed according to the data of the study of crack systems in the rock mass. In this case, the ellipse fits into the structural separateness formed by systems of cracks. In another way, the deformation ellipse can be obtained using the method of measuring residual stresses by drilling holes in a loaded array. According to this method, a round hole is drilled in the rock, the shape of which is deformed into ellipses under the influence of uneven stresses, as shown in Fig. 3.

The deformation ellipse makes it possible to determine the effective normal stress using Hooke's law

$$
\sigma=E \cdot \Delta d / d
$$

where $\Delta d / d$ - relative deformation;

$\Delta d=2 a-d$ ) - the magnitude of the absolute deformation of the hole;

$a$ - the large semi-axis of the ellipse formed as a result of the manifestation of residual stresses;

$d$ - bore diameter;

$E$ - the modulus of elasticity of the rock.

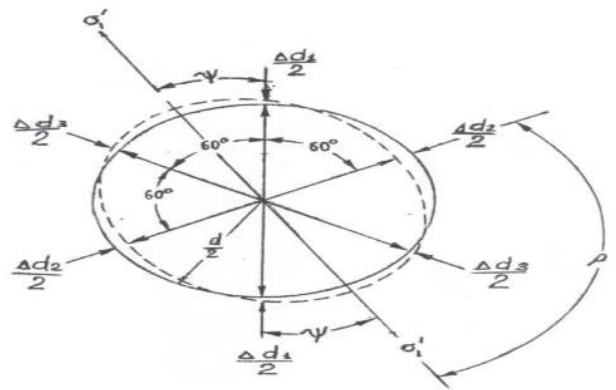

Fig. 3. Diagram of determining the direction and magnitude of the main compression stresses in the array by measuring the deformation of the cross-section of the borehole (hole)

The ellipse of the deformation obtained by distorting the hole of the initially round shape can serve as a "stress characteristic" of the rock mass. An ellipsoid (in the plane of an ellipse) is an image of the anisotropy of a triaxial space and finds application in many areas of 
mechanics, in particular, the construction of an ellipsoid of deformation of rocks is carried out by systems of cracks.

If the natural separateness of a rocky-fractured rock mass has a symmetrical shape (rectangle, rhombus), then the construction of cracks according to such systems is simplified, since the axes of these figures serve as ellipse diameters. In general, the construction of a deformation ellipse on the plane is reduced to its insertion into a parallelogram. The axes of this ellipse coincide in the direction of the main stresses.

In practice, a diameter measuring device is inserted into a round hole (borehole or borehole). To calculate the main stresses $\sigma_{1}, \sigma_{2}$ and the direction $\beta$ of the main voltage, the dependences should be used

$$
\begin{gathered}
\sigma_{1}\left(\sigma_{2}\right)=\frac{E}{6 d}\left[\left(\Delta d_{1}+\Delta d_{2}+\Delta d_{3}\right) \pm\right. \\
\left. \pm \sqrt{\frac{\left(\Delta d_{2}-\Delta d_{1}\right)^{2}+\left(\Delta d_{1}-\Delta d_{3}\right)^{2}+\left(\Delta d_{3}-\Delta d_{2}\right)^{2}}{2}}\right] \\
\beta=\frac{1}{2} \operatorname{arctg} \frac{3\left(\Delta d_{1}-\Delta d_{3}\right)}{2 \Delta d_{2}-\Delta d_{1}-\Delta d_{3}}
\end{gathered}
$$

If a parallelogram is described around the deformation ellipse, then we get an oriented model of natural separation, the sides of which are the dominant systems of cracks. The axes of the deformation ellipse indicate the directions of maximum and minimum deformations in the rock mass. In this case, the angle $\psi$ - deviation of the sides of the parallelogram from the diameters of the ellipse can vary from 0 to $45^{\circ}-p / 2$ and is determined by the dependence

$$
\cos \psi=b_{1} / b \cos 45^{\circ}(\cos \rho / 2-\sin \rho / 2),
$$

where $b_{1}$ - the short side of the parallelogram;

$b$ - the minor semimajor axis of the ellipse.

In our case, the reverse side is solved, but the angle $\psi$ will have the same meaning.

From all of the above, it follows that the holes should be drilled, if possible at equal distances from the crack systems, but in no case on the cracks themselves.

The charges should be positioned normal to the crack systems. To do this, it is necessary to determine the orientation of the dominant 
systems of cracks in the face by surveying and processing its results by known methods or using the residual stress method to construct a parallelogram of structural separation.

When calculating explosive charges, in addition to the structural attenuation coefficient in the direction of the main stress, the coefficient $\sigma_{2} / \sigma_{1}$ can be used, while the destructive load on the rock increases, since the main stress in the rock mass is added to the explosion force.

\subsection{Dependence of the quality of the contouring of the mine workings on the design of the explosive charge}

Recently, when developing mineral deposits, special attention has been paid to efficient resource-saving technologies for ore extraction. One of the promising ways to ensure the efficiency of ore deposit development technology is to increase the stability of mine workings and reduce the level of dilution of the extracted ore, which are achieved by accurately reproducing the design position of the contour of preparatory and rifled workings in the process of their implementation and reducing the seizure of waste rock during treatment excavation.

Deviation from the design contour, accompanied in practice by an increase or decrease in the section of the mining, leads to a larger volume of rock for each meter of penetration, the so-called rock sorting, or to unproductive work on the subsequent reduction of the contour of the workings to the position required by the project with a decrease in the section of the workings with poor-quality rock mass, accompanied by a "shortage of rock".

The reason for the mismatch of the excavation contour with the design position is a number of factors, among which the most significant are:

the impossibility of locating the holes directly on the surface of the design contour of the development;

a limited number of contouring holes in the faces of preparatory and cleaning workings;

sawtooth shape of rock mass separation, both in the cross section of the contour and along the length of the excavation;

the structural destruction of the rock due to the dynamic impact of the explosion of charges of considerable power; 
collapses in the roof of workings caused by the manifestation of increased mountain pressure.

Ensuring high-quality delineation of the design position of the mining is one of the serious tasks of drilling and blasting operations during the conduct of the cleaning excavation. Failure to comply with this condition leads, in some cases, to overburden of rock in excess of the design section, entailing dilution of the extracted ore, in others - to a shortage of the beaten ore, causing its loss in the bowels. Well-known methods of reducing the busting or shortage of the design contour surface (the use of small diameter boreholes, switching to another type of Explosive, etc.) do not give significant results, since the optimal ratio of the parameters of the borehole with the properties of the rock mass is not taken into account.

To obtain rational parameters of contour detonation, experimental explosions were carried out in laboratory conditions, taking into account the characteristics of the Yubileynoye deposit and different charge designs.

It is known that carrying out experimental work in production conditions causes certain difficulties, since the sinking of workings and the removal of ore in the treatment faces are carried out according to projects and passports approved and agreed with the mining inspection. Changing the parameters of blasting operations in the interests of research violates production plans and programs, requires coordination with supervisory authorities, etc.

Laboratory studies were carried out on models made of equivalent materials in compliance with the similarity criteria. A mixture of rosin, sealing wax and lead concentrate was used as an equivalent material, Such a composition ensured the uniformity of the structure of the model, made it possible to select the necessary strength properties of the equivalent material.

A rattlesnake chloride mixture was used as an explosive. The shell of the cartridges was made in the form of tubes glued together from paper tracing paper. The initiation of charges was carried out using a constantan wire, which was inserted directly into the explosive cartridge. The connection of the electrical circuit for detonating the charges ensured their sequential detonation with a deceleration of $0.5-1 \mathrm{c}$.

Laboratory studies of explosive rebounding were carried out to study the impact on the quality of contouring of mining such technological factors as 
the distance between contouring holes, the line of least resistance, the value of the specific flow rate of explosives, the design of the hole charge. The obtained results of laboratory studies are shown in Table 3.

The data obtained in the experiment are given in terms of nature in terms of the scale factor $M=1: 30$. In all series of the experiment, the length of the holes was assumed to be $1.4 \mathrm{~m}$, the diameter of the hole was $45 \mathrm{~mm}$.

As can be seen from the table, with a solid charge design, a change in the specific consumption of explosives for breaking from 2.5 to $2.9 \mathrm{~kg} / \mathrm{m}^{3}$, that is, by $16 \%$, led to an increase in the sorting of rock behind the production contour by $33 \%$, at the same time, the distance of the discarded rock mass increased by $12 \%$.

Table 3

Experimental data on the evaluation of the search of the sculptural array and the amount of waste of the recaptured rock mass from the parameters of drilling and blasting operations

\begin{tabular}{|c|c|c|c|c|c|c|}
\hline $\begin{array}{l}\text { Working } \\
\text { section, } \\
\mathrm{m}^{2}\end{array}$ & Charge design & $\begin{array}{l}\text { Distance } \\
\text { between the } \\
\text { holes, } m\end{array}$ & $\begin{array}{c}\text { Number } \\
\text { of holes, } \\
\text { units. }\end{array}$ & $\begin{array}{l}\text { The size } \\
\text { of the } \\
\text { bust, } \mathrm{m}^{3}\end{array}$ & $\begin{array}{c}\text { Specific } \\
\text { consumption } \\
\text { of Explo- } \\
\text { sives, } \\
\mathrm{kg} / \mathrm{m}^{3} \\
\end{array}$ & $\begin{array}{l}\text { Discarded rock } \\
\text { mass, } \mathrm{m}\end{array}$ \\
\hline 14,0 & Solid & 0,49 & 8 & 0,300 & 2,50 & 8,90 \\
\hline 14,0 & $\ll$ & 0,52 & 8 & 0,315 & 2,60 & 9,00 \\
\hline 14,0 & $\lll$ & 0,54 & 8 & 0,325 & 2,65 & 9,10 \\
\hline 14,0 & $\ll$ & 0,56 & 8 & 0,340 & 2,70 & 9,20 \\
\hline 14,0 & $\ll$ & 0,57 & 8 & 0,349 & 2,75 & 9,35 \\
\hline 14,0 & $\ll$ & 0,58 & 8 & 0,359 & 2,80 & 9,50 \\
\hline 14,0 & $\ll$ & 0,60 & 8 & 0,400 & 2,90 & 10,00 \\
\hline 16,0 & Dispersed & 0,45 & 9 & 0,023 & 1,30 & 4,85 \\
\hline 16,0 & $\ll$ & 0,48 & 9 & 0,028 & 1,40 & 4,88 \\
\hline 16,0 & $\ll$ & 0,53 & 9 & 0,033 & 1,45 & 4,90 \\
\hline 16,0 & $\ll$ & 0,55 & 9 & 0,036 & 1,55 & 4,92 \\
\hline 16,0 & $\ll$ & 0,56 & 9 & 0,040 & 1,65 & 4,95 \\
\hline 16,0 & $\ll$ & 0,58 & 9 & 0,042 & 1,80 & 4,98 \\
\hline 16,0 & $\ll$ & 0,60 & 9 & 0,046 & 1,87 & 5,00 \\
\hline
\end{tabular}

With a dispersed charge design, an increase in the specific consumption of explosives for breaking from 1.3 to $1.87 \mathrm{~kg} / \mathrm{m} 3$, or by $43.8 \%$, led to a 2 -fold increase in the structural sorting of the rock, and the rejection of the rock mass beaten off by the explosion increased by only $3 \%$. However, it should be noted that by absolute value, the level of rock sorting with dispersed charges turned out to be an order of magnitude less than with solid charges. A slight increase in the waste of rock with an increase in the specific consumption of explosives for breaking with dispersed charges indicates that 
the energy of the explosion in this case is more spent on crushing the rock than with a solid charge design.

The experimental data were processed by methods of mathematical statistics, the second-order equation was used as the functional dependence of the nonlinear regression

$$
y=a+b x+x^{2}
$$

For a solid charge, the amount of rock sampling $\Delta h$ is approximated by the following expression, $\mathrm{M}^{3}$

$$
\Delta h=0,329 q_{B 8}^{2}-1,53415 q_{B 8}+2,07816,
$$

where the correlation coefficient between the parameters is $R=0,98$.

For dispersed charges, the regression equation of the dependence of the rock sorting on the specific consumption of Explosives takes the following form, $\mathrm{m}^{3}$

$$
\Delta h=-0,04247 q_{B 8}{ }^{2}+0,17314 q_{B 8}-0,13022,
$$

where the correlation coefficient between the parameters is $R=0,96$.

The value of the distance of the rock ejection by explosion, depending on the specific consumption of the Explosive substance during solid charges, is approximated by the following nonlinear equation of the second order, $\mathrm{M}$

$$
l_{\text {om } \delta}=6,19047 q_{B 8}{ }^{2}-30,73807 q_{B \varepsilon}+47,06425,
$$

where the correlation coefficient between the parameters was $R=0,96$.

The equation of the relationship between the value of the discarded rock mass and the specific consumption of Explosives with a dispersed charge design is expressed by the following dependence, $\mathrm{M}$

$$
l_{\text {om } \sigma}=-0,11514 q_{B \beta}{ }^{2}+0,61735 q_{B \beta}+4,24357,
$$

where the tightness of the relationship between the parameters is characterized by a correlation coefficient $R=0,98$.

The correlation coefficient between the dependent variables was calculated by Bravais-Pearson [68] using the following relation

$$
r_{x, y}=\sum_{i=1}^{n}\left(x_{i}-\bar{x}\right)\left(y_{i}-\bar{y}\right) / \sqrt{\sum_{i=1}^{n}\left(x_{i}-\bar{x}\right)\left(y_{i}-\bar{y}\right)},
$$

Graphs of the dependences of the change in the size of the bust (26) and (27) and the distance of the discarded rock mass from the 
bottom of the mine, depending on the specific consumption of explosives (28) and (29) are shown in Fig. 4 and 5.
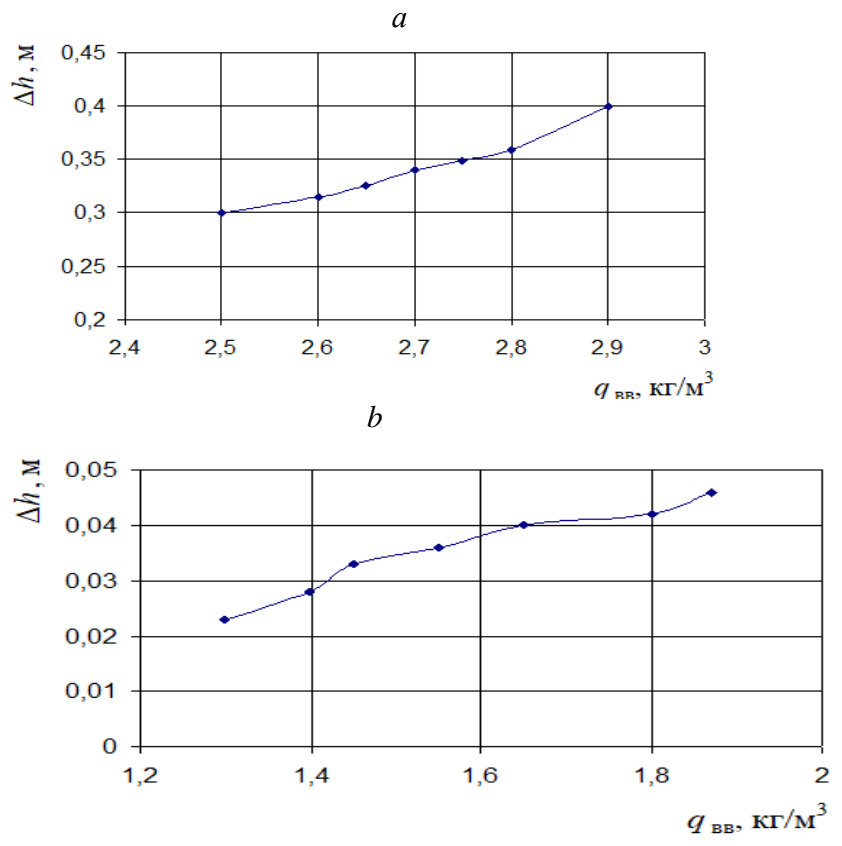

Fig. 4. Dependence of the change in the amount of rock sampling $(\Delta h)$ in the roof of the mine on the specific consumption of Explosive $(q v b): a$ - solid charge; $b$ - dispersed charge design

$a$

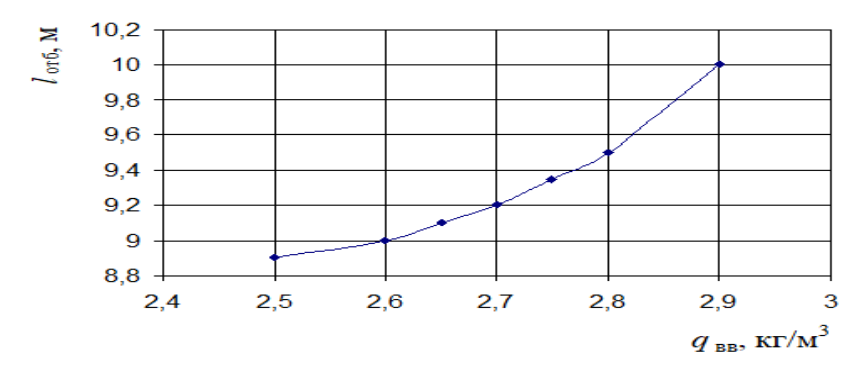




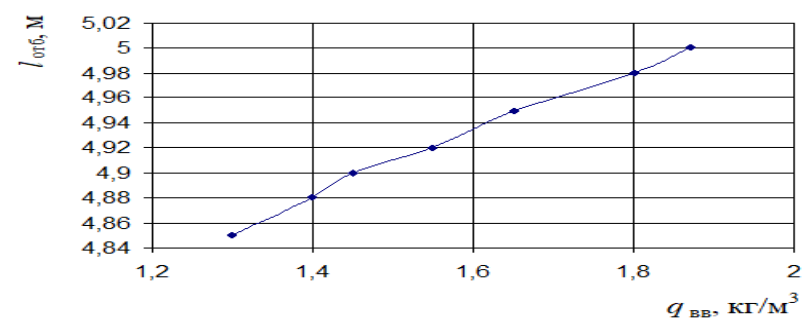

Fig. 5. The dependence of the value of the discarded rock masson the specific consumption of Explosives with different designs of the core charge: $a$ - solid charge; $b$ - dispersed charge design

\subsection{Investigation of the dependence of the utilization factor of the hole on the grid of the location of charges and the specific consumption of Explosives}

In the labor intensity of the extraction of strong ores, the specific weight of drilling and blasting operations is $26-37 \%$, including drilling operations $20-29 \%$. The share of drilling and blasting operations in the cost of ore in the general technological cycle of processes exceeds $60 \%$ [17].

Such a high importance of drilling operations in the technology of ore extraction determines the importance of maximizing such technical and economic indicators as the yield of ore from $1 \mathrm{~m}$ of the well and the utilization factor of the length of the hole.

When carrying out mining operations by drilling and blasting in underground mines, the losses of boreholes in the so-called "glasses" often exceed $20 \%$. At some mines, the utilization rate of boreholes is 0.5-0.6, which not only entails economic losses, but also increases the danger to miners, since with an increase in the depth of the abandoned glasses, the probability of accidents from the detonation of incompletely detonated charges sharply increases.

I.M. Murzikov et al. the authors [13] propose to provide an increase in efficiency through the use of powerful Explosives such as detonites, an increase in the specific consumption of Explosives from $0.6-0.7$ to $1-1.2 \mathrm{~kg} / \mathrm{m}^{3}$ and the number of holes in the kit. This recommendation is valid, except for the obviously underestimated values of the specific consumption of Explosives, most likely associated with the erroneous use of the given dimension. Table 4 shows the results of a study of the dependence of the utilization factor of the 
length of the hole on the number of holes in the set during mining operations at the Gaysky mine (Russia).

Table 4

Dependence of the utilization factor of the hole length on the number of holes

\begin{tabular}{c|c|c|c|c|c}
\hline \multicolumn{3}{c|}{ Basic technology } & \multicolumn{3}{c}{ Experimental technology } \\
\hline $\begin{array}{c}\text { Number of } \\
\text { holes }\end{array}$ & $\begin{array}{c}\text { the utili- } \\
\text { zation } \\
\text { factor of } \\
\text { the } \\
\text { length of } \\
\text { the hole }\end{array}$ & $\begin{array}{c}\text { Hole } \\
\text { losses, } \mathrm{m}\end{array}$ & $\begin{array}{c}\text { Number } \\
\text { of holes } \\
\text { zation } \\
\text { factor of } \\
\text { the } \\
\text { length of } \\
\text { the hole }\end{array}$ & $\begin{array}{c}\text { Hole } \\
\text { losses, } \mathrm{m}\end{array}$ \\
\hline 30 & 0,50 & 30 & 38 & 0,80 & 6,2 \\
30 & 0,50 & 31 & 40 & 0,99 & 9,8 \\
32 & 0,51 & 30 & 40 & 0,91 & 4,0 \\
32 & 0,52 & 30,7 & 42 & 0,96 & 6,6 \\
32 & 0,60 & 25,6 & 44 & 0,90 & 3,8 \\
35 & 0,55 & 31,5 & 44 & 0,86 & 2,6 \\
38 & 0,60 & 30,4 & 44 & 0,94 & 2,3 \\
38 & 0,60 & 30,4 & 44 & 0,90 & 6,9 \\
38 & 0,70 & 21,6 & 49 & 0,95 & 3,1 \\
\hline
\end{tabular}

* Note - the losses of boreholes in $\mathrm{m}$ are given for one set

From the above data, it can be seen that in the conditions of the Gaisky mine (the cross section of the output is $12-14 \mathrm{~m}^{2}$, the depth of the holes is $2 \mathrm{~m}$, the diameter of the holes is $42 \mathrm{~mm}$, the ore strength is 14-16), the optimal number of holes in the set is 40 , since a further increase in the drilling density of the holes is not accompanied by a corresponding increase in the utilization factor of the length of the hole.

A particularly noteworthy fact that requires stopping at it is that at the same mine, when working in quartz-ceritic rocks and tuffs with a strength of 6-15 on the M.M. Protodiakonov scale, the utilization factor of the hole length is $0.9-1$, and in the ore zone represented by copper pyrite, as well as in a hardening bookmark with a compressive strength of 3.5-5 $\mathrm{MPa}$, the kish decreases to 0.5-0.7.

To study the regularities of changes in the utilization coefficient of the length of the hole from the grid of the location of charges and the specific consumption of Explosives for breaking rock mass in laboratory conditions, a corresponding experiment was conducted. In the first series of experiments, layers were broken off on a model made of equivalent material with simultaneous changes in the lines of least resistance and the distance between the holes, as well as the 
specific consumption of Explosives. In the experiments, a uniform grid of holes $a=W$ was used. Modeling of the structural blockiness of the array was carried out by laying foil strips into the body of the model, creating an imitation of natural separateness with a size of $25 \times 25 \times 50 \mathrm{~cm}$. In the first series of experiments, the layer was broken off by rows of holes orthogonal to the leading crack system. The results of experimental explosions are shown in Table 5.

Table 5

Change in the utilization factor of the hole and the discarded rock mass from the distance between the holes and the specific consumption of Explosives

\begin{tabular}{c|c|c|c|c|c|c}
\hline № & $\begin{array}{c}\text { Diameter } \\
\text { hole, } d, \\
\mathrm{~m}\end{array}$ & $\begin{array}{c}\text { Hole } \\
\text { depth, } \\
h, \mathrm{~m}\end{array}$ & $\begin{array}{c}\text { Distance } \\
\text { between } \\
\text { holes, } a, \\
\mathrm{~m}\end{array}$ & $\begin{array}{c}\text { Specific } \\
\text { consumption } \\
\text { of Explo- } \\
\text { sives, } q, \\
\mathrm{~kg} / \mathrm{m}^{3}\end{array}$ & $\begin{array}{c}\text { Discarded } \\
\text { rock } \\
\text { mass, } L, \\
\mathrm{~m}\end{array}$ & $\begin{array}{c}\text { the utili- } \\
\text { zation } \\
\text { factor of } \\
\text { the length } \\
\text { of the } \\
\text { hole, } \eta\end{array}$ \\
\hline 1 & 0,038 & 1,4 & 0,20 & 2,6 & 12 & 0,78 \\
\hline 2 & 0,038 & 1,4 & 0,20 & 2,5 & 10 & 0,77 \\
\hline 3 & 0,038 & 1,4 & 0,23 & 2,6 & 11 & 0,75 \\
\hline 4 & 0,038 & 1,4 & 0,25 & 2,7 & 12 & 0,75 \\
\hline 5 & 0,038 & 1,4 & 0,25 & 2,8 & 12 & 0,74 \\
\hline 6 & 0,038 & 1,4 & 0,20 & 2,3 & 7 & 0,73 \\
\hline 7 & 0,038 & 1,4 & 0,23 & 2,4 & 8 & 0,75 \\
\hline 8 & 0,038 & 1,4 & 0,25 & 2,1 & 5 & 0,74 \\
\hline 9 & 0,038 & 1,4 & 0,25 & 2,2 & 6 & 0,73 \\
\hline 10 & 0,038 & 1,4 & 0,26 & 2,2 & 6 & 0,72 \\
\hline 11 & 0,038 & 1,4 & 0,30 & 2,3 & 5 & 0,73 \\
\hline
\end{tabular}

As can be seen from the table, reducing the distance between the holes leads to an increase in the utilization rate of the hole. For example, with a decrease in the distance between the holes from 0.26 to $0.20 \mathrm{~m}$, that is, by $30 \%$, the utilization factor of the length of the hole increases from 0.72 to 0.78 , or by $8.3 \%$. At the same time, there is an increase in the distance of the discarded rock mass by almost 2 times.

By processing the experimental data, the following empirical dependences were obtained: the coefficients of the use of boreholes on the distance between the boreholes and the specific consumption of Explosives

$$
\begin{aligned}
& \eta=2,4241 a^{2}-, 5516 \cdot a+0,9745 ; \\
& \eta=-9,2155 q^{2}{ }_{\mathrm{Bв}}+7,4642 \cdot q_{\mathrm{Bв}}+1,7559,
\end{aligned}
$$

where $\eta$ - he coefficient of use of the length of the hole in the explosion; 
$a$ - distance between the holes, $\mathrm{m}$;

$q_{\mathrm{Bв}}-$ the specific consumption of Explosives for breaking rock mass, $\mathrm{kg} / \mathrm{m}^{3}$.

Fig. 6,7 and 8 show graphs of the change in the utilization factor of the length of the hole from the distance between the holes and the specific consumption of Explosives.

In the second series of experiments (Table 6), explosions were carried out with the consumption of Explosives for breaking increased to $3.2 \mathrm{~kg} / \mathrm{m}^{3}$.

Table 6

Change in the coefficient of use of the length of the hole and the waste of rock mass during the explosion of ore layers with oblique stratification

\begin{tabular}{|c|c|c|c|c|c|c|}
\hline № & $\begin{array}{c}\text { Bore } \\
\text { diameter, } \\
d, \mathrm{~mm}\end{array}$ & $\begin{array}{l}\text { The } \\
\text { length of } \\
\text { the } \\
\text { holes, } 1 \text {, } \\
\text { m }\end{array}$ & $\begin{array}{c}\text { Distance } \\
\text { between } \\
\text { holes, a, m }\end{array}$ & $\begin{array}{c}\text { Specific con- } \\
\text { sumption Of } \\
\text { Explosives, } q \text {, } \\
\mathrm{kg} / \mathrm{m}^{3}\end{array}$ & $\begin{array}{c}\text { the } \\
\text { utiliza- } \\
\text { tion } \\
\text { factor of } \\
\text { the } \\
\text { length of } \\
\text { the hole }\end{array}$ & $\begin{array}{c}\text { Waste } \\
\text { of rock } \\
\text { mass, } \\
L, \mathrm{~m}\end{array}$ \\
\hline \multicolumn{7}{|c|}{ The slope of the face to the layering $\alpha=30^{\circ}$} \\
\hline 1 & 0,038 & 1,4 & 0,30 & 2,80 & 0,85 & 10 \\
\hline 2 & 0,038 & 1,4 & 0,20 & 2,60 & 0,90 & 12 \\
\hline 3 & 0,038 & 1,4 & 0,37 & 3,00 & 0,80 & 9 \\
\hline 4 & 0,038 & 1,4 & 0,31 & 2,85 & 0,85 & 7 \\
\hline 5 & 0,038 & 1,4 & 0,21 & 2,55 & 0,90 & 10 \\
\hline \multicolumn{7}{|c|}{ The slope of the face to the layering $\alpha=60^{\circ}$} \\
\hline 1 & 0,038 & 1,4 & 0,30 & 3,00 & 0,86 & 10 \\
\hline 2 & 0,038 & 1,4 & 0,27 & 2,80 & 0,90 & 12 \\
\hline 3 & 0,038 & 1,4 & 0,32 & 3,20 & 0,82 & 9 \\
\hline 4 & 0,038 & 1,4 & 0,35 & 3,10 & 0,85 & 8 \\
\hline 5 & 0,038 & 1,4 & 0,25 & 2,75 & 0,90 & 10 \\
\hline
\end{tabular}

A model of a structural-block medium with a secant position of the breaking line to the main crack system was used. In the first series of the experiment, the slope of the bump surface to the direction of the crack system was $30^{\circ}$, and in the second $-60^{\circ}$. 


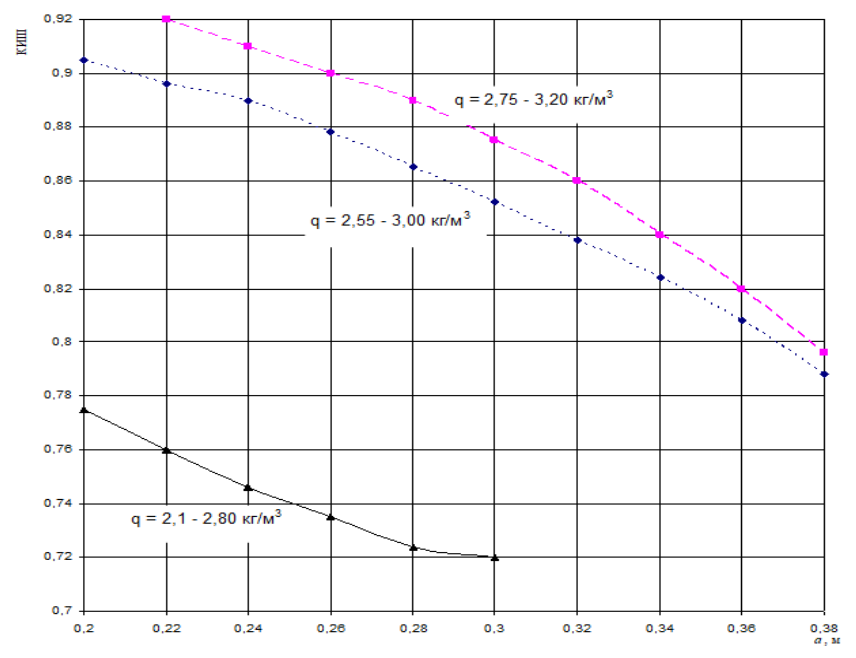

Fig. 6. Dependence of the utilization factor of the length of the hole (KISH) on the distance between the holes $(a)$

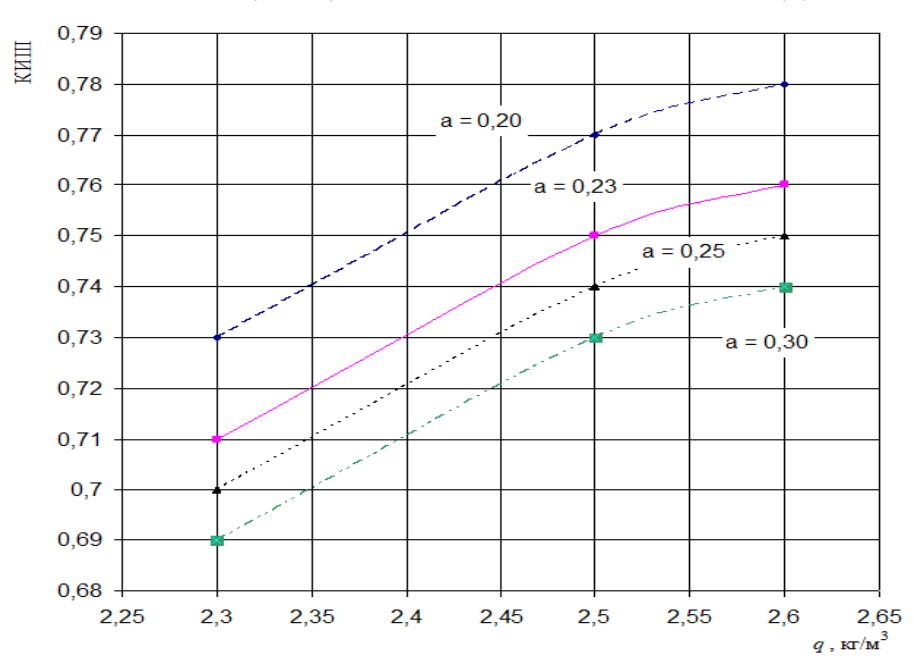

Fig.7. Dependence of the utilization factor of the length of the hole (KISH) on the specific consumption of explosives (q) at different distances between the holes 


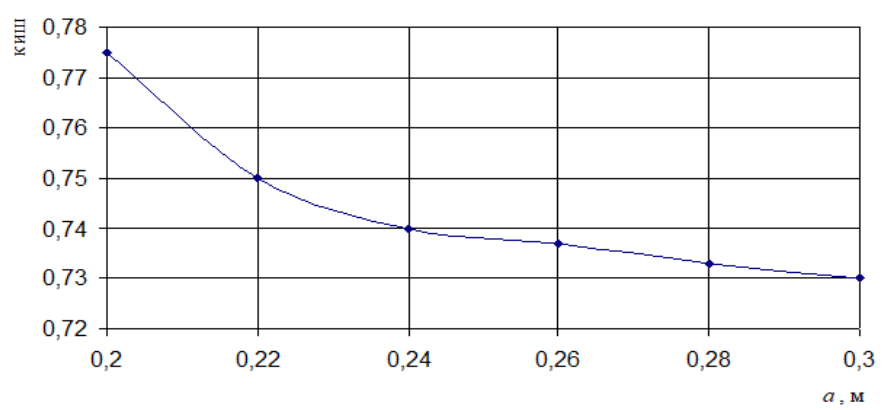

Fig.8. Dependence of the change in the utilization factor of the hole length on the distance between the holes when breaking rock mass in an array with normal fracturing to the face

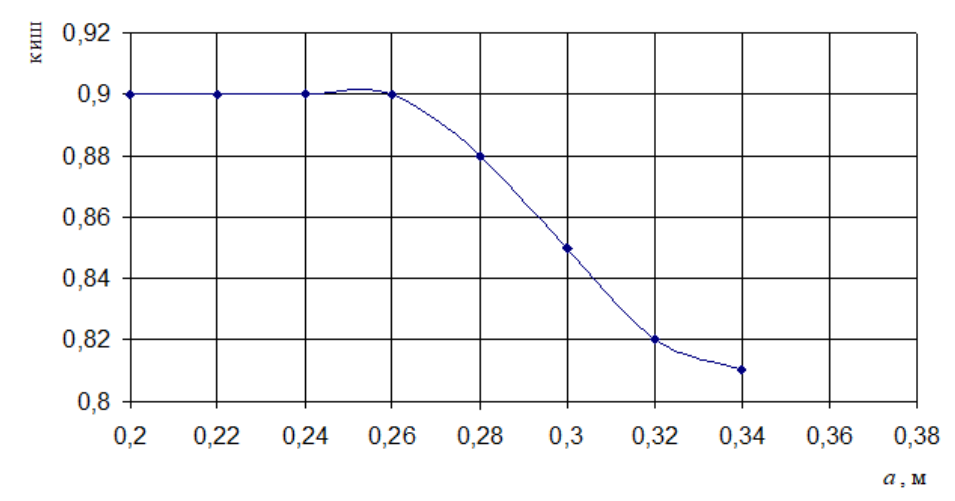

Fig. 9. Dependence of the change in the utilization factor of the hole length on the distance between the holes when breaking rock mass in an array with a slanting $\left(30^{\circ} \leq \alpha \leq 60^{\circ}\right)$ face fracturing

It is established that under these conditions the change of the distance between the holes from 0.20 to $0.27 \mathrm{~m}$ at the specific consumption of Explosives in the range of $2.55-2,80 \mathrm{~kg} / \mathrm{m}^{3}$ is stable level of utilization of the length of the hole in the explosion equal 0,90 (fig. 9).

Increase the distance between the holes to $0.30-0.37 \mathrm{~m}$, even when the corresponding increase in the specific consumption of Explosives to $3.0-3.2 \mathrm{~kg} / \mathrm{m}^{3}$ accompanied by a decrease of Kish, 0.80 is 0.86 . This result is explained by the fact that when the holes are extended by more than $0.30 \mathrm{~m}$, an uneven loading of the beaten array 
with explosion energy occurs and the interaction between adjacent explosive charges worsens.

\subsection{Investigation of the influence of drilling and blasting pa- rameters and fracturing of the massif on the lumpiness of the beaten ore}

In the work [18], a team of authors assesses the quality of ore crushing when wrapping on a clamping medium from collapsed rocks. The authors believe that with multi-row breaking with shortdelayed blasting, crushing is better than when breaking into an open space. With an increase in the number of beaten rows up to 5-7 or more, the crushing of ore worsens up to the camouflage drill holes. The displacement of the clamping material at the cleaning face reaches 2-3 $\mathrm{m}$, and the general compaction can be traced at a distance of up to 25-30 m.

A comparison of the quality indicators of explosive crushing of ore when breaking into an open space (chambers 1 and 3) and a clamping medium (chambers 5 and 7) produced in the same block showed that the specific consumption of explosives was 0.930 and $0.896 \mathrm{~kg} / \mathrm{t}$ in the first case, 0.778 and $0.837 \mathrm{~kg} / \mathrm{t}$ in the second case; the yield of oversized pieces, respectively, 8.5 and $9.8 \%$ and 4.4 and $6.8 \%$.

The ore bodies of the Yubileynoye deposit are characterized by a pronounced structural-block structure due to the fracturing of the meridional and north-eastern strike, as well as the presence of cleavage cracks. The ore strength reaches $12-15$ on the scale of M.M. Protodyakonov.

Due to such features of the structure of the ore bodies of the deposit, the impact of the diameter of wells, the grid of wells and the specific consumption of explosives on the rebound on the lumpiness of the beaten ore was determined in rocks of various fractures.

The ultimate goal of the research was to find the optimal parameters of drilling and blasting operations and develop recommendations for their calculation. The optimality criterion was the cost of $1 \mathrm{~m}^{3}$ of ore during extraction.

During the experimental-industrial explosions were recorded:

- consumption of explosives for rebounding and secondary crushing;

- output of oversized pieces and their dimensions; 
- the amount of beaten and unloaded ore;

- labor costs for drilling wells, their loading and blasting, release and loading of ore;

- CULH.

The volume of oversized ore after each explosion was determined by direct measurement of the pieces that did not pass through the screen. The degree of ore crushing during blasting was established by determining the yield of oversized pieces and distributing them by size classes. The productivity of the worker at the output was determined on the basis of time-lapse observations of the distribution of working time and the volume of ore released for each shift.

When planning research, it was important to reasonably determine the required number of experiments and evaluate the reliability of observations. In order to determine a sufficient number of experimental explosions and to establish the degree of variation of experimental data, pilot explosions were carried out, the measurement and calculation data for which are presented in Table 7.

The calculation of normalized indicators for the statistical evaluation of the output of the oversized during explosive ore stripping is given below.

The average value of the oversized output is

$$
\bar{\chi}=\frac{\sum \chi_{i}}{n}=\frac{62,9}{7}=8,98 \%
$$

where $\bar{\chi}$ - the arithmetic mean of the variation series, that is, the average value of the relative output of the oversized;

$\sum \chi_{\mathrm{i}}$ - the total value of the oversized output for all explosions;

$\sum \chi_{\mathrm{i}}=62,9$;

$n$ - number of explosions, $n=7$.

The standard deviation was determined by the formula

$$
\sigma=\sqrt{\frac{1}{n-1}\left[\sum \chi_{i}^{2}-\frac{\left(\sum \chi_{i}\right)^{2}}{n}\right]}=\sqrt{\frac{1}{6}\left[582,07-\frac{62,9^{2}}{7}\right]}=1,68
$$

Величина коэффициента вариации, выраженная в процентах от среднего значения исследуемого признака (выхода негабарита), вычисляется по формуле 


$$
K_{\text {sap }}=\frac{\sigma}{\chi} \cdot 100=\frac{1,68 \cdot 100}{8,98}=18,71 \% .
$$

The value of the coefficient of variation, expressed as a percentage of the average value of the studied feature (oversized output), is calculated by the formula

$$
K_{\text {sap }}=\frac{\sigma}{\chi} \cdot 100=\frac{1,68 \cdot 100}{8,98}=18,71 \% .
$$

The error of the arithmetic mean from its true value was

$$
\sigma_{\bar{\chi}}= \pm \frac{\sigma}{\sqrt{n}}= \pm \frac{1,68}{\sqrt{7}}= \pm 0,63
$$

The boundary of the confidence interval for the arithmetic mean with probability $p=0,9$ is determined by the dependence

$$
\Delta \chi= \pm \frac{\tau \sigma}{\sqrt{n}}= \pm \frac{1,9 \cdot 1,68}{\sqrt{7}}= \pm 1,21 .
$$

where $\tau$ - is the Student's coefficient for the number of observations equal to 7 (taken from the tables).

Thus, with a probability of 0.9 , it can be argued that the expected value of the oversized output is within $8.98 \pm 1.21 \%$, that is, it will not differ from the average value by more than $1.2 \%$.

The required number of experimental explosions for a given reliability and a calculated coefficient of variation equal to $18.71 \%$ will be

$$
n=t^{2} \cdot \frac{K_{\text {sap }}^{2}}{K_{\partial o n}^{2}}=1,65^{2} \cdot \frac{18,71^{2}}{15^{2}}=4,23 \approx 4 .
$$

where $K_{\partial o n}$ - the permissible error, the value of which for production and research work is usually assumed to be equal to $15 \%$;

$t$ - the normalized deviation with the specified reliability equal to 0.9 .

An analysis of the data in Table 7 shows that the data on the specific costs of explosives for secondary crushing have the greatest variation in the production of explosions. The required number of experiments to obtain reliable values for this feature is 9 , since the share of explosives costs during secondary burying in the total cost of mining 1 ton of ore is small, the minimum number of explosions to obtain reliable data, equal to 6 , was taken at the output of the oversized.

\begin{tabular}{l|l|l|l|l|l}
\hline$W=1,8$ & 2,0 & 2,2 & 2,3 & 2,4 & 2,5 \\
\hline
\end{tabular}




\begin{tabular}{l|c|c|c|c|c}
\hline$K=6,4$ & 8,0 & 8,4 & 9,3 & 9,5 & 11,8 \\
\hline$q_{1}=0,430$ & 0,422 & 0,478 & 0,478 & 0,420 & 0,478 \\
\hline$q_{2}=0,314$ & 0,324 & 0,505 & 0,446 & 0,515 & 0,548 \\
\hline$d_{c p}=72$ & 70 & 68 & 88 & 84 & 70 \\
\hline
\end{tabular}

With a change in the $1 \mathrm{lr}$ from 1.8 to $2.5 \mathrm{~m}$, there is a noticeable increase in the yield of oversized from 6.4 to $11.8 \%$, and, accordingly, an increase in the consumption of explosives for secondary crushing of oversized pieces of ore from 0.314 to $0.548 \mathrm{~kg} / \mathrm{m}^{3}$, there is a tendency to increase the average size of an oversized piece from 0.7 to $0.9 \mathrm{~m}$.

Fig. 10,11 shows graphs of empirical dependences of the change in the output of the oversized and the consumption of explosives for secondary crushing from the line of least resistance.

Table 7

Results of experimental explosions in panel 281

\begin{tabular}{|c|c|c|c|c|c|c|}
\hline \multirow[b]{2}{*}{$\begin{array}{c}\text { Explosion } \\
\text { numbers }\end{array}$} & \multicolumn{2}{|c|}{ Grid of wells } & \multirow[b]{2}{*}{$\begin{array}{c}\text { Oversize } \\
\text { d output } \\
\text { K, \% }\end{array}$} & \multirow[b]{2}{*}{$\begin{array}{l}\text { Specific } \\
\text { consump- } \\
\text { tion of } \\
\text { explosives } \\
\text { for primary } \\
\text { rebound, } \\
\mathrm{kg} / \mathrm{t}\end{array}$} & \multirow[b]{2}{*}{$\begin{array}{l}\text { Specific } \\
\text { consump- } \\
\text { tion of } \\
\text { explosives } \\
\text { for second- } \\
\text { ary crush- } \\
\text { ing, } \mathrm{kg} / \mathrm{M}^{3}\end{array}$} & \multirow{2}{*}{$\begin{array}{c}\text { The } \\
\text { average } \\
\text { diameter } \\
\text { of an } \\
\text { over- } \\
\text { sized } \\
\text { piece, } \\
\mathrm{cm}\end{array}$} \\
\hline & $\begin{array}{l}\text { the line of } \\
\text { least } \\
\text { re- } \\
\text { sistance, } \\
\text { (LLR) }\end{array}$ & $\begin{array}{c}\text { Distanc } \\
\mathrm{e} \\
\text { between } \\
\text { wells, } \mathrm{m}\end{array}$ & & & & \\
\hline I & 2,4 & 2,2 & 9,1 & 0,506 & 0,281 & 95 \\
\hline II & 1,8 & 1,8 & 6,4 & 0,430 & 0,314 & 72 \\
\hline III & 2,0 & 1,8 & 8,0 & 0,422 & 0,324 & 70 \\
\hline IV & 2,2 & 2,0 & 8,4 & 0,478 & 0,505 & 68 \\
\hline V & 2,3 & 2,1 & 9,3 & 0,478 & 0,446 & 88 \\
\hline VI & 2,5 & 2,2 & 11,8 & 0,478 & 0,548 & 70 \\
\hline VII & 2,4 & 2,1 & 9,9 & 0,420 & 0,515 & 84 \\
\hline$\Sigma$ & 15,60 & 14,20 & 62,9 & 3,212 & 2,933 & 547 \\
\hline Average & 2,23 & 2,03 & 8,98 & 0,459 & 0,419 & 78,14 \\
\hline $\begin{array}{l}\text { Coeffi- } \\
\text { cient }\end{array}$ & & & & & & \\
\hline of varia- & 1 & & & & & \\
\hline tion, $K_{\text {var }}$ & 1,21 & 8,37 & 18,70 & 6,10 & 26,25 & 13,71 \\
\hline$\sigma$ & 0,25 & 0,17 & 1,68 & 0,028 & 0,110 & 10,71 \\
\hline$\Delta \chi$ & 0,18 & 0,12 & 1,21 & 0,020 & 0,079 & 7,69 \\
\hline$n$ & 2 & 1 & 4 & 1 & 9 & 3 \\
\hline
\end{tabular}




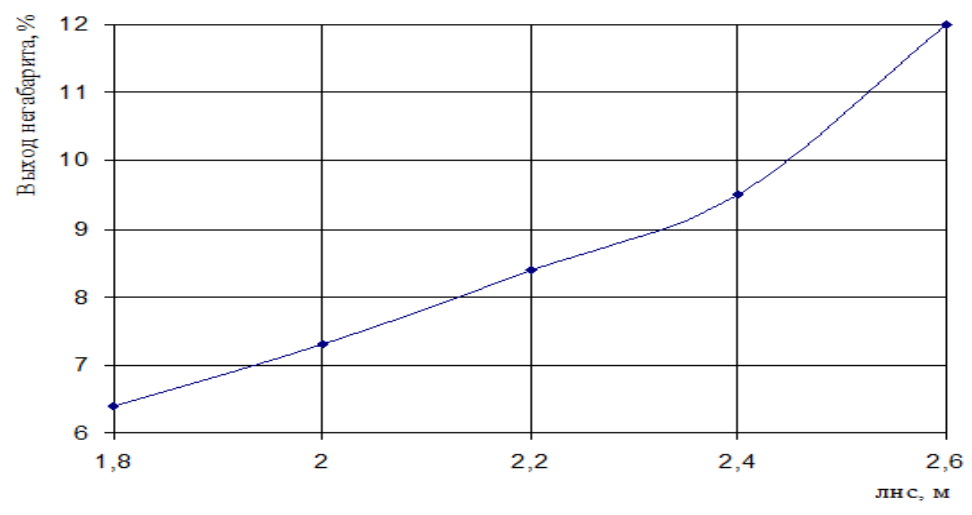

Fig. 10. Dependence of the oversized output $(+0.400 \mathrm{~m})$ on the $1 \mathrm{lr}$

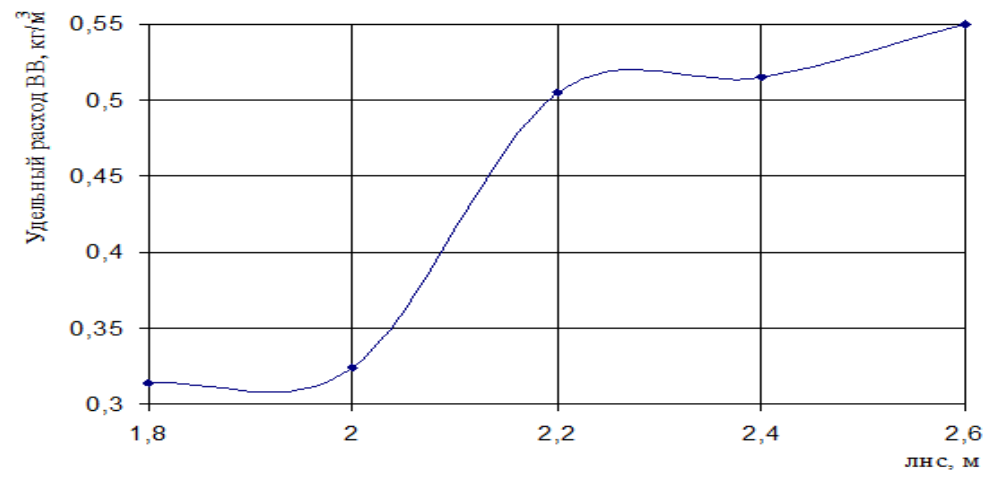

Fig. 11. Dependence of the specific consumption of explosives for secondary crushing on the llr

The adhesion along the cracks that separate natural rocks in the massif is no more than $2-3 \%$ of the adhesion of the rock in the monolith. Therefore, although the average size of natural separations in the ore massif is in the range of 250-300 $\mathrm{mm}$, the effect of explosive stress waves does not always cause the destruction of the rock along all cracks, and sometimes only along cracks forming large chunks represented by several undiscovered during the breaking of the separations.

The curve of the dependence of the number of pieces larger than $1000 \mathrm{~mm}$ on the LLR is shown in Fig. 12, from which it can be seen that with an increase in the LLR, with relatively identical specific 
costs of explosives, the output of large pieces, as well as the output of oversized, also increases. When blasting the fans of wells, the same specific consumption of explosives with an increase in LLR is achieved by a higher concentration of the mass of explosives being exploded simultaneously. This naturally causes an increased seismic effect of the explosion and the chipping of the massif over the drilling output.

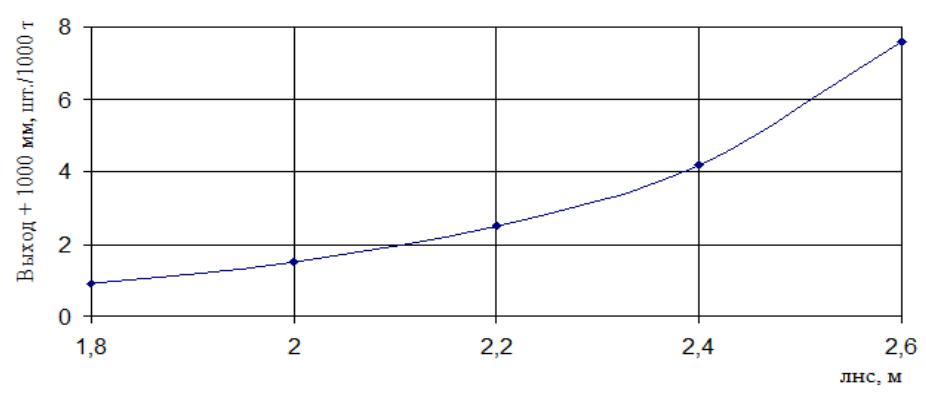

Fig. 12. Dependence of the yield of ore pieces with a grain size of $+1000 \mathrm{~mm}$ on changes in $1 \mathrm{lr}$

Fig. 13 shows the dependence of the specific consumption of explosives for secondary crushing, depending on the size of a substandard piece of ore.

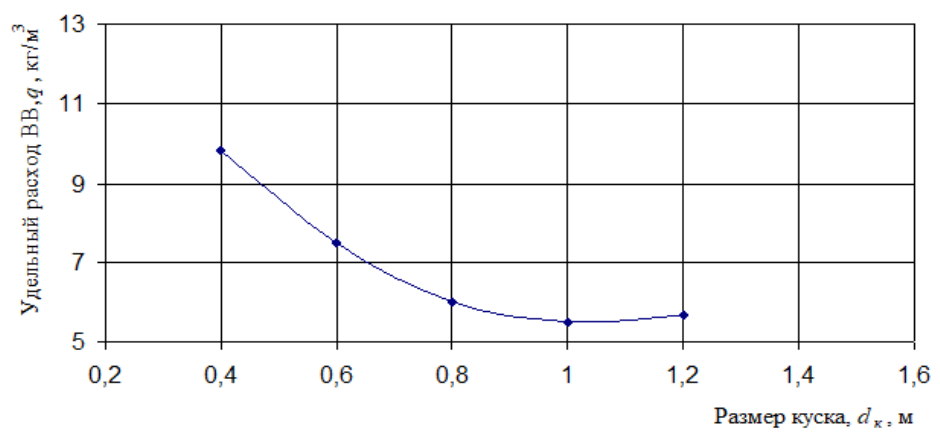

Fig. 13. Dependence of explosive consumption per $1 \mathrm{~m}^{3}$ during secondary crushing

Thus, both the size of the natural separation and the parameters of the cracks - their width and length - affect the results of crushing during chipping. When choosing the parameters of drilling and blasting operations, it is important to correctly assess their impact. The proposed method of frac- 
ture assessment based on the dynamic characteristics of elastic waves allows not only to determine the average size of the natural separation, but also to characterize the quality of cracks.

As a result of experimental and industrial work, it was found that part of the oversized pieces consists of a whole number of structural blocks, since the explosion energy is not enough to break the continuity of cracks in these pieces. This conclusion is confirmed by the results of laboratory experiments, which were discussed above.

Fig. 14 shows the dependence of the shift productivity of the LDM LC on loading and delivery of ore on the change in the output of the oversized in the beaten ore. Empirical data are described quite satisfactorily by an equation of the form, $\mathrm{m}^{3} /$ shift

$$
Q=\frac{C}{K+b},
$$

where $Q$ - ore output and delivery capacity, $\mathrm{m}^{3} /$ shift;

$K$ - the output of the oversized in the beaten ore, $\%$;

$C$ and $b$-empirical coefficients for the conditions of the «Molodezhny» mine $C=750, b=10$.

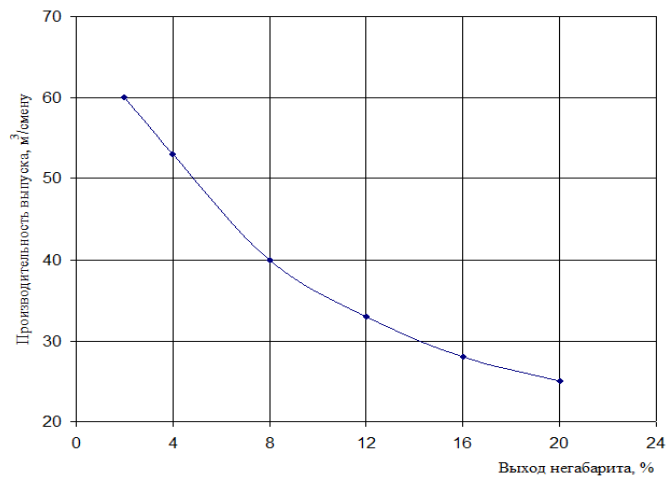

Fig. 14. Graphs of the dependence of the worker's productivity on the output of ore from the output of the oversized

\subsection{Recommended methods of breaking rock mass in a struc- turally block ore-containing array}

Based on the analysis of the world experience in the application of a mining system with a sub-storey collapse of ore and overlying 
rocks in the variant with the removal of ore in the clamp on collapsed rocks and the end release of ore mass to the drilling, based on the results of experimental studies, it is recommended to implement the following recommendations in production.

Taking into account the structural-block nature of the ore massif being worked out with the size of natural separations of $25-30 \mathrm{~cm}$, with sufficiently closed and coherent fracturing, it is advisable to increase the size of the conditioned piece of the beaten ore to the maximum extent possible. There is an opinion that during the breaking of the fractured rock mass is destroyed with the release of natural separations and the granulometric composition of the beaten ore is largely predetermined by the size of these separations. However, practice shows that even when breaking ore from fractured massifs with individual sizes of $20-25 \mathrm{~mm}$, there is an output of oversized pieces with dimensions exceeding 1.2-1.5 m and even more. Obviously, this is due to the fact that the chipped oversized piece of rock mass contains several natural separations that were not separated during the explosion.

A recognized direction in world practice for improving the efficiency of drilling and blasting operations is to increase the size of the conditioned piece at the strike to $1.2 \mathrm{~m}$. Increasing the size of the conditioned piece at the mines of Kazzinc JSC, Kazchrome JSC, Kazakhmys LLP allowed to reduce the yield of nega-barite from 20$25 \%$ to $5-7 \%$. At the same time, the local cost of ore extraction is reduced by $50-75 \%$ due to an increase in labor productivity at the ore output and an improvement in labor conditions due to a sharp reduction in the volume of secondary crushing of ore with overhead explosive charges. Crushing plants are equipped in underground chambers or on the surface of mines to meet the needs of the consumer in the rate of ore with a size of no more than $400 \mathrm{~mm}$.

The energy intensity of rock destruction during drilling and blasting of ore at iron ore quarries in Russia is estimated at $0.7-1 \mathrm{~kW} . \mathrm{h} / \mathrm{t}$, in the dry shops of processing plants $0.8-2.5 \mathrm{~kW} . \mathrm{h} / \mathrm{t}$. At the same time, the lower level of energy consumption during crushing obviously refers to the stage of large crushing, when pieces of 900-1200 $\mathrm{mm}$ in size are disintegrated to a size of $250-300 \mathrm{~mm}$. Thus, largescale crushing of rock pieces in crushers is quite comparable in energy costs with explosive breaking of rock mass, which is quite under- 
standable, since in both cases, large pieces are separated mainly by cracks of natural separations.

The reference book [19] provides an empirical relationship, proven by practice and recommended for calculations, between the maximum size of a piece of chipped rock mass $D_{\max }$ and the bucket capacity of the loading machine $V$, M

$$
D_{\max } \leq 0,75 \sqrt[3]{V}
$$

And a similar ratio between the maximum size of a piece of transported rock mass and the capacity of the transport vessel, $\mathrm{M}$

$$
D_{\max } \leq 0,5 \sqrt[3]{V}
$$

Taking into account the parameters of the LC-1 loading and delivery machine used at the Jubilee mine, it is advisable to switch to the size of the conditioned piece, determined based on the dependence (40), $\mathrm{M}$

$$
D_{\text {конд }}=0,5 \sqrt[3]{V}=0,5 \sqrt[3]{2}=0,63 \approx 0,6
$$

Conducting blasting operations with large specific explosive costs of the order of $2.0-2.4 \mathrm{~kg} / \mathrm{m}^{3}$ leads to deterioration of the stability of workings, greater dilution of ore, deterioration of the composition of the mine atmosphere, etc. Therefore, many foreign mines carry out blasting operations with small specific costs of Explosives:

Cleveland Mine (Canada)

Copper Cliff Court (Canada)

Dumbarton (Canada)

Meggen (Germany)

Mount Isa (Australia)

Minddelplatz (Germany)

Vihanti (Finland)
Specific consumption of explosives, $\mathrm{kg} / \mathrm{t}$

$$
\begin{gathered}
0,28-0,42 \\
0,6 \\
0,27 \\
0,2-0,5 \\
0,2-0,27 \\
0,33 \\
0,2
\end{gathered}
$$

When working with such a specific consumption of explosives, the size of the conditioned piece at the ore output is taken at the level of 600-800 mm, and at a number of mines $900-1000 \mathrm{~mm}$. To ensure normal loading conditions for transport and lifting vessels, the mines are equipped with precinct crushing complexes. The productivity of crushing complexes varies from 250 to $600 \mathrm{t} / \mathrm{h}$. The size of crushed ore is usually minus $130-150 \mathrm{~mm}$. The use of such an ore extraction technology leads to a reduction in costs by 0.4-0.5 USD/t [20]. 
To bring the requirements of ore consumers into line with the actual lumpiness of the ore mass, it is advisable to install a jaw or cone crusher with a $600 \times 900 \mathrm{~mm}$ intake opening on the mine site, or, taking into account the possibility of switching to more powerful mining equipment in the future, increase the intake opening of the crusher to $900 \times 1200 \mathrm{~mm}$.

Based on experimental work to establish the dependence of the utilization coefficient of the length of wells on influencing factors when conducting ore stripping in a structural block array, with the actual orientation of the main system of cracks in the plane of the strike of the ore bodies of the deposit, it is advisable to deploy the position of the surface of the ore stripping at an angle of $60^{\circ}$ to the axis of the drilling. To do this, it is recommended to switch to the removal of the cleaning layer with two half-veers of wells with the addition of a convex shape to the bottom of the face. According to the practice of the mines of the Kiruna iron ore basin (Sweden), this form of treatment face will additionally provide an improvement in the output of beaten ore for drilling [24].

V.I. Mashukov also believes that when drilling into the clamping medium, wells should be located according to a radially convex scheme [23].

\section{Conclusion}

1. When assessing the fracturing parameters of the ore-containing massif of the Yubileyny mine by measuring the amplitude of displacements in the rock mass during the passage of elastic waves generated by the explosion of calibrated explosive charges, it was found that the average size of the natural separations released by cracks is $345 \mathrm{~m}-25 \mathrm{~cm}$, and $331 \mathrm{~m}-32 \mathrm{~cm}$.

2 . The search of rock during the contouring of workings by blasting, first of all, is determined by the distance between the holes (wells) and the line of least resistance, and only then by the specific flow rate of explosives. The use of dispersed charges in contouring holes makes it possible to reduce the amount of rock sorting by an order of magnitude compared to solid charges.

3 . The coefficient of use of the hole when breaking rock mass in a structural block array significantly depends on the orientation of the surface of the treatment face relative to the main system of cracks. At 
the normal intersection of orthogonal natural separations with the surface of the chipping front, the utilization factor of the boreholes is 0.72-0.80, and when the orientation of the cleaning face changes at an angle of $30^{\circ}$ or $60^{\circ}$, it increases to 0.90 with sufficient density of boreholes on the face surface.

4. The lumpiness of the chipped rock mass is determined primarily by the ratio of the distance between the explosive charges and the size of the natural separation, the output of oversized pieces of ore is significantly determined by the established size of the conditioned piece, With a uniform distribution of explosive charges in the destroyed volume of the array and with an increase in the size of the conditioned piece size to $600 \mathrm{~mm}$, the output of oversized pieces in the chipped rock mass can decrease to $4-5 \%$.

\section{List of sources used}

1. Phillipov V.K., Aliev D.K. Razrusheniye krepkih porod pri razlichnyh sposobav vzryvanya. Alma-Ata: Nauka, 1973.-80s

2. Resultati issledovanyi po intensifikacy droplenya gornyh porod $\mathrm{v}$ uslovyah mednorudnyh karerov Urala.V.P. Ulybin,A.A Betmanova , G.V. Kuznetsov,S.V.Gubanov // Pervaya nauchno-tecgnicheskaya konferencya po sovershenstvovanyu burovzryvnih rabot na karerah tsvetnoy metallurgiy Urala. Sverdlobsk; UNIPROmed._1970._s.124-138.

3. Zaks L.Statisticheskyh ocevanye.M.:Statistika,1976.-599s $128 \mathrm{~s}$

4. Quen U. Opisatelnaya I induktivnaya statistika. M.: Financi I statistika, 1981-

5. Kolkot E. Proverka znachimosti. M.: Statistika, 1978.-128s

6. Finkel V.M. Physika razrushenya. Rost treshin $\mathrm{v}$ tverdih telah. M.:Metallurgiy,1970-376s.

7. Radenko E.S. issledovanye osnovnyh voprosov podzemnoy razrabotki sblizhennih zalezhei zhezkazganskogo mestorozhdenya: avtoreph kand. tech.nauk:Tashkent:TPY,1966-23S.

8. Borsh-Kompiec V.I. Mechanika gornyh porod, massivov I gornoe davlenye. M.:Izdanye MGI, 1968-484s.

9. Physenko G.L. Metody kolichestvennoy otsenki structurnyh oslableniy massiva gornyh porod v svyezi s analizom ix ustoichivosti/ Vtoraya vsesoyuznaya konferencia <<Sovremennye problemi mechaniki gornyh porod. L.: 1982.-S. 21-29.

10. Baklanov I.V., Kartozya B.A. Mechanika gornyh porod.M.:Nedra,1975271S.

11. Prochnost I deformiruemost gornyx gornyh porod/U.M. Kartashov,B.V. Matveev, G.v.Micheev, A.B.Phadeev. M: Nedra,1979.-269s.

12. Kim D.N. Issledovanie structurnogo oslablenye treshinovatih porod modelirovanya prochnostnyh svoistv v laboratornih usloviyah/ Tr. IGD UF AN SSSR. Sverdlovsk, st/№ 5, 1963.-S. 97-105. 
13. Povishenye effectivnosti I bezopasnosti burovzrivnyh rabot / I.M. Murzikov,Es. Gorev, V.I/ Lantev,A.N.Zamotaev// Tsetnaya metallurgiya/-1990. № $5 .=$ C. $1-5$.

14. Turchaninov I.A., Iosiv M.A., Kasparyan E.V. Osnovi mechaniki gornyh porod.L.:Nedra,1977.-503s.

15. Mashanov A.A Treshinovatost gornyh porod.Almaty, 2000.-124c.

16. Mostkov V.M. Podzemnye sooruzhenya bolshogo sechenya.M.:Nedra,1974.-320s.

17. Erofeev I.E. povizenye effectivnosti burovzrivnih rabot na rudnikah.M.:Nedra,1988.-271s.

18. Sovershenstvovanye metodov podzemnoy razrabotki Ziryanovskogo mestorozhdenya. Collectiv avtorov. Alma-Ata: Kazakhstan,1975.-384s.

19. Spravochnik. Otkrytie gornyh raboti. M.;Gornoe byuro, 1994.-512s.

20 Airapetyan L.G., Bogolubov A.A. Analiz issledovanya uchastkovih drobilnih kompleksov na podzemnih rudnika// Tsvetnaya metallurgiya.-1990, №.-S.8587.

21. Bronikov D.M., Vanesov N.F., Bogdanov G.I. Razrabotka rud na bolshih glubinah . M.; Nedra, 1982.-292s.

22. Rikovskyi B.B., Batuev M.A., Hudov S.V., Dubskih A.V Burimost I vzrivaemost piroksenitov Gusevogorskogo mestorozhdenya// Gornyi jurnal/-1991, №S.59-60

23. Mashukov V.I. Deistvie vzriva na okruzhayushuyu sredu I sposoby upravlenya im. M.;Nedra,1976.-248s.

24. Stazhevskyi S.B., Phreidin A.M. Rusin E.P. Na podzemnih rudnikah Swetci ( Sostoyanye I perspektivy)// Gorniy jurnal/-1991, № 10, S. 55-59.

https://doi.org/10.31713/m1114

\title{
RESOURCE-SAVING CONTROL SYSTEMS FOR ELECTRIC DRIVES OF MODERNIZED DRILL RIGS FOR OPEN-MINES OF UKRAINE
}

\author{
Khilov V.S. \\ Dnipro University of Technology. \\ Doctor of Technical Sciences, Professor, Ukraine
}

\begin{abstract}
A comparative analysis of the characteristics of DRGs used in opencast mining in Ukraine is given. Experimental studies of the influence of drive systems and drill rigs on the dynamics of the drill process were carried out in the mining and geological conditions of the Central Mining and Processing Plant (Kryvyi Rih, Ukraine). Frequency characteristics and analysis of dynamic properties of automated drive systems and frequency characteristics of transmissions of the rotation
\end{abstract}


mechanism are obtained. The behavior of natural frequency oscillations in closed control circuits of rotary actuators was studied and it was found that they cross the cutoff frequency and fall into the bandwidth from the attenuation band in frequencycontrolled asynchronous motors of new generation drill rigs when using the maximum number of connected tubes in the drill rod. It is established that the lowest oscillation frequencies due to the lateral frequencies generated by the oscillations of the drill rod fall into the fastest internal current loop.

The purpose and objectives of research is energy and resource saving in the process of drill subsoil wells by concentrating the flow of mechanical power in the bottom hole zone and ensuring minimum dynamic loads in the drill machine in the presence of elastic connections and variable natural frequencies in multi mass transmission with concentrated and distributed parameters.

The object of the study is the frequency compatibility of electromechanical processes in the electric drive rotation of the drill rig with distributed parameters taking into account the change of attached distributed and concentrated masses to the transmission.

The subject of research is the elastic properties of transmissions, frequency characteristics of control systems and their mutual influence on the quality of work in electric drives.

\section{Introduction}

In the general technology of open pit mining in the open-cast mines of the Krivoy Rog basin of Ukraine, the cost of drill and blasting operations is about $16-36 \%$ of the total costs of breaking hard rocks. In connection with the rise in the cost of energy carriers, electricity and consumables, the problem of using energy-saving technologies in the extraction of rocks becomes more and more urgent. Today, drill rigs (DRG) are operating in the open-cast mines of Ukraine, which have completely exhausted their standard resource. This state of the DRGs necessitates not only the modernization of existing ones, but also the introduction of a new generation of DRGs with longer DRDs and a multi-mass mechanical system of loweringlifting operations.

Efficiency drill blast holes using roller-cone method is directly determined by the perfection level of electric drive systems. Introduction fast-action transistor AC drive into rotation mechanism composition existing rigs, and also into the rotation and movement mechanisms in the rigs of the new generation instead of thyristor DC drive with middle-action is characterized by increased vibratory loads onto all mechanical designs of the rigs. These loads lead to the release of an energy flow not only in the bottomhole zone, where 
rocks are destroyed, but also in structural elements directly on the machine, which increases mechanical stresses, fatigue of the machine material and leads to emergency failures of the rig (usually of drill mast). The frequency characteristics of the drive systems must be compatible with the dynamic characteristics of multi-mass mechanisms with distributed and lumped masses with changing attached masses, which will ensure the release of the flow of mechanical power within the bottomhole zone and energy and resource saving when drill blast wells. Therefore, the solution of scientific and applied problems to establish the regularities of the influence to dynamic of electromechanical and hydromechanical parameters of DRGs as well as further development on this basis of the theory of high-speed automated electrical installations are now gaining relevance.

\section{The problem formulation}

Blast hole drill is one of the most energy-intensive and materialintensive processes in the existing technology for the extraction of iron ore raw materials on open-pit mining works in Ukraine. Increasing the efficiency of rock destruction with a roller cone bit, is connected which the level of perfection of the DRGs drive systems. The works (Quang 2010, Novotny 1996, Boldea 1992, Boldea 2006) and many others are devoted to the development of the modern electromechanical systems operation theory.

The purpose of this study is energy and resource saving in the drill blast holes' process by concentrating the flow of mechanical power in the bottomhole zone and also obtaining minimum dynamic loads in the DRG in the presence of elastic mechanical links and changing natural vibration frequencies of a multimass transmission with lumped and distributed parameters.

Achieving this purpose involves solving the following tasks:

- to develop a method for controlling the drill process with the formation of the mechanical characteristics with the variable stiffness on the roller cone bit, depending on the hardness of the rock which drill, through the influence on the motor rotation speed and DRD in bottom zone;

- to evaluate the effect of forced and natural oscillations of the DRD on the dynamics of the operation of DRG with a thyristor DC drive (DRG SBSh-250MN-32) and thyristor and transistor AC drives 
introduced with the participation of the author (DRGs SBSH250MN-32 and SBSHS-250N);

- to fulfill further evolution of the scientific basis of the creation system of electric drive rotation taking into account technological features and had being developed control method of drill;

- to study the electrohydromechanical transmission as an object of automatic control of the electric drive of lowering-lifting operations and to establish regularities in the change in the characteristic vibration frequencie;

- to fulfill further evolution of the scientific basis for constructing the drive of lowering-lifting operations in accordance with object peculiarities and had being developed a method for controlling the drill process;

- to fulfill further evolution of the active sequence correction method using fuzzy control systems for optimal control electric, electromechanical and electro-hydro-mechanical processes.

The object of study is the frequency compatibility of electromechanical processes and electro-hydro-mechanical processes in rotary DRD with distributed parameters and the drive round-trip and displacementing rod with lumped parameters associated with the changes in the distributed and lumped masses in the transmission.

The object of the research is the frequency compatibility of electromechanical and electrohydromechanical processes in the electric drive of rotation of the DRD with distributed parameters and in the electric drive of lowering-lifting operations and feeding rod with lumped parameters, taking into account changes of the added as well as distributed and lumped masses into the transmission.

\section{Materials of research}

3.1. State-of-the-art and development trends of drive systems for rotary cutter blast hole drill

In the open pits of Ukraine mainly in operation are rigs of medium type SBSh-250MN-32 with thyristor DC drives in the rotation mechanisms of the DRD and unregulated asynchronous drives in the mechanisms of lowering-lifting operations and feeding the DRD as well in the mechanisms of DRG movement and in the compressor of the pneumatic transport system. 
Machine-Building Plants of Ukraine have created:

- DRG of type USBShS-250A (developer Krivoy Rog Plant of Mining Machine Builder KZGM, Krivoy Rog, Ukranian, has been in operation at Poltava Ore Mining and Processing Plant since 2004; equipped with drive systems, which are similar to systems of DRG SBSh-250MN-32 type);

- new generation DRGs SBSh-250/ 270-32 (developer NovoKramatorsk Machine Building Plant NKMZ, Kramatorsk, Ukranian; operated at Ingulets Ore Mining and Processing Plant since 1999; equipped with thyristor DC drive in the mechanism of rotation, hydraulic drives in mechanism of movement and lowering-lifting of DRD);

- SBShS-250N (developer NKMZ; operated on the Central Ore Mining and Processing Plant since 2003; equipped with transistor $\mathrm{AC}$ drives in the mechanisms of rotation, rod lowering-lifting and movement of rig, which are introduced according to the recommendations of the author).

Along with the development of a new generation DRGs, the existing ones are being modernize. According to the author's recommendations, when upgrading rigs of type SBSH-250MN-32, have introduced drive $\mathrm{AC}$ system in the mechanisms of DRD rotation, which are operated in the Central Ore Mining and Processing Plant: thyristor drive AC with current source (in operation since 1998); Transistor AC drives with a voltage source (in operation since 2005).

The transistor AC drive systems using instead of DC thyristor drives has significantly changed the work dynamics of DRGs in the process of drill blast holes. To establish the quantitative characteristics of the operation of the DRGs electromechanical systems, experimental studies were carried out directly in the mining and geological conditions of the Central Ore Mining and Processing Plant. Dynamics of the head cross-arm of DRD rotation mechanism rig rod with four drive systems is experimental studed: for SBSh-250MN-32 type machines equipped with thyristor and transistor drives DC and $\mathrm{AC}$, and for SBShS-250N type machine equipped with transistor AC drive.

Oscillograms of transient in the transistor drive of the DRG rotation for SBShS-250N type shown in Fig. 1a (drill of leached oxidized martite-hematite hornfels: the strength factor on the scale of Prof. M.M. Pro- 
todyakonov - from 13 to 15 ; drill category by the scale of the Central Ore Mining and Processing Plant - IV; the rocks are very fractured, the distance between the fractures is from 0.2 to $0.3 \mathrm{~m}$ ).

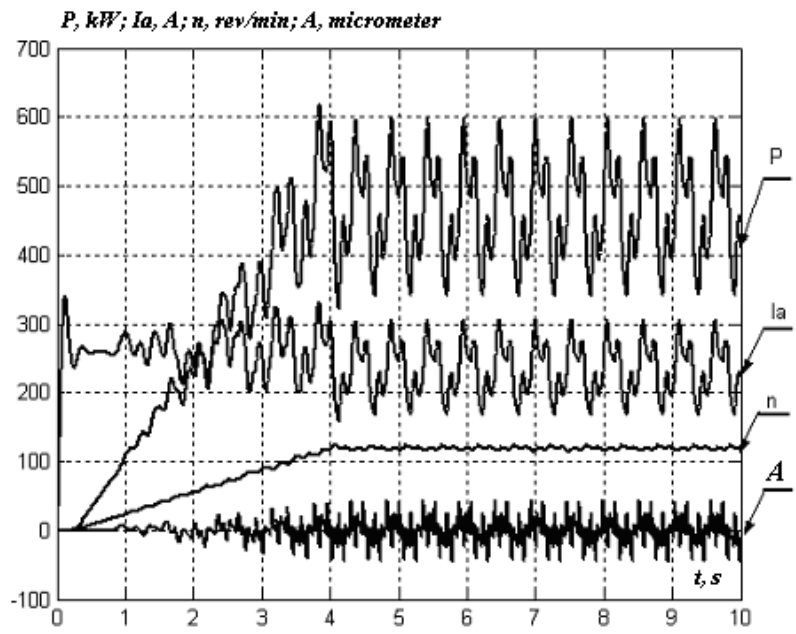

Fig. 1. Oscillograms of transients in the rotation drive of DRG SBSh $-250 \mathrm{MN}-$ 32 with system of frequency converter- induction motor with the inverter voltage: A-vibration displacement of the pressure traverses of the head top (axial pressure on the rod of $250 \mathrm{kN}$, the drill with the three DRDs)

Harmonic analysis (Fig. 2) of the vibrations of the drill head pressure traverse confirmed the well-known position that an increase in the bit rotation frequency leads to an increase in the frequency and amplitude of forced vibrations. Along with the known regularity, a new one appeared: in the spectra of the amplitude-frequency characteristics of the vibrations of the new generation DRG SBShS-250N type, a harmonic appears at a frequency of $f=1.02 \mathrm{~Hz}$, which does not depend on the rotation frequency of the DRD. Other harmonic components are subject to the same law, which was on the existing rigs type SBSh-250MN-32. 

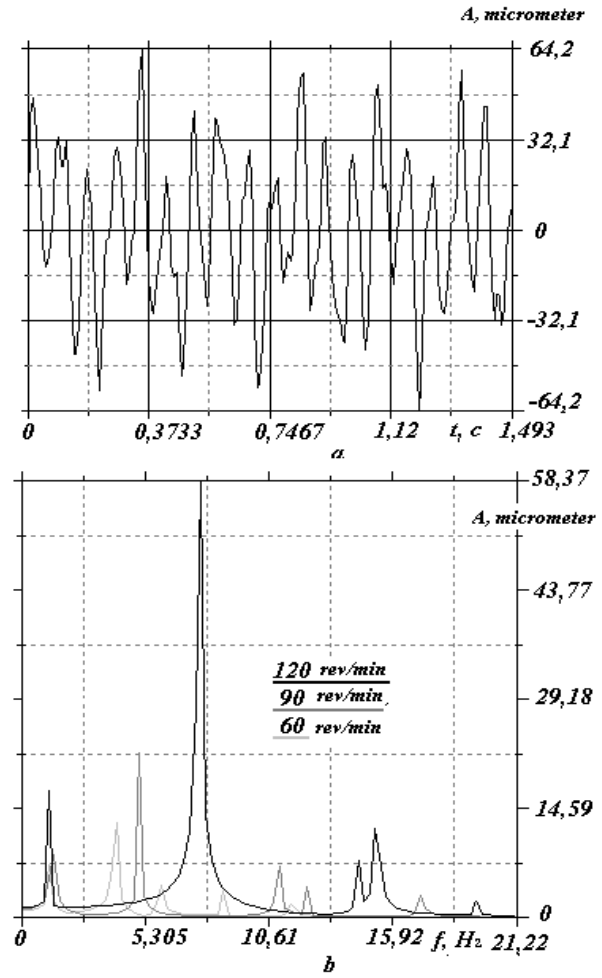

Fig. 2. Oscillogram vibration displacement of head projectile at $60 \mathrm{rev} / \mathrm{min}(a)$ and the amplitude spectrum of vibration frequency characteristics $(b)$ of the machine

SBSh -250MN-32 with transistor AC drive system SIV - induction motor (axial pressure on rod $250 \mathrm{kN}$, drill with three rods)

Other harmonic components obey the same regularity that turned out to be on the existing BS of the SBSh-250MN-32 type. The appearance of the oscillation harmonic, which does not depend on the rotation frequency and is located in the passband of the control system, indicates the need to take into account the effect on the dynamics of the drill process not only of forced oscillations, which are characteristic of the DRG SBSh-250MN-32 type, but also of the natural oscillation frequencies of the stave СБШС - $250 \mathrm{H}$ machine. The use of a transistor frequency-controlled drive on the SBSHS-250N machine led to an increase in high-frequency components in the shaft rotation frequency (DRD) and motor current, Table 1 (where denoted with SIT, VIN - standalone invert- 
er current and voltage).

Along with the general industrial electric drive, which is now implemented at the DRGs, object-oriented drives with automatic control of the modes of drill blast holes for roller cone machines are known, which are based on next control methods: stabilization of the torque, minimum costs for drill a meter of borehole, maximum velocity drill. However, such systems drive the widespread introduction in the Krivoy Rig basin did not find, as ideas have being putted into their foundation at experimental verification are not received confirmation. Therefore, when developing a method for controlling electric drives of feed and rotation of a rod in the process of roller cone drill, we take on based the control method put forward at the IvanoFrankivsk National Technical University of oil and gas and partially experimentally tested at the Poltava Ore Mining and Processing Plant (where mining and geological conditions are similar to those of the open pits of the Kryvyi Rih basin) with control of the power of the engine rotation of the rod, which helps to increase the durability of the bit and reduce the cost of drill and blasting operations.

In order to increase the durability of a roller cone bit by maintaining the power flow in the bottomhole zone, the author has developed a method for controlling the drill process with control of the electric drives of the rotation mechanisms and the lowering-lifting of the DRD, in which hard mechanical characteristics are formed on a roller cone bit when drill in rocks with a strength $f \leq 10-13$ on the scale of prof. M.M. Protodyakonov and soft mechanical characteristics in harder rocks. When drill rocks that are variabled by physical and mechanical properties, the control method provides automatic selection of mechanical characteristics depending on the strength of the rock. The control method is protected by a patent of Ukraine (Khilov V.S. 2003).

Table 1

Quantitative characteristics ripple depending on the type of electric drive systems rotation rod and DRGs

\begin{tabular}{c|c|c}
\hline \multirow{2}{*}{$\begin{array}{c}\text { The rotation drive types } \\
\text { and DRGs types }\end{array}$} & \multicolumn{2}{|c}{ Peak-to peak ripple during drill, \% } \\
\cline { 2 - 3 } & motor speed (rod) & motor current \\
\hline $\begin{array}{c}\text { Thyristor DC drive, } \\
\text { rig SBSh-250MN-32 }\end{array}$ & 0,51 & 28,4 \\
\hline Thyristor DC drive SIT - & 2,56 & 25,3 \\
\hline
\end{tabular}




\begin{tabular}{c|c|c}
\hline $\begin{array}{l}\text { induction motor, } \\
\text { rig SBSh-250MN-32 }\end{array}$ & \\
\hline $\begin{array}{c}\text { Transistor AC drive SIV - } \\
\text { induction motor, } \\
\text { rig SBSh-250MN-32 }\end{array}$ & 3,51 & 25,6 \\
\hline $\begin{array}{c}\text { Transistor AC drive SIV - } \\
\text { induction motor, } \\
\text { rig SBShS-250N }\end{array}$ & 3,02 & 27,1 \\
\hline
\end{tabular}

The implementation of the developed method for controlling the drill process leads to the need to control and limit at permissible levels in electric drives: of rotation of the DRD - the flow of mechanical power on a roller cone bit in the bottomhole zone; of the lowering-lifting DRD - the pressure in the hydraulic system and the linear velosity of movement of the drill, which requires further development of scientific foundations for the creation of object-oriented drive systems for the DRGs of a new generation.

Now the problem of the mutual influence of the dynamic characteristics of high-speed transistor AC drives and the frequency characteristics of the transmission of DRGs is insufficiently studied and is relevant. This is due to the introduction of both DRGs with new design solutions and electric drives of a new generation, which significantly changed the natural oscillation frequencies of the electrogidro-mechahical systems of lowering-lifting operations and feed and electro-mechanical rotation of the DRD.

3.2 Analysis of the DRD dynamic properties as an object of automatic control

In the control system of the rotation electric drive, as shown by experimental studies (Khilov 2004, Pivnyak 2005), it is necessary to take into account the frequency properties of the control object. For this purpose the frequency characteristics of DRDs (Khilov 2020), which are used in the open pits of Ukraine in the roller cone bit rigs, were determined.

The DRGs rods have a length from $8 \mathrm{~m}$ (rigs USBSHS-250A, SBSh-250MN-32) to $11 \mathrm{~m}$ (rig SBShS-250N). From a design point of view, they are hollow rods of circular cross-section, one end of which is pivotally supported on the roller cone bit, and the other one has a sliding pinching in the head cross-arm of DRD. The DRD is under pressure from the feed force. When determining the frequencies of natural vibrations, the DRD was investigated as a linear sys- 
tem with a uniformly distributed mass, in which longitudinal, torsional and transverse vibrations do not depend on each other. The mass of the roller cone bit was neglected in the analytical study.

As a result of theoretical studies, a mathematical model was obtained for determining the natural frequencies of longitudinal, torsional and transverse vibrations both for a DRD with one rod and during its growth, Table 2 (where $u$ - the longitudinal displacements of the current section of the rod; $t$ - the time; $\varphi$ - the angle of rotation of the cross section rod; $x$ current distance; $y$ - cross-sectional displacement of the rod). On the basis of the model, a method was developed for calculating natural vibrations, which made it possible to calculate the vibration frequencies of a DRD with a variable number of rods (Khilov \& Plakhotnik 2004, Pivnyak 2003, Kozhevnikov \& Khilov 2012).

From a comparison of the natural frequencies of longitudinal, torsional and transverse vibrations, obtained by calculation, with the natural frequencies that were identified in experimental studies (Khilov 2006), it follows that when drill with one or two rods, regardless of the type of DRGs, the natural frequencies of longitudinal and torsional vibrations of the rod do not fall within the passband of both DC and AC drives. When drill with three rods in the SBSH$250 \mathrm{MN}-32$ rig, low-frequency natural transverse oscillations of the rod with a value of $2.36 \mathrm{~Hz}$ were experimentally recorded, their calculated value according to the developed method was $2.48 \mathrm{~Hz}$. When drill with three rods with the SBShS-250N rig, the natural lowfrequency transverse vibrations of the rod with a cyclic frequency of $1.02 \mathrm{~Hz}$ were experimentally recorded. The calculated value of this frequency is $1.05 \mathrm{~Hz}$.

Table 2

DRD natural oscillations calculated equations

\begin{tabular}{c|c|c}
\hline $\begin{array}{c}\text { Longitudinal } \\
\text { oscillations }\end{array}$ & Torsional vibrations & Transverse vibrations \\
\hline$\frac{\partial^{2} u}{\partial t^{2}}=C_{1}^{2} \frac{\partial^{2} u}{\partial x^{2}}$ & $\frac{\partial^{2} \varphi}{\partial t^{2}}=C_{2}^{2} \frac{\partial^{2} \varphi}{\partial x^{2}}$ & $E \cdot J \cdot \frac{\partial^{4} y}{\partial x^{4}}+R \cdot \frac{\partial^{2} y}{\partial x^{2}}+m \cdot \frac{\partial^{2} y}{\partial t^{2}}=0$, \\
& $y=X_{y}(x) \cdot T(t)$. \\
\hline
\end{tabular}




\begin{tabular}{|c|c|c|}
\hline $\begin{array}{c}\text { Longitudinal } \\
\text { oscillations }\end{array}$ & Torsional vibrations & Transverse vibrations \\
\hline $\begin{array}{c}C_{1}=\sqrt{E / \rho} \\
E \text { - elastic mod- } \\
\text { ulus; } \\
\rho \text { - density }\end{array}$ & $\begin{array}{c}C_{2}^{2}=G / \rho \\
G \text { - shear modulus }\end{array}$ & $\begin{array}{c}m-\text { DRD distributed mass intensity } \\
E \cdot J-\text { DRD flexural rigidity; } J- \\
\text { inertia axial moment; } R \text { - displace- } \\
\text { ment force }\end{array}$ \\
\hline $\begin{array}{l}X_{u}=C_{u} \sin \frac{p_{u}}{C_{1}} x+ \\
+D_{u} \cos \frac{p_{u}}{C_{1}} x\end{array}$ & $\begin{array}{l}X_{\varphi}=C_{\varphi} \sin \frac{p_{\varphi}}{C_{2}} x+ \\
+D_{\varphi} \cos \frac{p_{\varphi}}{C_{2}} x\end{array}$ & $\begin{array}{l}\text { Equation solution } \\
\frac{\ddot{T}}{T}=-p^{2} ; \frac{E \cdot J}{m} \cdot\left(X_{y}^{I Y}+\alpha^{2} X_{y}^{I I}\right)=p^{2} \\
X_{y}=C_{1} \cdot \operatorname{sh}\left(S_{1} \cdot x\right)+C_{2} \cdot \operatorname{ch}\left(S_{1} \cdot x\right)+ \\
+C_{3} \cdot \sin \left(S_{2} \cdot x\right)+C_{4} \cdot \cos \left(S_{2} \cdot x\right)\end{array}$ \\
\hline $\begin{array}{l}p_{u} \text { - longitudi- } \\
\text { nal oscillations } \\
\text { natural frequen- } \\
\text { cy; } \quad l-\text { DRD } \\
\text { length }\end{array}$ & $\begin{array}{l}p_{\varphi}-\text { torsional nat- } \\
\text { ural frequency }\end{array}$ & $\begin{array}{c}p-\text { transverse oscillations natural } \\
\text { frequency }\end{array}$ \\
\hline$X_{u}^{\prime}=0$ & $X_{\varphi}^{\prime}=0$ & $\begin{array}{c}\text { Border conditions }(x=0) X_{\mathrm{y}}=0, \\
X_{\mathrm{y}}^{\prime}=0\end{array}$ \\
\hline$X_{u}^{\prime}=0$ & $X_{\varphi}^{\prime}=0$ & $\begin{array}{c}\text { Border conditions }(x=l) X_{\mathrm{y}}=0, \\
X_{\mathrm{y}}^{\prime}=0\end{array}$ \\
\hline $\cos \left(\frac{\mathrm{p}_{\mathrm{u}}}{\mathrm{C}_{1}} \cdot l\right)=0$ & $\sin \left(\frac{p_{\varphi}}{C_{2}} \cdot l\right)=0$ & $\begin{array}{l}\begin{array}{l}\text { Equations for Determining Natu- } \\
\text { ral Frequencies }\end{array} \\
X_{y}=C_{1} \cdot \operatorname{sh}\left(S_{1} \cdot x\right)+C_{2} \cdot \operatorname{ch}\left(S_{1} \cdot x\right)+ \\
+C_{3} \cdot \sin \left(S_{2} \cdot x\right)+C_{4} \cdot \cos \left(S_{2} \cdot x\right)\end{array}$ \\
\hline
\end{tabular}

The low-frequency components of the transverse vibrations of the DRD do not directly affect the dynamic processes in the drive system. However, they lead to unacceptable dynamic loads not only on the DRD, but also on the DRG as a whole, which significantly reduces the average time between failures of structural units and significantly limits the productivity of drill and blasting operations, therefore the drive system must limit transverse vibrations of the DRD to an acceptable level.

The dynamics of the AC drive system is directly affected by torsional vibrations of the $\mathrm{DRD}$, provided that its natural frequencies fall within the passband of the current loop as well as speed one. 
These conditions are fulfilled in the AC drive system introduced on the СБШС-250H rig with a transistor autonomous voltage inverter with pulse-width modulation (SIV-PWM) with a speed loop passband of $200 \mathrm{rad} / \mathrm{s}$, when drill with four rods.

Operation of a DC drive system with a thyristor voltage converter and a speed loop passband of no more than $50 \mathrm{rad} / \mathrm{s}$ in SBSHS-250N and SBSh-250MN-32 DRGs does not lead to the fall into passband of the natural frequencies of the DRD torsional vibrations.

\subsection{Drive system for rotation of the DRD}

To obtain the desired hyperbolic dependences between the rotation frequency of the rod and the strength of the rock, which is destroyed by the bit according to the developed drill method, it is necessary not only to maintain the rotation speed of the electric motor (bit) at a constant level when drill soft rocks, but maintain also the flow of power on the roller cone bit at a constant level when the destruction of hard rocks in the area of the work face. In this case, the control system should automatically, without operator intervention, select the rotation speed of the roller cone bit at a variable and a priori unknown value of the strength of the rock being drilled.

When drill with one or two rods (Section 3.2), the lowest frequency of torsional vibrations of DRD of the SBShS-250N, USBShS-250A and SBSH-250MN-32 type rigs is higher than the cutoff frequency of the stator current and the rotation speed control loops (Khilov V.S. 2006). Therefore, under such conditions, when developing an electric drive system for the rotation of the DRD with control of the electromagnetic power, it is possible to ignore the influence of the natural torsional oscillations of the DRD on the control dynamics, since they are in the attenuation band outside the passband of the control system.

It has been established (Khilov V.S. 2011) that the direct connection of the external loop of electromagnetic power leads to the parallel connection of the control loops of the rotation frequency and current through the presence of cross-links in the control object. For such a control system, a method has been developed for calculating the dynamic correction of the power control loop (Khilov V.S. 2012), which takes into account the perturbation across the motor stator current channel to the power control loop. With the introduction of a permanently switched on external power control loop, the power of the drive system is effectively maintained at a 
given level when drill in hard rocks, and hard mechanical characteristics are realized when drill soft and fractured rocks.

To implement this control method, a power control system using nonlinear correction in feedback (Khilov V.S. 2012) has proposed and investigated. For this purpose, the reference signal at the input of the speed controller is divided into a signal that is proportional to the moment of resistance on the roller cone bit (Fig. 3).

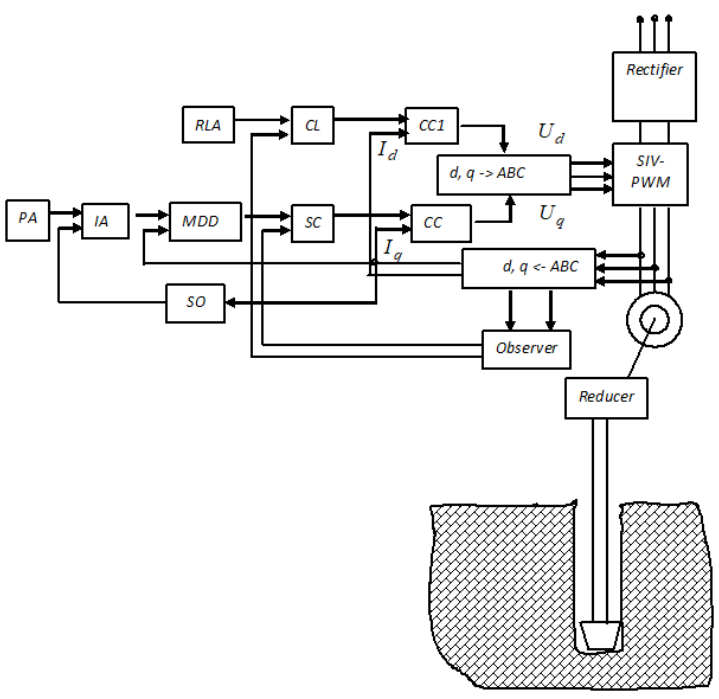

Fig. 3. Vector control system of destroyed rock power with roller cone bits: $P A$, $I A, R L A$ - setting devices of power, intensity and nominal linkage; $S C, C L, C C, C C 1$ - speed controller, linkage and stator currents; $S O$ - vibration sensor; $M D D$ - multiplier-divider unit; $S I V-P W M$ - autonomous voltage inverter with $P W M$

The influence of nonlinear power correction on the stability of the control system is investigated (Khilov V.S. 2013). The characteristic equation of the external control loop is distinguished, which is a polynomial of the third degree. Therefore, the quality of management is assessed using the Visegradskiy diagram (Fig. 4). 


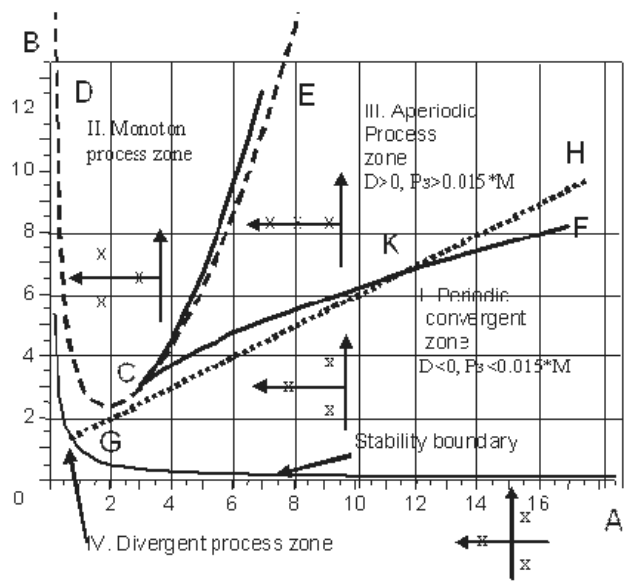

Fig. 4. Zones of quality transient of control system with nonlinear power regulator

The diagram used Vyshnegradsky coefficients $A, B$, which are quantitatively determined by the equations

$$
\begin{gathered}
A=\left(a^{2}{ }_{u} b^{2}{ }_{u} T^{2}{ }_{c} a_{u} b_{u} T_{c} P_{3} T_{M} / M / K_{u}\right) /\left(a_{u}^{2} b_{u} T^{3}{ }_{c}\right)^{2 / 3} ; \\
B=\left(a_{u} b_{u} T_{c} a_{u} b_{u} T_{c} P_{3} T_{M} / M / K_{u}\right) /\left(a^{2}{ }_{u} b_{u} T^{3}{ }_{c}\right)^{1 / 3},
\end{gathered}
$$

where $a_{u}, b_{u}$ - tuning coefficients; $T_{c^{-}}$circuit current time constant; $P_{3}$ - the reference signal; $M$ - motor torque; $T_{M}$ - mechanical constant; $K_{u}$ - transfer coefficient of the speed sensor.

In Fig. 4, the GH line is the locus of points belonging to the vertices of the parabolas at the current values of the task for the power of destruction of the rock and the moment of resistance on the bit. It characterizes the quality of the transition process. With the minimum values of the Vyshnegradskiy coefficients $A_{\min }=\sqrt[3]{a_{u}^{2} \cdot b_{u}}$, $B_{\min }=\sqrt[3]{a_{u} \cdot b_{u}^{2}}$ and the coefficients of the velocity loop tuning $a_{\mathrm{I}}=b_{\mathrm{I}}=1$ line $\mathrm{GH}$ begins on the stability boundary, while $a_{\mathrm{U}}=b_{\mathrm{\amalg I}}=2$ lies in the area of sustainable transient. The quality line of the transient process GH is located in zones I and III, without falling into zone IV. This indicates that the necessary and sufficient condition for maintaining the stability of the control system is not violated even with the introduction of nonlinear correction (Fig. 3).

If there are more than three rods in the DRD (Khilov V.S. \& 
Glukhova N.V. 2019, 2020.), torsional vibrations of the DRD are lowfrequency and fall within the passband of the control system of the drive AC rotation of the SBSHS- $250 \mathrm{~N}$ rig, i.e. they are affected onto the operation of the control system when drill with a completely assembled DRD, which degrade the control quality of the entire electromechanical installation and increase vibration loads on the DRG as a whole.

For the study, only the frequency of the lowest vibrations of the DRD was taken, which fell into the passband, and other frequencies that are in the attenuation band were not taken into account. The equivalent circuit of torsional vibrations is a system with concentrated masses of the rotor of an induction motor and the mass of the DRD reduced to the rotor speed. These two masses connected by elastic element stiffness is determined by the lowest frequency torsional vibrations of DRD. In selected calculation circuit there are additional dynamic links in the control loops (Table 3, where $T_{I}, T_{E M}$, $T_{y}$ - time constants: electromagnetic, electromechanical, torsional vibrations composition; $\Gamma, \gamma$ - coefficients ratio of inertial mass; $\xi_{y^{-}}$ damping coefficient of elastic vibrations DRD).

The dynamic characteristics of control loops under the influence of the elastic properties of the DRD on the control processes in the drive system are analysed.

It was established that when using classical PID controllers, only local optimal tuning of the control system is possible.

When the number of connected DRDs is changed from one to four, the classic PID control settings do not provide optimal dynamic performance over the entire range.

This is possible only with the use of adaptive controllers, which must change not only their parameters, but also the control structure within wide limits, and also provide the ability to find derivatives of the fourth-order error signal in the presence of noise in the control signal.

Therefore, the classical control system can function effectively only if decrease rapidity of 
Table 3

Additional dynamic links in the control loops of the drive rotation

\begin{tabular}{c|c}
\hline Loop & Loop additional dynamic link \\
\hline \multirow{2}{*}{ Current } & $\left(T_{I} \cdot p+1\right) \cdot p \cdot T_{E M} \cdot \gamma \cdot$ \\
\cline { 2 - 2 } & $\left(p^{2} \cdot T_{y}^{2}+p \cdot 2 \cdot \xi_{y} \cdot T_{y}+1\right)$ \\
\hline $\begin{array}{c}\text { Rotation } \\
\text { frequency } \\
\text { of motor }\end{array}$ & $+p^{2} \cdot \gamma \cdot T_{y}^{2}+p \cdot 2 \cdot \xi_{y} \cdot T_{y}+1$ \\
\hline $\begin{array}{c}\text { Linear } \\
\text { speed of } \\
\text { DRD }\end{array}$ & $\frac{p^{2} \cdot \gamma \cdot T_{y}^{2}+p \cdot 2 \cdot \xi_{y} \cdot T_{y}+1}{p^{2} \cdot T_{y}^{2}+p \cdot 2 \cdot \xi_{y} \cdot T_{y}+1}$ \\
\hline
\end{tabular}

action to a level where its own characteristic frequencies are shifted to the zone of damping control loops. In the field of classical control systems is only possible construction of control systems with a low rapidity of action, which is contrary to the quality requirements of the electromechanical system of DRD rotation.

The studies carried out allow us to formulate a concept for the construction of automated drives for DRD rotation of rigs for open pits, according to which, in order to save energy and resources, depending on the strength of the rock, the mechanical characteristic on the roller bit is supported with constant or variable stiffness and limitation of longitudinal vibrations of the DRD by the control system. The concept uses the principles of regulation, in which longitudinal vibrations are limited by influencing the setting signal of the speed setting unit with the simultaneous control and limitation of technological parameters, which leads to the concentration of the flow of mechanical power in the bottomhole zone.

3.4 The electro-hydro-mechanical transmission properties research as object of DRD lowering-lifting drive system control

The DRG SBSHS-250N type by Closed Joint-Stock Company NKMZ that had been designed, significantly differs from SBSh-250MN- 
32 type rig by electro-hydro-mechanical transmission in the mechanism of lowering-lifting of DRD. Into a kinematic link between the drive motor and the drill rog in SBSHS-250N type rig in rod translation displacement are included a hydraulic pump, hydraulic motor (HM) with reducer gear and rope-polyspast system (RTS) (Khilov 2012, Pivnyak 2005).

A mathematical model of the control object have obtained based on decomposition approach in the assumption that the motor and gear having lumped parameters; mass of oil which circulates in the hydraulic system (HS) is not considered in account of its small amount in comparison with other masses; change in viscosity with temperature is neglected, i.e., isothermal processes is considered; oil leakage from the HS is directly proportional to the pressure in the pipes; changing in the volume of lubricating oil in the pipeline directly proportional to the volume of supply pipeline and inversely proportional to the bulk modulus of the pipeline material.

Block diagram of the control object of electro-drive lowering-lifting operation is shown in Fig. 5, where $x_{1}$ - speed $\omega 1$ of the drive motor; $x_{2}$ the moment of $M_{2}$, that is developing by the $H S ; x_{3}$ - speed $\omega_{2} H M ; x_{4}-M_{y}$ moment that corresponds to the force that is transmitted by rope; $x_{5}$ - linear velocity of the DRD, which is reduced to a rotation speed $\omega_{3} ; J_{1}, J_{2}, J_{3}$ moment of inertia of the motor, HM, DRD; $K_{2}$ - hydraulic transmission coefficient; $T_{2}$ - time constant of the HS; $\delta$ - coefficient of leakage in the HS; $c, b$ - coefficients of stiffness and dissipative forces RTS; $M, M_{C}$ torque and resistance moment.

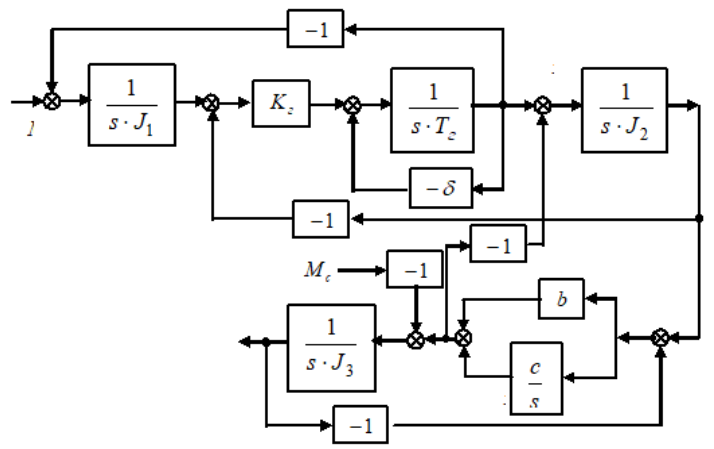

Fig. 5. Block diagram of the control object of the drive lowering-lifting operations and feed DRD 
From the analysis of the obtained mathematical model of the control object of the electric drive of the lowering-lifting and feed operations, it follows that in order to implement the developed method of controlling the drill process, it is necessary to control, in addition to the traditional coordinates (the current and motor speed), also technological coordinates it are the pressure in the hydraulic system, the rotation frequency of the hydraulic motor and linear the velocity of movement of the DRD, which needs a corresponding introduction of the control loops.

The presence of elastic links in the transmission leads to appearance of additional fractional-rational function, the zeros and poles of which are moved from the low to the high frequency region and cross the cutoff frequency of the loop with a decrease in the number of rods in drill string from four to zero.

\subsection{Constructing a system of motor control lowering-lifting and feed $D R D$}

According to the developed method for controlling the drill process, electro-hydro-mechanical drive control system with distributed correction along the loops of dynamic parameters is proposed and investigated (Pivnyak G.G. 2005). The system, in addition to the electro-mechanical parameters of the drive motor, controls the technological parameters defined in Section 3.4 (Khilov 2012), which make it possible to efficiently optimize the dynamic loads in the entire transmission, automate the processes of lowering-lifting and feeding the bit to the bottom, and implement the proposed method for controlling the drill process.

At the beginning of the movement of the drill string with more than three connected rods, in addition to the traditional aperiodic link, the fractional-rational fraction function of the sixth order also enters the current circuit. When tuning the loop to the technical optimum, the classical transfer function of the current regulator must have an inverse transfer function of the loop control object, which is a rather complex controller in implementation, since it is necessary to find high-order derivatives (up to the sixth inclusive) of the error signal. In addition, the regulator must have the properties of adaptation or robustness due to changes in the stiffness of the ropepolyspast system and the weight of the drill string. As the rope length 
is decreased, as well as the decrease in the number of DRDs in the drill string, the characteristic vibration frequencies shift towards large values on the complex plane, crossing the cutoff frequency of the loop.

A traditional PI current controller with a classical tuning does not suppress any of the poles of the control object of the loop, and the presence of additional element in the control object through a significant influence of the circulating electromotive force leads to the loss of astaticism in the current loop.

In addition to the closed loop of the stator current regulation of the induction motor, the mechanical link of the electric drive, an additional transfer link enters the control object of the rotation frequency, which takes into account the elastic properties of the transmission. For the electric drive of the lowering-lifting and feeding operations of a SBSHS-250N medium-type rig, the characteristic oscillation frequencies of the additional dynamic link when moving three or less rods lie in the region that is higher than the cutoff frequency of the rotation frequency loop, therefore, they do not affect the dynamic processes in this loop. When moving four DRDs, which are guaranteed by the manufacturer as a standard operating mode of the DRG, the characteristic oscillation frequencies fall into the passband and significantly change the dynamics of the closed rotation speed loop, i.e. when present four or more rods in the drill string, it is necessary to correct not only the influence of dynamic processes in the current loop by introduction of the first additional regulator, but also the rotation frequency by introducing a second additional regulator.

The characteristic frequencies of the numerator and denominator polynomials of additional dynamic elements that have founded (Table 3) made it possible to reveal the regularity in which the characteristic frequencies of the numerators and denominators (zeros and poles) are periodically repeated in adjacent contours. Only one characteristic frequency in the current loop is determined by the parameters of the induction motor itself and does not depend on changes in the transmission parameters. The characteristic frequencies of the current loops, the rotation speed of the electric motor shaft and the pressure are side ones with respect to the frequency $1 / T y$ and are generated by elastic oscillations of the rope-polyspast system with taking into account the hydravlic system influence, and change nonlinearly depending on the number of rods screwed onto the drill string and the ropes length. 
A regularity has been established between the parameters of the control object, in which the dynamic links, due to the presence of compliance in the transmission, will not be negatively denoted on the dynamic loads in the transmission. So for an electric drive of a medium-type rig, the characteristic oscillation frequencies of an additional dynamic link, when three or fewer rods are moved, lie outside the bandpass of the rotation frequency loop, and therefore they do not affect the dynamic processes in this loop.

On the basis of the research carried out, the scientific foundamentals for the construction of automated electric drives for the drill string lowering-lifting and feeding operations for DRGs new generation for Ukranian open-pit mines condition have been developed. According to which, in order to maintain optimal technological parameters, technological parameters are controlled and limited at an acceptable level - the linear velocity of movement of the drill string, the rotation frequency of the hydraulic motor and hydraulic pressure.

To implement the scientific concept of constructing a control system for electric drives of rotation (Section 3.3) and lowering-lifting operations and supply of the rod (Section 3.5) with correction distributed along the loops, we come to the need to solve the problem: to obtain normalized transient in control loops if the control object contains not only transfer functions of the second order, and fractional-rational functions inclusively up to the sixth order with zeros and poles that can move through the cutoff frequency of the loop. The solution was found in the field of control systems with fuzzy laws, which allow maintaining high-quality transient processes when changing the quantitative characteristics of the control object within wide boundaries.

\subsection{Method of active sequence correction using fuzzy control}

Generalized block diagram of the control object complex EM and EHM installations is shown in Fig. 6, where $W_{\text {оки }}(s)$ - transfer function of the control object compensated part; $\Sigma a_{m n} s^{m} / \Sigma b_{m n} s^{m}-$ additional transfer function that has defined by the transmission elastic properties and is represented as a fraction-rational function (Pivnyak G.G \& Khilov V.S. 2004).

To compensate action of the additional transfer function is necessary to each basic classic controller, an additional regulator connect 
or in series with the generalized transfer function having the form $W_{n}^{\prime}(s)=\Sigma b_{m n} s^{m} / \Sigma a_{m n} s^{m}$ or in parallel with the transfer function $W_{n}(s)$ $=1 /\left(s T_{O T} W_{o k n}(s)\right)\left(\sum b_{m n}-a_{m n}\right) s^{m} /\left(\sum a_{m n} s^{m}\right)$, which has the parameters according to the control loops.

With such compensation, we obtain regulators additionally distributed along the contours with the polynomials of the numerator and denominator, which are equal to the sixth degree - in the current loop of the drive of lowering-lifting and feeding operations, and the fourth degree - in the loop of the rotation frequency of the drive motor of the lowering-lifting drive and the current of the drive rotation of the drill string, which creates difficulties when regulators implemented in the classical form.

If the output signals of all other regulators reduce to the output of the inner regulator, then instead of several connected in parallel to each contour regulator come to the single concentration regulator, which the classical regulators cover in parallel. In this case, get one regulator that has concentrated in the inner-loop controller, and its work algorithm becomes more complex than the work algorithms of the each distributed controllers.

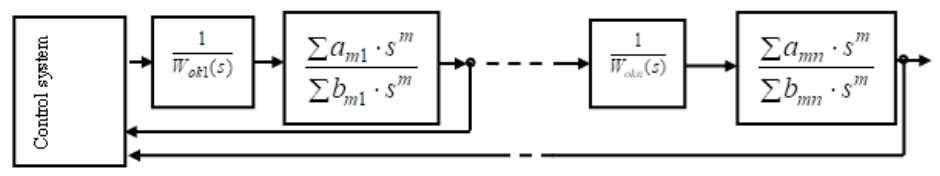

Fig. 6. Generalized block diagram of the control object

We solve the problem of compensating for elastic vibrations in control loops by applying the principles of fuzzy control of complex objects. Instead of classical corrective controllers, we introduce fuzzy controllers into each loop (Fig.7) or bring the action of all additional controllers to the output of the internal classical controller (Fig.8).

In the additional fuzzy corrective controller, there are no a priori assumptions regarding the number and relative position of membership functions, therefore, the synthesis of the fuzzy controller is carried out in two stages. At the first stage, we find the number of membership functions based on the cluster analysis of the input signal vector of the fuzzy controller, and at the second, we adjust the dynamics of its operation on the artificial neural network. 


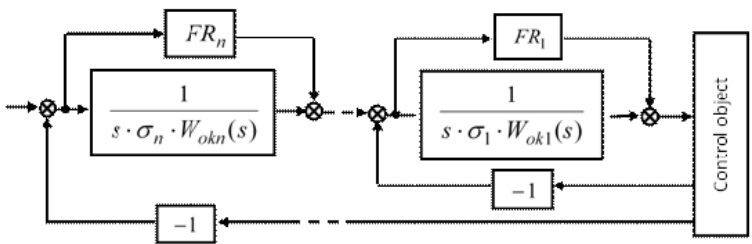

Fig. 7. Control system with additional parallel fuzzy corrective controllers, which are distributed in the loops

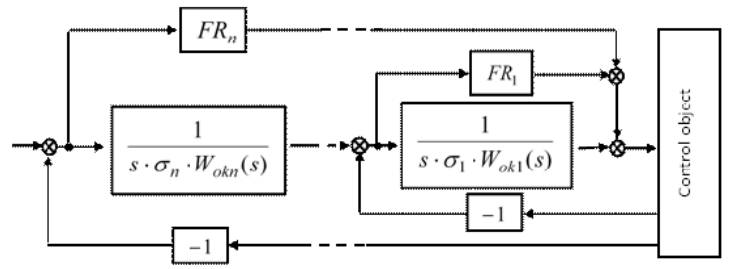

Fig. 8. The control system with additional parallel fuzzy corrective regulators, which concentrated in the inner loop

For a quantitative comparison of the quality of transient processes (Fig. 9), the introduced integral estimates, which take into account the decay rate and the value of the coordinate deviation in aggregate.

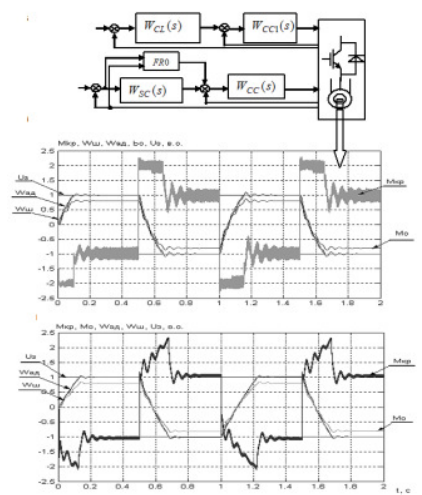

Fig. 9. Vector control system of the rotation drive with hysteresis current regulator, PID speed controller $W_{S C}(s)$, flux linkage $W_{C L}(s)$, current $W_{C C 1}(s)$, PD-fuzzy correction FR0 (a); transients in the system $(a)$ without the fuzzy correction $(b)$, and fuzzy correction (c) where $M_{K P}$ - drive torque, which is turned by phase in angle in $\pi$ radians, $M_{0}$ - reactive resistance moment at roller cone bits, $W_{a d}$ - frequency shaft rotation of $\mathrm{AD}, W_{u}$ - speed of roller cone bit, $U_{3}$ - reference signal to an external speed loop (all variables are given according to their rated values and in relative units are expressed) 
The deviation was calculated not only from the given level, but also the deviation of the motor current and the deviation of the rotation speed to the second and third derivatives, respectively (Yager \& Filev 1984, Zadeh 1976, Pivnyak 2004, Khilov 2011, Khilov \& Glukhova 2004, Terekhov 2001, Terekhov 1996, Leonenkov 2003, Medvedev V.S. 2002).

These estimates $I_{u}, I_{c}$ characterize the approach of transient to extremals, due to the solution of the differential equations of the characteristic polynomials of the optimized circuits of the rotation frequency and motor current. As follows from the analysis of the values $I_{u}, I_{c}$ of the integral estimates of the indicators of the transient process, the greatest deviation from the optimally tuned control system is observed when using a PI-fuzzy controller, and least of all - a PD-fuzzy controller. The PID controller has intermediate indicators of control quality. Therefore, in the algorithms for the operation of a fuzzy current and speed controller, it is enough to limit ourselves to two components - proportional and differential (Pivnyak G.G \& Khilov V.S. 2004).

The use of classical systems with the correction distributed over the loops makes it possible to effectively limit the current and limit values of the coordinates that are controlled, and the use of fuzzy laws effectively compensates for the actions of the elastic properties of the transmission in the control loops. Thus, we obtain the adaptation of control systems for electric drives of rotation, lowering-lifting and feed operations to the operating modes of the DRG and parameters of the control object, which allows the proposed energy and resource-saving control method to be applied in the process of drill blast holes.

Such approach to the action suppression of additional fractionrational functions of high order in the control loops allows implementing the proposed concept of object-oriented automated electric drives of rotation and lowering-lifting DRD of career DRGs of the new generation. In which to improve the quality of regulation the DRD natural torsional vibrations and elastic vibrations in hydro and rope-polyspast systems are suppressed by introducing into laws of the loops classical regulators additional fuzzy control laws.

\section{Conclusions}

As a result of the research, the following results were obtained. 
1. Analysis of dynamic properties of automated driving systems and frequency characteristics of transmission mechanisms of rotation, lowering-lifting and feed DRD of DRGs allowed to put forward the idea of building automatic control system, which concentrates the flow of mechanical power in the area of the bottomhole by suppressing forced transverse vibrations of rotating and natural torsional oscillations, which minimizes the dynamic load on the nodes of DRGs and provides energy and resource efficiency when drill blast holes.

2. The analysis of the methods of automatic control of the process of rotating drill of blast wells at the modern level of technological advances has shown that it is rational to carry out drill on the basis of the energy criterion, according to which the bit has the greatest durability at a uniform energy load, i.e. when supporting the linear growth of the mechanical energy of rock destruction or by keeping the mechanical power at a constant level, which is released in the bitbottom hole contact zone. In this case, depending on the strength of the rock, it is necessary to form a mechanical characteristic on a bit with variable or constant stiffness.

3. It has been established that the most important for the development of the theory of automated drives of rotation of the drill string are such revealed patterns of drill of blast holes:

- in drill modes with a fully assembled string of $33 \mathrm{~m}$ long, transverse natural low-frequency vibrations with a cyclic frequency of $1.05 \mathrm{~Hz}$ are generated in the SBSHS-250N rigs (for the СБШ$250 \mathrm{MH}-32 \mathrm{rig}-2.48 \mathrm{~Hz}$ with a string length of $24 \mathrm{~m}$ ), which do not directly affect on the dynamics of the drive system, but lead to the appearance of additional loads on the units of DRGs, the suppression of which is possible only by reducing the frequency of the rotation of the string, which leads to a decrease in the productivity of mining operations;

- when drill with the string with three or more rods, the angular frequencies of natural torsional vibrations in the SBSHS-250N rig are less than $1861 / \mathrm{s}$ and fall into the passband of the transistor AC drive system with a cutoff frequency of the external loop of 2001 / s, which significantly worsens the quality indicators control of the electromechanical system. It is advisable to compensate for such fluctuations by means of the control of the drive system; 
- low-frequency torsional oscillations of the drill string contribute to the emergence of additional fractional-rational functions of a high order both in the loop of the frequency rotation and in the loop of the current of the rotation electric drive, which, when using classical PID-Controllers, leads to the need to reduce the speed of the entire control system;

- the zeros and poles of additional transmitting functions in the control loops, which are caused by elastic vibrations in the DRD, are repeated in adjacent control loops and, when the added masses in the drill string, shift relative to the loop cutoff frequency.

4. On the basis of the established regularities during drill of blasting wells, the scientific foundations for the construction of automated electric drives for rotation of the drill were further developed, according to which the proposed and studied object-oriented drive systems for rotation of the DRG with a power flow regulator in the zone of rock destruction with nonlinear correction in the feedback channel were proposed and investigated. These systems implement a method for controlling the drill process based on an energy criterion, which provides for the formation of hard mechanical characteristics of an electric drive when drill rocks with a strength factor less than10-13 points on the scale of M.M. Protodyakonov and a transition to soft mechanical characteristics when drill in harder rocks, which will ensure resource saving of roller cone bits.

5. It was found that for the development of the theory of automated electric drives for lowering-lifting and feed DRD to the face, the following revealed regularities are most important:

- to implement an energy and resource-saving drill method, it is necessary to control, in addition to the shaft rotation frequency and motor current, also the pressure in the hydraulic system, the rotation frequency of the hydraulic motor shaft and the linear velocity of the drill string;

- from the elastic properties of hydraulic and rope-polyspast systems in the loops of control objects the oscillations appear, which quantitatively defined by the additional fraction-rational function of the sixth order in the current loop and the fourth - in the loop of frequency rotation;

- in additional dynamic links of adjacent contours, repeating zeros and poles appear, which are excited by elastic vibrations in hydroand rope-polispast systems. Repeated zeros and poles are shifted rel- 
ative to the cutoff frequency of the control loop when changing the added masses in the drill drill string.

6 . On the basis of the analysis of the regularities in rotation systems, lowering-lifting and feeding systems of drill string on bottom delivery, the scientific concept of constructing automated electric drives for DRGs was further developed, according to which, in order to energy and resources save, depending on the strength of the rock that is being drilled, on the roller cone bit is formed mechanical characteristic with constant or variable stiffness and limitation of lateral and torsional vibrations of the drill string, as well as vibrations in hydraulic and rope-polyspast systems. This concept differs in that the forced transverse vibrations of the drill string are limited by influencing on the signal of setting of the rotation speed of the rotation mechanism, and natural torsional vibrations and elastic vibrations in hydro- and rope-polispast systems - by introducing additional fuzzy laws into the control laws of classical loop regulators control with simultaneous control and limitation at the permissible level of technological parameters: in the rotation drive - mechanical power flow in the area of the work face; in the drive of lowering-lifting and feed operations of drill string to the bottom - the linear velocity of movement of the drill, the frequency of rotation of the hydraulic motor and the pressure in the hydraulic system.

7. Within the developed scientific concept of building automated electric drives:

- the behavior of the characteristic frequencies of closed control loops was investigated and it was found that they cross the cutoff frequency and fall into the pass band from the attenuation band of frequency-controlled asynchronous motors in new generation SBSHS-250N rig both in the rotation drive - in the current and rotation frequency loops, and in the drive of lowering-lifting and feed of the rod - in the current loop when the maximum number of connected rods in the drill string. It has been established that the lowest lowfrequency oscillations, which are due to lateral frequencies generated by oscillations of the drill string, hydro - and rope-polistpast systems, fall into the fastest-acting internal current loop;

- for effective suppression of elastic vibrations in the control loops both in the rotation drive and in the drive of lowering-lifting and feed of the bit to the rock face, the established need for the use of 
additional fuzzy controllers distributed along the loops or concentrated in the inner loops. It is proved that fuzzy controllers, which are concentrated or distributed outside the loops, should be applied in the loops, in the passbands of which additional fractional-rational functions have fallen, which are due to the elastic properties of the transmission, the characteristic frequencies of which are lower than the cutoff frequency of the contour with the maximum number of connected rods in the drill string;

- a method for calculating the training set for neuro-fuzzy controllers has been developed, which differs in that to find the training set, transfer functions are used in the form of high-order fractional rational functions, which are due to the properties of the control object.

\section{References}

1. Quang N. P., Dittrich J.-A. 2010. Vector Control of Three-Phase AC Machines: System Development in the practice (Power Systems). Springer, 340. New York.

2. Novotny D. V., Lipo T.A. 1996. Vector Control and Dynamics of AC Drives. Oxford science publications, 450. New York.

3. Boldea I., Nasar S.A. 1992. Vector Control of AC Drives (Handcover). CRC Press Taylor \& Francis Group, 240. New York.

4. Boldea I., S.A. Nasar S.A. 2006. Electric Drives. CRC Press Taylor \& Francis Group, 522. New York.

5. Khilov V.S., Beshta AS, Zaika V.T. 2004. Experience in the Use of Drilling Rigs with a Variable Frequency Drive in the Quarries of Ukraine. 285-289. Mountain information-analytical bulletin. Moscow State Mining University. \#10. (In Russian).

6. Khilov V.S. 2003. The Method of Controlling the Drilling Process. Patent 61548A, Ukraine, International Classification of Inventions E21B45/00. Bulletin \#11, 2003. (In Ukrainian).

7. Pivnyak G.G., Beshta A.S., Khilov V.S. 2005. AC Drive System for Actuator's Power Control. P.368-370. XIII International Symposium on Theoretical Electrical Engineering ISTET'05, Lviv.

8. Khilov V.S., Plakhotnik V.V. 2004. Evaluation of Natural Frequencies of the Drill Rod in Unsteady Modes. 145-150. Collection of scientific works. National Mining University. - 2004. - \# 19. (In Russian).

9. Pivnyak G.G., Beshta A.S., Khilov V.S.2003. Principles of Construction of the Control System of the Electric Drive of Rotation of the Rod String of the Cone Drilling Rig. 141-143. Bulletin of the National Technical University "Kharkiv Polytechnic Institute". Scientific works of National Technical University "Kharkiv Polytechnic".\# 10. V.1. (In Ukrainian).

10. Khilov V.S. 2006. Changing the Dynamics of the Drill Rotator Drive when Using the AC Drive System. 180-184. Bulletin of the Krivoy Rog Technical University. Development of ore deposits. Krivoy Rog. \# 1 (90). (In Russian). 
11. Pivnyak G.G., Beshta A.S., Khilov V.S. 2005. Drive System of Lowering Lifting Operations of the Drilling Rig. 223-225. Bulletin of the National Technical University "Kharkiv Polytechnic Institute". Scientific works of KhPI "Kharkiv: NTU" KhPI ".\# 45. (In Ukrainian).

12. Khilov V.S. 2006. Application of Computer-Aided Drives in New Generation Boring Rigs for Open Pit's in Ukraine. 72-76. Scientific herald National Mining University, \#5.

13. Pivnyak G.G., Beshta A.S., Khilov V.S. 2004. Adaptive Fuzzy Power Regulator to Control the Drilling Process. 47-52. Technical electrodynamics. - Kyiv, \# 6. (In Ukrainian).

14. Khilov V.S. 2011. Drill Spinner Drive Dynamic Performances Correction of Blast Hole Boring Rig. 90-95. The materials of the international conference of “Miners Forum 2012” Dnipropetrovsk, National Mining University.

15. Khilov V.S. 2012. Information and Analytical Characteristics of Drilling Rig Parameters. 90-95. Proceedings of the international conference "Miners' Forum 2012" Dnepropetrovsk, NGU. (In Russian).

16. Terekhov V.M. 2001. Fuzzy Controller Algorithms in Electrical Systems. 55-63. Electricity, \#12. (In Russian).

17. Terekhov V.M., Baryshnikov A.S. 1996. Stabilization of Slow Moving Vehicles Based on Fuzzy Logic. 61-64. Electricity, \# 8. (In Russian).

18. Zadech L.A. 1974. The Concept of a Linguistic Variable and its Application to Approximate Reasoning. 165. SpringerLink.

19. Yager R., Filev D. 1984. Essentials of Fuzzy Modelling and Control. 387. USA: John Wiley \& Sons.

20. Leonenkov A.V. 2003. Fuzzy Modeling in the Environment MATLAB and fuzzyTECH. 736. SPb.: BHV-Petersburg. (In Russian).

21. Medvedev V.S., Potemkin V.G. 2002. Neural network MATLAB 6. 496. Moscow: DIALOG-MEPHI. (In Russian).

22. Khilov V.S. 2013. A Solution to the Problem of Frequency Compatibility Between Drive System and Dynamic Parameters of Drill Rings. 93-103. Energy Efficiency Impotent of Geotechnical Systems. CRC Press.

23. Khilov V.S. 2012. Research of Dynamic-Informational Characteristics of the External Circuit of the Drive of the Drilling rig Movement. 92-97. Scientific Bulletin of the National Mining University. \#2. (In Ukrainian).

24. Khilov V.S. 2012. Research of Information-Analytical Properties of Electromechanical System at Nonlinear Correction by Power Task. 114-120. Scientific Bulletin of the National Mining University. \# 4. (In Ukrainian).

25. Kozhevnikov A.A., Khilov V.S., Belchitskiy A.P., Borisevich. 2012. Experimental Research Pulse Rotary Drilling Technology Tool. 96-108. Scientific Bulletin of the National Mining University. \# 6. (In Russian).

26. Khilov V.S., Glukhova N.V. 2019. Drive Systems of the Drill Machines for Open-Pits in Ukraine: the Situation State and Improvement Ways. 117-129. XIII International Scientific and Practical Conference "Ukrainian School of Mining" as a step towards a new direction of innovative technologies and intelligent systems in the mining industry, v.123. 
27. Khilov V.S., Triputen, V.M. Effect of The Types of Drive Systems of DRGs on The Rock Breaking Dynamics. 158-169. Seventh International Conference IEEE 2020 on Energy Efficient Systems (ESS) 2020.

28. Glukhova N.V., Khilov V.S. 2020. Integrated Assessment of the State of Sewage Mine Waters Based on Gas-Discharge Radiation Method. 129-144. XIV International Scientific and Practical Conference "Ukrainian School of Mining" as a step towards a new direction of innovative technologies and intelligent systems in the mining industry, v.132

https://doi.org/10.31713/m1115

\title{
IMPROVING THE EFFICIENCY OF THE TECHNOLOGICAL COMPLEX FOR THE DEVELOPMENT OF MARINE GAS AND GAS HYDRATE DEPOSITS
}

\author{
Pedchenko N.M. \\ National University «Yuri Kondratyuk Poltava Polytechnic», \\ $\mathrm{PhD}$ Student, Ukraine
}

\begin{abstract}
Purpose. Substantiation and the development of principled schemas, acceptable to the existing technique, methods of production and transportation of natural gas of the offshore fields of gas or gas hydrates. Improving their efficiency by way maximum reduction of the energy consumed is the result of complex consideration of thermal properties and parameters of interaction of the components system within the deposit what is developing.

Findings. The technology of gas hydrates withdrawing with the productive reservoir without energy consumption for the phase transition is proposed. The question of enrichment directly in situ of rocks what containing gas hydrates is considered. Dissociation of residue of the gas hydrates in the rock must be implemented at the expense low potential energy of sea water. The expediency of a compatible development of gas hydrate and gas fields, by way binding of free gas in gas hydrates at the expense of presence of necessary temperature and pressure conditions at passes it through the thickness of sea, is proved. Expediency combination into one a chain of the proposed technology of the development of the offshore fields of gas and gas hydrate with technology of gas transportation in hydrate form and its storage in terrestrial storages is proved.

Originality. Ability to extract gas hydrates from the productive reservoir without the energy consumption for the dissociation, by creating conditions of its recrystallization as a result compatible actions of flooded streams of sea water in a mixture with an abrasive material and pressure fluctuations, is proved. Ability to extract natural gas from residue of gas hydrates in the pulp at the expense of low energy of seawater and changes of its pressure with depth is proved.
\end{abstract}


Practical implications. The proposed gas hydrate technology creates important preconditions for the development of small and medium remote gas deposits (including the gas hydrate), the network of terrestrial storages of the hydrates, improves the efficiency and competitiveness of technology marine transport of natural gas in the hydrate form. Key elements of the technological complex production, transportation and storage of gas offshore fields of the gas and gas hydrate on the basis of gas hydrate technology are proposed and proved.

\section{Introduction}

Level of consumption of natural gas is growing. Its easily accessible reserves are depleted rapidly. However, about $80 \%$ of the gas fields, which open in the world, is a relatively small or remote from the transport infrastructure. Most of them are located on the shelf of seas (in the form of traditional deposits and in hydrate form). Thus, the existing technologies of the development do not contribute to the rational use of a substantial part of their resources (example, construction of pipelines can be economically unjustified).

Water molecules and low molecular components of natural gas have the property under certain conditions of temperature and pressure to form relatively stable compounds - gas hydrates. This property caused to the fact that in the depths of the earth and the waters of the World's ocean emerged almost unlimited resources of natural gas in solid hydrate form, which available most countries. Gas hydrates are crystalline compounds (clathrates) of the structure of the general formula $\mathrm{MnH}_{2} \mathrm{O}$, where $M$ - a molecule of gas hydrate-forming; $n-$ the number that describes the composition and depends on the formation of gas hydrates $(n=6-17)$. One volume of water contains the 70-210 volumes of gas.

Potential worldwide resources of the gas hydrate are estimated at $2.1 \cdot 10^{16} \mathrm{~m}^{3}$ (Kvenvolden, 1993). They approximately $98 \%$ are concentrated in the World Ocean at depths of 200-700 meters, and in the bottom sediments with thickness of 400-800 m. (Hence, their development does not require drilling of the ultra-deep wells).

In the Black Sea area gas resources in the hydration state is estimated at $25 \cdot 10^{12}-70 \cdot 10^{12} \mathrm{~m}^{3}$ (in the economic zone of Ukraine $7 \cdot 10^{12}-20 \cdot 10^{12} \mathrm{~m}^{3}$ ) (Vasilev \& Dimitrov, 2002).

Natural gas hydrates more evenly are distributed on the planet than a source of oil and gas. The wide introduction of technology their development can lead to inexpediency of imports of natural gas 
from other countries. Thus, natural gas hydrates will play an important role in the global energy balance as one of the major unconventional resources in the near future.

Analysis of the data concerning the today's known gas hydrates kicks and their features in the oceans and lakes permits to conclude that the submarine gas hydrates can form clusters, which are located at great sub-bottom depths (hundreds of meters) and are controlled by the zones of percolation in the conditions of distributed fluids filtering, or are located in the close proximity to the sea floor, at the bottom or at very shallow sub-bottom depths (first meters).

Most of hydrates are present in coarse-grained sedimentary deposits, but when performing the research, hydrates were also found in fine-grained sediments as small inter-layers, lenses and thin, almost vertical loads. For example, the study of well NGHP-01-10 detected a powerful range of fractured clays, the hydrates content of which is among the highest in the world (Timothy, 2010).

Formed in reservoir conditions hydrated crystals can be dispersed in the pore space without destroying of pores and with their destruction, may be in the form of particle $5-12 \mathrm{~cm}$, in the form of lenses of small size and in a well-seasoned, of long clean hydrate layers the thickness to a few meters.

There are three basic methods of extracting gas from gas hydratebearing layers: lowering the pressure below the hydrate formation equilibrium at a designed temperature, heating hydrate-containing rocks to temperatures higher than the equilibrium and their mechanical disintegration. Also solutions are known, suggesting to use the reagents, which can influence the chemical activity of water and gas, causing a shift in the equilibrium of formation and dissociation reactions of gas hydrates to the lower temperatures zone (the so called inhibitors: methanol, ethylene glycol, electrolyte solutions, etc.). Most of the presently known methods for gas hydrate deposits development suggest a combination of the above methods.

Classic examples of thermal methods for gas hydrate deposits development is the US Patent 6192691: it suggests hot water injection under the gas collecting dome, installed over the bottom set gas hydrates accumulation, and application US 20050161217: it suggests electric heating of a productive reservoir and to extract the gas re- 
leased through the production well. The international application WO 2007/136485 suggests gas hydrate reservoir heating by means of the laser radiation energy. An example of the combined action on a gas hydrate reservoir (in this case thermal energy and inhibitors are meant) are patents US 4.424.866 and US 6.733.573.

However, the disadvantage of thermal methods for gas hydrate deposits development is significant energy consumption. Thus, besides the relatively small energy consumption for gas hydrates dissociation (about 7\% of the extracted gas combustion energy), most of them will be used to heat hydrate saturated stratum's rocks and its surface and roof rocks. Moreover, considering the thermal and physical properties of rocks and gas hydrates, it is obvious that the heat action zone in the reservoir will be limited to a few meters.

The most profit-proved technology of gas hydrate deposits development in terms of energy costs is reducing the reservoir pressure below the equilibrium, followed by free gas extraction. An example the above method is described in international application WO 2007/072172, which suggests reducing pressure in the gas hydrate reservoir by degassing the lower horizons.

However, this method is available for deposits, where hydrates saturation is insufficient and a reservoir has sufficient gas or water permeability. Naturally, hydrate saturation growth (and, hence, permeability reducing), the above method's efficiency plunges.

Another disadvantage of the said method, based on reducing pressure in the hydrate bearing reservoir, is associated with the secondary anthropogenic formation of hydrates in the bottom-hole formation zone due to the Joule - Thomson effect and manifestation of effect self-preservation of hydrate in a layer. For example, the initial temperature of the reservoir $283 \mathrm{~K}$ and $5.74 \mathrm{MPa}$ pressure coefficient Joule - Thomson is 3-4 $\mathrm{K}$ at $1 \mathrm{MPa}$ depression. Thus, at the depression of 3-4 MPa, the bottom-hole temperature may reach the freezing point of water. The process is additionally complicated by the fact that the rocks containing over $60 \%$ of hydrate is virtually gas impermeable (Basniev, Kul'chitskiy, Shchebetov \& Nifantov, \& Nifantov, 2006). As a result, gas hydrate (hydrate layer) for a long time, which will depend on the speed of heat supply and will be determined by its thermo-physical properties and around in the sole and roof of rocks, will be "reliably", preserved by the ice layer. 
In addition, the results of experimental studies gas filtration through hydrate-saturated the rocks that are given in (Beznosikov \& Maslov, 1975), indicate that the permeability of gas into two, three or more orders less than the permeability of unsaturated by hydrates samples. Low permeability is associated and with initial water saturation because for some its meanings gas hydrate forms in all volume of the porous medium, filling all pores and micro-cracks.

In addition, gas hydrates could serve as "cement", for particles of the formation's rock. Dissociation of clathrates in sediments causes abnormally high porosity and releases large masses of water (Kvenvolden, 1993). Thus, the destabilization of gas hydrates will lead to a significant weakening of sedimentary structures in the dissociation zone. Therefore, destruction of a gas hydrate structure by reducing the pressure, raising temperature or introducing inhibitors may lead to decompaction of the hydrate cemented rock and transforming them into an over wetted unstable structure with gas bubbles inclusions. Due to the depression, created for extracting gas, over wetted stratum destruction and suction of an unlimited number of rock species together with water and gas into the reservoir's bottom hole, will inevitably happen, making for further exploitation of the well practically impossible.

There are also ways to simultaneously reduce pressure and heat supply to wells. Moreover, hydrate dissociation in the reservoir is mainly due to lower pressure; and heat, supplied to the bottom-hole, permits reducing the zone of secondary hydrate formation, thus positively affecting the gas flow rate. However, a combination of these methods does not solve the above disadvantages.

Methods are presented in applications US 2008/0088171, WO 00/47832 and RU 2004106857/03 suggests open-cut mine development of marine gas hydrate deposits by their mechanical disintegration. Thus, the method of selection of bottom hydratecontaining sediments by underwater excavators, their lifting to the surface in containers and accumulation of received gas under the dome, located in the ship's bottom, is described in the application US 2008/0088171.

The method of extracting gas hydrates from the seabed, described in the application RU 2004106857/03, suggests using an extraction device in the form of a self-propelled harvester and a device, 
delivering them to the surface as barge, which emerge to the surface own.

The method of extraction bottom and sub-bottom hydrates described in the application WO 00/47832, provides destruction of gas hydrate layer by compressed air and special high-density solution (or water pressured), served through the pipe, separation from the bottom of the pieces hydrate, them collection and dissociation. The possibility of heating the compressed air and fluid is also stipulated. However, the surface of gas discharge areas, which are located near the bottom gas hydrates deposits, is mainly covered with a layer of sediments (often submarine hydrates occur, starting from a depth of 0.4 to $2.2 \mathrm{~m}$ below the bottom surface (Shnyukov, Gozhik, Krayushkin \& Klochko, 2007) and based on the speed of attenuation of stream energy in the aquatic environment an insignificant depth of them cutting the effectiveness of this method will be questionable.

This also applies to the case, characteristic for most deposits of gas hydrates - attitude of volume of gas hydrates up the mineral party is insignificant (hydrates fills the pores or cements mineral party of layer). So, using a method, suggesting the gas hydrates disintegration by means of air or liquid streams, and also using the quarry rock cutting machinery, located directly on the seabed, will be inefficient.

\section{The main part of the article}

\subsection{Analysis of technology of the borehole hydro- mining}

In mining industry, the method of minerals hydro-mining (Arens et al., 2007) is well know, it stipulates drilling the well in the deposit field, reducing the density of rocks in the place of its location by means of transferring it into a moving state by means of a hydraulic monitor jet and extracting the hydraulic fluid (pulp) to the surface. Analysis of technological operations of the borehole hydraulic mining (bearing of the productive strata, hydraulic-ablation, the formation of a pulp, transportation from the unit to the inductive apparatus, raise of the hydraulic-mixture to the surface, enrichment) and consistency of their implementation has shown perspective of implementation of this method to develop of the gas hydrate deposits.

Hydraulic method to separate rocks from the block carries out 
through water jets which flow from jet-apparatus, main task which is the formation and direction of these jets. The hydraulic-production aggregate, which represents a combination of borehole jet and hoisting and transport mechanism of the borehole for extracting of the pulp to the surface, is mounted in a borehole. The transformation of static water pressure in the kinetic energy of the jet occurs in jet. The rate of the water increases as a result of decrease of cross section of the nozzles at a constant it expenditure (the potential energy of water nozzle converted into kinetic, stock of which with distance from nozzles is lost). In this case in the technologies borehole hydraulic-production jet is a working organ for destruction and transportation of rocks.

The mechanism of the process of the primary hydraulic destruction is characterized by versatility action of water on the block, which includes destruction due to shear stresses, impact, filtration pressure (Rehbinder, 1980), and at every point is described by the following formula

$$
\tau \geq\left(c_{t}-c_{p}\right)+\left(\gamma H \cdot 10^{-2} \operatorname{tg} \varphi_{t}-K_{l} \gamma H \cdot 10^{-2} \lg \varphi_{p}\right),
$$

where

$\tau$ - destructively-shear stresses, $\mathrm{MPa}$;

$c_{t}$ - temporary adhesion (maximum), $\mathrm{MPa}$;

$c_{p}$ - prolonged adhesion, $\mathrm{MPa}$;

$\varphi_{t}$ - temporary angle of internal friction, ${ }^{0} \mathrm{C}$;

$\varphi_{p}$ - prolonged angle of internal friction, ${ }^{0} \mathrm{C}$;

$\gamma$ - density of rocks, $\mathrm{kg} / \mathrm{m}^{3}$;

$H$ - depth of development, m;

$K_{l}$ - coefficient of lateral pressure.

Thus penetrating into a block at the expense of filtration through pores and cracks water lowers the strength of rocks (Rehbinder, 1980), causes local hydraulic fracturing and destruction. This should taken into consideration by adjusting laid dependence at the studying the mechanism of grinding of a particular block and introduction of appropriate coefficients. But in the process of movement of the jets in multiphase systems (water, solid inclusions, gas) phenomena occur so complex that sufficiently reliable methods of analytical determination does not exist today.

\subsection{The method of development of gas hydrate deposits}


Considering disadvantages of technology introduced above, method development of marine gas hydrate of deposits (Fig. 1) is proposed, which provides:

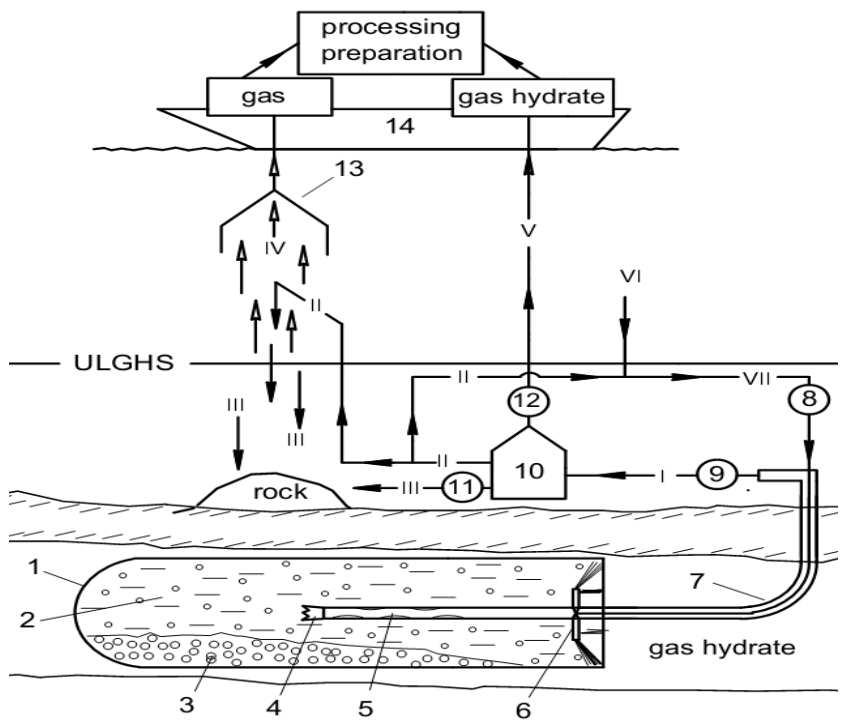

Fig. 1. Principal diagram of the method for marine gas hydrate deposits development: ULGHS - the upper limit of gas hydrate stability; 1 - excavation in the hydrate-saturated reservoir; 2 - space in the excavation site filled water-hydrate mineral pulp; 3 - sediment of rock solid inclusions; 4 - drill bit; 5 - pulp intake; 6 - jet gun device; 7 -well; $8,9,11,12$ - pump; 10 - gravity separator; 13 - gas collecting dome; 14 - production platforms; streams; I - water-hydrate mineral pulp; II - gas hydrates depleted pulp; III - empty rock; IV - gas released from the pulp as a result of gas hydrate dissociation; V - water gas hydrate mixture; VI - sea water;

VII - working fluid for rock disintegration (sea water and pulp mixture)

- disclosure of hydrate layer by horizontal boreholes, of the powerful - of vertical or obliquely directed to the their sole (7);

- the impact on the productive layer (starting with the well drilling) with the purpose of its disintegration by means of mechanical grinding at the minimum level of dissociation and gas hydrates recrystallization (due to the formation of local zones for a short time under the non-equilibrium conditions) as a result of immersed jets of high-pressure mixture of water and abrasive material (stream VII) using hydro-monitor (6). Notably, to increase the output volume, 
steel stems with jet gun nozzles are extended in the operating position, occupying the position perpendicular to the well's axis (7) and, turning around it, are moving along to the contact with the front of disintegration;

- formation, as a result of mixing the grinded hydrate containing rock with water of the water-hydrate mineral pulp (2);

- gravity separation of part of the relevant density and fractional composition rock mineral inclusions (3) from the water-hydrate mineral pulp (2) at some distance behind the active operating zone;

- withdrawal of the pre-enriched water-hydrate mineral pulp from the excavation site (1) through the pulp intake (5), located behind the active operating zone, to the separator (10), located at the seabed level;

- separation from the water-hydrate mineral pulp (stream I) (under the pressure higher than that of the hydrate formation equilibrium) in a gravity separator (10) as a deposit of empty rock's part, which is pumped out with the pump (II) to the bottom or through another well - to the discharged rock (stream III) and as a fraction that comes to the surface: a mixture of water and free gas hydrates (stream V) (natural and partly recrystallized);

- supply of the separated gas hydrates in a mixture with water (flow $\mathbf{V}$ ) as of the upper flow of the separator (10) by pump (12) to the extractive a platform (14);

- selection of the gas hydrates depleted water-hydrate mineral pulp's part (stream II) after separation, adding thereto sea water (stream VI) and supply (pump 8) resulting mixture (stream VII) under pressure to hydraulic jet gun (6) for rock disintegration (solid fraction of formed mixture acts as an abrasive);

- pumping out the rest of the depleted pulp (stream II) under the gas collecting dome (13) into the sea through a pipe, the open end of which is located above the upper limit of the gas hydrate stability (ULGHS). Meanwhile, as a result of being exposed to nonequilibrium conditions and the heat exchange with sea water, dissociation of the remaining gas hydrates into gas and water is taking place in the depleted pulp;

- sedimentation of the rocks onto the bottom (stream III), accumulation of gas in the gas collecting dome (13) and its supply to the platform (14). 
The suggested method for the hydrate deposit development suggests 4 basic stages: 1) hydrate containing rock disintegration in order to transfer it into the movable state; 2) concentrating pulp in the well as result of the rock cuttings sedimentation at a certain distance behind the active layer disintegration area; 3) separation (enrichment) of free gas hydrates in the gravitational separator and reducing the volume of pulp per the volume of water gas hydrate mixture and sedimentary rocks; 4) gas release as a result of the gas hydrate residues dissociation in the process of rock passing through the thickness of sea water at the interval exceeding the upper limit of this composition gas hydrate stability.

In this method of influence the gas hydrate layer is exposed:

- of salt sea water;

- of the heat energy released at transformation of mechanical energy of the jet;

- of pulsations of pressure of the working mixture in the process of the jet work.

Thus gas hydrate for some time enters non-equilibrium conditions and partially dissociates. However, considering the heat balance of the process and features of kinetics, the impact will be short and will carry local character (in a contact zone of the working stream with the rock). As a result, dissociation of the certain part of gas hydrates is associated with rocks, will occur in one and free gas will forms hydrate in another place. In addition, the permanent presence of free gas will be the result of recrystallization of gas hydrates in zone of the destruction of rocks. The presence of compressible gaseous phase in the zone of pressure fluctuations also will be an additional factor of the impact on the layer.

Thus, the advantage of the proposed method of development of the gas hydrate deposit is as follows: 1) basic quantity of gas hydrates are extracted without the spending of energy on the a phase transition; 2) dissociation of the gas hydrates residue in the pulp for the extraction of gas is carried out due of low potential energy of sea water and changing of it pressure with depth.

\subsection{Transportation of produced products}

Regardless of the form of gas in the deposit (free gas or gas hydrates), the level of perfection of technical and technological solu- 
tions of operations of its preparation and transportation significantly influences on the efficiency of the technology of extraction of gas too. Nowadays natural gas is transported by sea pipelines in the gaseous state and by tankers in liquefied state (LNG-technology). However, in recent years, technology based on the ability of gas molecules and water form gas hydrates, is actively developed. In the composition of gas hydrate considerable volumes of gas can long be stored at atmospheric pressure and a slight negative temperature. This technology has undeniable prospects for implementation in the near future, but needs improvement and testing of its elements.

At present several concepts the transportation of gas in hydrate form are considered. The technology for the transportation of nonequilibrium conditions (small negative temperature and atmospheric pressure) is the most attractive. It needs the production of gas hydrates in the most stable form under these conditions. At present granules of the gas hydrate is proposed transport today (Gudmundsson, 1996). However, over time freezing granular hydrates complicates unloading (Dawe, Thomas \& Kromah, 2003). Also granular gas hydrate only by $78 \%$ fills volume of vehicles or storages (Gudmundsson, Graff \& Kvaerner 2003). Besides, much of the total surface area of the granules and system of open channels between channels granules stimulates the process of volumetric dissociation of the gas hydrate mass. Keeping them stable at atmospheric pressure needs additional costs for cooling to temperatures below a $258 \mathrm{~K}$. Monolithic blocks of large size are a good option.

However, today the industrial technology of production does not exist (Yakushev, Gerasimov, Kwon, \& Istomin, 2008). Due to thermal properties and features process of transportation and storage, gas hydrates is proposed to produce in the form of gas hydrate of blocks maximum cooled large, preserved with the layer of ice and refrigerated in the production process to the desired level (Pedchenko, Pedchenko, 2012).

This technology provides intensive production synthetic gas hydrates. Moreover it must have maximum gas content (up to $160 \mathrm{~m}^{3} / \mathrm{m}^{3}$ ). According to the research the formation of hydrates proposed to perform in the contact devices on the basis of jet devices (ejectors with elongated mixing 
chamber or jet devices with free stream).Their application allows increasing efficiency and simplify the process of technological design of technology (Pedchenko, Pedchenko, 2014) (Fig. 2).

$a$

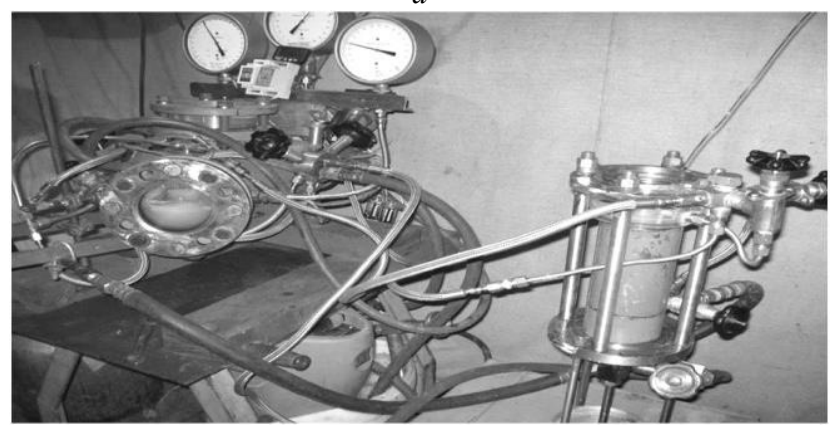

b

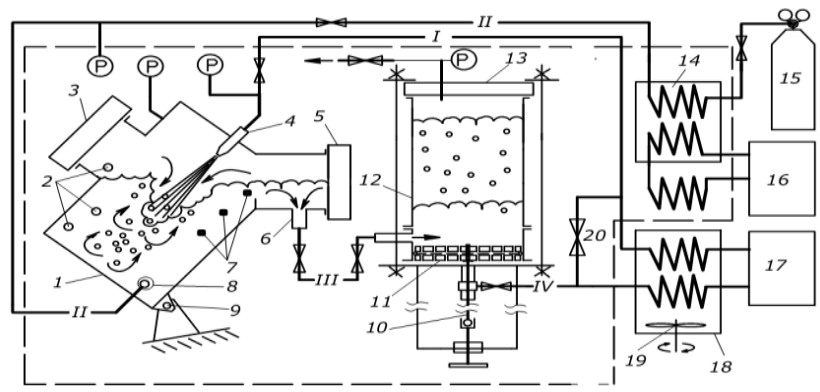

Fig. 2. The laboratory unit for continuous production of gas hydrates: a) photos; b) scheme ; 1 - reactor; 2 - temperature sensors; $3,5,13$ - observation windows; 4 inkjet apparatus; 6 - branch pipe; 7 - LEDs; 8 - bubbler; 9 - hinge; 10 - rod; 11 plunger with filter; 12 - separator; 14,18 - exchanger; 15 - balloon; 16 - refrigerator; 17 - pump; 19 - mixer; 20 - valve; flows; I, IV - water; II - gas; III - mixture of hydrate and water

Blocks will be formed from the previously cooled mixture of crushed and granulated hydrates of minimum porosity in the respective proportion. This solution allows to obtain blocks of uniform density and to waive the need them cooled (Fig. 3). 

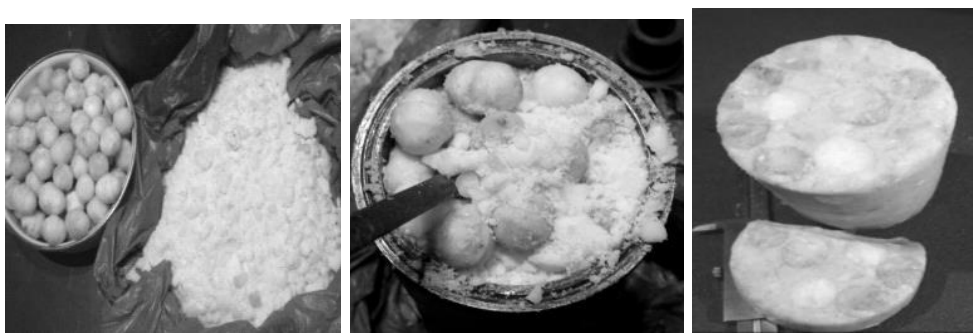

Fig. 3. Transverse section of the gas hydrate block after the formation

To increase stability and the mechanical strength of hydrate blocks necessary force to preserve with the layer of ice. For this purpose, on their surface freeze crust 1-2 mm is sufficient (ice crust, formed as result selfpreservation is thinner) (Gudmundsson \& Parlaktuna 1991).

In the study of the force preservation of the gas hydrate blocks the need re-application of water from endurance to crystallization of the previous layer was established. In the first application main part of the pores was blocked and «cementing» of the surface of the sample to a depth of water penetration. In the second - pores are blocked completely, surface defects are smoothed and ice layer are frozen (Fig. 4).

Consequently, the existence of the sample in equilibrium conditions (for example, as a result of application of water) thickness of the ice crust is determined by the balance of energy and amount of water in its pores and on the surface. Thus, forced preservation allows you to create for of gas hydrate under a layer of ice conditions its stability while the sample itself may be in equilibrium conditions.

$a$
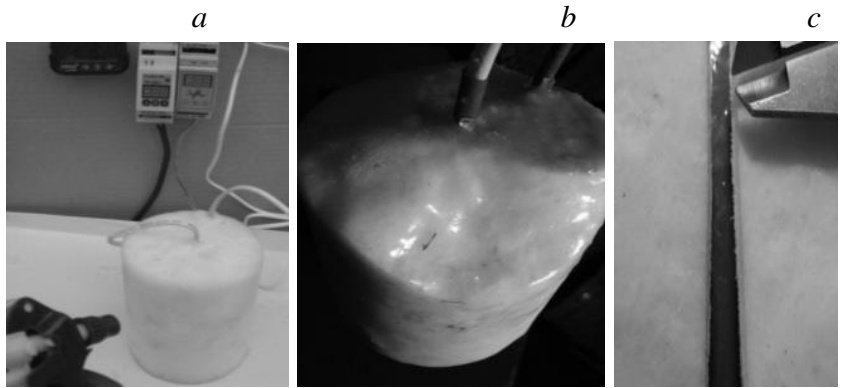

Fig. 4. Forced conservation of sample of gas hydrates with the ice layer: $a$ - application of water; $b$ - gloss of a layer of ice on a sample; $c$-ice layer on a section of a sample 
The method of production of gas hydrate in the form of blocks with internal energy source, preserved layer of ice is proposed, considering the properties of gas hydrate and experimental results (Fig. 5,6). It includes: gas hydrate production with a significant water content, its separation, enrichment of the gas hydrate mass by transferring of the residue water (between the crystalline and captured) to the hydrate and increasing filling with the gas molecules of the crystal lattice, single the cooling of gas hydrates $(T \leq 258 \mathrm{~K})$ granulating one part and crushing of the gas hydrates another, the formation of blocks with the mixtures forced their conservation with the layer of ice.

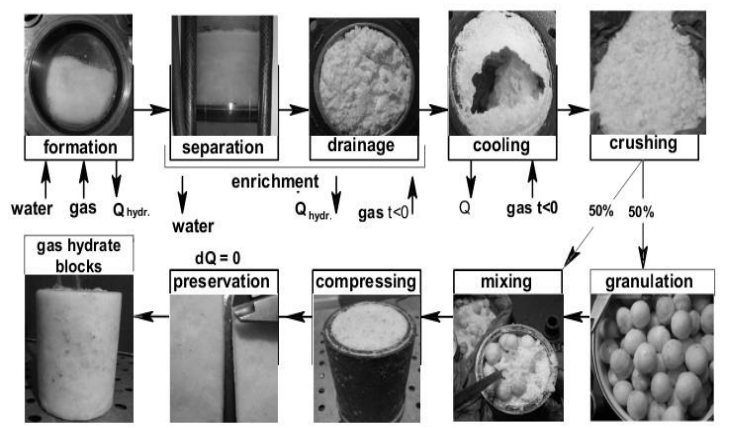

Fig. 5. Scheme of method of production of gas hydrate blocks

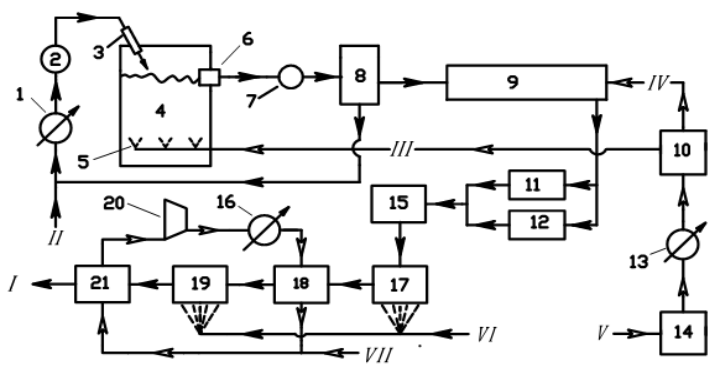

Fig. 6. Method of production of gas hydrate blocks: 1 - cooling of water; 2 - water pumping; 3 - feed water stream into the reactor; 4 - formation of gas hydrates; 5 bubbling gas; 6 - selection of gas hydrates; 7 - vibration treatment; 8 - separation; 9 - concentration and cooling; 10 - crushing of hydrate; 11 - granulated of hydrate; 12 - separation of gas; 13 - cooling of gas; 14 - preparation of gas; 15 - formation of blocks; 16 - cooling of air; 17 - the first water supply to the blocks; 19 - the second water supply on the blocks; 18 - cementing surface; 21 - freezing of layer of the ice; 20 - air circulation; stream: I - blocks; II, VI - water; III - methane; IV - condensate; V - gas; VII - air 
For realization of this method project pilot plant with a capacity of 20 thousand gas $\mathrm{m}^{3} /$ day (140 tons per day hydrate) is developed (Fig. 7). Pilot plant is designed for production of gas hydrate blocks weight to $250 \mathrm{~kg}$. Gas consumption for technological needs of the pilot plant during the summer installation is $2400 \mathrm{~m}^{3} /$ day (or $12 \%$ of its capacity). At low temperatures the gas consumption is reduced to $568 \mathrm{~m}^{3} /$ day (or $2.8 \%$ ).

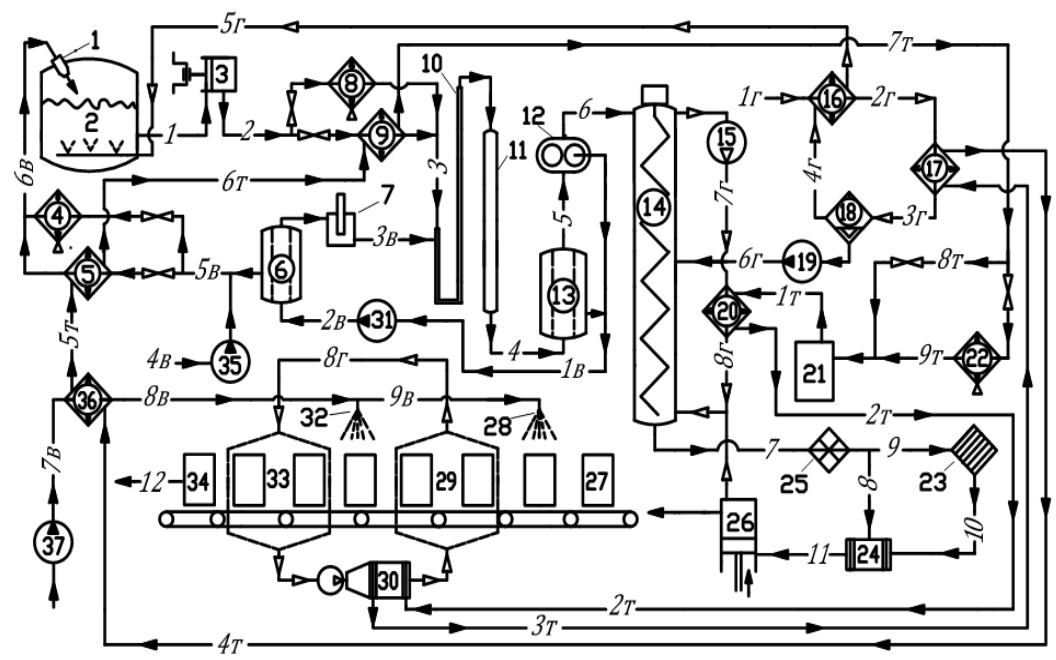

Fig. 7. Principle scheme of the installation for the production of hydrocarbon gas hydrate in the form of blocks capacity of $140 \mathrm{t} /$ day (20 thous. $\mathrm{m}^{3} /$ day of gas) 1 - inkjet apparatus; 2 - reactor; 3,7,19,31,35,37 - pump; 4,8,22,30 - device of air cooling; 5,9,16,17,20 - heat exchanger; $6,13.18$ - separator; 10 - coiled pipe;

11 - moderator; 12 - squeezing device; 14 - column of draining of gas hydrates; 15 - compressor; 21 - refrigerator; 23 - granulator; 24 - mixer; 25 - straw chopper;26 - press for the formation of gas hydrate blocks; 27,34 - gas hydrate blocks; 28,32 nozzle; 29,33 - zone of blowing gas hydrate blocks; streams: 1-4 - mixture of gas

hydrate and water; 5,6 - crude gas hydrate mass; 7 - drained and cooled gas hydrates; 8,9-crushed hydrates; 10 - granular hydrates; 11 - mixture of crushed and granulated of gas hydrates; 12 - gas hydrate blocks; $1_{\Gamma}-3_{\Gamma}-$ raw gas; $4_{\Gamma}, 5_{\Gamma}-$ dry gas; $6_{\Gamma}-$ condensate $; 7_{\Gamma}, 8_{\Gamma}-$ gas draining of; $1_{\mathrm{B}}-9_{\mathrm{B}}-$ water, $1_{\mathrm{T}}-9_{\mathrm{T}}-$ carrier of cold

Thus the gas hydrate blocks manufactured in accordance with the proposed technology (Pedchenko, Pedchenko, 2012) can be regarded as «devices» for concentrate the gas with an internal energy source. 
They suitable for long-term storage and transportation at atmospheric pressure and a slight negative temperature.

Deleting from the main part of deposit of the products in the form of gas hydrate in conjunction with the technology transport and storage of gas in hydrate form will significantly reduce the specific consumption and increase the competitiveness of the project.

\subsection{The method of development}

Today the natural gas transports by the pipelines and LNGtankers. However such transport technology, based on the significant investments, will be effective at presence of significant confirmed gas resources on this field (Seungyong, 2001). In many cases the traditional technologies of transport of gas can not fully solve the demands of projects of development of marine fields.

In the article (Gudmundsson \& Borrehaug, 1996) showed, that capital costs on a technological chain of the NGH- technologies for transporting 4 billion $\mathrm{m}^{3}$ of natural gas at a distance 5.5 thousand. $\mathrm{km}$ were lower on the $26 \%$ compared to the LNG-technology. Application of NGH-technologies will be economically feasible, starting from a distance of $1000 \mathrm{~km}$, for while LNG-technologies this distance should be greater than $3000 \mathrm{~km}$ (Gudmundsson, Graff \& Kvaerner, 2003).

Gas hydrates have the property at relatively low pressures to concentrate large volumes of gas (up to 160 volumes natural gas in one volume hydrate). But this figure is almost is four times smaller compared to liquefied natural gas. Considering the density of the hydrate, the specific contents of natural gas and rather soft thermo-baric conditions of storage, $\mathrm{NGH}$-tankers can be are built at least twice as big as LNG-analogues and can transport 250 thousand. $\mathrm{m}^{3}$ of cargo (Gudmundsson \& Borrehaug, 1996). The equipment of the factories for the formation of gas hydrates do not needs special of a unique equipments in contrast to the factories the liquefaction of natural gas greatly reduces the cost of NGH-technology (Kanda, 2006). In addition, the power of lines for the production of the gas hydrate may be in 4 times lower than in line production of LNG, without increase of its cost. This gives an opportunity smoothly adjust the production when changing the demand for natural gas (Gudmundsson, Parlactuna \& Khokhar, 1994) 
Proceeding from listed above considerations, method of the development (a compatible or separate) of marine gas and gas hydrate of the fields (Fig. 8) is proposed. It provides:

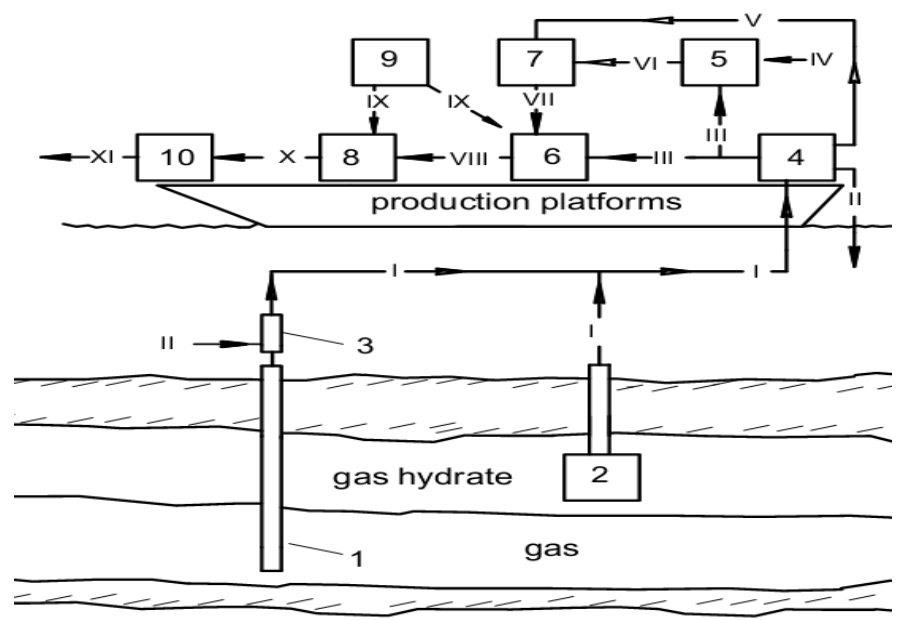

Fig. 8. Method of development (a compatible or separate) of the offshore fields of gas or gas hydrates: 1 - extraction of gas; 2 - extraction of gas hydrates; 3 - formation of a mixture of gas hydrates, gas and water; 4 - separation of the mixture of gas hydrates, water and gas on the gas, water (the gravitational) and the mixture that consists of gas hydrates, a film water and water captured between the crystals; 5 melting in the limited volume of party of the gas hydrates to obtain of gas flow of high pressure; 6 - draining of a mixture of gas hydrates, film and captured between crystals water by binding of remains of water in hydrates; 7 - compression in the jet compressor of gas flow, separated from the mixture due to the energy of flow gas of high pressure; 8 - a single cooling of gas hydrate mass; 9 - production of cold; 10 formation of gas hydrate blocks and their preservation with the ice layer; flows: I - a mixture of gas hydrates, water and gas; II - water; III - a mixture of gas hydrates, a film water and water captured between crystals; IV - supply of heat; $\mathbf{V}$ - gas of low pressure; VI - gas of high pressure; VII - gas of average pressure; VIII - gas hydrates; $\mathbf{I X}$ - the coolant

- uncovering of productive layers by the wells;

- impact on layer for the purpose of extraction of gas or gas hydrates;

- linking of the extracted gas in a gas hydrate;

- supply of gas hydrates mixture, water and gas to the extractive platform. This mixture at the developing of gas hydrate deposits is formed from extracted of gas hydrates, water, which carried destruc- 
tion of rocks, and the gas of released from hydrate as a result dissociation to create the effect of gas-lift in the pipeline. At the development of gas deposits mixture forms as a result of contact natural gas and sea water in process of removal of heat through the walls of the pipeline in the site with the thermo-baric conditions of the hydrate formation;

- separation of the mixture for gas, the gravitational water and mixture, which is composed of gas hydrate, a film water and water captured between the crystals;

- melting in the limited volume of the part the gas hydrate for receiving of gas of a high pressure for its further use in machineless compression (Makogon, 2001);

- compression of the separated from the mixture of gas of low pressure in the jet compressor due to the energy of the gas flow of a high pressure ;

- draining (concentration) of mixture gas hydrates and water (film and captured between the crystals) by binding it in the hydrate during it contact with the flow (refrigerated) of gas of the average pressure and removal of heat of the process;

- a single cooling obtained of the gas hydrate masses, taking into account of the heat balance the next of technological operations and processes up to the moment of gas consumption;

- formation of prepared gas hydrates in blocks and preservation with the ice layer;

- transportation and storage of gas hydrate blocks in terrestrial storages at atmospheric pressure and a temperature no higher than $278 \mathrm{~K}$.

\subsection{Storing gas in hydrate form}

The possibility of storage of natural gas in the form of gas hydrate, organization terrestrial storages of gas hydrates near large consumers of gas (Fig. 9) (Pedchenko, Pedchenko, 2013) is yet another promising direction use of gas hydrate technology. Building of similar storages could significantly smooth out the seasonal unevenness in gas production and represent an alternative to the construction of underground gas storage facilities. Moreover, these storages and technologies their exploitation can the best will supplement the tech- 
nological chain of production, transportation and storage of natural gas of the marine deposits.

To increase the effectiveness of the proposed technology hydrate blocks must be stored under a layer of polyurethane (thickness of 0.5-0.7 m) in terrestrial Inflatable structures covered with doublelayer soft shell with nonflammable gas locking layer. These structures present constructions that lies on the gas cushion with pressure above atmospheric only to maintain the shell (Fig. 9).

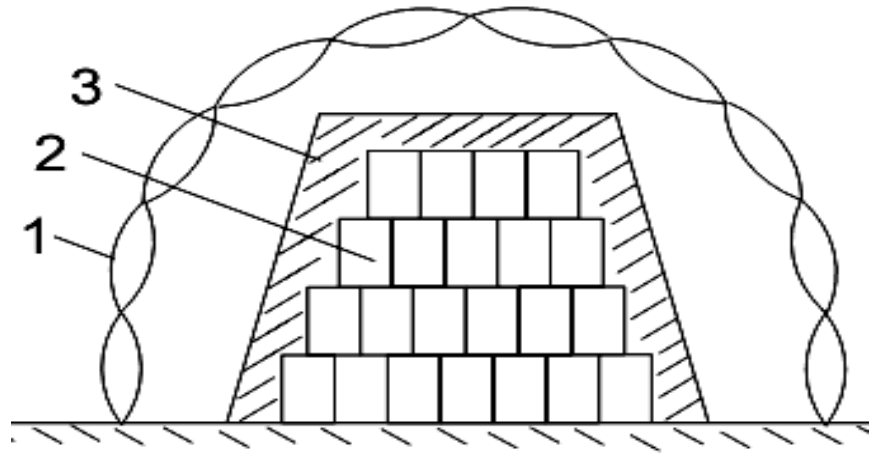

Fig. 9. Scheme storage of gas hydrates: 1 - elastic the double-layer shell; 2 - hydrate blocks; 3 - layer of polyurethane

To place such storage we propose near of gas consumers. This will allow give gas to distribution networks of low pressure. Therefore hydrate dissociates at a pressure of 0.3-0.4 MPa, and therefore at a much lower temperature (coolant temperature to melt the hydrate will not exceed $283 \mathrm{~K}$ ). Calculation of parameters of storage of the gas hydrates (2800 tons) in the terrestrial inflatable structures is given in the table 1 and Fig. 10 - the dynamics of temperature change on the surface of hydrate.

Cost of storage during the year in terrestrial Inflatable structures of the gas hydrate blocks amount to in terms of gas 15.86 thousand. $\mathrm{m}^{3}$, representing only $0.3 \%$ of the content terrestrial inflatable structures. In the production of of gas hydrates to $80 \%$ of the energy is consumed for recycling heat from the process. Before the gas consumption of the same amount of energy expended on melting hydrate. To improve efficiency of the technologies, dissociation of the gas hydrate blocks in the summer must be carried out by solar energy. 
Table 1

Calculation of parameters of storage of the gas hydrates in terrestrial inflatable structures

\begin{tabular}{|c|c|c|}
\hline The thermodynamic parameters & January & July \\
\hline \multicolumn{3}{|l|}{ Thermal resistance, $\left(\mathrm{m}^{2} \cdot \mathrm{K}\right) / \mathrm{W}$ : } \\
\hline - transition heat, $R_{\alpha}$ & 0.23 & 0.09 \\
\hline - coating of the layer of PVC, $R_{\mathrm{pvc}}$; & 0.025 & 0.025 \\
\hline - locking layer, Rloc; & 0.22 & 0.18 \\
\hline - covering (no layer of polyuret.), $R_{\text {cov }}$ & 0.34 & 0.28 \\
\hline - covering (with a layer of polyuret.), $R_{\mathrm{pu}}$ & 17.0 & 16.6 \\
\hline \multicolumn{3}{|l|}{ The heat flow to the hydrates, $\mathrm{W} / \mathrm{m}^{2}$ : } \\
\hline - without insulation polyurethane, $q$; & 20.58 & 104.1 \\
\hline - insulated with polyurethane, $q_{\mathrm{pu}}$ & 0.64 & 92.4 \\
\hline $\begin{array}{l}\text { The heat flux in the Inflatable structures to of gas } \\
\text { hydrates, } \mathrm{kW} \text { : }\end{array}$ & 80.77 & 409.0 \\
\hline $\begin{array}{l}\text { - without insulation polyurethane } Q_{\mathrm{ext}} \\
\text { - insulated with polyurethane, } Q_{\mathrm{ext}} \text { pu }\end{array}$ & 2.53 & 9.36 \\
\hline The flow of heat from the earth, $Q_{\text {ear }} \mathrm{kW}$ & 9.0 & 9.0 \\
\hline Energy consumption for cooling, $Q_{\text {cool }} \mathrm{kW}$ & 6.6 & 15.3 \\
\hline
\end{tabular}

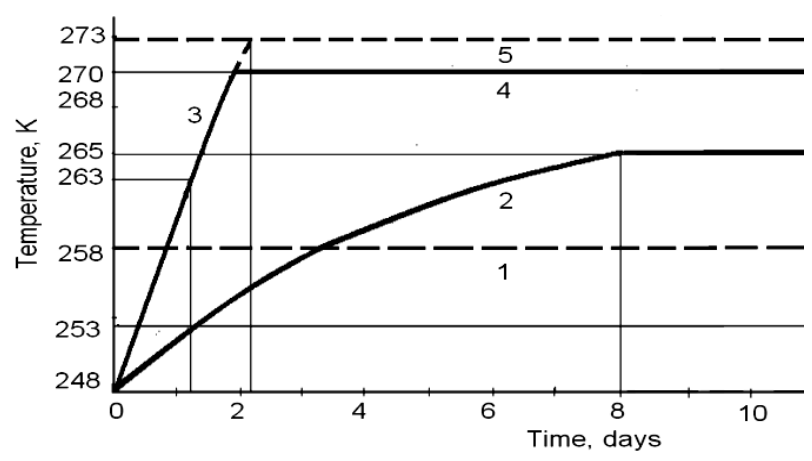

Fig. 10. Dynamics of change of surface temperature of gas hydrates in ground storage: limit of hydrate stability 1 - without preservation; 2 - winter without additional cooling; 3 - summer without additional cooling; 4 - summer with additional cooling; 5 - force preservation with the layer of ice

\subsection{Technological complex}

Accordingly, the proposed technological chain (Fig. 11), which involves: 


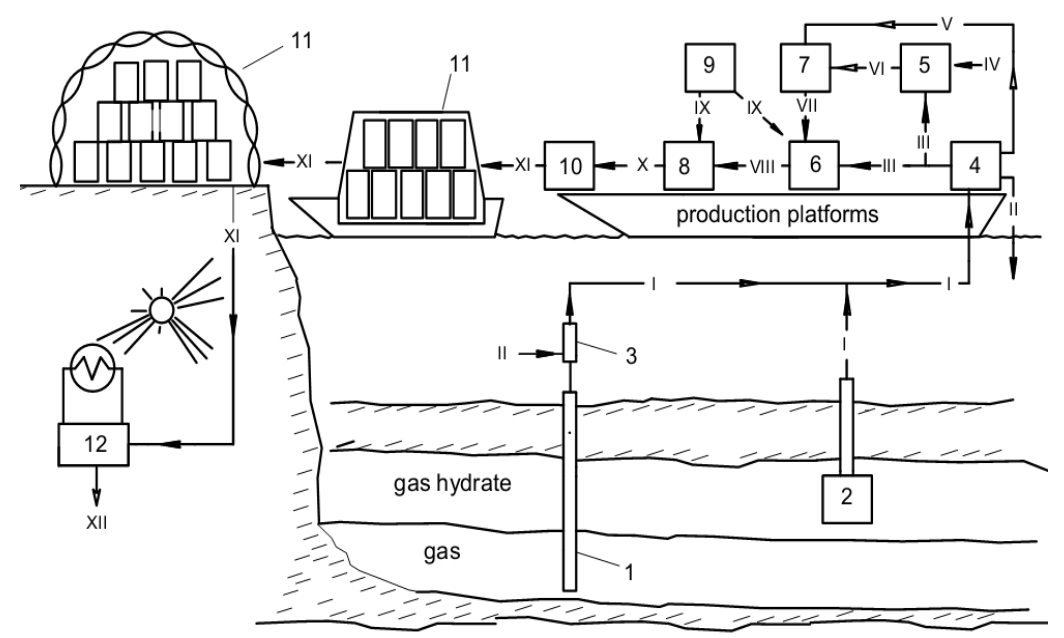

Fig. 11. Technological complex of production, transportation and storage of gas of the offshore fields of gas or gas hydrates: 1 - extraction of gas; 2 - extraction of gas hydrates; 3 - formation of a mixture of gas hydrates, gas and water;

4 - separation of the mixture of gas hydrates, water and gas on the gas, water (the gravitational) and the mixture that consists of gas hydrates, a film water and water captured between the crystals; 5 - melting in the limited volume of party of the gas hydrates to obtain of gas flow of high pressure; 6 - draining of a mixture of gas hydrates, film and captured between crystals water by binding of remains of water in hydrates; 7 - compression in the jet compressor of gas flow, separated from the mixture due to the energy of flow gas of high pressure; 8 - a single cooling of gas hydrate mass; 9 - production of cold; 10 - formation of gas hydrate blocks and

their preservation with the ice layer; 11 - transport and storage of gas hydrate blocks; 12 - dissociation of gas hydrates due to solar energy; flows: $\mathbf{I}$ - a mixture of gas hydrates, water and gas; II - water; III - a mixture of gas hydrates, a film water and water captured between crystals; IV - supply of heat; $\mathbf{V}$ - gas of low pressure;

VI - gas of high pressure; VII - gas of average pressure; VIII - gas hydrates;

IX - the coolant; $\mathbf{X}$ - cooled gas hydrate; $\mathbf{X I}$ - hydrate blocks, preservation with the ice layer; XII - gas on consumption

- extraction from deposits (hydrate and / or gas) products mainly in the form of moistened gas hydrates and partly - free gas, linking of this gas and the remaining water in the gas hydrates; 
- production of gas hydrates in the form of gas hydrate blocks of its transportation without additional cooling, storage vaults in the ground at a temperature of $270 \mathrm{~K}$, hydrate melting by solar energy.

\section{Conclusions}

1. The proposed method of extraction and transportation of natural gas from the offshore fields of gas or gas hydrate allows to receive technical result, which bears the maximum reduction of energy consumption as a result of a complex consideration of thermal properties and parameters of interaction of components of the system within the deposit, that the development.

2. The main idea of the proposed method of development of gas hydrate deposits is extracting the maximum amount from gas hydrates productive strata without spending of energy on the phase transition and dissociation its residue, given the physical properties, is carried out due of low energy of the sea water and changing its pressure with depth.

3. Proposed gas hydrate technology creates important preconditions of development of small and medium-sized remote of gas fields (including gas-hydrate), creating a network of terrestrial Inflatable structures, improve the efficiency and competitiveness of marine technologies of transporting of natural gas in hydrate form.

4. The use of alternative energy sources (natural cold and solar energy) at the production and dissociation of gas hydrate in terrestrial Inflatable structures allows considerably reduce capital and energy costs of the technological chain of the transportation and storage of hydrocarbon gases in hydrate form.

5. At their insignificant improvement of existing search technology, exploration, drilling and production of hydrocarbon energy resources can be successfully used for the development of gas hydrate deposits. Implementation of the gas hydrate technology allows abandon more of complex and expensive system of preparation, transportation and storage of the extracted products. 
6. Works on the borehole hydro- mining in the world do not have direct analogs by type of the extracted ores and by the parameters of the hydro-destruction. Furthermore, the parameters of the used hydraulic equipment in the borehole hydro-mining in connection with the specifics of this method of extraction also do not have analogues in the known hydraulic systems. Therefore testing of the proposed method development of gas hydrate deposits requires a number of experimental studies.

References

1. Arens. V.. Babichev. A.. Bashkatov. A.. Gridin. O.. Khrulev. A.. \& Khcheyan. G. (2007). Borehole Hydro-Mining: Proc. Manual. Mining Book, 2007. 295.

2. Basniev. K.. Kul'chitskiy. V.. Shchebetov. A.. \& Nifantov. A. (2006) Methods for the Development of Gas Hydrate Deposits. Gas industry. 7. 22-24.

3. Beznosikov. A.. \& Maslov. V. (1975). Influence of Water Ice Hydrates in the Reservoir on its Permeability. Proceedings VNIIEGazproma. 8. 84-89.

4. Dawe. R.. Thomas. M.. \& Kromah. M. (2003). Hydrate Technology for Transporting Natural Gas. Engineering Journal of the University of Qatar. 16. 11-18.

5. Gudmundsson. J. (1996). Method for Production of Gas Hydrates for Transportation and Storage. U.S. Patent US5536893 MPK C07C 7/20. 16 July 1996.

6. Gudmundsson. J.. \& Borrehaug. A. (1996). Natural Gas Hydrate an Alternative to Liquified Natural Gas. Trondheim, 1996, January. http://www.ipt.unit.no/ jsg/forskning/hydrater

7. Gudmundsson. J.. Graff. O.. \& Kvaerner. A. (2003). Hydrate non-pipeline Technology for Transport of Natural Gas. 22nd World Gas Conference Tokyo. http://members.igu.org/html/wgc2003/WGC_pdffiles/10056_1046347297_14776_1. pdf

8. Gudmundsson. J.. \& Parlaktuna. M. (1991). Gas-in-ice: Concept Evaluation. Technical report, Department of Petroleum Engineering and Applied Geophysics, Norwegian University of Science and Technology. Trondheim.

9. Gudmundsson. J.. M. Parlactuna. M.. \& Khokhar. A. (1994). Storing Natural Gas as Frozen Hydrate. SPE Production \& Facilities. 9 (1). 69-73.

10. Kanda. H. (2006). Economic Study on Natural Gas Transportation with Natural Gas Hydrate (NGH) Pellets. 23rd World Gas Conference, Amsterdam. http://members.igu.org/html/wgc2006/pdf/paper/add10399.pdf.

11. Kvenvolden. K. (1993). Gas Hydrates -Geological Perspectives and Global Change. Rev. Geophysics. 31. 173-187. 
http://eesc.ldeo.columbia.edu/courses/w4937/Readings/Kvenvolden.1993.pdf

12. Makogon. Yu. (2001). Natural hydrates: Opening and Prospects. Gas industry. 5. 10-16.

13. Pedchenko. L.. \& Pedchenko. M. (2014). Application of Liquid-gas Jet Apparatus with an Elongated a Camera of Mixing as a Contact Device for the Formation of Gas Hydrates. Ukraine Patent for Invention № 105208, 25 April 2014.

14. Pedchenko. L.. \& Pedchenko. M. (2012). Substantiation of Method of Formation of Ice Hydrate Blocks with the Purpose of Transporting and Storage of Hydrate Gas. Scientific Bulletin DGU. 127(1). 28-34.

15. Pedchenko. L.. \& Pedchenko. M. (2013). Calculation of Thermodynamic Parameters of Gas Hydrates Storage in Terrestrial Storage Facilities. Collections of the Scientific Labor SWorld. Iss. 4. Vol. 17. Ivanovo: Markov AD. 107-118. http://www.sworld.com.ua/konfer33/1257.pdf

16. Rehbinder. G. (1980). A Theory about Cutting Rock with Water Jet. Rock Mechanics. 12. 247-257.

17. Seungyong. C. (2001). Comparing Exploitation and Transportation Technologies for Monetisation of Offshore Stranded Gas. SPE Asia Pacific Oil and Gas Conference and Exhibition: Indonesia, Jakarta, 2001, 17-19 April.

http://www.onepetro.org/mslib/servlet/onepetropreview?id=00068680.

18. Shnyukov. E.. Gozhik. P.. Krayushkin. V.. \& Klochko. V.(2007). On the Eve of the World of Submarine Methane Hydrate Extraction. Reports of National Academy of Sciences of Ukraine. 6. 125-134.

19. Timothy. S. (2010). Geologic Implications of gas Hydrates in the Offshore of India: Results of the National Gas Hydrate. Program Expedition 01 - Marine \& Petroleum Geology, Volume 58, Part A, December 2014, 12. http://energy. usgs. gov -2010 .

20. Vasilev. A.. \& Dimitrov. L. (2002). Evaluation of the Spatial Distribution and the Reserves of Gas Hydratesin the Black Sea. Geology \& Geophysics. 43(7). 672-684. http://www.gashydat.org

21. Yakushev. V.. Gerasimov. Yu.. Kvon, V.. \& Istomin. V. (2008). The Current State of the Gas Hydrate Technology. Review. Inf. OOO "Gazprom RPI". 88. 
https://doi.org/10.31713/m1116

\title{
ELECTRIC TREATMENT AND REGULATION OF BIOTOXIC PROPERTIES OF DRILLING WATERS
}

\author{
Berezutskyi V.V. \\ National Technical University "Kharkiv Polytechnic Institute", \\ Head of the Department "Labor \& Environment safety" \\ Doctor of Technical Science, Professor, Ukraine \\ Berezutska N.L. \\ Kharkiv National University of Radio Electronics \\ Department of Occupational Safety \\ $\mathrm{PhD}$, Associate Professor, Ukraine \\ Khalil V.V. \\ O. M. Beketov National University of Urban Economy in Kharkiv, \\ Department of Labour Protection and Safety, \\ $\mathrm{PhD}$, Associate Professor, Ukraine \\ Ilinska O.I. \\ National Technical University "Kharkiv Polytechnic Institute" \\ Department "Labor \& Environment safety", \\ $\mathrm{PhD}$, Associate Professor, Ukraine
}

\begin{abstract}
Well drilling is accompanied by the formation of significant volumes of water that contain mechanical and biological impurities. The purpose of the work is to investigate the possibility of regulating the biological properties of drilling and other types of water that using the technologies of electrical processing (electrooxidation). The analysis of methods and technologies for the disinfection of aqueous solutions and emulsions is carried out. The process of electrooxidation of bacteria in contact with the surface of the electrode plates is considered. The determination of the electrokinetic charge of the surface of particles (bacteria) is carried out, which must be taken into account when calculating the processes and equipment for the electrooxidation of bacteria in technological aqueous solutions such as emulsions. The processes of electrooxidation of aqueous emulsions such as Ukrinol and Triethanolamine which are widely used in cutting, grinding, etc., are considered. Physical and mathematical models of disinfection processes at different values of electric current and surface area of oxidizing electrodes are studied. The factors influencing the disinfection process have been determined. Conceptual approaches to the creation of electrooxidizing devices for the disinfection of emulsions directly in the channels through which aqueous technological solutions move are proposed. Aspects of practical application of electrooxidation technology are considered.
\end{abstract}

Keywords: drilling water, emulsions, bacteria, micelles, surface charge, electrodes. 


\section{Introduction}

Among the problems of drilling wells is the environmental pollution from of drilling water. The drilling process uses drilling fluids and generates waste fluids and cuttings. The drilling fluids that used in drilling operations are including water based drilling fluids (WBF), oil based fluids (OBF) and synthetic based fluids (SBF). The wastes generated in the largest volumes during drilling oil and gas wells are drilling fluids and cuttings. There are several options to manage drilling wastes: discharge, down-hole injection and onshore disposal. In many regions of the world, some types of drilling fluids and drill cuttings may be discharged to the sea if they meet certain environmental requirements. Drilling fluids have operational properties that including cooling and lubricating.

Practically all technological operations of cutting, grinding, washing are accompanied by the use of aqueous solutions, that need for their subsequent storage, cleaning and disposal. The search of extending the use of each cubic meter of such a solution leads are need to develop chemical bactericidal additives or other drugs that only block the development process for a while, and then it continues all the same, but the rate of growth in the number of bacteria increases. The only available and effective bactericidal treatment is the electrooxidation of bacterial cells on the surface or in the electrode area. Such an oxidation process is achieved in electrolyzers (flow-through and non-flow-through) or by means of electrode units, which are placed directly in the channel along which the aqueous process medium moves. The choice of one or another method is determined by the volumes of water technological environments, their properties and the economic possibilities of the enterprise.

This article discusses the theoretical foundations for regulating the biotoxic properties of drilling fluids that had formulated on the basis of laboratory research.

\section{Literature review}

The article [1] affects issues of pollution concerns of water in developing countries and categorised in terms of physical, chemical and biological pollutants such as turbidity, organic matter and bacteria. The processes are involved in removing the contaminants are including physical processes such as sedimentation, filtration such as 
slow-sand filtration, coagulation and flocculation, and disinfectant processes such as chlorination reviewed.

Chemical methods of processing technical emulsions are widely was used in the production. But microorganisms adapt to them, and the cost of such additives is growing up every year. Besides, another article [2] states that chlorination is the most widely used method for disinfecting water, that supplies in the United States. However, the discovery of chlorination's can result in the formation of trihalomethanes (THM's) and other halogenated hydrocarbons has prompted the reexamination of available disinfection methodology with goal of determine alternative agents or procedures.

In article of author [3] suggests solar disinfection, or SODIS, refers the method of using sunlight to inactivate microbes in biologically contaminated water. The contaminated water is placed in transparent containers and it be exposed to strong sunlight for at least 6$8 \mathrm{~h}$. At the end of this solar exposure, the microbes, which could otherwise cause waterborne diseases, are inactivated and unable to cause illness. However, the use of this method for contaminated technical emulsions causes serious problems and is not effective enough.

In articale [4] says that the safe operation of water reuse depends on effluent disinfection. The authors of the article draw attention to the methods of electrochemical treatment of wastewater as a means for its disinfection. The electrochemical generation of chlorine dioxide from an un-buffered solution of sodium chlorite and sodium chloride mixture in an un-divided electrochemical cell under constant current mode, with a view to optimize various process parameters, has been studied, which have a direct bearing on the chlorine dioxide formation efficiency under laboratory conditions. However, in this case, the option of electrochemical dissolution of certain chemical compounds in order to obtain an oxidizing agent is considered, but not the oxidation process on the surface of the electrodes itself.

At this article [5] shown, that cutting fluids are widely used to ensure high production quality and process stability in machining processes. However, especially in case of water based cutting fluids microbial contamination leads to a reduced performance and thus, shortened service life. To control the growth of the microorganisms, biocides are used in practice. Biocides, however, can be toxic to humans and the use is officially regulated, whereby alternative disinfec- 
tion methods e.g. ultraviolet radiation or ozone are getting more in the focus.

In article [6] says that biocides can be toxic to humans and the use is officially regulated, whereby alternative disinfection methods e.g. ultraviolet radiation or ozone are getting more in the focus. It was mentioned in the article above, however, in terms of production, they are in no hurry to purchase expensive equipment.

At this article [7] talks about of metalworking fluids (MWF) that are mainly emulsions of oil in water containing additives such as corrosion inhibitors, emulsifiers, defoamers, and biocides. The future lies in the development of new molecules with biocidal activity corresponding to these ideal specifications, but in the meantime, it is possible to improve the performance of existing molecules currently on the market. As there is a diversity of the envelope structures of microorganisms and a diversity of molecular structures of biocides, each biocide presents its own inactivation mechanism and spectrum of activity.

In article [8] talks that some microbicides are suspected as being responsible for adverse health effects. Consequently, their usage has been restricted in recently adopted regulations. Given the limited number of microbicides currently approved for use in MWFs, alternative microbial contamination control strategies are needed. Makeup water whose content usually varies between 85 and $98 \%$ in the end use diluted MWF provides inorganic nutrients and a suitable growth habitat. Turbulent flow created by MWF recirculation at velocities of $\geq 0.8 \mathrm{~m}^{3} \mathrm{~min}^{-1}$ ( $\geq 200 \mathrm{gpm}$ ) creates an oxygenated environment for aerobic microbes.

This article [9] shows that there's two typical approaches for dealing with rejected MWFs are recovery and disposal, in which largely involve separation as the first essential step. The processes for separating MWFs emulsion are presented, including chemical coagulation, flotation, and electrocoagulation-flotation for their background and results from experiments. The effective separations with the highest efficiencies of $99 \%$ were attained from all conditions but at different operating time for electrocoagulation-flotation. The treatment rate was influenced by the condition for both electrode gap and current density. 
In article [10] authors say about of treatment of oil mist and miscellaneous oil. The removal mechanism and approach of microorganisms and the design principles of integrated recycling equipment are outlined. The scientific work [11] indicates the types of bacteria that were detected in both used MWF sump and mist samples. These included Ochrobactrum and Proprionibacterium at site visit one, and Methylobacterium at site visit two. Bacterial toxins in the form of "serinelike" proteases were detected within $76 \%$ of the MWF samples and in two of the mist samples. The study of bacteria species is very important for the development of disinfection technology. Work's conditions in production are not dangerous for the life and health of workers. However, if the coolant contains bacteria, this is become dangerous. In the article [12], the author points out that it is necessary to develop environmentally friendly fluids. But this is a difficult task because a lot of different specialists must take part.

In article [13] says that using of cutting fluids in machining processes is a serious concern because of their cost, and environmental and health effects. Reasons can be found in the excessive heat generated in the process, in the increase of the friction between the tool and the workpiece or in the necessity to evacuate the chips generated. The striving for sustainable products is also encouraging the developing of new cutting fluid formulations. In this paper, a comprehensive analysis of the use of cutting fluids and main alternatives in machining is carried out. Particularly, the analysis was done focusing on the economic, environmental and technical points.

The oil drilling industry is one of the most specific activities in the industrial world and, like any other industrial activity related to waste and the return of waste to the environment, connected with a planning to recycle, clean up and prevent long-term adverse consequences. It can have a long-term adverse effects for the climate [14].

In article [15] says that the main performance of problem with using of drilling water is as follows:

- pollution of surface water and groundwater;

- retention of heavy metals in soil, affecting plant growth and microbial reproduction, and at the same time due to plant absorption and enrichment, endangering human and animal health;

- salt and alkali in waste drilling fluid are very harmful to plant growth, even unable to grow, resulting in soil waste. 
The treatment methods of waste fluid generated during drilling are also constantly improving, from the original landfill method, incineration method and other methods to more environmentally friendly and harmless solid-liquid.

Separation method, demulsification method and other methods better protect the ecological environment of the ocean and land, and enable energy to be recycled and reused. However, no matter which kind of treatment method has a certain range of application, it should be selected reasonably. At the same time, in order to more effectively control the environmental pollution of waste drilling fluid, we should strengthen the source, control the process, and continue to develop more adaptable new technology.

The monograph [16] shows methods and technologies that allow to regulate the biotoxicity of drilling water and similar technological aqueous solutions. The such technologies are based on using of various devices, materials and devices based on electrochemical, gas and other methods of processing oil- and bio-containing waters. The most popular of them are electrochemical methods which are implemented in apparatuses (electrolyzers) with various types of electrodes and their arrangement in bloks. This allows to clean and decontaminate various aqueous process solutions and return them back for reuse.

However, there are many unresolved issues that require new research. One of these issues is the regulation of the ratio of the magnitude of the electric current relative to the flow rate of water, connected with the hardware design of the oxidation process of microorganisms directly in the channels through which water moves, and others.

\section{Research tasks}

- investigate the mobility of micelles in the interelectrode space,

- determine the possibility of using the method of electrooxidation of microorganisms for technical emulsions.

\section{Purpose}

to investigate the process of electrooxidation of microorganisms developing in the drilling and coolant water for example of lubricant coolants liquids.

\section{Research methodology}

The magnitude of the electric current flowing between the electrodes determines the speed of delivery of bacteria to the surface of 
the electrodes of oxidizers. This is especially important when disinfecting large volumes of aqueous media, since high linear velocity of fluid flows in the interelectrode space (between the electrodes) is limits the time of probable contact of bacteria with the oxidizing surface of the electrodes (contact time 1-5 s) [16].

Based on this, it is necessary to determine the $\zeta$ - potential of bacteria and their electrophoretic mobility in technological solutions such as lubricant coolants liquids (LCL) of a certain type. It is determined based on the fact that bacteria in aqueous media are located in between the micellar spaces and micelles formed by complexes of the type "water - oil - particles of pollution", "water - emulsifier oil", "oil - water", etc. By determining the electrophoretic velocity of the micelles, it is possible to determine the speed of their delivery to the surface of the oxidizing electrodes.

Measurements of the $\zeta$ - potential of micelles were carried out in accordance with the methodology and instrumentation equipment described in the literature $[17,18]$. The results of measurements and calculations are given in Table 1 . The applied voltage of $30 \mathrm{~V}$ corresponds to the voltage of an industrial rectifier of electric current.

Table 1

Values of $\zeta$-potential and electrophoretic velocity parameters micelles in MWFs

\begin{tabular}{c|c|c|c}
\hline $\begin{array}{c}\text { Characterization } \\
\text { of the coolant } \\
\text { micelles }\end{array}$ & $\begin{array}{c}\text { Linear velocity of } \\
\text { particles in an elec- } \\
\text { tric field, } \\
10^{-3} \mathrm{~m} / \mathrm{s}\end{array}$ & $\begin{array}{c}\text { Electrophoretic } \\
\text { speed, } \\
10^{-8} \mathrm{~m} / \mathrm{s}\end{array}$ & $\begin{array}{c}\zeta \text {-potential, } \\
\mathrm{mV}\end{array}$ \\
\hline Triethanolamine & 2,47 & 8,2 & 114 \\
\hline Ukrynol & 0,114 & 3,8 & 53 \\
\hline
\end{tabular}

From the results given in Table 1 seen that Triethanolamine can be disinfected more quickly because the mobility of its micelles is higher.

Microorganisms in the MWFs are mainly on the surface of emulsion micelles and in mud clots. Therefore, having determined the rate of movement of micelles between the electrodes during oxidation, it is possible to calculate the length of the plates for guaranteed contact of the particles with the surface of the oxidizing agent when they pass between the electrodes. 
Experimental installation. The experiment consisted in determining the influence of the size of the oxidation surface $(\mathrm{H})$ (the area of the electrode plates) on the efficiency of the oxidation process of bacteria. The material of the plates is stainless steel, the thickness $(D e)$ is $0.01 \mathrm{~m}$, the length $(L)$ is $0.052 \mathrm{~m}$. The volume of the processed liquid $(Q)$ is 0.21 . The vessel is a beaker with a diameter of $0.062 \mathrm{~m}$. Bacterial damage to the original liquid, according to the point system is equal to 4 points.

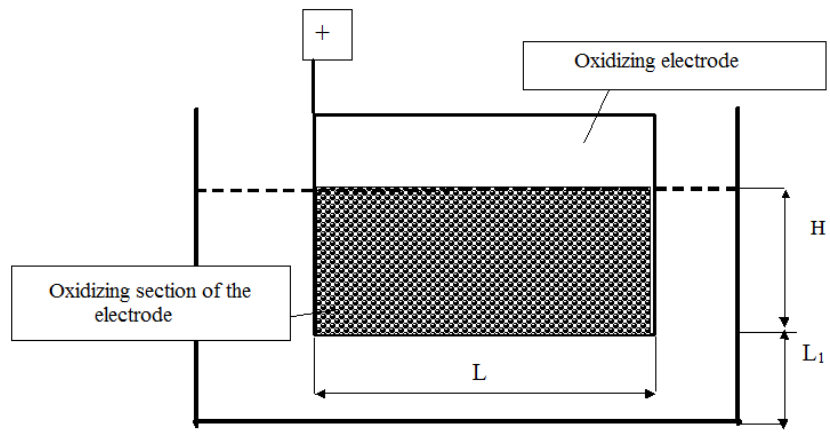

Fig. 1. Schematic of the experimental setup

To ensure the reliability of the experiment, the current value was kept constant, and the current density changed as a result of moving the electrodes in the beaker $(i=\mathrm{I} / \mathrm{S})$. The experimental results are shown in the Table 2. 
Table 2

Experimental parameters and results on bacterial oxidation on the surface of the oxidizing electrode

\begin{tabular}{c|c|c|c|c|c|c|c|c|c|c}
\hline \multirow{2}{*}{$o$} & \multicolumn{4}{|c|}{ Options } & \multicolumn{5}{c}{ Disinfection results, points } \\
\cline { 2 - 12 } & \multicolumn{4}{|c}{ Experiment } & \multicolumn{4}{c}{ Liquid processing time, s } \\
\hline & $L, M$ & $H, M$ & $i, A / \mathcal{M}^{2}$ & $L,, M$ & $I, A$ & 6 & 18 & 30 & 35 & 45 \\
\hline 1 & 0,052 & 0,01 & 961,5 & 0,055 & 0,5 & 3 & 4 & 4 & 4 & 4 \\
\hline 2 & 0,052 & 0,02 & 480,7 & 0,048 & 0,5 & 4 & 4 & 4 & 3,5 & 3 \\
\hline 3 & 0,052 & 0,03 & 320,5 & 0,035 & 0,5 & 3,5 & 3,5 & 3,5 & 3 & 3,5 \\
\hline 4 & 0,052 & 0,04 & 240,3 & 0,028 & 0,5 & 3 & 3 & 3 & 3 & 3 \\
\hline 5 & 0,052 & 0,05 & 192,2 & 0,015 & 0,5 & 3 & 3 & 2,5 & 2,5 & 1,5 \\
\hline
\end{tabular}

From the results shown in Table 2, we can conclude:

- the efficiency of the oxidation process on the surface of the electrode plates depends on the ratio of the volume of the liquid to be oxidized and the area of the electrode - oxidizer;

- the efficiency of oxidation processes is determined by the time of contact of the surface of the oxidizer plate with microorganisms.

These conclusions are confirmed by the curves in the Fig.2 and mathematical dependencies (1-5).

Dependence of electrooxidation of bacteria on the time of the process at different rates of electric current and oxidized surface shown in Fig. 2.

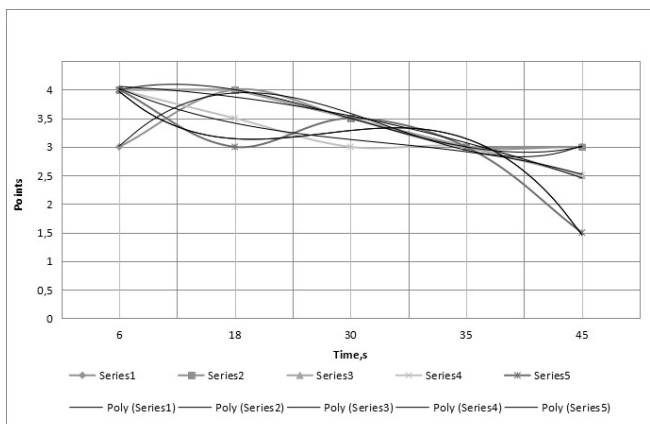

Fig. 2. Dependence of electrooxidation of bacteria on the time of the process at different rates of electric current and oxidized surface 
The resulting graphical curves (Fig. 2) are described by mathematical dependencies

$$
\text { series } 1, y=-0,208 x^{3}+1,732 x^{2}-4,5595 x+7 \text {, }
$$

by $R^{2}=0,974$

$$
\text { series } 2, y=0,0833 x^{3}-0,75 x^{2}+1,6667 x+3 \text {, }
$$

by $R^{2}=0,999$,

series $3, y=-0,071 x^{2}+0,0285 x+4,1$,

by $R^{2}=0,983$,

$$
\text { series } 4, y=-0,04166 x^{3}+0,41 x^{2}-1,5476 x+5,2 \text {, }
$$

by $R^{2}=0,975$,

$$
\text { series } 5, y=-0,2083 x^{3}+1,732 x^{2}-4,5595 x+7 \text {, }
$$
by $R^{2}=0,974$.

The obtained polyamial dependences make it possible to form a physical model of the process of electrooxidation of bacteria in a flow channel (pipe).

Description of the installation and process of disinfection. At Fig. 3 shows a diagram of a laboratory setup consisting of a collection tank for bacteria-infected drilling water (1), a valve for regulating the flow of disinfected water (2), electrode cells with metal plates made of insoluble metal $(3,4,5)$, a foam collection tank ( 6$)$, a container for collecting disinfected drilling water (7) and an electric current rectifier (9). Electrode cells 3,4,5, foam-collecting containers 6 and a container for collecting disinfected drilling water 7 are made of transparent organic glass, which allows you to visually observe the progress of the disinfection process and the hydrodynamics of flows. The disinfection process is carried out as follows: the drilling water affected by microorganisms from the container 1 through the valve 2 , with a previously set flow rate, is directed to the electrode cells 3 - 5 which are pre-filled with clean water or disinfected drilling water.

After that, the rectifier 9 is turned on, the set current value is set at 1-8 A. The disinfected drilling water is discharged through the foam collector 6 into the tank 7 .

If the process is carried out without foam separation and insufficient disinfection, a crust may form on the foam surface. After a day, swelling can be observed on the surface of the crust, which indicates the development of bacteria and the release of gases by them. The temperature of the medium varied within the range of $19-24{ }^{\circ} \mathrm{C}$. 


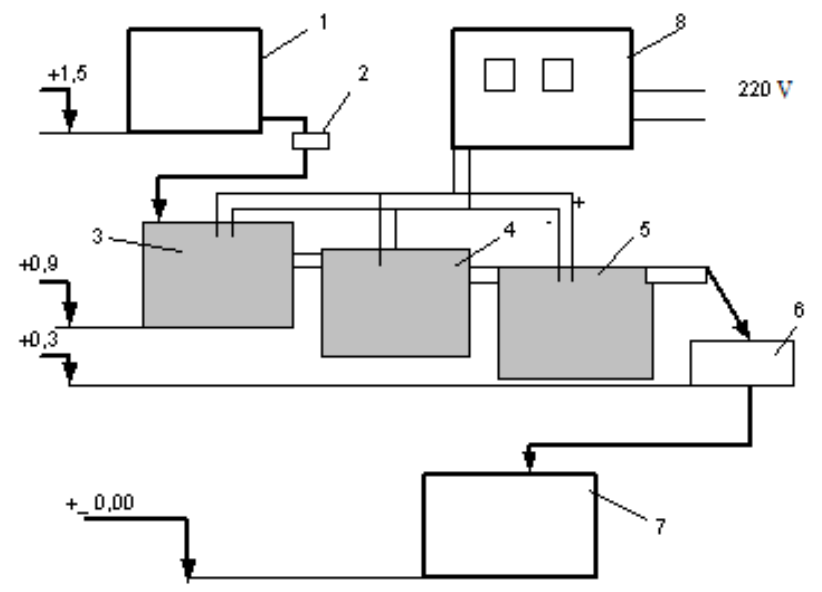

Fig. 3. Schematic of a laboratory electrooxidation plant of bacteria-infected drilling water

Laboratory tests have shown (Table 3) that at electric currents of up to $3 \mathrm{~A}$, disinfection is unsatisfactory, while a decrease in the number of bacteria is practically not observed, and an increase in the rate of their reproduction is characteristic.

Table 3

The results of laboratory studies on disinfection by electric current

\begin{tabular}{c|c|c}
\hline $\begin{array}{c}\text { Electric } \\
\text { current } \\
\text { strength, } \\
\text { A }\end{array}$ & $\begin{array}{c}\text { The degree of bacterio- } \\
\text { logical damage to water, } \\
\text { point }\end{array}$ & Visual observations \\
\hline 1 & IV & \multirow{2}{*}{$\begin{array}{c}\text { The original drilling water has IV } \\
\text { degree of bacterial lesion }\end{array}$} \\
\hline 2 & IV & \\
\hline 3 & III-IV & \\
\hline 4 & II & Abundant education \\
formation
\end{tabular}


With an electric current of 3-5 A, the drilling water is disinfected, however, after 2-3 days, an increase in the number of bacteria is observed. The reason for this may be: incomplete destruction of microorganisms; stationary storage - the liquid is stationary; bacteriological contamination of the storage tank. At a current of $5 \mathrm{~A}$, moderate foam release is observed (when disinfecting $1 \mathrm{~m}^{3}$ of water, $0.05 \mathrm{~m}^{3}$ $(50,1)$ of foam is released. An increase in the electric current of more than $5 \mathrm{~A}$ is accompanied by an abundant release of foam which worsens the disinfection process and significantly reduces the amount of disinfected emulsion. Given the large-scale transition, it should be recommended for industrial testing a current value in the range of 300-500 A.

In a laboratory facility, studies were carried out to disinfect cutting fluid in several cycles. One cycle of disinfection consists in passing the coolant through three series-connected electrode cells. Fig. 4 shows the results of cyclic disinfection of the coolant at a flow rate of $0.6 \mathrm{l} / \mathrm{min}$ and a current of $4.5 \mathrm{~A}$.

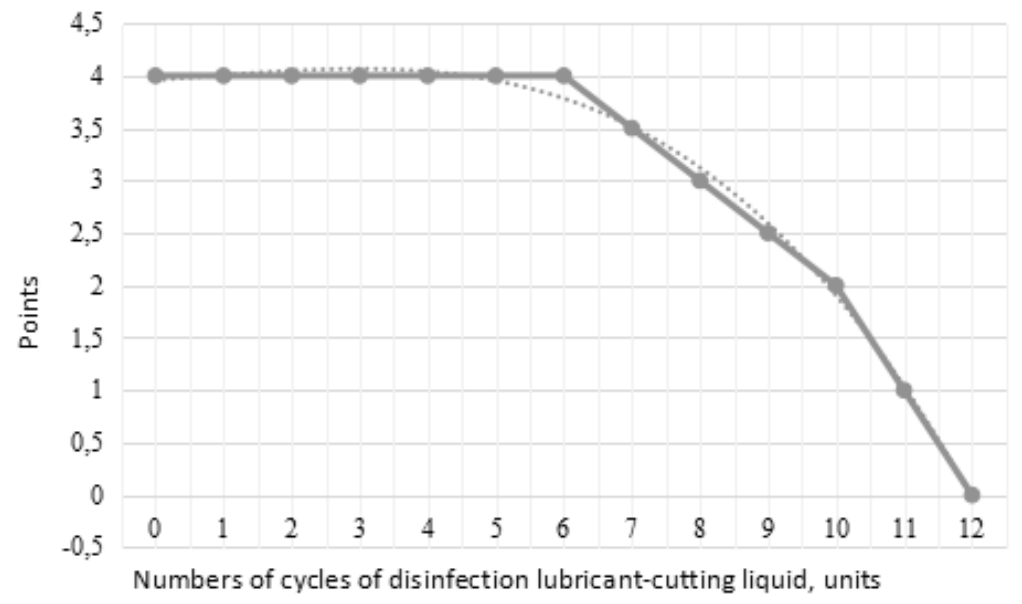

Fig. 4. Dependence of disinfection of cutting fluid on the number of cycles

The resulting graphical curves (Fig. 4) are described by mathematical dependencies by $R^{2}=0,996$.

$$
y=-0,0032 x^{3}+0,0169 x^{2}+0,0186 x+3,9266,
$$


It can be seen from the Fig. 3 that with 12-13 cycles of MWFs treatment, complete disinfection of the coolant occurs. The straight section on the line, characterizing the disinfection of the MWFs is determined by the time of decay of the coolant and the number of bacteria in it.

\section{Results}

Knowing the linear velocity of movement of micelles $\left(U_{m}\right)$ in an electric field, it is easy to determine the time for micelles to travel the distance between two electrodes that are at a distance one from another le $=0.01 \mathrm{~m}$ (the distance between the electrodes in industrial electrolyzers used to clean and disinfect water).

$$
t_{T}=\frac{l_{e}}{U m}=\frac{0,01}{0,114 \cdot 10^{-3}}=87 \mathrm{~s}
$$

$t_{T}$ is the time of passage of Triethanolamine micelles.

Similarly: $t_{U}=40.5=41 \mathrm{~s}$,

where $t_{U}$ is the time of passage of the Ukrynol type coolant micelles.

The development of bacteria disinfection equipment for production plants with a water flow rate of more than $100 \mathrm{~m}^{3} / \mathrm{h}$ was carried out on the basis of the following initial data: triethanolamine-based aqueous media; water consumption $-500 \mathrm{~m}^{3} / \mathrm{h}$; shop coolant storage capacity; the cross-sectional area is $1.2-5\left(\mathrm{~m}^{2}\right)$, the length of the tank is $10 \mathrm{~m}$. The sediment is deposited in the tank and is removed monthly from the bottom of the tank (1-2 tons).

Practical testing of the results of research in production has shown the promise of this area of research. It is necessary to take into account that an increase in current strength increases foam formation and can negatively affect the quality indicators of the MWFs. Therefore, it is necessary for each technical emulsion to select operating indicators for electric current.

The disadvantages of such oxidation of bacteria include the need to use electricity, but this is covered by the cost of purchasing, storing and using chemical additives of bactericides which are also harmful to workers and environment.

\section{Conclusions}

- the anodic oxidation of bacteria can be performed directly in the channels through which the flow of cutting fluid moves, with minimal structural changes to these channels; 
- the efficiency of the oxidation process on the surface of the electrode plates depends on the ratio of the volume of the liquid to be oxidized and the area of the electrode - oxidizer;

- the efficiency of oxidation processes is determined by the time of contact of the surface of the oxidizer plate with microorganisms;

- the decontamination effect depends on the optimal choice of the water flow rate and the magnitude of the electric current but the composition of the drill water is also of great importance. The presence of oils in the water complicates the process because oils cover the surface of the electrode plates and the oxidation process is inhibited.

References

1. Josephine Treacy. (2019). Drinking Water Treatment and Challenges in Developing Countries. Retrieved from https://www.intechopen.com/chapters/63707. DOI: 10.5772/intechopen.80780.

2. Drinking Water and Health: Volume 2. ISBN: 0-309-55406-3. Retrieved from https://www.ncbi.nlm.nih.gov/books/NBK234590/.

3. Javier Marugán. (2020). Solar Disinfection as a Water Treatment Technology / Javier Marugán, Stefanos Giannakis, Kevin G. McGuigan, Inmaculada Polo-López / DOI: https://doi.org/10.1007/978-3-319-70061-8_125-1.

4. Mohammad M. Amin. A review on wastewater disinfection / Mohammad M. Amin, Hassan Hashemi, Amir Mohammadi, Yung Tse Hung / International Journal of Environmental Health Engineering, 2013. No 2 (1): 1 - 9. DOI:10.4103/2277-9183.113209

5. Nadine Madanchia. Functional and Environmental Evaluation of Alternative Disinfection Methods for Cutting Fluids / Nadine Madanchia, Sebastian Thiedea, Christoph Herrmanna / The 24th CIRP CONFERENCE on Life Cycle Engineering, Volume 61, 2017. P. 558-563. DOI: https://doi.org/10.1016/j.procir.2016.11.175.

6. Yun-Hee Choi. Priority Setting for Management of Hazardous Biocides in Korea Using Chemical Ranking and Scoring Method / Yun-Hee Choi, Min-Sung Kang, Da-An Huh, Woo-Ri Chae, Kyong Whan Moon / International Journal of Environmental Research and Public Health, Mar 2020, No 17 (6). P. 1970. DOI: https://doi.org/10.3390/ijerph17061970 .

7. Patrick Di Martino. Ways to improve biocides for metalworking fluid / AIMS Microbiology, 2021, Volume 7, Issue 1: 13-27. DOI: https://doi.org/10.3934/microbiol.2021002 .

8. Frederick J. Passman, Peter Küenzi. Microbiology in Water-Miscible Metalworking Fluids / Tribology Transactions, Volume 63, 2020, Issue 6, P. 1147-1171. DOI: https://doi.org/10.1080/10402004.2020.1764684 . 
9. Nattawin Chawaloesphonsiya. Separation of Emulsified Metalworking Fluid by Destabilization and Flotation / Nattawin Chawaloesphonsiya, Nawadol Thongtaluang, Pisut Painmanakul / Scince and Technology Behind Nanoemulsions, 2018. DOI: 10.5772 /intechopen.75307

10. Wu X. Circulating purification of cutting fluid: an overview / Wu X, Li C, Zhou Z, Nie X, Chen Y, Zhang Y, Cao H, Liu B, Zhang N, Said Z, Debnath S, Jamil M, Ali HM, Sharma S / The International Journal, Advanced Manufacturing Technology, 26 Aug 2021, P. 1-36. DOI: https://doi.org/10.1007/s00170-02107854-1.

11. Jodi Brookes. Biological and chemical hazards in water-mix metalworking fluids and mists / Sheffield Hallam University, September 2017, 284 p. Retrieved from https://shura.shu.ac.uk/21507/1/Brookes_2017_PhD_BiologicalChemicalHazards.pdf .

12. Xifeng Wu. Circulating purification of cutting fluid: an overview / Xifeng Wu, Changhe Li, Zongming Zhou, Xiaolin Nie, Yun Chen, Yanbin Zhang, Huajun Cao, Bo Liu, Naiqing Zhang, Zafar Said, Sujan Debnath, Muhammad Jamil, Hafiz Muhammad Ali, Shubham, Sharma / The International Journal of Advanced Manufacturing Technology, No 117, P. 2565-2600, (2021), DOI: https://doi.org/10.1007/s00170-021-07854-1 .

13. Benedicto E. Technical, Economic and Environmental Review of the Lubrication/ Cooling Systems used in Machining Processes / E. Benedicto, D. Carou, E.M. Rubio / Procedia Engineering. (2017). Volume 184, P. 99 - 116, DOI: https://doi.org/10.1016/j.proeng.2017.04.075 .

14. Jalal Seyedmohammadi. The effects of drilling fluids and environment protection from pollutants using some models / Modeling Earth Systems and Environmwnt, 2017, No 3 (1). DOI: 10.1007/s40808-017-0299-7 .

15. Dianjie Sui1. Regulations and methods for disposal of waste drilling fluid / Dianjie Sui1, Mingwang Zhan, Dianxue Sui, Fulei Zhao / IOP Conference Series Earth and Environmental Science. No 631 (1):012045. DOI: http://dx.doi.org/10.1088/1755-1315/631/1/012045 .

16. Berezutskyi V.V. (2009). Ensuring safety in the application of water process emulsions and solutions in the production of metalworking technologies: Monograph. Kharkov: Fact, 400 p.

17. Kulsky L.A., Levchenko T.M, Petrova M.V. (1976). Chemistry and microbiology of water. Kiev: Vishcha schola, 115 p.

18. Monchenko E. (1974). Microbiology and hydrobiology of natural and waste waters. Novocherkassk, 201 p. 
https://doi.org/10.31713/m1117

\title{
STRESS-STRAIN STATE OF FLEXIBLE COMPOSITE \\ TRACTIVE ELEMENT WITH CABLE BREAKAGES \\ AT TUBULAR-SHAPED AND TRANSITIONAL AREAS
}

\author{
Belmas, I.V. \\ Dniprovsk State Technical University, Kamianske, Dr. Sc. (Tech.), \\ Prof., Head of Department of Mechanical Engineering Technology, \\ Ukraine \\ Kolosov, D.L. \\ Dnipro University of Technology, Dnipro, Dr. Sc. (Tech.), Associate \\ Professor, Head of Department of Structural, Theoretical \\ and Applied Mechanics, Ukraine \\ Samusia, V.I.
}

Dnipro University of Technology, Dnipro, Dr. Sc. (Tech.), Professor, Head of Department of Mining Mechanics, Ukraine

Kolosov, A.L.

LLC “Antes”, Korolyov, Cand. Sc. (Tech.), Assoc. Prof., Design Engineer, Russian Federation

\section{Onyshchenko, S.V.}

Dnipro University of Technology, Dnipro, Cand. Sc. (Tech.), Associate Professor of Department of Structural, Theoretical and Applied Mechanics, Ukraine

\begin{abstract}
.
The purpose of research is establishment of dependencies of the stress-strain state of a rubber-cable rope on its mechanical parameters and geometric parameters of a part where a flat rope gets a tubular shape considering the influence of a cable base breakage. Research methodology is construction of analytic models of interaction of cables in a rubber-cable rope as a composite structure, created from parallel cables regularly placed in one plane that interact through a layer of rubber, using the methods of mechanics of composite materials. Obtaining analytical dependencies in closed form for establishing the parameters of a stress-strain state of a rope in a part where it gets a tubular shape, which allows determining upper and lower boundaries of stresses in cables and in a rubber layer of a rope. Mathematical formulation of the process is based on the principles of mechanics of layered structures with hard and soft layers. Mathematical models were developed and investigated, what allows defining the boundaries of a stress-strain state of a flat rubber-cable rope, which gets a spatial shape of a cylinder. Obtained results allow predicting running abilities of a
\end{abstract}


rope with a high level of reliability including brakeages of its reinforcing cables. Scientific novelty is in obtained analytical dependencies for boundary values of rigidity characteristics of rubber inter-cable layer were obtained and solved what allows determining basic characteristics of a stress-strain state of the rope, which gets a shape of a pipe within the limited length including the case of a cable base breakage. Practical application of research is in the possibility to determine the boundaries of a stress-strain state of a rope, prediction of its stress state in case of cable breakage during operation, allows reasonable choosing of parameters of lifting and transporting machines, on which the rope gets a tubular shape. This increases the level of their operation safety and contributes to solving the problem of ecological compatibility of underwater oil extraction by removing the oil from the area of the well damage directly through the rope cavity, which gets a cylinder shape and which has a massive oil-receiving unit attached.

\section{Introduction}

Designs of modern machines, equipment and mechanisms of mining [1-4], transport [5,6] and technology engineering [7-9] are being continuously developed and improved in the direction of increasing the productivity, reliability, strength and energy efficiency.

Flat rubber-cable belts (RCB) and ropes (RCR) are widely used in mining and metallurgic engineering [10,11]. In particular, ropes in special conveyors are provided with a spatial tubular shape [12]. A rope of tubular shape is suggested to be used in mineral extraction systems $[13,14]$ that use an airlift $[15,16]$ to protect the water environment from oil leakage during its underwater extraction $[17,18]$, and also in systems of minerals extraction from near-bottom layers of reservoirs. Introduction of technical solutions, connected with the usage of belts and ropes, which get a tubular shape, is constrained by the lack of methods for determining their stress state, including the case of cable breakage.

\section{State of Question and Research Problem}

To simplify the report of the subject, the belt and the rope will hence be called 'the rope' for convenience. Giving a flat rope tubular shape is accompanied by an uneven distribution of forces between its cables. An uneven distribution of forces leads to the curvature of flat cross-sections of the rope and the occurrence of shear stress in its shell. The breakage of the rubber shell is not just dangerous because of a lost connection between the cables. It can also lead to aggressive water leakage to cables, their corrosion and breakage. 
The structure of the cable, as a system of twisted wires, leads to a twisting moment of the rope. Distribution of forces in a cross-section of the rope impacts the strength, twisting equilibrium and operation safety of rubber-cable ropes. It depends on the parameters of the rope (belt) and the part where it gets a spatial shape. The establishment of quantitative characteristics of the stress-strain state (SSS) of a rubber-cable rope during its spatial deformation under the action of external load is an actual scientific and technical problem. The solution of it will allow reasonable selection of parameters of the transitional part and the entire rope, ensure its strength and operation safety. The application of tubular-shaped ropes will contribute to solving the actual problem of ecological compatibility of underwater mineral extraction, including oil extraction.

The flat rubber-cable rope consists of a cable system that is put in an elastic shell and arranged parallel in one plane. The shell can be made of rubber or other elastomer. The shell material will hence be called 'the rubber'. It protects the cables from the influence of external environment, the interaction with the material being transported and elements of the machine it is installed on. The issue of a strainstrain state of a flat rope in the part where a flat rope gets a tubular shape was investigated in the paper [19]. There are no guidelines for calculating a rope and limits of their application. Papers $[10,11]$ are devoted to the issue of a stress state of a flat rubber-cable rope with cable breakage. The stress-strain state of a flat rope as a composite structure with soft and hard layers was considered there. The hard layers take tensile forces, the soft only take a shear stress.

\section{Construction of Transitional and Tubular-shaped Area Models}

Rubber-cable rope with a part where it gets a tubular shape is depicted in the Fig. 1.

Cables have a significant tensile rigidity compared to rubber. The rubber provides constructive integrity and mechanical interaction of the tractive element system. It creates a continuous body of the rope.

The interaction of cables is determined by normal and tangential stresses in rubber layers, as in elements of composite material. The first appear in the presence of relative displacement of cables in the planes normal to them. Tangential stresses appear due to a mutual 
shift of cables along their axes. The stresses depend on displacements of cables and rigidity of rubber layers.

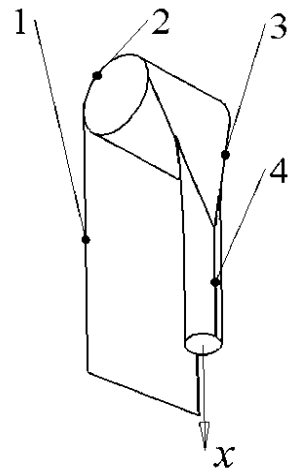

Fig. 1. Rope with a part of tubular shape: 1 - a flat part of a rope; 2 - a part of a rope interaction with a drum; 3 - a part where a flat rope gets a tubular shape;

$$
4 \text { - a part of a tubular-shaped rope }
$$

The problem of determining the stresses in a rubber-cable rope in a part where it gets a tubular shape is geometrically nonlinear. It is related to the determination of a mechanism of mutual deformation of all elements of the rope, including rubber layers, as components of a composite structure. In order to simplify the problem, determine not the stress-strain state, but the boundaries of possible values of stresses that may occur in the elements of the rope by giving it a tubular shape.

The boundaries of these values are determined by the shape that the rope cables get. In the cross-section of the rope running on (off) the drum and behind it the centers of cables are located along straight lines. The cable placement spacing is constant. The rubber located between the cables does not deform in a plane of the rope. The centers of cables are located on concentric circles in the cross-sections of completion of giving a cylindrical shape and the following crosssections. The rubber between the cables is deformed along a circle arc. The angular spacing of cable placement is constant.

Significant changes in a distance between the cables in crosssections of the rope occur in the part between the part of giving the cross-section of the rope a circular shape and the part of running-on (off) the drum. In this transitional part the cables get curvilinear 
shape. There is a compression stress in the rubber located between the cables. The rigidity of rubber in such compression affects the displacement of cables in a cross-section of the rope, curvature and internal forces of their tension respectively. Boundaries of a stressed state can be determined by considering two cases, taking the rigidity of the rubber between the cables in compression by the cables infinitely large and infinitely small.

Consider the case where the distances between the centers of adjacent cables remain unchanged in the cross-sections normal to axis of the rope. That is, the compression rigidity of rubber layers is considered infinitely large.

As indicated above, in a cross-section of running on the drum and behind it the cables are located along a straight line. Number the cables $\pm 1, \pm 2, \pm 3, \ldots, \pm \frac{M}{2}$. Perform the displacement of cables in a cross-section of completion of a part of giving a cylindrical shape, in a plane normal to the axis of the rope. Turn the centers of cables numbered $i \neq \pm 1$ around the first by the angles $a= \pm(\pi / M)$. The centers of cables numbered $i= \pm 2$ are located along the circle with a radius

$$
R=\frac{t M}{2 \pi} \text {. }
$$

Repeat the turns around the next cable centers by the same angles. Provide the placement of all the cable centers along the circle (Fig. 2).

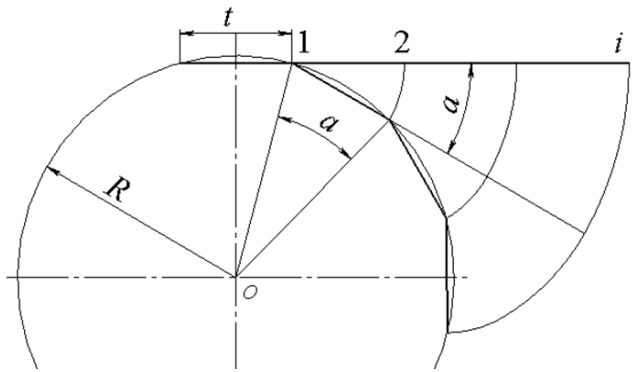

Fig. 2. Diagram of cable displacement in a part of completion of giving a cylindrical shape to the rope

The displacements of ends of discrete cables occur in circle arcs. For infinitely small cable placement spacing it occurs along evolvents. The distance between them is constant. It is equal to the 
cable placement spacing. Trace normal cylindrical surfaces through the movement trajectories of cable centers. Choose the height of surfaces equal to the length of a part of completion of giving a cylindrical shape to the rope - $L$.

Pairs of points are located on the formed surfaces that correspond to coordinates of placement of cable centers at the boundaries of a part of completion of giving a cylindrical shape to the rope. Trace geodesic curves between the points - curves of minimum length. Note that minimum lengths of deformed cables correspond to the minimum work of their deformation. Unfold the formed cylinders with the geodesic lines. Involutes of these lines are straight lines. Write lengths of the lines in the following form

$$
L_{i}=\sqrt{\left\{\frac{2 \pi}{M} t \sum_{j=1}^{i-1}(i-j)\right\}^{2}+L^{2}} .
$$

Relative elongations of cables do not depend on coordinate $x$

$$
\varepsilon_{1, \pm i}=\frac{\sqrt{\left[\frac{2 \pi}{M} t \sum_{j=1}^{i-1}(i-j)\right]^{2}+L^{2}}-L}{L} .
$$

Neglect the bending of a rope on a hoisting machine drum. Consider the rope to be located along the $x$-axis. Repeat the above rotations around the same lines in opposite directions at angles twice smaller $(\mp a / 2)$. At the same time, we rotate the deformed cables as absolutely rigid elements. As a result of this rotation, the centers of cables, which are located on a line of the rope running on a drum of a hoisting machine, will displace. The displacement will take place in a plane, which passes through the drum axis and normal to the rope axis. The centers of cables in cross-sections of beginning and completion of giving the rope its cylindrical shape are located on arcs of circles with a radius $2 R$ symmetrically with respect to the plane, which passes through the middle of a tubular rope section. Projections of displacement trajectories of cable centers in planes of beginning and end of an area of change of a rope shape are shown in Fig. 3. 


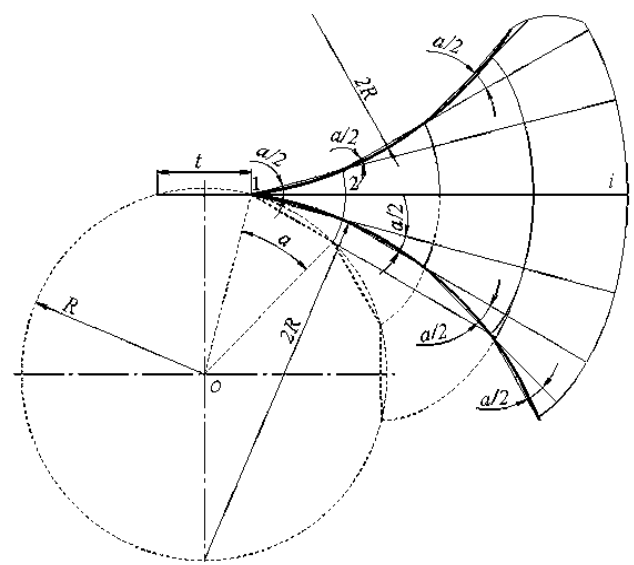

Fig. 3. Diagram of displacement of cables in cross-sections of beginning and completion of giving the rope a tubular shape

Note that the rotations of cables as rigid elements did not change their stress-strain state. The projections of distances between the axes of cables along the entire length of a rope also did not change, which corresponds to the hypothesis of absence of compression deformations in rubber layers. The relative elongations of the cables (1) are distributed symmetrically with respect to the middle (along the length) of the rope.

Consider the symmetry of rope deformation. Expand relative elongations in Fourier series in cosines

$$
f_{i}=\frac{1}{M}\left[\begin{array}{c}
\sum_{k=1}^{M} \varepsilon_{1, k}+2 \sum_{m=1}^{M-1} \sum_{k=1}^{M-1} \varepsilon_{1, k} \cos \left(\mu_{m}(k-0.5)\right) \times \\
\times \cos \left(\mu_{m}(i-0.5)\right)
\end{array}\right],
$$

where $\mu_{m}=(\pi m / M)$.

The rope length significantly exceeds the length of the part of interaction with a drum. Neglect it. Consider a rope consisting of two infinitely long segments. There is a part between them where a flat rope gets a tubular shape that has a length $L$. As shown above, relative elongations of cables are constant along the axis of the rope. Accordingly, the deformation of the rope occurs symmetrically respectively to the middle of the part where its cross-section changes the shape. Place the beginning of the $x$-axis in the middle of the specified part.

\section{Boundary Conditions of Model}


Deformed, and respectively, stressed state of the rope has two planes of symmetry. This allows determining the state of the fourth part of a rope. This rope part has a part where a rope gets a tubular shape. Give it the number 1 , and give the adjacent one number 2 . These numbers are used to indicate the parameters related to respective parts. Formulate boundary conditions for the accepted physical model

$$
\begin{aligned}
x & =0, \quad u_{1, i}=0 ; \\
x \rightarrow \infty, \quad u_{2,1} & =u_{2,2}=\ldots=u_{2, M}, \quad p_{2, i}=P,
\end{aligned}
$$

and the conditions of joint deformation of rope parts

$$
x=L / 2, \quad u_{1, i}=u_{2, i}, \quad p_{1, i}=p_{2, i},
$$

where $P$ is the average force of tension of cables - a part of an external load, that affects one cable.

\section{Assumed Forms of Solutions}

Considering the generally accepted assumptions concerning the character of deformation of rubber-cable rope components as a composite material with significantly different moduli of elasticity of its components [19] and boundary conditions (2), accept the following forms of solutions

$$
\begin{aligned}
& u_{1, i}=\sum_{m=1}^{M-1} A_{m}\left(e^{\beta_{m} x}-e^{-\beta_{m} x}\right) \cos \left(\mu_{m}(i-0.5)\right)+\frac{P x}{E F}, \\
& p_{1, i}=E F \sum_{m=1}^{M-1}\left(\begin{array}{c}
A_{m}\left(e^{\beta_{m} x}+e^{-\beta_{m} x}\right) \beta_{m}+ \\
+\frac{2}{M} \sum_{k=1}^{M-1} \varepsilon_{1, k} \cos \left(\mu_{m}(k-0.5)\right)
\end{array}\right) \times \\
& \times \cos \left(\mu_{m}(i-0.5)\right)+P, \\
& u_{2, i}=\sum_{m=1}^{M-1} B_{m} e^{-\beta_{m} x} \cos \left(\mu_{m}(i-0.5)\right)+\frac{P x}{E F}, \\
& p_{2, i}=P-E F \sum_{m=1}^{M-1} B_{m} e^{-\beta_{m} x} \beta_{m} \cos \left(\mu_{m}(i-0.5)\right),
\end{aligned}
$$

where $u_{i}, p_{i}$ - displacement of a cross-section of cable $i$ along the rope and its inner force of tension resistance; $M$ - the amount of cables in a rope; $E, F$ - reduced modulus of elasticity of cable material and its 
cross-section area; $\beta_{m}=\sqrt{2 \frac{G b k_{G}}{h E F}\left[1-\cos \left(\mu_{m}\right)\right]} ; G$ - rigidity modulus of elastic (rubber) rope shell material; $h$ - distance between cables; $b$ rope thickness; $k_{G}$ - coefficient that considers the influence of rubber shape between the cables on the rigidity of their connection; $A_{m}, B_{m}$ unknown constants of integration; 1, 2 - part number.

In dependencies (47) the components, which include constants of integration $, A_{m}, B_{m}$ reproduce the mechanism of deviation of deformations and forces from mean values. Their sums are zero, which is a consequence of the equality of the sum of internal forces and external load. Find unknown constants using the conditions of joint deformation of parts (3)

$$
\begin{gathered}
A_{m}=-\frac{\sum_{k=1}^{M-1} \varepsilon_{1, k} \cos \left(\mu_{m}(k-0.5)\right)}{M \beta_{m} e^{\beta_{m} L / 2}}, \\
B_{m}=-\frac{\sum_{k=1}^{M-1} \varepsilon_{1, k} \cos \left(\mu_{m}(k-0.5)\right)}{M \beta_{m}}\left(e^{\beta_{m} L / 2}-e^{-\beta_{m} L / 2}\right) .
\end{gathered}
$$

\section{Stress State Calculations in Transitional Area}

Calculations of internal forces in cables of the fourth part of a part where a rope gets a tubular shape for a rope with parameters matching a rope type $\mathrm{RCB}-3150$ are executed.

Figs. 4-5 indicate graphs of cable displacements $u$ and a ratio of internal forces to the permissible tensile force in a rope $P=10 \mathrm{kN}$.

Note that deformations (cable elongations) in Fig. 4 increase both along the width and length of the rope. Deformations increase along the rope width due to the redistribution of forces between the cables for a spatial rope. Deformations increase along the rope length due to the action of an external load on a rope as a working force. The longitudinal deformations also change due to the redistribution of forces between the cables. Fig. 5 indicates these rope deformations, when it is not conditionally loaded by external forces in order to determine this component.

The figure shows that the deformations of some cables are negative - they are compressed in the absence of an external load. The assumed external load of the rope with a force of $10 \mathrm{kN}$ almost bal- 
ances the compression loads of the cables, which can be seen from the graph of distribution of tensile forces of the rope cables, related to average (working) force values (Fig. 6).

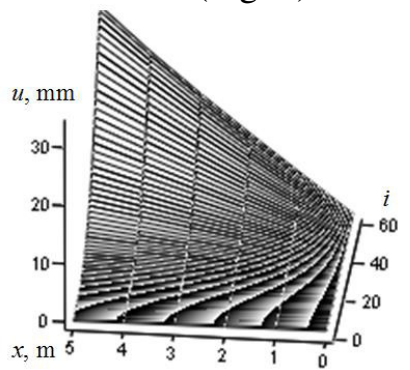

Fig. 4. Displacement of cables $u$ with numbers $i$ along the rope $x$-axis, loaded with external forces

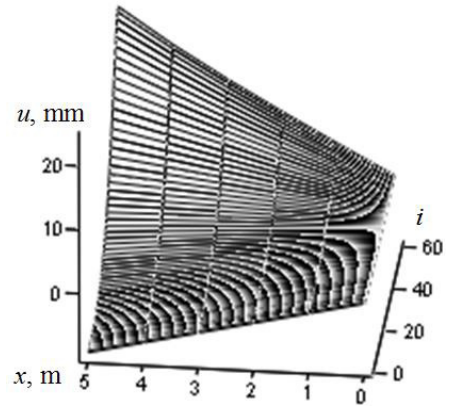

Fig. 5. Displacement of cables $u$ with numbers $i$ along the rope $x$-axis, not loaded with external forces

Fig. 6 shows the graph of a ratio of internal forces to the average force $P=1 \mathrm{kN}$ applied to rope cables. The ratio of actual stresses in the components of machines is the coefficient of stress concentration. Analogically, call the ratio above a coefficient of concentration of forces. The figure shows that internal forces in cables of the middle part of the rope are less than average. They are the smallest in cables with numbers $i \neq \pm 1$, in the cross-section $x=0$. The coefficient of concentration of forces for the considered case in this point is 0.746 . Accordingly, in the absence of an external load, compressive forces would occur in them. 


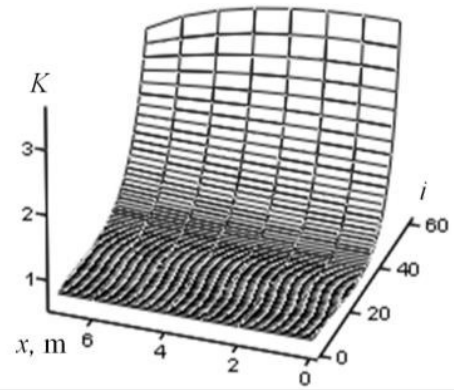

Fig. 6. A surface that reproduces the character of distribution of coefficients of concentration of forces distributed along the $x$-axis between cables with numbers $i$

Thus, in order to avoid the compression forces of cables to occur, the external load must not be less than the compression force of cables with numbers $i \neq \pm 1$. That is, the following condition must be fulfilled

$$
P M \geq 2 E F \sum_{m=1}^{M-1}\left(\begin{array}{c}
\sum_{k=1}^{M-1} \varepsilon_{1, k} \cos \left(\mu_{m}(k-0.5)\right) \times \\
\times\left(1-e^{-\beta_{m} L / 2}\right)
\end{array}\right) \cos \left(\frac{\mu_{m}}{2}\right) .
$$

According to Fig. 6, internal forces that occur in cables of a symmetrical part of a rope are decreasing. Overload coefficient of the extreme cable decrease from 3.582 in a cross-section of symmetry of the spatial deformation part to 2.765 at its edge. The decreasing character is caused by the influence of adjacent parts of a rope with unchanging cross-section geometry. This is a consequence of a perturbation locality due to a local deformation of rope cables. The manifestation of a local redistribution of forces in a part, which is their source, indicates insignificant length of parts of redistribution of forces. Thus, a deviation of maximum forces from their mean values does not exceed $5 \%$ in cross-sections with coordinates $x= \pm 3 L$. The length of a part where a rope gets a tubular shape is much smaller than its total length. Accepted assumption about boundless parts of a rope with unchangeable shape of cross-sections can be considered acceptable. Obtained results are quite reliable.

Fig. 6 shows that the most loaded are extreme rope cables. Maximum loads are in the cable $M$ in a cross-section $x=0$. It is determined by a dependency 


$$
\begin{gathered}
p_{\max }=2 \frac{E F}{M} \sum_{m=1}^{M-1}\left(\sum_{k=1}^{M-1} \varepsilon_{1, k} \cos \left(\mu_{m}(k-0.5)\right)\left(1-e^{-\beta_{m} L / 2}\right)\right) \times \\
\times \cos \left(\mu_{m}(M-0.5)\right)+P .
\end{gathered}
$$

According to Hooke's law, the intensity of a tangential force, distributed along the length of a rope, is determined by a dependency

$$
\tau_{i}=\frac{G b}{h} k_{G}\left[u_{i}-u_{i-1}\right], \quad(1 \leq|i| \leq M-1) .
$$

The figure shows the distributed tangential forces transmitted by the rubber in a part where a rope gets a tubular shape.

According to calculations, the maximum tangential distributed forces are not in the extreme rubber layers.

In the process of designing a part where a rope gets a tubular shape, there are problems of determining geometric parameters of such a part - the diameter of a formed pipe and a length of a part of its formation. Diameter of a formed tubular shape is determined by the rope width. In order to obtain the results suitable for comparison, consider a rope type RCB-3150. The length of a part where a rope gets a cylinder shape is $10 \mathrm{~m}$. Change only the amount of cables in it from 20 to 200 (from 10 to 100 cables in a half of the rope). Determine the ratio of the largest to the smallest internal forces of the load of extreme ropes $\left(K_{r}\right)$ for a middle part of a part of rope shape change and in a cross-section on its boundary. The results are shown in Fig. 7.

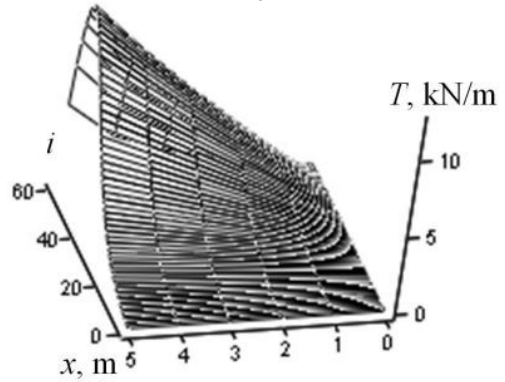

Fig. 7. Distribution of tangential forces transmitted by the rubber in a part where a rope gets a tubular shape

The given graphic dependency has its maximum at 75 cables. Growth of number of cables for the considered case will not lead to a significant decrease in a relative coefficient $\left(K_{r}\right)$. The specified al- 
lows determining the maximum forces in the cross-section, which corresponds to half the length of a transitional part. To apply the indicated conclusions to other types of ropes, it is necessary to determine the length of a transitional part as a value in the expression, $m$

$$
L_{2}=10 \sqrt{\frac{G_{2} b_{2} k_{G 2} h_{1} E_{1} F_{1}}{h_{2} E_{2} F_{2} G_{1} b_{1} k_{G 1}}} .
$$

In this expression, indexes indicate the attribute of a rope parameter. For the rope RCB-3150 the index is 1 . Index 2 refers to the rope, for which it is necessary to determine the length at which the results shown in Fig. 8 are realized. This is the result of dependency of forces and displacements from the exponent of the product of magnitude of the characteristic index $\beta_{m}$ and coordinate $x$.

The intensity of the maximum tangential forces distributed along the rope length significantly increases with increasing number of cables (Fig. 9).

The analysis shows that as the length of a part where a rope gets a tubular shape increases the indicators of the stress state decrease as curvature and relative deformations of cables decrease. The results obtained above correspond to the values of the upper boundary of stress.

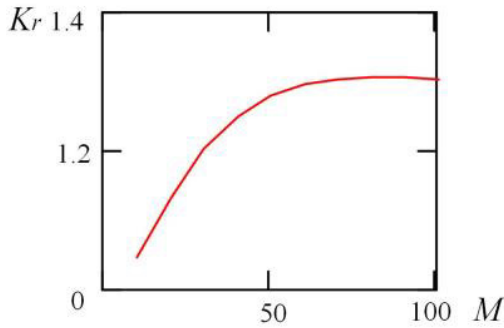

Fig. 8. Dependency of a relative coefficient $\left(K_{r}\right)$ on the amount of cables in a rope $M$

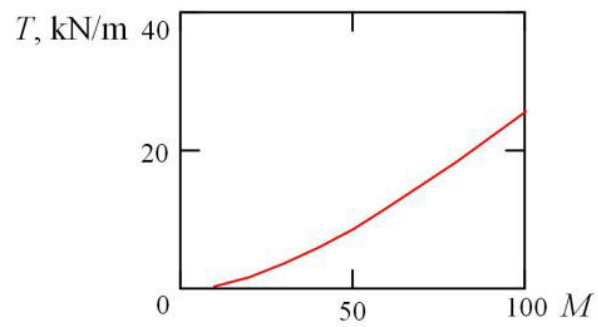

Fig. 9. Dependency of intensities of maximum tangential forces $T$ distributed along the rope length on the number of cables $M$ in it 


\section{Case of Infinitely Small Compression Rigidity of Rubber}

We considered the case of absolute high compression rigidity of rubber above. Accordingly, we accepted the condition of constant distances between the centers of cross-sections of adjacent cables in a rope. In case of infinitely small compression rigidity of rubber, flexible cables in a part where a rope gets a tubular shape, remain straight. The distances between them decrease, with exception for the cross-sections of the beginning and the end of a part where a rope cross-section changes. Adjacent cables receive different elongations, except for cables located in the middle of a rope. These elongations are smaller than the elongations in the case above. Shear rubber rigidity, as in the previous case, will cause redistribution of forces between the cables. Accordingly, the relative elongations of cables, their mutual shear will take smaller possible values.

Projections of axes of cables on a plane normal to the axis of the rope are shown in Fig. 10 with solid straight lines.

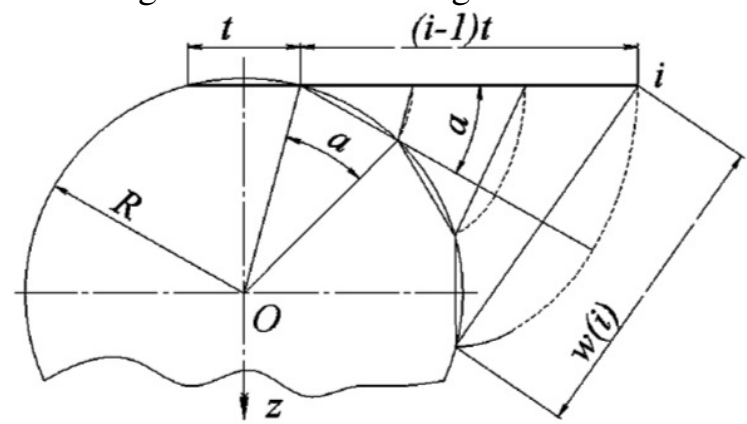

Fig. 10. Projection of a rope and its axes centers on a plane, normal to the axis of a rope

For comparison, dash lines also show the projections of cylinders formed by the corresponding equidistant evolvents and on which cables are located, provided the constant distances between them. Known lengths of projections of cables and the length of a part where a rope gets a tubular shape allow determining the relative elongations of cables

Relative elongations (11), as well as elongations (1), increase upon the increase of nominal values of cable numbers from zero - for cables with numbers $i \neq \pm 1$. Boundary conditions (2) determine the conditions of loading and deformation of ropes in cross-sections $x=0$, 
$x \rightarrow \infty$. They have not changed, as well as a condition of joint deformation of parts (3). Leave accepted forms of solutions (4-7) unchanged. Recalculations lead to forms of rope stress state similar to expressions (8-10). The only difference is that instead of the relative extensions $\varepsilon_{1, i}$ in the upper-mentioned expressions it is necessary to substitute for $\varepsilon_{2, i}$.

Calculations of deformations and internal forces of loads of cables on a fourth part of an area of giving it a tubular shape are executed for the rope type RCB-3150. Fig. 11 and Fig. 12 indicate graphs of cable displacements $u$ and the ratio of internal forces to the permissible tensile force in a rope $P=10 \mathrm{kN}$ in the area of change in the shape of a rope cross-section.

The obtained graphical dependencies (Figs. 11-13) are consistent with the distributions of deformations, internal tensile forces and tangential forces (Figs. 4, 6-7) in the absence of rubber compression. Quantitatively, the elongation, tensile forces and tangential forces are smaller, which is a consequence of shorter lengths of trajectories of cable centers in the planes normal to the rope axis.

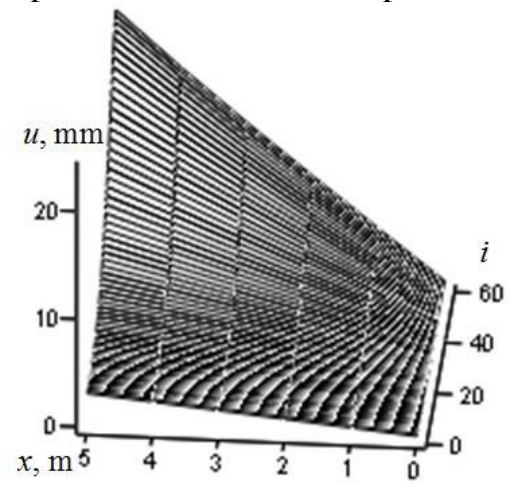

Fig. 11. Surface that indicates the character of displacements $u$ of cables with numbers $i$ and along the $x$-axis 


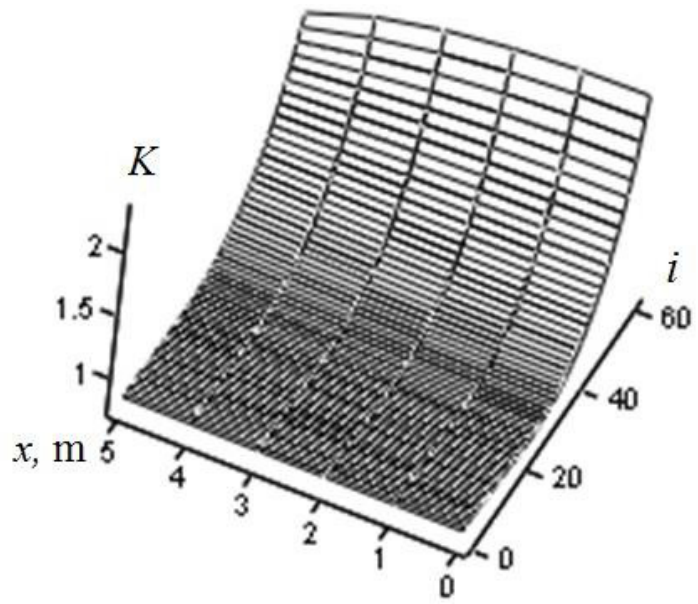

Fig. 12. Surface that indicates the character of distribution of tensile forces of cables between the cables with numbers $i$ and related to permissible force $P$ along the $x$ axis of the rope

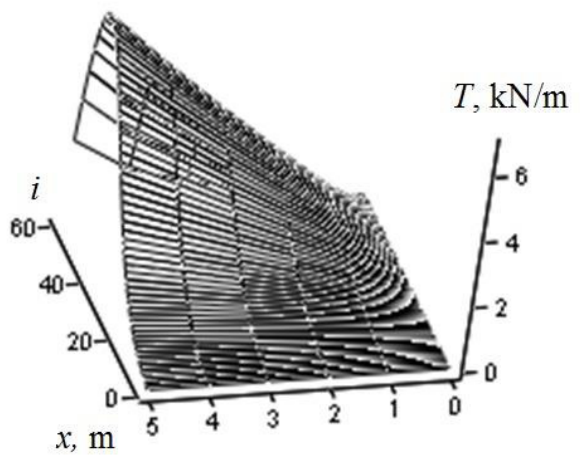

Fig. 13. Distribution of thickness-averaged tangential forces in the rubber-cable rope in an area of giving it a tubular shape

Insignificant difference in dependencies of rope stressed states for extreme cases of rigidity of rubber layers determines their qualitative coincidence. Thus, minimum force concentration coefficient (in cables numbered $i \neq \pm 1$, in cross-section $x=0) K=0.821$, whereas in the previous case - 0.746. Differences between the forces and stresses that occur at boundary rigidity for rubber layers referred to maximum values are $35 \%$ and $44 \%$. 


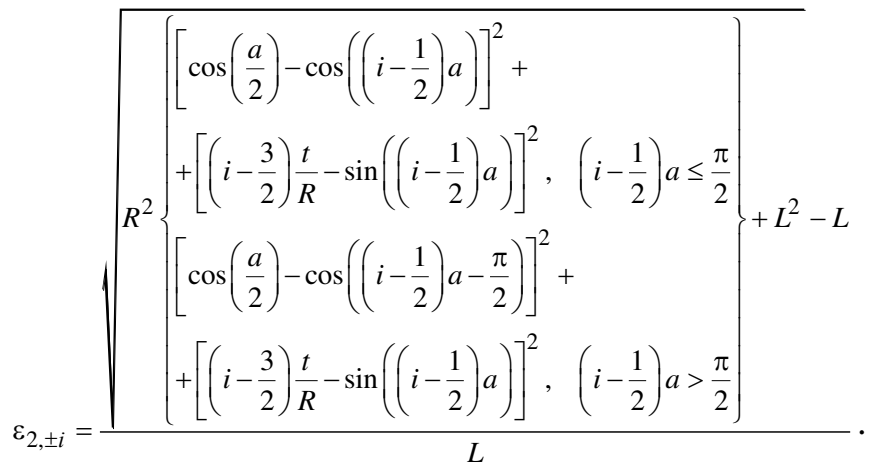

Considering two cases of a deformed state of a rope with extreme values of rigidity of rubber layers, located between cables, we can make the following inequality

$$
\begin{gathered}
\sum_{m=1}^{M-1}\left(\sum_{k=1}^{M-1} \varepsilon_{1, k} \cos \left(\mu_{m}(k-0.5)\right)\left(1-e^{-\beta_{m} L / 2}\right)\right) \times \\
\times \cos \left(\mu_{m}(M-0.5)\right) \geq \frac{\left(P_{a d}-P\right) M}{2 E F} \geq \\
\geq \sum_{m=1}^{M-1}\left(\sum_{k=1}^{M-1} \varepsilon_{2, k} \cos \left(\mu_{m}(k-0.5)\right)\left(1-e^{-\beta_{m} L / 2}\right)\right) \times \\
\times \cos \left(\mu_{m}(M-0.5)\right) .
\end{gathered}
$$

The resulting inequality (12) allows determining the possible boundaries of values of additional force $P_{a d}$ that occurs in the most loaded rope cables in a part where a rope gets a tubular shape.

Shear rigidity of rubber layers depends on a cable placement spacing in a rope. It infinitely increases with decreasing of a cable placement spacing to a minimum, equal to a diameter of cables. In rubber-cable ropes, provided that the rope weight is minimized, smaller cable placement spacing is used. The values of maximum cable tension forces in rubber-cable ropes are closer to the upper limit. The functional purpose of conveyor belts is dual. They perform the function of carrying the transported object on the belt during movement, and also transfer the traction force. The latter raises the problem of appropriateness of use of ropes with increased cable 
placement spacing. Increasing the thickness of a rubber layer between the cables reduces compressive rigidity of rubber and leads to a decrease in values of extreme tension forces of cables.

The condition of constant shape of all cables must be fulfilled together with a condition of strength. The fulfillment of the condition is possible by preventing the occurrence of compression forces of cables - the fulfillment of condition (8), considering the value of relative elongation described by dependency (11).

\section{Stress State in Tubular-shaped Rope with Broken Cable}

Tubular shape is provided to a rope via connecting its edges by special locks. The pulling capacity of a rope, including one of tubular shape, is ensured by its design, in particular the number of cables in it. Rope cable breakage is possible during operation. Breakage also affects strength of a rope. Strength loss caused by cable breakage must be taken into account when allocating a safety margin to avoid emergency situations.

Determine the stress-strain state of such tubular-shaped rope with a broken random cable $k$. Trace a plane through the axis of this cable and the axis of the tubular rope. It divides the tubular rope into two symmetrical parts. In case when the number of cables $M$ is not even, the plane will pass in the middle between the cables, as shown in Fig. 14. Taking this into account, consider a rope, which consists of an odd number of cables $M$. Number the cables from one to $M$.

Unfold this cut tubular rope. As a result, we have a stress-strain state of the rope that is symmetrical relatively to the broken cable. Displacements and loads of cables with numbers 1 and $M$ are the same. Shear stress in a rubber layer between them is absent. This shows that the breakage of any single cable leads to an identical stress state of the rope of tubular shape, relatively to a location of the cable. This state according to the computable model is characterized by the fact that specifically the middle cable is always broken. This allows us to apply a known form of solution for determining the SSS of a tubular tractive rope with a broken cable 


$$
\begin{gathered}
u_{i}=\sum_{m=1}^{M-1}\left(A_{m} e^{\beta_{m} x}+B_{m} e^{-\beta_{m} x}\right) \times \\
\times \cos \left(\mu_{m}(i-0.5)\right)+\frac{P}{E F M} x+c, \\
p_{i}=E F \sum_{m=1}^{M-1}\left(A_{m} e^{\beta_{m} x}-B_{m} e^{-\beta_{m} x}\right) \beta_{m} \times \\
\times \cos \left(\mu_{m}(i-0.5)\right)+\frac{P}{M}, 1 \leq i \leq M, \\
\tau_{i}=\frac{G b k_{G}}{h} \sum_{m=1}^{M-1}\left(A_{m} e^{\beta_{m} x}+B_{m} e^{-\beta_{m} x}\right) \times \\
\times\left(\cos \left(\mu_{m}(i+0.5)\right)-\cos \left(\mu_{m}(i-0.5)\right)\right), 1 \leq i \leq M-1,
\end{gathered}
$$

where $c$ - unknown constant.

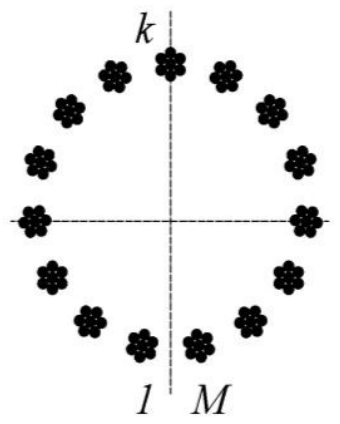

Fig. 14. Cross-section of a tubular-shaped rubber-cable rope

Consider a rope loaded with an external force $P$ as infinitely long one with a broken cable in the middle. Place the start of $x$-axis in a cross-section of cable breakage. Given the symmetry, consider a part of the rope in an interval $0 \leq x \rightarrow \infty$. The condition of symmetry indicates that in the cross-section $x=0$ there is no cable displacement except for the broken one. Edges of the broken cable are not loaded. Given the infinite growth of coordinate $x$, internal resistance forces of cables and displacements of their cross-sections cannot grow infinitely. Formulate this as boundary conditions 


$$
\begin{array}{ll}
x=0, & u_{i}=0, \quad(i \neq k), \\
& \frac{\partial u_{k}}{\partial x}=0, \quad(i=k), \\
x \rightarrow \infty, \quad & u_{i} \rightarrow \text { const }, \\
& \frac{\partial u_{i}}{\partial x} \rightarrow \text { const } .
\end{array}
$$

The last condition is provided by accepting $A_{m}=0$. Consider that dependencies (13-15) are constructed using cable numbers as a discrete coordinate axis. The boundary condition (16) has a form of a discontinuous - delta function. Take this into consideration. Calculate unknown constants in the form

$$
\begin{gathered}
B_{m}=\frac{P \cos \left(\mu_{m}(k-0.5)\right)}{M E F \sum_{m=1}^{M-1} \cos \left(\mu_{m}(k-0.5)\right)^{2} \beta_{m}}, \\
c=\frac{P}{2 M E F \sum_{m=1}^{M-1} \cos \left(\mu_{m}(k-0.5)\right)^{2} \beta_{m}},
\end{gathered}
$$

where $P$ - average internal force in rope cables.

Displacements of cross-sections of cables, internal forces and tangential stresses that occur in them when a single cable breaks depend on the number of cables and the properties of rope components according to expressions (13-15).

Using the dependencies (16)-(18), the obtained unknown differentiation constants were determined. The rope parameters with the following values were taken as a basis: $M=9 ; G=5 \mathrm{MPa} ; h=5 \mathrm{~mm}$; $b=30 \mathrm{~mm}$. The ratio $\frac{k_{G}}{E F}=\frac{8}{10^{10} \pi d^{2}}$ took into account the incomplete filling of a cable cross-section with metal, the value of a coefficient, which considers the influence of a rubber shape between the cables on the rigidity of their connection, lower rigidity of a cable compared to the rod. In the calculations, it was assumed that the average load on one cable is $1 \mathrm{~N}$. This allows the value of internal forces occurring in the cables to be considered as related to the average ones, i.e. equal to the coefficients of unevenness of their distribution. 
According to expression (13), the displacements of cable crosssections depend on three components - the sum of products of constants and cosines, the constant multiplied by the coordinate $x$ and the constant $c$. The latter regulates the rope displacement as a rigid body. The pre-last component represents the longitudinal rope deformation with a constant force. And only the first component describes the redistribution of displacements. Since the second component does not affect the redistribution of displacements, it was conditionally omitted in the calculations. The results are shown in Figs. 15-17.

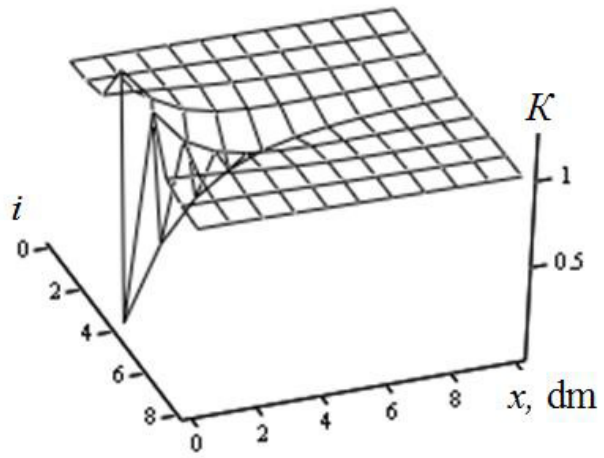

Fig. 15. Coefficients of uneven distribution of internal tensile strength of tubular rubber-cable ropes with nine cables in a cross-section and in case of breakage of one of them

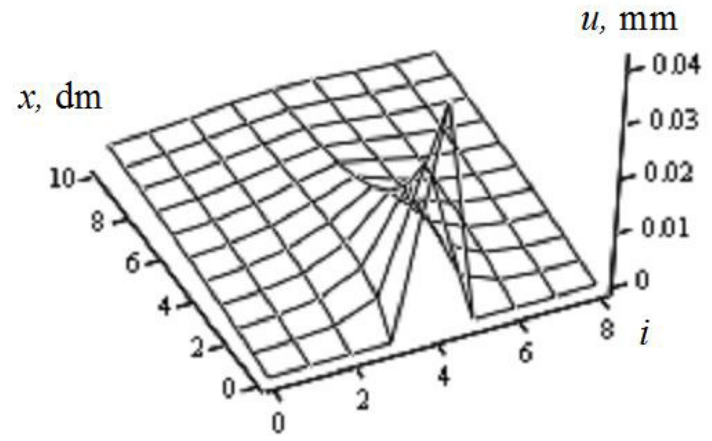

Fig. 16. Displacements of cables of a tubular rubber-cable rope with nine cables in a cross-section and in case of breakage of one of them 


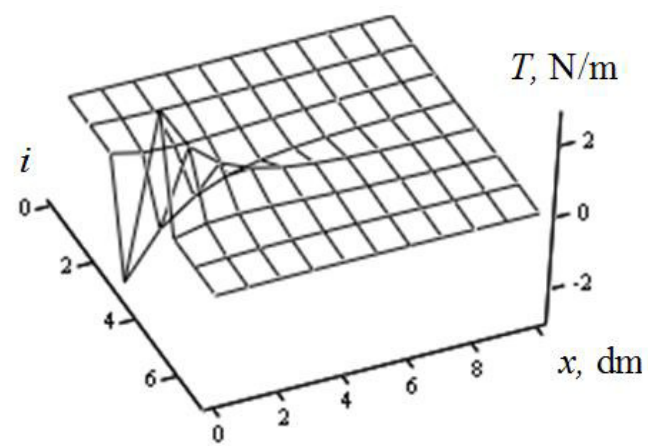

Fig. 17. Dependency of intensities of distributed tangential forces in rubber layers located between cables in a case of tension of tubular rubber-cable rope with one out of nine broken cables in its cross-section

According to the graphical dependencies, in the cross-section of the cable breakage, the values of displacements, internal forces of deformation of cables and tangential forces that occur in layers of rubber located between the cables change. The specified values reach the maximum values in a cross-section of breakage. This indicates the dependency of maximum displacements, internal forces of tensile strength of cables, and tangential forces on a total number of cables in a rope of tubular shape.

Fig. 18 and 19 show the dependencies of maximum values of coefficients of uneven distribution of forces $K$ and values of distribution intensity of tangential forces $T$ in layers of rubber, located between cables on the number of cables in a rope $M$.

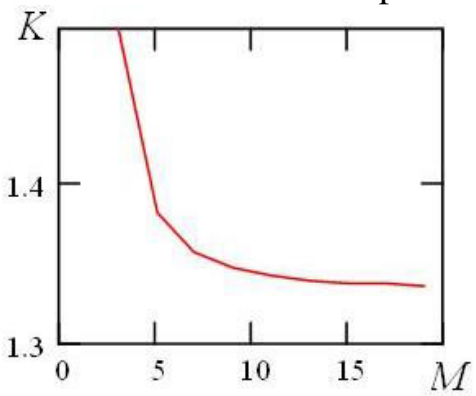

Fig. 18. Dependency of maximum values of coefficients of uneven distribution of forces $K$ on the number of cables in a rope $M$ 


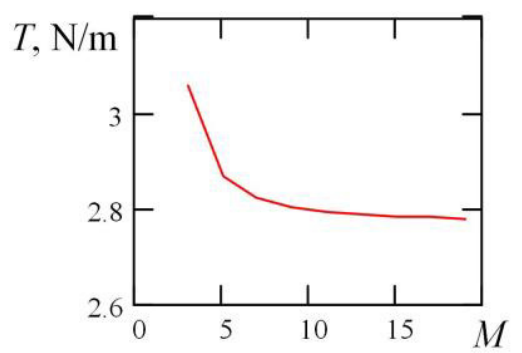

Fig. 19. Dependency of distribution intensity of tangential forces $T$ in layers of rubber, located between cables on the number of cables in a rope $M$

According to graphic dependencies (Fig. 18, Fig. 19), the maximum forces and tangential stresses are significantly dependent on the number of cables in a rope, if it is less than ten. This is a consequence of a local influence of a cable breakage on the stress-strain state of a tubular rope and the implementation of St. Venant's principle on the locality of influence of local load changes or a component design.

Consider the redistribution of forces across the width of a rope, depending on the number of cables in it. Fig. 20 shows the distribution of forces in a cross-section of a rope with different number of cables $M$ in case of the middle cable breakage.

In the figure, the number of cables is conditionally unchanged and is nineteen. The actual number of cables which is from two to eighteen was supplemented by conditional cables. Coefficients of forces concentration in imaginary cables are equal to zero. The figure shows that the growth of the number of cables in a tubular rope does not significantly affect the redistribution of forces between them. The same conclusion can be reached by examining problems regarding the quantitative part of the force perceived by adjacent cables from the value of the force that was perceived by the broken cable before its breakage. The indicated dependency is shown in Fig. 21.

The graph shows the quantitative dependency of a force part transmitted by the broken cable before its breakage from the number of cables in a rope. The middle cable takes place with an odd number of cables. The minimum number of cables in a rubber-cable rope is three. In this case, damage to one cable can lead to an additional load of only two cables. And just these cables take the load that occurred in the broken cable before its breakage. Accordingly, if there are only three cables in a tubularshaped rope, cables adjacent to the broken one will take the entire load; 
coefficient $K=1$. As the number of cables increases, the mentioned proportion decreases and does not get lower than 0.6.

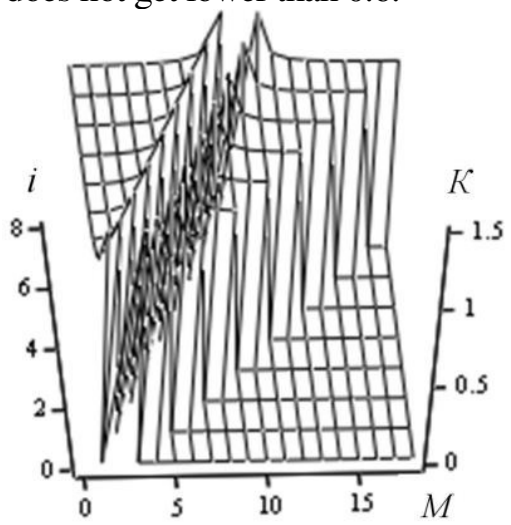

Fig. 20. Distribution of coefficients of forces concentration in ropes with $M$ cables in case of the middle cable breakage

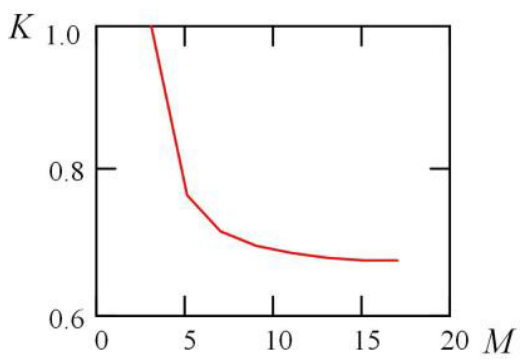

Fig. 21. Relative load part, perceived by two cables adjoining the middle broken one in a rope with $M$ cables

Established dependencies of maximum values of coefficients of uneven distribution of forces $K$, tangential forces $T$ in layers of rubber, located between the cables on the number of cables in a rope $M$, caused by the breakage of any cable of a flat rubber-cable rope, which gets a tubular shape, allow taking into account possible cable breakages during the design of lifting and transporting machines with a rubber-cable tractive rope of a tubular shape. 


\section{Calculation of Twisting Moments in Rope with Broken Cables}

The basis of a rubber-cable rope is cables. They are made of a twisted cable system. This structure of a cable leads to a distribution of a twisting moment while stretching throughout cable length. To avoid a twisting moment in a rope an even number of cables is used. Cables of opposite twist directions are arranged alternately in the rope. The balance of a rope is disturbed due to cable breakage. The locality of redistribution of forces in case of cable breakage leads to localization and distributed rope twisting moment. Assume that a cable twisting moment is directly proportional to the internal force of its load with a coefficient of proportionality $\gamma$. Determine a value of intensity of an unbalanced moment of a rope in the cross-section of cable breakage and in the cross-section which is remote from it by $0.5 \mathrm{~m}$. Fig. 22 shows dependencies of an unbalanced moment, related to an average load force of cables on their number in a rope. The values of moments are shown for breakage cases of the extreme cable and the most distant cable from the edge.

The figure shows insignificant dependence of maximum intensity of rope twisting moment on the location of a cable in it (when an extreme or a middle cable is broken) in the breakage cross-section (curves 1 and 2). The placement of a broken cable in a rope affects the length of a part of stress-strain state perturbation more significantly (curves 3 and 4). Thus, in case of breakage of a cable that is the farthest from the edges of a rope, the intensity of the unbalanced moment in a rope system is close to $10 \%$ of its maximum value (curve 4 ). A similar indicator is practically twice as large for a case of an extreme cable breakage (curve 3 ). This feature is fulfilled because the intensity of distributed twisting moments of a rope at a distance of $0.5 \mathrm{~m}$ is a whole degree smaller than their values in a part of cable breakage.

This character of distribution of moments of imbalance of system of cable ropes is caused by the placement scheme of cables with the opposite twisting direction. The twist direction determines the direction of twisting moment. Breakage of the extreme cable leads to a significant increase in the internal tensile force of only one adjacent cable. Non-extreme cable breakage leads to growth of internal tensile forces of two adjacent cables. In this case, as shown above, adjacent cables perceive at least $60 \%$ of a cable load, which it perceived be- 
fore the breakage. A similar ratio is accurate in case of extreme cable breakage. As a result, the breakage of one cable significantly increases twisting moments of adjacent cables.

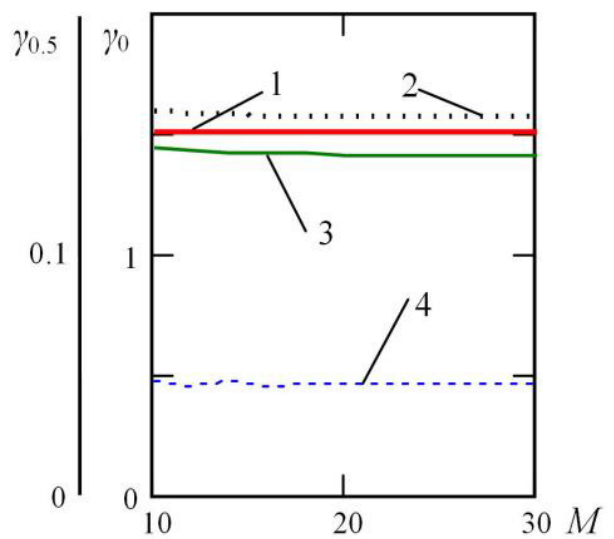

Fig. 22. Relative twisting moment of a rope with $M$ cables in the cross-section of cable breakage $\gamma_{0}$ and $\gamma_{0,5}$ at a distance of $0.5 \mathrm{~m}: 1-$ in the cross-section of extreme cable breakage, 2 - in the cross-section of middle cable breakage, 3 - in the crosssection at a distance of $0.5 \mathrm{~m}$ from the cross-section of extreme cable breakage, 4 in the cross-section at a distance of $0.5 \mathrm{~m}$ from the cross-section of middle cable breakage

According to a scheme of alternating placement of cables of the opposite direction the moments of one direction increase substantially (at least by $60 \%$ ). It is possible to decrease the mentioned growth provided the forces are distributed between the cables of the opposite direction. This distribution can be arranged in such a way that, any cable is adjacent to two other cables of the opposite twist direction. This can be ensured by placing cables in a rope according to a scheme, where two cables of one direction are alternately placed with pairs of cables of another twisting direction. Fig. 23 shows the dependencies similar to those shown in Fig. 22, but in a scheme of alternate placement of cable pairs of one twist direction.

According to Fig. 23, the placement of a broken cable in a rope more significantly affects the values of maximum intensity of a rope twisting moment (curves 1 and 2). At the same time, the maximum values during the middle cable breakage are almost one third less. In case of the extreme cable breakage, this indicator reaches 50\%. 


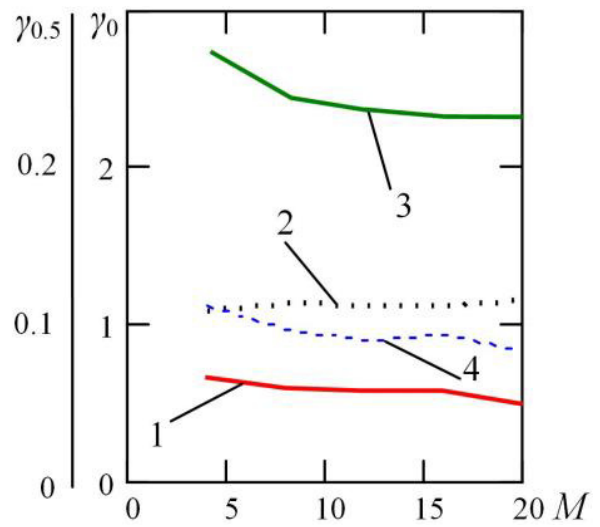

Fig. 23. Relative twisting moment of a rope with $M$ cables in the cross-section of cable breakage $\gamma_{0}$ and $\gamma_{0,5}$ at a distance of $0.5 \mathrm{~m}$ in a scheme of alternate placement of cable pairs of one twisting direction: 1 - in the cross-section of extreme cable breakage, 2 - in the cross-section of middle cable breakage, 3 - in the cross-section at a distance of $0.5 \mathrm{~m}$ from the cross-section of extreme cable breakage, 4 -in the cross-section at a distance of $0.5 \mathrm{~m}$ from the cross-section of middle cable breakage

Reduction of a twisting moment in the cross-section of cable breakage is accompanied by an increase in length of a perturbation part. Thus, in case of extreme cable breakage, an unbalanced twisting moment at a distance of $0.5 \mathrm{~m}$ from the cross-section of breakage decreased to $0.25 \gamma$. In case of middle cable breakage, practically, down to $0.1 \gamma$ which is 2.5 and two times more than in a previous case. The specified confirms an increase in length of imbalance occurrence part to rope twisting.

The balancing of cable twisting moments happens due to the occurrence of additional deformations and stresses in a rubber of a rope. Reduction of intensities of maximum twisting moments of a rope leads to a decrease of stresses in rubber and improvement of its operation conditions. But keep in mind that in a rope with a scheme of alternate placement of cable pairs of one twisting direction the number of cables must be a multiple of four.

\section{Stress-Strain State of Tubular Rope With Spatial Curvature of Axis \\ Operation of hoisting machines on a ship, underwater currents, determine a possibility of displacement of a drum axis, and rope axis}


in space. As a result, the rope axis can get a spatial shape. Spatial deformation can be represented as a sum of possible rotations of rope cross-sections and their longitudinal displacements along its length.

Stresses in material of cables, considering the strength condition, are less than the stresses that lead to plastic (residual) deformations. Within such stresses, the deformations depend linearly on them. The indicated linear dependency allows applying the hypothesis of independence of action of external forces - the principle of superposition in a study of the stress-strain state of the rope. Accordingly, allows considering the various factors of its deformation independently. Distribution of forces in a rope when giving it a tubular shape is studied above. Spatial deformation, accompanied by the acquired spatial curved axis in the tubular rope, can be represented as a sum of rotations of the cross-section in the plane normal to the axis of the rope and in the plane tangent to it.

Rotating the rope cross-section around the axis causes it to twist. Twisting a rope with tubular cross-section, in a case when the end of the rope is connected to the mechanism of extracting minerals, as a support for unilateral action, does not resist such displacement. Accordingly, it does not change the rope tension - does not affect its stress state.

Bending in the plane tangent to the rope axis leads to a redistribution of tensile forces of cables in a cross-section of a rope. Considering a possibility of arbitrary direction of underwater currents, a system of deep-water lifting of minerals with a hoisting rope of tubular shape is suggested. The tubular (cylindrical) shape of a rope is symmetrical with respect to the axis. Its resistance to underwater currents and the distribution of forces between the cables, provided that they are placed evenly, do not depend on the direction of bending. Consider rope bending in the plane $x y$. The $x$-axis coincides with the rope axis of the tubular shape. Assume that the cross-section $x=0$ is rotated around the $y$ axis by an angle $\gamma$, the rope is infinitely long. Determine the influence of rotation of a plane of attachment of a load on distribution of forces between the rope cables. We do not consider the force of tension of the rope evenly distributed between the cables. Considering the principle of Saint-Venan of the locality of redistribution of forces due to the action of local perturbations, the displacement of the cross sections of the cables $u$ and the forces of their tension $p$ determine the dependencies 


$$
\begin{aligned}
& u_{i}=\sum_{m=1}^{N} B_{m} e^{-\beta_{m} x} \cos \left(\mu_{m}(i-0.5)\right)+c, \\
& p_{i}=-E F \sum_{m=1}^{N} B_{m} e^{-\beta_{m} x} \beta_{m} \cos \left(\mu_{m}(i-0.5)\right),
\end{aligned}
$$

where $B_{m}, c$ - unknown constants; $i$ - cable number; $\beta_{m}=\sqrt{2 \frac{G d k_{G}}{(t-d) E F}\left(1-\cos \left(\mu_{m}\right)\right)} ; \mu_{m}=\frac{\pi m}{M} ; d$ - diameter of cables located in a rope with a spacing $t ; G$ - elasticity modulus of a cable; $E$ - elasticity modulus of cable material with a cross-sectional area $F$; $k_{G}$ - coefficient, which considers the dependency of shear rigidity of rubber located between cables on a shape of its cross-section.

Assume that the rope has $2 M$ cables. An even number of cables assumes that there is no zero cable, and cables with numbers $\pm 1, \pm 2, \pm 3 \ldots, \pm M$ are located symmetrically to the $y$-axis. According to the accepted conditions of deformation, the end of an arbitrary cable will move by a value

$$
\delta=R \sin \left(\frac{M+1-2 i}{2} a\right) \operatorname{tg} \gamma,
$$

where $a=\frac{\pi}{M} ; R$ is radius of a circle, on which the centers of crosssections of cables of a tubular-shaped rope are located.

Dependency (19) is expanded in Fourier series in cosines

$$
f_{i}=D_{0}+\sum_{m=1}^{\infty} D_{m} \cos \left(\mu_{m}(i-0.5)\right),
$$

where $D_{0}=\sum_{k=1}^{N} \frac{\delta_{k}}{N} ; D_{m}=\sum_{k=1}^{M} \frac{2 \delta_{k}}{M} \cos \left(\mu_{m}(k-0.5)\right)$.

Dependencies (17)-(20) represent a mathematical model of a stress-strain state of a rubber-cable rope, which is given a tubular shape during its deformation. Considering the dependencies (17)(20) we have 


$$
\begin{gathered}
u_{i}=\frac{R}{M}\left[\begin{array}{c}
2 \sum_{m=1}^{M}\left(\begin{array}{c}
\operatorname{tg} \gamma \sum_{k=1}^{M} \sin \left(\frac{M+1-2 k}{2} a\right) \cos \left(\mu_{m}(k-0.5)\right) \times \\
\times e^{-\beta_{m} x} \cos \left(\mu_{m}(i-0.5)\right)
\end{array}\right)+ \\
+\operatorname{tg} \gamma \sum_{k=1}^{M} \sin \left(\frac{N+1-2 k}{2} a\right)
\end{array}\right], \\
p_{i}=-2 E F \frac{R}{M} \sum_{m=1}^{M}\left(\begin{array}{c}
\operatorname{tg} \gamma \sum_{k=1}^{M} \sin \left(\frac{M+1-2 k}{2} a\right) \cos \left(\mu_{m}(k-0.5)\right) \times \\
\times e^{-\beta_{m}{ }^{x} \beta_{m} \cos \left(\mu_{m}(i-0.5)\right)}
\end{array}\right] .
\end{gathered}
$$

According to dependences (21) and (22) and Saint-Venant's principle, the uneven distribution of displacements and forces is realized over a limited length, which is due to the negative degree of the exponent, the maximum value of which is for the case $x=0$. Maximum tensile force of cable located at the greatest distance from the axis of the rope is

$$
\begin{aligned}
& p_{\text {max }}=2 E F \frac{R}{M} \times \\
& \times \sum_{m=1}^{M}\left(\begin{array}{c}
\operatorname{tg} \gamma \sum_{k=1}^{M} \sin \left(\frac{M+1-2 k}{2} a\right) \cos \left(\mu_{m}(k-0.5)\right) \times \\
\times \beta_{m} \cos \left(\frac{\pi m}{2}\left(1-M^{-1}\right)\right)
\end{array}\right)+\frac{P}{2 M},
\end{aligned}
$$

where $P / 2 M$ - part of the tensile force of the cable due to the tensile force of the rope.

Since the force of the most loaded cable is caused by the local rotation of the rope cross-section, and decreases with increasing distance from the bend cross-section and acts only in the farthest cable, the rotation of the cross-section in another plane and in another cross-section will not lead to greater cable loads than when bending the rope in the plane. This allows accepting the distribution of relative elongations of cables of a tubular-shaped rope, bent in a plane of radius $\mathfrak{R}$, according to the hypothesis of flat cross-sections 


$$
\Delta_{i}=\frac{R}{\Re} \sin \left(\frac{M+1-2 i}{2} a\right) .
$$

The known distribution of relative elongations (24) allows determining the distribution of internal forces occurring in cables of a rope loaded with tensile force $P$

$$
p_{i}=E F \frac{R}{\Re} \sin \left(\frac{M+1-2 i}{2} a\right)+\frac{P}{2 M} .
$$

In turn, expression (25) allows determining the force acting on the maximum loaded cable, when bending along the radius $\mathfrak{R}$ of an infinitely long rope loaded with tensile force $P$

$$
p_{\max }=E F \frac{R}{\Re}+\frac{P}{2 M} .
$$

According to the condition of strength

$$
E F \frac{R}{\mathfrak{R}}+\frac{P}{2 M} \geq[P],
$$

where $[P]$ - tensile force allowed from the strength condition.

Hence, the minimum permissible bending radius of a rubber-cable rope, which is given a tubular shape, must satisfy the following condition

$$
\mathfrak{R}_{\min } \geq \frac{E F R}{[P]-\frac{P}{2 M}} .
$$

In the area of giving the rope a tubular shape, the maximum forces occur in the extreme cables, so installing the drum of a hoisting machine so that its axis is located at right angles to the direction of the forces of horizontal resistance of the aquatic environment is impractical. The location of drum axis parallel to the direction of total horizontal resistance of aquatic environment should be considered the best. The vessel movement leads to a clear direction of one of the components of resistance. The second component of resistance is due to underwater currents. In the general case, the direction of its action is random, so the axis of rotation of the drum, in terms of strength, is advisable to be placed parallel to the axis of the vessel. The constant spacing of placement of cables in a rope, including in its lock, ensures the independence of resistance of a tubular rope and values of 
the maximum tensile forces in cables from a random direction of a force of water pressure normal to the axis of the rope.

\section{Conclusion}

Determination in analytical form of boundaries of a stress-strain state of a rope which gets a tubular shape, that occur including the case of broken cables, establishment of a mechanism of a rope balance disturbance to twisting, implementation of the system of cable placement in a rope as two cables of one twist direction after two cables of an opposite twist direction, establishment of dependencies of a stress-strain state of a cylinder-shaped rope during a spatial curvature of its axis, allow reasonable selection of the parameters of a rope of lifting and transporting machines, in which a rope gets a cylinder shape. This ensures its operation safety and contributes to solving the problem of ecological compatibility of underwater oil extraction.

\section{References}

1. Vayenas, N., \& Peng, S., 2014. Reliability analysis of underground mining equipment using genetic algorithms: A case study of two mine hoists. Journal of Quality in Maintenance Engineering, Vol. 20, Issue: 1, pp. 32-50.

2. Styp-Rekowski, M., Manka, E., Matuszewski, M., Madej, M., Ozimina, D., 2015. Tribological problems in shaft hoist ropes wear process. Industrial Lubrication and Tribology, Vol. 67, Issue: 1, pp. 47-51.

3. Ilin, S.R., Samusia, V.I., Ilina, I.S., \& Ilina, S.S., 2016. Influence of dynamic processes in mine hoists on safety exploitation of shafts with broken geometry. Naukovyi Visnyk Natsionalnoho Hirnychoho Universitetu, № 3, pp. 42-47.

4. Zabolotny, K.S., Zhupiiev, O.L., \& Sosnina Ye.M., 2012. Study of deflected mode of mine winder split drums. Naukovyi Visnyk Natsionalnoho Hirnychoho Universytetu, № 1, $\quad$ p. $\quad 82-87 . \quad$ Available at: $<$ http://nv.nmu.org.ua/index.php/ru/component/jdownloads/finish/31-01/453-201201-zabolot/0>

5. Bass, K.M., Kuvayev, S.M., Plakhotnik, V.V., \& Krivda, V.V., 2014. Planar and spatial mathematical motion simulation of open pit mining vehicles. Naukovyi Visnyk Natsionalnoho Hirnychoho Universytetu, № 3, pp. 60-65.

6. Protsiv, V.V., Ziborov, K.A., \& Fedoriachenko, S.A., 2013. On formation of kinematical and dynamical parameters of output elements of the mine vehicles in transient motion. Naukovyi Visnyk Natsionalnoho Hirnychoho Universytetu, № 4, pp. 64-68.

7. Shpachuk, V.P., 2016. Effect of mutually amplifying action of two coordinate shock loading in problems of dynamics of knots of machine. Naukovyi Visnyk Natsionalnoho Hirnychoho Universytetu, № 6, pp. 89-94. 
8. Samusya, V.I., Oksen, Y.I., \& Radiuk, M.V., 2013. Heat pumps for mine water waste heat recovery. Annual Scientific-Technical Collection - Mining of Mineral Deposits, pp. 153-157.

9. Pivnyak, G., Dychkovskyi, R., Smirnov, A., \& Cherednichenko, Yu., 2013. Some aspects on the software simulation implementation in thin coal seams mining. Energy Efficiency Improvement of Geotechnical Systems, pp. 1-11.

10. Zabolotny, K., \& Panchenko, Y., 2010. Definition of rating loading in spires of multilayer winding of rubber-rope cable. New Techniques and technologies in Mining, pp. 223-229. Available at:

<https://www.taylorfrancis.com/books/9780203093351>

11. Kolosov, D., Dolgov, O., \& Kolosov, A., 2013. The stress-strain state of the belt on a drum under compression by flat plates. Annual Scientific-Technical Collection - Mining of Mineral Deposits, pp. 351-357.

12. Grujić, M., \& Erdeljan, D. Advantages of high angle belt conveyors (hac) in mining, 2014. Applied Mechanics and Materials, 683, pp. 73-77.

13. Bondarenko, A.A., 2012. Mathematical modeling of soil dredger absorption processes in the underwater bottomhole. Metallurgical and Mining Industry, № 3, pp. 79-81. Available at:

<http://www.metaljournal.com.ua/read/ru/2012/3/>

14. Bondarenko, A.A., \& Zapara, Ye.S., 2012. Laws of determination of fine materials suction limits in submarine suction dredge face. Naukovyi Visnyk Natsionalnoho Hirnychoho Universytetu, № 4, pp. 59-64. Available at: <http://nv.nmu.org.ua/index.php/ru/component/jdownloads/finish/34-04/537-20124-bondarenko/0>

15. Kyrychenko, Y., Samusia, V., Kyrychenko, V., \& Goman, O., 2012. Experimental investigation of aeroelastic and hydroelastic instability parameters of a marine pipeline. Geomechanical Processes During Underground Mining - Proceedings of the School of Underground Mining, pp. 163-167. Available at:

<http://www.crcnetbase.com/doi/abs/10.1201/b13157-28>

16. Kyrychenko, Y., Samusia, V., \& Kyrychenko, V., 2012. Software development for the automatic control system of deep water hydrohoist. Geomechanical Processes During Underground Mining - Proceedings of the School of Underground Mining, pp. 81-86. Available at: <http://www.crcnetbase.com/doi/abs/10.1201/b1315714>

17. Kolesnik, V.Ye., Kulikova, D.V., \& Pavlichenko, A.V., 2016. Substantiation of rational parameters of perforated area of partitions in an improved mine water settling basin. Naukovyi Visnyk Natsionalnoho Hirnychoho Universytetu, № 6, pp. 120127.

18. Belmas, I.V., Kolosov, D.L., \& Bobylova I.T., Dniprodzerzhinsk technical university, 2012. The device for environment protection from casing pipes leakage in water mass. Ukraine. Pat. 75145.

19. Belmas, I.V., Kolosov, D.L., Kolosov, A.L., 2014. Study of stresseddeformed state of rubber-rope cable in the area of tubular transformation. Bulletin of PNRPU. Geology. Oil \& Gas Engineering \& Mining, № 12, pp. 48-55. DOI: 10.15593/2224-9923/2014.12.6. 
https://doi.org/10.31713/m1118

\section{DISINTEGRATION OF ORE-BEARING ROCKS AND ITS EFFECT ON THE CONTENT OF CONSTITUENT COMPONENTS}

\section{Toktosunova B.B.}

Kyrgyz State University of Geology, Mining and Natural Resources Exploitation named after Academician U.Asanaliev, $\mathrm{PhD}$, Professor, Head of the Department of "Natural Sciences" of the Geological Exploration Faculty, Kyrgyz Republic

\section{Abdibaitov Sh.A.}

Kyrgyz State University of Geology, Mining and Natural Resources Exploitation named after Academician U.Asanaliev, Candidate of technical sciences, Associate professor of the Department of UMMD Faculty of Mining and Metallurgy, Kyrgyz Republic

\section{Kushnazarova S.Z.}

State Enterprise "Kyrgyzgeologiya", Directorate "Hydrogeologiya" in the position of "Hydrogeologist", Kyrgyz Republic

Tutasheva A. Z.

Kyrgyz State University of Geology, Mining and Natural Resources Exploitation named after Academician U.Asanaliev, student gr. D-117, Mining and Metallurgical Faculty, Kyrgyz Republic Kozhogulov M.B.

Kyrgyz State University of Geology, Mining and Natural Resources Exploitation named after Academician U.Asanaliev, student gr. AG (G) -1-20, the Geological Exploration Faculty, Kyrgyz Republic

\section{Annotation}

In this paper we have studied, analyzed, summarized scientific information on the black-shale formation of the Saryjaz area, determined the chemical composition of initial samples, and ore-bearing minerals broken down into different sizes and evaluated their constituent components. Separated magnetically susceptible from magnetically unsusceptible components of raw materials brought from the three points of the coordinates of the deposit and derived their percentage ratio. The size of dispersed particles was determined on a scanning electron microscope (SEM), 
and the morphological structure of the mineral and the influence of the size of dispersed particles on the enrichment of useful components was studied by it.

The purpose of the work: Study of the influence of the size of dispersed particles on the manifestation of useful components in the composition of ore-bearing rocks of the Saryjaz area black shale formation.

The influence of dispersion of particles on the increase in the quantitative content of useful components in the composition of ore minerals was established. It is shown that in a finely divided sample, the yield of the quantitative content of noble metals is several times higher compared to the control one.

Keywords: ore, crushing, black shale formation, Saryjaz area, minerals, deposits, mineral reserves, research methods, size of dispersed particles, spectral and elemental analysis, scanning electron microscope, point coordinates.

\section{Introduction}

It is known that ores are complex, polymetallic natural formations. Joint presence of several valuable minerals in ores makes it difficult to use them in metallurgical processes without preliminary separation by enrichment methods. There is a number of opinions of experts that the scale of use of minerals is continuously increasing, and the quality of ores is systematically worsening; the content of useful components in ores is decreasing. In recent years with the development of modern technologies and techniques of enrichment allows to involve in processing of all new types of minerals and requires the use of the most advanced technological processes and methods of analysis.

It is known the method of enrichment of minerals, including crushing the ore, separation of minerals of higher density from the crushed ore and removal of the waste rock and minerals of light fractions to the dump.

The method of decryption (this is the property of individual minerals to crack when heated rapidly and to collapse when cooled) is widely used in mineral processing [1].The way of application of nanotechnology [2] in enrichment and extraction from fine-grained ores of "black-shale" type was considered.

The processes of physical-chemical and bacterial [3] in the processing of refractory ores, technogenic combined methods of cuvette and heap leaching of gold (Patent 2350665) were noted. The bacterial method [4] of leaching intensification makes use of the ability of autotrophic bacteria (Thiobacillus ferrooxidans, Thio-bacillus thiooxidans and others) to absorb the energy released for their vital activity 
during the oxidation of sulfides and thiosulfates of metals and sulfur as well as during the transition of $\mathrm{Fe}^{2+}$ into $\mathrm{Fe}^{3+}$.

Despite the existence of numerous methods, the search for new environmentally friendly, more effective and economically profitable ways of enrichment of useful minerals as well as the desire to optimize the process of extraction remains a topical problem.

Therefore, in this work we conduct research on the development of optimal parameters in the process of enrichment of valuable components of ore minerals of black-shale formation of the Saryjaz area.

\section{Preparation of source materials}

It is known that the preparatory processes include crushing, grinding operations, aimed at the disclosure of valuable components of ore-bearing rocks and bringing the material to the size required in the process of enrichment.

The object of the study is the ore minerals of the black shale formation of the Saryjaz area brought from three points of the deposits by coordinates

Table

\begin{tabular}{|c|c|c}
\multicolumn{3}{|c}{ Coordinates of points } \\
Point 1. BSSF (a) & Point 2. BSSF (b) & Point 3. BSSF (c) \\
\hline$x-14344641$ & $x-14344943$ & $x-14337830$ \\
\hline$y-4678073$ & $y-4679611$ & $y-4683314$ \\
\hline$h-2731$ & $h-2738$ & $h-2927$ \\
\hline
\end{tabular}

Table 2

Geographic coordinates

\begin{tabular}{c|c|c}
\hline Point 1. BSSF (a) & Point 2. BSSF (b) & Point 3. BSSF (c) \\
\hline$x-42^{\circ}, 13^{\prime}, 19.6^{\prime}$ & $x-42^{\circ}, 14^{\prime}, 9.6 ”$ & $x-42^{\circ}, 16 ', 4.4^{\prime}$ \\
\hline$y-79^{\circ}, 7^{\prime} .4 .3^{\prime \prime}$ & $y-79^{\circ}, 7^{\prime} .16^{\prime \prime}$ & $y-79^{\circ}, 2 ' .2 .2^{\prime \prime}$ \\
\hline
\end{tabular}



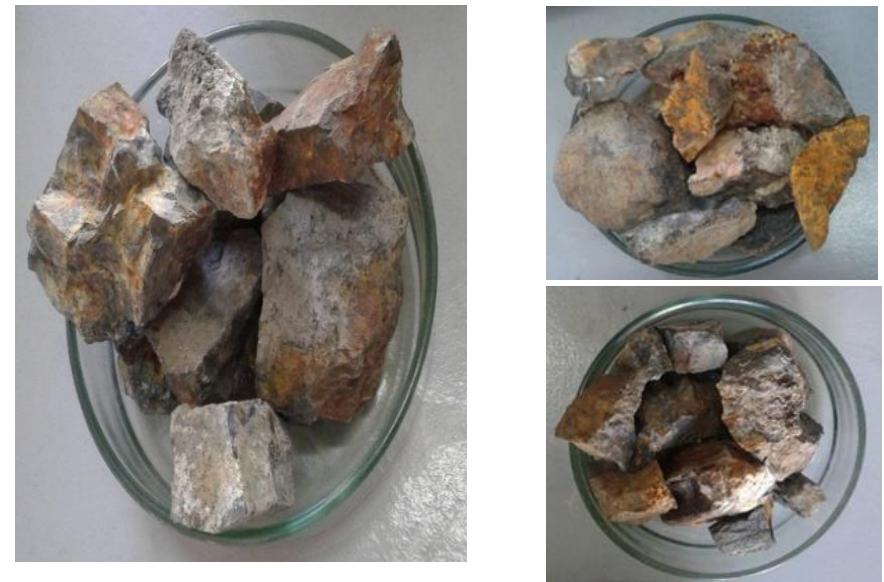

Fig. 1. Pieces of mineral brought from the deposits of the black shale formation of the Saryjaz area

At crushing used a mechanical method of crushing minerals, which was carried out in a crushing machine with a particle size (fine) $-10-15 \mathrm{~mm}$. For this purpose, the initial material weighed on scales of $20 \mathrm{~g}$ was taken. Further crushing is called grinding, which are used for ore going to enrichment. Then the crushed products obtained were sifted out on sieves (with three nearby mesh sizes) and each fraction was weighed separately.

At the same time, the duration and degree of crushing (grinding), power consumption (from the beginning to the end according to indications of the electric meter). The obtained data are presented in Table 3 .

Table 3

Ore crushing indicators

\begin{tabular}{l|l|c}
\hline № & \multicolumn{1}{|c|}{ Shredding indicators } & ore \\
\hline \multirow{2}{*}{1} & Size, mm: & $10-15$ \\
\cline { 2 - 3 } & Initial & $10-20 \mathrm{~g}$. \\
\cline { 2 - 3 } & intermediate & $15 \mathrm{~g}$. \\
\cline { 2 - 3 } & final & $5 \mathrm{~g}$. \\
\hline 2 & Crushing time, $\min$ & $30-60$ \\
\hline 3 & Crushing ratio, $i=$ Dmax $/ \mathrm{dmax}$ & $1,5-2 \mathrm{~mm}$ \\
\hline 4 & Specific power consumption, W/kg & 3-phase electric shift.3000 rpm, \\
& & $2 \mathrm{~kW}, 30-60 \mathrm{~atm} / \mathrm{cm}^{2}$ \\
\hline
\end{tabular}


Hence " $i$ " is the ratio of the diameter of the maximum piece of the source material $D_{\max }$ to the diameter of the maximum piece of the crushing or grinding product $d_{\text {max }}$.

With the method of separating magnetically receptive parts from magnetically non-receptive parts: it is observed that magnetically non-receptive parts amounted to $88.4 \%$; magnetically receptive $9.4 \%$; loss of $2.2 \%$ (Table 4 ).

Table 4

Results of separation of magnetically receptive parts from magnetically nonreceptive parts

\begin{tabular}{c|c|c|c|c|c|c|c}
\hline $\begin{array}{c}\text { Sample } \\
\mathrm{s}\end{array}$ & $\begin{array}{c}\text { Weight } \\
\text { of the } \\
\text { load } \\
\mathrm{c}, \mathrm{g}\end{array}$ & $\begin{array}{c}\text { magnetical- } \\
\text { ly non- } \\
\text { receptive } \\
\text { parts }\end{array}$ & $v, \%$ & $\begin{array}{c}\text { magnetical- } \\
\text { ly receptive } \\
\text { parts }\end{array}$ & $\begin{array}{c}\nu, \\
\%\end{array}$ & Loss & $v, \%$ \\
\hline $\begin{array}{c}\text { BSSF } \\
\text { (a) })\end{array}$ & $\begin{array}{c}24,4399 \\
0\end{array}$ & 21,50177 & 87,9 & 2,40100 & 9,8 & $\begin{array}{c}0,5371 \\
3\end{array}$ & 2,2 \\
\hline $\begin{array}{c}\text { BSSF } \\
\text { (b) }\end{array}$ & $\begin{array}{c}19,6845 \\
5\end{array}$ & 39,76 & 88,3 & 1,795 & 9,8 & 0,492 & 2,49 \\
\hline $\begin{array}{c}\text { BSSF } \\
\text { (c) }\end{array}$ & $\begin{array}{c}23,4779 \\
0\end{array}$ & 20,9504 & 89,0 & 2,0680 & 8,8 & 0,4595 & 2,0 \\
\hline Total: & & & 88,4 & & 9,4 & & 2,2 \\
\hline & & & & & & & $\begin{array}{c}100 \\
\%\end{array}$ \\
\hline
\end{tabular}

The study of the material composition of ore minerals consists of its two components: the determination of chemical (elemental) and mineral composition. Lumps of large size brought from the three points of the deposits were subjected to crushing to sizes $1.5-2 \mathrm{~mm}$ in a ball mill held screening $[5,6,7]$, then determined their chemical composition, which are presented in Table $5 a, b, c$. 
Table 5

Chemical composition of initial samples of the Saryjaz area black shale formation

\begin{tabular}{|c|c|c|c|c|c|c|c|c|c|c|c|c|c|c|c|}
\hline \multicolumn{16}{|c|}{$a$} \\
\hline 变 & $\mid \begin{array}{l}\mathbf{s} \\
\text { upó6 }\end{array}$ & Mn & $\mathrm{Ni}$ & $\mathrm{C}_{0}$ & $\mathbf{T i}$ & $\mathrm{v}$ & $\mathrm{Cr}$ & Mo & w & $\mathrm{Zr}$ & $\mathrm{Nb}$ & In & $\mathrm{Cu}$ & $\mathrm{Pb}$ & $\mathrm{Ag}$ \\
\hline & & $10-2$ & $10-3$ & 10-3 & $10-1$ & 10-2 & $10-3$ & 10-3 & $10-2$ & $10-2$ & $10-3$ & $10-3$ & $10-3$ & 10-3 & 10- 4 \\
\hline प-Сस & $1(\mathrm{k})$ & - & 4 & - & 4 & 15 & 5 & 12 & - & 0,5 & - & - & 9 & 12 & 3 \\
\hline \begin{tabular}{|l|}
$\mathrm{M}$ \\
$\mathrm{i} / \mathrm{in}$
\end{tabular} & \begin{tabular}{|l|}
$\begin{array}{l}\mathrm{Nk} \\
\text { mpo }\end{array}$ \\
\end{tabular} & $\mathrm{Sb}$ & $\mathrm{Bi}$ & As & $\mathrm{Zn}$ & Cd & Sn & $\mathrm{Ge}$ & $\mathrm{Ga}$ & $\mathrm{Yb}$ & $\mathbf{Y}$ & $\mathrm{La}$ & $\mathbf{P}$ & $\mathrm{Be}$ & $\mathrm{Sr}$ \\
\hline & & $10-2$ & 10-3 & $10-2$ & $10-2$ & $10-2$ & $10-3$ & $10-3$ & $10-3$ & $10-3$ & $10-3$ & $10-2$ & $10-1$ & 10- 4 & 10-2 \\
\hline ч.СЖ & $1(\mathrm{k})$ & - & - & 5 & 0,3 & - & 0,15 & - & 0,5 & 0,3 & 3 & - & - & - & 2 \\
\hline 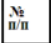 & \begin{tabular}{|l|}
$\begin{array}{l}\text { se } \\
\text { mpoб }\end{array}$ \\
\end{tabular} & $\mathrm{Ba}$ & Li & $\mathrm{Ta}$ & Th & $\mathbf{U}$ & Au & $\mathrm{Sc}$ & $\mathrm{SiO}_{2}$ & $\mathrm{AL}_{2} \mathrm{O}_{3}$ & $\mathrm{MgO}$ & $\mathrm{Fe}_{2} \mathrm{O}_{3}$ & $\mathrm{CaO}$ & $\mathrm{Na}_{2} \mathrm{O}$ & $\mathrm{K}_{2} \mathrm{O}$ \\
\hline & & $10-2$ & 10- 3 & 10. 1 & 10-2 & 10- 1 & $10-3$ & $10-3$ & $\%$ & $\%$ & $\%$ & $\%$ & $\%$ & $\%$ & $\%$ \\
\hline ч.Сж & $1(\mathrm{k})$ & - & - & - & - & - & - & - & 70 & 3 & 2 & 3 & 1,2 & - & - \\
\hline
\end{tabular}

There is still no consensus in the literature on the forms of finding noble and rare metals, on their effective methods for determining their actual concentration in iron oxides and hydroxides, clay minerals, micas, chlorites, alunite, quartz-chalcedony, jarosite, some other carrier minerals, as well as in carbon-bitumen inclusions in shales. The black-shale ores of the studied objects belong to the category of highly resistant and require special technological approaches.

\begin{tabular}{|c|c|c|c|c|c|c|c|c|c|c|c|c|c|c|c|}
\hline \begin{tabular}{|l|}
$x 6$ \\
$\pi / 4$ \\
$\pi / 4$
\end{tabular} & \begin{tabular}{|l|} 
Nó \\
mpoô
\end{tabular} & Mn & $\mathbf{N i}$ & $\mathrm{Co}$ & $\mathbf{T i}$ & V & $\mathrm{Cr}$ & Mo & W & $\mathrm{Zr}$ & $\mathrm{Nb}$ & In & $\mathrm{Cu}$ & $\mathbf{P b}$ & $\mathrm{Ag}$ \\
\hline & & $10-2$ & $10-3$ & $10-3$ & $10-1$ & 10-2 & $10-3$ & 10-3 & $10-2$ & 10-2 & 10-3 & $10-3$ & $10-3$ & $10-3$ & 10- 4 \\
\hline प-Cस & 2(k) & 12 & 15 & - & 4 & 30 & 15 & 15 & - & 2 & - & - & 40 & 15 & 5 \\
\hline \multirow[t]{2}{*}{ 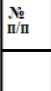 } & 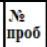 & $\mathrm{Sb}$ & $\mathrm{Bi}$ & As & $\mathrm{Zn}$ & $\mathrm{Cd}$ & Sn & $\mathrm{Ge}$ & $\mathrm{Ga}$ & $\mathrm{Yb}$ & $\mathbf{Y}$ & $\mathrm{La}$ & $\mathbf{P}$ & $\mathrm{Be}$ & $\mathrm{Sr}$ \\
\hline & & $10-2$ & $10-3$ & $10-2$ & $10-2$ & $10-2$ & 10-3 & $10-3$ & 10-3 & $10-3$ & $10-3$ & $10-2$ & $10-1$ & 10- 4 & $10-2$ \\
\hline Ч-Сस & $2(\mathrm{k})$ & - & - & 12 & 1,2 & - & 0,15 & - & 0,5 & 0,3 & 3 & - & - & - & 2 \\
\hline \multirow[t]{2}{*}{ 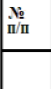 } & \begin{tabular}{|l|} 
Nó \\
mp0б
\end{tabular} & $\mathrm{Ba}$ & $\mathbf{L i}$ & $\mathrm{Ta}$ & Th & $\mathbf{U}$ & $\mathrm{Au}$ & $\mathrm{Sc}$ & $\mathrm{SiO}_{2}$ & $\mathrm{AL}_{2} \mathrm{O}_{3}$ & Mg0 & $\mathrm{Fe}_{2} \mathrm{O}_{3} \mid$ & $\mathrm{CaO}$ & $\mathrm{Na}_{2} \mathrm{O}$ & $\mathrm{K}_{2} \mathrm{O}$ \\
\hline & & $10-2$ & 10- 3 & $10-1$ & $10-2$ & $10-1$ & $10-3$ & $10-3$ & $\%$ & $\%$ & $\%$ & $\%$ & $\%$ & $\%$ & $\%$ \\
\hline Ч-Сस & $2(\mathrm{k})$ & 3 & - & - & - & - & - & - & 70 & 7 & 4 & 5 & 4 & 0,7 & 0,2 \\
\hline
\end{tabular}




\begin{tabular}{|c|c|c|c|c|c|c|c|c|c|c|c|c|c|c|c|}
\hline $\begin{array}{l}\mathrm{No} \\
\mathrm{n} / \mathrm{I}\end{array}$ & \begin{tabular}{l|} 
№ \\
Ipроб
\end{tabular} & Mn & $\mathrm{Ni}$ & $\mathrm{C}_{0}$ & $\mathrm{Ti}$ & $\mathrm{V}$ & $\mathrm{Cr}$ & Mo & W & $\mathrm{Zr}$ & $\mathrm{Nb}$ & In & $\mathrm{Cu}$ & $\mathrm{Pb}$ & $\mathrm{Ag}$ \\
\hline & & $10-2$ & $10-3$ & $10-3$ & $10-1$ & $10-2$ & $10-3$ & $10-3$ & $10-2$ & 10-2 & 10-3 & $10-3$ & $10-3$ & 10-3 & 10- 4 \\
\hline Ч.СЖ & $2(\mathrm{~K})$ & 12 & 15 & - & 4 & 30 & 15 & 15 & - & 2 & - & - & 40 & 15 & 5 \\
\hline \multirow[t]{2}{*}{$\begin{array}{l}\mathrm{No} \\
\mathrm{N} / \mathrm{m}\end{array}$} & \begin{tabular}{|l|}
\multirow{2}{*}{} \\
проб
\end{tabular} & $\mathrm{Sb}$ & $\mathrm{Bi}$ & As & $\mathrm{Zn}$ & $\mathrm{Cd}$ & Sn & $\mathrm{Ge}$ & $\mathrm{Ga}$ & $\mathrm{Yb}$ & $\mathbf{Y}$ & $\mathrm{La}$ & $P$ & $\mathrm{Be}$ & $\mathrm{Sr}$ \\
\hline & & $10-2$ & $10-3$ & 10-2 & $10-2$ & $10-2$ & 10- 3 & $10-3$ & $10-3$ & $10-3$ & $10-3$ & 10-2 & $10-1$ & 10- 4 & $10-2$ \\
\hline Ч.СЖ & $2(\mathrm{~K})$ & - & - & 12 & 1,2 & - & 0,15 & - & 0,5 & 0,3 & 3 & - & - & - & 2 \\
\hline \multirow[t]{2}{*}{ 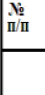 } & $\begin{array}{l}\mathbf{N} \mathbf{2} \\
\text { appố }\end{array}$ & $\mathrm{Ba}$ & $\mathbf{L i}$ & $\mathrm{Ta}$ & Th & $\mathbf{U}$ & Au & $\mathrm{Sc}$ & $\mathrm{SiO}_{2}$ & $\mathrm{AL}_{2} \mathrm{O}_{3}$ & Mg0 & $\mathrm{Fe}_{2} \mathrm{O}_{3}$ & $\mathrm{CaO}$ & $\mathrm{Na}_{2} \mathrm{O}$ & $\mathrm{K}_{2} \mathrm{O}$ \\
\hline & & $10-2$ & $10-3$ & 10- 1 & $10-2$ & $10-1$ & 10-3 & $10-3$ & $\%$ & $\%$ & $\%$ & $\%$ & $\%$ & $\%$ & $\%$ \\
\hline ч-Сж & $2(\mathrm{~K})$ & 3 & - & - & - & - & - & - & 70 & 7 & 4 & 5 & 4 & 0,7 & 0,2 \\
\hline
\end{tabular}

Then the ore-bearing rocks of the black shale formation crushed to the specified value were further crushed in a non-standard crushing unit with a three-phase electric motor $3000 \mathrm{rpm} 2 \mathrm{~kW}$, at a pressure of 30-60 atm/ $/ \mathrm{cm}^{2}$.

Non-standard crushing unit consists of a cylindrical cup and a lid, so that during crushing no dust is released into the environment the cup is tightly closed with a lid. The cup and the lid are made of ceramic. Crushing the loaded sample of 20 grams lasts for 30-60 minutes. At the same time the dust of the crushed mineral does not settle in water, this is one of the visual indications that, the size of the crushed particles is less than a micron.

The size and morphological structure of the dispersed particles were studied using a scanning electron microscope (SEM) [8,9] Fig. 2. 
$a$

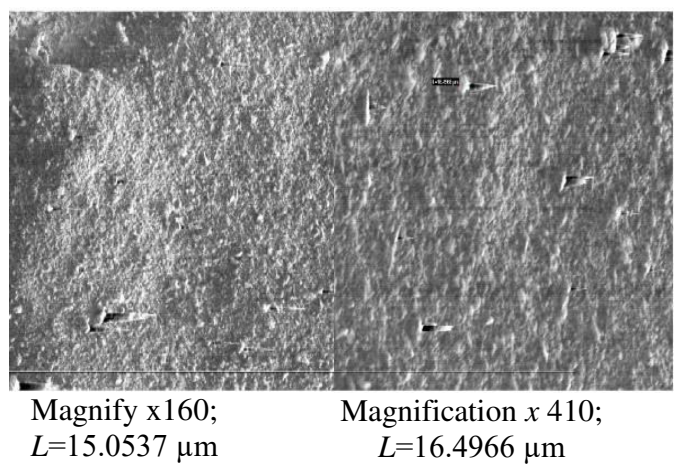

$c$

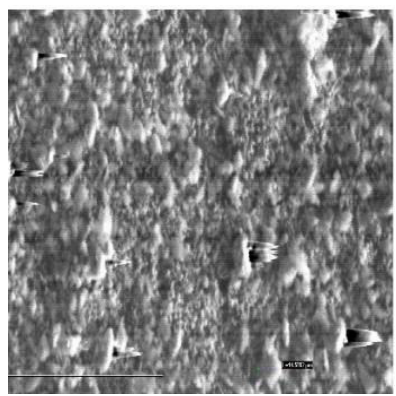

Magnification-E $x 1010 ; L=14.5782 \mu \mathrm{m}$

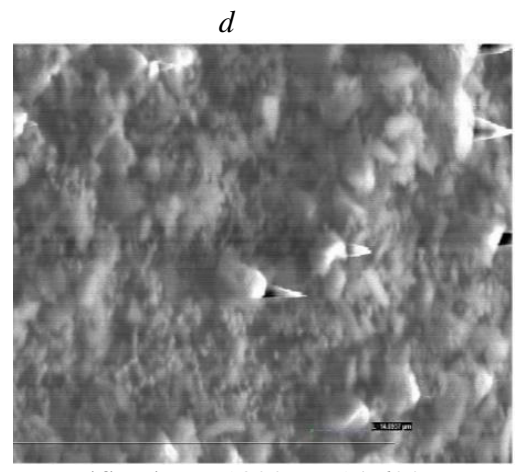

Magnification $x 1800 ; L=14.6937$

$\mu \mathrm{m}$

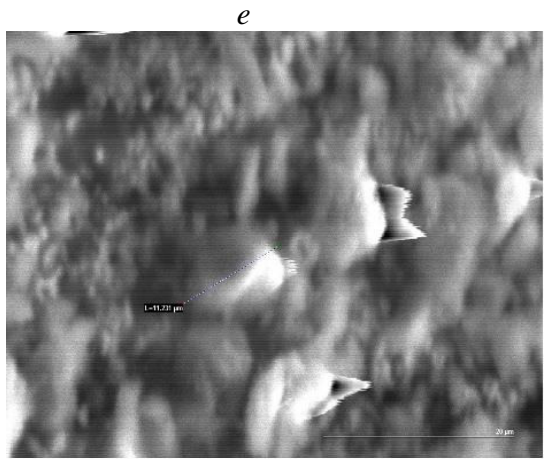

Magnification $x$ 4000; $L=11.231 \mu \mathrm{m}$

Fig. 2. Morphological structure of dispersed particles

From figure $2(a)(L=15.0537 \mu \mathrm{m})$ and $(b)(L=16.4966 \mu \mathrm{m})$ the mass uniformity and regularity of the mineral structure is observed, while figures $(c)(L=14.5782 \mu \mathrm{m}), \quad(d) \quad(L=14.6937 \mu \mathrm{m}), \quad(e)$ $(L=11.231 \mu \mathrm{m})$ suggest a gritty and slightly clastic structure.

In publications of scientists in the field of geology and mining, "black-shales" are considered as a new promising and unconventional source of noble and rare-metal raw materials.

Analysis of studies and publications confirms that black-shale ores of the studied objects belong to the category of highly refractory and require special technological approaches. 
During the fragmentation of the Saryjaz area black shale formation there are changes in the quantitative content of their constituent components, as evidenced by the obtained data on the spectral analysis of Table 6, 7, 8 .

As can be seen from Table 6, an increase in the quantitative content of metals $(\mathrm{g} / \mathrm{t})$ in the samples of coarse fraction milling from the first point coordinate BSSF 1(b) (g/t) Ni , Ti (from 3-4); Mo (from 212); $\mathrm{Cu}$ (from 5-9); $\mathrm{Pb}$ (from 1.5-12; Ag (from 1.5-3); such metals as $\mathrm{As}, \mathrm{Zn}, \mathrm{Sn}, \mathrm{Ga}$ begin to appear and the quantitative content of $\mathrm{V}$ (from 40-15); Cr (from 40-5); $\mathrm{Zr}$ (from 5-1.5); Yb (from 0.7-9.3) and Y (from 7-3) decreases;

The quantitative content of metals in coarse fraction samples from the second point coordinate BSSF 2 (b) (g/t) Ni (from 3-15); Ti (from 3-4); $\mathrm{Mo}$ (from 2-15); $\mathrm{Cu}$ (from 5-40); $\mathrm{Pb}$ (from 1.5-15) also increases: $\mathrm{Ag}$ (from 1.5-5); at the same time, there is a manifestation of metals $\mathrm{Mn}, \mathrm{As}, \mathrm{Zn}, \mathrm{Sn}, \mathrm{Ga}$ and a reduction of some metals as $\mathrm{V}$ (from 40-30); $\mathrm{Cr}$ (from 40-15); $\mathrm{Zr}$ (from 5-2); $\mathrm{Yb}$ (from 0.7-0.3); Y (from 7-3); $\mathrm{Sr}$ (from 3-2).

In samples from the third point coordinate BSSF 3(b) observed increase in the quantitative content of metals - Mo (from 2-20); $\mathrm{Cu}$ (from 5-7); $\mathrm{Pb}$ (from 1.5-12); $\mathrm{Ag}$ (from 1.5-4); remains unchanged $\mathrm{Ni}$ (3-3) and Ti (3-3); As, Zn, Sn, Ga and decreases of Ti (from 3-2); $\mathrm{V}$ (from 40-30); Cr (from 40-5); $\mathrm{Zr}$ (from 5-1,5); Yb (from 0,7-0,3) and $\mathrm{Y}$ (from 7-3).

Table 6 Comparative characteristics of the chemical composition of the fragmented samples of the black shale formation from the first coordinate point of BSSF $1(b)$ $L=16.4966 \mu \mathrm{m}$; BSSF $1(\mathrm{~m}) L=14.5782 \mu \mathrm{m}$; BSSF 1 (s) $L=11.231 \mu \mathrm{m}$; with initial data

\begin{tabular}{l|l|l|l|l|l|l|l|l|l}
\hline \multirow{2}{*}{ №o samples } & $\mathrm{Mn}$ & $\mathrm{Ni}$ & $\mathrm{Co}$ & $\mathrm{Ti}$ & $\mathrm{V}$ & $\mathrm{Cr}$ & $\mathrm{Mo}$ & $\mathrm{Zr}$ & $\mathrm{Cu}$ \\
\cline { 2 - 10 } & $10-2$ & $10-3$ & $10-3$ & $10-1$ & $10-2$ & $10-3$ & $10-3$ & $10-2$ & $10-3$ \\
\hline $\begin{array}{l}\text { Original } \\
\text { sample }\end{array}$ & & 3 & & 3 & 40 & 40 & 2 & 5 & 5 \\
\hline BSSF1b & & 4 & & 4 & 15 & 5 & 12 & 0,5 & 9 \\
\hline BSSF1m & 5 & 15 & 0,3 & 5 & 20 & 15 & 30 & 2 & 50 \\
\hline BSSF1s & 3 & 12 & 0,3 & 4 & 12 & 15 & 30 & 1,5 & 200 \\
\hline $\begin{array}{l}\text { №№ sam- } \\
\text { ples }\end{array}$ & $\mathrm{Pb}$ & $\mathrm{Ag}$ & $\mathrm{As}$ & $\mathrm{Zn}$ & $\mathrm{Sn}$ & $\mathrm{Ga}$ & $\mathrm{Yb}$ & $\mathrm{Y}$ & $\mathrm{Sr}$ \\
\cline { 2 - 10 } & $10-3$ & $10-4$ & $10-2$ & $10-2$ & $10-3$ & $10-3$ & $10-3$ & $10-3$ & $10-2$ \\
\hline $\begin{array}{l}\text { Original } \\
\text { sample. }\end{array}$ & 1,5 & 1,5 & - & - & - & - & 0,7 & 7 & 3 \\
\hline
\end{tabular}




\begin{tabular}{l|l|l|l|l|l|l|l|l|l}
\hline BSSF1b & 12 & 3 & 5 & 0,3 & 0,15 & 0,5 & 0,3 & 3 & 2 \\
\hline BSSF1m & 20 & 3 & 20 & 0,7 & 0,15 & 0,7 & 0,3 & 3 & 2 \\
\hline BSSF1s & 30 & 3 & 15 & 2 & 0,15 & 0,5 & 0,3 & 3 & 2 \\
\hline $\begin{array}{l}\text { № } \\
\text { № samples }\end{array}$ & & $\mathrm{Ba}$ & $\mathrm{SiO}_{2}$ & $\mathrm{Al}_{2} \mathrm{O}_{3}$ & $\mathrm{MgO}$ & $\mathrm{Fe}_{2} \mathrm{O}_{3}$ & $\mathrm{CaO}$ & $\mathrm{Na}_{2} \mathrm{O}$ & $\mathrm{R}_{2} \mathrm{O}$ \\
\hline $\begin{array}{l}\text { Original } \\
\text { sample. }\end{array}$ & & - & 70 & 5 & 2 & 2 & 0,5 & - & - \\
\hline BSSF1b & & - & 70 & 3 & 2 & 3 & 1,2 & - & - \\
\hline BSSF1m & & 2 & 70 & 5 & 4 & 9 & 2 & 0,2 & 0,1 \\
\hline BSSF1s & & 2 & 70 & 4 & 3 & 7 & 1,5 & 0,15 & - \\
\hline
\end{tabular}

Table 7

Comparative characteristics of the chemical composition of the fragmented samples of the black shale formation from the second coordinate point of BSSF $2(b)$ $L=16.4966 \mu \mathrm{m}$; BSSF $2(\mathrm{~m}) L=14.5782 \mu \mathrm{m}$; BSSF $2(s) L=11.231 \mu \mathrm{m}$; with initial data

\begin{tabular}{|c|c|c|c|c|c|c|c|c|c|}
\hline \multirow{2}{*}{$\begin{array}{l}\text { № } \\
\text { № samples }\end{array}$} & $\mathrm{Mn}$ & $\mathrm{Ni}$ & Co & $\mathrm{Ti}$ & $\mathrm{V}$ & $\mathrm{Cr}$ & Mo & $\mathrm{Zr}$ & $\mathrm{Cu}$ \\
\hline & $10-2$ & $10-3$ & $10-3$ & $10-1$ & $10-2$ & $10-3$ & $10-3$ & $10-2$ & $10-3$ \\
\hline $\begin{array}{l}\text { Original } \\
\text { sample. }\end{array}$ & & 3 & & 3 & 40 & 40 & 2 & 5 & 5 \\
\hline BSSF 2b & 12 & 15 & & 4 & 30 & 15 & 15 & 2 & 40 \\
\hline BSSF $2 \mathrm{~m}$ & 5 & 20 & & 4 & 5 & 12 & 30 & 3 & 300 \\
\hline BSSF2s & 2 & 15 & 0,3 & 3 & 15 & 12 & 15 & 2 & 300 \\
\hline \multirow[t]{2}{*}{ № samples } & $\mathrm{Pb}$ & $\mathrm{Ag}$ & As & $\mathrm{Zn}$ & $\mathrm{Sn}$ & $\mathrm{Ga}$ & $\mathrm{Yb}$ & $\mathrm{Y}$ & $\mathrm{Sr}$ \\
\hline & $10-3$ & $10-4$ & $10-2$ & $10-2$ & $10-3$ & $10-3$ & $10-3$ & $10-3$ & $10-2$ \\
\hline $\begin{array}{l}\text { Original } \\
\text { sample. }\end{array}$ & 1,5 & 1,5 & - & - & - & - & 0,7 & 7 & 3 \\
\hline BSSF2b & 15 & 5 & 12 & 1,2 & 0,15 & 0,5 & 0,3 & 3 & 2 \\
\hline BSSF2m & 30 & 9 & 15 & 1,2 & 0,15 & 0,5 & 0,3 & 3 & 2 \\
\hline BSSF2s & 20 & 4 & 9 & 1,5 & 0,15 & 0,5 & 0,3 & 3 & 2 \\
\hline \multirow{2}{*}{$\begin{array}{l}\text { № } \\
\text { № samples }\end{array}$} & & $\mathrm{Ba}$ & $\mathrm{SiO}_{2}$ & $\mathrm{Al}_{2} \mathrm{O}_{3}$ & $\mathrm{MgO}$ & $\mathrm{Fe}_{2} \mathrm{O}_{3}$ & $\mathrm{CaO}$ & $\mathrm{Na}_{2} \mathrm{O}$ & $\mathrm{R}_{2} \mathrm{O}$ \\
\hline & & $10-2$ & $\%$ & $\%$ & $\%$ & $\%$ & $\%$ & $\%$ & $\%$ \\
\hline $\begin{array}{l}\text { Original } \\
\text { sample. }\end{array}$ & & - & 70 & 5 & 2 & 2 & 0,5 & - & - \\
\hline BSSF2b & & 3 & 70 & 7 & 4 & 5 & 4 & 0,7 & 0,2 \\
\hline BSSF2m & & 3 & 70 & 9 & 4 & 7 & 5 & 0,9 & 0,1 \\
\hline BSSF2s & & - & 70 & 3 & 2 & 7 & 2 & 0,15 & - \\
\hline
\end{tabular}


Table 8

Comparative characteristics of the chemical composition of the fragmented samples of the black shale formation from the third coordinate point BSSF $3(b) L=16.4966$ $\mu \mathrm{m}$; BSSF $3(m) L=14.5782 \mu \mathrm{m}$; BSSF 3 (s) $L=11.231 \mu \mathrm{m}$; with initial data

\begin{tabular}{l|l|l|l|l|l|l|l|l|l}
\hline $\begin{array}{l}\text { № } \\
\text { № sam- } \\
\text { ples }\end{array}$ & $\mathrm{Mn}$ & $\mathrm{Ni}$ & $\mathrm{Co}$ & $\mathrm{Ti}$ & $\mathrm{V}$ & $\mathrm{Cr}$ & $\mathrm{Mo}$ & $\mathrm{Zr}$ & $\mathrm{Cu}$ \\
\cline { 2 - 10 } & $10-2$ & $10-3$ & $10-3$ & $10-1$ & $10-2$ & $10-3$ & $10-3$ & $10-2$ & $10-3$ \\
\hline $\begin{array}{l}\text { Original } \\
\text { sample }\end{array}$ & - & 3 & - & 3 & 40 & 40 & 2 & 5 & 5 \\
\hline BSSF3b & - & 3 & - & 2 & 30 & 5 & 20 & 1,5 & 7 \\
\hline BSSF3m & 0,5 & 1,2 & - & 3 & 20 & 2 & 5 & 1,2 & 5 \\
\hline BSSF3s & 15 & 15 & 0,3 & 4 & 15 & 20 & 20 & 5 & 500 \\
\hline $\begin{array}{l}\text { №№ } \\
\text { samples }\end{array}$ & $\mathrm{Pb}$ & $\mathrm{Ag}$ & $\mathrm{As}$ & $\mathrm{Zn}$ & $\mathrm{Sn}$ & $\mathrm{Ga}$ & $\mathrm{Yb}$ & $\mathrm{Y}$ & $\mathrm{Sr}$ \\
\hline & $10-3$ & $10-4$ & $10-2$ & $10-2$ & $10-3$ & $10-3$ & $10-3$ & $10-3$ & $10-2$ \\
\hline $\begin{array}{l}\text { Original } \\
\text { sample }\end{array}$ & 1,5 & 1,5 & - & - & - & - & 0,7 & 7 & 3 \\
\hline BSSF3b & 12 & 4 & 7 & 0,5 & 0,15 & 0,5 & 0,3 & 3 & 2 \\
\hline BSSF3m & 7 & 2 & 9 & 1,5 & 0,15 & 0,5 & 0,3 & 3 & 2 \\
\hline BSSF3s & 30 & 5 & 30 & 5 & 0,15 & 0,5 & 0,3 & 3 & 2 \\
\hline $\begin{array}{l}\text { №№ } \\
\text { samples }\end{array}$ & & $\mathrm{Ba}$ & $\mathrm{SiO}_{2}$ & $\mathrm{Al}_{2} \mathrm{O}_{3}$ & $\mathrm{MgO}$ & $\mathrm{Fe} 2 \mathrm{O}_{3}$ & $\mathrm{CaO}$ & $\mathrm{Na} 2 \mathrm{O}$ & $\mathrm{R}_{2} \mathrm{O}$ \\
\hline & & $10-2$ & $\%$ & $\%$ & $\%$ & $\%$ & $\%$ & $\%$ & $\%$ \\
\hline $\begin{array}{l}\text { Original } \\
\text { sample }\end{array}$ & & - & 70 & 5 & 2 & 2 & 0,5 & - & - \\
\hline BSSF3b & & - & 70 & 2 & 1,5 & 3 & 0,5 & - & - \\
\hline BSSF3m & & 2 & 50 & 2 & 1,2 & 1,5 & 0,4 & - & - \\
\hline BSSF3s & & - & 70 & 4 & 3 & 7 & 2 & 0,15 & - \\
\hline
\end{tabular}

Note:(b)-big; (m)-medium; $(s)$-small fract

According to the results of spectral analysis in Table 7, the same picture is observed: Increase in the amount of metals in the average fraction of the milled material from the first coordinate point $(\mathrm{g} / \mathrm{t}) \mathrm{BSSF} 1(\mathrm{~m}) \mathrm{Ni}$ (from 3-15); Ti(from 3-5); Mo (from 2-30); $\mathrm{Cu}$ (from 5-50); $\mathrm{Pb}$ (from 1.5-20); Ag (from 1.5-3); the metals Mn, Co, As, Zn, Sn, Ga, Ba decrease in quantitative content V (from 40-20); Cr (from 40-15); Zn (from 5-2); $\mathrm{Yb}$ (from 0.7-0.3); Y (from 7-3); Sr (from 3-2).

In the samples of the middle fraction of the crushed material from the second point of coordinate BSSF 2 (m) there is an increase in the quantitative content of metals $\mathrm{Ni}$ (from 3-20); Ti (from 3-4); Mo (from 2-30); $\mathrm{Cu}$ (from 5-300); Pb (from 1,5-30); Ag (from 1,5 -9); Mn, As, Zn, Sn, Ga, Ba manifestations and decrease of metals $\mathrm{V}$ (from 40-5); $\mathrm{Cr}$ (from 40-5); $\mathrm{Zr}$ (from 5-3); Yb (from 0,7-0,3); Y (from 7-3); Sr (from 3-2). 
In the middle fractions of the third point, the coordinate of the BSSF 3 (m) remains unchanged $\mathrm{Ti}(3-3)$; $\mathrm{Cu}(5-5)$; $\mathrm{Sr}$ (2-2); the quantitative content of metals $\mathrm{Mo}$ (from 2-5); $\mathrm{Pb}$ (from 1.5-7); $\mathrm{Ag}$ (from 1.5-2) increases; $\mathrm{Mn}, \mathrm{As}, \mathrm{Zn}, \mathrm{Sn}, \mathrm{Ga}, \mathrm{Ba}$ appear; and there is a decrease in the quantitative content of $\mathrm{Ni}$ (from 3-1.2), V (from 40-20); Cr (from 40-2); $\mathrm{Zr}$ (from 5-1. 2); $\mathrm{Yb}$ (from 0.7-0.3); Y (from 7-3) and $\mathrm{Sr}$ (3-2).

Table 8 shows the data of the spectral analysis of small fractions the coordinates of points BSSF1 (s), BSSF 2 (s) and BSSF 3 (s) where an increase of quantitative metal content by

BSSF 1 (s) Ni (from 3-12); Ti (from 3-4); Mo (from 2-30); $\mathrm{Cu}$ (from 5-200); $\mathrm{Pb}$ (from 1.5-30); $\mathrm{Ag}$ (from 1.5-3);

In BSSF 2 (s) Ni (from 3-15); Mo (from 2-15); Cu (from 5-300); $\mathrm{Pb}$ (from 1.5-20); Ag (from 1.5-4);

By BSSF 3 (s) Ni (from 3-15); Ti (from 3-4); Mo (from 2-20); Cu (from 5-500); $\mathrm{Pb}$ (from 1.5-30); $\mathrm{Ag}$ (from 1.5-5); $\mathrm{Zr}$ (5-5) remains unchanged.

Metals are revealed by BSSF 1 (s) Mn, Co, As, Zn, Sn, Ga, Ba; BSSF 2 (s) Mn, Co, As, Zn, Sn, Ga, Ba; BSSF 3 (s) Mn, Co, As, Zn, $\mathrm{Sn}, \mathrm{Ga}, \mathrm{Ba}$; Metals in samples BSSF 1 (s) V (from 40-12) are decreased; $\mathrm{Cr}$ (from 40-15); Yb (from 0.7-0.3); Y (from 7-3); $\mathrm{Sr}$ (from 32); BSSF 2(s) V (from 40-15); Cr (from 40-12); Zr (from 5-2); Yb (from 0.7-0.3); Y (from 7-3); Sr (from 3-2); BSSF 3(s) V (from 40-15); Cr (from 40-20); Yb (from 0.7-0.3); Y (from 7-3); Sr (from 3-2

The quantitative increase of metals in the samples is shown in Figures 3,4,5.

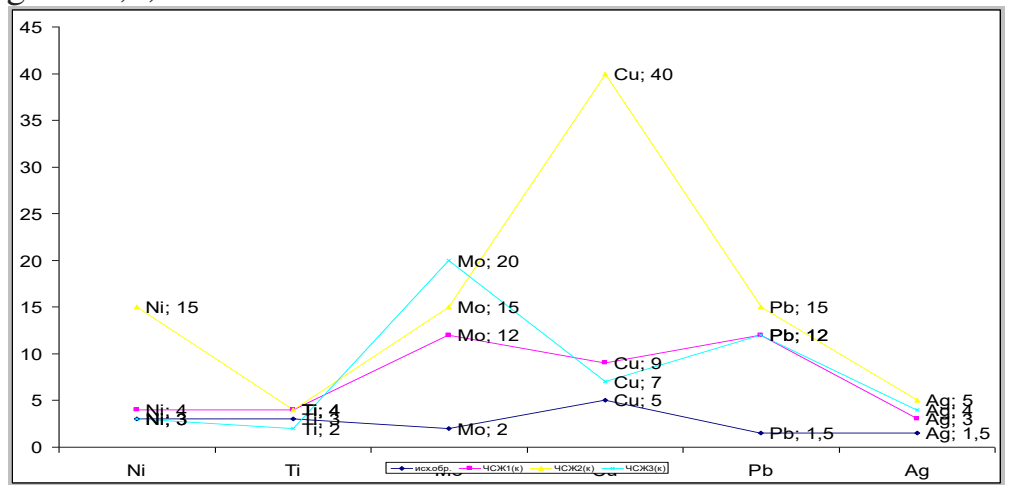

Fig. 3. Change in the quantitative composition of minerals during fragmentation to (b) $(L=15.0537 \mu \mathrm{m})$ and $(L=16.4966 \mu \mathrm{m})$ 


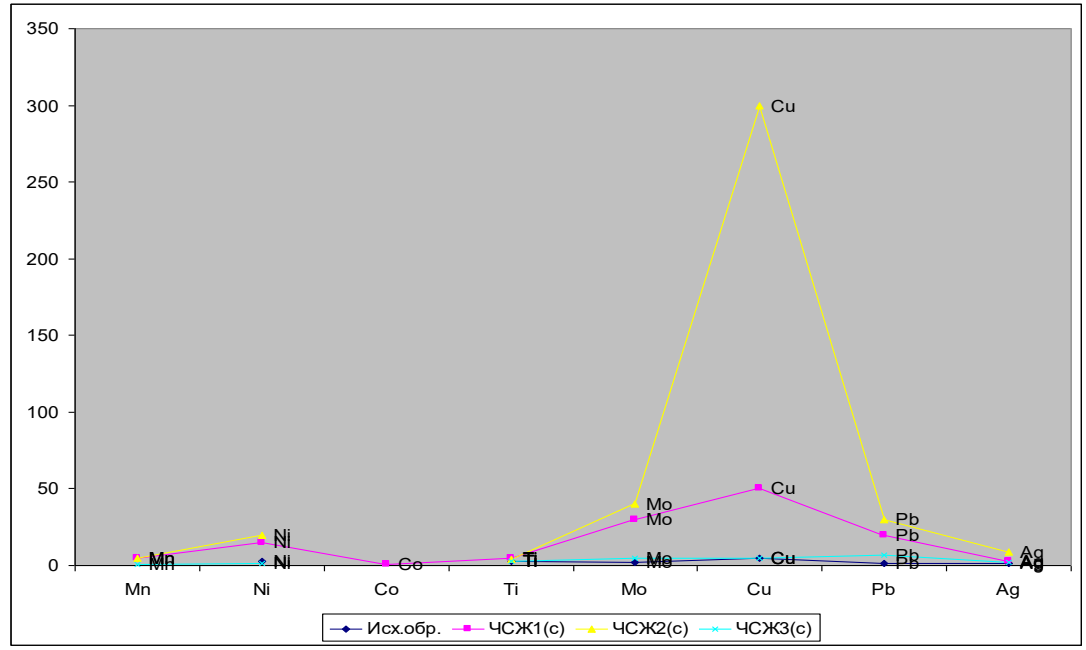

Fig. 4. Change in the quantitative composition of minerals during fragmentation to (m) $(L=14.5782 \mu \mathrm{m}),(L=14.6937 \mu \mathrm{m})$

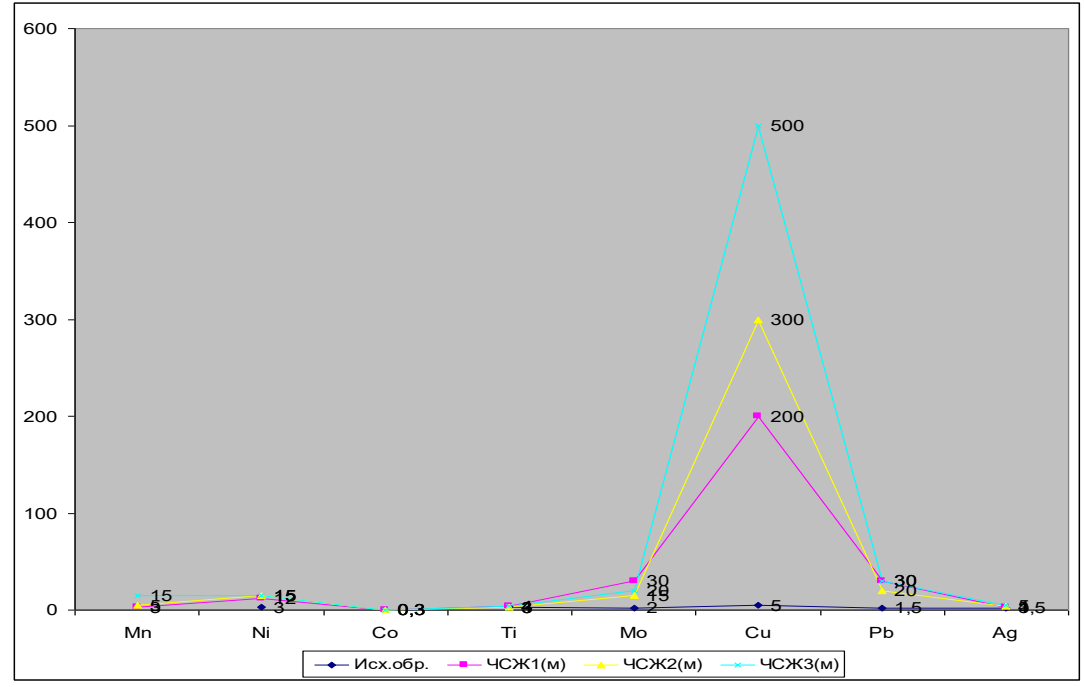

Fig. 5. Change in the quantitative composition of minerals during fragmentation to (s) $(L=11.231 \mu \mathrm{m})$

As can be seen from the table and figures, when the samples were broken down to chunk size $(b)(L=15.0537 \mu \mathrm{m}),(L=16.4966 \mu \mathrm{m})$; 
medium particle size $(m)(L=14.5782 \mu \mathrm{m}),(L=14.6937 \mu \mathrm{m})$ and in the smallest particles $(s)(L=11.231$ micrometers $)$ is observed a presence of some metals $\mathrm{Mn}, \mathrm{Co}, \mathrm{As}, \mathrm{Zn}, \mathrm{Sn}, \mathrm{Ga}$, Ba which were not detected in the original sample; also is observed an increase of the quantitative content of some metals in all fractured samples in comparison with the original sample, especially in the smallest sample $\mathrm{BSSF} 1(s) \mathrm{Ni}$ (from 3-12); Ti (from 3-4); Mo (from 2-30); $\mathrm{Cu}$ (from 5-200); Pb (from1,5-30); Ag (from 1,5-3);

In BSSF 2 (s) Ni (from 3-15); Mo (from 2-15); Cu (from 5-300); $\mathrm{Pb}$ (from 1.5-20); Ag (from 1.5-4);

In BSSF 3 (s) Ni (from 3-15); Ti (from 3-4); Mo (from 2-20); $\mathrm{Cu}$ (from 5-500); $\mathrm{Pb}$ (from1.5-30); $\mathrm{Ag}$ (from 1.5-5); $\mathrm{Ni}$ (from 3-15); $\mathrm{Mo}$ (from 2-20); $\mathrm{Pb}$ (from 120); $\mathrm{Ag}$ (from 120); $\mathrm{Ni}$ (from 400); $\mathrm{Ni}$ (from 110 ); $\mathrm{Ni}$ (from 110); $\mathrm{Ni}$ (from 110); $\mathrm{Pb}$ (from 110). (from 1.5-5);

\subsection{Technological scheme of enrichment of valuable components of the black shale formation}

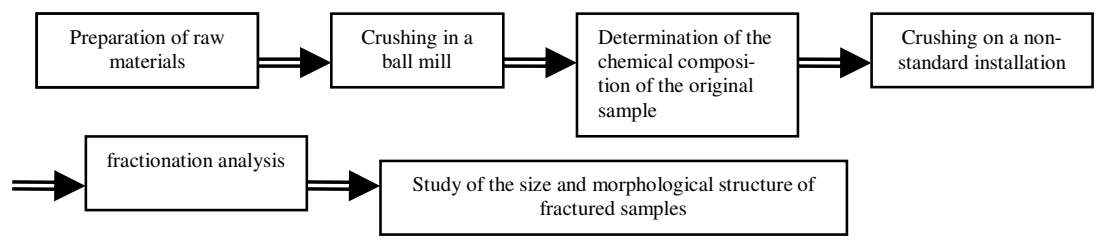

\section{Conclusions}

1. Chemical composition and technological properties of initial samples were studied;

2. Spectral analysis of initial and split samples was carried out;

3 . When the samples were crushed to the size of lumps $(b)$ $(L=15.0537 \mu \mathrm{m}), \quad(L=16.4966 \mu \mathrm{m})$; medium particle size $(\mathrm{m})$ $(L=14.5782 \mu \mathrm{m}),(L=14.6937 \mu \mathrm{m}) ;$ and to the small particles $(\mathrm{s})$ 
$(L=11.231 \mu \mathrm{m})$ is observed manifestation of some metals $\mathrm{Mn}, \mathrm{Co}$, As, $\mathrm{Zn}, \mathrm{Sn}, \mathrm{Ga}, \mathrm{Ba}$ which were not known in initial samples; increase of quantitative content of some metals is observed in all crushed samples in comparison with initial sample, especially increase of quantitative content of metals is observed in melkozrushed sample BSSF 1(s), BSSF 2 (s), BSSF 3 (s) Ni (from 3-15); Ti (from 3-4); $\mathrm{Mo}$ (from 2-30); $\mathrm{Cu}$ (from 5-500); $\mathrm{Pb}$ (from1,5-30); $\mathrm{Ag}$ (from 1,5-5);

4. Thus, to increase the quantitative content of the above metals Optimal size of dispersed particles is $L=11.231 \mu \mathrm{m}$.

\section{Literature}

1. http://www.miningexpo.ru/3672).

2. Patent for invention No. 2455237. Nanotechnological method for extracting rhenium from rocks and ores of black shale formations and products of their processing. (Date of application: 06.12.2010) 10.07.2012.

3. Shumilova L.V. Combined methods of cuvette and heap leaching of refractory gold-bearing raw materials based on directed photoelectrochemical effects. Abstract of the dissertation for the degree of Doctor of Technical Sciences. Chita, 2010.- http://textarchive.ru/c-1318156-pall.html-12.06.17.

4. Special and combined methods of mineral processing: textbook / V. G. Samoilik - Donetsk: OOO "Skhidniy vydavnichiy dim", 2015.- p. 108.

5. Vorobyov N.I., Novik D.M. Enrichment of minerals (textbook). Minsk: BSTU, 2008.-174p.

6. Adamov E.V. Technology of non-ferrous metal ores. M, 2001.-470 s.

7. GOST 30439 (96), Pesticides, Sieve analysis, OKS: 65100 KGS: L19, Test methods.

8. Scanning electron microscope. Study guide for students of the Faculty of Physics and Technology. / Compiled by: V.P. Makarov, O.N. Kanygina KyrgyzRussian Slavic University.-Bishkek. 2006.25 p.

9. Goldstein, J. Scanning electron microscopy and X-ray microanalysis: in 2 volumes / J. Goldstein, D. Newbury, P. Echlin et al. - M .: Mir, 1984. 
https://doi.org/10.31713/m1119

\title{
POSSIBILITIES OF USING ALKALINE EARTH BENTONITE CLAYS OF CHERKASY DEPOSIT IN PELLET PRODUCTION PROCESSES
}

\author{
F.M. Zhuravlev \\ State University of Economics and Technology, Candidate \\ of Technical Science, Associate Professor, Senior Lecturer, Ukraine \\ E.V. Chuprinov \\ State University of Economics and Technology, Candidate \\ of Technical Science, Associate Professor, Senior Lecturer, Ukraine \\ A.K. Tarakanov \\ Ukrainian State University of Science and Technology, Doctor of \\ Technical Science, Professor, Ukraine \\ D.O. Kassim \\ State University of Economics and Technology, \\ Doctor of Technical Science, Professor, Ukraine \\ I.A. Lyakhova \\ State University of Economics and Technology, Candidate \\ of Technical Science, Associate Professor, Senior Lecturer, Ukraine
}

\begin{abstract}
Annotation
Objective: to analyze and determine the potential of alkaline earth bentonite clays of Ukraine for use as a binder in the production of iron ore pellets.

Methods: performing rheological studies of bentonite clay samples and their chemical analysis, electron microscopic studies of samples.

Results: the analysis of the chemical composition and requirements for the rheological characteristics of bentonite clays used in the production of iron ore pellets at metallurgical enterprises of Russia and Ukraine is carried out. The swelling indicators and water absorption of monoionic forms of bentonites of some deposits in water of different hardness are given. The quality of pellets with bentonites, that have a different exchange complex, during an industrial water of various hardness usage is examined. The analysis of the mineralogical and chemical composition, as well as the size and composition of the exchange complex of alkaline-earth bentonite clays of the Cherkasy deposit (Ukraine), which has the largest reserves of such clays in the CIS is carried out. It is shown that clays suitable for the production of pellets are located near the surface of the earth. A comparative analysis of the strength characteristics of pellets using bentonites with an alkaline and alkaline-earth exchange complex is presented.
\end{abstract}


Comparative tests of pelletizing of charges with different humidity and with the addition of $0.5 \%$ alkaline bentonite and a mixture of clays of the IV and II layers of the Cherkasy deposit have been carried out. It is shown that with increasing humidity in granules with both types of binders, the dynamic strength, porosity and temperature of the "impact" of granules increase with a minimum difference in the absolute values of indicators with different binders.

\section{Introduction}

For the efficient smelting of cast iron in blast furnaces, it is necessary to use iron ore raw materials with the highest possible iron content, minimum silica content, high strength characteristics in the cold state and during heating and reduction in the blast furnace [1].

In the pellets production binders are used as hardening additive for pelletizing finely ground iron ore concentrates. Generally accepted in the industrial production of inorganic binder additives are: fired pellets and bentonite clay with an alkali exchange complex (natural or artificially produced), as well as active lime (slaked or hydrated). Sodium carboxymethyl cellulose, peridur, technical lignosulfonate, sulphitealcohol distillery distillate and other compounds have been used as organic binders in recent decades. The amount of bentonite clay in the charge is (by dry weight) $0,5-1,0 \%$, lime $-2-5 \%$. The amount of organic binder additives in the charge is $0,05-0,1 \%$, that is, an order of magnitude lower than bentonitic clay [2].

In the USSR, all pellet factories used alkaline bentonite clay of one large deposit, divided by the border between the Armenian SSR and the Azerbaijan SSR and named, respectively, at the extraction site on each side, Sarygyuhsky and Dash-Salakhlinsky. Due to the collapse of the USSR and conservation of bentonite production at this field, all pelletizing factories switched to soda ash modified alkaline-earth bentonite clays imported from India and Greece.

The purpose and objectives of research is determination of the possibility of using bentonite clays of Cherkasy deposit as a binder in the production of pellets at Ukrainian GOK.

The productive stratum of the Cherkasy deposit of bentonite and palygorskite clays consists of five layers clearly distinguished by macroscopic features (from top to bottom, of which layers II-IV are suitable for the production of pellets). The methods of research is 
rheological studies of bentonite clay samples and their chemical analysis, electron microscopic studies of samples.

\section{Analysis of problem statement}

Alkaline-earth bentonite clays of the II layer of the Cherkasy deposit, Ukraine, in previous years in a limited amount were also modified with soda ash, although using primitive technology, which did not provide them with high quality and, accordingly, demand. In addition, difficulties arose due to the need for mining and processing enterprises to pump highly mineralized water pumped from mines into the internal water cycle.

All clay minerals have a certain cation exchange capacity. This value is an important characteristic of the mineral and indicates the number of exchangeable cations (expressed in mg-equivalents) capable of being replaced by cations of another type per $100 \mathrm{~g}$ of clay. Montmorillonite, the main mineral of bentonite clay, has the highest cation exchange capacity among clay minerals (up to 90-120 $\mathrm{mEq} / 100 \mathrm{~g}$ of dry clay).

According to the composition of the exchange cations, bentonite clays are divided into:

- alkaline, where more than half of the components of the exchange complex are sodium and potassium cations $\left(\mathrm{Na}^{+}+\mathrm{K}^{+}, \mathrm{mEq} / 100 \mathrm{~g}\right.$ clay);

- alkaline-earth (calcium, magnesium, calcium-magnesium and magnesium-calcium), where more than half of the exchange cations belong to calcium and magnesium $\left(\mathrm{Ca}^{++}+\mathrm{Mg}^{++}, \mathrm{mEq} / 100 \mathrm{~g}\right.$ clay) [2].

Moreover, for the production of pellets by rheological characteristics, bentonite clays with an alkaline exchange complex are most suitable (in an aqueous medium of a certain hardness).

By generally accepted methods, all rheological characteristics of bentonite clays clarify itself in distilled water, and the process water at different enterprises has different hardness, amount and composition of dissolved salts.

Studies have shown that increasing water hardness significantly reduces the swelling and water absorption of bentonites with an alkaline exchange complex (table 1) and practically does not affect these indicators in bentonites with an alkaline-earth exchange complex [2]. Moreover, an increase in the hardness of process water, for example, 
Severny GOK (SevGOK) from $8,8 \mathrm{mEq} / \mathrm{dm}^{3}$ in 1979 to 127,6 $\mathrm{mEq} / \mathrm{dm}^{3}$ in 2017 led to a decrease in the swelling of bentonite from 10,2 to 4,3 times, and water absorption - from 344 to $178 \%$. This effect also affected the deterioration of the properties of raw pellets at the same consumption of bentonite in the charge.

Table 1

Swellability and water absorption of monoionic forms of bentonites of different deposits in water of different rigidity

\begin{tabular}{|c|c|c|c|c|}
\hline Material & Type of water & $\begin{array}{l}\text { Water hard- } \\
\text { ness, } \\
\mathrm{mg} \cdot \mathrm{eq} / \mathrm{dm}^{3}\end{array}$ & $\begin{array}{l}\text { Swelling, } \\
\text { once }\end{array}$ & $\begin{array}{c}\text { Water ab- } \\
\text { sorption } \\
\text { (Enslin), \% }\end{array}$ \\
\hline \multirow{4}{*}{ Na-Sarygyuhsky } & Distilled & 0,07 & 13,6 & 371 \\
\hline & $\begin{array}{l}\text { Industrial } \\
\text { SevGOK*1 }\end{array}$ & 8,8 & 10,2 & 344 \\
\hline & $\begin{array}{l}\text { Industrial } \\
\text { SevGOK } * 2\end{array}$ & 127,6 & 4,3 & 178 \\
\hline & Mine & 274,5 & 3,0 & 160 \\
\hline \multirow{3}{*}{ Ca-Sarygyuhsky } & Distilled & 0,07 & 3,4 & 247 \\
\hline & $\begin{array}{l}\text { Industrial } \\
\text { SevGOK*1 }\end{array}$ & 8,8 & 4,8 & 243 \\
\hline & Mine & 274,5 & 3,0 & 208 \\
\hline \multirow{5}{*}{ Na-Cherkasy } & Distilled & 0,07 & 13,2 & 398 \\
\hline & $\begin{array}{l}\text { Industrial } \\
\text { SevGOK*1 }\end{array}$ & 8,8 & 12,5 & 369 \\
\hline & Industrial CGOK & 43,6 & 7,6 & 352 \\
\hline & Industrial InGOK & 29,5 & 7,8 & 一 \\
\hline & Mine & 274,5 & 4,0 & 214 \\
\hline \multirow{3}{*}{ Ca-Cherkasy } & Distilled & 0,07 & 4,8 & 215 \\
\hline & $\begin{array}{l}\text { Industrial } \\
\text { SevGOK*1 }\end{array}$ & 8,8 & 3,0 & 200 \\
\hline & Mine & 274,5 & 2,4 & 180 \\
\hline \multicolumn{5}{|c|}{ *1 Technical water 1979} \\
\hline
\end{tabular}

Thus, an increase in the hardness of industrial water at enterprises producing iron ore concentrates worsens the rheological characteristics of alkaline bentonite clays, which are positive for the production of pellets, to the level of alkaline-earth clays and requires their increased consumption, which naturally reduces the iron content in the pellets. 
There are lots of bentonite clay deposits with hundreds of millions tons of raw material reserves in Ukraine and Russia, but they are not used in industry due to the lack of systematic and in-depth studies on their suitability. For example, only recently more in-depth studies of the Tikhmenevskoye field (Sakhalin) has begun, more attention are paid now to the deposits of the Central region [4], Voronezh anteclise [5], Cherkasy and others. Scattered works, devoted to these deposits showed that, for a number of qualitative characteristics, these clays do not fully meet the requirements contained in the technical specifications for bentonite clays for pelletizing factories [2], because these bentonites (table. 2) are alkaline earth, while specifications require Na-montmorillonite to be contained in the bentonite. The last leads to a high swelling of clay and the ratio of the amount of sodium with potassium to the sum of calcium with magnesium and the ratio of sodium oxide to potassium oxide naturally exceeding unity.

This factor was the main reason why some Russian and Ukrainian bentonites were found unsuitable for pelletizing iron ore concentrates. Probably the same factor can explain the lack of relevant research work, which would deeply reveal the relationship between the properties of bentonite and the characteristics of the finished pellet, the possibility of pre-processing clay to bring it to the required conditions.

Thus, the geographical location, favorable mountain and environmental conditions for the extraction of these clays in large quantities and the prospects for the use of pellets in the production process provide reliable grounds for choosing these clays as the most worthy object of research. The most effective method for improving the rheological characteristics of alkaline-earth bentonites is their modification, that is, changing their metabolic complex in alkaline with the least cost [2].

In the composition of the productive stratum, for example, Cherkasy deposit, there are three types of alkaline-earth bentonite clays: II layer, containing mainly $\mathrm{Ca}^{++}$ions and substantially less $\mathrm{Mg}^{++}$in the exchange complex; III layer, consisting of the palygorskite mineral, containing mainly $\mathrm{Mg}^{++}$ions in the exchange complex, is substantially less than $\mathrm{Ca}^{++}$and more than in the II layer of $\mathrm{Na}^{+}$ions; IV 
layer, representing a natural mixture of II and III layers in a ratio of an average of about $1: 1$.

Table 2

Chemical analysis of bentonite clays of some deposits used in pellet production in Russia and Ukraine

\begin{tabular}{|c|c|c|c|c|c|c|c|c|}
\hline \multirow[b]{2}{*}{ Clays deposit } & \multicolumn{8}{|c|}{ The content of oxides, $\%$} \\
\hline & $\mathrm{SiO}_{2}$ & $\mathrm{Al}_{2} \mathrm{O}_{3}$ & $\mathrm{Fe}_{2} \mathrm{O}_{3}$ & $\mathrm{CaO}$ & $\mathrm{MgO}$ & $\mathrm{SO}_{3}$ & $\begin{array}{c}\mathrm{Na}_{2} \mathrm{O}+ \\
+\mathrm{K}_{2} \mathrm{O}\end{array}$ & $\begin{array}{c}\text { Puncture } \\
\text { loss }\end{array}$ \\
\hline $\begin{array}{l}\text { Deposits Milos island } \\
\text { (Greece), activated } * 1\end{array}$ & 55,7 & 18,7 & 3,9 & 3,8 & 3,2 & 1,6 & 2,8 & 7,8 \\
\hline $\begin{array}{l}\text { 10th Khutor (Repub- } \\
\text { lic of Khakassia, } \\
\text { Russia)*1 }\end{array}$ & 59,7 & 18,6 & 3,9 & 2,8 & 2,4 & 0,1 & 2,6 & 8,4 \\
\hline $\begin{array}{l}\text { Zyryanskoye deposit } \\
\text { (Kurgan region, Rus- } \\
\text { sia)*1 }\end{array}$ & 57,4 & 19,4 & 6,0 & 1,8 & 3,0 & 0,1 & 1,8 & 9,4 \\
\hline $\begin{array}{l}\text { Dash-Salahlinskoye, } \\
\text { Sarygyuhskoye } \\
\text { (Azerbaijan, Arme- } \\
\text { nia)*2 }\end{array}$ & 58,6 & 13,4 & 4,7 & 2,1 & 2,3 & 0,3 & 2,7 & 15,3 \\
\hline $\begin{array}{l}\text { Konstantinovskoye } \\
\text { deposit (Ukraine)*1 }\end{array}$ & 52,2 & 16,2 & 8,9 & 5,0 & 2,3 & 0,3 & 2,8 & 9,1 \\
\hline Cherkasy II layer*1 & 58,5 & 17,4 & 6,6 & 1,3 & 1,4 & 0,1 & 0,16 & 7,32 \\
\hline Cherkasy III layer*3 & 55,1 & 17,3 & 6,83 & 0,42 & 7,3 & 0,1 & 1,83 & 10,6 \\
\hline Cherkasy IV layer*1+3 & 55,8 & 17,1 & 6,5 & 3,4 & 5,3 & 0,1 & 1,2 & 7,8 \\
\hline Wyoming (USA)*2 & 64,1 & 14,27 & $\begin{array}{l}\text { No } \\
\text { inf. }\end{array}$ & 1,6 & 2,2 & $\begin{array}{l}\text { No } \\
\text { inf. }\end{array}$ & 4,0 & 9,33 \\
\hline $\begin{array}{l}{ }^{* 1} \text { Alkaline earth } . \\
\text { *2 Alkaline. } \\
\text { *3 Palygorskite. }\end{array}$ & & & & & & & & \\
\hline
\end{tabular}

Palygorskite by structural features is a kind of clay mineral with the ability to high dispersion effect even in environments with a high concentration of electrolytes. In addition, its hydrophilicity exceeds any cation-exchange modification of any clay mineral [6]. These two qualitative characteristics determine the prerequisites for a positive effect in a mixture with alkaline-earth Ca-montmorillonite for the emergence of a stable coagulation dispersed structure, as is created in a dispersion with Na-montmorillonite. Palygorskite and montmorillonite in the IV layer of the Cherkasy deposit makes an even higher quality dispersion both in the sense of colloidal and structuralmechanical properties of the suspension. In addition, the higher dis- 
persion of these two converting minerals than for particles of other layers creates a higher surface area, which is also a favorable factor in the interaction of the particles of the strengthening additive with particles of the concentrate. The location of a large number of water molecules in the zeolite-like channels of the crystalline structure of palygorskite makes this mineral extremely moisture-resistant, supplying water molecules to the system during heating from room temperature to $400-450{ }^{\circ} \mathrm{C}$. Considering that water molecules in crude pellets are the main agent that holds the concentrate particles together, it can be assumed that additives such as palygorskite crystals play a significant role.

The surface of the palygorskite crystals cannot provide high adhesion to the concentrate particles in a dry pellet, but when interacting with montmorillonite particles, this mineral exhibits exceptional structure-forming ability, and alkaline-earth montmorillonite in the presence of palygorskite acquires a higher surface activity, which is successfully implemented in collaboration with the edges of ore minerals.

Another important circumstance is very essential in substantiating the need for introducing finely dispersed palygorskite into the strengthening additive - the presence of magnesium cations in its structure. Palygorskite is inherently a magnesian silicate with a layered tape structure; in the palygorskite of the Cherkasy deposit, a significant part of it is replaced by aluminum. This combination of these two cations is most favorable for the formation of aluminummagnesium spinel layers isostructural with magnetite edges, where magnetite acts as a matrix for the spinel phase. This factor, apparently, plays one of the most significant roles in the hardening of dry pellets when they are heated to $1100{ }^{\circ} \mathrm{C}$.

Thus, the choice of the bentonite and palygorskite clays of the Cherkasy deposit as the object of study was based on sufficiently compelling arguments, although the lack of clearly and comprehensively justified requirements for the quality of raw materials made it difficult to carry out work in terms of using natural forms of clay. 


\section{Thermographic and mineralogical research}

The mineralogical composition of layer I consists of 30-40 \% hydromica, 30-40\% montmorillonite, $20-30 \%$ calcite and it is not suitable for use in the production of pellets.

The mineralogical composition of layer II consists of 95-98 \% Camontmorillonite and 2-5\% quartz. The total distribution area of the layer is $625 \mathrm{~km}^{2}$, the average thickness of the deposit is $6 \mathrm{~m}$, the total clay reserves are about 5,8 billion tons. X-ray diffraction patterns of samples from numerous wells drilled over the entire area of the field give a typical diffraction pattern for montmorillonite (fig. 1).

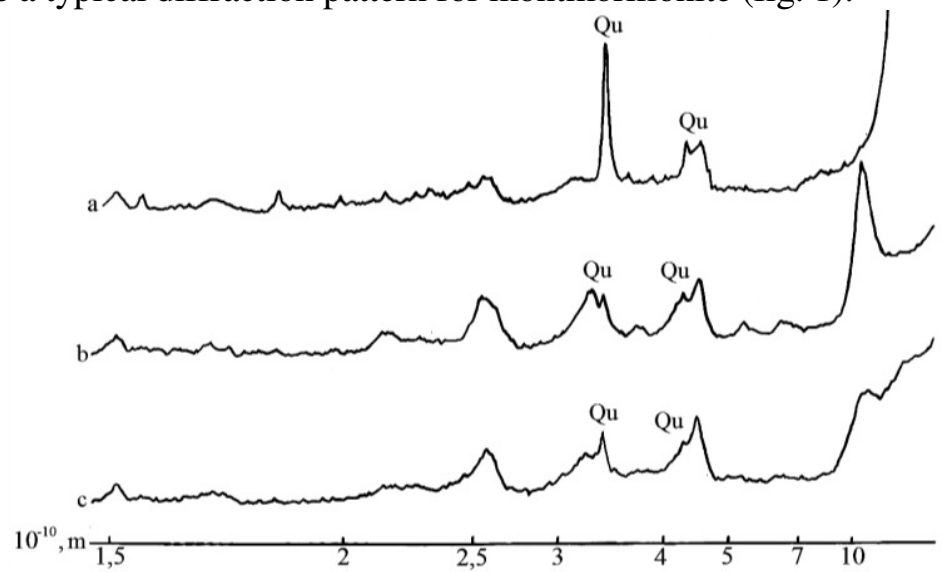

Fig. 1. X-ray diffraction patterns of productive clays the thickness of the Cherkasy deposit: $a$ - II layer (montmorillonite), $b$ - III layer (palygorskite), $c$ - IV layer, Qu - quartz

Thermograms of samples of layer II (fig. 2) have three endothermic effects: a deep endoeffect at $180^{\circ} \mathrm{C}$ with an excess at $250^{\circ} \mathrm{C}$. A weaker endo effect is also observed at $500-600{ }^{\circ} \mathrm{C}$, due to the release of the bulk of hygroscopic water, and the endoeffect caused by the loss of hydroxyl groups at $720-760{ }^{\circ} \mathrm{C}$ due to residues of removal of hydroxyl groups and recrystallization of montmorillonite. The somewhat lower temperature of the second and third endoeffects is caused by the increased iron content in the octahedral positions of the structure of Cherkasy montmorillonite. 


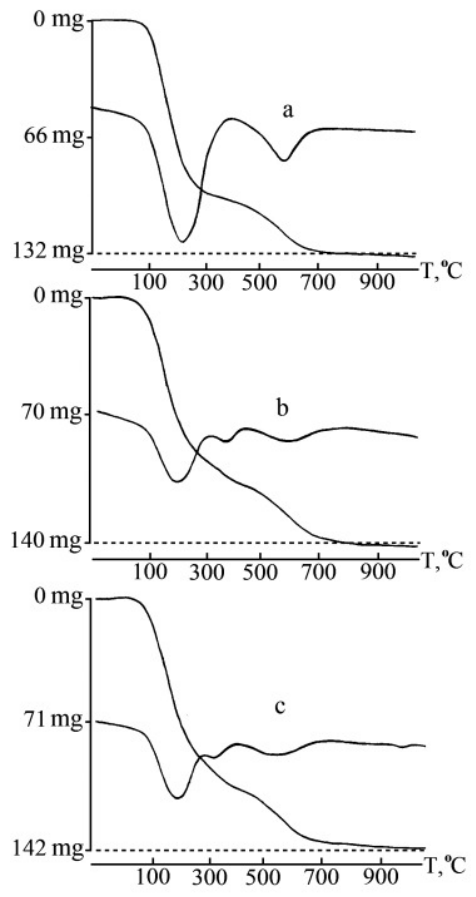

Fig. 2. Thermograms (differential and weight loss curves) of productive clays the thickness of the Cherkasy deposit: $a-$ II layer; $b$ - III layer; $c$ - IV layer

In electron microscopic images (Fig. 3), montmorillonite is represented by small flocculent particles with fuzzy outlines.
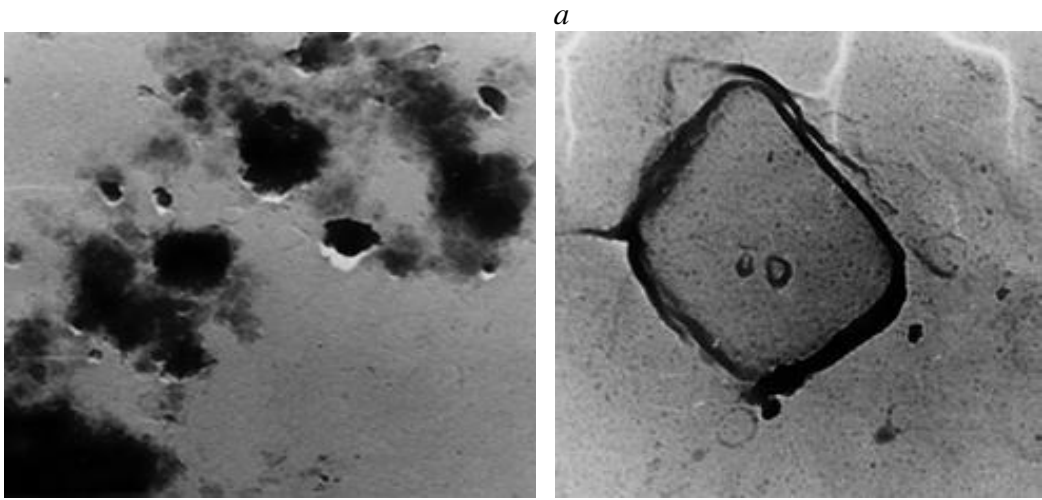

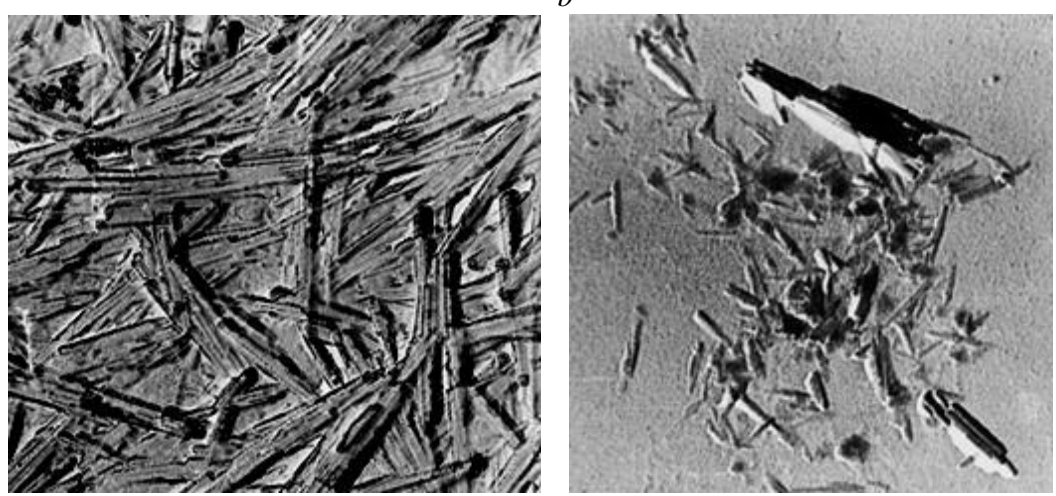

Fig. 3. Electron microscopic images of samples of productive clays the thickness of the Cherkasy deposit: $a-$ II layer (in suspension, in replica); $b-$ III layer (in suspension, in replica)

According to chemical analysis, Cherkasy bentonite is near to the montmorillonites of other deposits presented above (see table 2). Some difference is the increased content of $\mathrm{Fe}^{3+}$, which in Cherkasy bentonite ranges from 5 to $8 \%$. The calculated crystal chemical formula

$$
\mathrm{Na}_{0,03} \mathrm{~K}_{0,03} \mathrm{Ca}_{0,12}\left(\mathrm{Mg}_{0,13} \mathrm{Fe}^{3+}{ }_{0,44} \mathrm{Al}_{1,39}\right)\left[\left(\mathrm{Si}_{3,88} \mathrm{Al}_{0,12}\right)_{4,00} \mathrm{O}_{10}\right](\mathrm{OH})_{2} \cdot 2,6 \mathrm{H}_{2} \mathrm{O}
$$

confirms the montmorillonite composition of clays of the II layer. The deficit of lattice cations is compensated by the exchange cations $\mathrm{Ca}^{2+}, \mathrm{K}^{+}, \mathrm{Na}^{+}$. The total exchange capacity of Cherkasy bentonite is $92,6 \mathrm{mEq} / 100 \mathrm{~g}$ of dry clay.

The III layer consists of four main lenses, separated by erosion of the layer by rivers. The total distribution area of clays of the III layer is $323 \mathrm{~km}^{2}$, the average thickness is $3 \mathrm{~m}$. In the horizontal direction, the quality of clay changes gradually: its sandiness increases to the east. The clay layer is generally uniform; sometimes in the upper part or lower parts of the formation, intercalations of limestone with a thickness of up to $3 \mathrm{~m}$ are observed: in individual wells, the clay is completely replaced by limestone. The total reserves of clay of the III layer are 1195,7 million tons, including 8,4 million tons in the Dashukovsky area.

Clay of the III layer is 96-98\% composed of particles less than $0,01 \mathrm{~mm}$. The silt part is only $1-2 \%$ of the rock. The main rock- 
forming mineral of the III layer is palygorskite (an analogue of American attapulgite). All diffraction patterns of numerous samples from wells and the Dashukovsky quarry contain reflections characteristic of palygorskite $\left(10,48 \times 10^{-10} \mathrm{~m} ; 3,23 \times 10^{-10} \mathrm{~m}\right.$ and other), which do not change either upon heating to $300{ }^{\circ} \mathrm{C}$ or upon processing of samples with organic substances with polar molecules.

The heating curves of Cherkasy palygorskite (see fig. 2, b) have two low-temperature maxima caused by the removal of hygroscopic $\left(180{ }^{\circ} \mathrm{C}\right)$ and zeolite $\left(320{ }^{\circ} \mathrm{C}\right)$ water. The medium temperature endoeffect $\left(560{ }^{\circ} \mathrm{C}\right)$ is due to the formation of a compressed form of palygorskite-II, and the endoeffect at $720-760{ }^{\circ} \mathrm{C}$ is caused by recrystallization of it into enstatite, sillimanite and cristobalite. The electron microsoccopic images of all samples of layer III (see fig. 3, b) clearly show columnar crystals having the form of planks $0,2-0,5$ microns long and 0,02-0,03 microns wide. On the carbon replicas of these samples, it is clearly seen that the individual trims consist of the finest parallel needles [7].

Chemical analysis of clay layer III is given in table. 2. The crystalline formula in terms of layers

$\left[\mathrm{Si}_{8} \mathrm{O}_{20}\right]:\left(\mathrm{Mg}_{1,54} \mathrm{Fe}_{0,83} \mathrm{Al}_{1,49}\right)\left[\left(\mathrm{Si}_{7,43} \mathrm{~K}_{0,22} \mathrm{Ca}_{0,02} \mathrm{Mg}_{0,17} \mathrm{Al}_{0,57}\right)_{8} \mathrm{O}_{20}\right](\mathrm{OH})_{2}$. $\cdot\left(\mathrm{OH}_{3,1} \cdot 4,3 \mathrm{H}_{2} \mathrm{O}\right)$

The total exchange capacity is $27-29 \mathrm{mEq} / 100 \mathrm{~g}$ clay.

The IV layer is distributed in the field with separate lenses, the thickness of which varies from 0,4 to $5,7 \mathrm{~m}$ with an average thickness of $2 \mathrm{~m}$ in the field. The total distribution area of the layer is $344 \mathrm{~km}^{2}$.

Radiographs of clay samples of layer IV of the Cherkasy deposit (see fig. 1, c) contain reflections of montmorillonite and palygorskite. Typically, palygorskite is $30 \%$, and montmorillonite is $70 \%$ : in sandy varieties, the content of palygorskite is reduced to $10 \%$. Thermograms (see fig. 2, c) show a deep endothermic effect at 150 $180{ }^{\circ} \mathrm{C}$ due to the removal of adsorption water and endo effects at 600 and $740-760{ }^{\circ} \mathrm{C}$, reflecting the removal of $\mathrm{OH}$ groups and the recrystallization of montmorillonite.

Under an electron microscope, fibrous crystals of palygorskite and flake-like flakes of montmorillonite are visible (fig. 4). Palygorskite crystals are characterized by a significantly greater dispersion than in the case of layer III. The heat of wetting of clay of the IV 
layer is $21.2 \mathrm{cal} / \mathrm{g}$, the amount of bound water is $20,9 \%$, and the specific surface is $763 \mathrm{~m}^{2} / \mathrm{g}$.

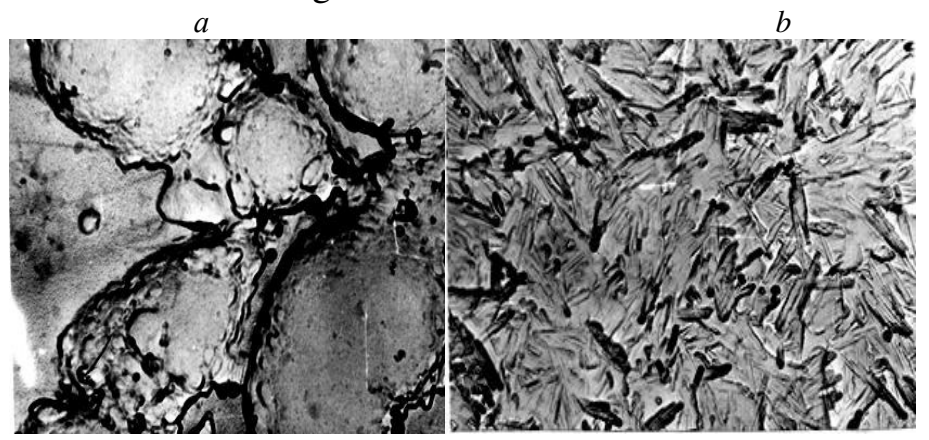

Fig. 4. Electron microscopic images of samples of productive clays the thickness of the Cherkasy deposit: $a$ - IV layer in suspension; $b$ - in replica

The $\mathrm{V}$ layer is represented by lower miocene sands and is not suitable for use as a binder.

The requirements for the quality of bentonite raw materials consumed for pelletizing iron ore pellets should be formulated on the basis of a study of the required technological characteristics of the pellets obtained by using one or another type of bentonite. In turn, the technological characteristics of the pellets obtained by laboratory methods should be as near as possible to the industrial conditions for the preparation of pellets at different stages of preparation.

According to V.M. Vityugin and P. N. Dokuchaev [8], the increased consumption of bentonite clays under industrial conditions is caused by several reasons, the main one is the extremely uneven distribution of dry finely ground bentonite powder in wet iron ore concentrate due to the ineffective mixing equipment used, which leads to an increase in clay consumption to achieve the necessary quality characteristics of the finished pellet. For example, the authors cite information that in the American practice of pelletizing iron ore concentrates with a moisture content of not more than $10 \%$, the theoretical consumption of high-quality bentonite should be $0,25 \%$, but in fact due to insufficient mixing efficiency, this amount doubles (i.e., 0,5 and $0,8 \%$ or even $1 \%$ ).

Various methods have been developed for using bentonite clays in the process of pelletizing, including: applying alkaline bentonite to 
the surface layer of pellets, preliminary mixing alkaline-earth bentonite with $7 \%$ soda ash, the use of mixed clay compositions with a small amount of high-quality bentonite, etc. These measures can reduce the percentage of bentonite additives and increase the strength of the pellets. Nevertheless, not only the chemical composition of the binder has an effect on the formation of the corresponding binder during high-temperature firing, but also the size and composition of the cation exchange complex, which determine the quality of the raw and calcined pellets.

Thus, it becomes quite obvious that the strength characteristics of the pellets depend not only on the colloidal characteristics of the clay, but also on a number of other indicators, among which the mineralogical and chemical compositions of bentonite clay, the composition and capacity of the exchange complex, the humidity of the concentrate, the rigidity of its process water, and the physical characteristics of the iron ore concentrate are significant.

From the long-term practice of using bentonite clays of different quality in the production of iron ore pellets, requirements have been formed for the rheological characteristics of bentonite (table 3) to ensure the properties of raw and calcined pellets with this binder required by the technology (table 4), and the maximum productivity of their calcining units.

Table 3

Requirements for rheological characteristics of the bentonite clays used in the production of pellet

\begin{tabular}{l|c}
\hline \multicolumn{1}{c|}{ The main clay mineral } & Montmorillonite \\
\hline Alkalinity coefficient in the exchange complex ${ }^{* 1}$ & More than 1,0 at $\mathrm{Na}^{+}>\mathrm{K}^{+}$ \\
\hline Swelling amount ${ }^{* 2}$, once & More than 12,0 \\
\hline Colloid $* 2, \%$ & $90-100$ \\
\hline Water absorption $(\text { Enslin })^{* 2}, \%$ & More than 250 \\
\hline The dynamic viscosity of the suspension $* 2, \mathrm{MPa} \cdot \mathrm{s}$ & More than 9,0 \\
\hline Heat limit without changing physical properties, ${ }^{\circ} \mathrm{C}$ & More than 200 \\
\hline Hydrogen ion concentration $(\mathrm{pH})$ & More than 9,0 \\
\hline Total specific surface, $\mathrm{m}^{2} / \mathrm{kg}$ & More than 35000 \\
\hline$* 1\left(\mathrm{Na}^{+}+\mathrm{K}^{+}\right) /\left(\mathrm{Ca}^{++}+\mathrm{Mg}^{++}\right)$. & \\
$* 2$ By standard techniques, rheological characteristics are determined in distilled \\
water.
\end{tabular}


Table 4

Technological requirements for the properties of raw pellets with qualitative alkaline bentonite

\begin{tabular}{c|c|c|c|c}
\hline $\begin{array}{c}\text { Compressive } \\
\text { strength*1, } \\
\mathrm{kg} / \mathrm{pellet}\end{array}$ & $\begin{array}{c}\text { Compressive } \\
\text { strength of the } \\
\text { dried*1, } \\
\mathrm{kg} / \mathrm{pellet}\end{array}$ & $\begin{array}{c}\text { Impact strength } \\
\text { of the raw } * 2, \\
\text { once }\end{array}$ & $\begin{array}{c}\text { Drying tempera- } \\
\text { ture limit } \\
\text { ("shock")*3, }\end{array}$ & $\begin{array}{l}\text { Content } \mathrm{C} \\
\text { valid } \\
\text { mm) class, \% }\end{array}$ \\
\hline $0,8-1,2$ & More than 3,0 & More than 4,0 & More than 400 & $\begin{array}{c}\text { More than } \\
90,0\end{array}$ \\
\hline
\end{tabular}

*1 Pellets diam. $14 \pm 2 \mathrm{~mm}$.

*2 The number of drops from a height of $500 \mathrm{~mm}$ onto a steel plate before the destruction of pellets diam. $14 \pm 2 \mathrm{~mm}$.

${ }^{* 3}$ It is determined at a coolant filtration rate of $1,2 \mathrm{~nm}^{3} /\left(\mathrm{m}^{2} \cdot \mathrm{s}\right)$.

As additional characteristics for montmorillonite, thermographic and $\mathrm{x}$-ray data are accepted: interval of the second endothermic effect on the thermogram $650-750{ }^{\circ} \mathrm{C}$, the value of the first basal reflection in the $\mathrm{x}$ ray for an air-dry sample $-(12-13) \times 10^{-10} \mathrm{~m}$, although it is undoubted that all of the indicated parameters of clay characteristics are largely arbitrary, since there are cases when "substandard" hardening additives create satisfactory strength characteristics of the finished pellets.

\section{Results of semi-industrial research}

Continuing the research, we conducted laboratory tests to determine the suitability of bentonite clays of different mineralogical composition and ion exchange complex for the production of pellets. Pellets with a diameter of $12-13 \mathrm{~mm}$ were obtained on a laboratory granulator with continuous operation. The preparation of charge materials was as follows: the averaged sample of bentonite clay was dried at a temperature of $105-110{ }^{\circ} \mathrm{C}$, and then crushed to a grain size of $95 \%$ of class $0,05 \mathrm{~mm}$. The crushed bentonite clay was dosed on a wet concentrate. Mixing a 100-kilogram sample was carried out in a drum mixer with mixing bodies and with a mixing efficiency of more than $95 \%$.

In the process of research, the following was determined: moisture content of pellets, the compressive strength of raw and dry pellets, the number of raw pellets dropped from a height of 0,3 meters on the rubber plate and the temperature of the «shock» at a rate of filtration of the coolant through a layer of raw pellets of $1,2 \mathrm{~nm} / \mathrm{sec}$.

The consumption of bentonite pelletizing powder is usually $0,5-0,7 \%$ in dry weight relative to the wet concentrate. In the first series of experiments, a slightly larger $(1 \%)$ consumption of binder was adopted so that 
the influence of the studied clays on the quality indicators of the pellets was revealed more noticeably. In addition to purposively selected samples (by layers), mixtures of samples in various ratios were tested (Table 5), taking into account that when mining in a quarry, the ratio of clays of different varieties can vary widely, and selective excavation and storage can be practically impossible.

Kaolinite was added to some mixtures. The experimental results (Table 5) indicate that, with increased specific consumption of bentonite, the impact resistance (drop) and compressive strength of raw pellets with the addition of Cherkasy Cabentonite are not inferior to the same properties of pellets using alkaline Sarygyuh bentonite as a binder. The strength of raw pellets in all experiments was higher than the prevailing pelletizing requirements in practice (impact strength of 5,6 drops without breaking, the compressive strength of $0,75-0,80$ $\mathrm{kg} /$ pell). The compressive strength of the dried pellets was approximate up to two times the minimum requirements of $2.3-2.5 \mathrm{~kg} /$ pell.

Properties of unfluxed pellets from different concentrates

Table 5 with the addition of alkaline bentonite and clays of the Cherkasy deposit

\begin{tabular}{|c|c|c|c|c|c|c|c|c|}
\hline \multirow{3}{*}{$\begin{array}{l}\text { Name of } \\
\text { additive }\end{array}$} & \multicolumn{4}{|c|}{ Raw pellets properties } & \multicolumn{4}{|c|}{ Burning pellets properties } \\
\hline & \multirow{2}{*}{$\begin{array}{c}\text { Number of } \\
\text { drops, } \\
\text { from } 300 \\
\mathrm{~mm} / \text { times }\end{array}$} & \multicolumn{2}{|c|}{$\begin{array}{c}\text { Compressive } \\
\text { strength, } \\
\text { kg/pell }\end{array}$} & \multirow{2}{*}{$\begin{array}{c}\text { The tem- } \\
\text { perature of } \\
\text { the } \\
\text { «shock», } \\
{ }^{\circ} \mathrm{C}\end{array}$} & \multirow{2}{*}{$\begin{array}{l}\text { Compressive } \\
\text { strength, } \\
\mathrm{kg} / \text { pell }\end{array}$} & \multicolumn{2}{|c|}{ Drum test } & \multirow{2}{*}{$\begin{array}{c}\text { The } \\
\text { degree of } \\
\text { recovery, } \\
\%\end{array}$} \\
\hline & & raw & dry & & & $\begin{array}{c}+5 \\
\mathrm{~mm}\end{array}$ & \begin{tabular}{|l|}
$-0,5$ \\
$\mathrm{~mm}$
\end{tabular} & \\
\hline \multicolumn{9}{|c|}{ CGOK } \\
\hline $\begin{array}{l}\text { Sarygukh } \\
\text { alkaline }\end{array}$ & 8,7 & 1,00 & 5,2 & 575 & 427,4 & 96,0 & 3,8 & 68,60 \\
\hline $\begin{array}{l}\text { IV layer } \\
\text { of } \\
\text { Ch.dep }\end{array}$ & 8,8 & 1,30 & 6,1 & 580 & 382,0 & 95,6 & 4,4 & 67,25 \\
\hline $\begin{array}{l}\text { II layer } \\
\text { of } \\
\text { Ch.dep }\end{array}$ & 12,4 & 1,35 & 6,1 & 540 & 446,6 & 96,1 & 3,9 & 60,90 \\
\hline $\begin{array}{l}\text { III layer } \\
\text { of } \\
\text { Ch.dep }\end{array}$ & 10,7 & 1,38 & 4,3 & 540 & \multicolumn{4}{|c|}{ not carried out } \\
\hline $\begin{array}{l}50 \% \text { IV } \\
\text { layer } \\
+50 \% \\
\text { III layer }\end{array}$ & 16,5 & $|1,67|$ & 5,5 & 510 & 419,6 & 96,0 & 4,0 & 62,10 \\
\hline
\end{tabular}




\begin{tabular}{|c|c|c|c|c|c|c|c|c|}
\hline $\begin{array}{l}50 \% \text { IV } \\
\text { layer } \\
+50 \% \\
\text { kaolinite } \\
\end{array}$ & 8,1 & 1,48 & 5,5 & 530 & - & - & - & - \\
\hline $\begin{array}{l}40 \% \text { IV } \\
\text { layer + } 40 \\
\% \text { II layer } \\
+20 \% \\
\text { kaolinite }\end{array}$ & 14,9 & 1,54 & 6,6 & 540 & 487,6 & 96,2 & 3,7 & 46,80 \\
\hline $\begin{array}{l}80 \% \text { II } \\
\text { layer +20 } \\
\% \text { III } \\
\text { layer }\end{array}$ & 16,5 & 1,20 & 6,4 & 540 & - & - & - & - \\
\hline $\begin{array}{l}50 \% \text { II } \\
\text { layer } \\
+50 \% \\
\text { III layer }\end{array}$ & 14,3 & 1,20 & 5,6 & 530 & - & - & - & - \\
\hline \multicolumn{9}{|c|}{ SevGOK } \\
\hline $\begin{array}{l}\text { Sarygukh } \\
\text { alkaline }\end{array}$ & 12,9 & 1,52 & 6,3 & 470 & - & - & - & - \\
\hline $\begin{array}{l}\text { IV layer } \\
\text { of Ch.dep }\end{array}$ & 18,8 & 1,51 & 5,9 & 490 & - & - & - & - \\
\hline $\begin{array}{l}\text { II layer of } \\
\text { Ch.dep }\end{array}$ & 14,5 & 1,54 & 4,6 & 495 & - & - & - & - \\
\hline \multicolumn{9}{|c|}{ LebGOK } \\
\hline $\begin{array}{l}\text { Sarygukh } \\
\text { alkaline }\end{array}$ & 12,0 & 1,45 & 5,7 & 560 & 455,7 & 97,7 & 2,3 & 60,30 \\
\hline $\begin{array}{l}\text { IV layer } \\
\text { of Ch.dep }\end{array}$ & 11,8 & 1,36 & 5,9 & 580 & 415,0 & 97,5 & 2,5 & 56,30 \\
\hline $\begin{array}{l}\text { II layer of } \\
\text { Ch.dep }\end{array}$ & 11,6 & 1,50 & 5,6 & 520 & 451,5 & 96,9 & 3,1 & 47,20 \\
\hline $\begin{array}{l}50 \% \text { IV } \\
\text { layer } \\
+50 \% \\
\text { III layer } \\
\end{array}$ & 11,5 & 1,70 & 4,9 & 595 & 428,3 & 97,4 & 2,6 & 70,40 \\
\hline $\begin{array}{l}40 \% \text { IV } \\
\text { layer + } 40 \\
\% \text { II layer } \\
+20 \% \\
\text { kaolinite }\end{array}$ & 10,6 & 1,40 & 5,2 & 570 & 528,7 & 97,7 & 2,3 & 47,30 \\
\hline
\end{tabular}

Thus, with the appropriate amount of bentonite powder in the mixture from clays of the Cherkasy deposit, you can get raw pellets of the required quality. When using clays of the IV layer, raw pellets 
from all types of concentrates were characterized on average by the highest values of compressive strength after drying and the temperature of the «shock». In the case of adding to the clay of the IV layer $50 \%$ palygorskite clay of the III layer, the strength of dry pellets from LebGOK and CGOK concentrates decreased, respectively, from 5,9 to $4,9 \mathrm{~kg} /$ pell and 6,1 to $5,5 \mathrm{~kg} /$ pell with stable values of dynamic and static strength of raw pellets.

The addition of only kaolinite $(50 \%)$ to the clay of the IV layer also did not improve the quality of the raw pellets. A favourable combination of the properties of the raw pellets of CGOK (dynamic strength of 14,9 drops, static strength of $1,54 \mathrm{~kg} /$ pell, resistance to compression after drying, $6,6 \mathrm{~kg} /$ pell, the temperature of the «shock» $540{ }^{\circ} \mathrm{C}$ ) was obtained by adding to IV layer $40 \%$ of clays layer II and $20 \%$ kaolinite. For LebGOK concentrate, the average quality values of raw pellets corresponded to the indicated composition of the mixture of bentonite clays. Pellets of good quality were obtained from LebGOK and CGOK concentrates with the addition of $1 \%$ bentonite clay of the II layer. The addition of a small amount of palygorskite to this clay (20\%) does not impair the quality of the pellets from the CGOK concentrate. Pellets of SevGOK with a bundle of clay of the II layer are characterized by reduced compressive strength after drying. The same applies to pellets from the CGOK concentrate using clay only of the III layer.

Table 6

Influence of the quantity of IV layers bentonite clay

of the Cherkasy deposit on the quality of raw pellets from SevGOK concentrate

\begin{tabular}{l|c|c|c|c|c|c}
\hline & \multicolumn{5}{|c}{ Raw pellets properties } \\
\cline { 2 - 5 } $\begin{array}{c}\text { Name of } \\
\text { additive in } \\
\text { charge }\end{array}$ & $\begin{array}{c}\text { The } \\
\text { number } \\
\text { of bun- } \\
\text { dles, } \%\end{array}$ & $\begin{array}{c}\text { Humidity, } \\
\%\end{array}$ & $\begin{array}{c}\text { Compressive } \\
\text { strength, } \\
\mathrm{kg} / \mathrm{pell}\end{array}$ & $\begin{array}{c}\text { The num- } \\
\text { ber of } \\
\text { drops } \\
\text { without } \\
\text { destruction, } \\
\text { times }\end{array}$ & $\begin{array}{c}\text { The tempera- } \\
\text { ture of the } \\
\text { «shock», }{ }^{\circ} \mathrm{C}\end{array}$ \\
\hline $\begin{array}{l}\text { Sarygukh } \\
\text { bentonite }\end{array}$ & 0,5 & 8,4 & 0,97 & 3,5 & 5,0 & 480 \\
\hline $\begin{array}{l}\text { IV layer of } \\
\text { Cherkasy } \\
\text { dep. }\end{array}$ & 0,5 & 8,5 & 1,04 & 3,5 & 5,2 & 550 \\
\hline
\end{tabular}


Influence of the quantity of IV layers bentonite clay

of the Cherkasy deposit on the quality of burning pellets from SevGOK concentrate

\begin{tabular}{l|c|c|c|c|c}
\hline \multirow{2}{*}{$\begin{array}{c}\text { Name of } \\
\text { additive in } \\
\text { charge }\end{array}$} & $\begin{array}{c}\text { Compressive } \\
\text { strength, kg/pell }\end{array}$ & \multicolumn{2}{|c}{ Drum test } & \multicolumn{3}{c}{$\begin{array}{c}\text { The recovery } \\
\text { strength, } \%\end{array}$} \\
\cline { 2 - 6 } & $+5 \mathrm{~mm}$ & $-0,5 \mathrm{~mm}$ & $-0,5 \mathrm{~mm}$ & $+5 \mathrm{~mm}$ \\
\hline $\begin{array}{l}\text { Sarygukh } \\
\text { bentonite }\end{array}$ & 472,7 & 98,1 & 1,9 & 2,8 & 80,35 \\
\hline $\begin{array}{l}\text { IV layer of } \\
\text { Cherkasy dep. }\end{array}$ & 509,2 & 97,9 & 2,0 & 5,75 & 76,6 \\
\hline
\end{tabular}

Thus, the clay variety of the Cherkassk deposit is most favourable for ensuring the good quality of the raw pellets of the Cherkasy deposit, which are a natural mixture of alkaline earth bentonite of the II layer and palygorskite (III layer) in a variable ratio, from 1:1 to 4:1. The high rates of pellets quality were obtained for clay mixtures of layers II and III (in the range of ratios characteristic for layer IV).

For all types of tested binder additives, calcined pellets were characterized by high physical, mechanical and metallurgical properties (Table 5). The effect of the bentonite type on the properties of the finished calcined pellets is not traced. Pellets with the clay of the IV layer of the Cherkassk deposit had the highest temperature of the «shock». It should be noted that the temperature of the "shock" according to experiments to a large extent also depends on the size of the concentrate. So for a thinner concentrate of SevGOK, it was lower by $45-90{ }^{\circ} \mathrm{C}$ in comparison with pellets from CGOK concentrate.

Table 8

Influence of the charges moisture with various binders on the quality indicators of raw pellets with basicity 0,5 of the concentrate of CGOK

\begin{tabular}{l|c|c|c|c|c|c|c}
\hline \multirow{2}{*}{$\begin{array}{c}\text { Name of } \\
\text { additive in } \\
\text { charge }\end{array}$} & $\begin{array}{c}\text { The } \\
\text { number } \\
\text { of bun- } \\
\text { dles, } \%\end{array}$ & $\begin{array}{c}\text { Humidity } \\
\text { of pellets, } \\
\%\end{array}$ & $\begin{array}{c}\text { Compressive } \\
\text { strength, } \\
\mathrm{kg} / \text { pell }\end{array}$ & $\begin{array}{c}\text { The number } \\
\text { of drops } \\
\text { without } \\
\text { destruction, } \\
\text { times }\end{array}$ & $\begin{array}{c}\text { Total } \\
\text { porosity, } \\
\%\end{array}$ & $\begin{array}{c}\text { The tem- } \\
\text { perature of } \\
\text { the } \\
\text { «shock», } \\
{ }^{\circ} \mathrm{C}\end{array}$ \\
\hline $\begin{array}{l}\text { Sarygukh } \\
\text { bentonite }\end{array}$ & 0,5 & 7,7 & 1,26 & 2,9 & 5,6 & 26,31 & 460 \\
\hline Same & 0,5 & 8,7 & 1,08 & 2,55 & 6,3 & 30,04 & 480 \\
\hline Same & 0,5 & 9,65 & 0,65 & 2,35 & 10,6 & 31,50 & 500 \\
\hline $\begin{array}{l}\text { A mix- } \\
\text { ture of }\end{array}$ & 0,5 & 8,0 & 1,04 & 2,7 & 5,2 & 28,28 & 480 \\
\hline
\end{tabular}




\begin{tabular}{l|c|c|c|c|c|c|c}
\hline $\begin{array}{l}\text { clay II } \\
\text { and IV } \\
\text { layers }\end{array}$ & & & & & & & \\
\hline Same & 0,5 & 9,3 & 0,82 & 2,25 & 5,8 & 31,80 & 460 \\
\hline Same & 0,5 & 9,74 & 0,68 & 2,47 & 10,1 & 32,45 & 535 \\
\hline
\end{tabular}

Considering the results of previous studies, further experiments were carried out with bentonites of the IV layer and a mixture of clays of the IV and II layers in a ratio of 1:2. Since clay of the IV layer is a natural mixture of clays of the II and III layers, the addition of clay of the II layer gives a new compositional mixture, which should be considered, also, as a special variety of the IV layer with a high content of alkaline earth bentonite, and as a mixture of clay of the III layer and II layers.

With a consumptions decrease of bentonite from $1 \%$ to $0,5 \%$, the quality indicators of raw pellets decreased to almost the same level, but acceptable for pelletizing for both types of bentonites: Sarygyuhsky and Cherkasy (IV layer) (Table 6, 7, burning temperature $1350{ }^{\circ} \mathrm{C}$, duration $-7 \mathrm{~min}$ ).

Burnt pellets with the addition of Cherkasy bentonite with the same physical and mechanical properties in the cold state showed a slightly greater destructibility during reduction than in experiments with alkaline Sarygyuhsky, although their strength during lowtemperature reduction corresponds to modern requirements: abrasion $5,75 \%$, class output $+5 \mathrm{~mm}-76,7 \%$ (with the required - at least 70 $\%$ ). The increase in bentonite consumption for SevGOK concentrate did not increase the temperature of the «shock».

Under industrial conditions, significant fluctuations in the humidity of the concentrate entering the pelletizing process can take place. In this regard, we conducted comparative experiments with different a moisture content of the mixture before pelletizing, respectively, at a different moisture content of the pellets, with the addition of $0.5 \%$ alkaline and Cherkasy bentonites (a mixture of clays of layers IV and II, Table 8). In both cases, with an increase in humidity, a similar pattern of changes in the properties of pellets is observed for both Sarygyuhsky and Cherkasy bentonites: the dynamic strength increases from 5.6-5.2 to 10.6-10.1 drops, porosity (in Fig. 5-7, the average 
values of three parallel experiments are presented) and the temperature of the "shock" of the pellets (Table 8).

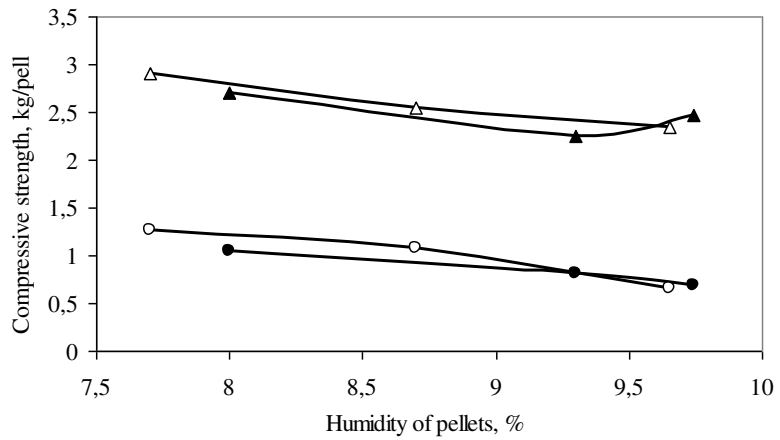

Fig. 5. The effect of humidity of raw pellets on their strength indicators:

$\Delta$ and $\boldsymbol{\Delta}$ are the strength of dry pellets, $\circ$ and $\bullet$ are the strength of raw pellets (with the addition of Sarygyuhsky and Cherkasy bentonite IV layer, respectively)

The temperatures of the "shock" of raw pellets with alkaline earth bentonite at the same humidity are approximately equal to the temperatures with alkaline bentonite. With increasing humidity of the raw pellets, the strength of the raw and dry pellets decreases, and the porosity and drop strength increase. An increase in the moisture of pellets above 9,3\% leads to a decrease in the static strength of the pellets below the minimum permissible limit $(0,75-0,8 \mathrm{~kg} /$ pell $)$ for Cherkasy $(0,68 \mathrm{~kg} /$ pell with $9,74 \%$ humidity of the pellets), and for Sarygukh bentonite $(0,65 \mathrm{~kg} / \mathrm{pell}$ with the pellet moisture content of $9,65 \%)$. At the same time, at relatively high humidity of pellets $9,3 \%$ with Cherkasy bentonite, their strength $(0,82$ $\mathrm{kg} / \mathrm{pell}$ ) is not lower than the minimum limit.

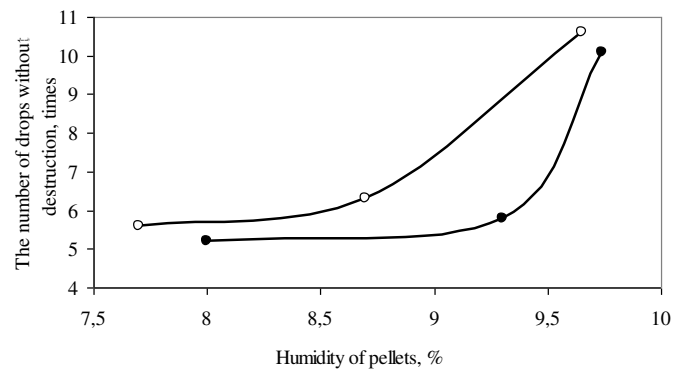

Fig. 6. The effect of humidity of raw pellets on their strength indicators when dropping: $\odot$ and $\bullet-$ with the addition of Sarygyuhsky and Cherkasy bentonite IV layer, respectively 
Graphical analysis of the data given in table 8 and in fig. 5-7 shows that at the same humidity the porosity of raw pellets with Cherkasy bentonite is about $0,8-1 \%$ higher. Graphical analysis of the data given in table 8 and fig. 5-7 shows that at the same humidity the porosity of raw pellets with Cherkasy bentonite is about 0,8-1\% higher. With increasing humidity of the pellets from 7,7-8,0 to 9,7 \%, their porosity increases from 27 to $32 \%$. \%. In this case, the compressive strength of raw and dry pellets with both bentonites is slightly reduced, and the impact strength of raw pellets increases. Thus, according to these tests, when using a mixture of layers IV and II, the quality of raw pellets with Cherkasy bentonite is slightly worse than with Sarygyuhsky, however, the absolute values of the indicators generally satisfy the requirements.

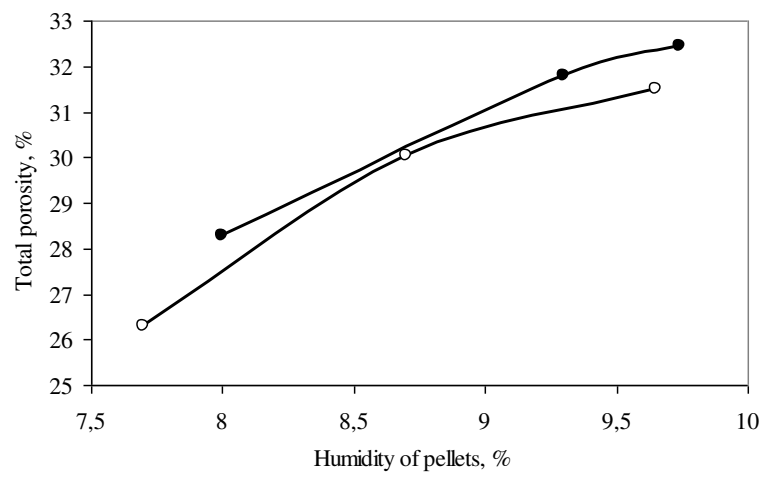

Fig. 7. The effect of humidity of raw pellets on their porosity: $\circ$ and $\bullet-$ with the addition of Sarygyuhsky and Cherkasy bentonite IV layer, respectively

Laboratory tests showed that, despite the relatively lower performance (determined by existing methods in distilled water) of Cherkasy bentonite, pellets from concentrates CGOK, SevGOK and LebGOK obtained with the addition of clays IV, IV and II, III and II layers, are not inferior or inferior insignificantly in properties in the wet and dried state to pellets with the addition of Sarygyukh bentonite.

When using Cherkasy bentonite, it is possible to obtain pellets in approximately the same humidity range of the concentrate as for Sarygyuh bentonite. To objectively confirm the possibility of using alkaline earth bentonite of the Cherkasy deposit (II-III-IV layers) in 
the production of pellets, it is necessary to conduct comparative industrial tests at a pelletizing plant (for example, SevGOK) using a concentrate with increased hardness of industrial water.

\section{Conclusions}

1. Bentonite clay is one of two (bentonite clay and active lime) important inorganic binder additives in the production of iron ore pellets, that provides the required optimal technological parameters of technical units for obtaining high-quality raw pellets and their heat strengthening, to obtain calcined product that meets the requirements of blast furnace smelting.

2. In the production of calcined pellets, it is advisable to use only bentonite clays with an alkalinity coefficient of the exchange complex equal to the ratio $\mathrm{Na}^{+}+\mathrm{K}^{+} / \mathrm{Ca}^{++}+\mathrm{Mg}^{++}>1,0$, wherein $\mathrm{Na}^{+}>\mathrm{K}^{+}$. Moreover, it is desirable that the hardness of the technical water in the concentrate be no more than $10-30 \mathrm{mEq} / \mathrm{dm}^{3}$.

3. An increase in water hardness leads to a partial or complete (depending on the hardness value) replacement of the alkaline exchange complex with an alkaline-earth complex and the conversion of alkaline bentonite clay to alkaline-earth with appropriate rheological characteristics, the deterioration of the lumpiness of the mixture, the characteristics of raw pellets and the need to increase the content of bentonite in the mixture.

4. In the case of increased water hardness in the concentrate, it is economically feasible to use alkaline-earth bentonite clay in the production of pellets, if it is cheaper than alkaline.

5. Palygorskite bentonite clay can be considered as the most promising for the production of iron ore pellets. Long industrial tests should be carried out with its use.

6. The effect of replacing alkaline bentonite in a mixture for the production of pellets with alkaline earth, palygorskite and their mixtures of bentonite clays has been studied. The possibility of using less scarce and expensive local bentonite clays instead of expensive exported alkaline clays without deteriorating the technology is shown by the example of the properties of raw, dry and calcined pellets.

7. The comparative effect of the moisture content of raw pellets on their porosity and strength characteristics with alkaline and alkaline-earth bentonites in the charge was studied. It is shown that the 
absolute values of the indicators with both bentonites at all humidity values correspond to the requirements of the technology, however, the strength when dropping pellets with alkaline earth bentonite is lower than with alkaline.

8. With the studied amounts $(0,5$ and $1,0 \%)$ of bentonites in the charge, the compressive strength of raw and dry pellets with alkaline and Cherkasy bentonite from layer IV (a natural mixture of alkaline earth and palygorskite) was almost the same, and the temperature of the «shock» at second $-20-70{ }^{\circ} \mathrm{C}$ higher.

9. An objective conclusion about the suitability of natural (without modification) Cherkasy bentonite clays and their replacement with alkaline can be determined only as a result of lengthy industrial tests with specific concentrates and industrial water.

\section{References}

1. Lyalyuk, V., Stupnik, N., Zhuravlev, F., Chuprinov, E., Lyakhova, I., Kassim D. (2017). Improving the technology and equipment for the production of iron ore for modern blast furnace smelting. Krivoj Rog: Dionat.

2. Zhuravlev, F., Lyalyuk, V., Stupnik, N., Morkun, V., Chuprinov E., Kassim, D. (2019). Theory, technology and equipment for the production of pellets and new iron ore raw materials for blast furnace. Krivoj Rog: FL-P CHernyavskij D.A.

3. Belousov, P. (2013). Comparative characteristics of high-quality bentonite deposits in Russia and some foreign countries. RUDN Journal of Engineering Researches, № 2, p. 55-61.

4. Demidenok, K., Ladygina, G., Lygach V. (2011). The material composition and technical properties of bentonite-like clays in the Central region of Russia and the assessment of the possibility of improving their quality for use in the most important sectors of modern production. Actual innovative research: science and practice. Tambov State University named G.R. Derzhavin, №4, 10 p.

5. Savko, A. (2014). Clay rocks and minerals associated with them in the Paleozoic and Meso-Cenozoic deposits of the Voronezh anteclise. Article 2. Clay rocks of the Meso-Cenozoic. Proceedings of Voronezh State University. Series: Geology, №1, p. 79-90.

6. Kukovsky, E. (1966). Structural features and physico-chemical properties of minerals. Kiev: Naukova dumka, 1966, 132 p.

7. Kukovsky, E., Ostrovskaya, A. (1962). X-ray analysis of bentont clays of the Dashukovsky site of the Cherkasy deposit of the Ukrainian SSR. Rentgenografiya mineralogicheskogo syr'ya, 1962, vol. 1, $56 \mathrm{p}$.

8. Vityugin, V., Dokuchaev, P. (1986). About the mechanism of action of bentonite additives in the process of pelletizing iron ore charge. M.: Metallurgiya, 1986, $157 \mathrm{p}$. 
https://doi.org/10.31713/m1120

\title{
ANALYSIS AND RESEARCH OF RESOURCE-SAVING TECHNOLOGIES FOR ANAEROBIC DIGESTION OF BIOMASS
}

\author{
Avksentieva A.P, Kuris Yu.V.
}

Zaporizhzhia National University, bachelor, $4^{\text {th }}$ year student in the Department of Thermal Power Engineering and Hydropower, Ukraine.

Zaporizhzhia National University d.t.s., prof., educator in the Department of Applied Ecology and Occupational Safety, Ukraine.

\begin{abstract}
.
Biogas is a methane-containing gas produced by anaerobic decomposition of an organic substrate. To date, biogas is a potential gaseous fuel - a source of electrical and thermal energy production, with the capabilities of which the whole world is not fully familiar.

As an alternative energy source, it has many advantages and is a solution to many economic and environmental problems in the world, which could be a definite important step in improving the position of the Energy System of the world.

In this article the construction of mathematical model of biothermal process of waste treatment is considered that gives the possibility to study in full the mechanism of this phenomenon, to determine and describe the relationship between the main parameters of the studied object with the aim of its automation, for example, to optimize technological processes in the microbiological industry.

The methods of pig manure processing, which has both energy potential and economic, economic and nature protection potential, are also investigated. Pig manure processing can be carried out in

The following directions: obtaining organic fertilizer; fuel; fodder. For this purpose different methods of manure processing can be used, which can be divided into physical, chemical and biological.

The article presents a detailed analysis of methods of pig manure processing, as well as positive aspects of using this method to obtain fuel, fertilizer and fodder from the energy and economic sphere.

\section{Introduction.}

The construction of mathematical models of any objects is associated with the formalization of their description and with the identification of essential features of the situation under consideration. The mathematical model, summarizing the quantitative relationships between process factors, allows us to analyze their role in interaction and determine the optimal conditions for conducting the process.
\end{abstract}


Mathematical models are divided into three types: search, portrait, and research.

Search models are used in conditions where the mechanism of the described phenomenon is insufficiently studied. In this case, observing the reaction of the system under study to external influences creates a hypothetical model of the phenomenon, which is then empirically tested under various conditions in order to clarify its individual parameters. The search model can accurately describe the relationship of the main parameters of a real phenomenon. The disadvantage of models of this type is their limitations, since they are valid only under conditions close to those under which empirical coefficients were determined. Search models are rational in determining the optimal parameters of a particular object in order to automate it, for example, to optimize processing procedures in the microbiological industry. There are known attempts to use search models to describe the main stages of biological wastewater treatment, but due to the shortcomings noted above, they are not widely used in practice.

Portrait models are used in cases where the object's mechanism is relatively fully studied, but difficult for direct observations. This situation occurs in biology when studying genetic processes that last for years, or when studying the development of plant and animal populations.

The research model is used to find out the potential capabilities of the object under study, i.e. ways to intensify processes. Such a model should be based on theoretical prerequisites, but may also contain specific empirical relationships to describe the stages of the process having minor importance.

\section{Formation of a mathematical model.}

The whole process of developing a mathematical model can be divided into several different stages related to the collection of necessary information, with the analysis of experimental data and the identification of patterns, as well as the actual construction of a model based on the identified patterns, interpretation of the results of its analysis and comparison of theoretical (model) data with experimental ones. At each stage, a well-defined set of problems is solved.

At the first stage, general factors of bio thermal decomposition (the influence of initial moisture content of manure, initial temperature and some other physical quantities on the rate of the process) are 
investigated. As a result of research, factual material is accumulated and conclusions are drawn, first of all, of a qualitative character about the nature of the process. At this stage, it is very important to conduct experiments, for example, to identify the nature of the dependence of the duration of the process on the initial humidity of manure, the growth of biomass temperature, the presence of organic substances, the influence of filler on the degree of decomposition of organic matter, to identify the dependence of changes in the process rate on various factors. A huge role at this stage is played by the development of methods for collecting experimental information. Based on the results of the conducted experiments, the main parameters for changing the process are established.

At the second stage, a statistical analysis of the accumulated material is carried out, which leads to the identification of existing patterns (for example, the dependence of the duration of the process on temperature, etc.). These regularities are laid down in the basis of prognostic algorithms, which allow predicting with a certain probability the realization of these or other phenomena.

At the third stage, based on the identified patterns and statistical analysis, a mathematical model is formed that reflects these patterns in the form of mathematical expressions, dependencies, and formulas. Note that, as a rule, mathematical models do not rely on all available factual material, but only reflect the features of the object being modeled in a very simplified form.

Analysis of the literature on this issue allowed us to determine the main parameters of the Bio thermal waste treatment process, on the basis of which a research mathematical model is designed. The description of the process was based on basic equations describing the development and death of microorganisms, decomposition of organic matter, reduction of moisture content in the mixture, change in temperature of the compostable mixture and oxygen consumption during the Bio thermal disinfection process.

Gas production per day depending on the level of loading under thermophilic and mesophilic modes respectively

$$
\begin{aligned}
& \sum V_{\text {gas }}=1,4087 \cdot V_{\text {load }}^{0,8639} \\
& \sum V_{\text {gas }}=1,7437 \cdot V_{\text {load }}^{0,6932}
\end{aligned}
$$


The proportion of methane in biogas, depending on the loading level under thermophilic and mesophilic modes, respectively, is described by the equations

$$
\begin{aligned}
& M=56,131 \cdot V_{\text {load }}^{0,0245} \\
& M=65,1363 \cdot V_{\text {load }}^{-0,0591}
\end{aligned}
$$

Methane production, L/day, during mesophilic and thermophilic fermentation at different loading levels is described by the following equation

$$
\begin{aligned}
& P r_{\text {term }}=0,7919 \cdot V_{\text {load }}^{0,8874} \\
& P r_{\text {mes }}=1,1363 \cdot V_{\text {load }}^{0,5152}
\end{aligned}
$$

where $P r_{\text {term }}, P r_{\text {mes }}$ - methane production during thermophilic and mesophilic fermentation, respectively, per day;

load - loading level, grams of volatiles per liter of reactor volume per day.

Having constructed the dependence of the load on the required gas production, we get the dependence.

The dependence of the load on the required methane production under mesophilic and thermophilic modes is described by the following equations

$$
\begin{aligned}
& V_{\text {load,therm }}=0,9406 \cdot \operatorname{Pr}^{1,7717} \\
& V_{\text {load,therm }}=0,3041 \cdot \operatorname{Pr}^{1,1251}
\end{aligned}
$$

where $V_{\text {load., term }}, V_{\text {load., mes }}$ - loading level under thermophilic and mesophilic fermentation modes, respectively, grams of volatiles per liter of reactor volume per day;

$\mathrm{Pr}$ - methane production, $L$ per day.

The efficiency of methane production in mesophilic and thermophilic modes, L of methane per L of reactor volume per day, at different loading levels is described by the following equations

$$
\begin{gathered}
V_{G, \text { mes }}=0,3755 \cdot V_{\text {load }}^{0,5191} \\
V_{G, \text { term }}=0,2655 \cdot V_{\text {load }}^{0,8832}
\end{gathered}
$$

where $V_{g r \text {,mes }}$ - methane output in mesophilic mode, L of methane per L of reactor volume;

$V_{g r, \text { term }}$ - methane output in thermophilic mode, $L$ of methane per $\mathrm{L}$ of reactor volume; 
$V_{\text {load. }}$ - reactor load level, gr of volatiles per liter of reactor volume per day.

The amount of methane in biogas at different loading levels, in thermophilic and mesophilic modes is described by the following equations

$$
\begin{aligned}
& M Q_{\text {term }}=56,131 \cdot \operatorname{Load}^{0,0245} \\
& M Q_{\text {mes }}=65,352 \cdot \text { Load }^{-0,791}
\end{aligned}
$$

The total biomass energy under mesophilic and thermophilic modes is described by the following equations

$$
\begin{aligned}
& T E_{\text {mes }}=32,83 \cdot \text { Load }^{1,154} \\
& T E_{\text {therm }}=35,818 \cdot \text { Load }^{0435}
\end{aligned}
$$

where $T E_{m e s}, T E_{\text {therm }}$ is total biomass energy under mesophilic and thermophilic fermentation modes, respectively, $k J$ per day;

load. - loading level, grams of volatiles per liter of reactor volume per day.

The measure of energy conversion to methane during thermophilic and mesophilic fermentation is determined by the following equations

$$
\begin{aligned}
& M C_{\text {therm }}=99,958 \cdot \text { Load }^{-0,0374} \\
& M C_{\text {mes }}=104,37 \cdot \text { Load }^{-0,0912}
\end{aligned}
$$

The output of biogas depending on the content of organic dry substance, determined by the formula

$$
\text { Out }=0,2885 \cdot C D^{0,9821}
$$

where (Out - output, $C D$ - content of dry substance).

Based on the above and analyzed material proposed by the authors $[1,2,3,4,5,6]$, a mathematical model of the efficient use of energy of various types of biomass in the global energy economy is substantiated. The formed information and energy network of the fuel and bioenergy balance represents the energy economy in the form of a set of objects of various types that exchange energy flows. The stages of energy flow are represented in the network nodes. The lines connecting the nodes corresponded to the energy flows between the corresponding nodes. Each type of node in the energy balance information network has its own computing unit in the form of a system 
of nonlinear equations. A flowchart of this mathematical model was developed.

\section{Methods and techniques of processing pig manure.}

Methods and techniques of processing pig manure depend on the properties and composition of the raw material, as well as on the purposes of processing and the type of final products.

When choosing methods and techniques of processing pig manure they proceed from a scientifically based system of views, namely:

- pig manure has an energy potential due to the content of organic substances that can give off a significant amount of energy during their mineralization;

- pig manure is an integral part of the natural-natural chain "soil plant - animal - manure - soil", and should be used in this chain with the greatest effect;

- being a residue of processing plant photosynthesis products by animals, pig manure contains a large amount of organic substances, biogenous elements, trace elements, enzymes and vitamins;

- the presence of organic substances makes pig manure an ideal food for soil microflora, the vital activity of which ensures the normal course of biochemical processes in the soil, contributes to the formation of humus and the growth of soil fertility;

- biological features of pig manure exclude the possibility of its direct use as an organic fertilizer and should provide for compliance with sanitary and veterinary requirements;

- the final products of pig manure processing should not contain conditionally pathogenic microflora, worm eggs and their use should not cause diseases of people and animals, accumulation of harmful substances in the soil, lead to secondary weed infestation;

- the content of biogenous substances in pig manure can significantly reduce the use of mineral fertilizers, the production of which requires significant costs of raw materials and energy resources;

- feed application of pig manure should be considered as an auxiliary to the main types of feed, because it contains nutrients that are not absorbed during digestion (due to the physiological characteristics of pig digestion);

- manure processing is an important economic, managemental and environmental task, which should be considered from the point of view of a systematic approach. 
Based on the above, pig manure processing can be carried out in the following recent trends: obtaining organic fertilizer; fuel; feed; for the purpose of destruction or all of the enumerated together (fig. 1.). For this purpose, various methods of manure processing can be used, which can be divided into physical, chemical and biological.

Physical methods include: mechanical, thermal, and electrical [10]. Mechanical methods include a number of methods for processing liquid pig manure, such as settling, centrifugation, and filtration. The presented methods are aimed at dehydrating manure and dividing it into fractions. Methods of dividing pig manure into fractions and dehydrating liquid manure can be divided into natural and mechanical.

Natural separation of liquid manure occurs in horizontal and vertical settling tanks under the influence of the Earth's gravitational field. These equipment is simple, but natural settling of manure does not occur if its humidity is less $90 \%$. The capacity of settling tanks is low. They are also bulky and expensive. Nevertheless, this equipment is used in processing lines for separating livestock effluents.

Mechanical separation of liquid manure into fractions is the main type of separation of livestock effluents in large complexes. It is made using filtering and precipitation machines and apparatuses, the common disadvantage of which is the high humidity of the resulting solid fraction. Of the filter apparatuses and machines, filter-presses and vibrating screens (vibroshaker screens) are the most widely used. Mechanical methods can be considered as auxiliary, because they do not solve the problem of disinfection in the processing of pig manure and are energy-intensive. The resulting liquid and solid fractions require subsequent treatment by biological, chemical or thermal methods.

Thermal methods of manure processing include drying, sharp steam treatment, and evaporation. Drying can be carried out by both low-temperature and high-temperature methods. Low-temperature drying is carried out under natural conditions and allows you to stop the fermentation of manure. This method significantly reduces the humidity of manure without attracting significant energy costs, reduces unpleasant odors, but there is no guarantee of complete disinfection, and during the drying process there are significant losses of valuable components of manure. In recent years the method of dry- 
ing manure in special units under the influence of high temperatures has become widespread. Manure drying plants provide a product that meets sanitary and veterinary requirements, is convenient for transportation and application to the soil. However, the high cost of hightemperature drying is due to the price of fuel and lubricants and high initial costs, which do not allow this method of processing to be widely used.

Treatment with sharp steam is aimed at complete disinfection of manure. This method is energy-intensive and the manure at the outlet has a higher humidity, which is associated with its dilution by steam. The use of this method is possible in relatively narrow production conditions and in the case of outbreak.

The method of heat treatment of manure in autoclaves is used for disinfection of liquid pig manure, but requires a large energy consumption.

The group of electrical methods includes ultrahigh frequency current treatment, electroosmose treatment, electrochemical coagulation, electroflotation, and ultraviolet radiation treatment. These methods are not widely used due to the high cost of equipment, high energy costs and increased requirements for personnel.

One of the types of processing of liquid pig manure is chemical methods]. They prevent contamination and the release of odors into the environment, in addition, some chemical reagents destroy bacteria, including those that give rise to moist aerobic processes accompanied by the release of harmful gases. Chemical methods involve contact treatment with chemicals and are used only for disinfection of manure. A common disadvantage of chemical methods is that they require material and energy costs, as well as chemicals that cause a certain load on the environment. 


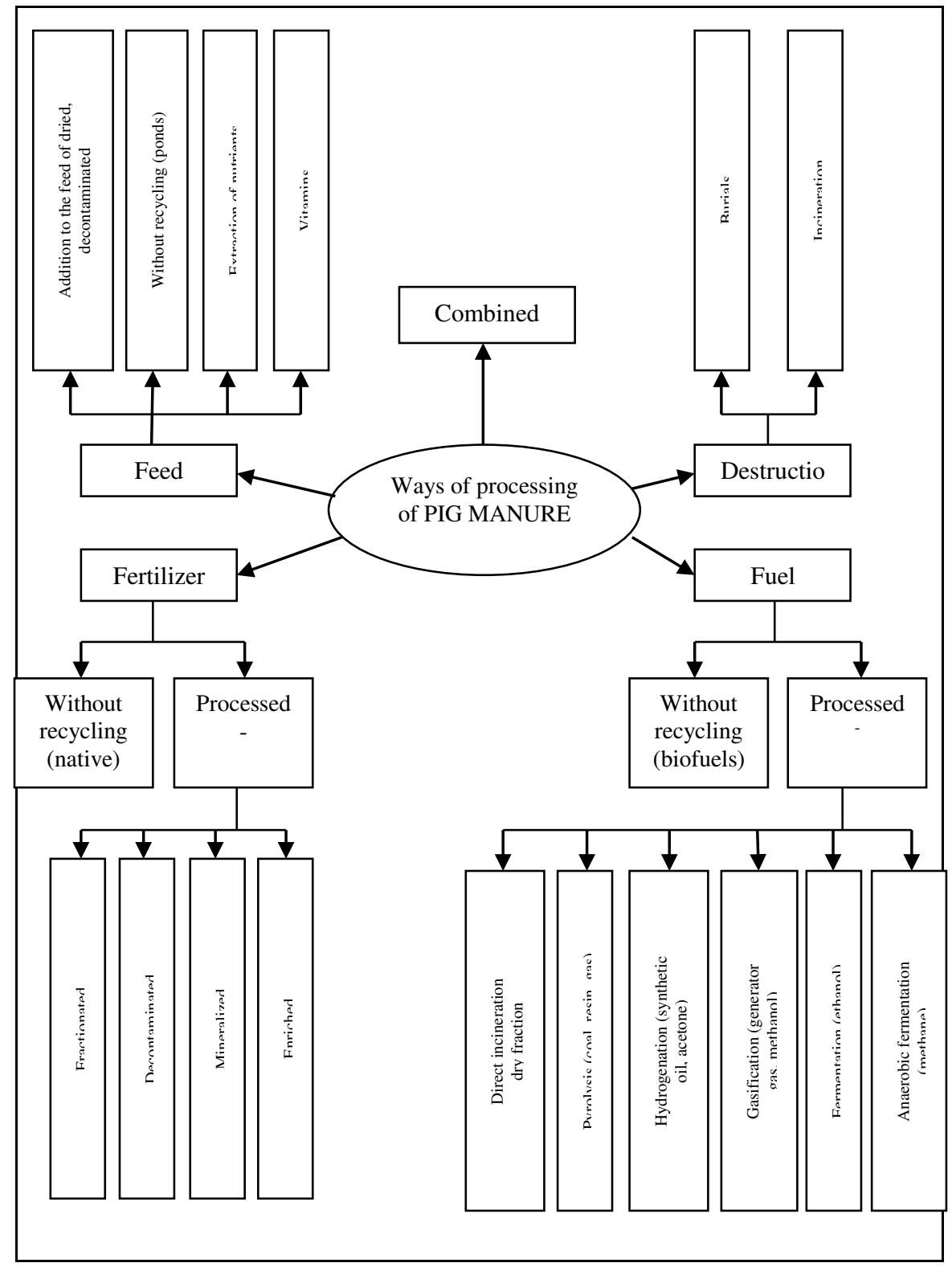

Fig. 1. Ways to process pig manure 
Biological methods are considered a promising area of pig manure processing. Biological methods are based on the biochemical destruction and mineralization of organic substances by microorganisms and are as close as possible to natural processes. At the same time, due to partial decomposition of organic substance, the content of pollution sources in liquid manure decreases, which turn into an insoluble or gaseous form. Biological methods are divided into natural and artificial. Natural methods are based on biochemical processes that occur in natural conditions - biological ponds, lagoons, soil and compost. Artificial methods are based on biochemical processes occurring under artificially created conditions - in aeration tanks, oxide trenches, methane tanks, anaerobic filters and other structures.

Depending on which groups of microorganisms are involved in the process, aerobic and anaerobic methods of biological treatment are distinguished.

Manure composting refers to aerobic biological decomposition processes. Disinfection of manure occurs during its decomposition and heating (up to $60{ }^{\circ} \mathrm{C}$ ) during the vital activity of thermophilic microorganisms. The main disadvantages of this method are the limited use in the climatic zones of the country, the duration of the process, significant losses of nutrients and the required large amount of filler.

The method of processing liquid pig manure in biological ponds has a relatively low processing cost. However, this method is long in time, requires the alienation of significant production areas, and there is a risk of freezing, increased stench, and contamination of ground water.

Aerobic treatment is used to intensify the process of decomposition and deposition of organic mass in pig manure. It occurs by aeration through pumping air from a compressor, or by using mechanical aerators, which, due to intensive mixing of liquid manure, ensure its contact with atmospheric oxygen, which creates favorable conditions for the vital activity of aerobic bacteria. But this method has a number of disadvantages: significant nitrogen losses, complexity and high cost of construction, high operating costs, as well as high energy costs for aeration and continuous mixing.

Anaerobic fermentation is considered a promising method. As a result of the fermentation process, organic substances contained in 
liquid manure undergo decomposition, with the formation of gaseous products in the form of a mixture of methane and carbon dioxide (biogas), [7]. At the same time, it is partially or completely decontaminated, dewormed, deodorized and devitalized. Various bioreactors are used for anaerobic fermentation: methane tanks and anaerobic filters. To ensure the process, it is necessary to maintain the temperature mode, the costs of which can be replenished by disposing of the released biogas. Anaerobic fermentation improves the fertilizing properties of manure as a result of mineralization of biogenous substances, almost without their loss to the environment. The method allows higher load rates than are possible during aerobic treatment, does not require the use of chemical reagents for the decomposition of organic matter; reduces the water-retaining capacity of manure. Anaerobic fermentation is the only method of discussed above that allows not only to cover the energy costs of conducting the process, but also to obtain an excessive amount of it. The resulting energy in the form of biogas is user-friendly, as it can be converted into thermal, electrical and mechanical energy. But this method practically does not reduce the volume and humidity of the treated manure.

Having considered the main methods and techniques of processing pig manure and manure effluents, we can draw the following conclusions:

- no method of processing liquid pig manure can completely solve the problem of disposal, so a combined solution is needed;

- the anaerobic fermentation method most meets the requirements, as it is the closest to natural conditions, which allows to get highquality organic fertilizer and an additional energy source in the form of biogas;

- to increase the efficiency of decomposition of organic matter, it is advisable to separate anaerobic treatment of the liquid and solid phases of pig manure in special bioreactors;

- it is necessary to improve the method of anaerobic treatment of pig manure and effluents. 


\section{The anaerobic treatment process of pig manure.}

Anaerobic treatment is a multi-stage process carried out with the participation of various microorganisms, and proceeds in a certain sequence. There are four interrelated stages: the stage of enzymatic hydrolysis, the stage of acid formation, the acetogenic stage and the methanogenic stage.

Depending on the temperature required for the anaerobic treatment process, the following fermentation modes are distinguished: psychrophilic $\left(10-25^{\circ} \mathrm{c}\right)$, mesophilic $\left(30-35^{\circ} \mathrm{C}\right)$, thermotolerant (40$\left.45^{\circ} \mathrm{C}\right)$ and thermophilic $\left(50-60^{\circ} \mathrm{C}\right)$. Two temperature modes, mesophilic and thermophilic, have found the greatest practical application, while mesophilic is considered less energy-intensive. Also, Davids V. E. points out that the intensity of the process under the mesophilic mode is not inferior to the intensity under the thermophilic mode, and the depth of mineralization of organic substances is greater. This is due to the better formation of the aggregated form of biomass.

Technologies of anaerobic processing of pig manure are classified into three main systems. There are flow-through (continuous) systems with alternating use of reactors (periodic) and a system with gas and sludge accumulation (accumulative), which differ significantly in labor costs, maintenance and servicing requirements, as well as in use.

In the flow-through system, the substrate is loaded into the reactor continuously or after short periods of time, removing the appropriate volume of sludge. The always constant volume of the substrate is calculated in accordance with the time of the mass stay in the reactor specified by hydraulic calculations.

A system with alternating use of reactors is characterized by an intermittent process that occurs in at least two reactors of the same size and shape. In the case of daily loading of fresh substrate, the reactors are filled with fresh substrate when a certain amount of sludge is formed and emptied after the specified fermentation period has elapsed so that only seed sludge remains in them.

The gas and sludge storage system is designed with only one liquid reactor. The latter plays the role of a fermentation chamber and accumulates sludge until it is taken out into the field. Therefore, the reactor is never completely emptied, the remaining sludge serves as an ignition for a new portion of the substrate. With a new cycle of 
operation, the maximum production of biogas is achieved after a significant time has elapsed.

In systems with alternating use of reactors and systems with accumulation of gas and sludge, gas production occurs periodically. In addition, this technology requires an increase in the volume of reactors for processing. Their advantage is that they do not require much attention when operating during the day, and they can be loaded with large waste.

Continuous operation of the reactors ensures gas output throughout the entire period of operation. By ensuring a constant concentration of organic matter capable of fermentation, an optimal fermentation temperature and uniform mixing of the mass, it is possible to obtain the maximum gas yield during a continuous gas formation process. The most effective in operation are horizontal fermenters of continuous action. The raw material entering from one side passes through the "maximum fermentation" zone, where the bacteria have the greatest activity, and then exits from the other end of the structure. In case of unsatisfactory fermentation results, the material can be sent for recycling.

Process schemes of single - stage and two-or multi-stage fermentation have also become widespread. Single-stage fermentation is used in low-load and high-load methane tanks. Low-load reactors have a fermentation time of up to 50 days and operate almost without mixing with little heating, so they have large volumes and high construction costs. High-load reactors are already equipped with good heating and mixing, as well as provide for continuous loading or short intervals between loads. In high-load reactors, sediment and entrapped water do not stratify, and therefore some process schemes provide for the use of second-stage reactors, that is, the transition to two-stage fermentation. Two-and multi-stage fermentation is based on the division into the stage of intensive fermentation with rapid release of biogas (Stage 1) and the stage of process attenuation, at which gas release stops and sediment and entrapped water stratification occurs (Stage 2). In multi-stage fermentation, post-fermentation and stratification are carried out in several successively located tanks. The use of two - and multi-stage fermentation reduces the vol- 
ume of fermented sludge supplied for dehydratation and reduces the cost of building sludge drying beds. However, step-by-step fermentation does not provide significant advantages in terms of biogas yield compared to a single-stage process with equal volumes of methane tanks. In Russia, stage fermentation has not found application, because of the great difficulties of their operation in the formation of a dense pop-up crust and filling of the cone with sand at the second stage.

The main element of any process of anaerobic manure treating is biogas plants of various designs. Biogas plants can be divided into solid-phase (methane tanks) and liquid-phase anaerobic bioreactors (anaerobic filters). Anaerobic treatment in methane tanks is carried out at a humidity of 90-93\% with an exposure of 5-50 days and is traditional for processing solid (dispersed phase) pig manure. The liquid (dispersed) phase obtained after separation has a high humidity of 97-99.5\% and existing solutions provide exclusively for aerobic oxidation, which has significant disadvantages. A promising area for processing the liquid fraction of pig manure is the use of liquid-phase anaerobic filters.

According to the classification given by Danylovych D. A. and Mongait L. I., liquid-phase anaerobic reactors of the second generation can be divided into the following types: anaerobic filters - reactors with an ascending flow (AF-reactor); reactors with a fixed (bio) film and an incident stream (IS-reactor); reactors with an extended (pseudo - liquefied) layer (PS-reactor); hybrid reactors, which are a combination of IS-and AF-reactor designs (ISF-reactor). These structures are most recommended for cleaning high-flow rates of highly concentrated livestock effluents. Analysis of the operation of the reactors showed that the load on PS - reactors can be up to $35 \mathrm{~kg}$ of $\mathrm{COD} / \mathrm{m}^{3}$ a day, they are quite sensitive to the content of suspended particles and the liquefaction of the carrier layer requires repeated recirculation of the treated flow using pumping equipment. At IS reactors with high nitrogen concentrations and complex effluents composition, poor granulation of the musk layer is noted. The AF 
reactor has a load of up to $25-30 \mathrm{~kg} \mathrm{COD} / \mathrm{m}^{3}$ a day, and resistant to cleaning, but has a disadvantage associated with the danger of colmation and the formation of better channels of the duct. The ISF reactor has the lowest load of about $6 \mathrm{~kg} \mathrm{COD} / \mathrm{m}^{3}$ a day. DF-reactor is less whimsical, the risk of colmation is less and the accumulation of suspensions at the bottom of the reactor does not occur, but it shows good performance at loads up to $15-20 \mathrm{~kg} \mathrm{COD} / \mathrm{m}^{3}$ a day and amount of biomass retained is less than in AF. Similarly, compared to $\mathrm{AF}$, the DF-reactor requires careful selection of the loading material. Hardware design research showed that it is advisable to arrange AF reactors in the form of vertical columns with the passage of treated effluents from bottom to top. This ensures the accumulation and maintenance of the required number of microorganisms and facilitates the removal of biogas, while different populations of microorganisms are arranged spatially in a sequence corresponding to the phases of anaerobic fermentation.

Analysis of technologies and equipment for anaerobic processing of pig manure allows us to accept the following conclusions:

- for anaerobic fermentation, the mesophilic fermentation mode and continuous reactor operation mode are more economical;

- of the liquid - phase anaerobic bioreactors, a vertical AF reactor with an upward flow is more used for processing the liquid phase of pig manure and effluents.

The main reason that hinders the use of non-traditional energy sources for energy purposes in Ukraine is that the resulting energy has a high cost, that is, it is relevant to search for processes and solutions that are characterized by low capital and operating costs, as well as low cost of energy products obtained through the production of related products. This is the technology of the anaerobic fermentation process of biomass, which makes it possible to produce fuel gas with a relatively high calorific value, as well as to obtain high-quality fertilizers, due to the implementation of which an additional profit can be obtained. 
The necessary data were determined on the basis of the performed studies of the process of anaerobic fermentation of biomass at the industrial livestock complex of the Zaporizhstal LLC at the existing biogas plant described in. The total number of livestock on the farm is 10,000 pigs.

Based on control measurements, it was found that 68 liters of liquid biomass are generated daily from one livestock. The total volume of biomass is: in the winter season $-75 \mathrm{~m}^{3} /$ day (from 10,000 pigs), in the summer season $-65 \mathrm{~m}^{3} /$ day (from 8050 pigs) [7].

The content of dry matter formed daily from excrement and litter is $6.2-6.3 \mathrm{~kg}$ per pig, and the average content of organic substances is $5 \mathrm{~kg} / \mathrm{pig}$. Taking this into account, the daily produced mass of organic matter is $5500 \mathrm{~kg} / \mathrm{day}$ in the winter season and $4750 \mathrm{~kg} / \mathrm{day}$ in the summer season.

The specific quantity of total biogas attributed to 1 ton of organic matter, according to the results of research, was assumed to be equal to $300 \mathrm{~m}^{3} / \mathrm{t}$ in the winter season.

In the summer season, when only $65 \mathrm{~m}^{3}$ of biomass is collected per day, the projected volume of the chamber allows you to ferment liquid biomass for more than 25 days, and less heat is required to maintain the temperature. Therefore, despite the smaller amount of organic matter, it is possible to obtain a larger amount of commercial gas, that is, $350 \mathrm{~m}^{3}$ from one ton of organic matter.

In the first series of tests, laboratory measurements of the biogas yield and the rate of its formation in the thermal chamber were carried out under mesophilic $\left(35^{\circ} \mathrm{C}\right)$ and thermophilic $\left(55^{\circ} \mathrm{C}\right)$ modes. The duration of the tests was assumed to be 35 days. The amount of dry matter, organic matter content, $\mathrm{pH}$ value, and volume weight were determined in a chemical laboratory.

The total amount of gas released was measured once a day. The measurement results were analyzed every 5 days. Processing of the obtained results was carried out according to generally accepted 
methods. The specific quantity of biogas was determined in liters per $1 \mathrm{~kg}$ of organic matter.

Table 1 shows the characteristics of liquid biomass of livestock used in experimental studies in the mesophilic fermentation mode.

Table 1

Characteristics of liquid livestock biomass in mesophilic fermentation mode

\begin{tabular}{c|c|c|c|c}
\hline Indicators of & \multicolumn{3}{|c|}{ Test number } & \multirow{2}{*}{ Average value } \\
\cline { 2 - 4 } fermented biomass. & 1 & 2 & 3 & 5.3 \\
\hline Volume, L & 6.0 & 5.0 & 5.0 & 0.477 \\
\hline $\begin{array}{c}\text { Dry matter content, } \\
\mathrm{kg}\end{array}$ & 0.582 & 0.425 & 0.425 & 8.9 \\
\hline $\begin{array}{c}\text { Organic matter } \\
\text { content, kg } \\
\%\end{array}$ & 9.7 & 8.5 & 8.5 & 0.383 \\
\hline pH value & 7.8 & 0.340 & 0.340 & 7.2 \\
\hline Volume weight, g / L & 6.8 & 6.8 & 6.8 & - \\
\hline
\end{tabular}

Indicators of liquid biomass used in the study in the thermophilic fermentation mode are shown in Table 2.

Table 2

Characteristics of liquid livestock biomass in thermophilic fermentation mode

\begin{tabular}{c|c|c|c|c}
\hline Indicators of & \multicolumn{3}{|c|}{ Test number } & \multirow{2}{*}{ Average value } \\
\cline { 2 - 4 } fermented biomass & 4 & 5 & 6 & 5.3 \\
\hline Volume, L & 6.0 & 5.0 & 5.0 & \\
\hline Dry matter content, & & & & 0.435 \\
$\mathrm{~kg}$ & 0.454 & 0.425 & 0.425 & 8.2 \\
$\%$ & 7.57 & 8.53 & 8.5 & 0.348 \\
\hline Organic matter & & & & 6.57 \\
content, kg & 0.636 & 0.341 & 0.340 & - \\
$\%$ & 6.1 & 6.82 & 6.80 & 1008 \\
\hline pH value & 7.1 & 6.8 & 7.0 & \\
\hline Volume weight, g/L & 1006 & 1010 & 1018 & \\
\hline
\end{tabular}

Determination of the total biogas yield and gas release rate.

Based on the totality of data obtained as a result of tests conducted at laboratory installations with thermal chambers during periodic fermentation, the amount of biogas formed from liquid livestock biomass was determined. Indicators that characterize the yield of biogas during 35-day fermentation under the mesophilic mode are shown in Table 3. 
Table 3

Indicators that characterize the yield of biogas during 35-day fermentation under the mesophilic mode

\begin{tabular}{c|c|c|c|c|c}
\hline \multirow{2}{*}{$\begin{array}{c}\text { Fermentation } \\
\text { period, days }\end{array}$} & \multicolumn{4}{|c|}{ Amount of biogas released, L } & \multirow{2}{*}{$\begin{array}{c}\text { Amount of gas, } \\
\text { relative to } 1 \mathrm{~kg} \text { of } \\
\text { org. matter, L/kg }\end{array}$} \\
\cline { 2 - 4 } $\begin{array}{c}\text { Ond number } \\
\text { average }\end{array}$ & $\begin{array}{c}|c| \\
\text { Test }\end{array}$ & 2 & 3 & 27.96 & 73.0 \\
\hline 5 & 17.89 & 39.80 & 26.68 & 27.3 & 111.3 \\
\hline 10 & 22.58 & 64.83 & 40.48 & 42.63 & 159.4 \\
\hline 15 & 25.66 & 93.92 & 63.53 & 61.04 & 194.4 \\
\hline 20 & 29.94 & 113.72 & 79.67 & 74.67 & 216.5 \\
\hline 25 & 37.66 & 126.88 & 84.23 & 82.92 & 231.2 \\
\hline 30 & 39.16 & 137.40 & 89.08 & 88.55 & 247.1 \\
\hline 35 & 42.6 & 148.58 & 92.76 & 94.65 & \\
\hline
\end{tabular}

The amount of biogas obtained during 35-day fermentation under the thermophilic mode is shown in Table 4.

Table 4

Indicators that characterize the yield of biogas during 35-day fermentation in thermophilic model

\begin{tabular}{c|c|c|c|c|c}
\hline \multirow{2}{*}{$\begin{array}{c}\text { Fermentation } \\
\text { period, days }\end{array}$} & \multicolumn{4}{|c|}{ Test number } & \multirow{2}{*}{$\begin{array}{c}\text { Amount of } \\
\text { gas, relative } \\
\text { to 1 kg of org. } \\
\text { matter, L/kg }\end{array}$} \\
\cline { 2 - 5 } & 4 & 5 & 6 & On average & 85.6 \\
\hline 5 & 17.64 & 8.81 & 63.16 & 29.87 & 127.6 \\
\hline 10 & 36.30 & 19.43 & 77.47 & 44.40 & 183.5 \\
\hline 15 & 77.30 & 31.08 & 83.24 & 63.37 & 239.4 \\
\hline 20 & 117.78 & 39.11 & 93.8 & 83.32 & 279.1 \\
\hline 25 & 138.04 & 45.95 & 107.34 & 97.11 & 309.2 \\
\hline 30 & 154.78 & 50.17 & 117.87 & 107.60 & 329.5 \\
\hline 35 & 164.72 & 53.26 & 126.09 & 114.69 & \\
\hline
\end{tabular}

When designing a biogas plant for anaerobic processing of liquid biomass, it is necessary to know the change in the rate of gas formation, that is, the amount of gas formed daily from $1 \mathrm{~kg}$ of organic matter. The gas formation rates were obtained as a result of tests performed in mesophilic and thermophilic fermentation modes. Knowledge of the pattern of speed reduction is necessary when choosing the fermentation time.

Taking the amount of gas produced during 35-day fermentation as $100 \%$, we investigated how the amount of gas decreases every 5 days. 
Analyzing the data in Table 6, we can conclude that about $87 \%$ of the amount of biogas formed in 35 days in the mesophilic mode was obtained already on the 25th day of treatment. When the fermentation time increases by 10 days, the amount of gas increases by only $13 \%$. Because the amount of biogas released is affected by the fermentation temperature.

It can be concluded that already on the 25th day, with the thermophilic mode, approximately $30 \%$ more gas is obtained than with the mesophilic one.

Hence, it is necessary that to obtain the same total yield of biogas in the thermophilic mode, a fermentation chamber of a smaller volume would be required than in the mesophilic mode, but due to the higher fermentation temperature, the heat consumption for the process's own needs in the thermophilic mode increases by 1.5 times (as a percentage of the thermal equivalent of the biogas released), while the amount of commercial biogas is almost the same with the mesophilic mode.

Environmental protection as a result of anaerobic biomass treatment is assessed by a decrease in the number of malignant pathogenic bacteria, as well as a change in COC (chemical oxygen consumption). Based on bacteriological studies, the paper determines the dependences of the number of malignant bacteria on the temperature and duration of anaerobic treatment, as well as the values of these parameters, at which the bacterial number during biomass treatment decreases to such a value when the risk of contamination of the environment becomes minimal, this was studied in $[2,3,4,5,6]$.

In addition to laboratory tests, practical observations were made on the intensity of the event during the storage of fermented liquid biomass.

The tasks of the research also included monitoring changes in nutrients in fermented biomass.

Experiences were performed for mesophilic and thermophilic fermentation modes. Liquid biomass samples were taken in a filled chamber and then every 3 days.

Results of studies of bacteriological properties of liquid biomass in the process of its fermentation. 
Both the literature data and our measurements confirm the fact that untreated liquid biomass should be considered a material of malignant bacteria.

Bacteriological studies were conducted on a laboratory machine with a water bath. Liquid biomass sampling are made at the beginning of fermentation, then every 3-4 days, and finally on Day 12 . The bacteriological index was calculated as the arithmetic mean value of the bacteria count: in the mesophilic zone at $30^{\circ} \mathrm{C}$ and $40^{\circ} \mathrm{C}$, in the thermophilic zone - at $55^{\circ} \mathrm{C}$ and $60^{\circ} \mathrm{C}$.

The effect of anaerobic fermentation on the reduction of malignant bacteria was determined by a change in the coliform, streptococcus faccalis bacteria count. In addition, the presence of salmonella was monitored in each sample.

The results of bacteriological studies are shown in Tables 5 and 6 .

Table 5

Results of coliform bacteria study

\begin{tabular}{|c|c|c|c|c|c|c|c|c|}
\hline \multirow{3}{*}{$\begin{array}{l}\text { Fermentat } \\
\text { ion time }\end{array}$} & \multicolumn{8}{|c|}{ Coliform bacteria, U/100 ml. } \\
\hline & \multicolumn{2}{|c|}{ mesophilic mode } & \multirow{2}{*}{$\begin{array}{l}\text { average } \\
\text { value }\end{array}$} & \multirow{2}{*}{$\%$} & \multicolumn{2}{|c|}{ Thermophilic mode } & \multirow{2}{*}{$\begin{array}{l}\text { average } \\
\text { value }\end{array}$} & \multirow{2}{*}{$\%$} \\
\hline & $350 \mathrm{C}$ & $400 \mathrm{C}$ & & & $550 \mathrm{C}$ & $600 \mathrm{C}$ & & \\
\hline 0 & $4.0 \cdot 106$ & $4.0 \cdot 106$ & $4.0 \cdot 106$ & 100 & $9.8 \cdot 106$ & $13.5 \cdot 106$ & $\begin{array}{c}11.6 \cdot 10 \\
6\end{array}$ & 100 \\
\hline 2 & - & - & - & - & $2.0 \cdot 106$ & - & $2.6 \cdot 106$ & 17 \\
\hline 4 & - & - & - & - & - & $1.0 \cdot 105$ & $1.0 \cdot 105$ & 0.8 \\
\hline 6 & $4.0 \cdot 104$ & $3.0 \cdot 104$ & $3.5 \cdot 104$ & 0.88 & $1.0 \cdot 104$ & - & $1.0 \cdot 104$ & 0.08 \\
\hline 8 & $1.0 \cdot 104$ & $1.0 \cdot 104$ & $1.0 \cdot 104$ & - & $8.0 \cdot 103$ & - & $8.0 \cdot 103$ & - \\
\hline 10 & - & - & - & - & $4.1 \cdot 103$ & - & $4.1 \cdot 103$ & - \\
\hline 12 & $1.0 \cdot 103$ & $6.0 \cdot 103$ & $3.5 \cdot 103$ & - & - & - & - & - \\
\hline
\end{tabular}

Table 6

Results of studies of the bacterium streptococcus faccalis

\begin{tabular}{c|c|c|c|c|c|c|c|c}
\hline \multirow{2}{*}{$\begin{array}{c}\text { Fermentation } \\
\text { time }\end{array}$} & \multicolumn{7}{|c|}{ Streptococcus faccalis bacteria, U/100 ml. } \\
\cline { 2 - 9 } & $350 \mathrm{C}$ & $400 \mathrm{C}$ & $\begin{array}{c}\text { average } \\
\text { value }\end{array}$ & $\%$ & $550 \mathrm{C}$ & $600 \mathrm{C}$ & $\begin{array}{c}\text { average } \\
\text { value }\end{array}$ & $\%$ \\
\hline 0 & $2.0 \cdot 106$ & $2.0 \cdot 106$ & $2.0 \cdot 106$ & 100 & $2.0 \cdot 106$ & $2.0 \cdot 106$ & $2.0 \cdot 106$ & 100.0 \\
\hline 4 & - & - & - & - & $5.0 \cdot 103$ & $2.0 \cdot 103$ & $3.0 \cdot 103$ & 0.15 \\
\hline 6 & $8.0 \cdot 104$ & $4.0 \cdot 104$ & $6.5 \cdot 104$ & 3 & $4.0 \cdot 103$ & $4.0 \cdot 102$ & $2.0 \cdot 103$ & - \\
\hline 8 & $2.0 \cdot 104$ & $1.4 \cdot 104$ & $1.7 \cdot 104$ & 0.85 & $3.6 \cdot 103$ & - & - & - \\
\hline 12 & $1.0 \cdot 103$ & $2.0 \cdot 103$ & $1.5 \cdot 103$ & - & - & - & - & - \\
\hline
\end{tabular}

Mathematical processing of experimental data showed that the number of bacteria in the fermentation process varies exponentially. The general form of an adapted dependency has the form 


$$
X=d \cdot e^{-B t}
$$

where $X$ - number of bacteria;

$d$ - regression constant;

$t$ - processing time;

$B$ - calculated coefficient.

As a result of mathematical processing of experimental data the empirical dependences of the bacteria count of coliform on the duration of fermentation were obtained:

- $\quad$ in mesophilic mode

$$
X=4 \cdot 10^{6} \cdot e^{-0,7085 t}
$$

- $\quad$ in thermophilic mode

$$
X=11 \cdot 10^{6} \cdot e^{-0,9896 t}
$$

The dependence of the bacteria count of streptococcus faccalis on the duration of fermentation has the expression:

- $\quad$ in mesophilic mode

$$
y^{\prime}=2 \cdot 10^{6} \cdot e^{-0,5818 \mathrm{t}}
$$

- $\quad$ in thermophilic mode

$$
y^{\prime}=2 \cdot 10^{6} \cdot e^{-1,38105 t}
$$

The decrease in the bacteria count during fermentation is shown in Table 7.

Table 7

The decrease in the bacteria count during

\begin{tabular}{c|c|c|c|c|c|c|c|c}
\hline \multirow{2}{*}{ Bacterial species } & \multicolumn{7}{c}{ Days } \\
\cline { 2 - 9 } & 0 & 2 & 4 & 6 & 8 & 10 & 12 \\
\hline \multirow{2}{*}{ coliform } & $350 \mathrm{C}$ & $4.0 \cdot 106$ & $9.7 \cdot 105$ & $2.3 \cdot 105$ & $5.7 \cdot 104$ & $1.4 \cdot 104$ & $3.3 \cdot 103$ & 812 \\
\cline { 2 - 10 } & $550 \mathrm{C}$ & $11.6 \cdot 106$ & $1.6 \cdot 106$ & $2.2 \cdot 105$ & $3.1 \cdot 104$ & $4.2 \cdot 103$ & 600 & 81 \\
\hline \multirow{2}{*}{$\begin{array}{c}\text { streptococ } \\
\begin{array}{c}\text { cus } \\
\text { faccalis }\end{array}\end{array}$} & $350 \mathrm{C}$ & $2.0 \cdot 106$ & $6.25 \cdot 105$ & $1.96 \cdot 104$ & $1.9 \cdot 104$ & $1.9 \cdot 104$ & $6.0 \cdot 103$ & $1.9 \cdot 103$ \\
\cline { 2 - 9 } & $550 \mathrm{C}$ & $2.0 \cdot 106$ & $1.27 \cdot 105$ & $8.0 \cdot 103$ & 506 & 32 & 3 & - \\
\hline
\end{tabular}

In the thermophilic mode, the decrease in the bacteria count occurs faster than in the mesophilic mode, but in both modes, the number of bacteria in the fermented biomass reaches its minimum value after 12 days of fermentation. Its presence was not detected in samples of liquid biomass contaminated with salmonella after anaerobic treatment.

Results of studies on the fertilizing properties of fermented biomass. 
During the study of the composition of liquid biomass, the content of dry and organic matters, the content of DO (dissolved oxygen), the $\mathrm{pH}$ value, the rate of sediment formation were measured, and the threshold was controlled as described in $[10,11]$.

The percentage change in the studied parameters was calculated using the following formula

$$
P=1-\frac{(100-A) \cdot B}{(100-B) \cdot A}
$$

where $P$ - percentage reduction of the studied parameter, $\%$;

$A$ - percentage of the studied parameter in untreated biomass, $\%$;

$B$ - percentage of the studied parameter in fermented biomass, $\%$.

The studies were conducted with samples treated at four temperature values, the results of the studies are shown in Table 8.

Table 8

The results of the studies

\begin{tabular}{|c|c|c|c|c|c|}
\hline $\begin{array}{l}\text { Mode tempe- } \\
\text { rature }\end{array}$ & $\begin{array}{c}\text { Chara-cteristics of } \\
\text { biomass }\end{array}$ & $\begin{array}{l}\text { Untreated } \\
\text { biomass }\end{array}$ & Ferme-nted biomass & Days & $\begin{array}{l}\text { of fermenta- } \\
\text { tion number }\end{array}$ \\
\hline \multirow{7}{*}{$35^{\circ} \mathrm{C}$} & Dry matter, $\%$ & 3.83 & 3.13 & \multirow{7}{*}{12} & 19 \\
\hline & Organic matter, $\%$ & 2.57 & 2.05 & & 21 \\
\hline & Nitrogen, $\%$ & 0.12 & 0.12 & & 0 \\
\hline & Phosphorus, $\%$ & 0.036 & 0.034 & & 6 \\
\hline & Potassium, $\%$ & 0.037 & 0.036 & & 4 \\
\hline & $\mathrm{pH}$ & 7.2 & 7.3 & & - \\
\hline & $\mathrm{CSA}, \mathrm{mg} / \mathrm{L}$ & 31515 & 17262 & & 55 \\
\hline \multirow{7}{*}{$40^{\circ} \mathrm{C}$} & Dry matter, $\%$ & 1.10 & 0.93 & \multirow{7}{*}{9} & 16 \\
\hline & Organic matter, $\%$ & 0.85 & 0.71 & & 17 \\
\hline & Nitrogen, $\%$ & 0.12 & 0.11 & & 8 \\
\hline & Phosphorus, \% & 0.049 & 0.048 & & 3 \\
\hline & Potassium, $\%$ & 0.032 & 0.030 & & 7 \\
\hline & $\mathrm{pH}$ & 7.1 & 7.1 & & - \\
\hline & $\mathrm{CSA}, \mathrm{mg} / \mathrm{L}$ & 12978 & 84413 & & 37 \\
\hline \multirow{7}{*}{$55^{\circ} \mathrm{C}$} & Dry matter, $\%$ & 5.80 & 4.50 & \multirow{7}{*}{10} & 23 \\
\hline & Organic matter, $\%$ & 4.29 & 3.09 & & 28 \\
\hline & Nitrogen, $\%$ & 0.15 & 0.14 & & 7 \\
\hline & Phosphorus, \% & 0.030 & 0.030 & & 0 \\
\hline & Potassium, $\%$ & 0.051 & 0.049 & & 5 \\
\hline & $\mathrm{pH}$ & 7.1 & 7.4 & & - \\
\hline & $\mathrm{CSA}, \mathrm{mg} / \mathrm{L}$ & 41988 & 26895 & & 38 \\
\hline
\end{tabular}




\begin{tabular}{|c|c|c|c|c|c|}
\hline \multirow{7}{*}{$60^{\circ} \mathrm{C}$} & Dry matter, $\%$ & 2.0 & 1.51 & \multirow{7}{*}{6} & 25 \\
\hline & Organic matter, $\%$ & 1.54 & 1.16 & & 25 \\
\hline & Nitrogen, $\%$ & 0.11 & 0.10 & & 9 \\
\hline & Phosphorus, $\%$ & 0.076 & 0.069 & & 10 \\
\hline & Potassium, $\%$ & 0.040 & 0.038 & & 5 \\
\hline & $\mathrm{pH}$ & 7.2 & 7.2 & & - \\
\hline & $\mathrm{CSA}, \mathrm{mg} / \mathrm{L}$ & 33058 & 22502 & & 47 \\
\hline
\end{tabular}

Content $N^{P K}$ in fresh and fermented liquid biomass (under periodic and continuous modes) is presented in Tables 9 and 10, respectively.

Table 9

Content $\mathrm{N}^{\mathrm{PK}}$ in fresh and fermented liquid biomass under periodic mode

\begin{tabular}{c|c|c|c|c|c|c|c|c|c|c}
\hline $\begin{array}{c}\text { Type of } \\
\text { biomass }\end{array}$ & $\begin{array}{c}\text { Dry } \\
\text { matter, } \\
/ \mathrm{kg}\end{array}$ & $\begin{array}{c}\text { Organic } \\
\text { matters }\end{array}$ & $\mathrm{N}$ & $\mathrm{P}$ & $\mathrm{K}$ & $\mathrm{N}$ & $\mathrm{P}$ & $\mathrm{K}$ & $\begin{array}{c}\text { Total } \\
\text { reage } \\
\mathrm{nts}\end{array}$ \\
\hline \multicolumn{3}{c}{} & \multicolumn{2}{|c|}{$\mathrm{g} / \mathrm{kg}$ of dry matter } & \multicolumn{3}{|c|}{$\mathrm{kg} / \mathrm{m}^{3}$ of liquid bio- } \\
mass
\end{tabular}

Table 10

Content $\mathrm{N}^{\mathrm{PK}}$ in fresh and fermented liquid biomass under continuous mode

\begin{tabular}{|c|c|c|c|c|c|c|c|c|c|}
\hline $\begin{array}{l}\text { Type of } \\
\text { biomass }\end{array}$ & $\begin{array}{c}\text { Dry } \\
\text { matter, g } \\
/ \mathrm{kg}\end{array}$ & $\begin{array}{c}\text { Organic } \\
\text { matters }\end{array}$ & $\mathrm{N}$ & $\mathrm{P}$ & $\mathrm{K}$ & $\mathrm{N}$ & $\mathrm{P}$ & K & $\begin{array}{c}\text { Total } \\
\text { reagents }\end{array}$ \\
\hline & & & \multicolumn{3}{|c|}{$\mathrm{g} / \mathrm{kg}$ of dry matter } & \multicolumn{3}{|c|}{$\begin{array}{c}\mathrm{kg} / \mathrm{m}^{3} \text { of liquid } \\
\text { biomass }\end{array}$} & \\
\hline Fermented & 41 & 690 & 70 & 21 & 39 & $\begin{array}{l}2 . \\
8\end{array}$ & 0.84 & 1.5 & 5.14 \\
\hline
\end{tabular}

Analysis of the study results showed that the decrease in organic matter in liquid biomass is proportional to the fermentation time. Two parameters - biological $\mathrm{BOD}_{5}$ (biochemical oxygen demand for 5 days) and chemical oxygen demand COD were used to quantify organic matter.

The results of reducing the COD value during fermentation are shown in Table 4. After 15 days of fermentation, COD decreases by $40 \%$. The reduction of organic matter and COD value during fermentation, in turn, reduces the harmful impact of liquid biomass on the environment, but the COD value equal to $75 \mathrm{mg} / \mathrm{l}$ provided for by water management standards is not achieved.

\section{General conclusions}


1. This paper analyzes the heat ratios obtained during anaerobic fermentation of biomass with a wide range of methane contained in biogas at different levels of bioreactor loading and under different temperature settings.

2. A mathematical model and algorithm for studying the efficient use of biomass energy in the energy sector of the agro-industrial complex are developed and justified, which make it possible to choose a rational layout of energy equipment, determine the optimal structure of energy resources consumed and the working cost of energy generated.

3. For a more correct assessment of the energy efficiency of an anaerobic reactor, it seems desirable to consider all factors by mass characteristics.

4. Based on the conducted studies, it can be concluded that after fermentation, more than $50 \%$ of the dry matter of liquid biomass deposits within 3 days. The odour of liquid biomass decreases after fermentation, and this is due to the rapid decomposition of primarily biologically unstable compounds (carbon, proteins, etc.). The reduction in odour depends on the fermentation time; as the fermentation time increases, the odour threshold decreases.

\section{List of references used}

1. Kuris Yu. V. Improving heat engineering and process performance of biogas combustion in heat generating equipment: dissertation for the degree of candidate of technical sciences, NUKhT, Kyiv, 2007.

2. Tkachenko S.I., Stepanov D.V., Kryuchkov Ye.M., Kuris Yu.V., Litvishkov I.V. Peculiarities of water heating boiler operation on biogas. / / Fahovy journal "Scientific Journal of the Kyiv Polytechnic Institute", Kyiv - №1. - 2006. - pp. 2529.

3. Kuris Yu. V., Tkachenko S. I. Analysis of the effectiveness of the global energy and environmental use of biomass // Professional Journal "Industrial Electricity". Kyiv, - № 5. - 2008. - pp. 35-41.

4. Kuris Yu.V., Kryuchkov E. N. Analysis of the energy balance of production-livestock complex of PJSC "Zaporizhstal" using a bioenergy plant // Collection of conferences "Biotechnology: Education, Science" - NTU KPI. - 2003. pp. 141143.

5. Kuris Yu.V., Tkachenko S. I. Systematization of the World Energy and Environmental Use of Biomass. // Specialized Journal "Energy News.", Kyiv, - № 1. 2009. - pp. 19-27.

6. Kuris Yu.V., Levitskaya I. N. The study of biogas production during anaerobic digestion of carbohydrates, fats and proteins // Proceedings of the interuniversi- 
ty scientific conference ZSEA "Modern environmental problems - IV" - Zaporozhye, - 2008. - pp. 37-39.

7. Kuris Yu.V., Yarmosh V.V., Olshansky S. N., Litvishkov I. V. General characteristics of methanogenesis and justification of technological schemes of biogas production. // Specialized Journal "Power Engineering and Electrification." Kyiv, - № 3. - 2009. - pp. 52-60.

8. Avksentieva A.P., Kuris Yu.V. A study on influence of biogas composition on harmul impurites emissions. Polish journal of science, 2021, №38, pp. 34-38.

9. Avksentieva A.P., Kuris Yu.V. Research on technology and methods for utilization of biogas. SWorld Journal, 2020, №38, pp. 12-18.

10. Agricultural biotechnology: textbook / B.C. Shevelukha, E. A. Kalashnikova, E. S. Voronin et al., edited by V.S. Shevelukha - $2^{\text {nd }}$ ed., revised and enlarged - Moscow: Vyssh. Shk., 2003. - 469p. il.

11. Skorokhodov A. N. General methodology of modeling process solutions and hardware and software for their implementation according to the criteria of energy and resource saving// Bulletin of the MSAU federal state educational institution of higher professional education. No. 4, 2005, pp. 56-61.

12. Kuris Yu. V., Tkachenko S. I. Description of the calculation of heat loss of a biogas plant / / Professional magazine "Power and electrification" Kuris Yu. V., Stepanov D. V., Tkachenko S. I., Khazhmuradov M. A., Karnatsevich L. V. Increasing the efficiency of further use and burning of biogas: "Achievements and prospects». // Professional magazine "Power and electrification". Kiev, No. 12, 2006, pp. 67-79.

13. Martyniuk A.A. Technical stability in dynamics. Kiev: Technika, 1973. $188 \mathrm{p}$.

14. Kuris Yu. V., Kriuchkov E. N. Analysis of the energy balance of the production and livestock complex of Zaporizhstal CJSC with the use of a bio - energy installation // The conference proceedings "Biotechnology: Education, Science", NTU KPI. - 2003. pp. 141-143.

15. Kuris Yu. V., Kriuchkov E. N., Shinkarenko L. M. Economic and ecological areas of using biotechnological methods in the environment. // The conference proceedings "Pont Evksinsky III", - Sevastopol, - No. 1. - 2003. - pp. 27-30.

16. Kuris Yu. V. Advantages of biotechnologies in solving energy issues. // Proceedings of the anniversary XXX international scientific and technical conference "Zaporizhstal XXX". - Zaporozhie: Zaporizhstal. 2003, pp. 53-57.

17. Kuris Yu. V., Maistrenko A. Yu., Tkachenko S. I. Systematization of biogas plant schemes and optimization of energy efficiency in works of an anaerobic reactor // Professional magazine "Power and electrification". Kiev, - No. 8. - 2008. pp. 31-39.

18. Kuris Yu. V., Tkachenko S. I. Analysis of the efficiency of global energy and environmental use of biomass // Professional magazine "Power Generating Industry". 4. Kiev, - No. 5. - 2008. - pp. 35-41. 
https://doi.org/10.31713/m1121

\title{
MACHINES AND EQUIPMENT FOR THE ARRANGEMENT OF RECESS FOR FOUNDATIONS OF QUICKLY INSTALLED TECHNOLOGICAL MINING FACILITIES WITHOUT DIGGING
}

\author{
V.I. Panteleienko \\ $\mathrm{PhD}$ (Engineering), Associate Professor State Higher Educational \\ Institution "Prydniprovska State Academy \\ of Civil Engineering and Architecture", Ukraine \\ S.O. Karpushyn \\ $\mathrm{PhD}$ (Engineering), Associate Professor Central Ukrainian National \\ Technical University, Ukraine
}

\begin{abstract}
Annotation.
In construction practice, for the construction of foundations without excavation and formwork, the methods of ramming and stamping of the soil base can be successfully used. Under ramming means the formation of a depression by directional dropping from a certain height of the rammer, which has the shape of a future depression, and under stamping, the formation of a depression by driving a template stamp to the required depth and then removing it from the ground. The resulting recess is filled with concrete directly or a prefabricated element is installed in it. The use of these methods makes it possible to reduce (by 3...6 times) the volume of earthworks in comparison with the traditional methods of construction of foundation pits. The presence of a compacted zone at the base and around the sidewalls of the recess can significantly reduce the size of the foundations and reduce the consumption of concrete by $1,2 \ldots 2$ times, and reinforcement - by 1,4...4 times. To increase the bearing capacity of the upper soil layers and in order to eliminate the effect of frost heaving of the soil into the walls and bottom of the deepening, waste from the mine, mining and processing industry is rammed in separate portions in the form of crushed stone, sand and gravel mixture, coarse sand, screening and other materials. The energy and number of strokes of the stamp are determined by the required depth of the deepening and the type of soil.

The questions of the rational shape and size of dies, technical and technological parameters of machines and equipment for the installation of recesses for the foundations of rapidly erected technological mine structures, taking into account the technogenic local soil bases and "waste" rocks, remain open.

Below is a description and analysis of methods for constructing recesses for foundations without excavation, the results of research and the creation of highly efficient working equipment are given. Recommendations are given on the choice of the parameters of the working equipment for the formation of depressions in the base with a seal.
\end{abstract}




\section{Problem statement and task formation.}

The technological complexes of mines and metallurgical enterprises in various combinations include buildings: heating installations, ventilation installations, electrical substations, crushing and screening complex, compressor installations, repair, electromechanical workshops, workshops, etc. [1].

Among them, one can conditionally distinguish:

- the main buildings and structures that are directly related to the technology of mining and distribution of minerals;

- auxiliary - not directly involved in the technological scheme of the movement of fossils. As a rule, these are one-story fast-assembly buildings.

One of the possible ways to improve the process of setting up foundations for mine objects is the use of the processes of stamping, ramming-out trenches, pits, various deepenings for free-standing foundations, for example, under the shop columns, as well as the implementation of thin-walled spatial reinforced concrete foundation shells into the upper layers of the soil. [2-5].

Not sufficiently studied, at this stage, are the processes of ramming and stamping of technogenic soil bases with significant inclusions of minerals themselves, as well as "waste" rock.

This study provides an analytical review of methods, machines and their working bodies existing in construction practice for local shaping compaction in order to intensify the process of erecting the zero cycle of the above-mentioned buildings and structures.

\section{Methods for constructing recesses for foundations and equipment used}

Installation of foundations in rammed recesses.

The foundations that compact the soil include driven prismatic, pyramidal piles; downtrodden blocks; rammed piles in drilled holes; vibro-stamped piles, etc. The most promising for rapidly erected technological buildings and structures of mine facilities are foundations in rammed or stamped depressions [6-10]. The device of recesses is carried out after the planning of the built-up area by cutting or adding soil from the level of the base of the floor. The ramming of the depressions is carried out by a rammer falling from a height of 4$8 \mathrm{~m}$ along a guide bar, which has the shape of a future foundation and a mass of 1,5-7 tons, stamping of depressions for small sizes of 
foundations and loads on them is carried out by driving a ramtemplate with its subsequent extraction [11-14].

After ramming or stamping, monolithic concrete is poured into the recess (without formwork) or a prefabricated foundation is installed, which has a shape and size close to the recess. The load from the foundations in rammed depressions is transferred to the soil of the compacted zone (Fig.1), thereby reducing the deformation of the soil from the load of the foundations, and the settlement of foundations from the load when the soil is soaked usually does not exceed $2-6 \mathrm{~cm}$. The settlement of the foundation in the depressions can be significantly reduced (1,5-3 times) by means of a broadened base (see Fig.16).

To create a widened base, hard material is rammed into the bottom of the finished pit with the same rammer: technological "empty" detrital rock, crushed stone, gravel, coarse sand, hard concrete, etc. This operation is performed, as a rule, immediately after ramming of the recess without changing the position of the mechanism and the guide rod.

Ramping of hard material into the bottom of the recess is carried out by dropping the rammer from a height of 4-8 $\mathrm{m}$. When the soil falls from the walls of the pit, the height of the ramming is reduced to 3-4 m.

An increase in the bearing capacity of foundations in rammed recesses is achieved by increasing the depth, as well as by arranging an expanded zone in the lower and upper parts of the foundation. Depending on the method of increasing the bearing capacity, foundations in rammed and stamped depressions are divided into the following: without a broadened base with a flat (see Fig.1a) or pointed sole, performed without ramming hard soil material into the bottom of the completed recess; with a widened base, obtained by ramming into the lower part of the deepening with separate portions of soil material "waste" rock, crushed stone, gravel, sand and gravel mixture, slag, coarse sand, etc. (see Fig.16); with a bearing a layer created by the formation of several depressions (two to four), filled with a rigid soil material, with its compaction with the same rammer and the subsequent formation of another recess between them for a foundation with a widened base (see Fig.18). 

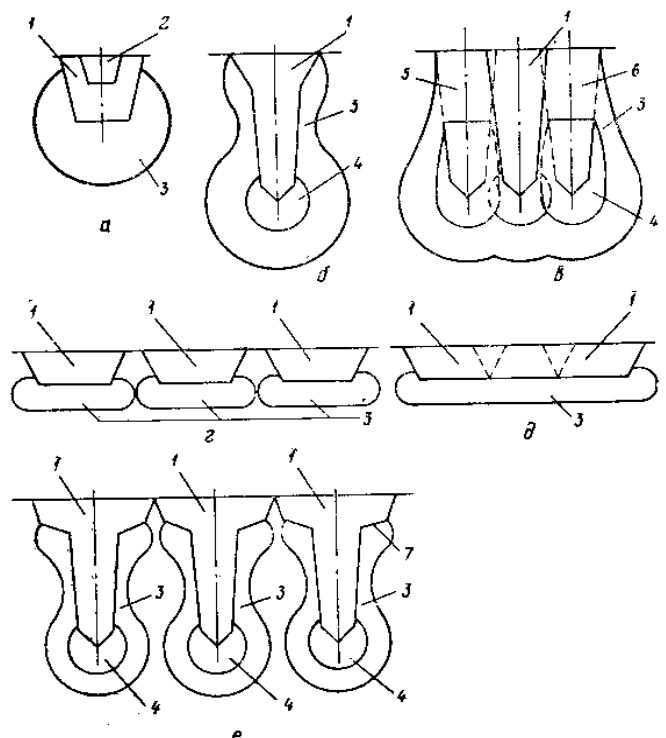

Fig. 1. Types of foundations in rammed recesses: $a$ - without a broadened base; $\sigma$ - with a broadened base; $\beta$ - with a bearing layer; $\Gamma$ - tape intermittent; $\partial$ - solid tape; $e$ - tape arched; 1 - foundation; 2 - glass for installing the column; 3 compacted area; 4 - rammed hard material; 5,6 - pits to create a broadened base; 7 consoles of soil from the walls of the pit, the height of the rammer dropping is reduced to $3-4 \mathrm{~m}$

According to their relative position and the nature of their interaction with the ground, foundations are divided into the following: stand-alone (columnar), which do not affect each other both during the formation of a depression and during the transfer of the payload from buildings to the ground; intermittent tape (see Fig.12), arranged in depressions closely spaced from each other, taking into account the mutual influence of neighboring foundations during the formation of a recess and during the operation of foundations with base soils; continuous tape (see Fig.1d), made with overlapping ramming traces; continuous arched (see Fig.1e), made by ramming with consoles-slats in the upper part.

Equipment for ramming recesses. The ramming of the recesses is carried out using attachments, consisting of a rammer, a guide rod or frame, which ensure that the rammer falls exactly in the same place, and a carriage, with which the rammer slides along the guide rod. 
Attachments are attached to a crane excavator or tractor. When forming small-sized recesses in the plan, piling equipment can be used.

For lifting and dropping the rammer, a hoisting mechanism winch is used; when using a pile driving unit, a template stamp is driven into the ground with a pile driving hammer.

The most convenient and productive attachments are attached to the excavator-crane, which has a friction winch and in this regard, provides lifting and dumping of the rammer. In this case, the type of excavator-crane is selected taking into account that its carrying capacity is 2,5-4 times greater than the mass of the rammer. When this condition is met, the normal operation of the excavator-crane is ensured during the movement and ramming of the depressions and its wear is practically excluded.

Equipment based on a crane excavator. Attachments to the excavator-crane can be of two types: with a hinged guide rod to the crane boom (Fig.2a), providing work with a rammer weighing 3-6 tons, and hinged fastening of the guide frame to the shovel boom (see Fig.26) for rammers weighing 6-10 tons.

The guide frame (see Fig.26) consists of a guide post with a length of $10-15 \mathrm{~m}$ and a spacer that increases the rigidity of the attachment and limits the boom reach, which improves maneuverability and more fully utilizes the lifting capacity of the excavator-crane.
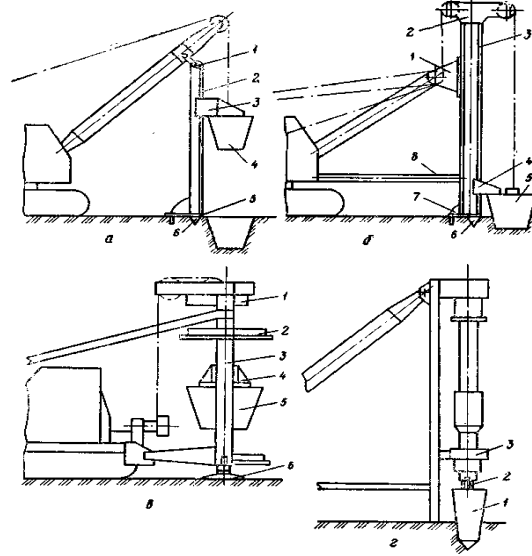

Fig. 2 - Equipment for ramming recesses:

$a$ - on the basis of an excavator with a dragline boom: 1 - hinge; 2 guide rod; 3 - carriage; 4 - rammer; 5 base plate; 6 - teeth;

$\sigma$ - on the basis of an excavator with a straight shovel: 1 - earring; 2 head; 3 - guide post; 4 - carriage; 5 rammers; 6 - teeth; 7 - base plate; 8 spacer.

6 - on the basis of the tractor: 1 head; 2 - stiffening element; 3 - guide frame; 4 - carriage; 5 - rammer; 6 base plate;

2 - on the basis of piling

equipment: 1 - ramming template; 2 - suspension; 3 - hammer 
The rammer (Fig. 3) is made of a metal sheet 10-16 mm thick by welding individual elements at the joints. On top of the rammer has a cover made of a sheet $20-30 \mathrm{~mm}$ thick with bolts with a diameter of $30-60 \mathrm{~mm}$, with which the carriage is attached to it. The inner part of the rammer is filled with concrete to a height at which its specified mass is provided.

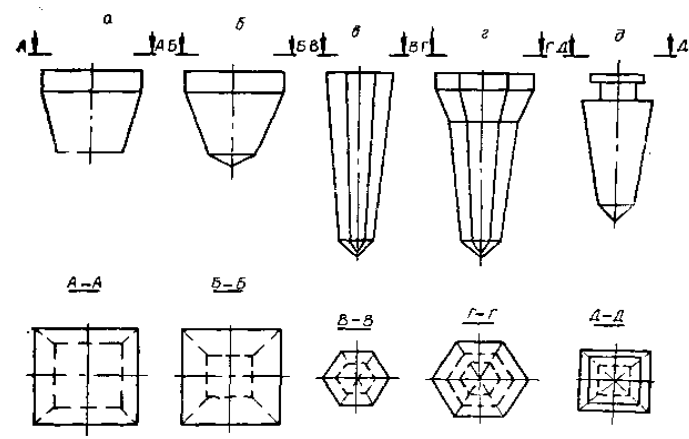

Fig. 3. The main types of rammers for ramming recesses: $a$ - with a flat sole; $\sigma$ with a pointed sole; $\boldsymbol{\theta}$ - elongated for the construction of foundations with a widened base; 2 - the same, with a broadened upper part; $\partial$ - for ramming using pile driving equipment

Tractor-based equipment. Attachments based on tractors provide the ability to work with rammers weighing 2,5-3 tons and consists (see Fig.26) of a guide frame attached to the rear of the tractor; block systems; pendants; counterweight installed at the front.

Equipment based on a pile driving unit. When using a pile driving unit for punching depressions, a hollow metal stamp-template is used as a working body, rigidly fixed with bolts on a hammer (see Fig.22) or attached to it using rope suspensions. Maximum stamp size at the top in width when using tubular diesel hammers should be no more than $1 \mathrm{~m}$, and rod $-0,9 \mathrm{~m}$. The immersion depth is $1,5-2,5 \mathrm{~m}$.

Crane-based attachments. The equipment is hung on a crane boom with an articulated guide bar suspension. Crawler cranes and pneumatic-wheeled cranes are usually used to ram the recesses. The guide bar to the crane is usually the same design as the bar to the lattice boom excavator.

A review of the methods for the formation of depressions by soil compaction and the equipment used in this case shows that when 
ramming depressions for foundations without a broadened base, rammers are used with a height of 1-2 $\mathrm{m}, 0,7-1,8 \mathrm{~m}$ at the top, 0,4$1,4 \mathrm{~m}$ at the bottom, and for foundations with a broadened base - a height of 1,5-3,5 m, a size at the top of $0,6-1,2 \mathrm{~m}$, at the bottom of 0,4-1 $\mathrm{m}$ with a pointed angle of $60-90^{\circ}$ the lower end, often with broadening in the upper part.

When stamping recesses, a template is used with a size in the upper part of 0,9-1 $\mathrm{m}$ at a depth of immersion of 1,5-2,5 $\mathrm{m}$. The choice of methods and type of working equipment is mainly determined by the size of the recess, soil conditions and dynamic impacts on closely located buildings and structures.

Analysis of scientific and technical solutions in the field of improving equipment for the formation of recesses in the ground.

Analysis of scientific and technical information, inventions and patents allows us to speak about the variety of design solutions for working equipment and working bodies aimed at ensuring the effectiveness of the formation of depressions by soil compaction. This problem is solved in various ways, for example, by reducing the breakout force of the working body, increasing the duration of the shock pulse, increasing the specific shock load, increasing the reliability of the gripper, using special and universal working bodies.

Installation for ramming individual recesses (Pat. № 1098996). The device is mounted on a base vehicle - a single-axle tractor (Fig.4a) with a semitrailer chassis, on which a guide mast 4 and a pivot frame 6 are pivotally attached, connected to the chassis by means of a power cylinder 1. By means of a device 5, mount mounted on the swing frame, it is quickly connected to the guide mast. In addition, the guide mast is equipped with a lock 7 for attaching the tamper lifting mechanism 2 to the rope 3 during the installation of the device in the working position and transportation. The latch 10 ensures reliable fastening of the guide mast to the chassis during transportation of the device.

At the place of work, the device is transferred from the transport position (dash-dot image) to the working one. To do this, the fixator 10 is removed from the corresponding hole in the chassis, after which, by turning on the tamper lifting mechanism, the guide mast is lifted until it takes a vertical position. With the help of the device 5, 
the guide mast is attached to the rotary frame 6 . The fixator 7 is disconnected from the rope and a rammer, movably installed on the guide mast, is suspended from the latter. By switching on the power cylinder 1, they provide precise guidance of the rammer. After that, with the help of the power cylinders 8 , the load taken by the guide mast through the base plate 9 is transferred to the ground.

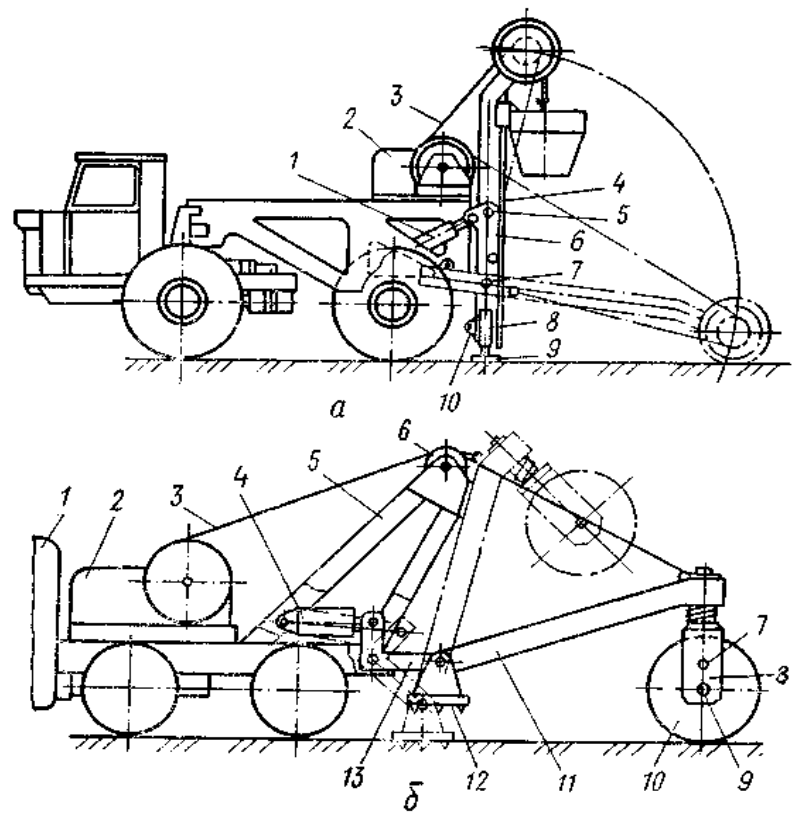

Fig. 4. Installations for ramming: $a$ - separate recesses; $\sigma$ - continuous recesses

Installation for ramming linear-extended and continuous recesses (Pat. № 1151643). On the base machine 1 (Fig.46), the mast 11 is mounted, connected to a stamp 10. To change the tilt of the mast, to set it in the working or transport position, on the base machine there is a mechanism 2. The rammer is installed on the axis $9 \mathrm{P}$-shaped traverse 8 , in the upper part of which there is a ball joint with a pivot (not shown in the figure), connected to the mast. The traverse 8 is equipped with fixing elements 7 to prevent the rammer from turning during operation, removable during transportation. The lifting and dropping of the tram is carried out with the help of the traction rope 3 , passing through the branch block 6 located in the upper part of the 
bracket 5 . The mast, connected by the traction rope with the mechanism 2, is installed on the support platform 12, which is connected to those mounted on the base machine with two-arm levers 13, equipped with a swing drive, for example, hydraulic power cylinders 4.

With the help of mechanism 2, the mast with a rammer is lifted to the extreme upper position and dropped into the place of ramming to formthe recess for the foundation accurately. To move the installation to a new place of work, the support platform 12 and the rammer are raised above the ground.

When ramming depressions for tape foundations, to eliminate at the bottom of the deepening of the soil ridges between the ramming zones, the rammer is lowered into the depression (with the support platform raised) and by moving the installation along the tape foundation, these ridges are removed, using the ram as a static roller

In the same way, the unit can compact the bottom of trenches which were made without it.

Working element for ramming continuous cantilever recesses (Pat. No. 817137).

The device consists of a rammer 1 (Fig.5a) with hollow cantilever elements 2 , symmetrically located relative to the vertical axis, having the shape of semi-arches and a radially decreasing cross-section. The device has guides made in the form of racks 3 and blocks 4 for a hoisting rope. The mass of the rammer is $15-20$ times the weight of the cantilever elements. The device allows you to obtain a continuous recess of the arched shape.

Working body for ramming continuous recesses with an inertial element (Pat. № 1067140). The device consists of a rammer 5 (see Fig.56) and an inertial element 3, which through an adapter 4 is rigidly attached to the upper end of the rammer coaxially with it. Guide rails 1 and devices 2 for connection with a vertical movement drive are mounted on an inertial element, the mass of which exceeds 15-20 times the mass of the rammer connected to it. The hollow rammer is made in the form of an elongated trapezoidal prism with a side slope of 1:10-1:20 and a large base upward. The ratio of the rammer width to its height in the middle of its height is not less than 0,7 , and to the length is in the range of $0,15-0,2$. 


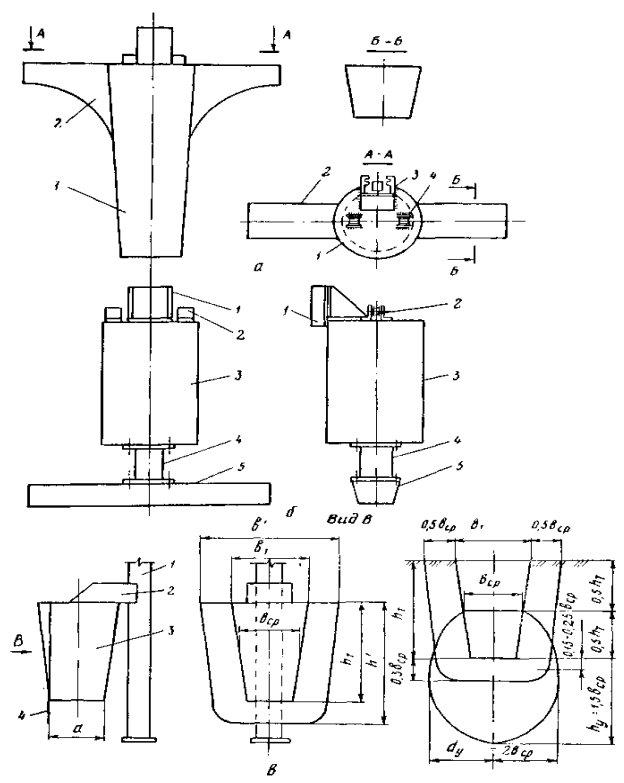

Fig. 5. Devices for ramming continuous recesses: $a$ - with cantilever elements; $\sigma$ - with an inertial element; 8 - with a flat element

The adapter 4 serves to increase the depth of ramming of a continuous recess or trench and has a tubular or box-shaped section, the diameter or width of which is less than the width of the upper end of the rammer.

After installing the device in its original position using a vertical movement drive (not shown in the figure), the rammer is periodically raised to the design height and dropped along the guides. In this case, continuous grooves or trenches are rammed in such a way that half the distance between adjacent ramming points (positions of the device's center of gravity) is $5 \ldots 10 \mathrm{~cm}$ less than the distance in plan from the ramming center to its edges.

Working body for ramming continuous recesses with a flat element (Pat. № 1153006). The device consists (see Fig.5в) of a guide rod 1, a carriage 2 and a rammer 3 with a flat element 4 . When ramming, the guide rod is installed, the ram is lifted and dropped until a deepening of the design depth is obtained. For ramming a continuous recess, the guide rod 1 is moved by the value of the 
ramming step and the lifting and dropping of the rammer is repeated, while the first element which is immersed in the soil is flat element 4, which fixes the direction of movement of the lower part of the rammer 3 and limits the movement of the compacted soil to rammed recess. A flat element has a width $b=h+h_{c p} / 2$. The device makes it possible to obtain both a separate and a continuous recess, which has a rectangular shape in the vertical plane.

Working element for ramming recesses with moulded casings (Pat. № 1046463). The device (Fig.6a) is installed on the base machine (not shown in the figure) with a vertical guide bar 6, a step rammer 5 is connected to the guide bar with the possibility of free movement and interaction with the stop resting on the ground. The stop consists of several hollow casings 1,2 nested one inside the other.

The hollow casing in vertical section has the shape of an inverted truncated cone, and in plan it can be round, square, rectangular, etc. Each casing is equipped with rigid supporting elements 4.

The rammer consists of several staggered sections. The shape of each section corresponds to the internal dimensions of the casing interacting with it.

Along the axis of the future foundation, hollow casings 1,2,3 are installed one into the other and they begin to ram the recess. After immersion in the ground of the first casing 3, its upper support element abuts against the lower element of the casing 2, and then both casings are immersed simultaneously. Then the next casing 1 is connected in the same way. The recess is concreted in parts. Having laid the first portion of concrete 8, they begin to remove the lower casing, applying a dynamic (vibration) and upward static load to it at the same time. Extraction is carried out, for example, using a vibration gripper 7 , the ends of which are inserted into special grooves of the upper supporting element 4 of the removable casing. The vertical force $P$ is created by any lifting mechanism. The following sections are concreted in the same way. 


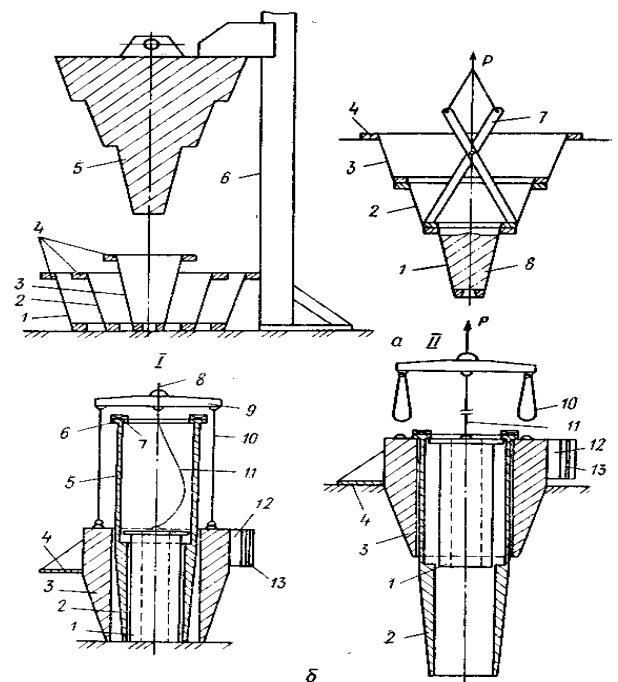

Fig. 6. Devices for ramming recesses: $a$ - with moulded casings; $\sigma$ - with multimass working body I - initial state; II - removal of the working body

Working element for ramming recesses with multi-mass working body (Pat. № 1090801). The working body includes a central impact mass 1 (see Fig.66) with a through hole for air outlet and a flange protrusion. An eyelet is attached to the upper end of the central shock mass. Mass 1 is covered by an intermediate shock mass 2, which is made in the form of a hollow truncated cone. Mass 2 has on a large base guides 5 of cantilever flange protrusions 6 , at the end sections of which stops 7 are installed on the inner side. External shock mass 3 , which is made in the form of a hollow truncated pyramid with a large base directed upwards, is installed coaxially with respect to mass 2 . Mass 3 is equipped with three cantilever support platforms 4 with stiffeners. The lugs and the carriage 12 with grooves 13 are attached to the shock mass 3 . The gripper 9 has a traction rope 8 and slings 10 , connected to the lugs by means of hooks with carabiners, as well as a flexible connection 11, which is attached to the lug of the central mass.

The working body is mounted on the guide bar of the attachment of the base hoisting machine and is attached to the traction rope 8 of the winch through the gripper 9 (the guide bar and the base hoisting 
machine are not shown). The tractive effort by means of slings 10 is transmitted to the external shock mass 3 with the carriage 12, which slides with grooves 13 along the guide rod, and the inner surface of the mass 3 along the cantilever guide 5. When moving upwards, the mass 3 reaches the end of the cantilever guide 5, abuts against the flange protrusion 6 and raises the intermediate shock mass 2 . When the intermediate mass abuts against the flange protrusion, the rise of the central shock mass 1 begins. The length of the flexible connection is chosen so that when the working body is lifted, traction force is not transmitted to it.

Having raised the working body to the required height above the ground level, it is dropped in a directed manner. First, the central mass 1 interacts with the soil, then the intermediate mass 2 and the outer mass 3.

A series of blows by the working body leads to the formation of a recess with a broadened upper part in the form of a truncated pyramid, while masses 1 and 2 ram the main part of the recess, and mass 3 forms a broadening. Masses 1 and 2 make up $70 \%$ of the total mass of the working body, and therefore the rate of penetration of the main part of the deepening exceeds the rate of penetration of the broadening. The maximum broadening depth is limited by the cantilever support pads 4 , i.e. when the support pads begin to interact with the ground surface, further deepening of the outer mass stops.

Equipment for ramming recesses with rotary motion of inertial masses (Pat. № 742528). The working body consists of a body 2 (Fig.7a) with a cavity and a bottom 1 and grooves 5 for directed movement, a rod 6 with inertial masses 3 and 4 and a thrust nut, an eyelet for fastening a hoisting rope. The bar 6 and the inertial masses 3 and 4 are equipped with screw guides, made along the right and left screw lines, respectively. The masses 3 and 4 are interconnected by flexible ties, and the mass 3 has thrust protrusions 7 in the form of hemispheres. 

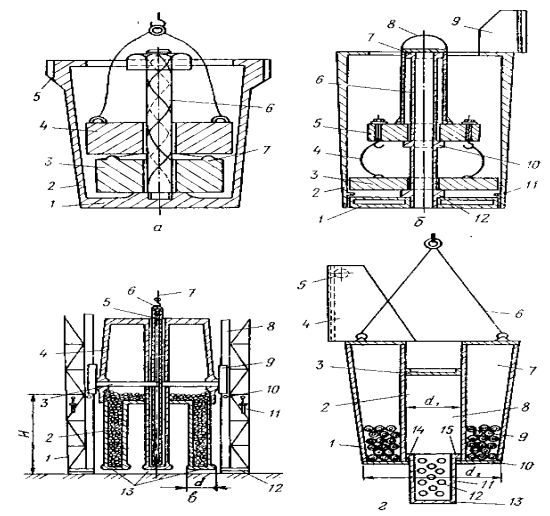

Fig. 7. Equipment for ramming recesses: $a$ - with rotary motion of inertial masses; $\sigma$ - with inertial masses and a movable bottom; 6 - with shock glasses; 2 with metal ballast

Using the winch of the base machine (not shown in the figure) by means of a rope fixed to the lugs of the inertial mass 4 , the working body is raised to a certain height. When lifting, the mass 4 moves along the screw guides along the rod 6 until it rests against its top edge against the thrust nut. Mass 4 is connected to mass 3 by flexible connections, therefore, simultaneously with the rise of mass 4 , the mass 3 rises, which also moves along helical guides.

Screw guides on the rod, as well as guides of inertial masses are made with a large helix rise angle equal to $70-88^{\circ}$, which excludes self-braking. For the perception of dynamic loads, the guides are trapezoidal. The length of flexible links is selected so as not to impede the movement of inertial masses both during the impact period and during their rise.

Having raised the working body to the required height, it is directed to the ground. During the period of free fall of the device, inertial masses are in the extreme position relative to the level of the bottom surface. Upon impact, the body with the bottom and the rod 6 rigidly connected to them are decelerated. However, under the action of inertial forces, the masses 3 and 4 continue to move downward in the direction of the impact, interact with the rod and thereby lengthen the contact time, creating optimal conditions for maximum penetration of the working body into soil. 
The stability of the plane-parallel movement of the working body during penetration into the ground is ensured by the fact that the inertial masses make a rotational movement. The sum of the moments of inertial masses relative to the axis of rotation is equal in magnitude and opposite in sign, which prevents reactive rotation of the body with the bottom and ensures that the conditions for the equilibrium of the system are met.

Equipment for ramming recesses with inertial masses and a movable bottom (Pat. № 1084366). The working body includes (see Fig.76) a hollow body 2 with a movably installed bottom 1, connected to the central rod 6 , inertial masses 3 and 5 , connected by flexible ties 4 , and a gripper 8 connected to the central rod 6 The projections $7,10,12$ are made along the height of the rod, between which inertial masses are placed, and the distance between the upper projections 7 and 10 exceeds the distance between the lower projections 10 and 12 . The body is rigidly connected to the carriage 9 and has a stopper 11 for interaction with the lower inertial mass. weight 3. The upper plane of the stopper is located above the level of the lower annular protrusion of the central rod.

The body with the carriage is lifted along a guide post mounted on the boom of the basic hoisting machine (not shown in the figure). In this case, the inertial masses are in the upper position, the flexible connections 4, with the help of which the lower inertial mass 3 is suspended, are in a stressed state. The body in a suspended state rests through the upper protrusion 7 of the central rod 6 on the upper inertial mass, which is lifted on the gripper 8 .

When dropping the working body, the movable bottom 1 first touches the compacted soil, then the lower inertial mass 3 is switched on, which, hitting the lower protrusion 12 of the central rod, acts on the bottom, increasing the pulse duration. Due to the difference in the distances between the projections 7 and 10, 12 and 10, the inertial mass 5 comes into operation later than all. It transfers the impact energy to the ground through the movable bottom, which receives the impact through the projection 10 of the central rod, after which the cycle is repeated.

Equipment for ramming recesses with shock cups (Pat. № 791843). The attachment contains (see Fig.78) a guiding space truss 1 , pivotally connected to the boom of the base machine (not shown 
in the figure), and a working body made in the form of a hollow body 4 , which is a truncated cone or pyramid. The large base of the body is equipped with hollow shock cups 13, which are evenly spaced and rigidly fixed. The shock nozzles are arranged so that the intervals between them are equal to $d / 2$, where $d$ is the diameter of the shock cup, and the sum of the areas of the shock cups is equal to 0,2-0,4 of the area of the small flat base of the body. The body from the side of the larger base has a horizontally located axis 3, the ends of which are equipped with fixed wedge enclosing guides 9. Part of the body volume is filled with movable masses in the form of cast iron balls 2 . Inside the plane of the central shock cup, there is a loop 5 , made, for example, of a steel rope with the possibility of limited movement. Spatial truss 1 is equipped with wedge-shaped male guides 8 of rectilinear movement. The lower part of the guides 8 has holes 10 and corresponding locking pins 11 . In the place of bearing on the ground, a base plate 12 with pintles is attached to the truss.

Attachments are installed in the place of the future recess, the position of which is fixed using a base plate with pintles. The winch of the base machine by means of a rope 7 and a hook 6 , the working body is lifted by the eyelet along the guides 8 to a certain height. Shock cups are in the down position. After lifting, the working body is dropped to the ground. A series of blows with glasses leads to perforation of the soil mass and the formation of compacted soil cores at their base. For the formation of a common soil core and the final ramming of the recess, the working body is rotated $180^{\circ}$ around the axis 3. For this, the working body is raised to a height $\mathrm{H}$ so that the guides 9 are above the holes 10 in the guides 8 , and the locking pins 11 are inserted into the holes 10 , which fix the working body at a certain height with the possibility of turning it around the axis 3 . Then the hook 6 with the rope 7 is released from the eyelet, the loop 5 is moved inside the pipe of the central glass with the formation of a new eyelet and, by lifting, the working body is rotated in the vertical plane by $180^{\circ}$ around the axis 3 . During the turn, the moving masses in the form of cast iron balls move from the cavities of the shock cups into the cavity of the body. The working body occupies a vertically stable position.

The supply of the working body with shock cups allows to increase the shock load on the soil mass by 1,5-2 times without 
increasing the total mass and falling speed of the device, that is, without increasing the kinetic energy, which leads to an increase in the productivity of ramming depressions with this equipment by $40 . .50 \%$ in comparison with solid mass rammers in the form of a truncated cone.

Equipment for ramming recesses with a metal ballast (Pat. № 1040040). The device mounted on the boom (see Fig. 72) of the base machine contains a guide bar (not shown in the figure) along which the working body moves. The working body includes a body 1 with a vertical channel 2 of circular cross-section and a console 4. The working body is a truncated cone with a side wall slope of 1:8...1:10 and a lower diameter $d_{2}$. The ratio of diameters $d / d_{2}$ is $0,3 \ldots 0,35$. In the vertical channel 2 there is a hollow cup 11 with a flange 15 . At the lower edge of the vertical channel 2 there is an elastic gasket 14 . The hollow cup has a bottom 13 , and the perforated side walls are openings 12 for air outlet. The limiter of the vertical movement of the cup is a hole in the bottom plate 10 of the working body, the diameter of which is less than the diameter of the vertical channel 2 , but into which the glass 11 freely passes. The vertical channel is closed from above by a sealed plug 3. The working body moves along the guide rod using a carriage rigidly mounted on it 4 with a roller 5 . The required rigidity of the working body is achieved by installing vertical ribs 7 in its inner cavity, to which the body elements are attached. To achieve the required static pressure on the ground, metal ballast 9 (for example, steel balls) is poured into the cavity of the working body. The specific static pressure of the working body is no more than 0,03-0,035 $\mathrm{MPa}$.

The volume of the cavity of the vertical channel 2 is regulated by changing the location of the plug 3 .

The total period of contact of the working body with the ground can be divided into two half periods. The first is the penetration of the working body into the soil, the second is the jump under the action of the elastic forces of the soil medium. In the first period of impact interaction with the ground, the hollow cup 11 first contacts, since it protrudes beyond the bottom 10 of the working body. In the same period, the working body, moving downward, overlaps the cavity of the excavation from communication with the atmosphere, and the air in the cavity of the recess through the holes 12 in the side 
walls of the glass is pumped into the cavity 8 , covered by the plug 3 . Then the bottom plate 10 interacts with the soil, creating on the surface of the bottom of the recess has a ring load of high intensity. In the area under the bottom of the glass 11 , the vertical stresses are not equal to zero, since the compressed air in the cavity 8 exerts pressure on the bottom of the glass. Under the action of these compressive stresses, the soil moves under the bottom 10 and the bottom 13 of the glass.

In the second half-period, the working body moves under the influence of elastic aftereffect forces, i.e., the soil is unloaded. However, soil decompaction in the upper contact layer does not occur, since under the bottom 10 it is loaded by the weight of the working body, and under the bottom 13 - by the pressure of compressed air. When the working body is lifted with a rope 6, compressed air, expanding, blows through the annular gap between the bottom plate 10 and the side wall of the cup 11 and pushes this cup out of the vertical channel 2 .

The device allows to reduce the mass of the working body by 20 $25 \%$ due to the presence of a vertical axial cavity and to prevent jamming of the working body in the cavity of the recess due to the action of compressed air.

Equipment for ramming recesses with inertial mass (Pat. №1135841). The rammer consists of a metal body 1 (Fig.8a) with a vertical channel in which the inertial mass 3 and the shock absorber 4 , installed under the inertial mass, are located. The shock absorber of the spring-friction or hydraulic type is attached to the bottom of the rammer body, the vertical channel in the upper part is equipped with a stop 5. The inertial mass is installed with a gap relative to the stop. Unlike spring dampers, spring-friction and hydraulic dampers make it possible to adjust the recoil time in a much wider range and, if necessary, to stretch it. The latter contributes to an increase in the time of the stress state of the soil and thereby to an increase in the efficiency of compaction. However, the design of the selected shock absorbers does not provide a return of the inertial mass to its original position, and therefore an attachment of the shackle 6 is provided on the inertial mass in the upper part. 

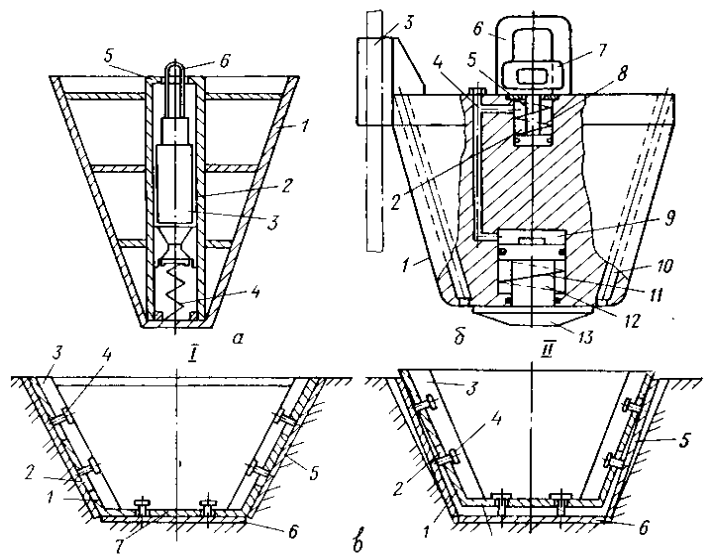

Fig. 8. Working bodies for ramming recesses: $a$ - with inertial mass; $\sigma$ - with a hydraulic device; $\boldsymbol{\beta}$ - with flexible elastic elements; I - submerged working body; II extraction of the working body from the soil

The rammer is lifted and dumped using the excavator's lifting mechanism. To carry out a working operation, the rammer, suspended by means of a shackle from the boom of the base machine, is located at a predetermined height above the surface and is dropped. At the moment of contact with the ground, the tamper body 1 and the inertial mass 3 in it have the same speed. In the process of joint movement of the soil and the ramming body 1, the speed of the latter decreases faster than the speed of the mass 3. As a result, the inertial mass creates additional pressure on the lower part of the ramming body 1 through the shock absorber 4 , which is transferred to the compacted soil surface.

Upon completion of the impact, the lifting mechanism of the excavator lifts the inertial mass 3 through channel 2 up to the stop 5 with the help of the shackle 6 , after which the rammer body 1 begins to rise to the specified height, then the cycle repeats.

The use of a rammer will make it possible to obtain a greater depth of working out of the soil layer, and, consequently, to increase the productivity of work.

Equipment for ramming recesses with a hydraulic device (Pat. № 1057621). The working body (see Fig.86) consists of a housing 1 with a pulling bracket 6 , in which an earring 7 is installed with the possibility of longitudinal movement. The earring is attached to the 
rod 5 of an additional hydraulic cylinder 2 and has a spring 8. The hydraulic cylinder is connected to the main hydraulic cylinder 9, to the rod 12 of which a tip 13 with a spring 11 is connected. Channels 10 in the body 1 are designed to release air from the pit when the working body is immersed. With the help of the slider 3 , the working body is movably connected to the guide structure.

The working body is gradually submerged into the ground by lifting to a predetermined height and dropping to the ramming site. At the same time, to raise the working body, the bracket 6 is grasped with the hook of the load-gripping mechanism of the base machine (not shown in the figure).

If the traction force of the base machine, designed for unhindered lifting of the working body, is insufficient to remove it from the recess, the hook of the load-gripping mechanism is removed from the clamp 6 and introduced into the traction shackle 7, moving it then upward. This leads to the compression of the spring 8 and the displacement of the working fluid from the hydraulic cylinder 2 through channel 4 into the hydraulic cylinder 9, as a result of which there is a simultaneous movement of the housing 1 upward relative to the currently stationary tip 13 and compression of the spring 11 . As a result of the significant stroke of the housing 1 and the development in the hydraulic cylinder 9 of a large lifting force, there is a reliable separation of the body 1 from the ground. Then the hook of the load-gripping mechanism is removed from the shackle 7 and inserted into the bracket 6 , lifting the working body to a predetermined height. In this case, due to the elasticity of the springs 8 and 11, the working fluid flows from the hydraulic cylinder 9 to the hydraulic cylinder 2 and the shackle 7 and tip 13 return to their original position. Thanks to this design of the working body, it is reliable when working on wet clay soils and provides a high quality of recesses.

Equipment for ramming recesses with flexible elastic elements (Pat. № 909011). The rammer (see Fig.86) consists of rigid side walls 1 forming the body, connected by a bottom 7 . In the walls and bottom of the rammer, guide holes 2 are made through which pins 4 pass, with which the rammer is connected to the cladding. The cladding consists of a base 6 and separate additional sheets 5, which are hinged or welded to the base sheet. The edges of the additional 
sheets 5 are located with a gap relative to one another. If the working body is filled with concrete (the stiffeners and concrete are not conventionally shown in the figure), the strips in which the holes 2 are located can be fenced off with channels 3 . Between the side walls and the cladding there is a thin layer of grease, for which known devices can be used (grooves, nozzles, etc.).

When the working body is immersed in the ground, the lining sheets 5 adhere tightly to the ground and the walls of the stamp and therefore practically work only for compression. This allows them to be made from a thin elastic material. The rammer is in contact with the ground only with its ribs. When it is removed, the friction between the sheets and the ground turns out to be about 3...4 times greater than between the stamp and the sheets. Therefore, the rammer begins to move relative to the cladding, the sheets of which, in turn (under the influence of the elastic force of the compacted soil), due to the gaps between the sheets and their flexible fastening, also approach each other until the pressure on the sheets from the ground decreases so much that the ramming will be extracted by an effort that does not significantly exceed its mass. For tamping with a conical shape, the cladding is suitably made of tapered sheets.

This design of the working body allows you to improve the quality of the pit by preventing the collapse of its walls.

A device for ramming recesses with a flexible cover (Pat. № 958592). The device includes (Fig.9a) a body 1, covered by a flexible cover 2 , which is attached to the frame 3 . The frame has bushings 4 designed to install guide pins in them 5. Through powerful compression springs 6 , the frame 3 rests on the body 1 . With the help of the suspension unit 7 , the device is connected by a rope of the lifting mechanism of the base machine.

After lifting to a predetermined height, the device is dropped to the ramming point. When it is removed from the cavity formed by it, the housing 1 initially moves relative to the stationary cover 2 held by the forces of adhesion to the ground. Due to the fact that the frictional forces between the housing and the cover (especially when it is made of plastic) are extremely insignificant, the lifting force of the housing is spent mainly, to overcome the force of gravity of the device and to deformation of the compression springs.

A device for ramming grooves with a movable rod (Pat. № 
1074960). The device consists of a body 1 (see Fig.9 б) and a rod 2 placed in it with a base plate 9 attached to it, pressed to the bottom of the body by means of springs 3 , levers 4 and rods 7 . Flexible protective elements 8 prevent the ingress of soil into the gap between the bottom of the body and the plate.

By gripping the flexible element 5 with the hook of the loadgripping mechanism, the carriage 6 with the body is raised to a predetermined height and dropped to the ramming site. When removing the device as a result of the development of significant forces in the flexible element and due to the ratio of the arms of the levers, forces are transmitted to the body through the rods 7 , ensuring its reliable departure from the walls of the recess when moving upward relative to the "head-rod-base plate" system. The device provides high reliability of extraction and reliable operation when ramming high quality recesses.
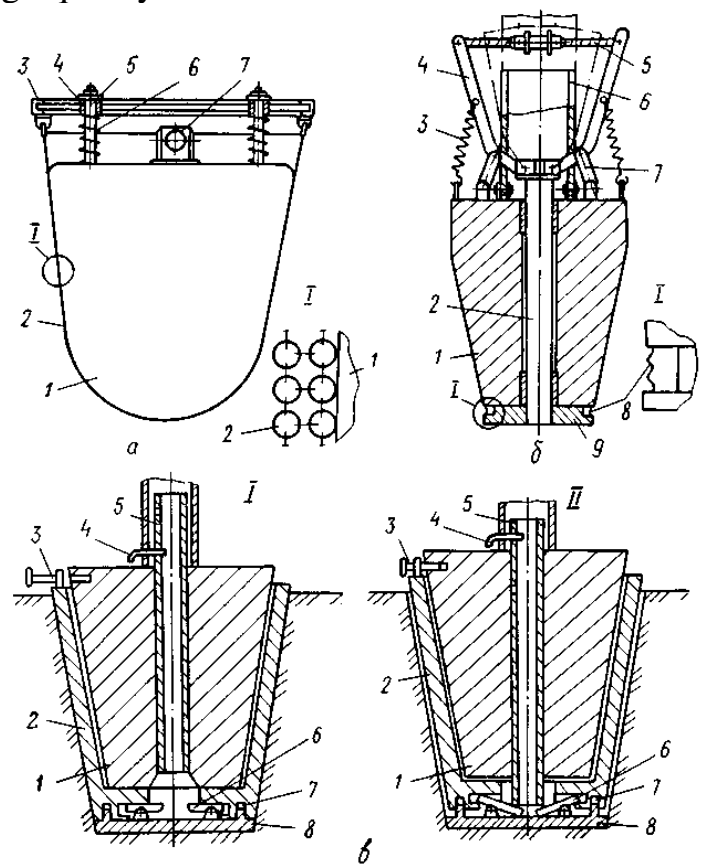

Fig. 9. Devices for ramming recesses: $a$ - with a flexible cover; $\sigma$ - with a movable rod; $в$ - with a transmitting plate; I - submerged working body; II - due to the extraction of the working body from the ground 
A device for ramming recesses with a transmitting plate (Pat. № 973706). The device (see Fig.98), installed on the boom of the base machine, includes a guide rod (not shown in the figure), along which the ramming body 1 with a movable stop 5 moves reciprocally; transfer plate 8 with levers 6 truncated cone 2 with grooves 7; clips 3,4.

When ramming the recess, the retainer 3 is disconnected from the rammer, and the movable stop 5 is fixed in the upper position. When removing the rammer, the stop is fixed in the lower position, after which the rammer is dropped. The stop 5, acting on the levers 6, separates the truncated cone 2 from the ground. By connecting the truncated cone with the tamper with the retainer 3, the entire tamper is removed. The use of the device allows you to completely eliminate jamming of the rammer in the ground during ramming.

A device for ramming recesses with separate vertical elements (Pat. № 1043254). A rammer in the form of a regular square truncated pyramid (Fig.10a) includes a body of separate vertical elements 1 and 2, connected in pairs by jumpers 4 and 5 and forming movable blocks 10 and 11 . The movable blocks interact with each other through rollers 12, installed in the niches of the inner edges of the vertical elements. Channel 3 and socket 9 serve for air release. On the movable block 11 , the carriage 8 is rigidly attached for fixed movement along the guide rod (not shown in the figure).

With the help of the winch of the base hoisting machine, by means of the traction rope 7 and the gripper 6 , the working body is raised to a certain height and then dropped.

The rammer is reliable in operation due to the elimination of skewing and jamming of the vertical body elements, a small extraction force, as well as the elimination of the possibility of the formation of a soil plug (the walls of the vertical channel for air outlet during ramming move relative to one another).

A device for ramming recesses with a rotary transmission plate (Pat. № 1139798). The device includes a rammer 2 (see Fig.10б) in the form of a truncated cone with longitudinal blades 1 and a transmitting base plate 7 , movably interconnected by compression springs 3 and radial fingers 5 located in inclined slots 6 .

When the rammer is dropped, it moves relative to the transmitting plate by the size of the gap 4 with the simultaneous rotation of the plate around its axis. The consumption of the kinetic energy of the 
falling rammer for the compression of the springs is insignificant and does not exceed 5\%.
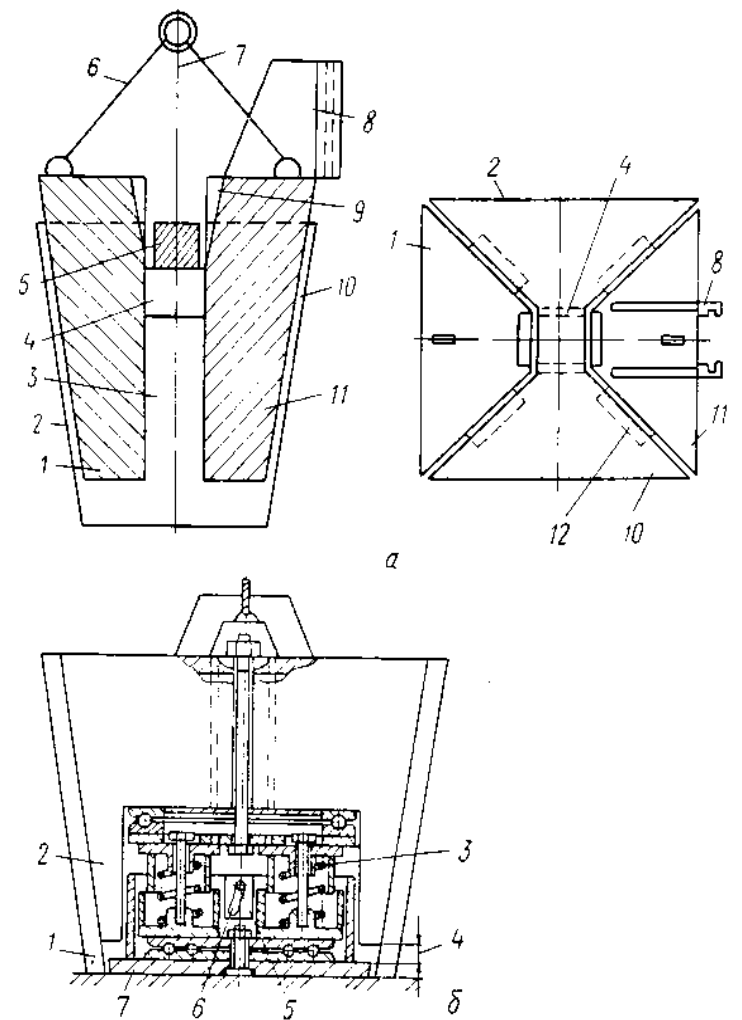

Fig. 10. Devices for ramming recesses: $a$ - with separate vertical elements; $\sigma$ - with a rotary transmitting plate

A device for ramming recesses with an extraction mechanism (Pat. № 1141162). The device consists (Fig.11a) of a basic machine with a frame (not shown in the figure), on which a guide 1 with a working body 6 with a hydraulic lifting mechanism is installed, and outriggers 5 , fixed by clamps 4 in guide brackets 3 . The brackets are articulated connected to the guide 1 , to which the hydraulic power cylinders 2 are also pivotally attached, connected by rods with the corresponding free ends of the brackets 3 . 

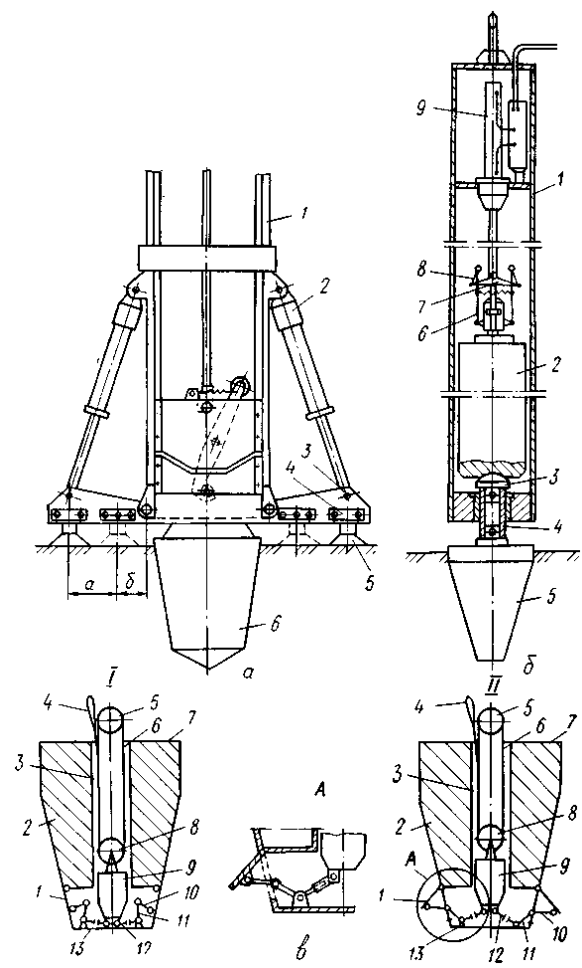

Fig. 11. Devices for ramming recesses: $a$ - with an extraction mechanism; $\sigma$ shock action; 8 - with a broadened lower part; I - with closed extension flaps; II with extended flaps

By changing the size of the arms $a$ and $\sigma$, the force required to detach the working body from the walls and bottom of the recess is regulated (depending on the depth and ground conditions). At the moment of separation of the working body, surface compaction of the side walls of the recess occurs, which significantly affects the bearing capacity of the foundation.

The use of this device ensures the minimum energy consumption of separation of the working body from the ground.

A device for ramming of impact recesses (Pat. № 926153). The device is made in the form (see Fig.116) of a tubular body 1, in which the firing pin 2 is freely installed, acting on the shabot 3 , which is connected by means of a rod 4 with a working tool - a 
stamp 5. The gripping device is made in the form of a traverse 7, pivotally connected to the drive, for example with the rod of the hydraulic cylinder 9 , fixed in the housing. The system of connecting rods 6 and rocker arms 8 provides automatic disconnection (when lifting) and connecting (when lowering) the gripper with the shank of the striker.

Due to the fact that the separation of the shank of the striker with the traverse occurs in the process of their simultaneous uniformly accelerated fall, the contact stresses in the areas of mating surfaces are extremely small, which practically excludes their wear.

A device for ramming recesses with a widened part (Pat. № 1048052). The device contains a body 2 of the working body rammers (see Fig.11b), on which the flaps are fixed with hinges extenders 1. The flaps are pivotally connected through a system of levers 10,11,12 with the bottom of the body 13 and the counterweight 9 , which is fixed with hinges, located in the cavity 3 and is suspended by means of a chain hoist 6 to the housing cover 7 , the lower block 8 of the chain hoist being attached to the counterweight, and the upper block to the housing cover.

The deepening in the ground is rammed by dropping the rammer along the guide bar using the base machine. After the end of ramming, a loop 4 of the chain hoist is put on the hook of the cargo rope and lifted. The counterweight is lifted and rotated through the system of levers of the extension flaps, which leads to a widening of the recess. When the counterweight is lowered, the extension flaps close.

A device for ramming recesses with retractable sealing cheeks (Pat. № 1074940). The rammer is (Fig.12a) a hollow body 1, inside which there are guide rods 5 and a wedge-shaped vertically movable element 2 , connected by the upper part to the carriage 11 . Sealing cheeks 3 are pivotally connected to the lower part of the body 1 , installed on the axes 6 with supports. The cheeks are equipped with rolling bearings 9 . The body has locks 10 for moving the sealing cheeks. 

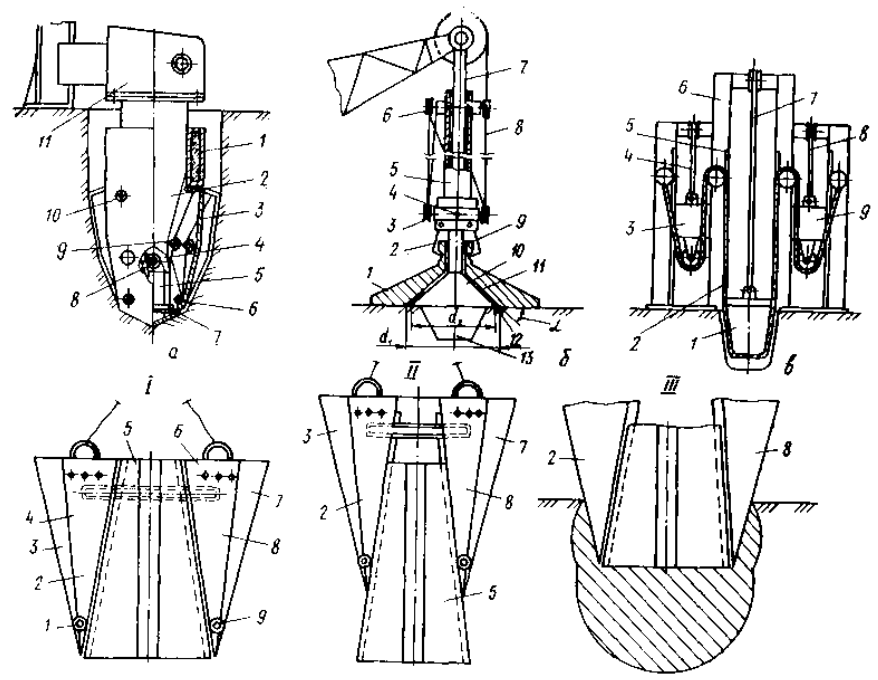

Fig. 12. Devices for ramming recesses: $a$ - with retractable sealing cheeks; $\sigma$ with a sealing heel; 8 - with dynamic extraction of the working body; $\Gamma$ - with movable percussion elements; I - starting position; II - pre-shock position; III - the formation of a compacted zone

When lifting the carriage along the guide post, the rollers 8 of the wedge-shaped element engage with the hooks 4 and move the sealing cheeks to the upper position. At the moment of impact, the sharpened part of the body of the working body is introduced into the ground, then after stopping the body, the wedge-shaped element continues to move and through the rolling bearings 9 transfers kinetic energy to the sealing cheeks. The latter, moving forward, compact the deepening of the soil in the walls. The angle of rotation of the sealing cheeks, which determines the width of the recess, is set by adjusting the values of the vertical movement of the wedge-shaped element, for which the thickness of the replaceable plate 7 is changed.

A device for ramming recesses with a sealing heel (Pat. № 1184902). The device contains (see Fig.126) a guide rod 5, to which the heel 10 is attached from below, equipped with a spur 13. The telescopic part of the rod 7 is attached to the boom axis of the base machine or to its hook. A block cage 6 is rigidly fixed on the upper part of the pipe, and a platform 4 is mounted on the pipe with the 
possibility of vertical movement, carrying the articulated block cage 3 and a coupling mechanism 2 with remote control. The rammer 1 has an element 9 of the coupling mechanism in the upper part, and in the lower part - an open cavity and, similar in shape to the heel 10 . The diameter of the cavity $d$ is $5-10 \mathrm{~cm}$ greater than the diameter $d_{2}$ of the base of the heel, the angle $\alpha$ is $30-60^{\circ}$. Between the blocks of clips 3 and 6 , a rope 8 is stored, which goes to the winch of the base machine and forms, with clips 3 and 6, the tamper hoist pulleys. With the help of the mechanism 2, the block cage 3 is connected to the rammer and, during the operation of the winch, rises along the rod 5 to a predetermined dumping height. At the desired height, the gripping mechanism releases the rammer, which falls freely down along the rod. The compacted soil is partially displaced into the gap between the heel and the rammer and forms an interlayer 12, due to which the subsequent blows of the rammer on the heel are somewhat absorbed by the soil.

Device for ramming recesses with dynamic extraction of the working body (Pat. № 1276752). The device (see Fig.126) is installed on the base machine (not shown), to the boom of which a U-shaped post 6 with guides 5 is attached. On them, a working body is movably fixed on a lifting rope 7 , on both sides of which they are located in separate guiding shock masses 3 and 5, connected by ropes 4 and 8.

The working body by periodic lifting and dropping is immersed in the ground, while the shock masses are in the upper position and do not interfere with the movement of flexible rods 2, covering the working body. After the immersion of the working body, the shock masses are discharged, interacting with flexible rods, which transmit a dynamic effect to the working body.

A device for ramming recesses with movable percussion elements (Pat. No. 744073). The device includes (see Fig.122) side impact elements 2 and 8 with edges 3,4,6,7, covering the central impact element 5 with sliding guides. In the lateral impact elements, the faces are interconnected by hinges 1 and 9 and fix their position, for example, using a sector lock with a cotter pin, which allows you to change the angle of inclination of the lateral faces when changing the physical and mechanical properties of soils.

In the first period of impact interaction, a central percussion 
element is introduced into the soil, which creates a depression with vertical walls and a compacted zone in the face, while the soil on the vertical walls of the depression is loosened. In the second period of impact interaction, impact lateral elements come into contact with the vertical walls of the already created recess, which, under the action of inertial forces, form slopes from the loosened soil.

A device for ramming recesses with a hollow truncated cone (Pat. № 1260442). The device (Fig.13a), mounted on the base machine with a boom, consists of a guide bar; working body drive (not shown in the figure); transfer plate 1 with a device for lifting it in the form of compression springs 16 and ledges 2 in the grooves of the hollow truncated cone 4 of the rammer with a lifting loop 15, a bar 18 and a movable stop 8 . In the rammer there is a chain link 25 connected by a flexible connection 17 to the drive of the working body. The upper cage 10 of the chain hoist is fixed in a movable stop 8 , and on the axis 6 of the lower cage 5, which can be vertically displaced to the stops 7, a grip 13 is installed, which interacts with both the lifting loop 15 and the dump roller 12. The movable stop 8 in the lower part has slots 14 for the lifting loop 15, and in the upper part it rests with its butt end against the collar 9 of the through channel of the rammer during the lifting of the last one. The device, which automatically connects the hollow truncated cone 4 with the rammer 3 , has a cam 23 with a working profile 21 facing the center of the rammer. The cam is installed in the vertical hole of the protrusion 22 of the truncated cone 4 and is equipped with a compression spring 20 and a pusher 19 in the form of a bracket with a working roller 24. The roller, moving reciprocally in the hole of the protrusion 22 , at a certain moment of immersion of the hollow truncated cone connects and disconnects it from the rammer organ 3 by means of bar 18 . 

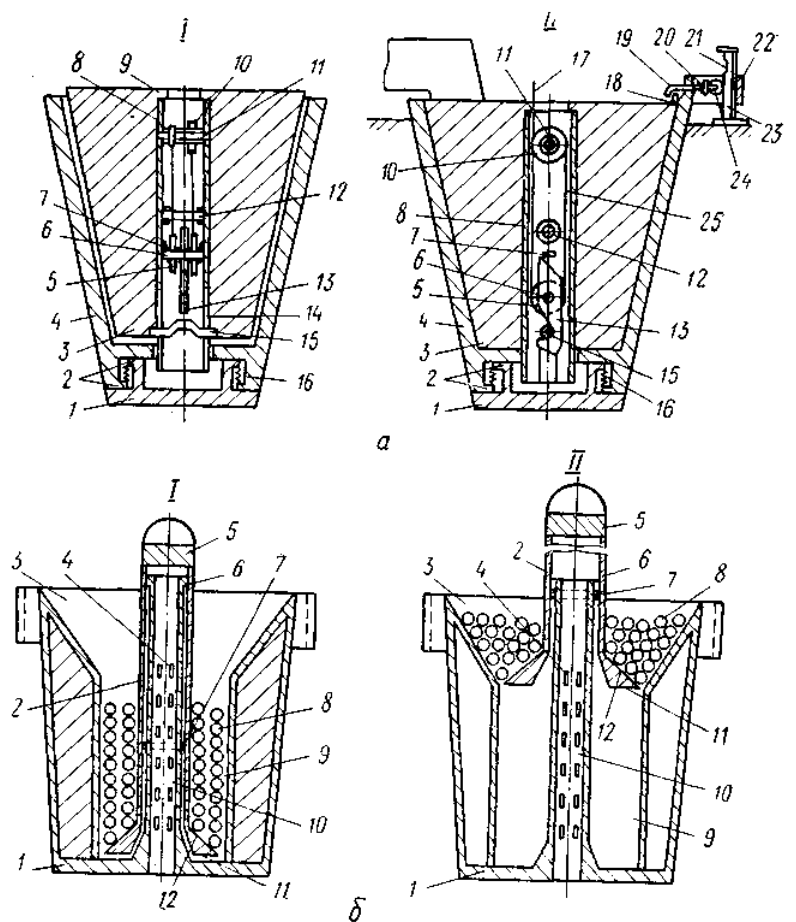

Fig. 13. Devices for ramming recesses: $a$ - with a hollow truncated cone; $\sigma$ with inertial bulk material; I - when immersed; II - when extracting

The simultaneous dropping of the rammer and the transfer plate with the hollow truncated cone occurs automatically until the rammer is disconnected from the hollow truncated cone. After that, the ramming body is dropped separately until the hollow truncated cone is completely immersed in the ground. Then the hollow truncated cone is connected with the rammer, their separation from the ground (separation is possible at any immersion value) and further simultaneous lifting.

Device for ramming recesses with inertial bulk material (Pat. №1172995). The rammer includes a body 1 (see Fig.136) with a bottom, an upper chamber 3 and a lower cylindrical chamber 9. A vertical pipe 10 is installed in the center of the rammer with a stop 6 for venting air from under the bottom, which is covered by a rod 2 with a flanged pad 11 at the end. A gripping device 5 with a hoisting rope is mounted on the bar, which has an annular protrusion 7 . The 
vertical pipe is equipped with 4 holes for air outlet. The flange platform is located under the bulk material 8 , for example in the form of steel balls, and its upper edge 12 is made with a slope towards the body.

When dropping the rammer, the bottom touches the ground first, while most of the bulk material is located on the conical surface of the upper chamber, under the action of inertia forces it continues to move down the inclined surface, creating a movable load on the body and thereby increasing the duration of the shock pulse. Then the flanged platform 11 strikes the bottom, and then the impact of the bulk material with increasing energy follows in the form of an avalanche of flying balls, which, in turn, increases the pulse duration, after which the cycle is repeated.

\section{Conclusions:}

1. The considered technical solutions ensure the effectiveness of the formation of recesses due to the design features of the working equipment and working bodies. The performed studies show that the parameters of the working body and the impact energy have a significant effect on the efficiency of the formation of recesses.

2. Analysis of scientific and technical solutions in the field of improving working equipment for the formation of recesses without excavation allows us to conclude that it is possible to effectively ram out recesses for foundations without a widened base with freely falling rammers $1-2 \mathrm{~m}$ high, with a bottom size of $0,4-1,4 \mathrm{~m}$, at the top $0,7-1,8 \mathrm{~m}$, with a taper (slope) of the side walls from 1:20 to 1:5, and for foundations with a broadened base - with rammers 1,5...3,5 $\mathrm{m}$ high, size along the bottom $0,4-1 \mathrm{~m}$, at the top $0,6-1,2 \mathrm{~m}$. The ramming of recesses is carried out by driven working bodiestemplates (rammers) with a height of 1,5-2,5 $\mathrm{m}$ and a size of $0,9-1 \mathrm{~m}$ at the top. The choice of design and parameters of working bodies and working equipment is determined by the size of the deepening, soil conditions and dynamic loads on nearby buildings and structures.

3. Increasing the efficiency of using the working equipment in the considered technical solutions is achieved by reducing the efforts to extract the working body from the soil; using rammers of a special shape to form separate recesses, extended (con-tinuous) recesses and 
depressions with a widened cavity; increasing the time of interaction of the working body with the ground; re-duction of dynamic loads on the base machine.

4. Recesses recesses by free falling of the working bodies is most expedient in subsiding soils with low natural density $\left(\sigma_{d}<1,7 \Gamma / \mathrm{cm}^{3}\right)$ and a degree of moisture $S \leq 0,75$. The equipment can be used to form both recesses for the foundations of structures (individual and strip) and recesses that do not require significant bearing capacity, for example, ditches, wells for fence posts, etc. Under the conditions of creating static soil pressure around the working body, it is possible to stamp only individual depressions.

\section{References}

1. V.I. Panteleienko, S.O. Karpushyn Energy-effective method of installation of foundations under objects of mine surfaces. UDC 622:658.589 (063) 2 nd International Scientific and Technical Internet Conference "Innovative Development of Resource-Saving Technologies of Mineral Mining and Processing”. Book of Abstracts. - Petroșani, Romania: UNIVERSITAS Publishing, 2019. - 220 p. ISBN 978-973-741-656-8 (Print) ISBN 978-973-741-663-9 (Online) S.104-107. URL: http://surl.li/bbfuw

2. Panteleienko V.I., Karpushyn S.O. Doslidzhennya procesu zanurennya tonkostinny`x fundamentiv-obolonok pry`zvedenni nul’ovogo cy`klu budivel` i sporud.// Naukovi zapy`sky`KNTU Vy`pusk 10, Naukovi zapy`sky`: zb. nauk. pr. Kirovograd: KNTU, 2010. - Vy p. 10, ch. 3. - S. 228-225. URL: http://dspace.kntu.kr.ua/jspui/handle/123456789/5654

3. Panteleienko V.I, Karpushyn S.O. Spetsializirovannoye oborudovaniye dlya pogruzheniya svay i fundamentov-obolochek. / Materialy Mizhnarodnoyi naukovopraktychnoyi konferentsiyi, prysvyachenoyi 40-richchyu kafedry budivel'nykh, dorozhnikh mashyn i budivnytstva. «Problemy rozvytku dorozhn'o-transportnoho i budivel'noho kompleksiv» 03-05 zhovtnya 2013r. - Kirovohrad, PP EksklyuzyvSystem, 2013. S.337-340.

4. Khmara L.A., Panteleienko V.I., Kulik I.A. Opredeleniye parametrov mashin dlya pogruzheniya svay i fundamentov-obolochek. Dnepropetrovsk: OOO «ENEM», 2005. 144s.: tabl., skhemi, ris.

5. Khmara L.A., Shypilov O.S., Musiyko V.D., Kuz'minets' M.P., Panteleyenko V.I., Karpushyn S.O. Dorozhni mashyny. Mashyny dlya budivnytstva, remontu ta utrymannya avtomobil'nykh dorih. Navch. Posibnyk. Chast. II. KyyivDnipropetrovs'k: NTU, 2013. 400s.: tabl., skhemy, rys.

6. Khmara L.A., Panteleienko V.I., Xvostenko Yu.V. Innovacijny`j energoefe-kty`vny`j sposib ustroyu pogly`blen` nul`ovogo cy`klu bez vy`yimky` gruntu. «Budivny`cztvo. Materialoznavstvo. Intensy`fikaciya robochy`x procesiv budivel`ny`x ta dorozhnix mashy`n. Seriya: pidjomno-transportni, budivel’ni, dorozhni, mashy`ny` i obladnannya» №107, 2019. S-136-144. 
7. Panteleienko V.I. Razrabotka y opredelenye osnovnykh parametrov oborudovanyya dlya pohruzhenyya fundamentov-obolochek: dys. ... kand. tekhn. nauk: 05.05.04 - mashyny dlya zemlyanykh y dorozhnykh rabot. Dnipropetrovs'k, 2004. $227 \mathrm{~s}$.

8. Panteleyenko V.I., Karpushyn S.O., Chervonoshtan A.L., Ihnatov A.B. Do-slidzhennya napruzhenoho stanu metalevykh shtampiv pid fundamenty dlya budi-vel' riznoho pryznachennya / Naukovyy visnyk budivnytstva. Naukovotekhnichnyy zhurnal Kharkivs'koho natsional'noho universytetu budivnytstva ta arkhitektury KHNUBA. Kharkiv 2020, t.101 №3, S 99-107.

doi.org/10.29295/2311-7257-2018-101-3-99-107..

9. Shevchenko D.S., Panteleyenko V.I., Karpushyn S.O Doslidzhennya vytrambuvannya pohlyblen' v hrunt // Tezy dopovidey I Vseukrayins'koyi student·s'koyi naukovo-praktychnoyi konferentsiyi "Dosvid vprovadzhennya u navchal'nyy protses suchasnykh k omp"yuternykh tekhnolohiy". - Kropyvnyts'kyy: TSNTU, 2019. - s 30-31.

10. Khmara L.A., Panteleyenko V.I., Karpushyn S.O. Metodyka provedennya eksperymental'nykh doslidzhen' koprovoho robochoho obladnannya $\mathrm{v}$ umovakh protsesu zanurennya tonkostinnykh fundamentiv-obolonok pry zvedenni nul'ovoho tsyklu budivel' i sporud. Zb. naukovykh prats' KNTU "Tekhnika v sil's'ko-hospodars'komu vyrobnytstvi, haluzeve mashynobuduvannya, avtomatyzatsiya” №16, Kirovohrad, 2005. - S 165-172.

11. Patent na korysnu model' 148692 Ukrayina, MPK (2021.01) G01M 7/08. E02D 17/00 Stend dlya doslidzhennya protsesu vytrambovuvannya zahlyblen' u hrunti. Panteleyenko V.I., Karpushyn S.O., Chervonoshtan A.L., Matsevych I.M., Abyel'tsev YE.D.; zayavnyk i vlasnyk patentu DVNZ PDABtaA - № a 2008 08807; zayavleno 18.01.2021; opublikovano 08.09.2021, byuleten' № 36 .

12. Patent na korysnu model' 147293 Ukrayina, MPK (2021.01) E05D 13/00 Stend dlya doslidzhennya protsesu zanurennya obolonok v hrunt v naturnykh umovakh. Panteleyenko V.I., Karpushyn S.O., Chervonoshtan A.L., Danylenko I.O.; zayavnyk i vlasnyk patentu DVNZ PDABtaA; zayavleno 06.11.2020; opublikovano 28.04.2021, byuleten' №17.

13. Patent na korysnu model' 147297 Ukrayina, MPK (2006) E05D 13/00 Stend dlya doslidzhennya yakisnykh zakonomirnostey protsesu zanurennya modeley obolonok v hrunt. Panteleyenko V.I., Chervonoshtan A.L., Ihnatov A.B.; zayavnyk i vlasnyk patentu DVNZ PDABtaA; zayavleno 06.11.2020; opublikovano 28.04.2021, byuleten' №17.

14. Patent na korysnu model' 148700 Ukrayina, MPK (2006) E02D 7/00 Prystriy dlya zanurennya obolonok. Panteleyenko V.I., Chervonoshtan A.L., Karpushyn S.O., Pushenko V.A.; zayavnyk i vlasnyk patentu DVNZ PDABtaA; zayavleno 15.03.2021; opublikovano 08.09.2021, byuleten' №36. 
https://doi.org/10.31713/m1122

\title{
CLASSIFICATION THE SALT STOCK AREAS (SAKHALIN FIELD) WITH THE DETECTION OF HYDROCARBON POTENTIAL FOR OPTIMIZATION OF EXPLORATION WORK AND DRILLING FOR OIL AND GAS
}

\author{
Vynnykov Yu.L. \\ The National University "Yuri Kondratyuk Poltava Polytechnic", \\ professor, $\mathrm{ScD}$, professor at the department of drilling and geology, \\ Ukraine \\ Petrash O.V.
}

The National University "Yuri Kondratyuk Poltava Polytechnic", $\mathrm{PhD}$, associate professor at the department of oil and gas engineering and technologies

\section{Vovk M.O.}

The National University "Yuri Kondratyuk Poltava Polytechnic", senior lecturer at the department of drilling and geology, Ukraine

\section{Volchenkova A.V.}

The National University "Yuri Kondratyuk Poltava Polytechnic", senior lecturer at the department of drilling and geology, Ukraine

\section{Novozhenina A.R.}

The National University "Yuri Kondratyuk Poltava Polytechnic", student, Ukraine

\footnotetext{
Abstract

Classification of stock areas is proposed and described based on the features of the internal and external structure of geologic bodies, occurrence mode, height, and reservoir properties (RP). The RP analysis of prospective and discovered reservoir types within traps sealed by salt stocks is carried out. Potential oil and gas areas within the Sakhalin field salt stock have been identified.

\section{Introduction}

Exploration of hydrocarbons depends on a large number of studies and analyses, drilling of wells for different purposes and depths, the correct interpretation of the obtained geological, lithological, geophysical information. From exploration to production (operation) of oil and gas often takes a lot of time and money, but it is much more
} 
profitable than the cost of buying and transporting gas to Ukraine. It is necessary to continue work on expanding our own resources portfolio through the development of new fields because it requires four times less investment.

Modern exploration of oil and gas fields takes into account the principles of optimization and economical use of hydrocarbon and financial resources, drilling resources for exploration and exploitation.

Among the main principles, in addition to the principle of the least time and cost in an energy-saving fashion, it is important to select the minimum number of surveys and wells that will rationally and evenly study each individual formation or field.

To select the best methods for hydrocarbons exploration, it is necessary to assess in detail the prospects of geological bodies. Reservoir rocks discovered by drilling and geological research have uneven properties and characteristics within each geological section. This is often due to the facies environment (primary), but active tectonic (lowering or raising the area, halokinesis, magmatism) environment leads to secondary changes in the strata.

\section{Formation of reservoir rocks and hydrocarbon traps}

The process of formation of rocks, which is a reservoir of oil and gas, begins on the Earth's surface with the formation of terrigenous or carbonate sediment enriched in organic matter. Over millions of years, the thickness of loose sediment turns into a dense rock, which changes with depth its shape, texture, structure, composition, often metamorphosed. This rock can be a source rock [8] or a reservoir rock. If there are certain features (porosity, permeability, mineralogical and particle size distribution, etc.), the rock may be included in the list of objects for the selection of rational methods of exploration and drilling. But, as practice shows, this geological body is not always a formation, and not always the found formation contains enough resources and opportunities for their extraction.

To form a trap, it is necessary: the presence of the source rock, reservoir rock, seal rock, and structural factor that will keep hydrocarbons from migrating.

Porosity (pore volume) and permeability (the ability of the rock to pass liquid) are important factors in the migration and accumulation of oil and gas. Most traditional accumulations of oil and gas are 
found in debris (sandstones and siltstones). Next in number are carbonate reservoirs (limestones, dolomites). Accumulations of some types of unconventional hydrocarbons are extracted from shales, igneous and metamorphic rocks, due to the porosity resulting from destruction.

The porosity in reservoir rocks usually ranges from 5 to 30 percent, but all available pore space is not occupied by oil or gas, there is always a certain amount of residual formation water [12].

\section{Analysis of the geological structure of the oil and gas region with the manifestation of salt tectogenesis}

On the territory of Ukraine, there are 3 oil and gas regions, one of which is the Dnieper-Donetsk basin (DDB).

The Dnieper-Donetsk depression is located in the southwestern part of the Eastern European platform. It is bounded by the Ukrainian Shield (US) and the Voronezh Massif, and has an Archean-Early Proterozoic foundation.

The Dnieper-Donetsk depression is a typical graben with a complex geological structure. The formation of the depression is associated with the processes of rifting (Late Devonian) and tectonic movements (Paleogene). Accordingly, the main coverages in the structure of the depression are the lower coverage - Upper Devonian and upper - Upper Paleozoic-Cenozoic.

The rift contains a thick layer of sedimentary rocks, among which the special by its composition and mode of occurrence are Devonian salt rocks, with which oil and gas reservoirs are associated.

According to the stage of rift formation and the composition of rocks, the Devonian structural coverage is divided into the following complexes: subsalt, lower saline, intersalt, upper saline, and supersalt. Further, with angular and stratigraphic inconsistencies in the Devonian and partly Precambrian formations lie three divisions of the coal system. Within the adjacent parts and marginal zones of the DDB, the Lower Permian ones lie inconsistently, and the Meso- and Cenozoic formations on top of them with the same discrepancy.

Salt tectonics (halokinesis) - movement vertically in the direction of the day surface relative to the light plastics of rock salt. It is believed that the main driving mechanism of this process is the dense inversion at the salt boundary and its overlap. In addition, it is assumed that a certain role in the implementation of this process was 
played by the erosion of the coverage, the weakening of the supersalt complex by faults and uneven load distribution [4].

Salt structures are the result of the pressure of a thick stratum of rocks, which have a higher density and zones of compaction, through which the salt moves towards the day surface.

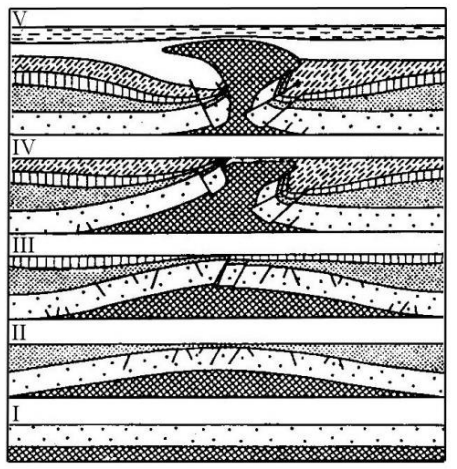

Fig. 1. (Lukiienko O.I.) Schematic representation of the gradual growth and transformation of the diaper body of the shoptein salt in northern Germany (by F.Trusgame, 1960). Roman numerals indicate the phasing of this process, which is expressed in the gradual capture of the horizons of the overlying rocks and the deformation of these horizons (the formation of diapir folds, the development of cracks, etc.)

Saline tectogenesis has been studied at DDB for a long time, not only as a phenomenon but also as one of the factors in the formation of hydrocarbon traps. A significant amount of hydrocarbon reserves at DDB was discovered near the stocks at the Novoukrainske, Chutivske, ZakhidnoKhrestyschenske, Chervonoyarskoe, Vesnyanske, etc. fields.

Salt structures that have the same rheology differ in structure, history of formation, and genesis. In addition, they are still considered "alive", ie those that continue to grow, move and change in space. In such conditions, the lithological-stratigraphic correlation becomes very complicated and the reliability of geophysical surveys decreases.

So, for example, MV Lubkov [5] in 2011 conducted modeling of the salt structures movement within the DDB. The results indicate the inconsistency of these structures in their location and as a result of the existence of modern influence on the adjacent layers of rocks and oil and gas deposits. 
Salt structures within the DDB (according to Lubkov) are divided into three genetic groups.

I - groups are characterized by the fact that all the time over the salt complex of sedimentary rocks, regardless of the level of Devonian salt, forms around the salt core of the dome or anticline. They are formed due to the complication of salt tectonics of the main genetic types of unsalted structures: near-fault, top-fault, stamped, and gutter structures. The cores of group I structures have the shape of a salt cushion or massif.

II - the group of salt structures does not have dome-shaped elevations around the salt core in the lower part's top salt thickness. They have the shape of salt shafts.

Salt structures of group III also have the shape of stocks, are placed between large salt structures of group I or on their periclines, separated by compensating troughs; formation is also linked to regional tensions.

\section{Formation of salt structures and zonation of adjacent zones}

The formation of salt structures is a long process, consisting of two main stages: the formation of thick salt strata and the movement of salt through faults; breaking of salt in unstable areas of overlying rocks. Faults are broken into separate blocks the entire adjacent area.

Vertical movement of salt links took place within the DDB during rifting (Late Jurassic), during the period of intensive stretching, subsidence, backfilling by the overlying rocks with the formation of a thick caprock. This process affected the growth of salt cushions, followed by intense salt removal and, finally, the beginning of the significant vertical movement (late Cretaceous), when the sedimentary load on the salt contributed to its differential movement and rapid rise. Therefore, salt tectonics in the basin is accompanied by prolonged deformation from $\mathrm{J}$ to $\mathrm{Q}$ period.

As salt changes its location and shape, it also changes the shape and location of rocks it breaks through, which in turn affects "neighboring" or higher buried sediments. All rocks involved in the process are subjected to stresses that gradually transfer to each other. The intensity of stress, direction, and form of change of rocks depends on their power, composition, and physicochemical properties. 
The strata of halokinesis rocks are divided into several zones separated by faults and zones of rock disintegration - the body of the salt stock, the adjacent area of intensive change and destruction of rocks, and the area of strata that have not changed their position and properties after breaking the salt stock.

Exploration work in stock adjacent areas is not effective enough, because often the resolution of most methods (seismic, gravimetric, and others) does not allow to accurately trace the boundary between the rock and stock and choose the location for drilling.

In the process of raising the salt massif and its movement along the faults, the rocks through which it passes are destroyed and often bent, forming small in size, but multi-level anticline structures.

Salt stocks destroy the primary form of rocks, creating new forms of geological bodies that meet all the criteria of hydrocarbon structure - traps. The stock adjacent areas have a significant level of fractures of rocks, and some blocks of rocks are raised by tectonic faults.

The adjacent areas are not stable, because the process of halokinesis, like most tectonic processes, is repetitive and can resume its activity in the long-formed salt domes (and other forms of saltinternal and external factors provide (may provide) migration of fluids, not least oil and gas. Among the internal factors can be identified physicochemical properties of the environment, and external include the mass of fluids and their place of greatest concentration, as well as horizontal or vertical stress.

Stress zones or tectonic active zones are found by geophysics as separate anomalies. These anomalies then become areas of compaction, thinning, or displacement of rocks near the stock. Salt stock tectonics affects the surrounding formations with varying intensities. The area of direct contact with the salt stock is the most changed, the area of tectonic faults and blocks, there are minor changes in the structure and content of rocks, the area of monoclinic strata - is part of the strata least susceptible to tectonics and changes.

The leading role of neotectonic and modern movements that determine the conditions of migration and accumulation of oil and gas is recognized by many researchers $[1,5,11]$ and is reflected in the following:

1) areas of oil and gas accumulation are genetically related to deep faults that are currently developing and are manifested in modern movements of the earth's surface; 
2) oil and gas deposits are formed in the zones of unloading of fluid systems on the way of their migration through the zones of increased fracture, where the processes of formation of secondary reservoirs take place;

3) location of oil and gas structures correlates with places of activation of tectonic processes and manifests itself in the form of relatively more intense modern vertical movements of the earth's surface and variability over time of geophysical and geochemical fields;

4) formation of oil and gas fields continues at the present stage of geological development, which makes it appropriate to use neotectonic oil and gas criteria at the exploration stage.

\section{Analysis of reservoir rocks in the stock adjacent areas of the Sakhalin deposit}

The field is located in the northern stock adjacent part of the DnieperDonetsk basin and is confined to the strip of the north-western siege of the Vysokopolsky protrusion of the foundation. (fig. 2).

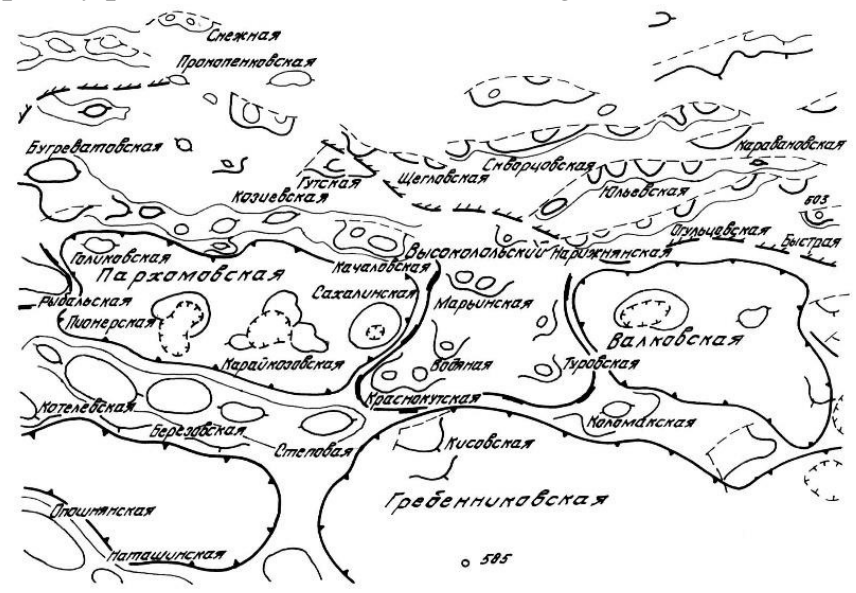

Scale 1:500000

Fig. 2. Tectonic map of the central part and east of DDB (fragment) [7]

According to the existing zoning scheme developed by MP Zyuzkevych on the predominant development of structural forms, Sakhalin field belongs to the Komyshnyansko-Kolomatsky zone of anticline uplifts [3], due tothe combined manifestation of halokinesis and block tectonics. 
The most complex geological structure is observed on the Lower Viseu-Tournai structural subfloor. There is a sharp fluctuation of thicknesses from 0 to $134 \mathrm{~m}$ in the most elevated areas and up to 193 $\mathrm{m}$ - in the submerged ones.

Along with the sedimentary super salt complex, within this part of the depression, a whole group of structures can be traced, which have a certain orientation and form separate long structural-tectonic lines, large shafts, and their deflections.

The Sakhalin uplift has a fairly clear planar position and forms a chain of annular anticlinal forms, which can be traced in the coal complex (Fig. 3).

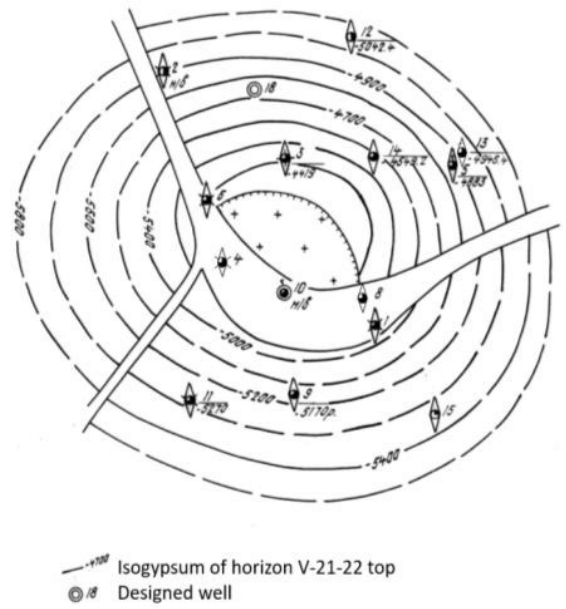

Fig. 3 Lifting structure and layout of designed wells 1,2,4,5,6,8,9,10,11,12,13,14,15 on the top of the horizon V-21-22 Sakhalin field (Solodkyi, Koliada 2009)

According to its genetic characteristics, the Sakhalin uplift (Bilyk OD, Vitenko VO, Ivanyuta MM) belongs to the type of anticlineintermittent-sedimentation salt dome class, cryptodiapir subclass, tectonically disturbed species.

Trace of the main dislocation has amplitudes of 50-800 $\mathrm{m}$ and angles of inclination of the displacement plane of rocks from varying from $30^{\circ}$ to $50^{\circ}$ up the section.

Wrench dislocations complicating the central part of the structure with amplitudes of displacement of rock strata from 20 to $100 \mathrm{~m}$, 
have a multidirectional slope, which gives it a horst and graben stepblock shape.

In general, the Sakhalin uplift on the Upper Serpukhov and Bashkir geological surface of oil and gas has a less pronounced anticlinal dome shape compared to the Upper Viseu structural plan, due to lower intensity of halokinesis. Due to this, the angles of inclination of the rocks decreased, which lie within: the northern wing $20-24^{\circ}$ and the south wing $8-10^{\circ}$, the eastern periclinal $6-7^{\circ}$ and the western $18-20^{\circ}$.

Such diverse dynamics of the manifestation of uplift in different periods of sedimentation led to the creation of three geological structural and tectonic subfloors [8].

- Visean - Lower Serpukhovsky, broken by Devonian salt and divided by the main downthrows into three stepped-submerged parts: northern, southern, and western;

- Upper Serpukhov-Lower Bashkir, formed over the Lower Serpukhov-Visei diapir structural form;

- Upper Bashkir-Moscow-Kasimov hemibrachianticlinal-horstgraben-terraced-monoclinic slope developed over the apical part of the deep diapir fold.

All three geological floors have their own structural differences, and they differ from each other in complexity and severity of structural form, its size, the degree of dismemberment of downthrow dislocations, and oil and gas saturation.

According to the results of our analysis, the differences between the floors are manifested in the values of porosity, permeability, and thickness of the layers.

Common to all structural geological floors is the heredity of the general shape and the coincidence of the apical part of the rise.

Wells 15,16,21, and 12 reveal carbon deposits, which are almost intact, in places raised layers, which are remote from the salt stock (fig. 2). In all strata discovered by wells of Viseu, Serpukhov, Moscow, and Upper Coal ages, the porosity does not exceed $8.5-2.5 \%$ (in one case $13 \%$ ).

In the blocks located close to and above the salt stock, wells $4,5,7,8,9$, and 13 have porosity values greater than 10 to $15.75 \%$. Layers of rocks that are exposed to these wells have an unsustainable 
capacity, often wedged, especially closer to the faults and above the stock.

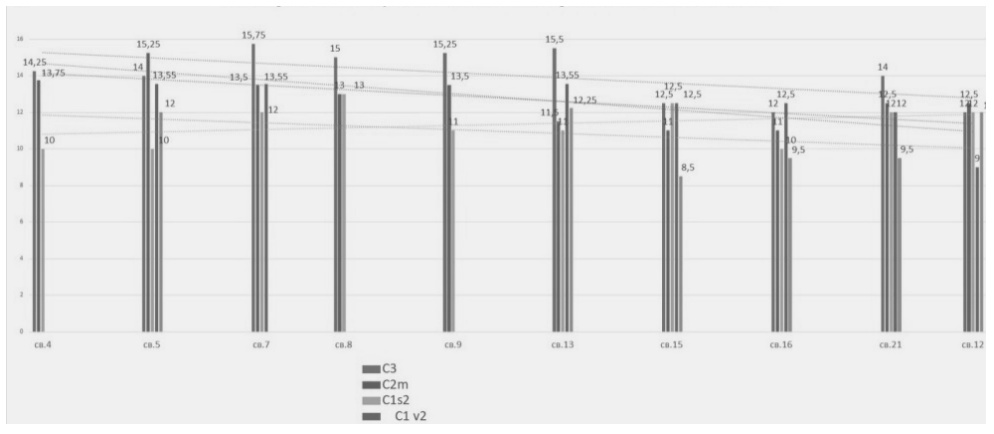

Fig. 4. Graph of changes in the porosity of coal deposits within the tributary zone of the Sakhalin deposit (Vovk M.O.)

Deposits within the section are reservoir, vaulted, dislocated, limited by downthrow dislocations, and salt stock. The total amount of sandiness of the section of the formation in the field is $62,4-82,5 \%$.

The well taking the apical position (№ 8) at the depth of $4581 \mathrm{~m}$ under the upper part of the Lower Serpukhov deposits penetrated the stock Devonian salt, and in well № 1, which is $50 \mathrm{~m}$ deeper, the stock salt was not discovered. This once again confirms the high degree of complexity of the geological composition of the structure, and especially its roof part, on the lower coal complex. Well №8 discovered the production gas potential of the Upper Serpukhov and oil saturation of the Moscow deposits (layers C-4b2, C-5b and M-2a).

The terrigenous material of pay zones is well sorted, which provides it with high filtration-capacity properties: gas permeability is

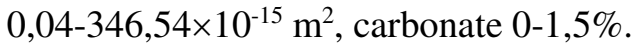

The well № 15, remote from the salt structure, with a design depth of 5,800 m, gave a weak gas manifestation in the Viseu deposits (B-16). The obtained geological information indicates a decrease in the reservoir properties of the formation rocks of the upper Viseu section.

Reservoir properties of core samples studied in the laboratory are: open porosity varies within 7,2-14,5\%, gas permeability - 0,21$94,21 \times 10^{-15} \mathrm{~m}^{2}$, carbonate $-0-21,9 \%$. 
Thicknesses of sandy rocks are quite variable, varying from $0.6 \mathrm{~m}$ (well № 12), 2.2 m (well № 16), 1.4-2.0 m (wells №№ 5, 13) to 11, 8 $\mathrm{m}$ (well 21) on the submerged parts of the field. Much higher effective thicknesses from $3.8 \mathrm{~m}$ to $16.2 \mathrm{~m}$ are confined to the central roof and the northernmost elevated part.

Thus, within the field, there may be identified areas of influence of halokinesis and potential oil and gas saturation.

After analyzing the results of exploration work within the salt stock of the Sakhalin deposit [7], we identified the main structures and elements that exist in the stock zone, the zonation of forms and the properties of rocks.

In our opinion, the rock zone associated with the salt stock has the following characteristics:

1. Tributary blocks have angles of occurrence of rock layers > $30^{\circ}$;

2. The presence of tectonic breccia. It is a mixture of rock salt and ruined rock in the stock zone;

3. The presence of a system of downthrows, or rather the presence of SSS (salt-shear structures) - zones of ancient deep faults, which are channels of fluid heat and mass transfer and are the causes of changes in the properties and types of reservoirs [1];

4. Rocks of tributary zones are weakly cemented, not compacted;

5. There is an increase in the thickness of the stratigraphic horizons (depending on the rock) from the periphery to the roof of the super salt dome.

6. The porosity of potential reservoir rocks of tributary zones is higher than within remote zones. Porosity decreases in areas of maximum deposition of layers of rocks that are least exposed to changes in shape during halokinesis (fig.3).

According to the described features, we propose to introduce a classification of tributary zones:

I - zone RR (relict rocks) - rocks that had / have the minimal influence of the halokinesis process, have a smooth, monoclinic occurrence, the lowest indicators of reservoir properties, primary rock heights (formed during diagenesis and catagenesis of rocks without the influence of tectonics). The area is characterized by the absence of deposits or is an aquifer. 
II - zone MAU (multi-storey anticline ups and downthrows), arising over the salt body as a result of its vertical movement. Reservoir rocks are maintained over the area, partially dislocated, have the original RP. The thickness and shape of the layers are slightly changed, can be reduced over the stock as a result of partial compaction (compression). The zone is often gas-bearing (aquifer) in apical uplifts tectonic-shielded by downthrow dislocations of significant amplitude, anticlinal uplifts over the salt structure.

III - TZ (tributary zone) and CRA (over the stock area, or caprock area) - the most changed zone of rocks, which contains a large number of separated blocks, shifts, thrusts, raised layers, loosened and fractured reservoir rocks. The zone is oil and gas saturated.

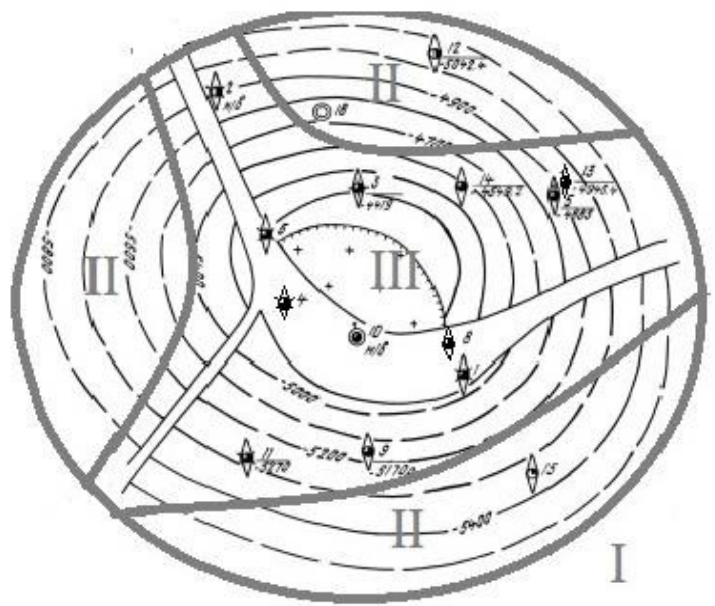

Fig. 4. Division of tributary zones according to classification and prospects of oil and gas potential: I - zone RR (relict rocks); II - zone MAU (multi-story anticline ups and downthrows); III - TZ (tributary zone) and CRA (over the stock area, or cap rock area)

The selected areas of perspective structure coincide with the drilling materials and confirm the fact that the process of halokinesis directly affects the change in the properties of reservoir rocks and the formation of hydrocarbon traps.

\section{Conclusions}

After analyzing the geological structure of DDB as a region with active halokinesis, as well as the structure of the Sakhalin field there was performed: 
- a division of tributary zones according to the features of geological, tectonic structure, forms of reservoir rocks, and their RP;

Such features of the geological structure are due to the manifestation of halokinesis structure-forming oscillatory movements in different periods of sedimentation with the inheritance of forms of structural surfaces, differing in their complexity and lithofacial type of section, type of traps, and the number and size of industrial hydrocarbon accumulations.

- the main differences in the characteristics of the reservoir rocks of the halokinesis zones are highlighted, according to which the classification of tributary zones is created;

- the model of the field corresponding to the spatial arrangement of hydrocarbon pay zones is created, based on repeated complex field and thematic seismic researches and data of prospecting and exploratory and production drilling.

It is confirmed by geological, productive profile sections and structural reference maps and can be used to perform further directions of oil and gas exploration work and rational choice of methods for studying new or additional exploration of partially discovered deposits associated with salt structures.

\section{Bibliography}

1. Vasylenko O.L. (2016) Fliuidodynamichna model pokladiv vuhlevodniv u soliano-zdvyhovykh strukturakh Dniprovsko-Donetskoi zapadyny. Visnyk Kharkivskoho natsionalnoho universytetu imeni V. N. Karazina, 23-27. http://nbuv.gov.ua/UJRN/VKhG_2016_45_5

2. Zyuzkevich M., Pavlenko P. (2003). Heolohiia, raionuvannia ta vyznachennia reitynhu perspektyvnosti heolohichnykh zon i naftohazonosnosti kompleksiv pivdenno-skhidnoi chastyny Dniprovsko-Donetskoi zapadyny. UkrNDIhaz, 46-54

3. Instruktsiia iz zastosuvannia klasyfikatsii zapasiv i resursiv korysnykh kopalyn derzhavnoho fondu nadr do heoloho-ekonomichnoho vyvchennia resursiv perspektyvnykh dilianok ta zapasiv rodovyshch nafty i hazu. DKZ (1998) https://zakon.rada.gov.ua/laws/show/z0475-98\#Text

4. Lukienko O.I. (2008) Strukturna heolohiia. TOV «KNT», 234-235.

5. Lubkov M.V. (2011) Modeliuvannia suchasnykh rukhiv lokalnykh struktur Dniprovsko-Donetskoi zapadyny. Heoiformatyka,(3), 54-60.

6. Solodkyi V.M., Bulishchenko O.M. (2009) Proekt poshukovorozviduvalnykh robit na naftu i haz u vizeiskykh vidkladakh Sakhalinskoho rodovyshcha vuhlevodniv. DP «Poltava RHP», 224 
7. Solodkyi V.M., Koliada M.I. (2009) Detalna heoloho-ekonomichna otsinka Sakhalinskoho naftohazokondensatnoho rodovyshcha Kharkivskoi oblasti Ukrainy. DP «Poltava RHP», (1), 31

8. Ustenko E.V., Petrunyak V.D., Vyzhva S.A. (2014). Suchasni pohliady na teoriiu vuhlevodnevykh system. KNU im. Tarasa Shevchenka, 59-57.

9. Fedyshyn V.O. (2003) Naukovi zasady otsiniuvannia nyzkoporystykh kolektoriv vuhlevodnevoho hazu. Lviv.

10. Jones F., Davison Ian. Seismic imaging in and around salt bodies. SEG Technical Program Expanded Abstracts 2014. https://doi.org/10.1190/segam20140047.1https://www.britannica.com/science/diapir. .

https://doi.org/10.31713/m1123

\section{EXPERIENCE IN IMPLEMENTING THE METHOD FOR DETERMINING THE INTEGRATED RISK ASSESSMENT OF ENGINEERING AND GEOLOGICAL PROCESSES FOR THE TERRITORY OF THE VOLYN-PODILSKY PLATE}

Koshliakov O. Ye.

Doctor of Geological Sciences, Professor,

Head of the Department of Hydrogeology and Engineering Geology, Institute of Geology, Taras Shevchenko National University of Kyiv

Kyiv, Ukraine

\section{Dyniak O.V.}

Candidate of Geological Sciences, Associate Professor of the Department of Hydrogeology and Engineering Geology, Institute of Geology, Taras Shevchenko National University of Kyiv Kyiv, Ukraine

\section{Koshliakova I.Ye.}

Engineer of the Department of Hydrogeology and Engineering Geology Institute of Geology, Taras Shevchenko National University of Kyiv, Kyiv, Ukraine

\section{Summary}

The condition of infrastructure facilities is directly dependent on the engineering and geological conditions of their location. Natural transformations are usually rather slow and are often determined only by consequences. The rate of destruction under the influence of man-made factors significantly exceeds the rate of natural development of the geological object. The main purpose of allocating engineering- 
geological classes (at the regional level) is to identify the most dangerous objects at the local level that require priority engineering intervention. The aim of the study is to identify, map and forecast the patterns and dynamics of negative changes in the geological environment and its main parameters which directly or indirectly affect the state of territories, regions, state as a whole for planning and monitoring the geological environment. The paper proposes an approach to the implementation of the assessment of the state of the geological environment and developed a system of criteria and indicators of assessment, both as a whole and its individual components.

The obtained maps can be used not only to study the conditions of activation and development of hazardous processes, but also for engineering and geological substantiation of measures to prevent and prevent the destruction of foundations and foundations, select priority areas for priority intervention and engineering protection of infrastructure and serve as a basis for planning and monitoring the geological environment.

\section{Introduction}

Today, almost $80 \%$ of the territory of Ukraine is in a man-made state. Urbanization of the country, the creation of powerful mining, hydraulic, reclamation, agro-industrial and other technological complexes, nuclear and thermal power plants have led to a significant increase in man-made loads on the upper geological environment and intensification of exogenous geological processes in the regional plan.

Changes in engineering and geological conditions have developed regionally as a result of intensification of dangerous geological processes - flooding, karst, landslides, reducing the bearing properties of forest soils and swellable clays, subsidence and subsidence of the loess soils due to man-made factors. This process continues to this day. Problems of assessment of engineering and geological conditions (IGC) of territories, activation of dangerous geological processes, issues of studying the conditions of their development have become a number of priority and urgent. The relevance of the research topic is determined by the rapid spread of exogenous processes, both in urban areas and in natural conditions, and the search for ways to predict and prevent them. Despite the decrease in the last 1015 years in the volume of production of some types of minerals, the general ecological condition of the environment in Ukraine as a whole is deteriorating, especially in the mining regions [1].

Due to the underflooding of large areas in Ukraine, the seismic resistance of rock massifs has significantly decreased. Large-scale shifts of the roof in underground workings cause frequent local 
earthquakes. An increasing area is covered by the underflooding process, which is progressing in industrial and urban agglomerations, where there is a significant change in landscapes and there are significant losses from water-bearing communications. In the areas of activity of coal mines, the area of subsidence of the earth's surface above the mine workings exceeds 5 thousand $\mathrm{km}^{2}$. Flooding and water saturation of soils of the aeration zone contribute to the activation of landslides, increase the area of subsidence of loess soils.

The intensification of the karst process removes large areas of developed land from economic development and threatens the functioning of economic facilities in areas of distribution of rocks that are capable of karstification. On the territory of Ukraine with intensive economic activity revealed almost 23 thousand landslides, 26 thousand karst and suffusion-karst formations. It should be noted that out of 429 cities, about $75 \%$ need engineering protection: 244 of them are underflooded; 144 are affected by gravitational processes, 50 are located on subsidence loess soils. Agricultural development of Ukraine is more than $70 \%$, of which plowed land - more than $50 \%$.

Agricultural works are associated with reclamation measures drainage and irrigation, which contribute to the integrated development of several processes: erosion, flooding, salinization, suffusion, karst, subsidence of forest soils and others. A special danger is the development of karst in the areas of sulfur deposits. The development of karst causes the loss of agricultural land and the destruction of buildings. Landslides are taking place on the sides of quarries and sludge storage facilities, which directly threaten settlements. The intensive development of karst associated with the development of potassium salt deposits in Lviv and Ivano-Frankivsk regions is extremely dangerous. Ensuring environmental safety in mining regions is one of the largest and long-term challenges, and therefore requires the development and implementation of appropriate programs.

The complex problem of formation of engineering-geological conditions and their changes under the influence of man-made factors requires the development of scientific bases and scientifically sound comprehensive assessments of these changes and their implementation $[2 ; 3 ; 4]$. 


\section{Methods of integrated assessment of ecological and geological conditions}

Integral assessment of ecological and geological conditions and implementation of zoning of the territory based on the results of studying the individual components of the geological environment is an urgent and quite difficult task.

The IGC assessment is based on the principles of combining geological, historical and environmental approaches, and has the following distinctive features: relativity, special character and specificity. Relativity is due to incomplete knowledge of the studied volume of geological environment, its structure, the processes that control its development. The special nature and specificity stem from the fact that evaluations are always carried out with a fixed purpose. The IGC assessment can be presented in quantitative and qualitative form. As the assessment is detailed, the role of quantitative assessments of indicators increases. In the process of field and laboratory geological research it is possible to obtain more than 200 characteristics of IGC, reflecting the structure, development, properties of the components of the geological environment.

The purpose of integrated assessment is to identify, map and forecast the patterns and dynamics of negative changes in the geological environment (GE) and its main parameters (geochemical, hydrogeological, engineering-geological), which directly or indirectly affect the ecological state of territories, regions, state as a whole, and preparation of a cartographic framework for planning and monitoring the geological environment. One of the main issues of assessing the ecological status of the GE is the development of a system of criteria and indicators for assessing both the geological environment as a whole and its individual components. Without an agreed system of such criteria, it is impossible to perform a reasonable mapping of parameters and characteristics of the geological environment that can be used for ecological-geological or ecological conclusions.

The main task is to collect and systematize the necessary geological, hydrogeological, geochemical, geophysical, ecologicalgeological, etc. information on the materials of previous work and research, the formation of databases of relevant starting and original data, compiling a set of preliminary, auxiliary maps or maps. In modern methodological developments, proposals for the formation of 
criteria for only certain components of the geological environment are often presented. Integral indicators are often far from clear and unambiguous.

When collecting the necessary materials and data, it is necessary to proceed from the position that the accumulated and systematized information should highlight the role and importance of natural and man-made (anthropogenic) factors in shaping the ecological state of the geological environment. Accordingly, data on the state of the geological environment and the factors that determine it can be divided into two groups: natural and man-made.

The first group combines data on climatic, landscape, geological, structural-tectonic, geochemical, hydrological, engineeringgeological, hydrogeological, seismic conditions and pollution of geological components under the influence of natural processes and factors. The second group includes information on man-made objects, sources of environmental pollution and various economic activities, as well as the nature, features, levels of changes in the geological environment under their influence.

The value of different types of information about the natural conditions of the territory, which can be used in assessing the state of the geological environment and solving problems of ecologicalgeological mapping, is determined as follows:

Information on climatic conditions should provide an assessment of the impact of climate on the development of exogenous geological processes, the formation of geochemical characteristics of landscapes, the properties of rocks in the aeration zone, the formation of groundwater (regime, quality). It is recommended to collect information on the following indicators:

- air temperature, its annual fluctuations;

- soil temperature, depth and duration of seasonal freezing;

- humidity (absolute, relative), its annual change;

- the amount of precipitation (annual, average monthly, maximum, minimum, duration of dry and wet periods);

- snow cover (thickness, duration of standing, maximum - minimum for the period of observations);

- long-term trends in temperature, precipitation, snow cover;

- wind rose, predominant directions and speed of air flows;

- state and changes in solar activity. 
Hydrological information should provide an assessment of: the role of the river system in the formation of ecological and geological conditions of the geological environment (landscape, relief, water intake, migration routes of chemical elements and their compounds, etc., features of functional use; hydrodynamic connection of surface and groundwater; and the natural hydrochemical state of surface waters (rivers, reservoirs).

The information includes data on:

- catchment area of major rivers;

- surface watercourses (length, duration of floods and flood areas);

- river runoff (average annual, average monthly water flow, minimum and maximum levels, runoff modulus, flow velocity, longterm trends in flow and water levels);

- natural and artificial reservoirs (water mirror area, depth and volume of water mass, water level regime);

- hydrochemical and qualitative composition, mineralization, salt composition, geochemical relationship between composition, water type and lithological composition of rock complexes);

- the possibility of using surface water for drinking water supply (subject to minimal man-made pollution);

- bottom sediments (lithochemical composition, capacity, nature of distribution in the channel, geochemical characteristics, the presence of sediments that can be used as organic fertilizer in agriculture and other sectors of the economy - type of sapropel);

- bogs (area of distribution, genesis, water supply conditions, capacity of peat and silt).

Information on the state of natural landscapes should be the basis for assessing their importance in the system of ecological and geological conditions of territories, the formation of geochemistry of the modern landscape, definition and interpretation of migration conditions of chemical elements and their compounds. At the same time, such information should be used as a morphogenetic basis of the landscape-geochemical map [5].

Prior to collection, data on:

- types of landscapes (bioclimatic latitudinal-altitude zonation);

- classes of landscapes (composition, nature of soil cover);

- genera of landscapes (groups of genetic types of relief); 
- types of landscapes (paragenetic series or groups of series of Quaternary formations);

- intensity of the biological cycle of chemical elements;

- the nature of physico-chemical migration of elements and their compounds in soils;

- intensity of water exchange and mechanical migration of elements;

- participation of the root substrate in the formation of geochemistry of the modern landscape;

- geochemical specialization of landscapes (natural);

- the ability of landscapes to self-clean;

- biogeochemical provinces and their characteristics.

Geomorphological data is an important component of information used in mapping ecological and geological conditions of the territory, in particular to clarify the position of tectonic faults, decipher neotectonic movements, determine the role of relief elements in migration and concentration of chemical elements and various compounds, substances; distribution and intensity of exogenous geological processes.

Data that characterize or determine are subject to collection and systematization:

- relief morphometry, its vertical and horizontal dismemberment, meso- and microforms of relief;

- density of modern river and ravine network;

- relief structure, its forms and genesis, connection with morphostructural and geological-tectonic factors;

- the influence of relief morphometry on the distribution and intensity of exogenous geological processes;

- influence of relief morphostructure on lateral and vertical migration and concentration of chemical elements, their compounds; substances in solid and liquid state.

Information on soil types, their agrochemical and agrogeochemical features and condition is extremely important for determining, assessing, forecasting ecological and geological conditions of territories. Soils should be considered, on the one hand, as a biomineral substrate for the existence and nutrition of all living things, and, on the other hand, as a sorption barrier that protects groundwater from pollution. Soils are the most sensitive indicator of ecological- 
geochemical and ecological conditions of the territory, because they are located at the intersection of all migration routes of chemical elements and their compounds, including toxic ones. Therefore, they require careful and detailed study of ecological and geological mapping.

Soil information is collected and systematized by the following items:

- main genetic types of soils;

- vertical and horizontal zonation of soils;

- plowing and erosion of soils;

- humus content;

- spotting of soil composition;

- geochemical specialization of soils (associations of chemical elements that can accumulate and elements of removal; leading elements that determine the specialization of soils, geochemical backgrounds of elements, natural geochemical anomalies and fields, geochemical barriers);

- values of biogeochemical transition coefficients in the soil-plant system;

- spatial and genetic connection of geochemical composition of soils with parent rocks;

- sufficient or insufficient supply of soils with macronutrients (phosphorus, potassium);

- sufficient or insufficient supply of soils with micronutrients (manganese, zinc, copper, cobalt, molybdenum, boron);

- threshold values of the content of chemical elements in soils;

- maximum permissible concentrations of pesticides in soils.

Data on the composition, basic properties and characteristics of rocks will allow in combination with other information to fully assess the ecological and geological conditions of a particular area. You need to ensure the collection of data on:

- the nature of the geological section, lithological and petrographic composition of rocks, lithological-facial features of rocks at depths determined by geological tasks;

- mechanical properties of rocks (humidity, cavernousness, porosity, cracking, porosity, mechanical composition, etc.);

- basic stratigraphic-genetic complexes; 
- geochemical specialization of rocks and complexes, individual zones and fields, including aeration zones;

- natural radioactivity of rocks;

- zones with anomalous filtration, migration and gas-geochemical parameters (mercury vapor, radon, methane, etc.);

- geophysical fields (magnetic, gravitational, electromagnetic) and their anomalous zones;

- geopathogenic zones.

Data on the main characteristics and parameters of rocks are supplemented by information on structural-tectonic and neotectonic conditions of the territory, including:

- main tectonic structures and their position, influence on exogenous and endogenous characteristics and conditions of the geological environment;

- zones of compaction, fracturing, crushing of rocks, which can be considered as channels of gas components from the geological subsoil to the surface, and as zones of penetration of pollution into the lower horizons of the geological-hydrogeological section;

- zones of modern tectonic movements and their influence on the distribution and activity of exogenous geological processes (velocities, velocity gradients, total amplitudes of movements); changes in hydrodynamic parameters of groundwater;

- zones of seismogeological activity.

Information on hydrogeological conditions should provide their ecological assessment and ecological-geological mapping.

The following indicators and characteristics are subject to systematization and analysis [6]:

- features of geological and hydrogeological development, distribution and depth of the main aquifer complexes and horizons;

- geological structure and characteristics of the aeration zone (capacity, lithological composition, physical-mechanical and waterphysical properties, the presence of anomalous zones, windows, etc.);

- depth of static levels of groundwater and interstratal waters;

- natural protection of the first from the surface and other aquifers;

- groundwater regime, the nature of changes in time of groundwater levels, major operational and other aquifers and complexes; 
- patterns of changes in the filtration properties of water-bearing and water-resistant rocks in space (in plan and depth); features of filtration (horizontal and vertical) of waters in the aeration zone;

- the main hydrogeological parameters of the water-saturated stratum, which lies above the first regional and local water-resistant layers, and in the case of interconnection - and the underlying aquifers and complexes, especially those used for commercial (drinking) water supply, including filtration and water conductivity, piezoconductivity;

- the direction of regional and local groundwater runoff, the main areas (places) of supply and unloading of groundwater of major aquifers and horizons;

- the relationship of groundwater and interstratal waters, as well as groundwater and surface water, with the definition of modules of groundwater and surface runoff and their changes in space and time;

- the presence of abnormal conditions of nutrition and pollution of groundwater with an assessment of their structure, values and contribution to the overall balance of the aquifer system or its parts;

- changes in mineralization and hydrogeochemical composition of groundwater by area and section (macro- and microcomponents, gas composition, aggressiveness, Eh, $\mathrm{pH}$ );

- spatial parameters of the distribution of temporary ground water and underflooded areas that occur under the influence of man-made activities;

- current state of groundwater resources, groundwater deposits with approved and unapproved operational reserves, which are operated and not operated.

To assess the engineering and geological conditions of territories, the impact of hazardous geological processes and phenomena (exogenous and endogenous) on the ecological state of the geological environment, the following information on exogenous geological processes is required:

- characteristics of areas prone to the development of dangerous processes and phenomena (flooding, karst, landslides, villages, landslides, etc.) under natural conditions;

- assessment of the degrees (levels) of damage to the territory by dangerous exogenous processes and phenomena, determination of natural factors arising from their development and spread; 
- assessment of the spread and development (both in area and depth of the geological section) of dangerous processes and phenomena;

- assessment of the risk of exogenous geological processes and phenomena that can cause significant damage to structures, facilities, various services or lead to catastrophic consequences for endogenous geological processes:

- characteristics of the modern block structure of the territory (macro- and meso-blocks, the direction and speed of their modern vertical movements, the magnitude of the absolute rises and falls of individual blocks and the resulting stresses in the subsoil);

- characteristics of the identified seismogeological zones (zones of natural seismicity);

- characteristics, hazard assessment of seismically generating tectonic zones;

- assessment of the impact of mud volcanism on the increase of seismicity of the territory.

The second group of information indicators, which must be collected and systematized, includes data on:

- functional use of the work area;

- man-made changes (pollution) of the state and quality of the environment, certain components of the geological environment in particular;

- man-made objects and sources of pollution that affect or may affect the ecological state of the environment and the geological environment in particular;

activation of dangerous exogenous and endogenous geological processes and phenomena.

Information on the functional use (zoning) of the territory should characterize:

- modern structure of perspective economic use of the territory;

- zoning of the territory according to the levels of man-caused disturbance of natural landscapes;

- main objects, zones of different types of natural resources that are used or can be used for economic development;

- areas of objects under special protection. 
Information on man-made objects and sources of pollution should determine:

- type, name of the object or source of pollution (enterprises, industries, agriculture, utilities, toxic and radioactive waste storage, solid waste landfills, storage of mineral fertilizers and agricultural chemicals, communication facilities and systems - oil and gas pipelines, railways, highways, canals);

- field of activity or nature of operation;

- administrative position and geographical coordinates;

- time of commissioning of the facility;

- characteristics of industrial waste entering the environment or stored;

- condition or type of insulation of solid waste and various discharges from the environment;

- type of waste - gaseous waste (emissions into the atmosphere), liquid discharges, solid waste;

- volumes (volumes) of waste ( $\mathrm{t} /$ year, $\mathrm{m}^{3} /$ year);

- chemical (geochemical) composition of waste, quantitative content of chemical elements;

- availability of treatment facilities, places of storage and disposal of waste;

- pollution of atmospheric air, groundwater, soil in comparison with current regulations;

- intensification of hazardous geological processes associated with the activities of the enterprise.

Based on the collected data, an inventory of hazardous man-made objects and sources of pollution and a scheme (map) of man-made objects and sources of pollution are compiled.

At the final stage of research, a generalized (integrated) assessment of the ecological state of the geological environment and zoning of the study area, according to the levels of ecological state of the geological environment $[7 ; 8]$.

\section{Methods of integrated assessment of engineering and geologi- cal conditions}

Depending on the natural and economic conditions and the priority tasks to be solved in specific urban areas, the methodological approaches to the assessment of the IGC vary widely. 
Due to the fact that there are no common approaches to such research, the method of integrated assessment of IGC is being developed independently. The selection of calculation systems that characterize the properties of the components of the GE is based on the following requirements: they must be universal; to reflect as much as possible the conditions influencing stability of buildings and constructions; easy to determine on the basis of standard cartographic materials, or easy to deduce on the basis of processing laboratory, experimental, field observations. When estimating IGC, such calculation complexes can be: for relief characteristics - morphometric parameters of relief; to assess the properties of soils - physical and mechanical properties, as well as the conditions of occurrence; for the assessment of groundwater - the conditions of their occurrence and quality composition; to assess geological processes - the type of process, its intensity and the impact of the defined area.

As the IGC integrated assessment for different types of engineering development is detailed, the role of quantitative indicators increases significantly. Given the diversity of IGC and the goals of engineering development of GE, it is almost impossible to offer a single, universal list of calculation systems.

In determining the role of selected calculation complexes in the formation of IGC specific GE and their impact on engineering activities, their ordering is carried out with the determination of the quantitative value of the weighting factor.

To identify the main factors in the formation of IGC and determine the list of settlement complexes, it is advisable to use basic maps that have a common and legitimate content, as well as a way to display the information provided. In order to take into account, the properties of GE components and their degradation under the influence of engineering activities, to determine the category of favorable IGC for engineering development, maps are grouped as follows: soil suitability - geological and engineering-geological; geomorphological conditions - geomorphological and manifestation of geological processes; influence of groundwater - hydrogeological and manifestation of geological processes. The need for grouping of maps is dictated by the procedure of checking the significance of the selected calculation complexes on the main one, which is the basic one. The main requirement for maps is uniformity and display of indicators on 
the basis of which it is possible to make a reasonable selection of areas homogeneous in structure and with a close response to engineering development. To take into account the spatial variability of the IGC, all maps are divided into an equal number of equal squares operational-territorial units. Each of them is assigned an operating index.

Based on the fact that each point of the operational-territorial units has a set of indicators that characterize its properties, and operations with a multidimensional field of indicators are very time consuming, the introduction of an integrated indicator allows to deal with a field of one value that characterizes the whole set of properties. Of course, the integrated indicator should represent as much as possible the variety of states of the components and contain the maximum information about them.

If the area for which the IGC is estimated is quasi-homogeneous in terms of components, then one value of the integrated indicator is obtained. In the case of inhomogeneity of the territory, the integrated indicator for each quasi-homogeneous area is calculated and the model of the field of integrated indicators is rebuilt, which allows to estimate the category of IGC complexity in any part of the modeled territory. For the transition to scalar quantities in the calculation of the integrated indicator used the method of scoring expert assessments. This method is one of the few methods of quantifying indicators that are mostly classified as "qualitative" and their mathematical processing together with quantitative indicators that have different units of measurement. Due to the different level of scientific and methodological development of the selected calculation complexes in the regulatory documentation, each of them was divided into a certain number of conditional points.

The introduction of normalized scores and coefficients of significance reduces the subjectivity inherent in the expert method of solving multicriteria problems. An integral indicator of IGC is the weighted average estimate, which is defined as the sum of the given normalized score estimates of calculation complexes, taking into account the prevalence of the latter in the territory $[9 ; 10]$. 


\section{Basic principles and stages of integrated assessment risk of engineering and geological processes.}

This technique is presented in the form of an algorithm of actions that can be used to study any area, which determines the universality of the development.

To start research in the selected area, you need to have a set of primary information materials. A very important stage of the study is a preliminary analysis of the territory for the presence or absence of engineering and geological processes. At this stage, it is necessary to analyze a set of factors and conditions that determine the probability of occurrence and the degree of activity of each process. The analysis of factors of formation is carried out, as a rule, on the results of monitoring observations for the presence of cases of intensification of processes in the area, stock materials of past research, cartographic materials and meteorological observations in the research area.

Next, the analysis and selection of factors for the formation of engineering and geological processes in the area. A number of factors of formation are analyzed for the presence of a dangerous process and the result is a list of engineering and geological processes specific to the area.

The next stage of the study is to build maps of manifestations of engineering and geological processes types from a number of previously selected. An assessment of the area of existing distribution and the degree of activity of this process, as well as the area of influence of this process during its activation.

Thus, based on the analysis, each type of exogenous processes characteristic of the area, receives a specific parameter and spatial position parameters. Based on this, it is possible to plot the calculated areas on a cartographic geoinformation basis and obtain maps of the distribution (areas of influence) of exogenous geological processes by types. A separate map of its distribution and impact is built for each researched process. The obtained maps of engineering and geological processes manifestations will have a binary type, ie the territory will be divided into several zones, depending on the intensity of the manifestation of the process.

The next step is to directly build risk maps of exogenous geological processes specific to the study area. Using GIS technologies, the plane parameter of the spread of the impact of the dangerous process 
obtained earlier is assigned a score of the intensity of the impact of each type of engineering and geological processes separately. As a result, we obtain a set of risk maps of engineering and geological processes manifestations for each of their types separately.

Next, it is necessary to implement the spatial combination of previously obtained maps. The purpose of summarizing the data is to determine the integrated risk of exogenous geological processes characteristic of the study area. The summary of these risk maps can be performed using the tools of GIS technologies implemented in software packages such as ArcGis and ArcViev. Using automated summation and spatial aggregation algorithms, not only the planar parameter is summed, but also the score for each of the engineering and geological processes types.

Final schematic maps of integrated risk of exogenous processes. is a visual summary of engineering and geological processes risk maps, which shows the imposition of different types of process risks. Map shows the result of summing the score of the intensity of manifestations of exogenous processes in the study area [9;11].

Implementation of the method of determination integrated risk of engineering and geological processes on the territory of Volyn-Podilska plate.

The basis for the construction of cartographic material is information of two types: graphic (positioning of objects in the coordinate system) and attributive (properties of the object). In accordance with the purposes of mapping the areas of presentation of engineering and geological processes manifestations, graphic information can be obtained both by the field mapping method and by processing the results of aerospace surveys.

The main principle in the construction of cartographic material is to determine the area of plots in which the manifestations of engineering and geological processes were recorded. To identify areas with active processes and areas where processes have ever been recorded, monitoring data, information on engineering and geological processes manifestations on Volyn-Podilska plate as technical reports on engineering and geological surveys in the area were used. 
The result of the analysis of engineering and geological processes, characteristic of the study area, was the construction of schematic maps of the following list of natural geological processes:

- landslide processes;

- karst process;

- flooding and inundation processes;

- plane erosion processes.

Thus, after determining the characteristic engineering and geological processes, it is necessary to set the spatial boundaries of the zones within which the presence of a certain process is detected. With the help of the ArcGis 10.1 software package, operations of summation of polygonal objects are determined, which determine the spatial distribution of conditions and factors that determine the manifestation of one or another exogenous geological process.

To further assess the integrated risk of engineering and geological processes, it is necessary to divide the study area into parts of the most representative dimensions, in the scale of cartographic material $1: 3000000$ and the area of the study area $90783 \mathrm{~km}^{2}$ is a cell of $1000 \times 1000 \mathrm{~m}$. The construction of all maps in this work is performed for their further analysis. These notations on the map are not accurate representations of real-world objects and have been chosen for convenience and clarity. Therefore, given these circumstances, the size of the cell $1000 \times 1000 \mathrm{~m}$ is considered sufficient.

The division into elementary cells was performed using the software package ArcGis 10.1, namely GeoWizards (create Vector Grid). Created Vector files, after filling them with attribute information, were converted to Raster files using Conversion Tools (Feature to Raster).

The formed raster images, spatially and geometrically coincide with the studied area. The pixels of this raster image were created in the size of $1000 \times 1000 \mathrm{~m}$ according to the conditional cells.

Since $74.2 \%$ of the territory of Ukraine has widespread rocks in which karst can develop under certain conditions, it was decided to start building maps from this process. The whole territory of VolynPodilska plate is changed by karst formations (Fig. 1). The large karst region is represented by the southern part of Polissya and the Volyn-Podilska Upland, which adjoins it from the south. Affected 
areas of karst landforms range from 0 to 76 units $/ \mathrm{km}^{2}$, the average values are in the range of 4-12 units $/ \mathrm{km}^{2}$. The average area affected is $105.5 \mathrm{~m}^{2} / \mathrm{km}^{2}$ and the volume affected is $57.6 \mathrm{~m}^{3} / \mathrm{km}^{2}$. The average age of the studied karst funnels is 25-40 years. Some forms of 100 , 120 and more than 200 years of age were identified, as well as numerous cases of new failures; the dynamics of the development of the surface karst relief is significantly differentiated by the territory from the rapid leveling of depressive forms and reducing their number to intensify the process with the constant formation of new funnels and depressions.

Within the study area, sub-areas of covered $45 \%$, semi-covered karst $48 \%$ and to a much lesser extent open karst $7 \%$ predominate.

Landslides are the most dangerous exogenous geological processes in Ukraine. Landslides can occur on all slopes, starting with a slope of $19^{\circ}$, but on clay soils and cracked soils, landslides can occur with a slope of $5-7^{\circ}$. They are formed mainly in areas of moist soils, when the force of gravity of the products of rock destruction accumulated on the slopes exceeds the force of soil adhesion. [12]

Landslide processes are intensified in the south of on the territory of Volyn-Podilska plate (Fig. 2).

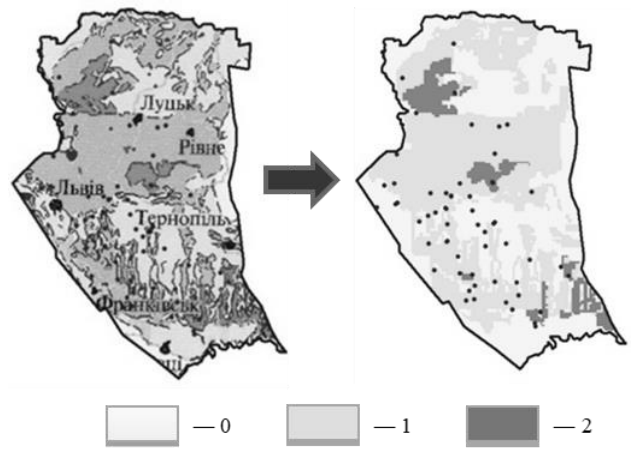

Fig. 1. Map -scheme of karst manifestations on the territory of Volyn-Podilska plate ( 0 - areas of covered karst, 1 - semi-covered karst, 2 - open karst) 


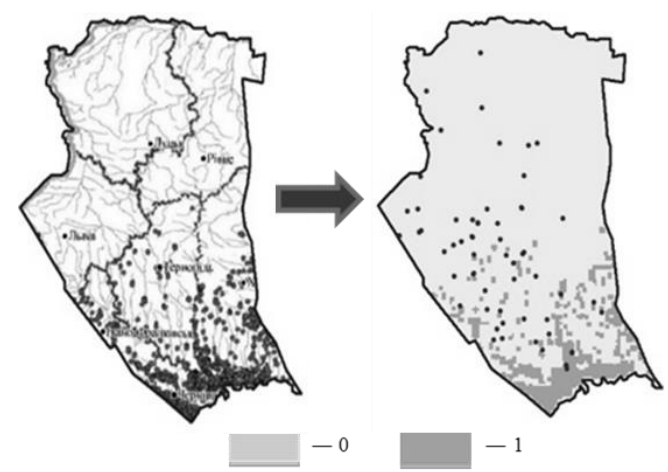

Fig. 2. Map -scheme of the spread of landslides on the territory of VolynPodilska plate ( 0 - no landslides, 1 - development of landslides 1 and 2 categories)

Almost $10 \%$ of the region's territory is affected by landslides, their area is about $908 \mathrm{~km}^{2}$, and the total number is more than 640 landslide-prone areas, $80 \%$ of which are related to economic activities.

Most landslides are concentrated on the right bank of the Dniester River (within Ternopil, Khmelnytsky, Chernivtsi regions). The largest meanders of the Dniester River are dominated by frontal landslides, where there are shifts of considerable size - from several thousand square meters to 13 million $\mathrm{m}^{2}$. It is safe to say that all facilities in the south of the territory of Volyn-Podilska plate are at risk.

Quite large areas of $49 \%$ of the territory of Volyn-Podilska plate have a high degree of subsidence (Fig. 3).

Sedimentary processes are characteristic of areas in the geological structure of which there are connected, often loess soil. To confirm this statement, it is advisable to build a schematic map of cover soils the territory of Volyn-Podilska plate (Fig. 4).

On the territory of Volyn-Podilska plate is dominated by $52 \%$ sand, with inclusions of boulders, and cohesive soils of $27 \%$, represented by moraine-boulder loams. The central part of the territory of Volyn-Podilska plate is characterized by $21 \%$ loess soil. 


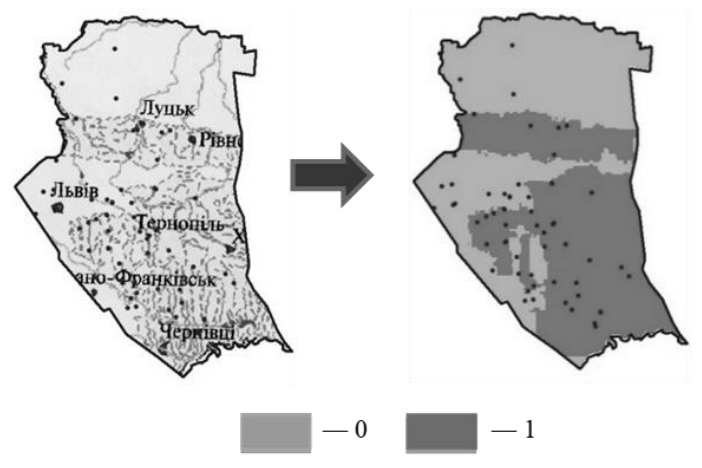

Fig. 3. Map -scheme of subsidence processes on the territory of Volyn-Podilska plate ( 0 - no landslides, 1 - development of landslides 1 and 2 categories)

It is safe to say that the prevalence of cohesive and loess soil has determined the subsidence in the south part of the territory and in its central part.

These soils are waterproof - easily and quickly eroded, soaked, in areas of their distribution are also widely developed ravine-beam formations, rapidly destroying the banks of rivers, lakes, reservoirs, many manifestations of landslides, upflows, solifluction, landslides on the slopes.

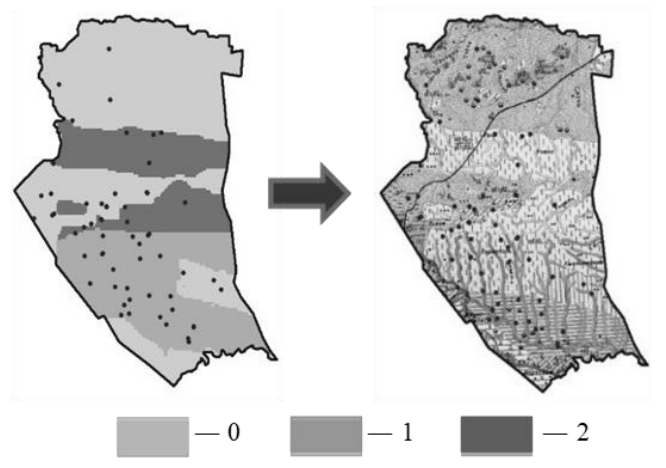

Fig. 4. Map -scheme of cover soils on the territory of Volyn-Podilska plate (0 sandy soils, 1 - cohesive soils, 2- loess soil) 
This geological structure of the territory determines the development of not only subsidence, but also underflooding processes (Fig. 5).

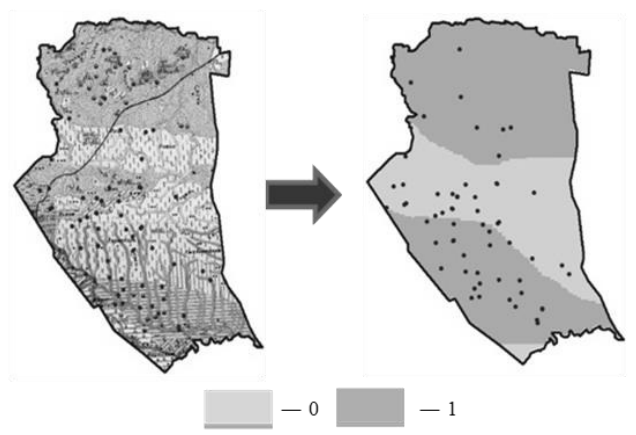

Fig. 5. Map -scheme of underflooding on the territory of Volyn-Podilska plate ( 0 - groundwater depth from the surface $>5 \mathrm{~m}, 1$ - groundwater depth from the surface $<5 \mathrm{~m})$

About $68 \%$ of area the territory of Volyn-Podilska plate is underflooded, with a groundwater depth of $0-5 \mathrm{~m}$ from the surface. In the region the territory of Volyn-Podilska plate and the HalychVolyn basin, the spread of underflooding is observed on the area of 26.03 thousand $\mathrm{km}^{2}, 415$ settlements are underflooded. The largest areas of underflooding were recorded within Rivne (11.7 thousand $\mathrm{km}^{2}$ ) and Volyn regions (9.14 thousand $\left.\mathrm{km}^{2}\right), 216$ settlements are underflooded. Within the rest of the underflooded regions (Lviv, Ternopil and Khmelnytsky) the area of underflooding is 5.19 thousand $\mathrm{km}^{2}, 199$ settlements are flooded. The total area of flooding within the Lviv region alone is 0.25 thousand $\mathrm{km}^{2}$. The total area of underflooding within the Lviv region alone is 0.25 thousand $\mathrm{km}^{2}$.

Underflooding is both natural, sources of flooding - precipitation (melt, flood and rainwater) and man-made. A significant area of underflooding is due to the natural conditions of the territory and is associated with the formation of the region of regional high position of groundwater levels $(0-2.0 \mathrm{~m})$.

The largest areas of flooding are due to mining operations in the Lviv-Volyn basin in the Lviv region. In addition, due to the destruction of sewerage and mine drainage systems and leaching of groundwater toxic components from the rocks of mine dumps, which 
are widely used to fill flooded areas, groundwater has become polluted and unfit for domestic drinking.

Ivano-Frankivsk, Ternopil and Chernivtsi oblasts generally belong to the territories for which the underflooding process is not typical, but flooding areas are also recorded within these territories. It is in the southern part of of Volyn-Podilska plate that partial underflooding is associated with local manifestations of rising groundwater levels.

The position of the groundwater levels deeper than $5 \mathrm{~m}$ allows to refer the areas to areas with a low probability of flooding. Geomorphologically, the Malopolska Upland corresponds to them.

In order to comprehensively assess the impact of engineering and geological processes and phenomena on the current state of geological envairoment within the research area, it is necessary to take into account not only engineering and geological processes that are active, but also factors influencing their activation and further development. In this regard, it is advisable to build the following schematic maps of natural and geological factors:

- map of tectonic movements of the Earth's surface;

- map of erosion of cover soils;

- map of man-caused load;

- map of dynamic impact from main roads;

- and seismicity map.

Tectonics and neotectonics are crucial in the formation of relief and the development of geological processes that affect engineering objects. Endogenous geological processes increase the contrast of the relief and create its most significant forms, respectively - the conditions for the development of exogenous processes. Different direction of tectonic movements contributes to the vertical dismemberment of the terrain and the activation of certain groups of exogenous processes: for areas of uplift - it is erosion, landslides, landslides; for areas of subsidence - flooding, salinization, subsidence of loess soil.

On the territory of the the territory of Volyn-Podilska plateonly in small areas of $21 \%$ there are stable modern movements of the earth's crust (Fig. 6). Such seemingly insignificant areas of active tectonic zones (in the south-west and north) do not ensure the stability of the central part of the the territory. The intensity of 
activation of dangerous exogenous processes depends on the intensity of movements of the earth's crust and can occur in remote areas for thousands of kilometers. It is the spatial differentiation of the velocities of modern movements of the earth's crust that determines the intensity of manifestations of modern geological processes.

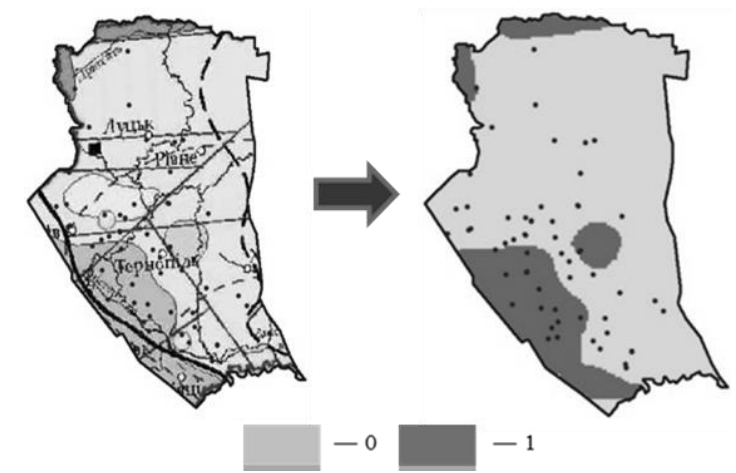

Fig. 6. Map -scheme of of neotectonic movements on the territory of VolynPodilska plate $(0$ - movements are absent or insignificant, 1 - constant modern movements of the earth's crust)

Seismicity is one of the most influential factors that determine the engineering and geological conditions of the territory. The most intense seismic influence is present in the south-western part of Ukraine within the narrow zones of seismically generating deep faults. Until the $70 \mathrm{~s}$ of the twentieth century. It was mistakenly believed that in most of Ukraine, located on the ancient Eastern European tectonic platform, significant seismic events are impossible, so most structures were built without seismic protection measures.

But as we know today, in general up to $40 \%$ of Ukraine can be directly affected by dangerous seismic events and up to $70 \%$ - the combined effects of earthquakes and floods, landslides, subsidence and other engineering and geological processes that adversely affect the stability of structures.

The most intense seismic influence is present in the south-western part of Ukraine. The result of the schematic map of the impact of the Vrancea zone on the study area (Fig. 7) is the following conclusions: $43 \%$ of the the study teretory is in the 6-point impact area, $44 \%-7$ points and $13 \%$ - in the area of possible shocks with an intensity of 8 
points. In addition, local earthquakes can occur in different parts of the Ukrainian Carpathians, the impact of which cannot be ignored either.

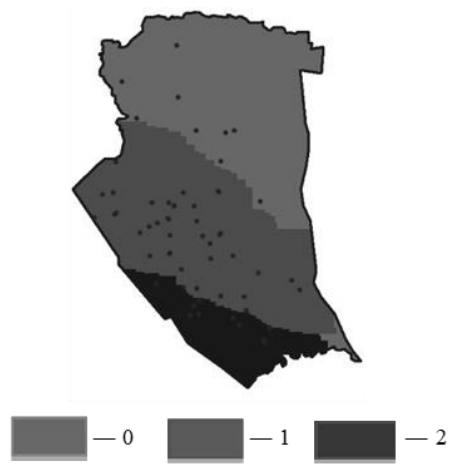

Fig. 7. Map -scheme of seismic activity on the territory of Volyn-Podilska plate (0 - 6 scores, 1 - 7 scores, 2 - 8 scores)

A special factor is man-made (induced) seismicity, which reduces the seismic stability of rocks in the upper zone of the geological section (conditional increase in score). Dynamic loads experienced by geological bodies in wave fields during earthquakes, as well as vibrations from the work of mechanisms and transport, cause changes in physical and mechanical properties of soils and the nature of geological processes, which mainly determines changes in engineering and geological conditions.

That is, in urban areas, in addition to the threat of seismic activity, there is a kind of vibrational background (from roads and highways). Most often during the action of seismic waves there is a decrease in the stability of soils in the foundations of structures, sometimes to a critical state.

Under the influence of man-caused vibrations, certain negative engineering-geological processes (rarefaction, compaction, subsidence) are at the stage of activation or become potentially active, which can cause damage to engineering structures. Vibrational oscillations propagating from highways are transmitted to the soil, affecting their strength properties, and then to the 
foundations of buildings and structures, leading to damage to their structures.

The loss of soil strength under dynamic loads is influenced by a large number of interrelated factors. These are external (parameters of dynamic influence) - acceleration of oscillations, frequency; internal factors - mineral composition, structure, condition, physical and chemical properties; the third group of factors depends on the structure of the array.

The intensity of dynamic oscillations are directly dependent on the intensity of road traffic (Fig. 8). It is logical that the maximum threat is posed by European (E) roads, with maximum road congestion. Ways of international $(\mathrm{M})$ and national $(\mathrm{H})$ connection with less dynamic load within the agglomerations, Lviv, Ternopil, Lutsk, due to their combination create significant dynamic loads on the territories.

Vibrations from transport propagate mainly in the upper part of the soil layer, according to Lokshin up to $10-15 \mathrm{~m}$, because most of their energy is transported by surface Rayleigh waves.

Approximately to these marks the foundations of most buildings and communications are deepened [13].
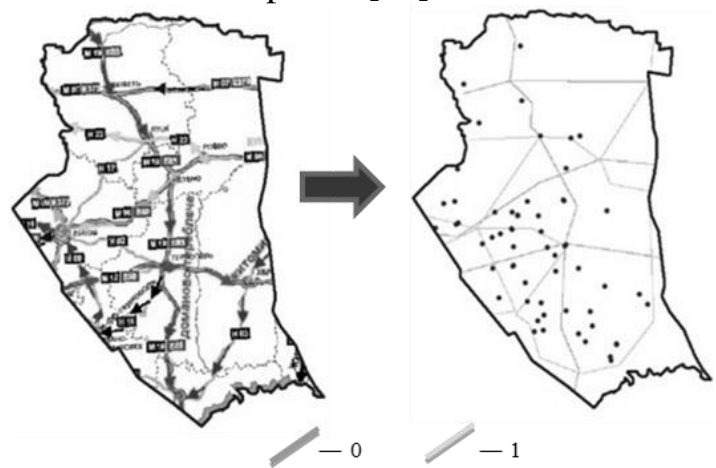

Fig. 8. Map - scheme of highways on the territory of Volyn-Podilska plate (0 ways of international / national communication, 1 - ways of European communication)

Another rather unfavorable process is planar soil erosion. The intensity of erosion depends on a number of factors, the main of which are climatic conditions (precipitation intensity, amount of 
snow cover), terrain, mechanical and structural composition of soils, waterlogging of the territory.

Eroded soils ( $24 \%$ of the total area) can be traced in the south and southwest of the territory of Volyn-Podilska plate. This is due to the terrain, altitude differences increase from north to south, the nature of the soil base, on sandy and structured soils erosion is weaker than on clay, cohesive and poorly structured soild, clays and loams are easily eroded, and seasonal ground water.

The consequences of man-caused impact on the geological envairoment are manifested in changes in mineralogical, geochemical, geodynamic, geomorphological, hydrogeological and engineering-geological nature.

Often the consequences of the above changes are the intensification and development of dangerous geological processes.

In Fig. 9 shows the intensity of the spread of pollution as a consequence of man-made impact on urban areas. Most of the territory of Volyn-Podilska plate, $75 \%$, belongs to halos with aboveaverage pollution levels, of which $10 \%$ have a critical man-made load. It is logical that such territories correspond to the cities and the Chernobyl Exclusion Zone. Since in almost all regions of Ukraine, including the territory of Volyn-Podilska plate, created powerful agro-industrial technological complexes of nuclear and thermal power plants man-made loads on the upper zone of the geological environment is growing and only in small areas $25 \%$ level of manmade load does not exceed average. [14]

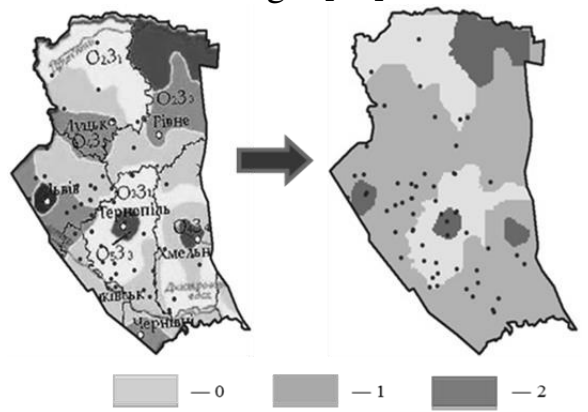

Fig. 9. Map - scheme of the intensity of man-made load highways on the territory of Volyn-Podilska plate ( 0 - pollution below average, 1 - pollution above average, 2 - high pollution) 
The obtained raster images of the territory, with the values of the score coefficient separately, must be summed up using cartographicmathematical algorithms for adding raster images, such as MapAlgebra. The values of the cells that coincide in area location are summed and a matrix of values is formed, ie a new raster layer with a cell size of $1000 \times 1000 \mathrm{~m}$ and the total value of the coefficients of scoring the intensity of detection of the processes under consideration [11].

Thus, the total raster (Fig. 10) is a visual reflection of the result of an integrated assessment of the spread ofengineering and geological processes on the on the territory of Volyn-Podilska plate.

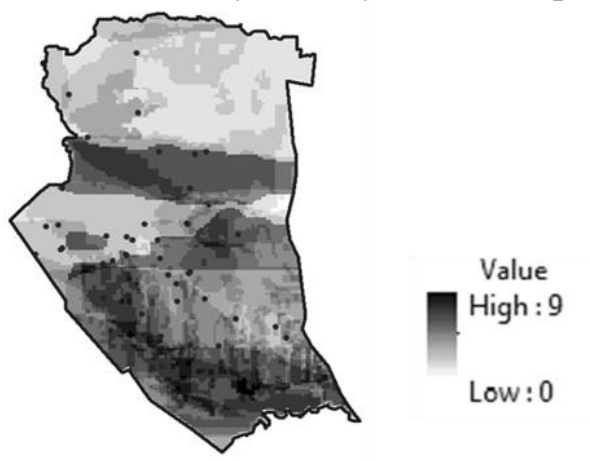

Fig. 10. Map - scheme intensity of manifestations of engineering and geological processes on the territory of Volyn-Podilska plate

According to the results of the study, the area of the territory of Volyn-Podilska plate was divided into 226960 cells measuring $1000 \times 1000 \mathrm{~m}$ with a total area of $567,400 \mathrm{~km}$. The range of permissible cell values is from 0 to 2 , based on a 3 -point rating scale. Valid range of cell values from 0 to 9 .

The given map - scheme (Fig. 9) is auxiliary and overview. The large number of classes makes it inefficient and inconvenient for further use, so the final stage is the process of reclassification and creating a map of the complexity of the engineering and geological processes of the study area.

In Figure 10 shows the resulting schematic map by thinning the area according to the degree of complexity of the engineering and geological condition. Figure 11 shows the final schematic map of the integrated risk of exogenous processes. This shows the result of 
summing the score of the intensity of exogenous processes in the study area and is the resulting schematic map with the ranking of the area according to the degree of risk of engineering and geological processes. This diagram shows the ranking by degree of risk into three classes. First class - less than 3 points, which is a low risk; second - from 3 to 7 points (average degree of risk); third - more than 7 points (high risk).

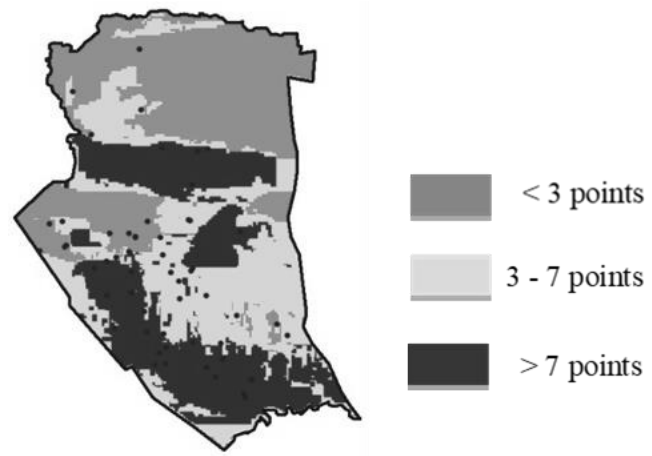

Fig. 11. Map - scheme complexity of engineering and geological conditions on the territory of Volyn-Podilska plate

This scheme reflects the division of the territory into three classes. The first class - less than 3 points, represents rather favorable conditions; the second - from 3 to 7 points (unfavorable); third - from 7 to 9 points (destructive).

The first class - intensity of displays of dangerous geological processes can be carried to neutral - the processes destroying constructions or are absent, or their display on stability of a monument does not influence.

The second class - a combination of dangerous processes in the area is unfavorable, but they develop slowly or a set of processes is not critical.

The third class - areas where the development of engineering and geological processes is complex, maximum and its impact on geological environment can be defined as destructive, it is characterized by a significant area of development of many dangerous processes that develop at a significant rate. 
The main purpose of the allocation of such engineering and geological classes (at the regional level) is to identify the most dangerous objects at the local level that require priority engineering intervention.

From the economic point of view, it is much more expedient to conduct a periodic integrated assessment, which will provide for the intensification and development of hazardous engineering and geological processes and help reduce the cost of protection measures against their impact, than capital restoration work.

\section{Referens}

1. Prusov, D.E. (2015). The methodology for the forecasting consequences of engineering preparation for transformation the urban areas in dense building and complex geology conditions. Proceedings of the National Aviation University, 63, 2. $40-45$.

2. Bondaryk, G.K. (1981) General theory of engineering (physical) geology. Moscow: Nedra. [in Rassian]

3. Gozhyk, P.F., Demchyshyn, M.G., Bida, S.V. (2010). Features of engineering-geological processes in the conditions of urbanized territories. III all-Ukrainian scientific-practical conference "Problems and prospects for the development of academic and university science", Poltava, Ukraine. 9-13. [in Ukrainian]

4. Kril, T.V. (2008). Vibration influence on the geological environment of cities. Geological Journal, 2, 91 - 99. [in Ukrainian]

5. Koshliakov, O., Dyniak, O., Koshliakova, T., Koshliakova, I. (2018). Hydrogelological peculiarities of calculation of scarps and slopes stability within urbanized territories. Visnyk of Taras Shevchenko National University of Kyiv. Geology, 4 (83), 79-83. http://doi.org/10.17721/1728-2713.83.11. [in Ukrainian]

6. Koshliakov, O., Dyniak, O., Koshliakova, I. (2019). Modeling in monitoring system of underground hydrosphere for territories under technogenic pressure. XI International Scientific Conference "Monitoring of Geological Processes and Ecological Condition of Environment", Kyiv, Ukraine. https://doi.org/10.3997/2214-4609.201903232..

7. Veklych, M.F. et al. (1993). Stratigraphic scheme of Quaternary deposits of Ukraine. Kyiv: Hoskomheolohyia. [in Rassian]

8. Richards, L. E. (1986). Conserving geological sites. British geologist, 3 (12), 92-95.

9. Hrokholskyi, N.S. (2013). Methodology for determining the integral risk of exogenous geological processes. Heorysk, 2, 46-47. [in Rassian]

10. Demchyshyn, M.G., Anatskyi, O.M., Kril, T.V. (2007). Information security of entry into protection and preservation of cultural and natural decline. VI International Scientific and Practical Conference - Modern information technologies for environmental safety management, nature management, emergency measures, Kyiv-Kharkiv-Crimea, Ukraine.

11. Dyniak, O., Koshliakova, I. (2021). Experience in the implementation of methods of spatial and system analysis in the study of the geological environment of 
historical sites. International Scientific and Practical Conference "World Heritage Sites: Sustainable Urban Heritage Practices", Kyiv, Ukraine. [in Ukrainian]

12. Exogenous geological processes. SRPE "Geoinform Ukrainy". http://geoinf.kiev.ua/ekzohenni-heolohichni-protsesy

13. Kahan, A. A., Kryvonohova, N.F. (2005). Methodology of geotechnical research in the reconstruction of buildings and structures. Geoekologiya, 3, 275-282.

14. Lomtadze, V.D. (1978). Engineering geology. Special engineering geology. Moscow: Nedra. [in Rassian].

https://doi.org/10.31713/m1124

\section{ESTABLISHMENT OF REGULARITIES OF FLUVIOGLACIAL DEPOSITS AND PROBLEMS OF THEIR EXTRACTION IN THE DEVELOPMENT OF ROCK DEPOSITS OF BUILDING MATERIALS}

Frolov A. A.

National Technical University of Ukraine "Igor Sikorsky Kyiv Polytechnic Institute", Doctor of Technical Sciences, Docent, Professor, Ukraine

\section{Zhukova N. I.}

National Technical University of Ukraine "Igor Sikorsky Kyiv Polytechnic Institute", Candidate of Technical Sciences, Docent, Ukraine

\section{Lytvynchuk I. D.}

National Technical University of Ukraine "Igor Sikorsky Kyiv Polytechnic Institute", PhD Student, Ukraine

\section{Beltek M. I.}

National Technical University of Ukraine "Igor Sikorsky Kyiv Polytechnic Institute", PhD Student, Ukraine

\section{Lukomskyi V. R.}

Taras Shevchenko National University of Kyiv, student, Ukraine

\section{Abstract}

The subject of research in the presented scientific work are the patterns of distribution and features of fluvioglacial deposits on the territory of Ukraine, as well as possible technological schemes and equipment complexes for extraction of fluvioglacial deposits. 
Methodology. To solve these problems was used a comprehensive approach, which consists of: analysis and generalization of previous research in the field of studying the peculiarities of occurrence of fluvioglacial deposits, as well as the effectiveness of using technological complexes for the extraction of gravel-sand mass; technological substantiation of the offered scientific decisions; analytical calculation of the productivity of the technological complex depending on the size of the rock mass.

The aim of the research is to substantiate the expediency and efficiency of using the proposed bulldozer-excavator-automobile complex with the use of ripperbulldozers to remove the overburden layer of fluvioglacial deposits in rock deposits.

Results of the research. Based on the current state of mining operations and the availability of the existing equipment in the quarries of Sosnivsky and Yaroshivsky deposits for the removal of the layer of fluvioglacial deposits, the use of a combined bulldozer-excavator-automobile complex is recommended. Depending on the size of the work area, there are two options. In the first case, it is proposed to use a hydraulic excavator with a backhoe, placed on the covering of overburden. In the second version of the excavator type «straight shovel» is located below the working horizon and is loaded with gravel-sand mass, which is dumped by a bulldozer.

Empirical and graphical dependence of the variable productivity of the excavator on the average size of a piece of gravel-sand mass for the quarry conditions of the Sosnivsky deposit is obtained. It is established that within the limits of change of size of gravel-soil materials from 20 to $120 \mathrm{~mm}$, productivity of excavators decreases 1,43 times: for the return shovel from $624,1 \mathrm{~m}^{3} / \mathrm{shift}$ to $436,2 \mathrm{~m}^{3} / \mathrm{shift}$; for straight shovel from $728,1 \mathrm{~m}^{3} / \mathrm{shift}$ to $508,8 \mathrm{~m}^{3} / \mathrm{shift}$. In general, the productivity of the excavator with a straight shovel is $17 \%$ higher than the productivity of the backhoe.

\section{Introduction}

In recent years, the mining of mineral raw materials (mainly building materials) in an open way reveals new patterns of structure of the sedimentary complex and even the upper part of the crystalline basement of the Middle Dnieper. In particular, this applies to fluvioglacial deposits, which are distributed in sufficient quantities in Ukraine.

The features of the extraction of fluvioglacial sediments, which affect the justification of the parameters and the choice of technological schemes of their development, include [1-3]:

- a wide range of changes in the properties of rocks that are part of these deposits, particle size distribution, the presence of layers of other rocks;

- a variety of conditions of mineral occurrence;

- the degree of water of fluvioglacial deposits;

- heterogeneity of quality indicators of deposits; 
- a significant change in the volume of their occurrence in some areas.

Timely detection of these features determines the further efficiency of the removal of fluvioglacial deposits. The reliability of geological information at the stage of geological surveys is important in this case. Taking into account changes in the geological conditions of deposits within the land allotment, namely changes in the fractional composition of gravel and sand mass, especially the content of coarse gravel and boulders, and the presence of interlayers allows at the design stage of the mining company to take measures to prevent complex emergencies in the workplace.

In the development of gravel and sand deposits, ie when fluvioglacial deposits are classified as minerals, geological assessment of occurrence conditions is performed for an individual object when preparing a feasibility study to calculate reserves. According to the instructions for the application of the classification of reserves, gravel and sand deposits are divided by size and quality characteristics of the productive layer, [1] namely:

- large and medium-sized stratum and stratum-type with variable quality properties of sand and gravel;

- small lenticular with unsustainable power and inconsistent quality of useful components.

As we can see, the volume of minerals within the field, the structure of the deposit, and the content of gravel and boulders are the most important indicators that determine the economic efficiency of field development.

When designing the development of rocks, the deposits of which are covered with gravel-sand mass, fluvioglacial deposits are referred to as overburden. In this case, little attention is paid to the structure of their occurrence and patterns of distribution of the fractional composition, which in the future, during the development of the field, may be difficult, and in some cases impossible, to remove the layer of overburden.

In recent years, in mining in the development of mineral deposits in the open method, scientists have identified several important areas for improving the extraction of minerals [4,5]. These include determining the conditions for safe and efficient operation of mining equipment, qualitative justification for establishing rational parame- 
ters of development systems, improvement of technological schemes of mining and processing of minerals and selection of the most expedient technological complexes of equipment.

If these areas are attributed to the removal of fluvioglacial deposits, the issue of safety and efficiency of their development is particularly acute, as they have received insufficient attention. Therefore, the development of recommendations that determine the effective operation of a particular technological complex in specific conditions of the field is an important scientific and technical task.

Thus, the analysis of scientific publications and industrial experience in the development of fluvioglacial deposits shows that the technological process of their extraction needs to be improved primarily through justification and selection of optimal for the given conditions, technological complex of equipment.

\section{Regularities of fluvioglacial deposits on the territory of Ukraine}

Fluvioglacial includes a group of sediments that are formed as a result of washing out, transfer and deposition of moraine material by streams of melting glacial waters. There are two main genetic types of fluvioglacial deposits: intraglacial and glacial (periglacial). Intraglacial deposits are formed as a result of deposition of material inside the melting glacier (in the upper and inside glacial ice channels). Glacial deposits have accumulated outside the melting glacier as a result of the deposition of meltwater material washed from intraglacial areas and marginal moraines.

Fluvioglacial deposits are genetically related to moraines, but in contrast they usually have a certain sort by size of material, can be layered and occur in the form of removal cones, lenses and channels of intraglacial flows. Glacial deposits are characterized by rapid change of coarse pebbles and boulder sands with fine-grained obliquely stratified sands as they move away from the glacier.

Fluvioglacial deposits in the form of cones of removal are the most common and occur cloak-shaped with erosion on the final and main moraines. Their thickness is quite unstable, ranging from 0.5$3.5 \mathrm{~m}$ above the moraine to $16-35 \mathrm{~m}$ on the beds and hills. The removal cones are mainly composed of packs of well-washed and sorted sand-gravel-pebble material from boulders, sand and gravel- 
pebble-boulder deposits (Fig. 1) [6]. These deposits are often overlayered in sections and contain inclusions of ablative moraine. The thickness of fluvioglacial rocks has a horizontal stratification with a small distal slope, and in the interlayers and lenses - oblique and horizontal stratification. The angle of inclination of the obliquely layered series is $7-45^{\circ}$. In the removal cones, subsidence dislocations are observed, which are expressed in discharges, flexor-like bends of stratification, and others. More coarse pebble-boulder and sand-gravel material usually lies on high inland areas. In the distal direction, the debris of the removal cones becomes smaller and more homogeneous. Fluvioglacial deposits often contain lenses, pellets and blocks of the main moraine, and on the slopes are covered with a cover of ablative moraine.

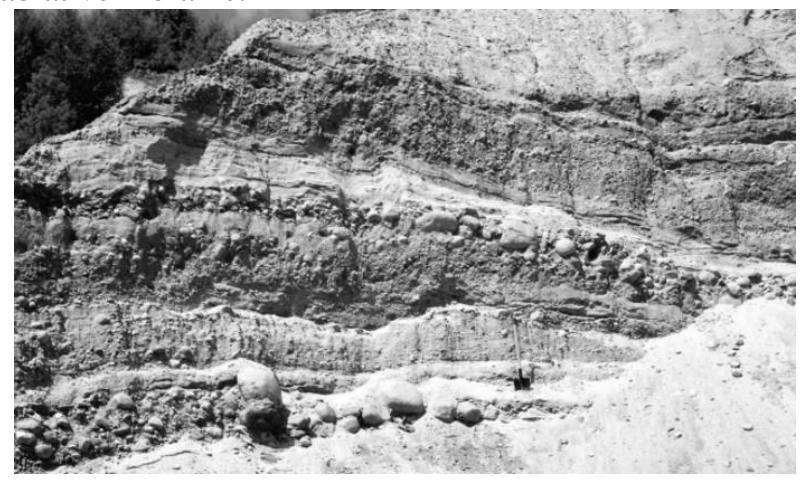

Fig.1. An example of the deposition of fluvioglacial cones of removal in the quarry [6]

Fluvioglacial deposits, according to the ICS (International Stratigraphic Commission), belong to the Quaternary system and are confined to the upper tier of the Pleistocene part of the Quaternary system (Table 1) [7].

Table 1

Subdivisions of the Quaternary sediment system

\begin{tabular}{c|l|l|l}
\hline \multirow{2}{*}{ System } & \multicolumn{1}{|c|}{ Series } & \multicolumn{1}{c|}{ Stage } & \multicolumn{1}{c}{ Age, m.y.a } \\
\hline \multirow{5}{*}{ Quaternary } & \multirow{3}{*}{ Holocene } & Meghalayan & $0,0042-0$ \\
\cline { 3 - 4 } & & Northgrippian & $0,0082-0,0042$ \\
\cline { 3 - 4 } & & Greenlandian & $0,0117-0,0082$ \\
\cline { 2 - 4 } & \multirow{4}{*}{ Pleistocene } & Upper & $0,129-0,0117$ \\
\cline { 3 - 4 } & & Chibanian & $0,774-0,129$ \\
\cline { 3 - 4 } & & Calabrian & $1,80-0,774$ \\
\cline { 3 - 4 } & & Gelasian & $2,58-1,80$ \\
\hline
\end{tabular}


Continental types of Quaternary deposits are widespread on the territory of Ukraine: aeolian-deluvial, glacial (actually glacial and waterglacial), alluvial (Figs. 2 and 3) [8,9]. They are the result of the Middle Pleistocene glaciation of the Oka River and the Dnieper River.

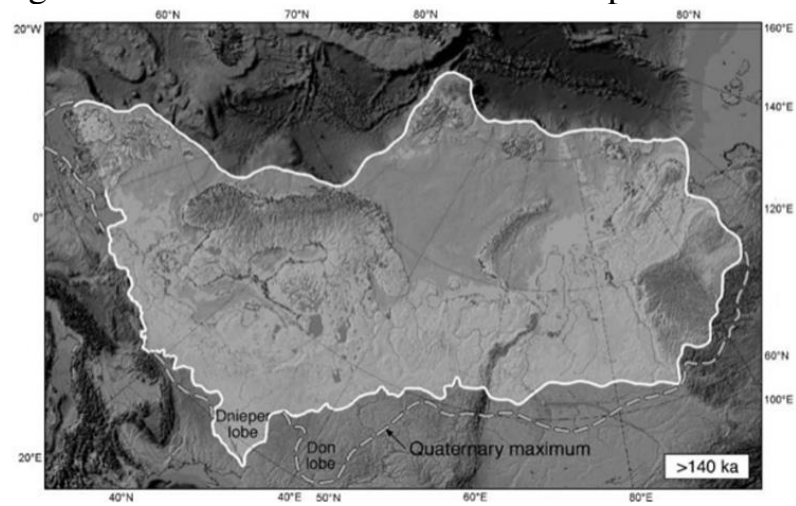

Fig. 2. Limits of distribution of cover glaciers [8]

Actually glacial deposits, or moraines, consisting of unsorted fragments of bedrock, boulder clays, loams, sands are common within the ancient (Oka and Dnieper) glaciation.

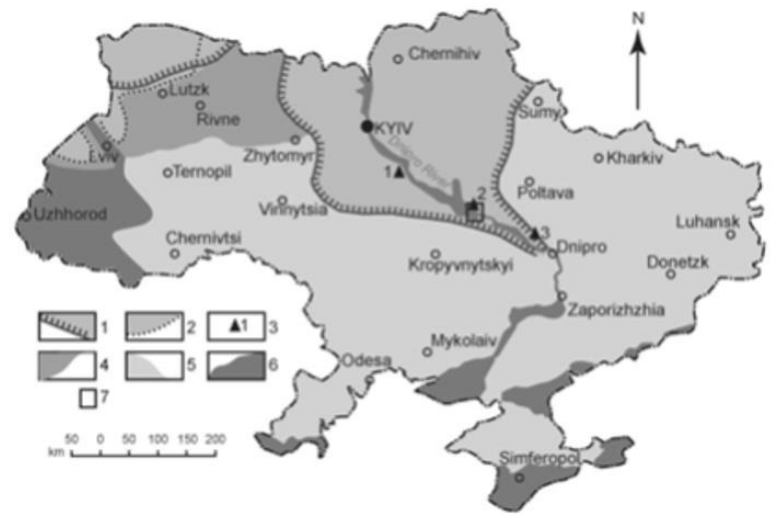

Fig. 3. Simplified map of Quaternary glacial deposits of Ukraine: 1 - the southern border of the Dnieper glaciation; 2 - the southern boundary of the Elster (Oka) glaciation; 3 - glaciodislocations (1 - Kaniv, 2 - Pyvykha, 3 - Kalytva); 4 - falling out zone of fluvioglacial deposits; 5 - territory of forest and forest-like deposits; 6 - areas where glacial deposits are not common; 7 - the area under study [9] 
The Oka Glacier was distributed only in the extreme northwestern part of Ukraine. This glacier is comparable to the Ulster Glacier of Western Europe.

The Dnieper Glacier is comparable to the Western European Saalia Glacier. The Dnieper moraine is spread over large areas of the Polissya lowland, Podil upland, Dnieper upland and Dnieper lowland. The most distinctive features of the Dnieper (Ryska) ice age in the north of the Middle Dnieper are the giant erratic boulder on the right bank of the Dnieper near the village Domotkan' and morainefluvioglacial hill, known as Mount Kalytva. The glacial tongue stretched far to the south and reaches the latitude where the city of Kamyanske is located [9].

The southern limit of the distribution of glacial deposits passes near the Dnipro. The thickness of rocks of glacial genesis varies from a few to $20-30 \mathrm{~m}$, sometimes up to $100 \mathrm{~m}$. Glaciodislocations and glaciodistrictors are widespread in the regional zone of the Dnieper Glacier. Water-glacial (fluvioglacial) deposits (sands, pebbles, sandy loams, loams, clays) lie above and below the moraine, and also form peculiar landforms (kames, eskers, sandr). Subaquatic clays, sandstones, sands, peat, gyttja with a total thickness of up to 5-10 m accumulated in the interglacial period, and subaquatic fossil soils accumulated outside the glaciation. In the periglation zone of the glacier (the so-called cold steppe) loess were formed.

In the northern regions of Ukraine there are both glacial and fluvioglacial deposits. Glacial deposits or tills composed of unsorted boulders and pebbles of different composition and age in a fine-grained clay silt matrix. Sediment thickness from 0,5 to more than $18 \mathrm{~m}$ [9].

Fluvioglacial deposits often underlay and even cover the till and create characteristic landforms - kames, eskers and sandy plains. Terrain forms are mainly composed of sandy, clayey rocks. The thickness of water-glacial formations varies from the first meters to $50 \mathrm{~m}$, the maximum - 100-120 $\mathrm{m}$.

Areas to the south and east of the tills are covered with loess deposits in which burial horizons of paleosoils are found. Total capacity from 5 to $50 \mathrm{~m}$.

Scientists have identified two mutual glacial sheets. The NorthWestern or Scandinavian-Finnish stream, dominated by boulders from Sweden and Western Finland, occupies a large part of Belarus 
and the territory west of the Volyn region of Ukraine. The second Nord Stream covered large areas of the European part of Russia, Belarus, as well as the northern and central parts of Ukraine. The Nord Stream was formed later than the Scandinavian-Finnish Stream and was much longer. Boulders and pebbles of northern and northeastern origin have in their composition mainly of Vyborg rapakivi, Shokshin sandstones, Silurian Devonian and coal sandstones [9].

The Dnieper climatolite is composed of glacial formations that lie on pre-Quaternary deposits and are widespread in the glacial zone. Dnieper climatolite is divided into lower, middle and upper Dnieper stadials. The Lower Dnieper stadial is composed of fluvioglacial deposits - fPIIdn1. The Middle Dnieper stadial is represented by lakeglacial, moraine and fluvioglacial deposits, which correspond to the middle and upper packs of the "Shevchenko suite" - $\lg$ PII $d n 2$. The section of the lower part of the Middle Dnieper climatolite is completed by lake-glacial deposits that cover the bottom moraine. The Upper Dnieper stadial is represented by the regional moraine $g k$ PII $d n 3$, the outputs of which are best represented on Mount Kalytva. Fluvioglacial deposits of Kalytva are very dislocated, oblique layered, diverse in granulometric composition, sometimes containing carbonized plant remains, fragments of petrified wood [8].

\section{Technological complexes of equipment for extraction of fluvi- oglacial deposits}

Of the total number of quarries of non-metallic building materials located within the Dnieper glaciers, a significant share (10-20\%) are quarries that develop sand-gravel deposits of fluvioglacial deposits, ie they are used as minerals for sand production, stone and rubble. However, in many cases, in particular in the extraction of building stone on rubble or blocks, fluvioglacial deposits are classified as overburden, because they are located on top of the rock mass and completely or partially block access to the mineral [10]. The average thickness of such deposits is about $10 \mathrm{~m}$. Traditional technologies for removing the layer of fluvioglacial deposits, which are used in their development as minerals, in deposits of rock building materials are usually inefficient and impractical, as the vast majority of them use hydromechanization equipment. Deposits of boulders of considerable size require powerful extraction and loading equipment. It should 
also be noted that the problem of removal of fluvioglacial deposits usually arises in quarries not at the stage of discovery of the deposit, but in the process of its development. In this case, the process of removing the layer of sand-gravel mixture is further complicated by the limited working space and the lack of appropriate extraction equipment.

The technology of development of fluvioglacial (sand-gravel) deposits depends on the percentage of gravel-boulder material in them. Gravel-boulder material can be placed on the entire thickness of the sediment, and form local areas of accumulation. Therefore, it is very important at the stage of field exploration to study in detail the composition and structure of the thickness of the overlying rocks composed of fluvioglacial deposits.

In [11] the following classification of fluvioglacial (sand-gravel) sediments (Table 1) is proposed.

Table 2

Fractional composition and size of fluvioglacial deposits

\begin{tabular}{l|l|c}
\hline \multicolumn{2}{c|}{ Fractions } & Size, mm \\
\hline \multirow{4}{*}{ Boulders } & Large & more 400 \\
\cline { 2 - 3 } & Medium & $201-400$ \\
\cline { 2 - 3 } & Small & $101-200$ \\
\hline \multirow{4}{*}{ Gravel } & Large & $41-100$ \\
\cline { 2 - 3 } & Medium & $21-40$ \\
\cline { 2 - 3 } & Small & $5-20$ \\
\hline \multirow{4}{*}{ Sand } & Coarse-grained & $1-5$ \\
\cline { 2 - 3 } & Medium-grained & $0,5-1,0$ \\
\cline { 2 - 3 } & Medium-fine-grained & $0,25-0,5$ \\
\cline { 2 - 3 } & Fine-grained & $0,1-0,25$ \\
\hline Dusty and silt particles & & $0,005-0,1$ \\
\hline Clay particles & & less 0,005 \\
\hline
\end{tabular}

The thickness of sediments in different areas can vary from a few meters to 25-40 $\mathrm{m}$ and more.

Also, according to scientists, when estimating fluvioglacial sediments, depending on the average content and ratio of sand, gravel and boulders, it is necessary to use certain geological terms (Table 3) [12]. 
Table 3

Names of gravel-sand rocks depending on the ratio of sand, gravel and boulders

\begin{tabular}{l|c|c|c}
\hline \multirow{2}{*}{ Rock } & \multicolumn{3}{c}{ Contents, \% } \\
\cline { 2 - 4 } & sand & Gravel and boulders & Boulders \\
\hline Sandy & $90-100$ & $\leq 10$ & 0 \\
\hline Gravel-sandy & $10-90$ & $10-90$ & $\leq 5$ \\
\hline Boulder-gravel-sandy & $10-90(85)^{*}$ & $10-90(85)^{*}$ & $>5(5-80)^{*}$ \\
\hline
\end{tabular}

Technological schemes for the development of sand and gravel deposits and the equipment used are very diverse. This is due to the difference between mining and geological and hydrogeological conditions, the volume and thickness of sediments, the service life of the quarry, the fractional composition of the material that makes up the thickness of the cover rocks, and the availability of equipment to effectively remove the fluvioglacial layer.

The most common equipment for the extraction of such rocks are excavators, namely excavators such as «mechanical shovel», hydraulic excavators with direct or reverse shovel and draglines. Rotary and multi-bucket excavators, wheel loaders, bulldozers, wheel scrapers, rope scrapers, tower excavators and hydromechanization equipment are much less commonly used. If the field is flooded, floating dredgers with different types of executive body are used.

At development of dry layers of fluvioglacial deposits the technological scheme with excavator extraction of breeds frontal pit face and loading in motor transport is recommended. The main advantages of this scheme are the operational separation of boulders and coarse-grained material from the main rock mass, selective extraction of layers of sand, clay and sand-gravel rocks (if fluvioglacial deposits are represented by them). However, if the volumes of fluvioglacial deposits are small and they are developed as the mining front advances in the quarry, the technological scheme of excavation of this layer of rocks with the help of excavators is very difficult to implement, and in some cases impossible. This is due to the limited space for mining, namely the small size of the work site, or the lack of powerful quarry excavator equipment capable of developing a compacted boulder-gravel stratum. 
If the deposit is partially flooded, draglines are mainly used, which stack gravel-sandy rock mass in piles for dewatering to natural humidity. After that, the rocks are shipped by different types of loading equipment to vehicles. There are several technological schemes for processing fluvioglacial deposits with draglines, depending on the degree of waterlogging of rocks, the thickness of the gravel-sand mass and its volume and the width of the mining front [11]. However, in deposits of rocks covered with fluvioglacial deposits, which are related to overburden, the use of dragline to extract sand-gravel stratum is possible only in powerful deposits with a significant volume of overburden, low content of boulder and gravel material and at the stage of discovery the front of mining operations (namely the width of the work site) is not limited by mining ledges.

Rope scrapers and tower excavators can be used effectively in the development of dry and waterlogged rocks. The capacity of the rope scraper bucket can be $4 \mathrm{~m}^{3}$ and more, and the distance between the towers can exceed $200 \mathrm{~m}$. The main tower of the rope scraper can be movable or immovable. There is experience in the use of rope scrapers in the development of sand and gravel deposits, ie when fluvioglacial deposits are classified as minerals. The main disadvantages of field development with rope scrapers and tower excavators include: leaving the pillars in places adjacent to the main support, losses in which can reach up to $20 \%$ [13]; sharp decrease in productivity of work of the equipment at increase in distance of scraping; inability to use in the winter. Also, the efficiency of the tower equipment is significantly affected by the particle size distribution of sand-gravel mass and the presence of boulders.

Therefore, it is obvious that the use of rope scrapers and tower excavators in rock deposits to remove the layer of fluvioglacial deposits will be inefficient and impractical due to the small volume of disclosure.

Scraper technological complexes are mainly used for mining and preparatory works, as well as as the main equipment in the development of placer and sand-gravel deposits. The extraction of sand and gravel rocks is carried out under the condition that the mountain massif is represented by soft rocks and in the absence of boulders. Movement of the scraper is possible on rise no more than 10 . The effective average transport distance is not more than $600 \mathrm{~m}$ with a 
bucket capacity of 6-10 $\mathrm{m}^{3}$ [14]. Scraping schemes are characterized primarily by the location of the dump relative to the contour of the quarry. For the removal of the layer of fluvioglacial deposits, the most acceptable schemes are the placement of rock mass on board the quarry (the simplest and most economical) (Fig. $4 a$ ) or on external dumps (less appropriate) (Fig. 4b).
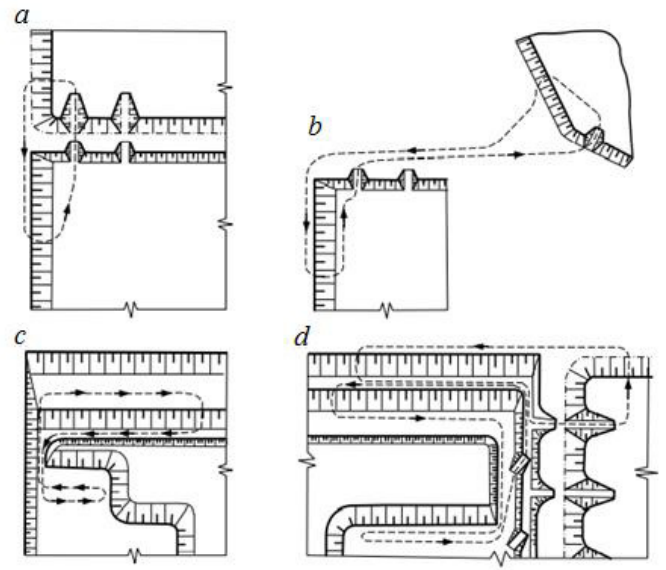

Fig. 4. Basic scraping schemes [14]

When using scraper technological complexes, the extraction of rocks is usually carried out by end faces. The minimum length of the face should not be less than the distance of filling the rock with a scraper bucket $1 \mathrm{H}$. For medium power and powerful scrapers, it is 30 $50 \mathrm{~m}$.

At preliminary preparation of breeds for extraction by mechanical loosening of inclined layers the minimum length of a face $l_{\text {B.min }}>50 \mathrm{~m}$. To reduce the downtime of the scraper complex in the presence of strong inclusions (boulders, etc.), waterlogging of rocks, etc. it is necessary that the length of the face satisfies the condition.

$$
l_{\mathrm{B}}>2 l_{\mathrm{B} \cdot \min },
$$

that is, the length of the scraper face during the development of soft and dense rocks was not less than 60-100 m.

Therefore, the possibility of using scraper complexes in the extraction of overburden rocks represented by fluvioglacial deposits is 
influenced by the presence (absence) of boulders and a sufficient length of the face to fill the scraper bucket.

Bulldozers are widely used in mining and preparatory, planning and ancillary works, as well as the main equipment in the development of placer and sand-gravel deposits. The development is carried out by fans, parallel longitudinal or transverse, diagonal or combined approaches (Fig. 5). The average distance of rock mass transportation by bulldozers varies between $70-120 \mathrm{~m}$. When calculating the productivity of the bulldozer complex, it is necessary to take into account the complexity of rock excavation, the distance of rock mass movement and the content of boulders.
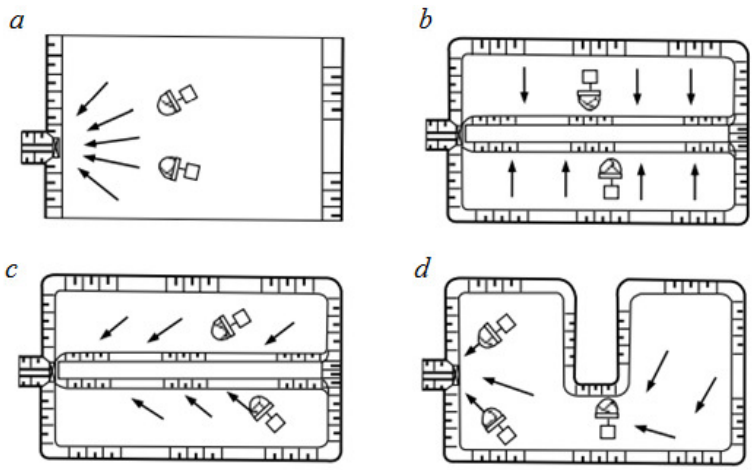

Fig. 5. Options for the development of placer and sand-gravel deposits [14]

Bulldozer development of overburden is considered appropriate if it is performed at the power of overburden $H_{p} \leq 3-4 \mathrm{~m}$ and moving a distance $L \leq 100-150 \mathrm{~m}$ in external dumps. With increasing power of bulldozers ( $200 \mathrm{~kW}$ and more), their use in the open pit in the development of fluvioglacial deposits is effective in $H_{p} \leq 6-10 \mathrm{~m}, L \leq 200$ $250 \mathrm{~m}$ and at an angle of rise up to $27^{\circ}$.

From the combined technological complexes which can be applied to extraction of fluvioglacial deposits, it is possible to allocate scraper-bulldozer and bulldozer-excavator complexes $[14,15]$. They are used to create the most efficient working conditions for each or the main type of equipment. First of all, the distance of movement of the rock mass by bulldozers decreases. Scraper-bulldozer technological complexes are usually used in mining operations in the develop- 
ment of placer deposits and deposits of construction rocks. In this case, the scrapers remove the rock by pits-platforms (transverse steps, Fig. 6a) or frontal pits (Fig. 6b). Bulldozers carry out dump formation.
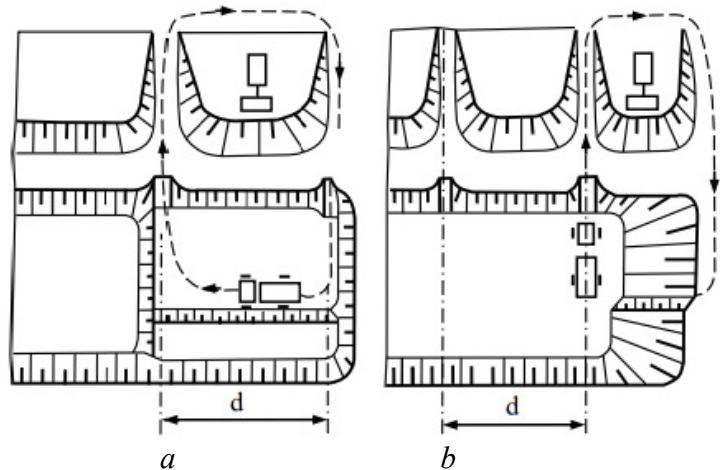

Fig. 6. Schemes of scraper-bulldozer technological complex [14]

Since the scraper is used as the main equipment, the area of its effective application in the extraction of sand-gravel mass is limited by the presence of boulders in the sediments.

Bulldozer-excavator technological complexes are effective for performing excavation works in quarries and placer deposits [14, 15], if:

1) the width of the work front up to 40-60 $\mathrm{m}$ and the thickness of the opening up to 4-6 m, the extraction and movement of rock is carried out by bulldozers, and dumping or loading of rock mass into vehicles-excavators (Fig. 7a,b);

2) the width of the work front is more than 40-60 m and overburden capacity is more than 4-6 m, the extraction and movement of rock is carried out by bulldozers, and dumping - excavators and bulldozers (Fig. 7c);

3 ) the excavator moves the pre-loosened rock mass into a temporary dump, and the bulldozer moves it to a permanent dump (Fig.7d). 


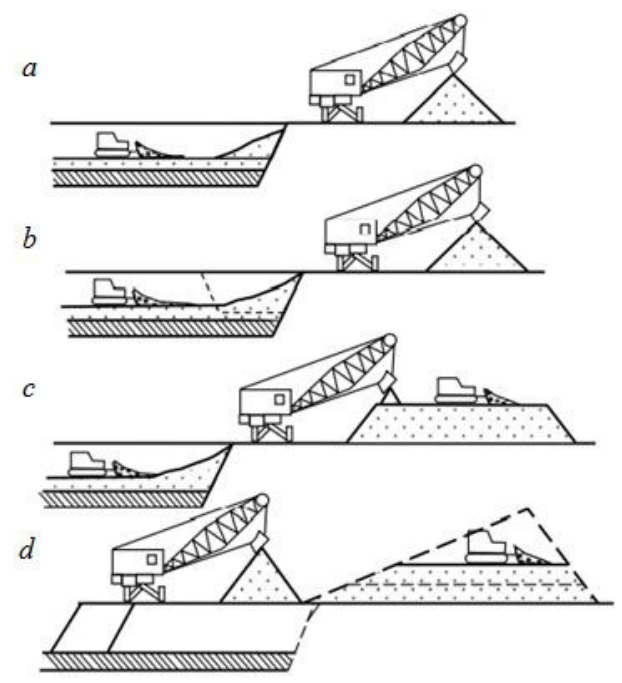

Fig. 7. Schemes of bulldozer-excavator technological complex

In this complex, bulldozers move the rock mass over short distances, and excavators remove mostly already loose rock. This creates the preconditions for achieving maximum performance of each unit of equipment.

When developing sand and gravel mass with a thickness of 6-10 $\mathrm{m}$ and the presence of boulders in it, the most appropriate will be the use of bulldozer-excavator-car (Fig. 8) or bulldozer-loader-car complex (Fig. 9) [14].

When bulldozers and excavators are used as extraction and loading equipment, the rock mass is moved by bulldozer to the stack after removal, from which it is loaded into vehicles by an excavator (Fig. 8 ). Bulldozer and loosening equipment is mounted on one tractor tractor, which allows you to alternately perform the processes of preparation and removal of one equipment, and intermediate stacking of rock mass ensures high technical and operational performance of the loading excavator. 

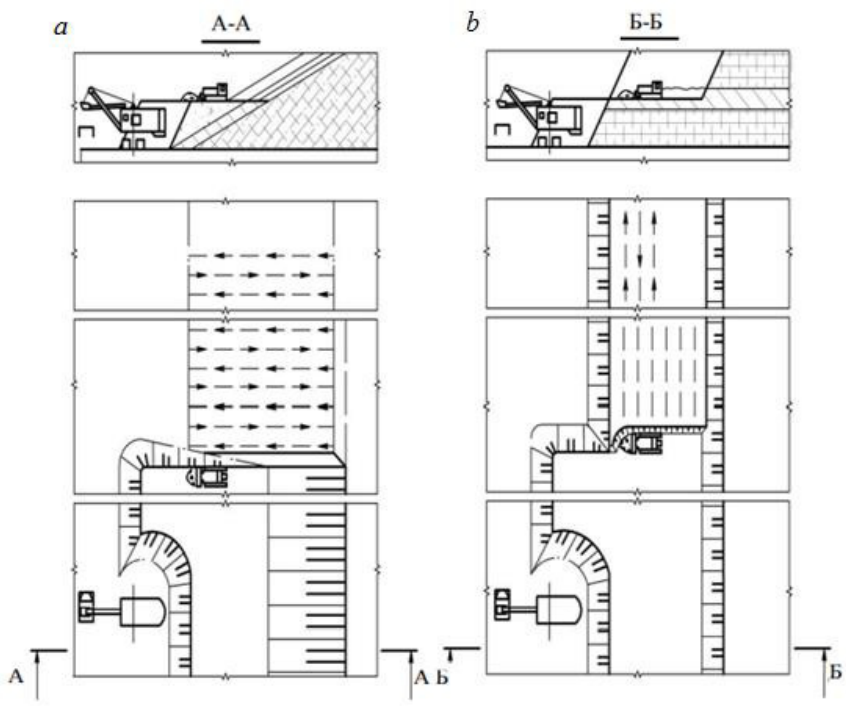

Fig. 8. Schemes of bulldozer-excavator-automobile technological complex: $a-$ loosening and extraction of inclined layers of rock; $b$ - loosening and removal of horizontal layers of rock [14]
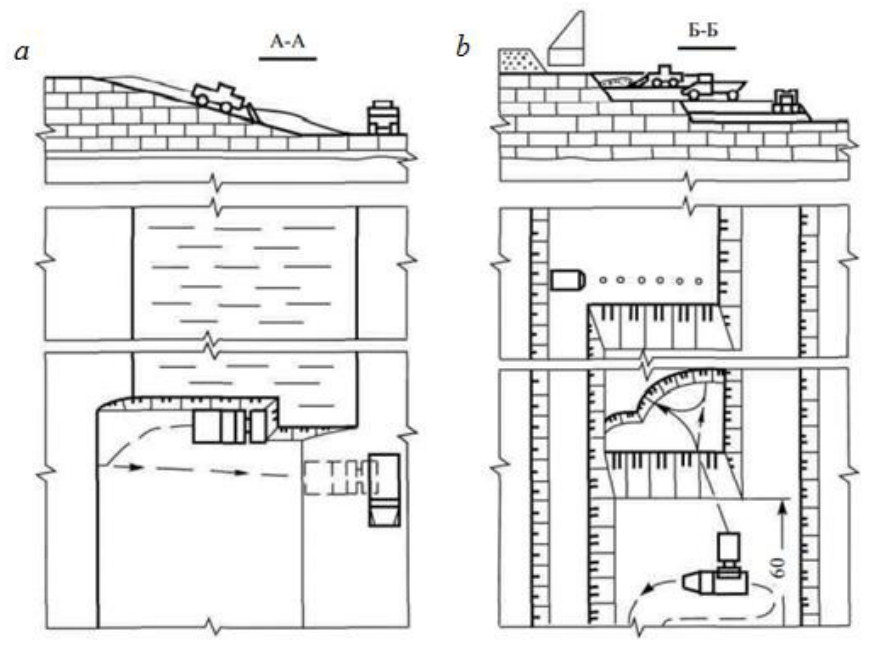

Fig. 9. Schemes of development of fluvioglacial deposits by inclined ( $a$ ) and horizontal $(b)$ layers with the use of loaders [14] 
When using loaders, the most effective scheme is the work of the front face (Fig. 9a) with the excavation and movement of the rock at an angle. Excavation end face in longitudinal holes, as well as site face and longitudinal face in transverse holes, which causes a rigid relationship of preparation, excavation and loading of rocks, is rational in some cases - with limited quarry length, storage of rocks in the produced space, to reduce the angle of the working board of the quarry.

High productivity of the excavator, absence of trench opening of ledges, reduction of width of working platforms and distances of transportation of rock mass are reached at bulldozer transfer of breeds on the lower ledges. The rock mass can be transferred from one or more ledges to the transport horizon of the lower ledge, where the excavator is shipped to vehicles. Such bulldozer handling is used in low-capacity quarries with limited surface area.

The height of the working ledge at the gross excavation is determined by the thickness of the layer of fluvioglacial deposits or the parameters of the excavator. At separate excavation by a face-site the possible height of a ledge with a normal frontal slope depends on its stability. When excavating the rock by a loader frontal face (inclined layers) or face-off platform with the slope of the ledge with subsequent loading of the rock into dump trucks, the rational height of the ledge depends on its angle of inclination and the thickness of the excavation layers and is 5-10 m. High productivity of the bulldozerripper and the excavator is reached at bulldozer extraction by inclined layers with stacking of breed, providing at the same time rational height of a ledge. It is usually 6-15 m, with the height of the stack varies from 3,5 to $5 \mathrm{~m}$, and its width - from 6 to $9 \mathrm{~m}$.

The productivity of bulldozers and loaders during the development of horizontal thin layers depends on the size of the ledge panel. Rational width of the ledge panel is $20-35 \mathrm{~m}$ and $30-60 \mathrm{~m}$ when loading sand-gravel mass, respectively, at the level of the sole and loosened layer of the ledge. The minimum length of the panel block (excavator block) during gross development is $70-100 \mathrm{~m}$.

Operational productivity of this complex of equipment can be limited by: productivity of a transport link; excavator performance; productivity of loaders - at their use as the extracting and transport equipment, and also at loading in dump trucks at big width of the 
panel and height of a ledge; productivity of bulldozers - at the big width of the panel and height of a ledge accordingly at excavation by a face-off platform and a frontal face.

Therefore, the choice of the type of technological complex of working equipment, its qualitative and quantitative complete set should be carried out taking into account the required amount of extraction of sand-gravel mass and the size of the working area [14].

Floating dredger are used only in the development of naturally or artificially watered sand and gravel rocks. Grab buckets and a ladle chain are most often used as an executive body [11]. Despite the low cost of extraction of sand-gravel mass by floating multi-bucket and grab shells, the technology of their extraction is generally not suitable for excavation work in the existing quarries of rocks. It requires, first of all, a clear organization of work on flooding of mining areas and prevention of water leakage from them, which is very difficult to achieve in the presence of lower ledges for the extraction of rocks.

\section{Geological situation within the studied deposits}

Within the studied Sosnivsky and Yaroshivsky deposits, the Dnieper climatolite is represented by water-glacial deposits of the lower stage - fP II $d n 1$ and the Upper Dnieper stage, represented by the marginal moraine $g P$ II $d n 3$ (Fig. 10, the arrow shows the direction of glacier movement).

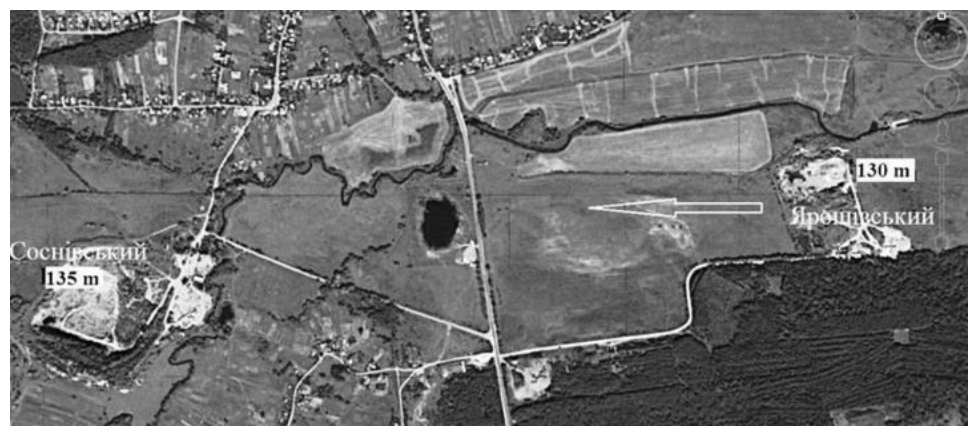

Fig. 10. Location of Sosnivsky and Yaroshivsky quarries [16]

Yaroshiv Granite Quarry is located on the right bank of the Irpin 
River in the village of Sosnivka, Northeast of the road Fastiv - Byshiv at a distance of $1 \mathrm{~km}$. Sosnivsky quarry is located 1,5 km southwest of Yaroshivsky.

Fluvioglacial deposits of the Sosnivskoye deposit are very dislocated, obliquely layered in the upper strata, various in granulometric composition, in the upper parts of the section there are remains of plants and trees.

Studies of water glacial and moraine deposits and boulders within the Sosnivsky deposit are reflected in scientific works [16].

Within the Sosnivskoye deposit, moraine and fluvioglacial deposits are spread over the entire area. The thickness of the sediments varies from $1 \mathrm{~m}$ to $25,6 \mathrm{~m}$. The section is represented by waterglacial sediments - $f P$ II $d n 1$ and marginal moraine $g P$ II $d n$.

Lithologically the rocks are represented as follows (bottom up):

- dense gray clay with a significant content (up to $45 \%$ ) of gravel and boulders of crystalline rocks with layers and lenses of sand, loam and sand (Fig. 11 and 12);

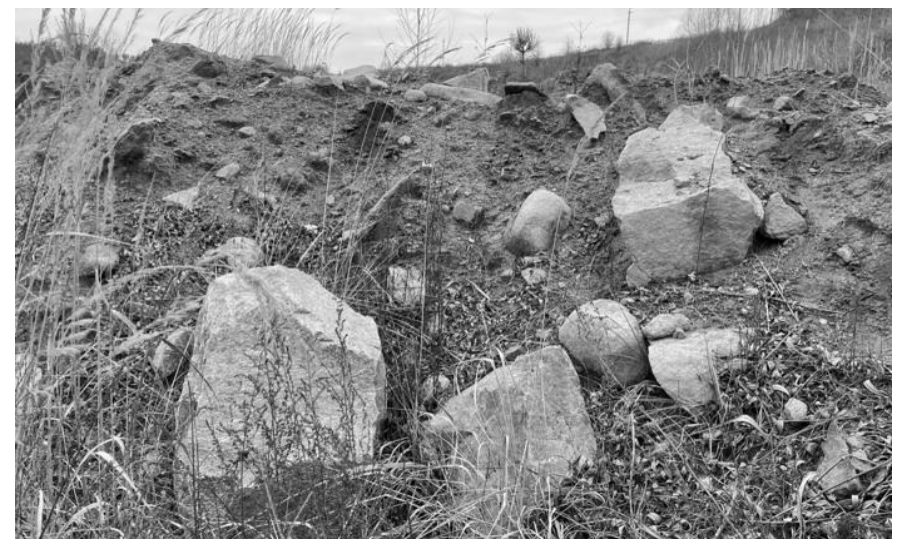

Fig. 11. Gravel-boulder material at the Sosnivsky deposit in the northern part of the overburden horizon

- next lies fine-grained sand, light gray to yellow-gray, with layers of clay. Closer to the day surface, the content of gravel-boulder material gradually decreases to $20-25 \%$. At the observation point in the northern part of the Sosnivsky quarry, oblique stratification of 
sand and sand with layers of loam is observed in fluvioglacial deposits (Fig. 13);

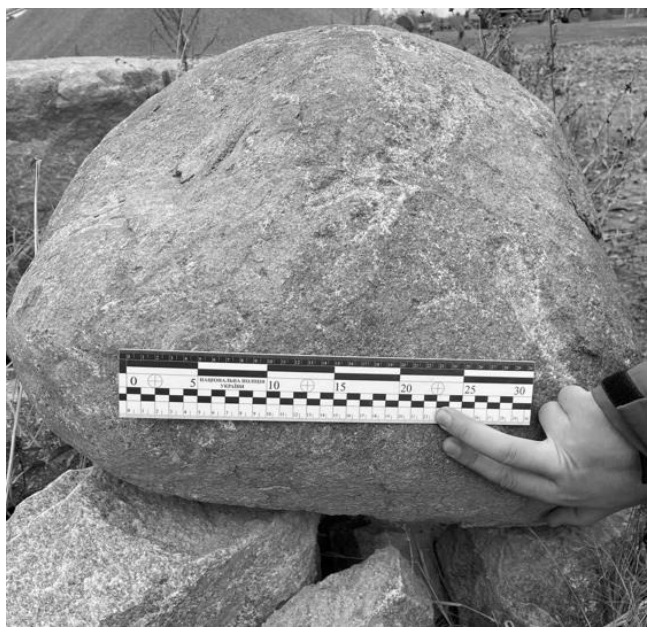

Fig. 12. Gravel-boulder material of the lower part of the section of fluvioglacial deposits

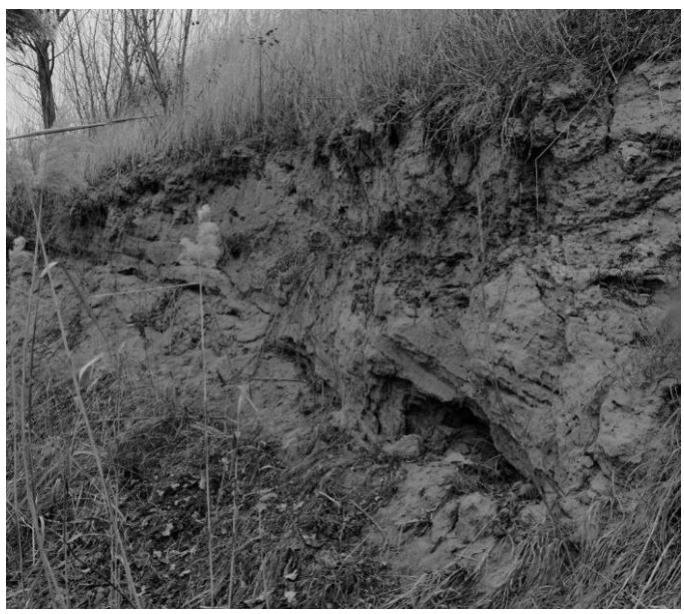

Fig. 13. Oblique stratification of sands, sandy loams and layers of loam

- cover the thickness of moraine and water-glacial deposits layers 
of loamy sandy gray, light gray with lenses of sand. The content of gravel of crystalline rocks from 5 to $10 \%$ is noted in the loam layers. Also in the upper part there is a layer of plant and wood remains (Fig. 14).

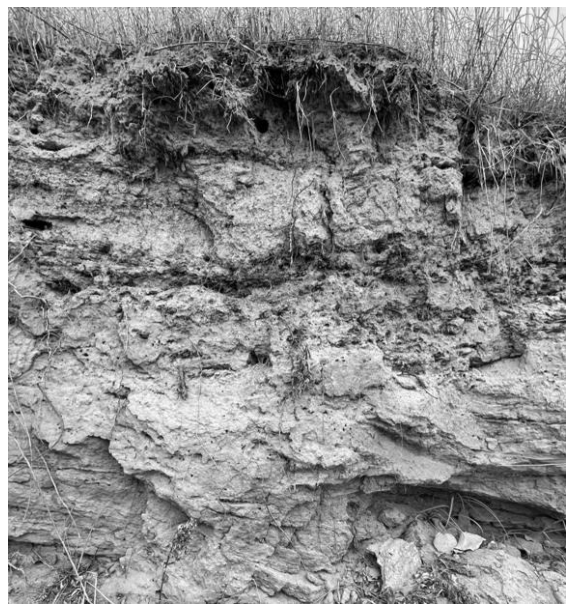

Fig. 14. The upper part of the thickness of fluvioglacial deposits

The image in fig. 12 gives a good idea of pellets of the crystalline rocks. The presence of holes on the surface indicates that the spherical shape is the result of contact with fragments of equal strength. The second factor that contributed to the pelletting was the movement inside the plastic-bulk mass, which limited the deviation from the general trajectory and did not allow, due to significant kinetic energy, to stop the picked up debris. The sizes of pellets fluctuate in the range from 1 centimeter to 3,0 $\mathrm{m}$. In general the oval form is considered inherent in contact zones at mutual movement of blocks [16]. The size of the katuns is determined by the scale of the phenomenon.

Thus, the fluvioglacial deposits of the Sosnivskoye deposit are very dislocated oblique-stratified in the upper strata, varying in granulometric composition, in the upper parts of the section there are remains of plants and wood. The deposit contains moraine and submoraine deposits of the Dnieper Glacier ( $v d \lg g P I I$ ) represented by loams, sands, sands with layers of clay, gravel, pebbles and granite boulders. Water-glacial deposits cover a large area of the Sosnivsky 
deposit and lie on the crust of granite weathering.

The geological situation within the Yaroshivsky deposit is as follows. In the south-eastern wall of the quarry (from bottom to top) are observed:

- lower proterozoic granites of the Fastiv complex visible thickness 10-15 m;

- black-gray thickness, the thickness of which in the depressions of the granite surface reaches $2 \mathrm{~m}$;

- Kyiv marl (thickness about $1 \mathrm{~m}$ );

- loess loam;

- alluvial sand.

Comparing the structure of Yaroshivsky and Sosnivsky granite quarries, we can note the following differences in the structure of the sedimentary stratum. The weathering crust is located above the granite surface in the Sosnovsky quarry. The most significant, up to 16 $\mathrm{m}$, is a layer of medium and fine-grained sand with layers of clay and inclusions of boulders and pebbles [16].

There is no weathering crust in the Yaroshiv quarry, and a blackand-glaucous layer lies over the granite massif. It opened when a quarry was developed on the north wall. There is a clear hollow in the wall, which is filled with black-glaucous sandstone loam with a significant content of gravel-boulder material (similar to the Sosnivsky deposit). This can also create a problem in the development of the deposit (Fig. 15).

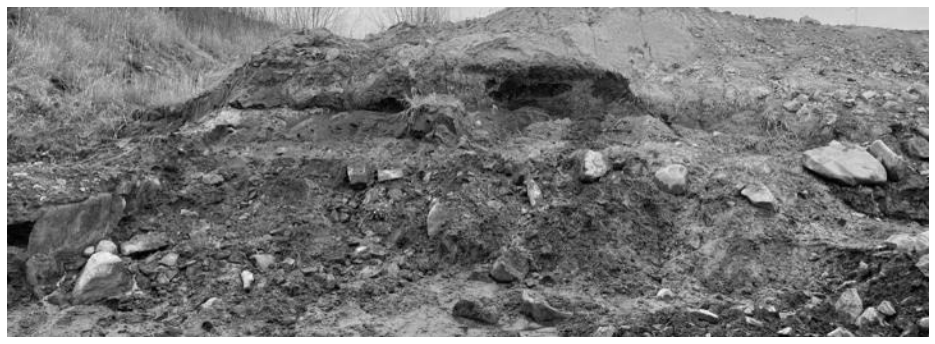

Fig. 15. Black-glaucous stratum of the rock mass in the Yaroshivsky quarry

Current state of mining operations at the open pit in the quarry of Sosnivsky deposit and proposed technological solutions

During the development of the Sosnivsky granite deposit, there 
was a problem of removing the layer of fluvioglacial deposits on the overburden ledge in the north-eastern part of the quarry. It turned out that the gravel-sand mixture has a significant amount of pebbles and boulders in some areas (from 40 to $80 \%$ ), and the existing equipment in the quarry is not able to remove this layer of sediment due to technical characteristics [10].

According to the classification of rocks for mechanical rotary drilling fluvioglacial deposits belong to category V. However, due to the sharp change in the concentration of gravel-boulder material of crystalline rocks, the drilling category may increase to $X$ (in some cases to $X I$ ).

The decision to prepare a layer of fluvioglacial deposits for extraction by drilling and blasting did not provide the desired result. When drilling wells, the drill rod is jammed in the massif due to the presence of a large amount of gravel-pebble-boulder material in the thickness of the layer (Fig. 16). Therefore, in these conditions it is necessary to develop special technological solutions based on a detailed study of the structure of occurrence of fluvioglacial deposits, existing technologies for the development of sand and gravel deposits and innovative approaches to solving this problem.

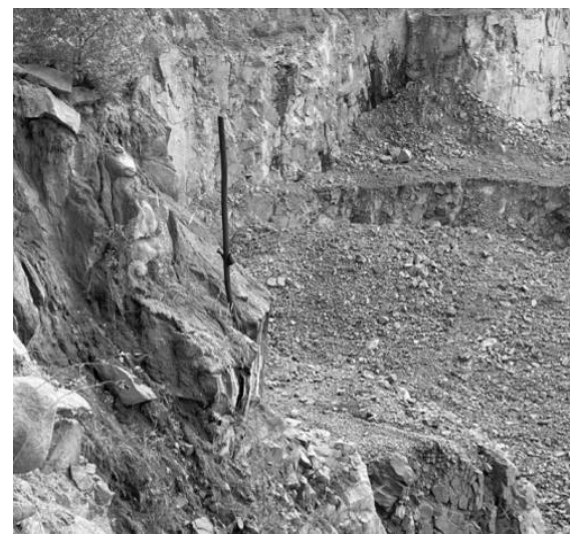

Fig. 16. Jammed drill rod in the layer of fluvioglacial deposits in the quarry of the Sosnivsky granite deposit [10]

As a result of assessing the current state of mining works and existing equipment in the quarries of Sosnivsky and Yaroshivsky de- 
posits, as well as analysis of possible technological complexes of equipment for removing the layer of fluvioglacial deposits, the authors concluded that the most efficient and technologically feasible will be combined bulldozer-excavator-automobile complex with the use of bulldozers-rippers (Fig. 17) [17].

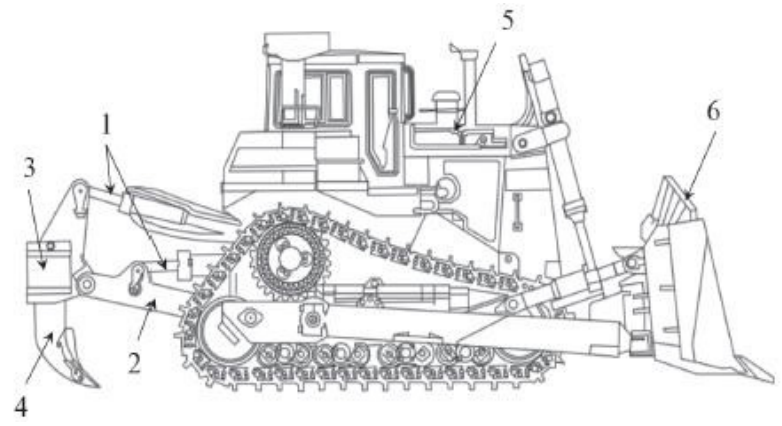

Fig. 17. Basic construction diagram of ripper: 1 -hydraulic system; 2 - frame;

3 -weather vane; 4 - ripper shank; 5 - bulldozer; 6 - dump [17]

At the same time, depending on the size of the working area, there are two options for bulldozer-excavator-automobile complex. The first option is to use a hydraulic backhoe excavator as a loading equipment, which should be placed on the roof of fluvioglacial deposits (Fig. 18) [18]. In the second option, it is proposed to use an excavator with a straight shovel, which loads the gravel-sand mass that dumps the bulldozer from the lower horizon of rocks (Fig. 19). These complexes are also the most acceptable in terms of the possibility of working in a limited working area and in the presence of a significant number of boulders in the sediments, which can be shifted and moved by powerful bulldozers-rippers.

The advent of powerful bulldozers and improvements in the design of modern rippers significantly expanded the scope of mechanical loosening, which allowed at this time its powerful use by some of the highly efficient production processes in opencast mining, in particular when removing a layer of fluvioglacial deposits/ 


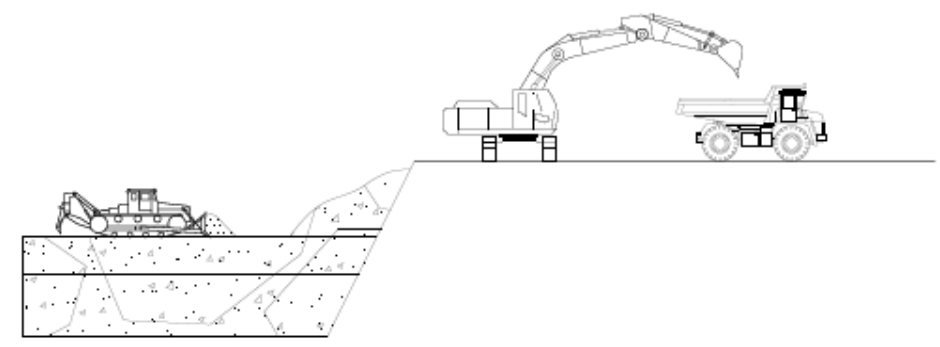

Fig. 18. Technological scheme of extraction of fluvioglacial deposits by a hydraulic excavator with a backhoe

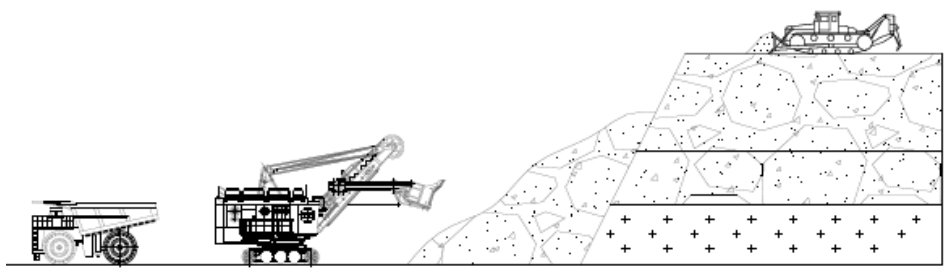

Fig. 19. Technological scheme of extraction of fluvioglacial deposits by an excavator of the "straight shovel" type from the lower placed horizon

As noted in [19], the variable productivity of excavators, namely the cycle time $t_{c}$, is significantly affected by both the average size of the fraction of rock mass and the percentage of oversized fractions. According to the results of research, scientists have established graphical and empirical dependences of the cycle duration of the excavator $t_{\mathrm{c}}, \mathrm{s}$, on the average size of a piece of rock mass

$$
t_{c}=a \cdot d_{m}^{b}
$$

where $d_{m}$ - the average size of a piece of rock mass, $\mathrm{m} ; a, b$-empirical coefficients that depend on the uniformity of the distribution of particle size distribution (variance).

If we assume that the rock mass is a sand-gravel mixture with unevenly distributed content of boulder material (logarithmic variance 1,3), then, according to [19], formula (3) will take the form 


$$
t_{c}=53,9 \cdot d_{m}^{0,2}
$$

In fig. 20 is a graph of the dependence of the change in the duration of the excavator cycle on the average size of the piece of fluvioglacial deposits $d_{\mathrm{m}}, \mathrm{mm}$. The analysis of the figure shows a gradual increase in the duration of the cycle with increasing average piece size in the fractional composition of gravel-sand mass, which is quite logical and natural. Within the studied interval of change of the size of a piece from 20 to $120 \mathrm{~mm}$ duration of a cycle changes 1,43 times from 24,6 to $35,3 \mathrm{~s}$.

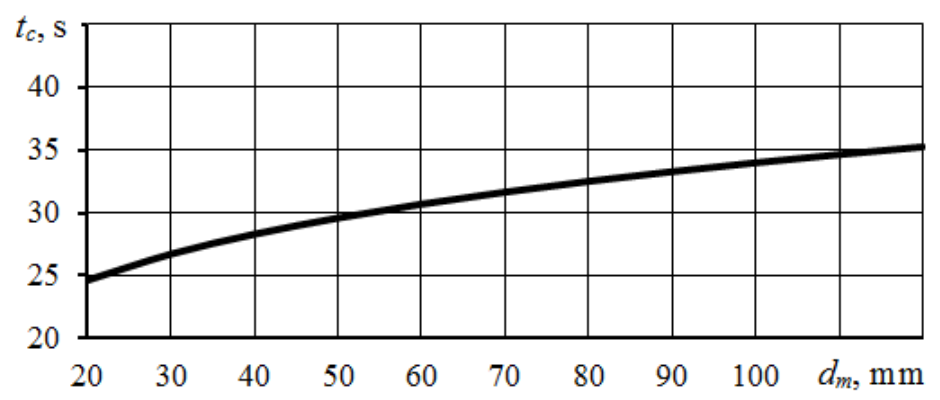

Fig. 20. The dependence of the change in the duration of the excavator cycle on the average size of the piece of fluvioglacial deposits

Variable performance of the excavator depends on the working equipment, physical-mechanical properties of rocks, parameters of the face and in general can be represented by the formula, $\mathrm{m}^{3} / \mathrm{sh}$

$$
Q_{s h}=\frac{3600 \cdot E}{t_{c}} \cdot T_{s h} \cdot k_{e} \cdot k_{i} \cdot k_{u},
$$

where $E$ is the capacity of the excavator bucket (Volvo EC460BLC bucket capacity is $\left.E=2,1 \mathrm{~m}^{3}\right) ; T_{\mathrm{sh}}$ - duration of work shift, $h$; $t_{c^{-}}$duration of the excavation cycle, $\mathrm{s} ; k_{u}$ - the coefficient of use of the excavator in time; $k_{u}=0,6 ; k_{i}$ - coefficient of influence of face parameters; $k_{e}$ - is the coefficient of excavation [2]

$$
k_{e}=\frac{k_{b f}}{k_{l}},
$$


where $k_{b f}$ - bucket filling (for backhoe $k_{b f}=1$; for a straight shovel $k_{b f}$ $=1,05$ ) [20]; $k_{l}$ - the coefficient of loosening of the rock mass in the bucket, $, k_{l}=1,2$

$$
k_{3}=k_{h} \cdot k_{a} \cdot k_{l r} \cdot k_{k},
$$

where $k_{h}$ - coefficient that takes into account the influence of the height of the face on the filling of the bucket of the excavator; $k_{h}=0,95 ; k_{a}$ - coefficient that takes into account the influence of the angle of rotation of the excavator on unloading (for the angle of rotation $180^{\circ} k_{a}=0,7$, for $\left.90^{\circ} k_{a}=1,0\right)$ [18]; $k_{l r}$ - coefficient that takes into account the conditions of loading the rock into the vehicle; $k_{k}$ - coefficient that takes into account the qualifications of the driver, $k_{k}=0,85$

The value of the coefficient, which takes into account the loading conditions of the rocks in the vehicles $k_{l r}$ is: for loading the rock mass with a backhoe excavator $k_{l r}=0,9$; for a straight-shovel excavator $k_{l r}=1,0$ [2].

For the conditions of the quarry Sosnivsky granite deposit using a hydraulic backhoe excavator, which is proposed to be placed on the roof of fluvioglacial deposits (see Fig. 17), formula (4) taking into account (5) and (6), as well as all recommended numerical indicators of coefficients, will take the form, $\mathrm{M}^{3} / \mathrm{sh}$

$$
Q_{s h}=\frac{15383,844}{t_{c}} .
$$

When using the second technological scheme of removal of fluvioglacial deposits, when the excavator with a straight shovel loads gravel-sand mass from the lower placed horizon of rocks (see Fig. 19), productivity, depending on the length of the cycle, will be determined, $\mathrm{M}^{3} / \mathrm{sh}$

$$
Q_{s h}=\frac{17947,818}{t_{c}} .
$$

In fig. 21 presents graphs of changes in the productivity of excavators depending on the size of the average piece of rock mass of fluvioglacial sediments for the two proposed technological schemes of excavation: when placing an excavator with a backhoe on the roof 
of fluvioglacial sediments (1); when placing the excavator type "straight shovel" on the lower level than working horizon (2).

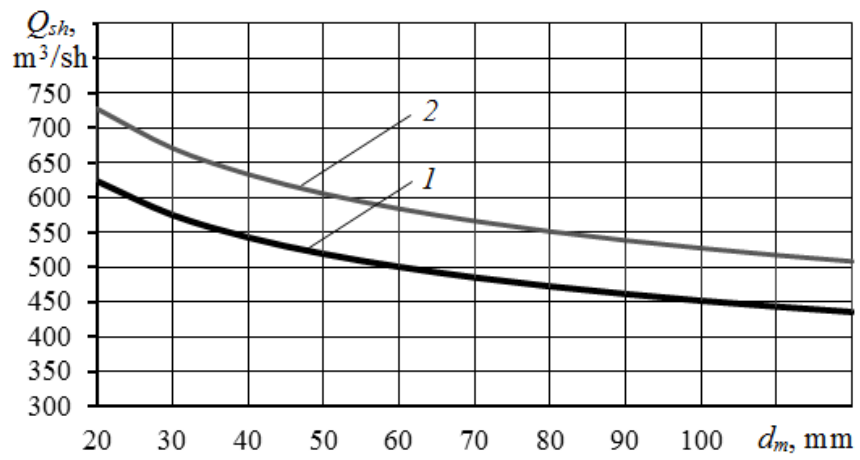

Fig. 21. Dependence of variable productivity of the excavator on the average size of a piece of gravel-sand mining mass: 1 - the backhoe excavator; 2 - excavator type «straight shovel»

As can be seen from Fig. 21, in general, the productivity of the excavator with a straight shovel is higher by $17 \%$ of the productivity of the backhoe. Within the studied change in the size of gravel-sand material from 20 to $120 \mathrm{~mm}$, the productivity of excavators also decreases 1,43 times: for the backhoe from $624,1 \mathrm{~m}^{3} / \mathrm{shift}$ to 436,2 $\mathrm{m}^{3} / \mathrm{shift}$; for straight shovel from $728,1 \mathrm{~m}^{3} / \mathrm{shift}$ to $508,8 \mathrm{~m}^{3} / \mathrm{shift}$.

According to the results of geological assessment of fluvioglacial deposits of overburden rocks at the Sosnivsky granite deposit, an approximate distribution of the fractional composition of gravel-sand mass was obtained (Table 4) according to the recommendations [11]. It is established that the average size of a piece of boulder-gravelsand mass is $101 \mathrm{~mm}$.

According to the graph presented in Fig. 21, the performance of the excavator will be:

- according to the first technological scheme of development (see Fig. 18) $450 \mathrm{~m}^{3} / \mathrm{shift}$;

- according to the second technological scheme of development (see Fig. 19) $530 \mathrm{~m}^{3} / \mathrm{shift}$.

Thus, it is established that the main reason for increasing the duration of the operating cycle and reducing the productivity of the ex- 
cavator is the increase in the size of the rock mass and the uneven distribution of the fractional composition characterized by dispersion.

Table 4

Fractional composition of overburden rocks of Sosnivsky deposit

\begin{tabular}{c|l|c|c}
\hline \multicolumn{2}{c|}{ Fractions } & Size, mm & Content, $\%$ \\
\hline \multirow{4}{*}{ Boulders } & large & $>400$ & 4,4 \\
\cline { 2 - 4 } & medium & $201-400$ & 7,53 \\
\cline { 2 - 4 } & small & $101-200$ & 8,57 \\
\hline \multirow{4}{*}{ Gravel } & large & $41-100$ & 7,4 \\
\cline { 2 - 4 } & medium & $21-40$ & 6,3 \\
\cline { 2 - 4 } & small & $5-20$ & 8,73 \\
\hline \multirow{5}{*}{ Sand } & coarse-grained & $1-5$ & 4,13 \\
\cline { 2 - 4 } & medium-grained & $0,5-1,0$ & 12,33 \\
\cline { 2 - 4 } & medium-fine-grained & $0,25-0,5$ & 14,8 \\
\cline { 2 - 4 } & fine-grained & $0,1-0,25$ & 17,57 \\
\hline \multicolumn{2}{l}{ Dusty and silt particles } & $0,005-0,1$ & 7,13 \\
\hline \multicolumn{2}{l}{ Clay particles } & $<0,005$ & 1,1 \\
\hline
\end{tabular}

\section{Conclusions}

According to the results of the research, the regularities of distribution, features and forms of distribution of fluvioglacial deposits on the territory of Ukraine have been established. The analysis of possible technological schemes of development of fluvioglacial deposits and equipment complexes is carried out, and the conditions of their effective application are established. Within the mining allotment of Sosnivsky and Yaroshivsky deposits, the main characteristics of occurrence of overburden rocks represented by fluvioglacial deposits were determined, and problems of mining in the quarry of Sosnivsky granite deposit were identified.

Based on the results of the assessment of the current state of mining operations and the availability of existing equipment in the quarries of Sosnivsky and Yaroshivsky deposits to remove the layer of fluvioglacial deposits, the use of a combined bulldozer-excavatorautomotive complex with the use of ripper bulldozers is proposed.

Depending on the size of the working area, there are two options for bulldozer-excavator-car complex. The first option involves the use of a hydraulic backhoe excavator, placed on the roof of fluvioglacial deposits. In the second option, it is proposed to use an excavator type «straight shovel», which is located on the lower placed 
horizon of rocks and loads the gravel-sand mass, which is dumped by a bulldozer.

There is obtained an empirical and graphical dependence of the variable productivity of the excavator on the average size of a piece of gravel-sand rock mass for the conditions of the quarry of the Sosnivsky granite deposit for the proposed technological schemes of working off overburden. It is established that within the studied changes in the size of gravel-sand material, namely from 20 to $120 \mathrm{~mm}$, the productivity of excavators is reduced by 1,43 times: for the backhoe excavator from $624,1 \mathrm{~m}^{3} / \mathrm{shift}$ to $436,2 \mathrm{~m}^{3} / \mathrm{shift}$; for straight shovel from $728,1 \mathrm{~m}^{3} /$ shift to $508,8 \mathrm{~m}^{3} / \mathrm{shift}$. In general, the productivity of the excavator with a straight shovel is $17 \%$ higher than the productivity of the backhoe.

Given the average size of a piece of boulder-gravel-sand mass, which is equal to $101 \mathrm{~mm}$, the productivity of the excavator will be:

- according to the first technological scheme of mining of $450 \mathrm{~m}^{3} / \mathrm{shift}$;

- according to the second technological scheme of mining $530 \mathrm{~m}^{3} / \mathrm{shift}$.

Since fluvioglacial deposits, as overburden rocks, in the contours of the field usually have a complex structure of occurrence and significant changes in the fluctuations of the deposit capacity, and the working area of the equipment may be limited, it is advisable to determine the productivity of the whole technological complex for extraction of gravel-sand mass. Therefore, the obtained performance of the excavator must be consistent with the capabilities and performance of the ripper bulldozer and road transport. This will be the direction of further research.

\section{References}

1. Berezovskij, N.I., Berezovskij, S.N., Dovnar, S.V., Onika, S.G. (2011). Razrabotka algoritmov dlja upravlenija proizvodstvennymi tehnologijami: monografija. Minsk: BIP-S Pljus.

2. Bujanov, Ju.D., Krasnopol'skij, A.A. (1980). Razrabotka mestorozhdenij nerudnyh poleznyh iskopaemyh. Moskva: Nedra.

3. Rzhevskij, V.V. (1975). Tehnologija i kompleksnaja mehanizacija otkrytyh gornyh rabot. Moskva: Nedra.

4. Arsent'ev, A.I. (2002). Opredelenie proizvoditel'nosti i granic ka-r'erov. Sankt-Peterburg: S.-PGI. 
5. Onika, S.G. (2006). Proektirovanie kar'erov. Minsk: BNTU.

6. Komarovskij, M. E. (2011). Uchebnaja obshhegeologicheskaja praktika na Minskom poligone: uchebnoe metodicheskoe posobie. Minsk: BGU.

7. Vovk, V.M. (2022). Geologichnyj slovnyk https://geodictionary.com.ua/node/4428

8. Manjuk, V. V. (2017). Pro zminennja polozhennja pivdennoi' granyci Dniprovs'kogo (rys'kogo) zledeninnja. Visnyk Dnipropetrovs'kogo universytetu. Serija : Geologija. Geografija, 21, 99-110.

9. Ohar (2021) Carboniferous fauna from erratics in the Hradyzk area (Poltava region, Ukraine): paleo-ice streams indicator of the Dnipro glacial maximum, Historical Biology, 33:1, 78-87.

10. Lytvynchuk, I.D., Frolov, O.O. (2021). Problemy vyjmannja fljuviogljacial'nyh vidkladiv na rozkryvnyh ustupah rodovyshh skel'nyh budivel'nyh porid. Tezy VIII Vseukrai'ns'koi' naukovo-praktychnoi' konferencii' studentiv, aspirantiv ta molodyh vchenyh «Perspektyvy rozvytku girnychoi' spravy ta racional'nogo vykorystannja pryrodnyh resursiv». Zhytomyr: Zhytomyrs'ka politehnika, 65-69.

11. Malysheva, N.A., Sirenko, V.N. (1977). Tehnologija razrabotki mestorozhdenij nerudnyh stroitel'nyh materialov. Moskva: Nedra.

12. Jarcev, V. I., Gubin, V. N., Vysockij, Je. A., Il'kevich, G. I., Gurinovich, A. I. (2001). Poiski i razvedka mestorozhdenij mineral'nogo stroitel'nogo syr'ja: Ucheb. posobie. Minsk: BGU.

13. Bujanov, Ju.D. (1988). Razrabotka gravijno-peschanyh mestorozhdenij. Moskva: Nedra.

14. Rakishev, B.R. (2015). Tehnologicheskie kompleksy otkrytyh gornyh rabot: Uchebnik. Almaty.

15. Drizhenko, A.Ju. (2011). Kar'ernye tehnologicheskie gornotransportnye sistemy: monografija. Dnepr: NGU.

16. Pazynych, V.G. (2019). Rekonstrukcija postgljacial'nyh podij v basejni Dnipra: monografija. https://www.academia.edu/11219641/Reconstruction_of_ postglacial_events_in_Dnipro_river_basin

17. Argimbaev, K. R., Ligockij, D. N., Loginov, E. V. (2020). Bul'dozernaja tehnologija otkrytoj razrabotki izvestnjakovo-dolomitovyh mestorozhdenij: Gornyj informacionno-analiticheskij bjulleten', 3, 16-29.

18. Frolov, O., Beltek M. (2021). Influence of the hydraulic excavator location with a backhoe in the face on the efficiency of rock mass excavation. Вісник КрНУ імені Михайла Остроградського. Кременчук: КрНУ, 3/2021 (128), 70-75.

19. Ugol'nikov, V.K., Gavrishev, S.E., Ugol'nikov, N.V. (2007). Vlijanie granulometricheskogo sostava gornoj massy na proizvoditel'nost' jekskavatorov. Gornyj informacionno-analiticheskij bjulleten', 2(6), 73-81.

20. Normy tehnologicheskogo proektirovanija predprijatij promyshlennosti nerudnyh stroitel'nyh materialov (1977). Leningrad: Strojizdat. 
https://doi.org/10.31713/m1125

\title{
METHOD OF CALCULATING THE STRESS-STRAIN STATE OF THE DEPTH WELL AND AREA AROUND THE WELL
}

\author{
Mykhailovska O.V.
}

\author{
Ph.D., Senior Researcher, Associate Professor of the Department \\ of Oil and Gas Engineering and Technology, National University \\ «Yuri Kondratyuk Poltava Polytechnic», Ukraine
}

\begin{abstract}
A mathematical model was used to solve the problem of estimating the stressstrain state of an array near a vertical well of great depth. The model includes equations of equilibrium, dependences between components of deformations and components of displacements, equations of properties of the environment, intensity of stresses and intensity of deformations, and also boundary conditions.

To derive the calculated dependences, an elementary cylinder with a hole is considered. Cylinder of constant radius. The elementary cylinder of constant thickness is loaded with internal and external pressure. It is determined that for operative decision-making related to various problems arising in the process of construction of deep wells (oil, gas, etc.), their operation, as well as in their design, very relevant analytical studies based on the use of engineering method assessment of the stress-strain state of the deep wellbore.

It is determined that the results of the application of the proposed method are the rapid assessment of the stress state of the rocks of the shaft, near the wellbore and in the array. The result is a qualitative assessment of the possible distortion of the productivity of the formations before their tests and scientific substantiation of the parameters of the technological process that prevent possible complications in the drilling of deep wells. Recommendations for the use of this method are given.
\end{abstract}

\section{Introduction}

Most of the complications in wells (absorption, landslides, etc.) are the result of a certain stress state of the array with all its internal processes that took place before and are now. Without establishing and evaluating the stress-strain state of the array around the well, identifying its nature and mechanism of occurrence. In this case, it is quite difficult to take scientifically sound measures to prevent complications when drilling wells.

Modern technologies allow to effectively drill wells at elevated temperatures, formation pressures. To calculate the parameters of such technologies, data on the stress state of rocks are needed, both 
along the wellbore and in the wellbore zone. It is also necessary to study formation pressure and rupture pressure of rocks in wells and on the surface - in identical laboratory conditions. Modern deep wells are drilled using the same techniques and the same technological processes as at shallow depths (up to 2.5-3.0 km). However, the drilling speed in the same rocks is much lower, and the accident rate and complexity in wells is higher. The complexity of dealing with complications in deep wells is also higher [1].

There are many methods for determining the stress-strain state of wells during drilling using analytical expressions, which became the basis of the mathematical apparatus of software packages. Numerical methods are currently the main methods of solving mathematical problems. They are characterized by reducing the process of solving a mathematical problem to a finite sequence of operations on numbers. They lead to results presented in the form of numbers, numerical vectors and matrices, numerical tables and so on. Their value is being clarified in parallel with the development of computer technology [8].

At the same time, the results obtained by numerical methods usually contain errors, being only approximations to the required answers. This is due to a number of objective reasons, among which are not directly related to calculation methods. Therefore, there is a need for preliminary rapid assessment of the state of the deep well using engineering techniques.

\section{Basic investigation}

2.1 Analysis of the features of the stress - strain state of the shaft and the shaft zone of a deep well

Analysis of drilling wells in the areas showed that the most common complications are due to the violation of the stability of the well walls. For this reason, sometimes wells do not reach design depths and must be eliminated. They do not fulfill their purpose at the expense of their construction of large funds. In order to reliably assess the stress-strain state of wells, it is necessary to substantiate the integral parameter (crack opening pressure), which characterizes the state of rocks in terms of their occurrence in the well. Rocks near the well are exposed to three main pressures: gravitational $P_{g}$, lateral geostatic $P_{2}$, and well back pressure $P_{1}$. The array pressure from the 
wellbore consists of the hydrostatic pressure of the drilling fluid column and the hydrodynamic pressure due to the technological processes in the well.

Hydrodynamic pressure (usually an order of magnitude less than hydrostatic) plays an indirect role in the occurrence of barrel deformations. It accelerates the time of destruction, ie is not the cause. The determinants are the pressures $P_{1}, P_{2}, P_{\mathrm{g}}$, [11,12]. According to modern ideas, the main factors influencing the stability of well walls are the stress state of rocks and physico-chemical interaction of rocks with drilling fluid. The direction of physicochemical processes in the system "formation - well" is determined by the chemical potential of the drilling fluid and the chemical potential of rocks. In the general case, involuntary thermodynamic processes are directed towards equalization of potentials. One of the methods of influencing the formation is the use of inhibited and mineralized solutions. Inhibition, as a rule, is achieved by mineralization of the solution, and in parallel with this are regulated and osmotic processes. Additives are introduced into the solutions to ensure saturation of their ions in the well: $\mathrm{K}^{+} ; \mathrm{Ca}^{2+}$, $\mathrm{Mg}^{2+}$ and $\mathrm{Na}^{+}$.

The use of inhibited solutions in wells prone to deformation, gave positive results [10]. And since osmotic processes are regulated along with inhibition, it can be assumed that the osmosis process, along with other factors, has a certain effect on the stability of well walls. The practice of drilling has shown that in some cases weighting of drilling mud without its chemical treatment has not solved the problem of stability of the wellbore. At the same time, it has not yet been possible to completely solve the problem of eliminating complications and increasing the stability of well walls when drilling in unstable rocks by the method of inhibition. As a result of physicochemical action of the solution on the formation, it is possible to achieve the stability of the wellbore only in conditions of stress close to equilibrium. In this case, the osmotic pressures, the value of which is at best 1-3 MPa, can only compensate for the hydrodynamic pressures in the well.

Thus, the main factor determining the stability of the wellbore is its stress state. It depends on the magnitude of external influences $\left(P_{1}, P_{2}, P_{\mathrm{g}}\right)$, formation fluid pressure and physical and mechanical 
properties of rocks in the conditions of their occurrence. Predicting the current stresses in rock massifs is of great practical importance. These components together with physical and mechanical and rheological properties of rocks serve as a basis at calculation of stability of walls of not fixed trunks of wells and calculations on durability of casings. Also, these components are the basis for assessing the possible distortion of the productivity of formations before testing, the rationality of the adopted scheme of destruction of rocks at the bottom and the reliability of separation of productive formations from aquifers after casing casing.

Based on the analysis of the results of research [3,4], it was found that for the stability of the wellbore walls in any case (any rock) it is necessary to strive to obtain in the well conditions close to equilibrium. Most of the complications that currently occur in the practice of drilling are due to non-compliance with this requirement. To eliminate this circumstance, the method of engineering calculation of the stress-strain state of the array can be used. With which it is possible to quickly and reliably establish the stress state of the rocks that make up the walls of the well, near the well and in the depth of the massif and make objective decisions under given conditions. Known methods for estimating the stress state of an array of rocks: using analytical calculations and methods of mechanical and mathematical modeling.

The reliability of analytical calculations is determined by the degree of conformity of the mathematical model to the natural state. And also depends on how accurately the indicators of mechanical properties characterize the behavior of the rock in a given stress state of the array. The greatest relevance, in connection with the efficiency of calculations of stresses and displacements are engineering methods of calculation. They, in turn, are the most complex because they require sufficient accuracy of the calculated information.

Compared with analytical methods for studying the stability of the wellbore as a function of the stress-strain state of rocks, mechanical modeling has a number of advantages. One of them is the possibility of further complicating the model to achieve greater compliance with the natural sample. That is why mechanical modeling in the study of the stability of the wellbore and wellbore is often the main. However, the complexity of the studied processes 
leads to the complexity of the equipment to be used and the complexity of the experiments. The results of experiments, in most cases, can be interpreted and used only for qualitative evaluation of the studied process. For this reason, the analytical method of estimating the stress state of an elastic - plastic array with a vertical deep well was used.

\subsection{Current trends in the method of calculating the stress- strain state of a deep wellbore}

The condition of the problem is formulated as follows. We have a heavy array bounded on top by a horizontal plane, from the plane to the depth of the array (Fig. 1) is a vertical well. The elastic array is in equilibrium under the action of its own weight, no other effort is applied to the array. You need to find the voltage in such a weakened well array. Instead of an elastic half-space with a cylindrical well of finite depth, a cylinder of radius $r_{2}$ with a vertical cavity $r_{1}$ is usually considered. The influence of end effects (wellhead and bottom of the well) is not taken into account, because the depth of the well is many times its diameter. As a result, the dependence of normal stresses $\sigma_{r}$, $\sigma_{t}$, and displacements $u$ on the radius of the cylinder $r_{1}, r_{2}$, stresses and displacements must be inseparable and unambiguous functions $r$ and $z$ inside the array.

To date, the solution of the problem, in the formulated formulation, is used for engineering assessment of the stress state of rocks in the wellbore zone. As we approach the well walls, the normal radial stresses $\sigma_{\mathrm{r}}$ decrease (in absolute value), and the normal tangential stresses $\sigma_{\mathrm{t}}$ increase. Vertical normal stresses $\sigma_{\mathrm{z}}$ do not depend on the distance to the well walls, but remain constant and are determined by the value of geostatic pressure. However, along with experimental studies, a significant difference from the above stress distribution was found. Therefore, to establish the pattern of stress distribution in the shaft zone of a deep well, the task was to study the stress state of this zone of the well drilled in the formation, subject to gravitational forces and back pressure (Fig. 1).

The real relationship between stresses and strains for rocks is curvilinear and plastic deformations often appear immediately after loading. 


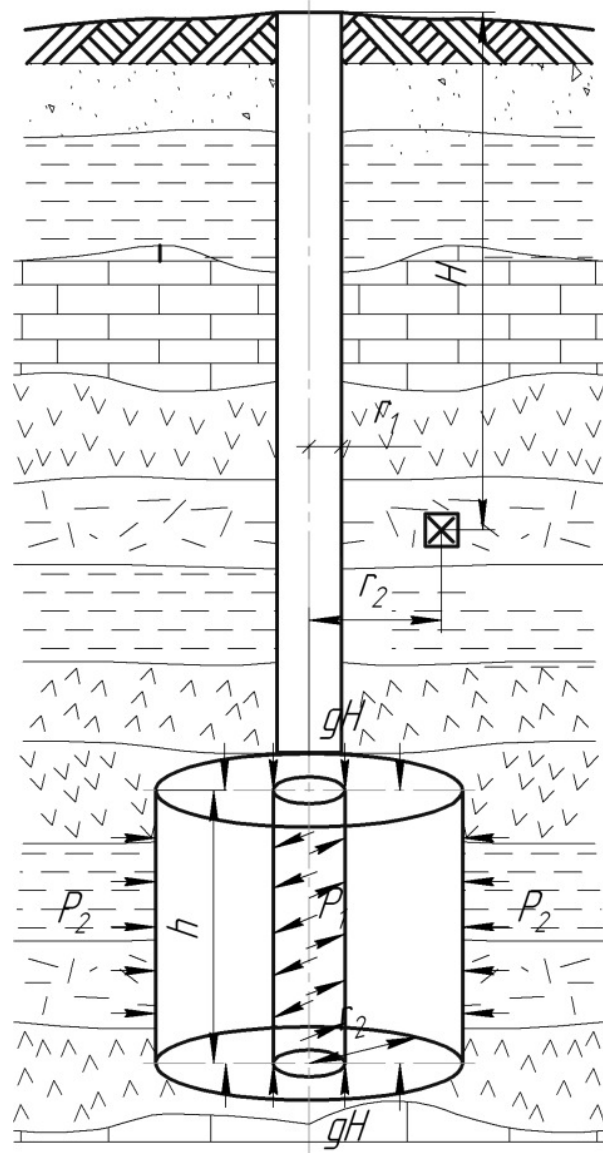

Fig. 1. Calculation scheme

Therefore, it is necessary to introduce the concept of the modulus of deformation $E_{0}$, equal to the ratio of the normal stress to the total relative longitudinal deformation, including residual: $E_{0}=\sigma / \varepsilon_{\Pi}$

The magnitude of the modulus of elasticity for the same rock sample is slightly larger than the modulus of deformation $\left(E>E_{0}\right)$. and the angle of internal friction $\rho$. Among the characteristics of strength, the tensile strength of uniaxial compression is of particular importance. This is the main constant of various materials, including rocks. Practically all geomechanical researches begin with definition of a limit of durability on uniaxial compression of samples of rocks. 
The study began with the determination of the tensile strength $\sigma_{\mathrm{T}}$ by the parameter - fracturing stresses $\sigma_{\mathrm{gr}}$. In the study of samples, the tensile strength is set by the load when the failure of the sample and the tensile strength of uniaxial compression is defined as the ratio of the destructive force $P$ to the cross-sectional area of the sample $F$, ie, MPa

$$
R_{c}=P / F \text {. }
$$

However, there are external and internal reasons that contribute to the fact that the field of stresses and strains in the rock sample will be heterogeneous. Studies show that for the same lithological difference, different test conditions can change the strength limit to uniaxial compression up to 5 times. Internal causes that lead to a violation of the homogeneity of the field of stresses and strains in the natural structural heterogeneity of rocks (latent fracture, the inclusion of different sizes and different strengths, pores, etc.). It is impossible to obtain a perfectly homogeneous field of stresses and strains in the formation according to the sample. It is possible to obtain a state close to homogeneous. It can be assumed that the uniaxial compressive strength of the rock samples will always be higher than the strength of the rock mass. It is established that the problem of linear heredity can be formally considered as a problem of the theory of elasticity, in which instead of elastic constants $E$ and $\mu$ it is necessary to use their temporary analogues (integral operators) $-\bar{E}, \bar{\mu}$.

The difficulty of solving problems by methods of hereditary creep theory is to decipher temporary operators. Often, when the boundary conditions are constant, the method of variable modules is used to solve geomechanical problems, which consists in using time functions $E(t)$ and $\mu(t)$ instead of integral operators, which can be found by the formulas

$$
\begin{gathered}
E(t)=E /(1+\Phi) \\
\varepsilon(t)=\frac{\sigma_{0}}{E}\left(1+\frac{\delta t^{1-\alpha}}{1-\alpha}\right)=\frac{\sigma_{0}}{\bar{E}} ; \\
\Phi=\frac{\delta t^{1-\alpha}}{1-\alpha}
\end{gathered}
$$


where $\delta$ and $\alpha$ are the rheological characteristics obtained experimentally; $F$ is the creep function. The time function for the Poisson's ratio is defined by the expression $\mu(t)=0,5-\frac{0,5-\mu}{1+\Phi}$.

It should be noted that the use of the theory of hereditary creep is justified only if the operating stresses do not exceed the long-term strength of the array. The mechanical properties of rocks obtained in the laboratory do not correspond to the mechanical properties of real rock massifs and this discrepancy manifests itself in the form of a large-scale effect. The sample of rocks can be said as some idealized model of the rock mass. This circumstance became the reason for the search for mechanical constants in kind, ie directly in the reservoirs (Fig. 1).

According to the hypothesis of homogeneity of the rock mass, we select the space around an arbitrarily chosen point of elementary volume in the form of a cube (Fig. 2). When the rock is deformed, internal forces $\left(P_{x} \cdot P y \cdot P_{2}=\gamma H\right)$ are applied to the faces of the cube, the intensity of which is stresses. In the general case, the stresses form an angle $\alpha$ with the normal drawn to the face of the cube. For ease of consideration, they can be decomposed into normal and tangent components (Fig. 2).

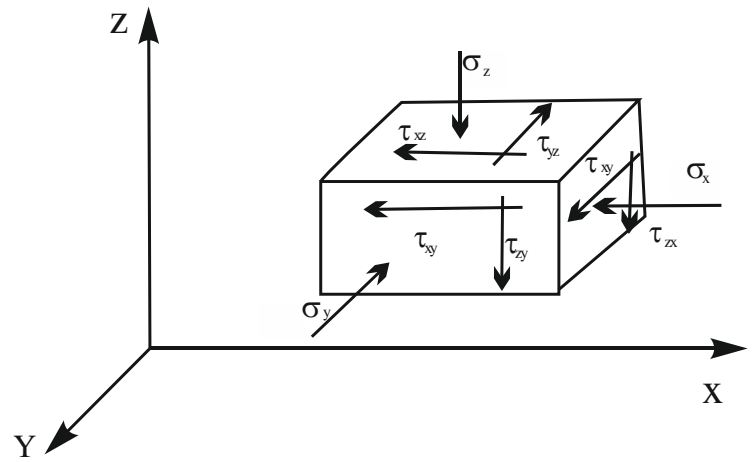

Fig. 2. Estimated stress scheme in the rock sample according to the hypothesis of array homogeneity

These components are called stress components. Thus, there are three components of normal $\sigma_{x}, \sigma_{y}$ and $\sigma_{z}$ and six - tangential stresses - $\tau_{x y}, \tau_{y x}, \tau_{x z}, \tau_{z x}, \tau_{y z}, \tau_{z y}$. For the convenience of analysis of the stressstrain state introduce the concept of average or geostatic stress. $\sigma_{0}=3^{-1}\left(\sigma_{x}+\sigma_{y}+\sigma_{z}\right)$. By analogy with the stresses can be introduced 
into the concept of average deformation: $\varepsilon_{c p}=\frac{1}{3}\left(\varepsilon_{x}+\varepsilon_{y}+\varepsilon_{z}\right)$. The coordinate system can always be changed so that the direction of the coordinate axes coincides with the lines of action of such normal stresses at which the tangential stresses are zero. These stresses are called principal and denote $\sigma_{1}, \sigma_{2}$ and $\sigma_{3}$. And $\sigma_{1}>\sigma_{2}>\sigma_{3}$. Under the action of stresses applied to the faces of the elementary cube, it is deformed.

Each of its faces will change linear and angular dimensions. Linear changes are estimated by the components of displacements $y, v, w$ and linear relative deformations $\varepsilon_{x}, \varepsilon_{y}, \varepsilon_{z}$, and angular - by angular deformations $\tau_{x y}, \tau_{y x}, \tau_{x z}, \tau_{z x}, \tau_{y z}, \tau_{z y}$ etc.

Mechanical failure due to force can be defined as the result of some deformation and rupture of structural connections of the structural material. The study of this process, as well as any problem, is based on physical and mathematical models that mimic real solids. The results of their research on the laxative effect of microdefects on the strength of rocks A.A. Griffiths embodied the theory of strength. The theory formed the basis of further research in the field of socalled microdefect strength theories. The criteria used to determine whether the destruction of the rock will be

$$
\begin{aligned}
& \left(\sigma_{1}-\sigma_{2}\right)+8 R_{p}\left(\sigma_{3}-\sigma_{1}\right)=0 \text { if } 3 \sigma_{3}+\sigma_{1}>0, \\
& \sigma_{3}=R_{p}, \text { if } 3 \sigma_{3}+\sigma_{1}<0 .
\end{aligned}
$$

Accepting in the first expression $\sigma_{3}=0$, we obtain the ratio between the tensile strength of uniaxial compression and the tensile strength of uniaxial tensile

$$
R_{\mathrm{c}}=-8 R_{p},
$$

which is fully consistent with the research data for rocks. Microdefective theories are unique in that they consider fracture as the result of disintegration of a solid body along a single trunk crack. On the walls of the well brittle destruction is a little different, it is realized in the form of a system of cracks. To describe such a mechanism of crack formation, it is necessary to introduce special preconditions into working hypotheses. When deforming solids, there are always two mechanisms by which the material is destroyed - plastic flow and brittle fracture (cracking, tearing). The concept of brittle and viscous fracture is the physical basis for the development of certain cri- 
teria of strength. If the plastic deformation caused by tangential stresses loosens the material and prepares it for rupture, the violation of continuity occurs under the action of normal tensile stresses. In solids such as rocks, plastic deformations begin at relatively low loads. Among the many chaotically arranged crystals, there will always be a number of the least favorably oriented in relation to external forces and having internal defects such as dislocations. These crystals are deformed plastically even with relatively small external forces. The number of these crystals is relatively small and local plastic deformations do not significantly affect the overall relationship between force and displacement, which are inherent in the initial stage of loading. With high external forces, plastic deformations become predominant. According to the criteria of Moore's theory, the fracture process in the local region of a solid body, the tangential stresses of which are quite fully characterized by the intensity of stresses and loosen the material by shear. Under the action of normal stresses $\sigma$ cracks open. The combined action of two types of destruction (shear and separation) leads to a loss of strength of the rock. Such a scheme of destruction is consistent with dislocation and dilaton theories of brittle cracks.

According to Mora's hypothesis, we can assume that the strength of the rock practically depends only on the members of this expression. That is, determines the time of transition of the rock to a plastic state.

$$
\sigma_{i}=\frac{\sqrt{2}}{2} \sqrt{\left(\sigma_{1}-\sigma_{2}\right)^{2}+\left(\sigma_{2}-\sigma_{3}\right)^{2}+\left(\sigma_{3}-\sigma_{1}\right)^{2}},
$$

Theories of rock pressure to determine the load on the casing in relation to deep wells are characterized by three directions.

The first direction is based on the use of simple physical models, according to which the load on the walls of wells is created by lateral rocks that have some degree of destruction. The magnitude of the load does not depend on the time, technology and characteristics of the casing. The calculation methods of this direction are based on the theory of calculation of retaining walls.

The second direction is based on the hypotheses of the interaction of casing, which are deformed together with the surrounding rock mass. In this case, the load on the pipes depends on the rigidity of the casing and the parameters of the technology of its construction. 
The third direction is formed by empirical methods, which are based on the results of properly processed and presented results of laboratory experiments. The pressure on the casing in the wellbore occurs in rocks of any strength and at any depth in proportion to this depth. However, practice shows that when crossing strong rocks, the walls of the well can remain stable for a long time, even without casing.

The condition is expected to be fulfilled

$$
\left[\sigma_{T}\right] \geq \frac{2 \mu}{1-\mu} \gamma H
$$

where $\left[\sigma_{T}\right]$ - the strength limit of rocks in terms of its occurrence.

In the first approximation, the following dependences were used to analyze the stress state of an elastic massif with a hole (for calculations of the stress state of an element (Fig. 2) of a wellbore) $[1,12]$. In the case of vertically acting geostatic pressure of rocks - $\gamma H$. If there are horizontal forces of the lateral strut and (in the general case, they are equal to each other) $-P_{x}=P_{y}=P_{2}$.

In cases where $\mu=0$ and, and at $\mu=0.25$, at $\mu=0.5$ already, ie always less than $\gamma H$. In the case of a well filled with liquid $\mathbf{P}_{1}$, it will be equal to the hydrostatic pressure.

To solve this problem Dynnyk A.N, and Tymoshenko S.P. [9, 10] recommend calculation dependences that allow to find on the basis of the known Lamé solution for a thick-walled cylinder loaded with external and internal distributed load. Makarov L.V. special studies were conducted to verify the validity (scope) of the formulas proposed by Dynnyk A.N, Tymoshenko S.P. and Lekhnitsky S.G. For research he used generalized equilibrium equations of an elastic body in cylindrical coordinates

$$
\begin{gathered}
(1-\mu)\left[\frac{1}{r} \frac{\delta u}{\delta r}-\frac{u}{r^{2}}+\frac{\delta^{2} u}{\delta r^{2}}\right]+\frac{1-2 \mu}{2} \frac{\delta^{2} u}{\delta z^{2}}+\frac{1}{2} \frac{\delta^{2} w}{\delta z \cdot \delta r}=0 \\
\frac{1}{2}\left[\frac{1}{r} \frac{\delta u}{\delta z}+\frac{\delta^{2} u}{\delta z \cdot \delta r}\right]+\frac{1-2 \mu}{2}\left[\frac{1}{r} \frac{\delta w}{\delta r}+\frac{\delta^{2} w}{\delta r^{2}}\right]+(1-\mu) \frac{\delta^{2} w}{\delta z^{2}}=k g \frac{(1+\mu)(1-2 \mu)}{E}
\end{gathered}
$$

The components of the stress tensor in this problem are found in the form

$$
\begin{gathered}
\sigma_{r}=\lambda\left(\frac{u}{r}+\frac{\delta w}{\delta z}\right)+(\lambda+2 \bar{\mu}) \frac{\delta u}{\delta r} ; \sigma_{t}=\lambda\left(\frac{\delta u}{\delta r}+\frac{\delta w}{\delta z}\right)+(\lambda+2 \bar{\mu}) \frac{u}{r} \\
\sigma_{z}=\lambda\left(\frac{\delta u}{\delta r}+\frac{u}{r}\right)+(\lambda+2 \bar{\mu}) \frac{\delta w}{\delta z}
\end{gathered}
$$


Where

$$
\begin{aligned}
& \lambda=\frac{\mu E}{(1+\mu)(1-2 \mu)} ; \bar{\mu}=\frac{E}{2(1+\mu)}: \\
& \tau_{r t}=\tau_{t z}=0 ; \tau_{r z}=\bar{\mu}\left(\frac{\delta u}{\delta z}+\frac{\delta w}{\delta r}\right) .
\end{aligned}
$$

Boundary conditions

$$
\begin{array}{lll}
\text { for } z=h & \sigma_{z}=0 ; & \tau_{z r}=0 ; \\
\text { for } z=0 & u=0 ; & w=0 ; \\
\text { for } r=r_{1} & \sigma_{r}=0 ; & \tau_{r z}=0 ; \\
\text { only when } P_{1}=0 u & r=r_{2}, & u=0, \\
& \text { a } \sigma_{z}=-\frac{\mu}{1-\mu} g(h-Z) .
\end{array}
$$

For the accepted equations, the components of the stress tensor were found numerically using the grid method and replacing the equations in the derivatives with the equations of differences. Computers were used to solve these equations. As a result of the study it was found: 1) Vertical normal stresses decrease in absolute value as you approach the walls of the well, the maximum reduction in the main calculated version was $5 \%$ 2) The decrease is due to the protrusion of rocks towards the well. With increasing $\mu$ there is a more intense protrusion. Subsequently, the same conditions with a mathematical description were extended to the elastic-plastic region. The problem in the new interpretation was solved first in an elastic formulation.

The values were found $\sigma_{i}$ and compared with the value accepted for a particular material on the basis of experimental data. If, $\sigma_{i}<\sigma_{i n p}$ then it was considered that the solution describes the elastic deformation, if, $\sigma_{i}>\sigma_{i n p}$ then it is a plastic region. The solution was made with additional, in addition to the boundary conditions of the problem and assumptions for the adopted method.

According to Makarov L.V. $\sigma_{i}=\phi\left(\varepsilon_{i}\right)=3 Y\left(1-w_{i}\right) \varepsilon_{i} ; \sigma_{i}<\sigma_{i n p}-$ elastic area; $\sigma_{i}>\sigma_{i n p}$ - not an elastic area. $Y$ - modulus of elasticity of the second kind; $w_{i}$ - some function, $w_{i}=w_{i}\left(\varepsilon_{i}\right)$, which varies within the region in the region of plastic deformations and is equal to 0 in the elastic region; $\sigma_{i}, \varepsilon_{i}$ - intensity $\sigma$ and deformations $\varepsilon$.

Conclusions based on the results of research were reduced to conclusions based on the solution of the same problem in an elastic formulation. As you approach the walls of the well in any of the hori- 
zontal planes, the stresses increase in absolute value, and the stresses decrease. This conclusion coincides with the currently widespread statement, including the results of research conducted by the author. The above shows once again that the task - to create an engineering method of calculation near the well drilled in the elastic-plastic massif, is quite difficult. This problem is difficult to solve even with the help of a computer, if the decision is made insufficiently sound initial equations and prerequisites for their solution.

The solution of the problem in this production was carried out like Makarov LV J.S. Erzhanov [5,6]. The difference of his decision is that Erzhanov Zh.S. instead of the grid method, he used the time step method. During the step-by-step transition, the stress-strain state was assumed to be altered due to the deformation of the body boundaries and the presence of physical nonlinearity. A computer is used to solve the system of equations. This allows to obtain the stress state of the array, to calculate the creep and relaxation and at the same time to compare the calculated and experimental data. Erzhanov's decision Zh.S. obtained in a fairly accurate form. The most acceptable solution for engineering practice is the one proposed by Yu.M. Lieberman $[9,10]$. He solved the elastic-plastic problem with respect to an unloaded massif composed of homogeneous, isotropic rock, in which the stress components are the same in all directions and are determined by the value before production $\gamma H$.

In deriving the calculated dependences, the condition of the boundary state of rocks is accepted, as which the hyperbolic curve from the origin is used (ie the solution is proposed in hyperbolic functions). This curve describes a material that is not able to withstand tensile strength, but partially retains compressive strength. However, recommended by Lieberman Yu.M. dependencies for calculations are in conflict with the accepted condition of the limit state. In them, the main value that characterizes the rock is $\sigma_{D}$ - the strength of the rock in the array in tension.

As a source Lieberman Yu.M. the equation of equilibrium, elementary volume in polar coordinates is accepted $\frac{d \sigma_{r}^{n n}}{d r}+\frac{d \sigma_{r}^{n \pi}-d \sigma_{r}^{n n}}{r}=0$, after substituting the values of stresses describing the condition of the limit state in the form of a hyperbolic 
curve, the basic differential equation is derived. $2 S h 2 \xi \frac{d \xi}{d r}-2 \sin \eta C h \xi \frac{d \xi}{d r}-2 \sin \eta \frac{S h 2 \xi}{r}=0$

The solution of this equation is obtained implicitly under the following boundary conditions:

1 - Stresses act on the well circuit $\sigma_{\mathrm{r}}=-P_{1}$.

2 - At the boundary between the region of inelastic deformations and intact array, the equality of stresses is observed: $\sigma_{r}^{n n}=\sigma_{r}^{y n}$ and $\sigma_{t}^{n n}=\sigma_{t}^{y n}$ or $\sigma_{t}^{n n}+\sigma_{r}^{n n}=\sigma_{t}^{y n}+\sigma_{r}^{y n}=2 \gamma H$.

The derived formulas determine the radius of the region of inelastic deformations and the stress distribution in the inelastic and elastic zones depending on the strength of the rock properties, the size of the production $r$, the depth from the surface $\mathrm{H}$ and the reaction of production P1. Despite the complexity of the mathematical description, these formulas can be used for engineering analysis of the problem. In such a setting, attempts were made to solve the problem of D.V. Danish, E.G. Leonov, I.K. Matrosov, Yu.P. Yellow, N.I Yagubov and others [8]. N.I. Yagubov in describing the behavior of the stump zone used viscoelastic models of Alpheus with the Laplace transform, as a result he obtained complex computational dependencies, the use of which in engineering calculations is quite complex.

Other of these authors used as mechanical characteristics of rocks: the coefficient of displacement of the rock in the region of inelastic deformations, the angle of internal friction of the rock, yield strength and compressive strength, the values of which are determined by the core. Given that the data obtained on the core do not always correspond to reality, because the interaction of rock with drilling mud and unloading of the core from rock pressure will cause serious distortions in the value of mechanical properties of the rock. Also, such indicators as compressive strength, coefficient of adhesion, internal friction angle and dynamic viscosity change during the transition of the rock to a plastic state, the solution becomes uncertain, does not meet the requirements of engineering practice. The study of the problems of analysis of the stress-strain state of deep wells is devoted to the work of V.I. Kareva, E.I. Shemyakina, I.L. Chernyaka, I.K. Fomenko, A.M. Papushi, E.M. Baranovsky, V.M. Stasenka [1-12]. Today there are a number of solutions taking into 
account certain properties of the array (anisotropy, inhomogeneity, time factor, etc.). The problems of drilling deep exploration wells in the Dnieper-Donetsk basin are that quite often there are situations when it becomes technically impossible and economically unprofitable to continue drilling. Based on a significant sample of factual data, it is investigated that complications and accidents, the elimination of which requires significant material costs, caused primarily by the manifestations of the destruction of the mountain massif, and occur mainly due to its imbalance. Virtually none of the wells over $5,500 \mathrm{~m}$ deep were drilled without complications and accidents.

Due to the uncertainty of the actual current stress-strain state and its failure to take into account when normalizing the density of flushing fluids, both in the design and drilling of wells, the mountain massif is always unbalanced. It is always heterogeneous in its structure and properties of rocks. The stress-strain state of rocks in the massif in the same stratigraphic horizons can have different values, which at the stage of development of drilling projects is impossible to predict. Prediction of current stresses in rock massifs is of great practical importance, because these components, together with the physicomechanical and rheological properties of rocks are the basis for calculating the stability of the walls of unfixed wells. Appropriate calculations are performed when assessing the productivity of formations before the tests, substantiation of the rationality of the adopted scheme of destruction of rocks at the bottom. Also, such calculations are necessary to determine the reliability of the isolation of productive strata from aquifers after cementing the casing. The main factor determining the stability of the wellbore is its stress state depending on the magnitude of external influences, reservoir fluid pressure and physical and mechanical properties of rocks under conditions of their occurrence.

Methods of mechanics of deformable media, in particular the theory of elasticity, plasticity, creep, etc., are widely used in the study of the stress-strain state of an array that has not lost its continuity. The scientific bases of the analysis of the stress-strain state of rocks are contained in the works of O.K. Angelopoulou, A.A. Gaivoronsky, V.D. Gorodnov, X. Feket, B.S. Filatov, L.A. Schreiner, R.M. Eigeles, R.S. Yaremiychuk and others. 
Recently, there is an intensive accumulation of information on the influence of various factors on the stress-strain rocks around the well and the improvement of research methods [6]. Methods of research of rocks around deep and superdeep wells can be divided into analytical, numerical, methods of physical modeling. Methods for studying the stress-strain state proposed by I.K. Fomenko, include a generalization of the experience of mathematical modeling of arrays of anisotropic rocks and the use of one of the numerical methods for solving problems of the theory of elasticity of anisotropic media - the method of boundary elements. In the general case, to determine the stresses in the selected mountain massif, there are known cases of using the finite element method under specific boundary conditions, such as the software package ANSYS and COMSOL Multiphisics [4]. Global stresses of the mountain massif make significant changes in the distribution of local stresses near the vertical deepest well (about $8000 \mathrm{~m}$ ). At the same time, the author proved that only classical calculation methods are sufficient for the preliminary assessment of the stress-strain state on the well wall.

Analysis of the current state of the problem allows us to draw the following conclusions:

1. The problem of predicting the stress-strain state of deep wells is quite relevant and widely studied, but the use of classical analytical approaches solves the problem only for certain partial cases.

2. The use of phenomenological approaches with the use of generalized parameters for assessing the state of deep wells requires the presence of objective, uncorrected input actual geological and physical information, which is not always possible.

3. Satisfactory results of predicting the stress-strain state of wells can be obtained using the finite element method in already tested software in combination with classical calculations and physical modeling, but solving the problem in this way requires appropriate scientific level of specialists. The issues of estimating the stress-strain state of deep wells remain incompletely studied and require certain engineering techniques for rapid assessment of the state of the well.

\subsection{The method of the analysis of elastic - plastic defor- mations of a deep well and a zone around a well is offered \\ The problem was solved in the following formulation (close to the problem of YM Lieberman) [2,4]: the stress state of a heavy iso-}


tropic, homogeneous elastic-plastic massif near the vertical cylindrical development of the final depth in this massif was studied. The elementary section (element) of a deep well was considered as an element with a hole of constant cross-section with a radius having an internal pressure $P_{1}$ and an external radius and external pressure $P_{2}$. The solution investigated a mathematical model that includes the equations of equilibrium, the relationship between the components of deformation and the components of displacement. Equations describing the properties of the medium, stress intensity and strain intensity are studied. The following boundary conditions are accepted: on the walls of the well evenly distributed stresses $\sigma_{r}=-P_{1}$; at the boundary of elastic and inelastic deformations, the continuity of the values of stresses and strains is observed.

The calculation is based on the assumption of uniform load distribution over the thickness of the element and the absence of loads in the planes parallel to the longitudinal axis of the element. The problem is axisymmetric, because weight is the only external force acting on the array, and deformation movements in the considered halfspace with a vertical cylindrical circular work take place only in the planes passing through the axis of symmetry. In all such planes the distribution of deformations and stresses will be the same. From the accepted assumptions it follows that the stress state of all points of the element is flat. This allows to reduce the solution of the volume problem to the solution of the distribution of deformations and stresses in one plane passing through the axis of symmetry of the well (to a flat deformed state).

The assumption is valid if $\left(r_{2} / t\right) \geq 2$ (where $t$ is the thickness of the element of the deformed part of the array). From the condition of load symmetry it can be assumed that stresses, deformations and displacements are functions of the radius and mechanical properties of the array material. When deriving the calculated equations, the influence of well contour irregularities, which lead to the concentration of local stresses, was neglected. The calculation assumed that the tensile diagram of the array material has no reinforcement. Depending on the external influence and the state of mechanical properties of rocks of the considered element of a deep well and physicochemical properties of clay solution used for drilling (flushing fluid), its most loaded points may be points located on the inner contour of the well. 
There begin to occur plastic deformations, ie the plastic region is adjacent to the inner contour of the well. The radius of the boundary of the plastic and elastic regions is marked (Fig. 3).

To derive the basic equation of equilibrium of the investigated element of a deep well by circumferential and radial stresses $\sigma_{r}$, their action on the average radius of the element $(r+d r / 2)$ is considered [8].

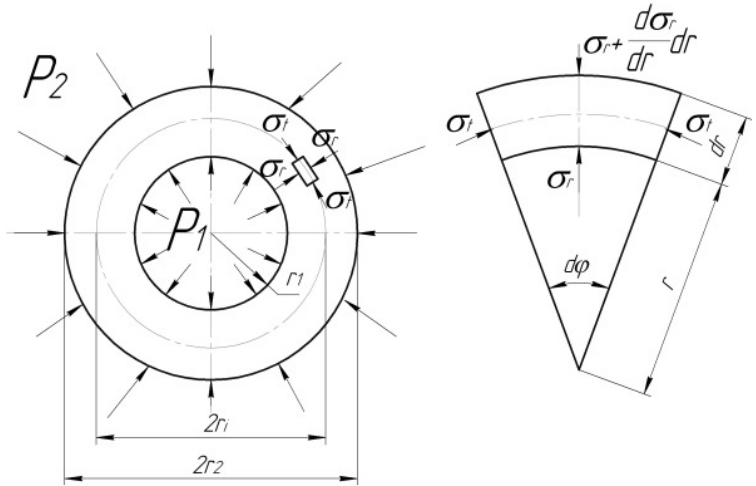

Fig. 3. Stress in the investigated element of the deep well

For a face at a distance away from the center of the element $r+d r$, the stresses will be equal to

$$
\sigma_{r}+\frac{d \sigma_{r}}{d r} d r
$$

To write the relationship between $\sigma_{t}$ and $\sigma_{r}$ design all the forces acting on the element in the direction of the mean radius we obtain

$$
\sigma_{r} r d \varphi+2 \sigma_{t} d r \sin \frac{d \varphi}{2}-\left(\sigma_{r}+\frac{d \sigma_{r}}{d r} d r\right)(r+d r) d \varphi=0 .
$$

Given that $\sin d \varphi / 2 \approx d \varphi / 2$ and neglecting the members of the higher order of smallness, the equation of equilibrium can be represented as follows

$$
r \frac{d \sigma_{r}}{d r}+\sigma_{r}-\sigma_{t}=0 .
$$

In the resulting equation there are two unknown stresses $\sigma_{t}$ and $\sigma_{r}$. To determine them, it is necessary to derive another equation, taking into account the boundary conditions of the problem:

1. On the contour of the well and the considered array of stress $\sigma_{r}=-P_{1}\left(P_{2}\right)$; 
2. On the boundary of elastic and non-elastic deformations of the array (at $r=r_{c}$ ) the equality of stresses is observed $\sigma_{r}^{e l}=\sigma_{r}^{p l}$ and $\sigma_{t}^{e l}=\sigma_{t}^{p l}$ displacement $u^{e l}=u^{p l}$, where $P_{1}$ is the back pressure in the well, $P_{2}$ is the lateral component of the gravitational forces acting on the formation, $r$ is the current value of the radius in the considered zone of the well. Due to the peculiarities of the problem, where the elastic-plastic massif is considered, plastic, elastic-plastic and elastic deformations can take place in the wellbore zone. Therefore, the plastic and elastic zones of the loaded massif with the well were investigated. The values of stresses at which plastic deformations appear on the inner surfaces of the well are found from the Mises plasticity condition [7]

$$
\left(\sigma_{r}-\sigma_{z}\right)^{2}+\left(\sigma_{t}-\sigma_{z}\right)^{2}+\left(\sigma_{r}-\sigma_{t}\right)^{2}=2 \sigma_{T}^{2} .
$$

Since normal stresses are not considered in the element (they are assumed to be evenly distributed throughout the array), the equation can be represented as (equivalent stresses of the energy hypothesis of plastic deformations)

$$
\sigma_{t}^{2}-\sigma_{t} \sigma_{r}+\sigma_{r}^{2}=\sigma_{T}^{2}
$$

where $\sigma_{T}$ - the yield strength of the material of the well element at the considered depth.

\section{Stress in the plastic zone.}

Using the known dependences [4,7], to identically satisfy the last equation, we introduce the function $\varphi$, with which we write $\sigma_{t}$ and $\sigma_{r}$ in the plastic stress region as follows

$$
\sigma_{t}=\frac{2}{\sqrt{3}} \sigma_{T} \cos \left(\varphi-\frac{\pi}{6}\right) ; \sigma_{r}=\frac{2}{\sqrt{3}} \sigma_{T} \cos \left(\varphi+\frac{\pi}{6}\right) .
$$

We enter dimensionless values of radiuses

$$
q=\frac{r}{r_{1}} ; \quad \beta=\frac{r_{c}}{r_{1}} ; \quad \alpha=\frac{r_{2}}{r_{1}} .
$$

Substituting the values of the circumferential and radial stresses (9) into equation (8), after the transformation we obtain the differential equation for the function $\varphi$

$$
q \frac{d \varphi}{d q}+\frac{\sin \varphi}{\sin \left(\varphi+\frac{\pi}{6}\right)}=0
$$

After integration we get 


$$
q=\frac{C(\sin \varphi)^{-\frac{1}{2}}}{e^{\frac{\sqrt{3}}{2} \varphi}}
$$

The constant integration $\mathrm{C}$ can be expressed in terms of the value of the function on the inner radius of the condition: when, $q=1, \varphi=\varphi_{1}$ and therefore.

Substituting the value of $C$, we obtain

$$
q=e^{\frac{\sqrt{3}}{2}\left(\varphi_{1}-\varphi\right)} \sqrt{\frac{\sin \varphi_{1}}{\sin \varphi}}
$$

Let us denote the value of $\varphi$ at the boundary of the elastic and plastic regions (for $r=r_{c}, q=\beta$ ) by $\varphi_{c}$. From equation (13) we have

$$
\beta=e^{\frac{\sqrt{3}}{2}\left(\varphi_{1}-\varphi_{c}\right)} \sqrt{\frac{\sin \varphi_{1}}{\sin \varphi_{c}}}
$$

To find the function $\varphi_{1}$, we use the boundary condition of the problem: $r=r_{l}$, for $q=1, \sigma_{r}=-P_{1}$. Then, given expression (9), we find

$$
-P_{1}=\frac{2}{\sqrt{3}} \sigma_{T} \cos \left(\varphi_{1}+\frac{\pi}{6}\right) .
$$

The obtained dependences (9), (14) and (15) allow to determine $\sigma_{t}$ and $\sigma_{r}$ in the plastic region.

\section{Stress in the elastic zone.}

Formulas for calculating stresses in the elastic region have the form [11]

$$
\sigma_{t}=\frac{2}{\sqrt{3}} \sigma_{T}\left(c_{1}+\frac{c_{2}}{q^{2}}\right) ; \sigma_{r}=\frac{2}{\sqrt{3}} \sigma_{T}\left(c_{1}-\frac{c_{2}}{q^{2}}\right) ;
$$

Using the condition of continuity $\sigma_{t}$ and $\sigma_{r}$ at the boundary of elasticity and plastic regions, for formulas (13) and (14) we take

$$
\begin{gathered}
\varphi=\varphi c, q=\beta \\
\cos \left(\varphi_{c}-\frac{\pi}{6}\right)=C_{1}+C_{2} \beta^{-2} ; \cos \left(\varphi_{c}+\frac{\pi}{6}\right)=C_{1}-C_{2} \beta^{-2}
\end{gathered}
$$

Solving these equations with respect to $C_{1}$ and $C_{2}$, we find

$$
C_{1}=\frac{\sqrt{3}}{2} \cos \varphi_{c} ; C_{2}=\frac{\beta^{2}}{2} \sin \varphi_{c}
$$

Substituting the values $C_{1}$ and $C_{2}$ found in (17), we obtain the dependences for stresses in the elastic region

$$
\sigma_{t}=\sigma_{T}\left(\cos \varphi_{c}+\frac{\beta^{2}}{\sqrt{3}} \frac{\sin \varphi_{c}}{q^{2}}\right) ; \sigma_{r}=\sigma_{T}\left(\cos \varphi_{c}-\frac{\beta^{2}}{\sqrt{3}} \frac{\sin \varphi_{c}}{q^{2}}\right)
$$


To find the value we use the boundary condition of the problem: when $r=r_{2}$, for $q=\alpha, \sigma_{r}=-P_{2}$

To find the value $\varphi_{c}$ we use the boundary condition of the problem: when we obtain

$$
-\frac{P_{2}}{\sigma_{T}}=\cos \varphi_{c}-\frac{e^{\sqrt{3}\left(\varphi_{1}-\varphi_{c}\right)}}{\alpha^{2} \sqrt{3}} \sin \varphi_{1}
$$

The calculation $\sigma_{t}$ and $\sigma_{r}$ is performed as follows: by formula (14) is the dimensionless radius $\beta$ of the boundary of the elastic and plastic regions; by formula (17) the values $\varphi_{c}$ are calculated; by formula (13) $-\varphi$, and from equations (19) the value of $\sigma_{t}$ and $\sigma_{r}$ is calculated.

\section{Radial displacements}

In solving the problem, the assumptions of the theory of plasticity about the incompressibility of the material both outside and within the elasticity are used. The incompressible material is characterized by the coincidence of the graphs of the dependence of the stress intensity on the intensity of deformations $\varepsilon_{i}$ with the tensile diagram. To calculate the radial displacement in the plastic region, we use the dependences of deformations on stresses $\sigma_{i}$ outside the elasticity at the biaxial stress state of incompressible material [11,12]

$$
\varepsilon_{t}=\frac{\varepsilon_{i}}{2 \sigma_{i}}\left(2 \sigma_{t}-\sigma_{r}\right) ; \varepsilon_{r}=\frac{\varepsilon_{i}}{2 \sigma_{i}}\left(2 \sigma_{r}-\sigma_{t}\right)
$$

$\varepsilon_{r}$ and $\varepsilon_{t}$ - respectively radial and circumferential relative deformation, $\varepsilon_{t}$ - intensity of deformation, $\varepsilon_{i}=\frac{2}{\sqrt{3}} \sqrt{\varepsilon_{t}^{2}+\varepsilon_{r}^{2}+\varepsilon_{i} \cdot \varepsilon_{r}}$. Dividing $\varepsilon_{r}$ by $\varepsilon_{t}$ we get

$$
\frac{\varepsilon_{r}}{\varepsilon_{t}}=\frac{2 \sigma_{r}-\sigma_{t}}{2 \sigma_{t}-\sigma_{r}}
$$

Circular $\varepsilon_{t}$ and radial $\varepsilon_{r}$ deformations are associated with radial displacement and dependencies [12]

$$
\begin{aligned}
& \varepsilon_{t}=\frac{\nu}{r} \text { and } \varepsilon_{r}=\frac{d \nu}{d r} \\
& \varepsilon_{i}=v / r a n d \varepsilon_{i}=d v / d r
\end{aligned}
$$

Substituting the obtained values is represented, as 


$$
\frac{d v}{v}=\frac{2 \sigma_{r}-\sigma_{t}}{2 \sigma_{t}-\sigma_{r}} \cdot \frac{d q}{q}
$$

Differentiating $q$ we obtain

$$
\frac{d q}{q}=-\frac{1}{2}(\sqrt{3}+\operatorname{ctg} \varphi) d \varphi .
$$

Substituting expressions into formula (24), we obtain

$$
\frac{d v}{v}=\frac{\sin \left(\varphi-\frac{\pi}{6}\right)}{\sin \varphi} d \varphi
$$

After integration, we write the equation for finding the radial displacement in the plastic zone.

$$
\frac{v}{r_{1}}=\frac{\sigma_{T}}{2 E} C_{3} \frac{e^{\frac{\sqrt{3}}{2} \varphi}}{\sqrt{\sin \varphi}},
$$

where $E$ is the modulus of elasticity. Formula for radial movement in the elastic zone for incompressible material using Hooke's law will be

$$
u=\varepsilon_{t} r=\frac{r_{1}}{2 E}\left(2 \sigma_{t}-\sigma_{r}\right) q
$$

Substituting the value $\sigma_{t}$ and $\sigma_{r}$ into the obtained expression, we obtain the equation of radial displacements in the elastic zone during elastic-plastic deformation

$$
\frac{u}{r_{1}}=\frac{\sigma_{T}}{2 E}\left(q \cos \varphi_{c}+\frac{\sqrt{3} \beta^{2} \sin \varphi_{c}}{q}\right)
$$

From the condition of equality of radial displacements at the boundary of the plastic and elastic regions, it is possible to determine the constant integration of $C_{3}$ by equating radial displacements by formulas (26) and (28) when $q=\beta, \varphi=\varphi_{c}$

$$
C_{3}=\frac{2 \beta \sqrt{\sin \varphi_{c}} \sin \left(\varphi_{c}+\frac{\pi}{6}\right)}{e^{\frac{\sqrt{3}}{2} \varphi_{c}}}
$$

Then the equation of radial displacements in the plastic zone will be 


$$
\frac{u}{r_{1}}=\frac{\sigma_{T}}{E} \beta e^{\frac{\sqrt{3}}{2}\left(\varphi-\varphi_{c}\right)} \sqrt{\frac{\sin \varphi_{c}}{\sin \varphi}} \sin \left(\varphi_{c}+\frac{\pi}{6}\right)
$$

\section{The order of calculation.}

For a given pressure $P_{1}$ from relation (17) are the value $\varphi_{1}$, and for a given value $P_{2}$ from formula (21) find $\varphi_{\mathrm{c}}$. After that, from relation (16) get $\beta$. Stresses in the plastic region are calculated by formulas (9), and in the elastic region by equations (20).

The transition from $\varphi$ to the dimensionless radius $q$ in the plastic zone is carried out by expression (15). Radial displacements in the plastic and elastic regions are calculated by equations (30) and (28), respectively.

The stress field formed in the shaft zone differs from the initial concentration of stresses in the well walls, resulting in elastic and inelastic movements of rocks. The above method is valid only in the presence of the latter, in other cases, the assessment of the stressstrain state of rocks can be performed using the following equations

$$
\sigma_{t}=\frac{P_{1}-P_{2} \alpha^{2}}{\alpha^{2}-1}+\frac{\left(P_{1}-P_{2}\right) \alpha^{2}}{\left(\alpha^{2}-1\right) q^{2}} ; \quad \sigma_{r}=\frac{P_{1}-P_{2} \alpha^{2}}{\alpha^{2}-1}-\frac{\left(P_{1}-P_{2}\right) \alpha^{2}}{\left(\alpha^{2}-1\right) q^{2}}
$$

Radial displacements during elastic deformations of an element of incompressible material can be found by the formula obtained after substitution (31) in (27)

$$
v=\frac{r_{1}}{E\left(\alpha^{2}-1\right)}\left[(1+\mu)\left(P_{1}-P_{2}\right) \alpha^{2}+(1-\mu)\left(P_{1}-P_{2} \alpha^{2}\right) q^{2}\right] \frac{1}{q}
$$

The recommended calculation method allows to assess the stressstrain state of the deep wellbore on a sufficient (for engineering practice) scientific basis. And also the method allows to formulate, in particular, requirements concerning stability of a well. It should be borne in mind that it is very difficult to eliminate the inelastic deformation of the well walls, which has already begun, and sometimes it is simply impossible to stop it. It is much more effective in such cases to prevent the possibility of violating the integrity of the array, and for this it is necessary to pre-establish its stress state. In order to formulate the strength condition (the condition of plastic deformations at the point), the strength criterion is introduced into the calculation. 
Assuming that the well element is exposed to evenly distributed internal and external pressures, the deformations will be symmetrical about the longitudinal axis of the element, then the stress intensity (based on the Mises plasticity condition) - a generalized strength condition will be

$$
\left[\sigma_{i T}\right] \geq \frac{1}{2} \sqrt{\left(\sigma_{r}-\sigma_{z}\right)^{2}+\left(\sigma_{z}-\sigma_{t}\right)^{2}+\left(\sigma_{r}-\sigma_{t}\right)^{2}}=\sigma_{i p a c},
$$

where $\sigma_{\mathrm{ipac}}$ - the calculated value of stresses $\sigma_{\mathrm{i}}$; [ $\left.\sigma_{\mathrm{i}}\right]$ - intensity of stresses at which plastic deformations appear in the rocks of the massif at the studied depth of the well. The criterion of strength does not contain any elastic constants. The condition of transition of material from elastic state to plastic beyond the yield strength is accepted, ie the condition of plasticity (if the material is able to accept plastic deformations without collapsing).

It is known $[13,25]$ that the plastic state or destruction of the material occurs when a certain ratio between octahedral and normal stresses is satisfied

$$
\sigma_{0}=\frac{1}{3}\left(\sigma_{z}+\sigma_{r}+\sigma_{t}\right) \leq\left[\sigma_{T}\right],
$$

where $\sigma_{0}$ - hydrostatic (average normal) pressure at the point. It does not depend on the choice of coordinate axes, ie it is invariant. In addition, it should be borne in mind that the hydrodynamic fluctuations of pressure in the well also cause changes in the stress state of the rocks of the array at the considered depth of the well. The pressure in the well increases above the hydrostatic $P_{1}$ during the operation of the pumps during drilling due to hydraulic resistance of the fluid pressure and during the descent of the tool due to the compression of the fluid. When lifting the tool, the pressure decreases due to the piston effect, as well as when the fluid level in the well decreases. The change in the stress state of rocks in this case can be determined as follows $\Delta \sigma_{z}=0$ since the change in hydrostatic pressure does not affect the geostatic pressure $P$

$$
\begin{array}{lc}
\sigma_{r}=\sigma_{r}-\left[\left(\lambda P_{r}-P_{1}\right) \frac{r_{1}^{2}}{r^{2}}-\lambda P_{r}\right] & \lambda=\frac{\mu}{1-\mu} ; \\
\sigma_{t}=\sigma_{r}+\left[\left(\lambda P_{r}-P_{1}\right) \frac{r_{1}^{2}}{r^{2}}-\lambda P_{r}\right] & P_{1}=\gamma_{\rtimes} H \pm P,
\end{array}
$$


where $\gamma$ - specific weight of flushing fluid, $\Delta \mathrm{P}$ - dynamic change of fluid pressure in the well. Using the principle of independence of forces, add the stresses due to various factors, and get

$$
\Sigma \sigma_{z}=\sigma_{z} ; \Sigma \sigma_{r}=\sigma_{r}+\square \sigma_{r} ; \sigma_{t}=\sigma_{t}+\square \sigma_{t}
$$

In this case, the strength condition in the cylindrical coordinate system will be

$$
\sigma_{i s} \geq \frac{1}{2} \sqrt{\left(\sum \sigma_{z}-\sum \sigma_{r}\right)^{2}+\left(\sum \sigma_{z}-\sum \sigma_{t}\right)^{2}+\left(\sum \sigma_{r}-\sum \sigma_{t}\right)^{2}} \leq\left[\sigma_{T}\right]_{(37)}
$$

According to experimental data, the long-term strength of rocks in deep wells is $0.85-0.95$ of its original value, ie: $\sigma_{i s_{p a c}}=(0,85-0,95) \sigma_{i s}$

\subsection{Interpretation of the results of calculations of the stress- strain state of the wellbore and wellbore}

Drilling a well significantly changes the stress-strain state of the elastic and elastic-plastic massif. In the shaft zone, in comparison with the massif located outside the boundary of the well, the rocks undergo a qualitatively new stress-strain state even in the presence of rocks prone to elastic-plastic deformation. The components of the stress tensor in this region at certain values of the external forces $\left(P_{r}, P_{1}, P_{2}\right)$ can have both positive (tensile) and negative (compressive) values (Fig.4).

Rocks in this interval (depth $3935 \mathrm{~m}$ in the well № 230 Borysivska Square) are in a difficult stressful state. They are simultaneously exposed to normal compressive $\sigma_{r} \cdot \sigma_{z}$ and tensile stresses $\sigma_{\mathrm{t}}$. Quite high compressive normal stresses are distributed along the trunk walls. They exceed the values of compressive normal stresses of the rock (1.0-0.8 times) and the maximum value of tensile stresses $+20.0 \mathrm{MPa}$. 


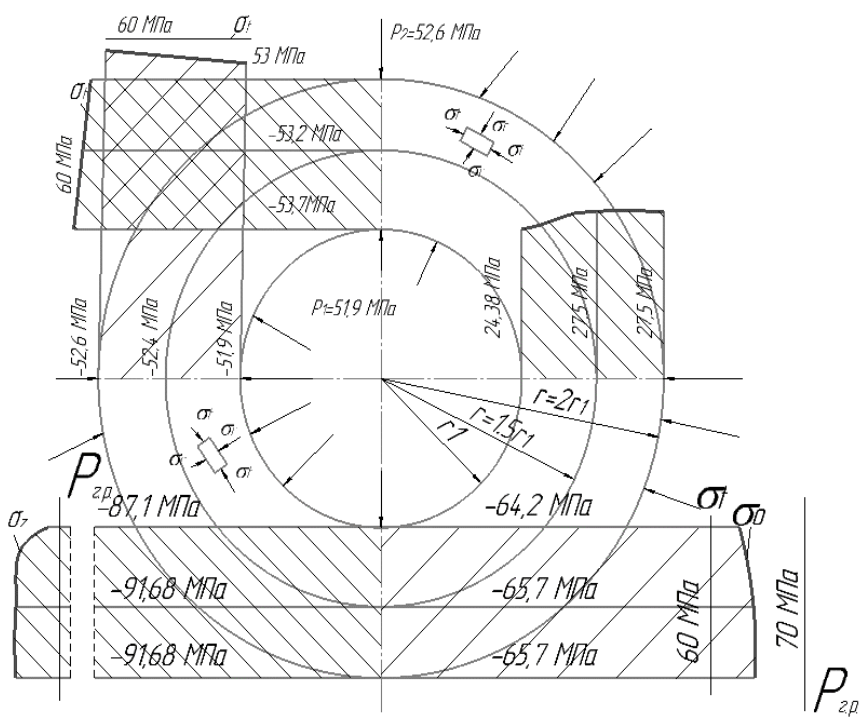

Fig. 4. Quasi equilibrium stress distribution along the well cross section

The intensity of stresses on the well circuit also has a maximum value $\sigma_{\mathrm{T}}$ exceeding 1.1 times. Only stresses $\sigma_{0}$ are minimal here, their valuesare almost $0.5 \sigma_{T}$

For $\sigma_{T}$ the accepted conditional yield strength, which characterizes the allowable amount of stresses that cause plastic deformation of the rock in terms of its occurrence. On the horizontal plane (when passing the array) near the wellbore, all stresses change their magnitude. At the boundary of the array, represented by a surface with radiuses $r_{1}$ and $r_{2}$, only compressive normal stresses act. Here $\sigma_{\mathrm{z}}$ they are growing rapidly at the level of reaching their limits.

In this area, the stresses $\sigma_{t}$ with a large gradient decrease, change the sign to the opposite, and again with a large gradient begin to increase. At the boundary where $r=r_{2}$ the stress has positive values $\left(\sigma_{t}\right.$ $=+3.94 \mathrm{MPa}$ ). Stresses $\sigma_{i}$ with approximately the same intensity $\sigma_{t}$ without jumps and differences are sharply reduced. Of all the calculated compressive stresses on the surface, which is limited by radiuses $r=r_{1}$ and $r=r_{2}$, only $\sigma_{0}$ have minimal values.

When passing through the section from $r_{1}$ to $r_{2}$ the absolute value of these stresses increases according to the linear law. Next, the cross 
section into the depth of the array, all components of the stress tensor remain compressive: $\sigma_{t}$ they increase intensively and reach their maximum value at: $r=1.5 r_{1}$ slightly decrease, then increase to the value of lateral pressure $\left(\sigma_{r}=-P_{2}=-52,6 \mathrm{MPa}\right)$.

Remain constant and equal (in absolute value) to geostatic pressure. The magnitude of stresses $\sigma_{i}$ decreases to its minimum values. Further removal of the wellbore from the cross section into the depth of the massif indicates that all stresses $\left(\sigma_{r}, \sigma_{t}, \sigma_{0}, \sigma_{z}, \sigma_{i}\right)$ are close to their constant values, Here the rocks are in a state of stable equilibrium, close to the state of comprehensive compression (Fig. 4). The magnitude of the applied stresses, determined by this state, also exceeds the yield strength of rocks. But it is below the values corresponding to fracturing.

The hydrostatic pressure in this case has a maximum value of approximately $66 \mathrm{MPa}$. That is, the rocks in the intact massif are in a state of elastic-plastic deformation. The instantaneous radial displacements of the loaded rock enclosed in the zone of influence of the well on the array and prone to elastic-plastic deformations are (1.5-1.3) $\mathrm{mm}$. The values of stresses outside the zone of influence of the well on the rock mass are: $\sigma_{r}=-52,6 \mathrm{MPa} ; \sigma_{z}=-91,68 \mathrm{MPa} ; \sigma_{t}=-$ $56,2 \mathrm{MPa} ; \sigma_{i}=26,4 \mathrm{MPa}$ and $\sigma_{0}=-66,8 \mathrm{MPa}$.

Here the rocks are in a state of stable equilibrium, close to the state of comprehensive compression. As can be seen from the diagram in Fig. 4, the value of the applied stresses, determined by this state, also exceeds the value of the yield strength of rocks, but below their fracturing. The hydrostatic pressure in this case has a maximum value of approximately $66 \mathrm{MPa}$. That is, the rocks in the intact array are in a state of elastic - plastic deformation. The instantaneous radial displacements of the loaded rock enclosed in the impact zone of the well are $1.5-1.3 \mathrm{~mm}$.

For the case under consideration, the size of the zone of influence of the well on the rock mass is limited to the surface with a radius $r=1.5 r_{l}$. Outside this zone there is a stress state due to gravitational forces. There is a quasi-equilibrium state of rocks (under the influence of comprehensive non-uniform compression) is prone to impaired stability in cases of additional influence or degree of freedom. The appearance of an additional degree of freedom will negatively affect the state of equilibrium. This will cause a sharp redistribution 
of stresses, destruction of rocks or their creep due to plastic deformation. Deformation can occur in almost any direction.

A number of researchers based on the analysis of experimental data stated a pattern. At loading of rock and its endurance under loading within 8-10 hours there is a change of a stressful condition of breed. In this case, there is a relaxation of stresses. In the future, the process stabilizes. The stress-strain state of rocks remains virtually unchanged. The most intense reduction of stresses is observed in the trunk zone and in the initial period after loading (weakening). Analysis of the values of relaxation and design stresses showed a decrease in their time by $5-15 \%$ (in clay rocks up to $10 \%$ ).

The effect of relaxation on the magnitude of stresses found using the proposed method can be taken into account by introducing correction factors $K_{\mathrm{p}}$ and $K_{\mathrm{m}}$. They take into account the relaxation of stresses in the shaft zone and outside the impact of the well on the rock mass $\left(K_{\mathrm{p}}=0.9-0.85 ; K_{m}=0.9-0.95\right)$. When quantifying the values of operating stresses in rocks, it is necessary to take into account another feature. In rock in the conditions of its natural occurrence both properties of breed, and values of its mechanical characteristics change in due course. Experimental and theoretical studies have shown a decrease in allowable stress values, ie their change according to the law of long-term strength of rocks in well conditions is $0.85-0.95$ from the initial [12].

Taking into account the above two features in the behavior of rocks in terms of their occurrence, we can assume that the stress state of rocks during well drilling changes over time in proportion to changes in the values of rock strength characteristics under the condition of their long strength. The decrease in the strength of rocks in the well according to the law of long-term strength is compensated by the relaxation of the applied stresses. At final comparison of results of calculation (quantitative estimation of settlement data $\sigma_{T}$ ) it is necessary to enter a correction factor. It takes into account the discrepancy of the values of $\sigma$ obtained by the calculation method with the real ones, due to stress relaxation and long-term rock strength. The values of this coefficient are in the range of $0.85-0.95$

The rock mass is considered as an elastic medium in which the well is drilled. In this environment under the influence of loads there is a creep of deformations and relaxation of stresses. The wellbore is 
deformed inward by some amount. After continuing to deepen the well, the process of contour movements continues due to the creep of deformations, but it is opposed by the resistance of the wellbore and the pressure of the drilling fluid. Their joint deformation continues until the state of equilibrium is realized in the system "wellbore rock". Deformation is characterized by a fairly rapid process and a sharp increase in displacement after they reach a certain critical limit in the previous area - the limit of elasticity. This circumstance is usually repeated, which in itself suggests that the cause of this pressure is some general physical pattern. Its characteristic feature is the very rapid growth of deformations in a relatively short period of time, which occurs after the plastic deformations reach some critical limits.

From the energy point of view, the following happens: with a slight change in the stress state associated with the deformation of the face, there is a relatively rapid release of potential energy spent on additional destruction of structural bonds in the rock mass under tensile stresses $\sigma_{t}$. This is accompanied by a significant increase in volume (landslides, falling into the well). After that, the mechanical system finds a state of equilibrium again. The rate of transition from one energy state to another is determined by the stress state and structural features of rocks in the array. For fragile rocks, it can be very high. For rocks containing a large number of clay particles, the transition rate will be relatively small, and the subsequent process will be long (Fig. 4). In this phenomenon - is the elastic-plastic loss of stability of the equilibrium of the rock mass (wellbore). When drilling a well in the bottomhole zone, the level of stresses in the array (on the walls of the well) changes due to the appearance of caverns of different sizes.

Sometimes fragile layers, not of great power, lie directly above the drilled layer. This layer is destroyed, as a rule, immediately after the drilling of the formation and its retention with the solution is very difficult. Crashing occurs in small areas along the wellbore. The nature of the direct profile of the well in this case is determined by the capacity of the destroyed rocks after the transfer of the drilling process into the well. The time of involuntary formation of the profile of the wellbore is several times less than the time of formation of the main profile. 
At the time of the first collapse of the wellbore there is a rapid change in the nature and magnitude of the loads directly on the wellbore. During this period, there may be a large deformation of the trunk, which sometimes leads to complete destruction of the well. After the first collapse, the thickness of the weakened rocks of the wellbore decreases, the stress level in the bottomhole part of the rock mass decreases and the operating conditions of the wellbore improve. The wellbore, in this case with a cavity, may not be fixed for a long time. This sometimes allows you to go through the whole layer without significant complications. To control the condition of the wellbore and the zone of impact of the well, rock pressure $P_{2}$ and hydrostatic pressure $P_{1}$ in deep wells provide, taking into account the stress-strain state of the wellbore and stump zone of the rock mass, change the drilling fluid density $\gamma$. The same role is performed by works related to the change of stresses acting on the wellbore and the wellbore zone.

The rock mass before the extraction of the rock is in an equilibrium stress-strain state, which is called the initial. Stress components that can be caused by neotectonic processes are usually considered absent. As the well deepens and the bottom moves, the stress field around the well changes. The area of the rock mass within which these changes occur is called the impact zone of the well. This zone of influence of the well is small, but often the deformation processes affect the entire thickness of the drilled formation (Fig. 4). There are two characteristic areas around the well. The area within which the voltages are less than the initial ones is called the discharge zone. The area within which stresses in excess of the initial are called the reference pressure zone. As the bottom of the well moves in space, the selected areas also move with it. In this case, the rocks of the array, according to changes in the stress-strain state, can gradually move from one zone to another. Under the influence of significant stresses of the rock in the shaft part of the formation, located close to the wellbore, are destroyed. Their bearing capacity decreases and the maximum stress moves deep into the array. The destroyed part of the rocks is intensively pressed into the well (cavern formation). The parameters of this well zone depend on many factors: determining the depth of the well, the ratio of the components of the initial stress field, the size and configuration of the impact zone of the well on the 
rock mass, deformation and strength properties of rocks, their structure and texture.

When calculating the stress-strain state of the walls of deep wells, considerable attention should be paid to the coefficient of strength, its justification. with Depending on the tasks, its values are taken equal to 1.8-3.0. The fracture pressure value is calculated as the difference between the downhole pressure during fracturing and the crack closing pressure. In this regard, the problem of estimating the strength of the unfixed part of the formation is important for establishing the stress-strain state of the shaft and the shaft zone of a deep well. The stability of an unfixed well is assessed by the absence of dumps, destruction of rocks in its walls, debris.

The study of mechanical processes in the wellbore massif of rocks is carried out on the basis of the above general principles of mechanics of continuous media. Although these processes in the well and in the rocks of the formation are a whole, the features of the stress-strain state in these elements have significant differences; in the massif outside the zone of influence of the well, the rocks work on compression and can be destroyed by crushing. In the walls of the well and in the massif of the impact zone of the rock are bending deformations, more dangerous in terms of destruction. Therefore, to assess the stability of the unfixed part of the well, it is advisable to consider separately the strength of the rocks of the shaft part of the array, the strength of the rocks of the wellbore.

The proposed method of calculation allows to find the values of radial and tangential stresses and displacements and the radius of the region of inelastic deformations of rocks. We can determine the displacements that occur both on the walls of wells and in adjacent areas, in non-elastic and elastic zones. The method allows you to easily, quickly and reliably establish the stress state of the rocks that make up the walls of the well, as well as near it. After that, make objective decisions when drilling wells under specified conditions. Thus, to 
ensure a reduction in material and labor costs, especially in the arrangement of oil and gas fields, should take into account the state of the mountain pores. The state of rocks is determined by the action of gravitational and tectonic forces. This allows you to make the recommended engineering method of calculation.

\section{Conclusions}

The method is recommended for quick decision-making related to various problems that arise during the construction of deep wells (oil, gas, etc.) and their operation. It can also be used in the design and implementation of analytical research. For engineering calculations of wells in a narrow range of stresses, the elastic and strength parameters of the rock can be considered constant. Thus, the known laws of elasticity and plasticity were used to determine deformations and stresses.

Therefore, the values of the instantaneous (calculated characteristics of the rocks by values) and the ratio of the applied stresses, taking into account the long-term strength will be approximately the same and equal to about one. Therefore, the quantitative assessment of the stress state of the rocks along the wellbore and near the wellbore with an accuracy sufficient for engineering practice, can be performed using the proposed method.

\section{References}

1. Alimzhanov, A.M. (1994). Stress-strain state around deep wells in conditions of heterogeneity of mechanical properties of rocks near the wellbore zone: Ph.D. dis. for the scientific degree Physics and Mathematics, 01.02.04 Mechanics of a Deformable Solid Body. Novosibirsk. $-32 \mathrm{p}$.

2. Alimzhanov, A.M. Spatial axisymmetric stability of a vertical well in an array containing a layer with reduced strength properties [Electronic resource] / A.M. Alimzhanov. - Access mode: http://www.ogbus.ru/authors/Alimzhanov/ Alimzhanov_1.pdf

3. Bandurina, O.V. (2012) Perspective of analysis of the stress-strain state of a deep wellbore // Abstracts of the 64th scientific conference of professors, academics, scientific practitioners, graduate students and students of the university. Volume 1. (Poltava, April 17 to May 11, 2012) - Poltava: PoltNTU, 2012. - PP 147 - 149. 
4. Blokhin, V.S. Bandurina, O.V. (2013) Assessment of the stress state of a deep wellbore // Bulletin of the KrNU named after Mikhail Ostrogradsky. -Vol 1/2013(78). - PP. 71 - 75.

5. Blokhin, V.S. Stability criteria for carbonate and terrigenous deposits in deep wells // Improving the efficiency of drilling deep wells in abnormal geological conditions / V.S. Blokhin, V.V. Ippolitov, V.D. Terentiev, F.K. Gimadeeva - Orenburg: TSNTI, 1983. - $44 \mathrm{p}$.

6. Blokhin, V.S. (1984) Method for assessing the stability of the well walls / V.S. Blokhin, V.V. Ippolitov, V.D. Terentiev // Oil industry. - 1984. - N. 7. - PP. $28-31$.

7. Investigation of the stress-strain state of the massif around the well with timevarying strength properties of rocks / P.I. Svitalka, V.V. Solovyov, M.P. Nesterenko, O.V. Bandurina // Scientific journal (Geology. Mining. Oil and gas business) / Poltava National Technical University named after Yuri Kondratyuk. - Vol. 1 (1). Poltava: PoltNTU, 2012. - PP. 144 - 148.

8. Eremenko, S.Yu. (1991) Finite element methods in the mechanics of deformable bodies / S.Yu. Eremenko. - Kharkov: Basis, 1991. - 272p.

9. Isakov, V.B. (2003) Elements of numerical methods: Textbook for students studying in the specialty Mathematics group Pedagogical special. - M.: Academy, 2003. -192 p.

10. Iudin, M.M. (1997) Stress-strain state of the frozen rock mass around a vertical shaft. - Yakutsk: YaGU, 1997. - 26 p.

11. Kalashnik, A.I., Kalashnik, N.A. (2010) Technogenic deformation of the bowels // Rational development of mineral resources, 2010. - №2. PP. 48 - 53.

12. Karev, V.I. (2010) Influence of the stress-strain state of rocks on the filtration process, and well flow rate: abstract of the thesis. dis. for the academic degree of doctor of technical sciences 01.02.04 - mechanics of a deformable solid body St. Petersburg. - 34 p.

13. Papusha, A.N., Gontarev, D.P. (2010) On the issue of calculating the stress-strain state of a rock mass in the vicinity of a superdeep vertical well // Visnik MSTU. - No. 5. - PP 81 - 93.

14. Svitalka, P.I. Solovyov, V.V. Bandurina, O.V. (2013) Methods and results of determining the mineral content of salty rocks fallow in terms of firmness of nonspring deformation //Collection of scientific practices: branch mechanical engineering. - Vol.3 (39). - PP.175 - 181.

15. Stasenko, V.M., Karpenko, V.M., Kozachenko, M.I. (2008) Problems of evaluation and forecasting of the geobaric and stress-strained mill of the mountain massif during the drilling of deep oil and gas sverdlovins // Oil and gas industry, 2008. - №. 2. - PP. 20 - 22.

16. Alimzhanov, M.T. (1992) Methods of continuum nonlinear mechanics in problems of rock pressure control at drilling deep wells / M.T. Alimzhanov // Advances in Mechanics, Int.Jour., Warsaw, 1992. - Vol.15. - № 3-4. - P. 41 - 69.

17. Gass R. (1998) Mathematica for scientists and engeneers: using Mathematica to do science/ monography — New Jersy «Prentice Hall», 1998 - 499 p. 
https://doi.org/10.31713/m1126

\title{
EXPERIENCE OF IMPROVING THE OPERATING RELIABILITY OF DRILLING MACHINES AT THE INSTALLATION OF EXTRA DEEP WELLS IN COMPLEX GEOLOGICAL CONDITIONS
}

\author{
Vynnykov Yu.L. \\ National University «Yuri Kondratyuk Poltava Polytechnic» \\ DSc, Professor, Head of the Department of Drilling and Geology, Ukraine \\ Kharchenko M.O. \\ National University «Yuri Kondratyuk Poltava Polytechnic» \\ $\mathrm{PhD}$, Associated professor, Associate Professor of the Department of Drill- \\ ing and Geology, Ukraine

\section{Lartseva I.I.} \\ National University «Yuri Kondratyuk Poltava Polytechnic» \\ $\mathrm{PhD}$, Associated professor, Associate Professor of the Department \\ of Oil and Gas Engineering and Technology, Ukraine

\section{Yaholnyk A.M.} \\ National University «Yuri Kondratyuk Poltava Polytechnic» \\ $\mathrm{PhD}$, Associated professor, Associate Professor of the Department of Drill- \\ ing and Geology, Ukraine
}

\begin{abstract}
.
Constructive and geotechnical solutions for the arrangement of bases and foundations of drilling rigs for the construction of wells up to $6000 \mathrm{~m}$ deep in complex engineering and geological conditions, as well as the results of approbation of these solutions are given. The thickness of non-building soils (soil-plant layer, peat, fluidplastic and fluid loams) is $5.6 \mathrm{~m}$, and the groundwater level is $1 \mathrm{~m}$ from the earth's surface. Different thicknesses of soil layers, as well as various layers and lenses were recorded within the massif. Geotechnical solutions of engineering preparation for prefabricated foundation slab from 5 rows of road slabs for a drilling machine with a capacity of 450 tons are analyzed, in particular: cutting weak soils with piles; improvement of the base under the machine by vertical reinforcement of weak soils with rigid elements and replacement of the top layer with a compacted sand cushion; improving the base with vertical gravel drains within water-saturated weak soils and replacing the top layer with a compacted sand cushion; improving the base with horizontal gravel drains and replacing the top layer with a sand cushion.

Keywords: drilling rig, foundation, base, subsidence, roll, weak soil, sand cushion, gravel drain, field test.
\end{abstract}


Introduction. A well is a complex innovative engineering project for mining. A modern well is an extremely complex system, which each time has an original trajectory in space, and sometimes it is a system of wells made from one point. (Fig. 1.1).

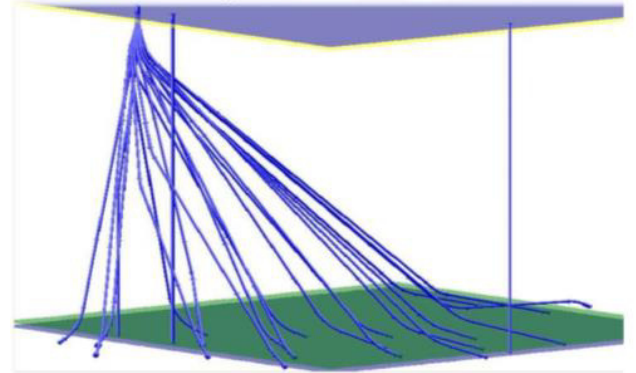

Fig. 1.1. Example of a modern well system (multi-well)

Modern powerful drilling rigs of various companies are used in the construction of deep and ultra-deep wells, including complex trajectories. This equipment is subject to extremely high requirements in terms of displacements and rolls in the process of their work, which can be caused by absolute and uneven subsidence of the base of their foundations. Very often (especially in the areas of the central part of Ukraine) drilling rigs have complex engineering and geological conditions (floodplains, swamps, weak soils, etc.). Due to the fact that the construction of the well is a temporary process (currently the leading companies have experience in drilling wells over 5,000 $\mathrm{m}$ deep for up to 4 months), to build under the drilling machine massive monolithic foundation slabs, reinforced concrete piles and other capital foundations provided on construction sites, impractical for many reasons (economic, environmental, the need for complete dismantling after completion of drilling, etc.).

\section{Experience and problems of laying foundations for drilling rigs in complex engineering and geological conditions}

Prefabricated foundation slabs are usually used as foundations. As a rule, they consist of road slabs in several rows. This design is not rigid and in the process of drilling may receive excessive deformation. Drilling rigs can lead to well construction accidents and significantly increase both the time and cost of the well drilling pro- 
cess. Therefore, the problem of improving the operational reliability of drilling rigs when installing ultra-deep wells in difficult geological conditions is extremely relevant. Some of the above problems are analyzed in scientific papers [1,2].

Studies of subsidence of the foundations of heavy and high equipment, which is intended to be temporarily operated (less than a year), in complex engineering and geological conditions were almost not conducted. Therefore, this issue requires the systematization of various experience in the operation of equipment in complex engineering and geological conditions under different geotechnical solutions [3-8], in particular with the improvement of the soil base, which is why this article is devoted.

\section{Methods of research of the bases under drilling rigs}

When constructing ultra-deep wells in Ukraine, and especially in the Poltava region, drilling contractors often use a drilling rig with a capacity of 450 tons (general types of equipment are shown in Fig. 2.1).

In Fig. 2.2 shows a photo of one of the sites where the installation of the drilling rig was planned.

Adverse physical and geological processes and phenomena for many sites include:

1) thick (from 4.5 to $5.6 \mathrm{~m}$ ) thickness of non-building (soil-plant layer, peat on the base of the layer silty, rubberized, with organic residues, fluid, very heterogeneous) and weak soils (loam (bottom silt) light dusty, from fluid-plastic to fluid, with layers of sand, layered; modulus deformation of soil $E \leq 5 \mathrm{MPa}$ ). When using them as a natural basis for foundations, excessive and uneven deformations of the soil mass are possible; 

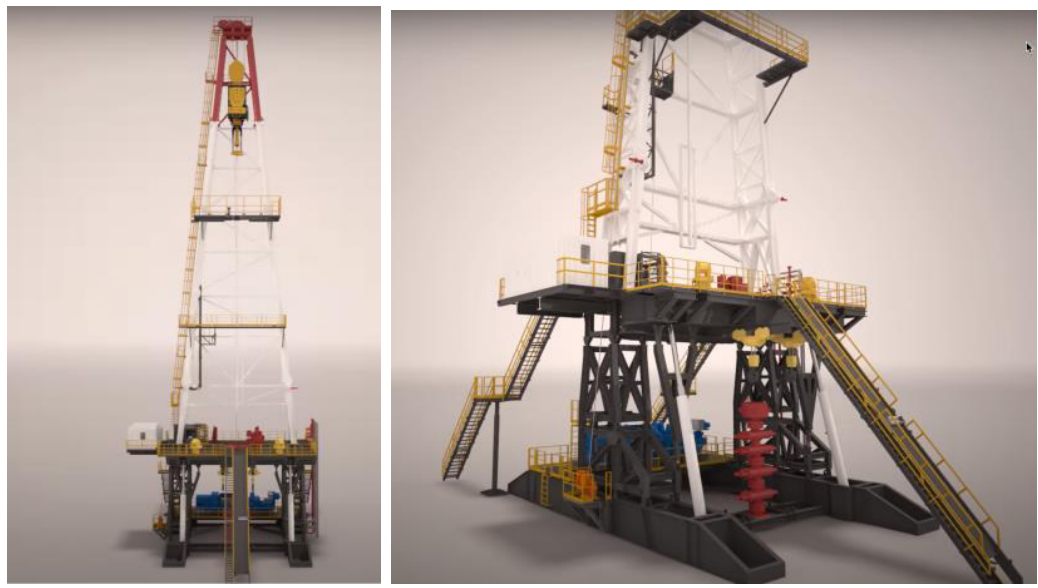

Fig. 2.1. General view of the drilling machine

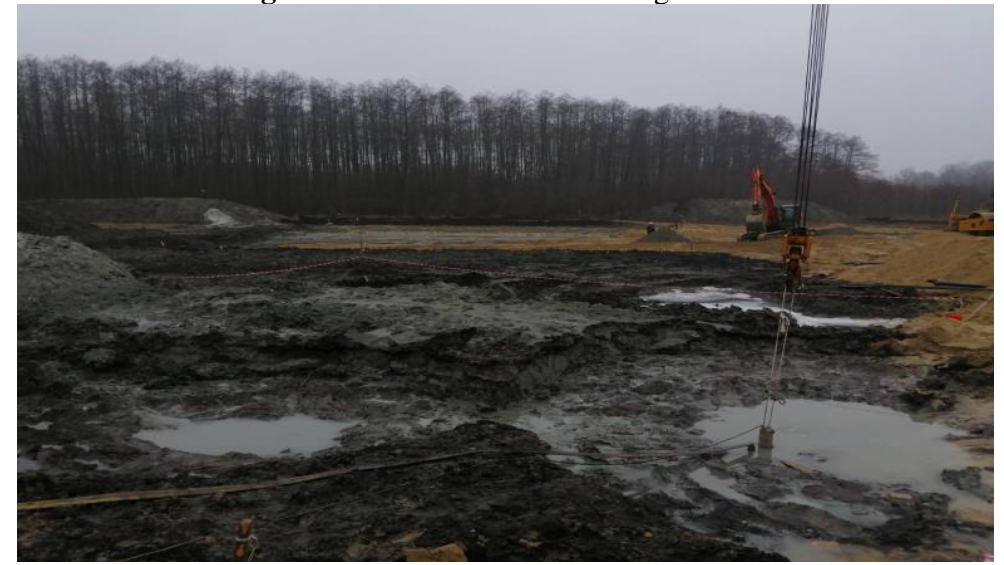

Fig. 2.2. Engineering and geological conditions of the site for drilling machine installation

2) soils capable of thixotropic rarefaction in the case of dynamic loads;

3) significant heterogeneity of the soil mass - different thicknesses of soil layers, the presence of layers and lenses;

4) flooding of the territory.

For drilling rigs as foundations, as a rule, use a foundation slab with dimensions in the plan of approximately $20 \times 32 \mathrm{~m}$ and a thickness of $700 \mathrm{~mm}$, which is arranged from 5 rows of road slabs with 
appropriate bandaging and which are combined with holders from the channels (Fig. 2.3).

Without proper engineering training, the above solution will not be able to ensure trouble-free operation of the drilling rig.

The following is an example of the arrangement of the drilling rig in the complex engineering and geological conditions of Poltava region.

Engineering and geological conditions of the site are represented by the following soils:

EGE-1 - loam gray, dark gray, light dusty, from hard to soft plastic, layered, with layers of sand, humus-bath, thickness 0.4-0.7 m;

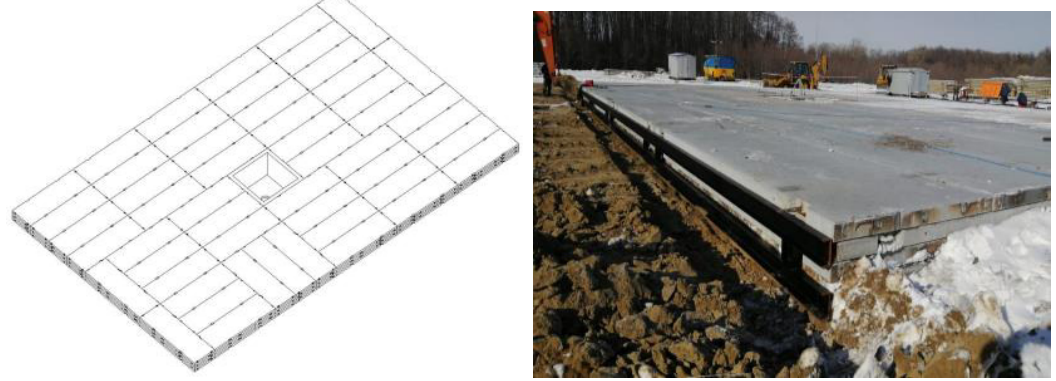

Fig. 2.3. Space image and photo of the foundation for the drilling rig

EGE-2 - sands loam gray, blue-gray, dusty, from plastic to fluid, heterogeneous, with layers of sand, thickness 1.0-2.1 m;

EGE-3 - sands gray, bluish-gray, dusty, from loose to medium density, with layers and lenses of sandy loam, thickness $1.5-2.5 \mathrm{~m}$;

EGE-4 - sands blue-gray, shallow, medium density, saturated with water, with layers and lenses of sand, thickness 0.4-1.4 m;

IGE-5 - sands gray, shallow, medium density, saturated with water, thickness $1.2 \mathrm{~m}$.

At the time of engineering and geological surveys (June 2020), the groundwater level was at a depth of $1 \mathrm{~m}$ from the earth's surface. This level was established after the installation of a ring drainage system with forced pumping around the site.

Thus, the unfavorable physical and geological processes include:

- man-made processes - the territory is under the influence of manmade factors and human engineering activities. At the time of the survey, the site was planned and the upper layers of soil to a depth of $1.0 \mathrm{~m}$ were cut and planned into a dump near the site; 
- weak and heterogeneous soils - at the moment the territory to a depth of 2.8 to $4.4 \mathrm{~m}$ is composed of heterogeneous sandy or clay soils. Dusty sands are loose sandy layers with layers and lenses. Clay soils (loams and sands) are in a state from soft-plastic to fluid with layers and lenses of sand. When using them as the basis of foundations, non-uniform deformations of the soil mass are possible;

- flooding of the territory - the territory at the time of the survey is flooded. With a significant rise in water levels in rivers (seasonal or heavy rainfall), the area may be flooded.

In the given difficult engineering-geological conditions some geotechnical decisions of engineering preparation or effective bases under the prefabricated base plate for the drilling rig with a loading capacity of $450 \mathrm{t}$ for construction of a well up to $6000 \mathrm{~m}$ deep (Fig. 2.4-2.7) are offered:

- cutting weak soils with pile foundations [9-11] (Fig. 2.4);

- improvement of the soil base for the drilling rig by vertical reinforcement of weak soils with rigid elements and replacement of the top layer with a compacted sand cushion [10-14] (Fig. 2.5);

- improvement of the base under the drilling rig by arranging vertical gravel drains within water-saturated weak soils and replacement of the upper layer with a compacted sand cushion [15] (Fig. 2.6);

- improving the soil base for the drilling rig by installing horizontal crushed stone drains and replacing the top layer with a compacted sand cushion [15] (Fig. 2.7).

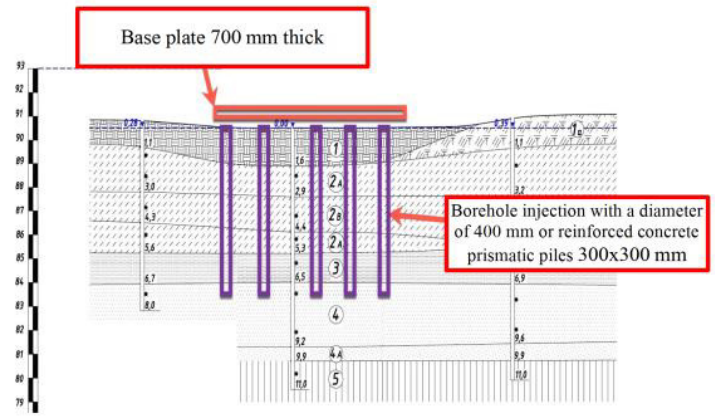

Fig. 2.4. Option of cutting weak soils with pile foundations 


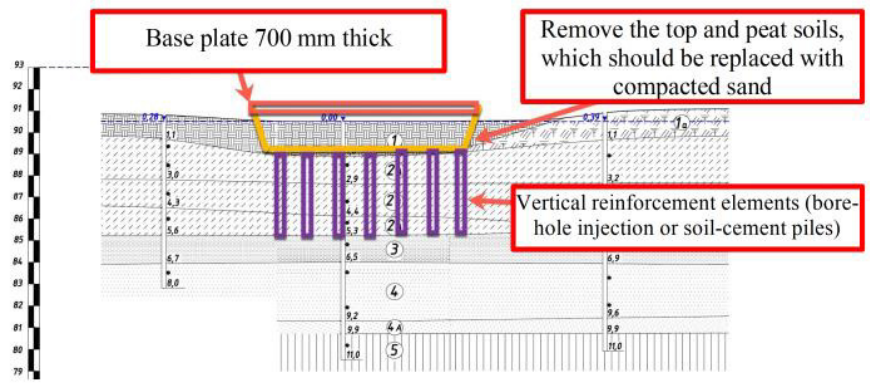

Fig. 2.5. Option to improve the soil base for the drilling rig by vertically reinforcing weak soils with rigid elements and replacing the top layer with a compacted sand cushion

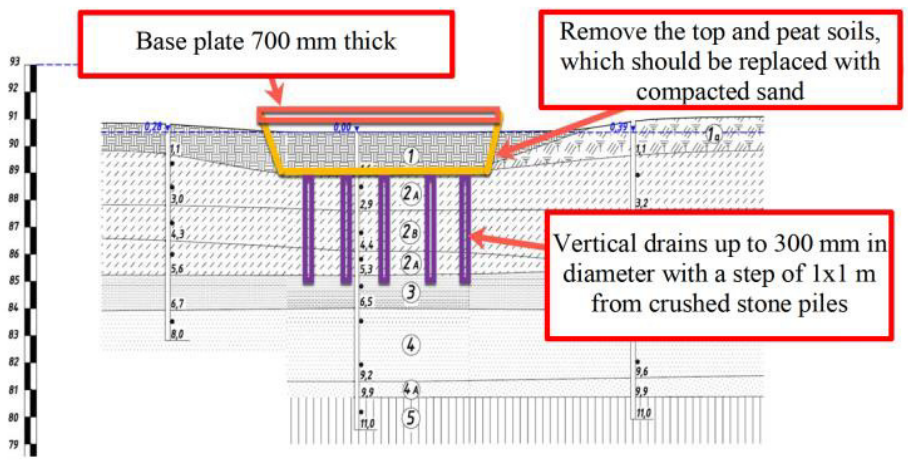

Fig. 2.6. Option to improve the base for the drilling rig by arranging vertical gravel drains within water-saturated weak soils and replacing the top layer with compacted sand cushion

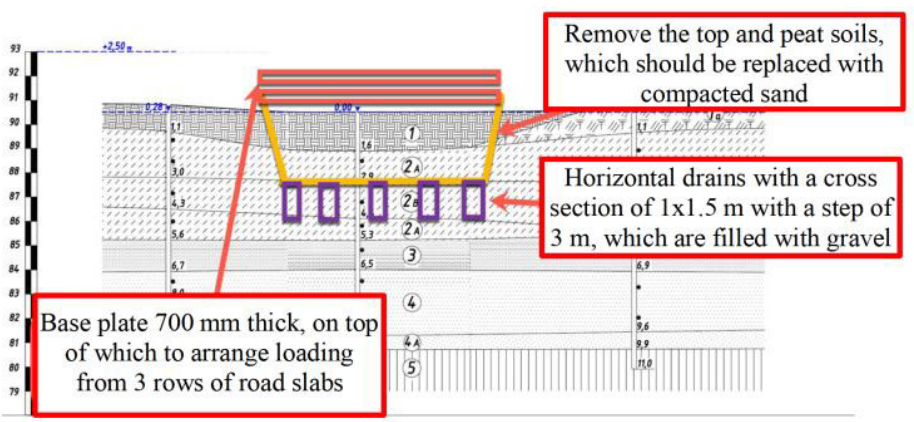

Fig. 2.7. Option to improve the soil base for the drilling rig by installing horizontal crushed stone drains and replacing the top layer with a compacted sand cushion 


\section{Results of research of the arrangement of the foundations for the drilling rig in complex engineering and geological condi- tions}

The main option was to improve the soil base for the drilling rig by installing horizontal crushed stone drains (Fig. 2.7). Upon completion of the work, the gravel drains were replaced with a solid gravel base. The work was performed as follows: first, an excavator performed a trench $1.5 \mathrm{~m}$ wide to the maximum depth (almost to the design mark) and immediately filled it with gravel and sand to the groundwater level; then a retreat was made and a new trench was arranged according to the same method and so on over the entire area of the foundation slab; further trenches were made between the already arranged ones, but the design depth of these trenches could not be reached by 0.4-0.6 m. The trenches were flooded rather quickly, but it was almost immediately filled with rubble, and the entire area of the excavation was covered with sand. From the mark approximately $20 \mathrm{~cm}$ above the groundwater level, the sand cushion began to be compacted in layers.

As a result of monitoring the technology of earthworks for the construction of the pit with partial replacement of gravel and sandy soil, it was found that in general the contractor achieves design solutions.

The control of the sand cushion arrangement was carried out by sampling of compacted soils from the pits. At the same time, soil samples and monoliths were taken from different horizons with an interval of $0.3 \mathrm{~m}$. The average value for the mass of compacted soil is $\rho_{\mathrm{d}}=1,667 \mathrm{t} / \mathrm{m}^{3}$, which is in the range of normalized values of dry soil density for compacted bases $\left(\rho_{\mathrm{d}}=1,65-1,7 \mathrm{t} / \mathrm{m}^{3}\right)$.

The main task of the reinforcement was to ensure the maximum subsidence of no more than $10 \mathrm{~mm}$ at the worst combinations of loads and impacts when drilling a well.

Therefore, in order to confirm the calculated data, field tests were conducted by loading the paved slab with road slabs to achieve the design loads and impacts when drilling a well. The experimental loading on the foundation slab was selected from the conditions of the most unfavorable combinations of loads and influences during the operation of the drilling rig. 
The weight of the drilling rig according to the passport data in total with technological loads when drilling wells is 680 tons $(6800 \mathrm{kN})$.

The weight of the foundation slab is $260 \times 4.2+208 \times 0.0184=1096$ tons (where 4.2 tons is the weight of the road slab; 260 is the number of road slabs in the foundation; $208 \times 0.0184=4$ tons is the weight of the clip made of channels).

Thus, the total weight of the foundation with technological equipment will be $680+1096=1776$ tons.

During the tests it was decided to use the maximum number of available road slabs 156 pieces. At the same time their placement is provided similarly to the scheme of transfer of loadings from the drilling rig. The total weight during the tests was $156 \times 4.2=655.2$ tons, which is $96 \%$ of the maximum possible value.

The scheme of loading of a base plate and a photo of the loaded plate is given in Fig. 3.1 and Fig. 3.2 respectively. The results of the corresponding geodetic measurements are given in Table. 3.1. The leveling results are presented in Fig. 3.3.

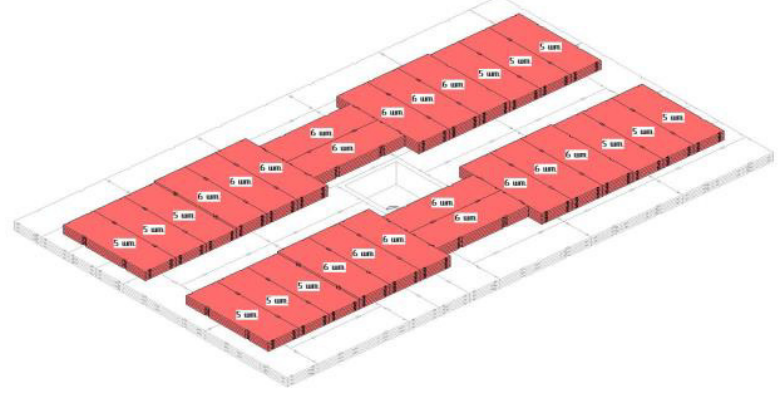

Fig. 3.1. The scheme of loading of a base plate

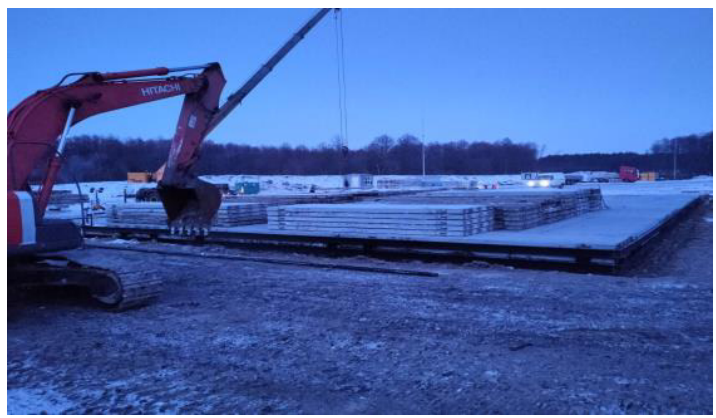

Fig. 3.2. A photo of the loaded plate 
Table 3.1

The results of geodetic measurements in field tests of the base plate on an improved soil basis by arranging horizontal crushed stone drains

\begin{tabular}{c|c|c|c|c|c|c|c|c|c|c}
\hline \multirow{2}{*}{$\begin{array}{c}\text { № } \\
\text { points }\end{array}$} & \multicolumn{7}{|c|}{ Measurement date (load percentage) / Sedimentation value in mm } \\
\cline { 2 - 13 } & $\begin{array}{c}15.02 \\
(0 \%)\end{array}$ & $\begin{array}{l}16.02 \\
(65 \%)\end{array}$ & 17.02 & 18.02 & 19.02 & 21.02 & 22.02 & 23.02 & 26.02 & 28.02 \\
\hline T1 & - & +4 & 0 & -1 & 0 & 0 & 0 & 0 & -1 & -1 \\
\hline T2 & -2 & +2 & -2 & -2 & -2 & -1 & -1 & -2 & -2 & -2 \\
\hline T3 & +3 & +5 & +3 & +2 & +2 & +3 & +3 & +3 & +3 & +2 \\
\hline T4 & -2 & -3 & -8 & -7 & -7 & -6 & -4 & -6 & -4 & -3 \\
\hline T5 & -3 & 0 & -6 & -6 & -4 & -3 & -3 & -3 & -3 & -2 \\
\hline T6 & -8 & -4 & -10 & -10 & -10 & -9 & -9 & -9 & -9 & -8 \\
\hline T7 & -7 & -4 & -11 & -11 & -10 & -10 & -10 & -10 & -11 & -10 \\
\hline T8 & -6 & -5 & -10 & -10 & -10 & -10 & -10 & -10 & -9 & -8 \\
\hline
\end{tabular}

Field tests recorded a maximum vertical subsidence of $6 \mathrm{~mm}$, with the rise of the plate did not exceed $4 \mathrm{~mm}$, and the roll $-3.3 \times 10^{-4}$. These values are less than the maximum allowable requirements for the operation of the drilling rig, the roll will also not affect the normal trouble-free operation of the rig. In the process of unloading the elastic component of deformations was fixed, the rise of the plate was $1 \mathrm{~mm}$.
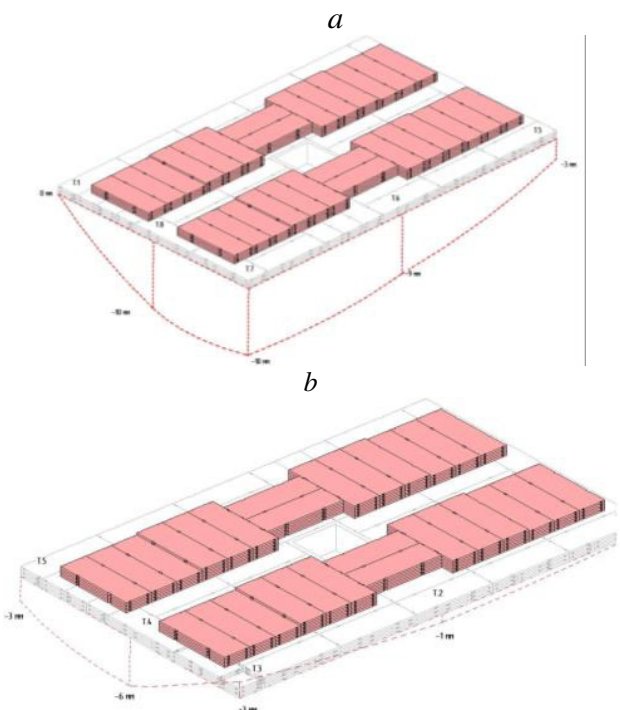

Fig. 3.3. Results of geodetic measurement of loadings by road plates of the basis and the base plate of the drilling rig: $a$ - for marks $1,5,6,7,8 ; b$ - for points $2,3,4,5$ 
Very often, under similar conditions, it is rational to arrange a system of embankment of geogrids and geotextiles. The technology of works includes the following stages:

1) cutting of the top soil and its separate assembly outside the area where the embankment is arranged;

2) backfilling with clay soil up to $30 \mathrm{~cm}$ thick with surface compaction by rollers (vibration-free mode); the function of this layer is to reach the surface above the existing groundwater level and for ease of installation of the next layer of geotextile;

3) laying geotextiles, which are attached with pins to the previously poured clay soil;

4) installation of a spatial geogrid $20 \mathrm{~cm}$ high, the cells of which are covered with fine-grained rubble;

5 ) erection of the embankment body from layer-by-layer compacted sand by rollers in the vibration mode (the thickness of the embankment depends on the required level of its top: under the foundations of the drilling rig - up to $0.5 \mathrm{~m}$; under the other part - up to $1.2 \mathrm{~m}$ );

6) laying geotextiles, which are attached to the embankment with pins;

7) installation of a spatial geogrid $20 \mathrm{~cm}$ high, the cells of which are covered with fine-grained rubble;

8) arrangement of the site (installation of road slabs) - construction of the foundation for the drilling machine.

Conclusions. All the above solutions provide the necessary operational requirements for drilling rigs with a lifting capacity of 450 tons, and have proven themselves in the construction of deep wells in complex engineering and geological conditions.

\section{References}

1. Koroviaka Ye.A., Khomenko V.L., Vynnykov Yu.L., Kharchenko M.O. \& Rastsvietaiev V.O. (2021). Burinnia sverdlovyn: navch. posib. Dnipro: NTU «P»».

2. Voitenko V.S., Vitryk V.H., Yaremiichuk R.S. \& Yaremiichuk Ya.S. (2012). Tekhnolohiia i tekhnika burinnia. Lviv: Tsentr Yevropy.

3. Manjriker A. \& Gunarante I. (2006). Foundation Engineering. New York: Taylor and Francis.

4. Van Impe W.F. \& Verastegui Flores R.D. (2007). On the design, construction and monitoring of embankments on soft soil in underwater conditions. Saint Petersburg: NPO «Georeconstruction - Fundamentproject». 
5. Phoon K.K. (2008). Reliability-based design in geotechnical engineering. Computations and applications. New York: Taylor \& Francis.

6. Briaud J.-L. (2013). Geotechnical Engineering: Unsaturated and Saturated. Soils. Wiley.

7. Katzenbach R., Leppla S., Seip M. \& Kurze S. (2015). Value Engineering as a basis for safe, optimized and sustainable design of geotechnical structures. Proc. of the XVI European Conf. on Soil Mechanics and Geotechnical Engineering for Infrastructure and Development. Edinburgh, 601-606.

8. Chau K. (2013) Numerical Methods. Proc. of the $18^{\text {th }}$ Intern. Conf. on Soil Mechanics and Geotechnical Engineering. Paris, 647-654.

9. Fleming K., Weltman A., Randolph M. \& Elson K. (2008). Piling Engineering. London \& New York: Taylor and Francis.

10. Illichov V.A. \& Mangushev R.A. (2014). Spravochnik geotehnika. Osnovaniy, fundamentu i podzemnue soorugeniy. Moskva: Izd-vo ACB.

11. Zotsenko M.L. \& Vynnykov Yu.L. (2019) Fundamentu sho sporudguutsy bez vuymanny gruntu. Poltava: PoltNTU imeni Yuri Kondratuka.

12. Denies N. \& Lysebetten G.V. (2012). Summary of the short courses of the IS-GI 2012 latest advances in deep mixing. Proc. of the Intern. Symposium on Ground Improvement IS-GI. Brussels, 73-123.

13. Zotsenko M.L. Vynnykov Yu.L. \& Zotsenko V.M. (2016). Burovi gruntotsementni pali, yaki vyhotovliaiutsia za burozmishuvalnym meto-dom: Monohrafiia. Kharkiv: «Drukarnia Madryd».

14. Vynnykov Yu., Voskobiinyk O., Kharchenko M. \& Marchenko V. (2017) Probabilistic analysis of deformed mode of engineering constructions' soilcement grounds. Materials Science, Engineering and Chemistry. MATEC Web of Conf. Proc. of the $6^{\text {th }}$ Intern. Scientific Conf. "Reliability and Durability of Railway Transport Engineering Structures and Buildings", Kharkiv, vol. 116, 02038.

15. Vynnykov Yu.L., Kharchenko M.O., Lopan R.M. \& Manzhaliy S.M. (2017). Heotekhnichni vlastyvosti shtuchnykh osnov dlia obiektiv hirnychozbahachuvalnoho kompleksu: Monohrafiia. Poltava: PoltNTU imeni Yuri Kondratuka. 


\title{
PROSPECTS FOR DEVELOPING RESOURCE-SAVING TECHNOLOGIES IN MINERAL MINING AND PROCESSING
}

\author{
Multi-authored monograph
}

First publication

\begin{abstract}
The materials of the multi-authored monograph are in the authors' edition. References are obligatory in case of full or partial reproduction of the monograph content. All rights are reserved by the monograph contributors including their scientific achievements and statements.

Co-editor

Co-editor .

Deputy editor

Technical editor

\section{Valerii KORNIYENKO,}

Professor, Doctor of Sciences (Engineering), Head of Department of

Development of Deposits and Mining, National University of Water and Environmental Engineering, Ukraine

Maria LAZAR - Professor, Ph.D., Research Vice-Rector University of Petroșani, Romania.

Serhii CHUKHAREV, Associate Professor, PhD (Engineering),

\section{Elena SAMOILUK}

Signed to print 04.02.22. Format A5.

39 conventional printed sheets.

The printing run is 300 copies.

UNIVERSITAS Publishing, Petroșani, University of Petroșani Str. Universității nr. 20, 332006,

Petroșani, jud. Hunedoara, Romania 